
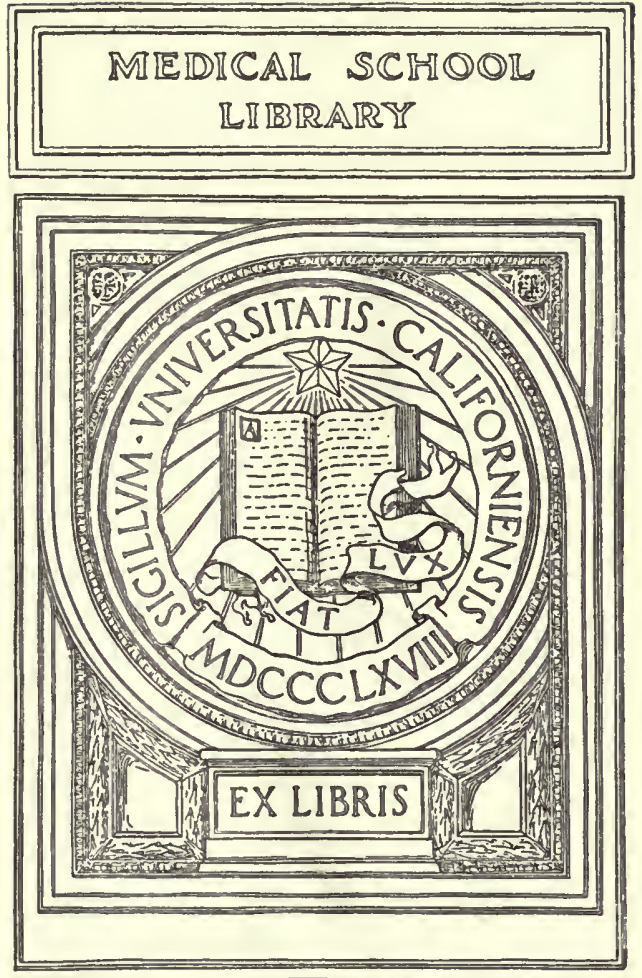

\section{Gift of}

Dr. Janes Hopper, Jr. 


AN INTRODUCTION TO BIOPHYSICS 
PRINCIPLES OF HUMAN PHYSIOLOGY. By E. $\mathrm{H}$. Starling, C.M.G., F.R.S., M.D. Third Edition. 579 Illustrations. 25s. net.

TEXT-BOOK OF PHARMACOLOGY AND THERAPEUTICS. By A. R. Cushny, M.D., LL.D., F.R.S. Seventh Edition. 71 Illustrations. 24s. net.

PRACTICAL PHYSIOLOGICAL CHEMISTRY. By P. B. Hawk, M.S.; Ph.D. Sixth Edition. 185 Illus* trations. 21s. net.

SYNOPSIS OF PHYSIOLOGY. By Ffrangcon Roberts, M.D. 73 Illustrations. 15s. net.

By EMIL HATSCHEK.

LABORATORY MANUAL OF ELEMENTARY COLLOID CHEMISTRY. 20 Illustrations. 7s. 61. net.

INTRODUCTION TO THE PHYSICS AND CHEMISTRY OF COLLOIDS. Third Edition. 17 Illustrations. 5s. net.

J. \& A. CHURCHILL. 


\title{
AN INTRODUCTION TO
}

\section{BIOPHYSICS}

\author{
LC? ? \\ DAVID BURNS, M.A., D.Sc.
}

GRIEVE LECTURER ON PHYSIOLOGICAL CHEMISTRY IN TIIE UNIVERSITY OF GLASGOW

WITH A FOREWORD BY

D. NOËL PATON, M.D., LL.D., F.R.S.

REGIUS PROFESSOR OF PHYSIOLOGY AND DIRECTOR OF TIIE PHYSIOLOGICAL INSTITUTE, UNIVERSITY OF GLASGOW

With Eighty-five Illustrations

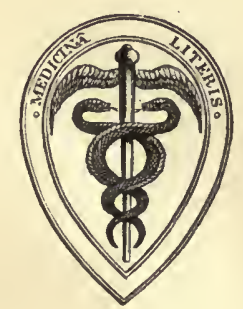

LONDON

J. \& A. C H UR C H I L L

7 GREAT MARLBOROUGH S'TREET

I 92 I 
I. R. V. M. 


\section{PREFATORY NOTE}

THIs book makes no pretensions to be a complete or even a systematic survey of Biophysics. Its object is partly to be explanatory. Current medical publications are full of terms culled from physico-chemical and physical terminology; the clinician of to-day clothes his ideas in words unknown to his brethren of yesterday; his phraseology, at least, is physical.

Apart from and beyond a mere explanation of physico-chemical terms, an attempt has been made in the following pages to present physiological phenomena from a purely physical standpoint. The problems of life, and vertebrate life in particular, have been viewed through a physicist's eyes. This does not necessarily imply that the matter of the book is permeated with mechanistic philosophy. We are all, more or less, amateur philosophers, but we would be.poor scientists indeed if our " views "were permitted to colour our facts. Phenomena, as they appear to-day, are set out for the critical examination of the student. "He will have all the facts and circumstances fully mobilised, standing up side by side before him like an awkward squad, and there is nothing more awkward than some facts that have to stand out squarely in the daylight ! And he inquires into their ancestry, makes them hold out their tongues, and pokes them once or twice in the ribs, to make sure that they are lively and robust facts capable of making a good fight for their lives. He never likes to see one thing too large... lest he sees something else too small; but will have everything in true proportion." (David Grayson.)

It is a great pleasure to me, on reading over the final proofs, to notice how gencrously my masters and colleagues have come to my aid. Quite apart from the direct help given me by Professors Noël Paton and E. P. Cathcart, who contribute the opening and closing chapters of the theoretical part of the book, I have received daily encouragement from them in my task, for which I express my sincere gratitude. If this effort to make plain the 
essentials of Biophysics is in any way successful it is due to the truly scientific atmosphere of the Institute of Physiology which they govern and inspire.

I beg to record my obligation to Dr. Shanks for the care he has devoted to the chapter on the eye ; to Dr. Morris for reading the first three sections of the book in slip-proof ; to Dr. Watt, Lecturer on Psychology in this Institute, for reading the chapters on Receptors and for his suggestions thereon; to Dr. Wishart, because, by reading many of the proofs and by checking mathematical matter, he has saved me from many a fault and blunder.

My debts to previous authors are many and I cannot own them all. Discerning readers will see, for example, the ideas of my old teacher, Professor Soddy, mirrored in certain of the earlier chapters; Professor Thompson's Growth and Form is the basis of part of Chapters XVI., XXIV. and XXXIV.; McKendrick, Gray, Wrightson, Keith, and Watt are the sources from which much of Chaps. XIX. and XXIX. have been drawn. A book of this nature could not be written without constant refcrence to the Principles of General Physiology. If my Introduction but serves to turn some student to the great book of Professor Bayliss, to meet the master mind, it will have succeeded.

I am under obligation to the authors and publishers of several books from which illustrations have been borrowed.

To Professor Noël Paton and Messrs. Green for permission to use eight figures from the Essentials of Human Physiology (viz. Figs. 25, 27, 58, 59, 69, 72, 73 and 85) ; to Professor Starling and Messrs. Churchill for the following figures from Principles of Human Physiology: 1, 5, 8, 16, 35-41, 43, 45, 50, 70, 74, 75, 80 and 83 ; to Mr. Crowther for Fig. 21 from Molecular Physics, and to Mr. Emil Hatschek for Figs. 7, 9 and 10 taken from An Introduction to the Physics and. Chemistry of Colloids, both books from Messrs. Churchill.

To Professor Cushny for lcave to reproduce the ideal diagram of a Malpighian corpuscle (Fig. 28) from his monograph on The Secretion of Urine (Messrs. Longmans, Green and Co.); to Professor Soddy and "The Elcctrician" Publishing Co., for the diagram of the gold-leaf electroscope (Fig. 22) from Radioactivity.

To Dr. Bradford for allowing me to reproduce, from the Biochemical Journal, his photograph of adsorptive stratification (Fig. 11) and to Professor Roaf for the $p \mathrm{H}-\mathrm{C}_{\mathrm{н}}$ graph reproduced from the Proceedings of the Physiological Society (Fig. 84). 
To Messrs, the Cambridge and Paul Seientific Instrument Co. for the figures illustrating the eleetro-cardiograph (Figs. 64-67); to Messrs. Hawksley for those of the viscosimeter (Figs. 77 and 82) and to Messrs. Gallenkamp for Figs. 2 and $\mathbf{3}$ of the bomb ealorimeter.

The remaining forty illustrations were drawn by Dr. G. M. Wishart, Assistant in the Department of Chemical Physiology, and by Mr. John Waters, a student of medieine here. To their skill and eare I owe much.

I am greatly obliged to Mr. A. V. Steen, B.Sc., one of our demonstrators, for reading all the proofs. The freedom of the matter from certain errors is the result of his painstaking efforts.

Finally, I desire to record my gratitude to my publishers for their patience and courtesy during the prolonged period of publication and to the printers for the care they have taken and the consideration shown when my ignorance made large demands on their time and patience.

Institute of Physiology,

University of Glasgow. 



\section{CONTEN'TS}

Introduction. By Professor D. Noël Paton, M.D., LL.D., F.R.S. - xi

\section{PART I. SYSTEMATIC}

CIIAP.

\section{SECTION I. ENERGETICS}

I. LAWS OF ENEROY - - $\quad$ - $\quad$ - $\quad$ - $\quad$ - $\quad$ - $\quad$ - 1

II. The Storage of Energy - - - - - - - - 13

III. Liberation of Energy-(1) Calorimetry - - - - . - 21

IV. Liberation of Energy-(2) The Animal as a Machine - 32

V. Liberation of Energy--(3) Energy of Substance in Solution. Osmotic Pressure - - - $\quad$ - $\quad$ - $\quad$ - 36

VI. Liberation of Energy-(4) Surface Tension - - - - 46

\section{SECTION II. CELLULAR MECHANICS}

VII. Ions -

VIII. Disperse Systems

IX. ENZYMES -

X. Membranes

XI. Radio-ACTIVITY

XII. The Cell.

\section{SECTION III. CELL COMMUNITIES}

XIII. Muscle Cells -

135

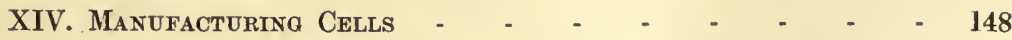

XV. Eliminatina Cells - - - . - - - - - 155

XVI. Connective Tissue Cells - - - . - - - - 166

XVII. Intelligence Service-Nerve Cells - - - - - 182

XVIII. OUtposts of the Intellianence Service-General Receptors 191

XIX. Outposts of the Intellitance Service-Ear - - - 200

XX. Outposts of the Intelligence Service-Eye - - - 215 
CHAP.

\section{SECTION IV. TRANSPORT}

XXI. Inland Transport-The Blood -

XXII. Inland Transport-Respiratory Function of Blood

XXIII. InLaNd Transport-Loading UP

XXIV. Inland Transport-Circulatio

XXV. Inland Transport-Electrocardiogram - - - - 295

XXVI. Overseas Transport-External Respiration - - 301

XXVII. Overseas Transport-Almmentary Canal - _ _ $\quad$ - 313

XXVIII. Overseas Transport-Looomotion - - - - - 320

XXIX. Overseas Transport-Vorce - - _ - - $\quad$ - $\quad 325$

SECTION V. THE ANIMAI AS A WHOLE

XXX. The Preservation of Neutrality - - - - - 331

XXXI. The Regulation of Temperature - - - - - $\quad 336$

XXXII. TropISMS - - - - - - - - - - 354

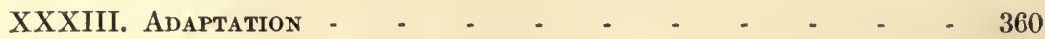

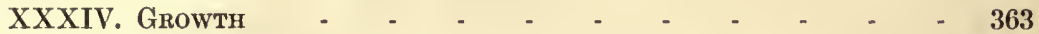

XXXV. DeVelopment - - - - - - - - - 377

XXXVI. Death and Dissolution - - - - - - - $\quad$ - 388

XXXVII. EFFICIENCY - $\quad$ - $\quad$ - $\quad$ - $\quad$ - $\quad$ - $\quad$ - $\quad$ - 391

PART II. ILLUSTRATIVE EXPERIMENTS - - 398

INDEX - - - - - - - - - - - 44 


\section{INTRODUCTION}

By Professor D. Nö̈L Paton, M.D., LL.D., F.R.S.

ON looking back over a forty years' association with physiology nothing is more striking than the influence which the application of physics has exercised upon the progress of the sciences.

I well remember that, as long ago as 1878 , my first teacher began his lectures on the Institutes of Medicine by defining physiology as the application of physics and chemistry to the study of the body in action.

But at that time the possibility of applying these sciences was limited. In the first place, their development, and especially the development of physics, was not sufficiently advanced. The dissociation of atoms into ions was hardly recognised, the significance of Graham's colloids was not appreciated, and the phenomena of surface tension had hardly been applied to molecular physics. In the second place, physiologists were then generally men trained for medicine whose education in physics and chemistry had been extremely limited. Of course, there were notable exceptions-e.g. Helmholtz and du Bois Reymond.

These older physiologists had to be content with recording phenomena rather than with explaining them, and they loved to chronicle their observations in high-sounding Greek names. Can one ever forget the sense of profound knowledge which one enjoyed as a junior student in mastering such terms as "delomorphous" and "adclomorphous" as descriptive of the cells of the stomach? The so-called chemical physiologists were perhaps the worst offenders. For, having isolated, or thought they had isolated, some constituent of the body of quite unknown chemical constitution, they promptly gave it a name with no connection with its chemical nature, and these names have generally continued in use, to the confusion of generations of students. In the present age of "hormones" and "vitamines" one wonders how far the tendency has been eradicated. 
It was the "what happens?" which interested these older workers: "Why it happens ?" was generally beyond them, and vague theories of some peculiar and special vital action took the place of actual demonstration.

Undoubtedly the association of physiology with the more exact science of physics, based as it is so largely upon mathematics, has had an enormous effect in getting rid of this habit of vague theorising and has materially helped to clarify minds "debauched with the so-called science of biology" as Tait, in the early eighties, was wont to describe our mental condition.

It has also stimulated the critical faculty, which insists upon a clear proof and demonstration as a basis of conclusions.

It is much to be regretted that even at the present time the importance of a mathematical training, so essential for the study of physics, is not generally recognised, and that it is still possible to take a higher degree in science without this necessary preparation.

It has been through the co-operation of physics and chemistry that the solution of many of the problems of life have been reached, and as the possibility of reaching these solutions has become more generally recognised, the spirit of scientific curiosity - the desire to know, which is the basis of all scientific workhas been stimulated; although probably in the future as in the past, humanity will still be divided into the enormously large class of those who have no real desire to understand the workings of nature and the very small class of those who have the spirit of curiosity, who do desire to know. These alone are the scientists, although many science graduates belong to the major class.

With or without any wider diffusion of the spirit of curiosity, the development of the critical faculty and the better training of the younger workers in physics and chemistry has brought physiology nearer to the position of an exact science, and with this, its value as a training for students of medicine has greatly increased. The doctor, in making a diagnosis, has not merely to observe and record what has happened, but he must ascertain why it has happened. His problems are the same in nature and his methods are the same as those of the physiologist, and thus physiology has regained its position as the Institutes of Medicine.

The doctor of the past considered that he had made a diagnosis when he was able to give his patient's disease a name. The physician of the future will care less and less for such names. He will simply be concerned with the solution of the questions- 
"What is abnormal ?" "Why is it abnormal ?" Perhaps it is wiser not to enquire too curiously into the position of the physician of the present.

The development of physiology on the lines indicated has also made possible the growth of the sciences of experimental pathology, of experimental medicine and of pharmacology; and the knowledge of disease and of its treatment has thus been put upon a sounder basis.

All this has followed the adoption of physics and chemistry as the guides of the physiologists.

In the present volume, Dr. Burns attempts to show the part which physics has come to play in the solution of the problems of physiology. A science of bio-physics has evolved in the same way as that of bio-chemistry. Perhaps some attempt should have been made in the title to indicate that it is the problems of the physiology of vertebrates rather than the basic problems of life generally which are dealt with.

The book is intended for students of human physiology, although it cannot fail to interest all workers in biology.

It demonstrates what a very large number of the characteristic reactions of living matter may be cxplained in terms of ordinary physical processes, and it thus shows the reduction which is taking place in the number of phenomena which some are still content to explain as due to a mysterious vital action instcad of simply confessing that they are yet not understood.

As the application of physics and chemistry to physiology is extended, it is safe to predict that fewer and fewer of thesc vital manifestations will remain unexplained.

The origin of living matter, its increase and dispersion all over the globe, its marvellous and endless developments and evolutions, and its reactions with its surroundings may all be explained in terms of physics and chemistry. But consciousness and its association with living things will ever remain the mystery it has been and is. 



\section{BIOPHYSICS}

\section{PART I. SYSTEMATIC}

\section{SECTION I.: ENERGETICS}

\section{CHAPTER I}

\section{LAWS OF ENERGY}

"The history of man is dominated by and reflects the amount of available energy."

Biopirssics deals with the application of physical and physicochemical laws to the actions of living things. It is necessary at the outset to have a clear understanding of what is meant by a natural law, or principle of nature. A law in scicnce is a different concept from a law in philology or in jurisprudence. Repeated observation of a recurring phenomenon lcads to the conclusion that there is a natural and unalterable sequence of events. This is summarised in a law. Newton's Law, for instance, epitomises the conclusions of a large series of observations, viz. that objects free to do so always fall towards the earth. A natural law, then, is not a principle governing the action of nature, but a generalisation drawn from observation of the phenomena, stating, in short, how these phenomena have always becn known to act in the circumstances. If the observations are correct, the law is true and, in like circumstances, will always hold. If at any time a reliable observation were made that scemingly went against the law, scientists would not doubt the validity of the law, but would carefully examine the concomitant circumstances to see in what point they differed from those defined in the law. The problem before us is to detcrmine whether laws deduced from the study of non-living matter may be applicd to the elucidation of biological phenomena. Physical 
science is the most fundamental of the experimental sciences and, so far as is known, its laws are applicable to all non-living matter. Biochemists have attempted to break down the wall of partition which has been reared by common consent between the chcmical constitution of living and non-living. They have been partially successful in that they have been able to build up certain typical products of life from non-living material. No one, however, has, as yet, either analysed or synthesised living matter. The finest chemical technique available cannot be employed without injury to the tissue studied. In spite of this drawback, the science of nutrition may be classed as exact. Mathematical formulæ may be employed to express results, and chemical response to a definite stimulus may be predicted.

Life has been compared to a flame. The Ancients looked on fire as a living thing, and is their view not, to some extent, justifiable? The continual ringing of the changes - of form, of colour, or of position-by the flickering flames of our house fires draws the eye. Constantly, alterations are going on. No flame is still for any length of time. All is seemingly unordered and uncontrolled change. Yet down to the most minute movement all is governed by physico-chemical laws. Every flicker can be accounted for, and could be recorded as due to pressure of liberated gas, pressure and direction of draught, temperature of fire, etc. Fire-mysterious and all-powerful gift of the gods-has yielded to the prying endeavours of the scientist, and can be harnessed and employed in the service of man.

Similarly, while not committing oneself to a vitalistic or to a mechanistic conception of life, one may study, with considerable profit, the various physical phenomena exhibited by living matter. Examination of even the simplest form of life is sufficient to show that a characteristic phenomenon is change. No living thing is absolutely still. It is undergoing change in one way or another. It may alter its position relatively to its environment ; it may alter in its parts; it may grow ; it may undergo alterations in internal (atomic or molecular) structure. The physicochemical processes indicated by these changes or initiated by them are studied under the term metabolism (Gr. met $a=$ change). Metabolism may consist in a building up of matter, anabolism (Gr. $a n a=u p)$ or in the reverse process, a breaking down of matter, catabolism (Gr. $k a t a=$ down). If anabolism is greater than catabolism, the organism grows ; if the two processes balance, the organism exists. The predominance of catabolism leads to 
disintegration. Complete immobility denotes death. Change indicates the utilisation of energy, which obviously must have come from some souree outside the organism. "The mechanistic notion of life, the representation of the body as primarily and fundamentally a machine, is often bitterly and not very intelligently opposed. We arc told that the machine-the scientists' imitation of life-is not merely a purely inanimate mechanism. In its cunning combination of valves and regulators it has a brain, part of the brain of its designer. The partial likeness is that of the machine to the man, of the limited imitation to the original, not the other way about, which is true enough. But let us bear in mind one essential and undeniable fact. Machine or man, inanimate mechanism with the mechanical imitation of a brain, or brain controlling an animate mechanism, what of the power? The power to live, the power to do work is not in the brain nor in the body, not in the valves nor the moving parts. The power, whether of life or of mechanism, is external. This is the real ground of analogy" (Soddy). We must determine the source of this energy, study its laws, see how it is made available for living matter, and then see how it operates in living matter.

Energy is the underlying cause of all ehanges in matter. This does not seem a very satisfactory definition but, so far, it is the only one possible. It is a very striking fact that the two fundamentals of our external world, matter and energy, have for us no existence apart from their effect on us. We cannot prove that there are such things except in so far as they manifest themselves, matter by being changed, and energy by producing changes, which in turn alter our sensation-complex.

There can be no change of any sort without free energy. Energy exhibits itself in many forms-heat, light, movement of matter, electricity, radio-activity, ete.

In 1798, Count Rumford, who was engaged in boring cannon, showed that movement-or kinetic-energy could be transformed into heat. Later, Joule demonstrated the equivalence of thesc two forms of energy. 427 kilogrammetres of work always produee (under standard conditions) one Calorie of heat. Conversely, heat may be transformed into mechanical movement. Indeed, any form of energy may be converted into any other form of energy. (Radio-active matter evolves energy which manifests itself in various forms, yet all attempts to change other forms of energy into radio-active energy or even to influence the rate of transformation have failed. Chap. XI.) 
TABLE I.

Mechanical Equivalent of Heat.

UNITS.

\begin{tabular}{|c|c|c|c|c|c|}
\hline $\begin{array}{l}\text { Tempera- } \\
\text { ture. }\end{array}$ & Time. & Mass. & Length. & Force. & $\begin{array}{l}\text { Equiva- } \\
\text { lent. }\end{array}$ \\
\hline $1^{\circ} \mathrm{C}$. & Second & Gram & Centimetre & Dyne at $15^{\circ} \mathrm{C}$. & $4 \cdot 2 \times 10^{7}$ \\
\hline $1^{\circ} \mathrm{C}$ & $"$ & ," & $"$ & $\begin{array}{l}15^{\circ} \mathrm{C} \text {. at lat. of } \\
\text { Greenwich }\end{array}$ & 42700 \\
\hline $1^{\circ} \mathrm{F}$ & ", & Pound & Foot & $\begin{array}{l}\text { Poundal at } 59^{\circ} \mathrm{F} \text {. } \\
\mathrm{Wt} \text {. of a pound at }\end{array}$ & $2504 \cdot 7$ \\
\hline $1^{\circ} \mathrm{F}$ & " & " & " & $\begin{array}{l}59^{\circ} \mathrm{F} \text {. at lat. of } \\
\text { Greenwich }\end{array}$ & $778 \cdot 1$ \\
\hline $1^{\circ} \mathrm{C}$ & ", & $"$ & $"$ & $\begin{array}{l}\text { Wt. of a pound at } \\
15^{\circ} \mathrm{C} \text {. }\end{array}$ & $1400 \cdot 6$ \\
\hline
\end{tabular}

To convert to ergs : Calories $\times 4.2 \times 10^{7}=$ ergs.

From observation it is found :

(1) That one form of encrgy may be transformed into any other form.

(2) That when any quantity of energy in any one form disappears, an cxactly equal quantity of another form of energy makes its appearance.

Energy like matter is therefore indestructible (Law I.).

Every substance possesses a certain amount of energy. This is ealled its internal or intrinsic cnergy. Further, every group of substances has associated with it a certain definite amount of energy as long as it remains unchanged. When any change takes place in the group, or in any member of the group, there is usually a corresponding change in its total energy, either an increase, due to the reception of energy from its environment, or a deerease due to an evolution of energy. Put into other words, each of the new substances will have its own eharacteristic intrinsic encrgy, and the new group will, in general, have a different total energy-content from that of the original group.

E.g. $\quad$ Cane sugar $+\mathrm{O}_{2} \underset{\leftarrow}{\longrightarrow} \mathrm{CO}_{2}+\mathrm{H}_{2} \mathrm{O}+$ heat energy.

\section{Corollaries of the First Law.}

The following two deductions are of biological interest :

1. The total energy of a system in a given state is for the system 
in question a definite characteristic of that state, and it is totally independent of how the system reaehed that state.

The energy that would be liberated by the fall of a kilogram, e.g. of lead, from a height of 300 metres would be the same no matter how the kilogram was first elevated to the point from which it was dropped. For instance :

(a) It might be lifted bodily and vertically.

(b) It might be lifted bodily and up an inclined plane.

(c) It might be lifted bodily and rapidly.

(d) It might be lifted bodily and with infinite slowness.

(e) Or it might be lifted in small pieces, say 1 milligram, at a time.

$(f)$ It might be lifted as a series of chemical compounds weighing more than 1 kilogram as salts of lead and reduced to metallic lead before dropping.

(g) Or it might be dug out from the top of a hill, 300 metres high, and transported horizontally by aeroplane.

The essential conditions are that it weighs 1 kilo. and that it falls 300 metres, cosmic influences being constant.

Similarly, glucose has the same energy-content no matter how it has been prepared provided the measurement is earried out under similar conditions, e.g. glucose may be synthesised from simple substances ; it may be prepared by the natural or artifieial hydrolysis of more complex carbohydrates, or it may be derived from such substanees as proteins, fats, ete.

2. When a system changes from one state to another, the alteration of total energy which accompanies that ehange is altogether independent of the process by which the ehange is brought about.

The examples given above, if reversed, will act as examples of this corollary. The rate and angle of fall are not determining factors in the liberation of energy, nor does the way in which the energy of glucose is liberated have any effect on the total amount set free.

These two corollaries, as we shall see later, make it possible to eonstruct a balanee sheet of the energy intake and output of the organism.

Degraded Energy (Law II.).

When a substance or group of substances is changed into a substance or group of substanees with a smaller energy-content, the energy thus liberated is, in theory, available for work. In practice, it is found that all this surplus cnergy cannot be recovered as work. No system is absolutely isolated, and though the total cosmieal energy may be eonstant its distribution and its state may alter. Some of the freed energy is always eonverted into heat, part of which is dilfused among surrounding objeets 
and is thus lost, as far as work is concerned. The quantity of energy is not decreased, but its dispersion is so great that in quality it has not sufficient potential gradient to be of use. As an example of dispersion of energy, consider a stone dropped into an infinitely large lake. As the radius of the series of concentric ripples increases the wave-height decreases, till at infinite radius the wave height will be infinitely small. The wave energy has been so spread that it may be disregarded.

The second law is usually worded, "The entropy of an isolated system tends to increase." Entropy is a function which, while theoretically of great value as indicating the direction in which chemical or other processes take place, cannot be directly measured. Further, one never has, in Biology, to deal with an isolated system. The difficulty as well as the great interest of our science depends on the close interrelation and co-ordination of all the systems in it. A simple expression of the law, and one suited to our purpose would be, "Every change takes place at the cost of a certain amount of available energy." The amount of energy " degraded" during å transformation from one form of energy to another may be taken as an inverse index of the efficiency of the transforming mechanism.

\section{States of Energy.}

A substance may be endowed with kinetic energy, or with potential energy, or with both. Kinetic energy is directly available for work, potential energy requires the use of some kinetic energy to liberate it. The energy of a substance may be in the motion of the substance itself or in the motion of the ultimate particles composing it. This kinetic energy and its value depend on the mass of the substance and the rate at which it moves or at which its particles vibrate.

Potential energy, on the other hand, is said to be possible to a substance in virtue of its configuration, i.e. position, composition, history, etc. A quantity of energy that may be measured is stored up (or rendered passive in some way), and this same quantity is theoretically recoverable in a measurable form. It may not be apparent hozo energy is stored up, but it may be demonstrated that it is stored and is recoverable. The simplest example is the application of force to a perfectly elastic system. On removal of the force the system will return of itself to its original configuration, and an amount of work will be done by it, in returning, exactly equivalent to the amount of the force of 
distortion. The hackneyed example of energy storage is, of course, our coal supply.

Energy in the potential state, as long as it remains potential, is useless. It cannot be transformed into any other form of energy without altering its state, and its state cannot be altered without the employment of kinetic energy. This point is biologieally important.

1. A weight hanging from a string has potential energy aceording to its mass and its distance from the centre of the earth, ete.

2. An explosive has potential energy depending on its chemieal composition and physical state.

3. Petrol, coal, or any other fuel has similar cnergy bound in it.

4. A sleeping man may be said to have potential energy. Now, in order to get work out of these quiescent bodies, all that is neessary is the application of a suitable stimulus, i.e. a small quantity of free kinetic energy. E.g.

(1) The resistance that prevents the weight from falling must be overcome, i.e. the string severed.

(2) The explosive must be fired or detonated.

(3) The fuel must reach ignition temperature.

(4) 'The sleeper must be awaked.

In 1882 Helmholtz introduced the terms "free" and "bound" to denote respectively that part of the kinetic energy of a system free or available for conversion to work, and that part not free or not available for this purpose. Later writers, realising that potential energy as such was not available for work, widened the connotation of "bound" to include this dormant cnergy. As a matter of logical definition, only potential energy is really bound. That which is bound can be frced by cutting the bonds, i.e. by doing an amount of work which bears no relation to the amount of energy bound, but depends on the nature of the bonds. Dissipated or degraded energy is not in any true sense bound. It is not free to do work, i.e. it is not available. To render it available an amount of energy would have to be expended on its environment at least equal to the amount of energy rendered available.

A weight resting on the ground may be considered as representing a body having degraded energy. Its energy potential is the same as its environment. No work could be got from it without the previous expenditure of work on it. If a certain amount of work were done in raising it from the ground, then the same amount of work would be recovered on letting it fall to the ground (taking into account the mechanical equivalent of the degraded heat). On the other hand, a weight resting on a ledge 
above the ground may perform work in falling if sufficient free energy be applied to tip it over. The quantity of work done in tipping over the weight bears no relation whatever to the amount of energy liberated in falling.

The following seheme may help to make the matter elear :

$$
\text { Total Energy of the Universe }
$$

(1)

Available for work,

i.e. Free Kinetic Energy

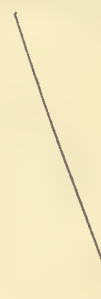

Free Energy

Total Available Energy
(2)

Not directly available for work Potential Energy Add trigger Energy from (1)

Degraded Heat (Entropy)

Totally unavailable

(3) Called " bound" energy by Helmholtz in 1882.

$(3+4)$ Called " bound" energy by later workers.

(4) Called " bound" energy by Physicists.

One of the most important problems in biology is the means by which potential energy is translated into work and the mechanism by which this translation is eontrolled.

"The struggle for existence is the struggle for free energy "(Boltzmann).

Of potential energy there is an abundant supply. Some of it, e.g. eoal, requires the employment of only small quantities of free energy to render it immediately available for work, while other varieties, e.g. radio-aetive minerals, have their energy bound in sueh a way that it is evolved with exeessive slowness. Uranium eontains the same amount of energy as 250,000 times its weight of eoal (or more), but little more than $\frac{1}{10,000,000,000}$ part of this is given out in a year (Chap. XI.). To enable mankind to avail himself of this kind of energy, some means will have to be devised for speeding up and eontrolling the output. As Professor Soddy puts it: "Primitive man froze on the site of what are now eoal mines, and starved within sound of the waterfalls that are now working to provide our food. The energy was there, the knowledge to utilise it was not. So while we are 
leading eramped lives and fighting among ourselves, whether in peace or war, for a modicum of the means of existenee, science tells us that, in the commonest materials that make up the framework of the world, there is energy of a magnitude of which we have no experience, and the means of livelihood of which we have no standard. The energy is there. The knowledge that ean utilise it is not-not yet." In a similar way, the nations had difficulty in procuring rations of sufficient energy-content during the later days of the war, while all around them were abundant supplies, but no method existed by which their energy could be made available.

\section{Physiological availability.}

This introduces a further point. The energy-content of cellulose is much the same as that of stareh, yet as a source of energy for man the former substance is useless, while the latter is perhaps his main souree of energy supply. An inorganic example may make this clearer. Two lakes may be exactly similar exeept that one has an outlet, while the other is surrounded by impassable mountains. The water power, i.e. the stored energy of the former, is utilisable, while the latter could not be tapped without arduous engineering labours. The energy-eontents of the radio-elements (atomie energy) of cellulose (as human food) and of the undrained lake are said to be non-utilisable. Future seientists may discover how to draw upon this surplus energy supply.

\section{Inertia.}

The second law of energeties lends itself to the deduetion that the cause of all action (change) is the tendency of energy to attain the same uniform degree of intensity as its environment. Further, the degradation of energy follows the line of least resistance. This is known as the "Law of Least Action" or the "Principle of Le Chatelicr." It is a law common to all seiences, and is considered by some to be a universal principle. Physieists tell us that bodies remain in a state of rest or of uniform motion in a straight line unless energy be imparted to them to overeome their inertia. Inertia is the resistance to change possessed by everything, living and non-living.

One may take a step further and qualify the law by stating that the nature of the change induced by an alteration in any factor which influenees the system will depend on what will, in 
the circumstances, give relief from strain with the least possible expenditure of energy. When a state of strain is made more or less permanent, the organism readjusts itself to meet the strain. That is, the easiest course is not to remove the cause of strain, but to make such an alteration in itself as shall render the external change innocuous. This is the principle underlying the theory of adaptability. A tree arranges its branches so as to offer least resistance to the prevailing wind. Other examples might be drawn from the sciences of physiology, economics, psychology and ethics.

Physiology. The introduction of an irritating substance into the alimentary canal causes vomiting to remove the cause of irritation, i.e. to relieve strain. Some less exhausting means of relieving strain has to be taken to meet the more or less continuous administration of poison. The cells of the organism so alter as to be immune from such irritation. Mithridates is said to have qualified for the throne of Pontus by the ingestion of all sorts of poisons in his youth.

Economics. The law of supply and demand, rates of exchange, etc., are merely restatements of this principle of least action.

Psychology and Ethics. The unjust judge met the early appeals of the widow with a firm refusal. His mind was relieved, his case settled. Because of her very importunity, persistent strain was set up which had to be relieved by reopening the case and giving a just decision.

Enough has been said to show the possibilities of this deduction from the second law of energetics. The thorough-going mechanist states that this law of least action is the principle governing the action of living as well as dead matter.

All action, it is said, is a response to stimulus, and is such as will most pcrmanently and with "least action" relieve the state of strain. The mechanist denies any cause of action but this. What has been taken for the effect of will or instinct is in reality the effect of light, of gravity, of friction, of chemical force, or of some other known or knowable external force. In short, some alteration in an external factor has brought about an instability in the physico-chemical equilibrium of the object or of the organism, and thus a shift in the equilibrium will take place in such a direction as to decrease the magnitude of the alteration which would otherwise occur. The animal, human or otherwise, is but a machine, working according to physico-chemical principles, 
reacting blindly and quantitatively to every chance force which plays on it. While, to a certain extent, we may regard this as true, we must, nevertheless, draw a sharp distinction between those actions which may be regarded as pertaining to organic life and those which pertain to conscious life dominated by personality. Plants and animals may be governed by this law of equilibrium, and every one of their actions may be regarded as a blind response to stimuli, just as the swing of a galvanometer needle is. Man, in so far as he is an animal, may also be considered a blind agent. Is there not, however, something superadded-not to interfere or even to govern, but to carry out a function of its own ? For example, there are no grounds for dealing with volition merely as a complex chemical equation or as a problem in molecular physics, resulting merely from physical or chemical changes in the body or environment. Suppose a man meets another man in the street who suddenly strikes him. The injured man has several courses open to him :

1. He may hit back.

2. He may run away.

3. He may fetch a policeman, and so on.

The action taken depends on several factors:

1. The previous history of the two men.

2. The relative sizes of the two men.

3. The nature of the spectators.

4. The nearness of the policeman.

5. The real business of the injured man, whether pressing, etc.

6. The personality of the injured man.

Knowing the man one may predict his action in a certain case, and one may probably be right, but it is only a probability -not a certainty. While the cause of volition is still unknown and cannot but be regarded as mysterious, there is nothing to hinder research into the mechanism whereby the Will causes its dicta to become acta.

To summarise, the physical necessities of man have become a problem of energy pure and simple. The fact that man is living scarcely makes the problem more complicated than one arising out of the fuel demands of an inorganic machine. So much work has to be done, so much energy must be provided.

Energy is indestructible, and in itself is only valuable in its conversion from what may be called higher to lower forms. This 
transformation involves the loss of some available energy. A certain amount finds its way into the great ocean (or "sink") of heat energy of nearly uniform temperature. The attainment of this dead level is the final goal of all energy whether it is utilised or not. 


\section{CHAPTER II}

\section{THE STORAGE OF ENERGY}

"The energy available for each man is his income. Stored energy is a legacy deposited in Nature's bank."

ALL life processes demand for their eontinuation and maintenance a continuous supply of energy. In metabolism, as far as matter is coneerned, there is a closed cycle. Animals feed on plants, and plants feed on the products of animal metabolism and disintegration. The net result is practically nil. Energy, however, must be supplied from outside. The one essential physical factor that makes the process possible is the supply of energy as sunlight to the plant.

The ultimate source of all the energy upon which existence on this planet depends is the sun. (One need not here enter on the interesting question of how the sun evolves energy; see Soddy, Matter and Energy, Chap. X.) As far as we know, the higher forms of life are unable directly to use, either heat or light as sources of bodily energy. Some of the lower forms of animal life may have this power; plants certainly have. As we shall see latcr, light energy may aet as the trigger, setting free potential energy and eausing work to be done.

All living matter may be divided into two distinet classes: (a) that subsisting upon the matcrials which they take from the earth and the air, and $(b)$ that dependent upon other organisms either living or dead. Examination shows that the main chemical difference between these two classes is that the former contains a green pigment called chlorophyll as a regular functioning constituent, while the latter does not. It is evident that chlorophyll is correlated with the state of independence that is typical of plant life.

\section{Chlorophyil.}

(Revise : Physies of light, especially that of absorption spectra, page 71 ; chemistry of chlorophyll and its relation to xantho- 
phyll, erythrophyll, etiolin and carotin ; botany of grecn plants, distribution of chlorophyll in leaves; variegation in leaves ; and structure of chloroplasts) (see Fig. 1).

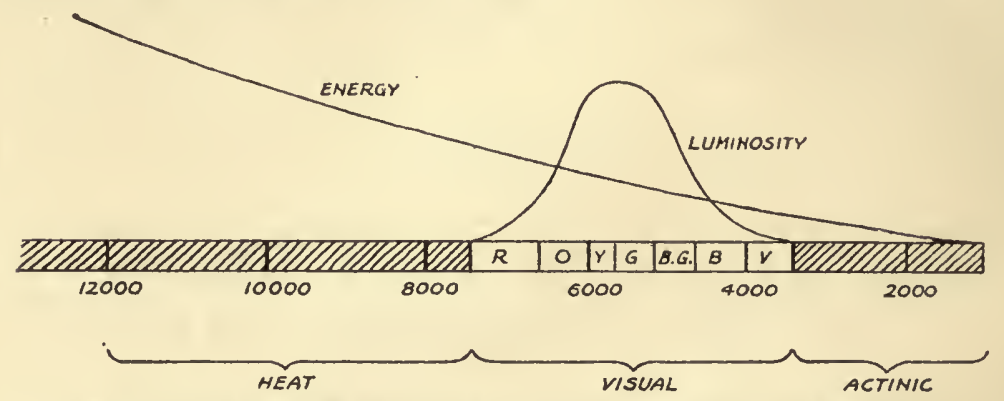

Fia. 1.-Curves showing relative energy and luminosity of different regions of the spectrum. (Abney.) The wave-lengths are given in Ångström units. An Ångström unit (A.U.) = one ten millionth of a millimetre $=0^{*} 1 \mu \mu$.

\section{Absorption Spectrum of Chlorophyll.}

An optical property of primary importance in a substance is its differential absorption of light. The wave motion of the ether, which constitutes white light, is very complex, consisting not only of transverse vibrations in every plane, but of waves of different lengths associated together. Now each wave length produces a definite colour-sensation in the optical receiving mechanism. The shortest wave length optically perceptible to man is $4 / 10,000 \mathrm{~mm}$. (violet), the longest $7 / 10,000 \mathrm{~mm}$. (red). Between these extremes there are blue rays $470 \mu \mu$, green $510 \mu \mu$, and orange $620 \mu \mu$. (These are average figures, e.g. the various lengths classed under orange vary from 595 to $645 \mu \mu[\mu \mu=$ $1 / 1,000,000 \mathrm{~mm}$.].) Beyond these visible rays exist both shorter (ultra-violet) and longer (infra-red) rays. From physics one learns that the ultimate constituents of matter exist, not in a state of rest, but in a state of ordered motion. That is, the electrons (or other ultimate complex, see colloids, p. 75, and radiant energy, p. 117) vibrate with a definite periodicity dependent on the intrinsic energy of the system to which they belong. From the study of the emission spectra of gases, a relationship may be deduced between the period of vibration of a particle and the position of the light bands emitted by the element in gaseous form. Conversely, if one views the absorption spectra of that gaseous element, black bands will be found in place of the light emission bands. To take a concrete example, if a substance when emitting light produced rays consisting for the most part of waves $680 \mu \mu$ long, the colour of the light evolved would be 
red. The substance, if viewed through a spectroscope, either when undergoing combustion or in the gaseous state, would produce a dark band in the red section of the spectrum. Further, light falling on a coloured substance is not completely absorbed. A red substance reflects red light and absorbs the other rays. Only light corresponding to the spectral bands is absorbed. Grotthus proved that no effect could be produced by light unless it was absorbed. He showed that red iron-thiocyanate was bleached by exposure to green light, yellow chloride of gold and blue starch-iodine complex by blue and yellow light respectively.

1. A mere glance at the absorption spectrum of the green leaf is sufficient to show that the light best absorbed is that having a wave length less than $500 \mu \mu$, the amount absorbed becoming greater as the wave. length becomes shorter, i.e. the chloroplasts absorb the actinic rays (violet and a small amount of the ultraviolet rays). There is also a well-marked absorption band in the red portion of the spectrum between 665 and $685 \mu \mu$. The figure for the maximal energy of solar radiation is given by S. P. Langley as 650 to $666 \mu \mu$ for high sun, so that the green leaf is able to $(a)$ utilise the actinic rays, and $(b)$ absorb light of that wave length (red) which is emitted by the sun in greatest amount. The pigments of the chloroplast do not utilise greenyellow light, nor do they absorb the heat (infra-red) rays at all.

2. Consider next the physical (and chemical) changes brought about by the absorption of light. Although this is the primary problem in Biology and has attracted many investigators, it remains unsolved. Research has made it more apparent that the mechanism for converting solar radiation into bound energy is not so simple as was at first thought. Certain facts, however, have been brought to light.

(1) Matter is assimilated. Elements taken from the environment are built into organic compounds. Boysen-Jensen has shown that in July the accumulation of matter (dried) may reach 16.5 per cent. of the total dry weight of the plant. A large proportion of this matter can be shown to be carbohydrate by a very simple experiment. It is only necessary to screen a portion of a leaf from the light, leaving a certain portion exposed, and then observe any differences between the normal and the darkened portions. If a leaf, like sunflower or fuchsia, is chosen and previously kept overnight in the dark, exposure to light for 15 minutes is sufficient, and one hour is mole than ample for our purpose. The leaf is then bleached with warm alcohol, and 
iodine is applied. The part exposcd to light will appear blueblack-rich in starch, while the screencd portion is starch free. It has been shown that during the day the starch content of leaves may rise to 6.44 per cent. of the dry leaf weight. At night the starch value may drop as low as 0.38 per cent. Timiriazeff has devised a very neat experiment which demonstrates that starch formation is greatest where there is greatest absorption of light. Living hydrangea lcaves, previously deprived of starch by retention in the dark, have then projected on them a solar spectrum for 5 or 6 hours. The leaf is decolorised and treated with iodine, and then the absorption bands of the chloroplast pigment complex are found mapped out in blue, showing that starch has been formed only where light has been absorbed. Other carbohydrates are also found. Cane sugar is formed and ean be detected before starch ean be found, and it is generally present in greater amounts, $7 \cdot 63$ per cent. to $2 \cdot 63$ per cent. of the dried-leaf weight. Other sugars are present in small variable quantities.

(2) It secms that $\mathrm{CO}_{2}$ is absorbed beyond the needs of respiration, and that $\mathrm{O}_{2}$ is evolved. Engelmann has provided in a striking manner a demonstration of the fact that the maximum evolution of oxygen takes place where there is the maximum absorption of light and, as stated above, the maximum formation of starch. He placed a filament of cladophora in water, to which he added some motile bacteria having an avidity for oxygen. On the thread of alga he projected a minute solar spectrum and kept it under the microscope. It was seen that the bacteria gathered just at those places (red and violet) where light was absorbed.

Kniep and Minder have determined the carbon assimilation, and they find it directly proportional to the amount of energy absorbed as light. Further, Willstatter and Stoll have estimated

(a) The $\mathrm{CO}_{2}$ taken up by a leaf area in the dark, i.e. respiratory $\mathrm{CO}_{2}$.

(b) The $\mathrm{CO}_{2}$ absorbed in light of a definite intensity.

(b) $-(a)=$ assimilated $\mathrm{CO}_{2}$.

(c) The $\mathrm{O}_{2}$ evolved in the dark - respiratory $\mathrm{O}_{2}$.

(d) The $\mathrm{O}_{2}$ evolved in the light - total $\mathrm{O}_{2}$.

(d) $-(c)=$ non-respiratory $\mathrm{O}_{2}$.

(e) $\frac{(b)-(a)}{(d)-(c)}=\frac{\mathrm{CO}_{2}}{\mathrm{O}_{2}}=$ assimilation coefficient.

(Cf. respiratory quotient, see Chap. III.). 
They find that under all conditions of light the assimilation coefficient is 1 . From this it may be inferred that $\mathrm{C}$ not $\mathrm{CO}_{2}$ is being built into the leaf. In short, the chloroplast acts as a machine for converting $\mathrm{CO}_{2}$ into $\mathrm{C}$ and $\mathrm{O}_{2}$ which is evolved. The carbon then unites with water to form some simple sugar, which one is not known. The final product is starch. The process may be represented by the equation :

$$
x \mathrm{H}_{2} \mathrm{O}+x \mathrm{CO}_{2} \text { +light energy }=\mathrm{C}_{x} \mathrm{H}_{2 x} \mathrm{O}_{x}+x \mathrm{O}_{2} \text {. }
$$

It has been proved that the first step is the formation of formaldehyde, i.e. $x=1$.

$$
\mathrm{H}_{2} \mathrm{O}+\mathrm{CO}_{2}+112,090 \text { gram cals }(?) \rightleftharpoons \mathrm{O}_{2}+\mathrm{CH}_{2} \mathrm{O}
$$

(formaldehyde).

Formaldehyde is injurious to plant tissucs, and it is rapidly transformed into other products.

If $x=2$ then the formaldehyde would condense to form glycollic aldehyde-a diose.

$$
\mathrm{CH}_{2} \mathrm{O}+\mathrm{CH}_{2} \mathrm{O}+\text { energy } \rightarrow \mathrm{C}_{2} \mathrm{H}_{4} \mathrm{O}_{2} \text {. }
$$

Similarly, glucose could be formed.

$$
\mathrm{C}_{2} \mathrm{H}_{4} \mathrm{O}_{2}+\mathrm{C}_{2} \mathrm{H}_{4} \mathrm{O}_{2}+\mathrm{C}_{2} \mathrm{H}_{4} \mathrm{O}_{2}+\text { energy } \rightleftharpoons \mathrm{C}_{6} \mathrm{H}_{12} \mathrm{O}_{6} \text {. }
$$

Two molecules of glucose combine to form maltosc.

$$
\begin{aligned}
\mathrm{C}_{6} \mathrm{H}_{12} \mathrm{O}_{6} & +\mathrm{C}_{6} \mathrm{H}_{12} \mathrm{O}_{6}+3300 \text { gram-calories } \\
& ? \mathrm{C}_{12} \mathrm{H}_{22} \mathrm{O}_{11}+\mathrm{H}_{2} \mathrm{O} .
\end{aligned}
$$

(v) The gums or dextrins are composed of condensed molecules of maltose, e.g.

$$
\mathrm{C}_{12} \mathrm{H}_{22} \mathrm{O}_{11}+\mathrm{C}_{12} \mathrm{H}_{22} \mathrm{O}_{11}+\mathrm{H}_{2} \mathrm{O}+\text { energy } \rightarrow \mathrm{C}_{24} \mathrm{H}_{46} \mathrm{O}_{23}
$$

and so on.

(3) The energy value of $\mathrm{CO}_{2}$ is $2 \cdot 1$ cals. per gram, that of $\mathrm{H}_{2} \mathrm{O}$ is $6 \cdot 5$, while starch has a value of 4191 gram cals. It is evident, therefore, that in some way the plant has converted a certain amount of kinetic energy into potential energy. Now, as the formula for starch is uncertain, let us consider the amount of energy required to form glucose from $\mathrm{CO}_{2}$ and $\mathrm{H}_{2} \mathrm{O}$. Carbon dioxide and water are fully oxidised. Theoretically, they may be considered as undergoing a process of reduction before combining to form the aldehyde, but as the cnergy evolved during reduction would be balanced by the energy absorbed during formation, we may limit our problem to the total energy change according to the two equations given above, viz. (i) and (iii). 
From (i) we see that a gram-molecule of formaldehyde has an energy-content approximating 112,300 gram calories. This store of energy is derived from the constituents $\mathrm{H}_{2} \mathrm{O}$ (117 gram cals.), $\mathrm{CO}_{2}(92 \cdot 4$ gram cals.), and from absorbed sunlight $(112,090 \cdot 6$ gram cals.).

With the formation of formaldehyde, practically all the energy necessary for the formation of carbohydrates has been absorbed. As we shall learn later (Chap. V.), osmotic energy is a function of concentration. Therefore, when six molecules of formaldehyde are condensed to one molecule of glucose, a corresponding amount of osmotic energy is liberated, and this may be utilised in part in endowing the glucose with the slightly higher content of chemical energy which it possesses over that of the formaldehyde. Sunlight here acts as a catalyst (Chap. IX.).

As we have seen, all the light falling on the leaf is not utilised - even all the light absorbed is not stored. Some energy is required for direct domestic use, e.g. transpiration. It has been calculated that about 10 per cent. of the incident light is absorbed by the chloroplast pigments. In an experiment by Brown and Escombe it was found that a total amount of incident light, which, if converted into heat units would correspond to $\mathbf{0 . 0 4 1}$ cal. per sq.cm. per minute, caused the decomposition of 0.00034 c.cm. of $\mathrm{CO}_{2}$ per sq.cm. per minute. In the conversion of $1 \mathrm{c.cm}$. of $\mathrm{CO}_{2}$ into glucose 5.02 gram cals. are stored. Therefore, in building $0.00034 \mathrm{c.cm}$. of $\mathrm{CO}_{2}$ into sugar the amount of energy rendered potential would be

$0.00034 \times 5.02=0.0017$ gram cals. per $\mathrm{cm}$. per minute.

As that is about 4 per cent. of the total incident radiation, the efficiency of the chloroplast under maximal conditions is somewhere about 40 per cent. When the process is reversed and carbohydrate split up with the assimilation of oxygen and the evolution of carbon-dioxide, this encrgy is again set free. It may be freed in such a way that a certain proportion of it appears as light. This light has, according to Trautz, the same wave length as the originally absorbed light. Of course, in general, the energy will be evolved in a form more suitable for utilisation than this (see Chaps. on Osmosis, Surface Tension, etc.).

Fats are stored up also in the plant. Very little research has been done on the synthesis of fats in the plants. Whether the plant can form these compounds directly or whether they are only synthesised from carbohydrate is not known. That they 
can be formed from carbohydrates is known, and Leathes states that this action is exothermic, several molecules of simple sugar going to the formation of one (larger) moleculc of fat, having, of course, a higher caloric value. The fat is almost exclusively found in the fruit.

Incidentally, energy is bound in the formation of proteins. This energy comes indirectly from the sun. Atmospheric nitrogen is fixed in a form available for plant use by certain bacteria. Each gram of nitrogen so fixed carries with it a considerable quantity of energy which is obtained from the oxidative decomposition of $100 \mathrm{mg}$. mannitol, the parent alcohol of the carbohydrate, mannose.

To conclude, the plant acts as a transformer of kinetic into potential energy by the formation of carbohydrates, fats, proteins (the so-called proximate principles of food) and a ferv other substances of minor importance as storehouses of energy.

Having regard to the fact that free energy is of vital importance, and that the potential energy of the foodstuffs is readily rendered available, one would consider it a profitable study to determine the exact mechanism of this conversion. So far, study of pure chlorophyll has led to negative results. Kremann and Schnidlerschitsch have recently shown that pure chlorophyll, in alcohol, absorbed the same amount of $\mathrm{CO}_{2}$ as the alcohol itself, and it made no difference whether the solution were exposed to light or kept in the dark. The absorption spectrum of neither chlorophyll $a$ nor chlorophyll $b$ nor chlorophyll $a+b$ is similar to the spectrum of the living green leaf. Knowledge is incomplete both of the chemical nature of the various constituents of the chloroplast and of the distribution and physical state of the components of this heterogeneous system. The pigments are associated with a colloid complex and the absorption of $\mathrm{CO}_{2}$ with alterations in the electrical state.

To sum up, man obtains the energy necessary for his maintenance and for the performance of physical work from the disruption of proteins, carbohydrates and fats, synthesised in the first instance by green plants which trap and store solar energy. Historically and until quite recently, the energy of sunlight, apart from an insignificant amount drawn from the tides, was the sole income of energy available for the world. Mankind still maintains himself solely on the energy derived from the sun through the intermediary of plant and animal metabolism, but he derives his energy for work to an increasing extent from 
a legacy of potential energy laid by in former times. He has devised detachable limbs (machines and tools) able to utilise the energy of coal, petrol, etc., of which he could not avail himself without their aid. This made possible an enormous increase in the world's work-work done no longer by human beings and beasts of burden, but by inanimate machines using the energy of fire, electricity, etc. To-day, a single machine does the work of an army of men. In this way he conserves present-day solar energy and lives on the banked income of past ages. Some time in the future he may learn how to synthesise food from inorganic constituents by the use of any form of available energy. Then and only then will he be able to dispense with plant life. Steps in this direction have been made. Moore and Webster have synthesised formaldehyde by exposing an aqueous solution of $\mathrm{CO}_{2}$ to ultra-violet light (Chap. XI.) in the presence of inorganic colloids (Chap. VIII.). They have also shown that dilute solutions of nitrates exposed to ultra-violet rays are converted into nitrites with an absorption of energy. One gram molecule of nitrite formed from nitrate transforms about 10,000 gram-calories of radiant energy into the potential statc-a strong endothermic reaction. This is similar to the change taking place in the plant in the formation of nitrogen compounds-the first stage in protein anabolism. 


\section{CHAPTER III}

\section{LIBERATION OF ENERGY}

\section{(1) CALORIMETRY}

"From the use of materials arise physical results, such as work, heat and electricity, which we can express in heat units. This is the power derived from metabolism."

Vort.

THE next matter for consideration is the method of measuring the potential energy of foodstuffs and comparing the value so found with the actual amount of energy liberated in the organism. It should then be apparent whether living matter in its various energy-changes obeys the laws of energetics. For purposes of measurement, it is customary in biology to convert all forms of energy into that of heat. This is scientifically correct, as heat is the "lowest grade" of energy, and all other forms of energy (ordered motion) may be degraded to unordered motion (heat); and it is not possible completely to convert any form of energy into any other form of energy but heat. In any such conversion, as we have seen, there is always a certain loss as heat. The unit of heat adopted in biology is the large calorie-that is, 1000 times the amount of heat required to raise one gram of pure water from $15^{\circ}$ to $16^{\circ} \mathrm{C}$. This value is almost the same as that required to raise one kilogram of water $1^{\circ} \mathrm{C}$.

Just as a country must have a standard coin of the realmpound or dollar-in which its assets may be computed, so must there be a standard unit for the computation of energy. The bank-teller totals up his day's transactions in $£ \mathrm{~s}$. $d$., no matter how various are the forms in which he has received or parted with the money. Cash, notes, cheques, deposit receipts, etc., all appear on his final balance-sheet under one denomination. Similarly, all energy transactions can be summed up and balanced as so many calories received, so many calories expended. Further, the fact that not a single sovereign may have crossed the counter; 
does not hinder the banker from entering $\mathfrak{E}$ sterling in his books. So calories may be the units employed, although heat may not necessarily enter the reaction.

\section{A. Measurement of energy-value (E.V.) of foods by ultimate analysis.}

The energy of a pure chemical compound may be calculated from its chemical formula. The amount of heat evolved when $\mathrm{C}$ is oxidised to $\mathrm{CO}_{2}$ and when $2 \mathrm{H}$ is combined with $\mathrm{O}$ to form water has been determined. The equations of these two reactions could therefore be written :

$$
\begin{aligned}
& \mathrm{C}+\overline{\mathrm{O}_{2}}=\overline{\mathrm{CO}_{2}}+94 \cdot 31 \text { cals. } \\
& 2 \mathrm{H}_{2}+\overline{\mathrm{O}_{2}}=2 \overline{\mathrm{H}_{2} \mathrm{O}}+117 \cdot 4 \text { cals. }
\end{aligned}
$$

(A horizontal line above the formula of a substance in a thermo-chemical equation indicates that the substance is in the gaseous state, the absence of any line indicates the liquid state, while a line below the formula indicates the solid state. The suffix aq is intended to convey the idea that the substance is in solution in such a large volume of water that the addition of more water would not produce any appreciable effect-that is, the substance is so dilute that its heat of dilution on the further addition of water would be negligible.)

One must note that any alteration of gaseous volume or of any other physical characteristic of any of the reacting units would, by utilising some energy as positive or negative work, produce an alteration in the amount of heat evolved. Welter enunciated a rule whereby one might arrive at an approximate value of the heat of oxidation of a compound containing oxygen as well as carbon and hydrogen. According to this rule the oxygen is subtracted from the molecular formula with as much hydrogen as would serve to convert it completely into water, the heat of oxidation of the carbon and hydrogen in the residue then gives a rough value of the heat of oxidation in the whole compound. For example :

A fat, tripalmitin, has the following formula $\mathrm{C}_{51} \mathrm{H}_{98} \mathrm{O}_{6}$ Deduct intramolecular water - - - $\frac{\mathrm{H}_{12} \mathrm{O}_{6}}{\mathrm{C}_{51} \mathrm{H}_{86}}$ Leaving for oxidation - $\quad-\quad-\quad-\overline{\mathrm{C}_{51} \mathrm{H}_{86}}$

$$
\begin{aligned}
\mathrm{C}_{51} \mathrm{H}_{86}+145 \mathrm{O}_{2} & =51 \mathrm{CO}_{2}+43 \mathrm{H}_{2} \mathrm{O} \\
& =51 \times 94 \cdot 31+43 \times 58 \cdot 7 \\
& =7333.9 \text { cals. }
\end{aligned}
$$

That is, a gram molecule (806 grams) of tripalmitin in being completely oxidised to $\mathrm{CO}_{2}+\mathrm{H}_{2} \mathrm{O}$ would liberate 7333.9 cals. of heat. Similarly, the energy stored in the form of carbohydrate may be calculated. A difficulty, however, occurs with proteins. 
In the case of carbohydrates and fats the end-products are those of complete oxidation, but in the case of proteins, the final results of metabolism are not substances of the lowest

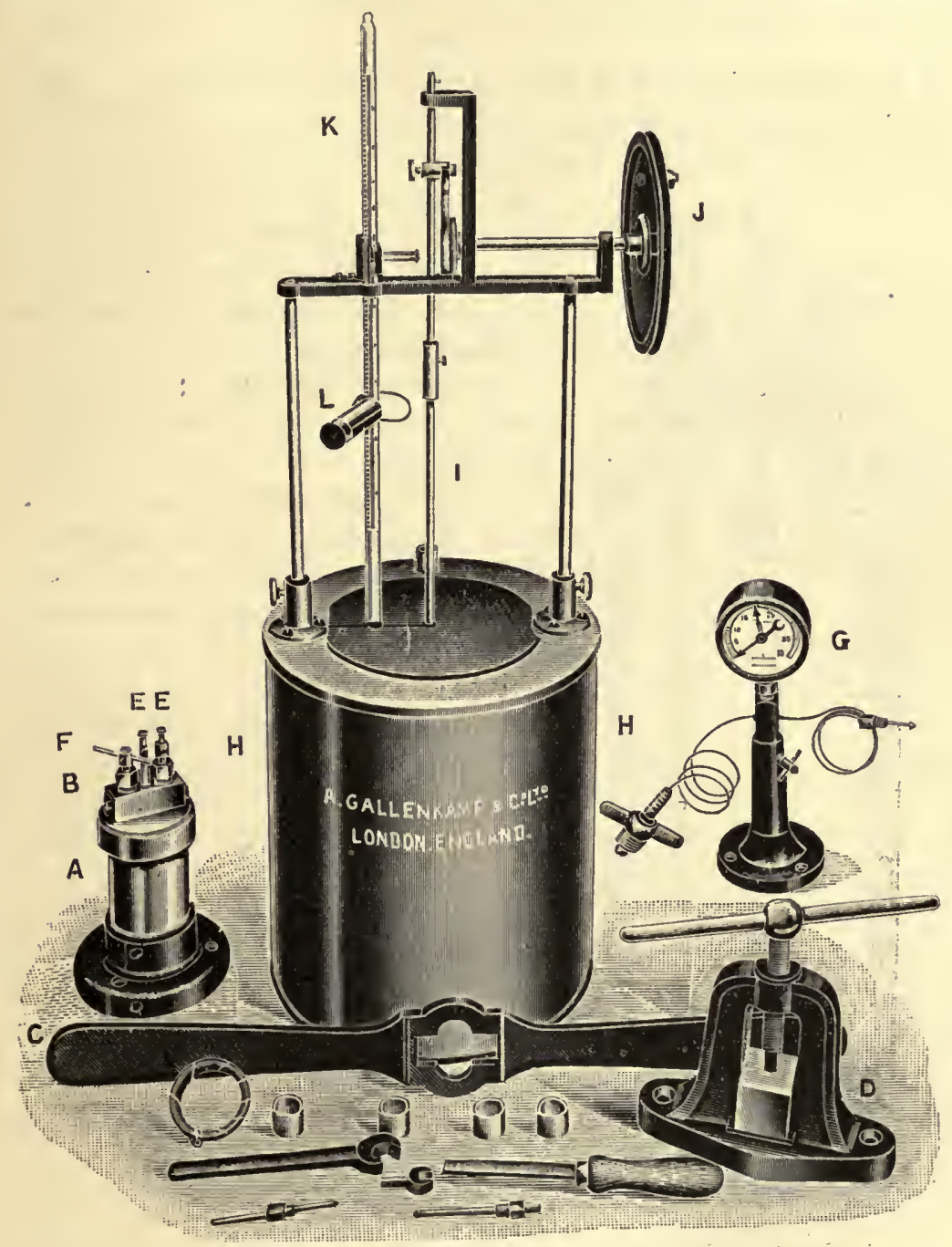

Fif. 2.-Berthelot-Mahler Bomb Calorimeter.

A. Bomb or autoclave (see Fig. 3).

I. Insulating vessel.

G. Manometer on stand with unlons to fix to oxygen cylinder and to bomb (at $S$, Fig. 3).

D. A steel nould for making pellets from the material to be burned.

energy content, i.e. protein is not complctely oxidised. Further, these protein end-products are eliminated in solution, and this requires some correction. Finally, to obtain the correct content 
of the foodstuff of $\mathrm{C}, \mathrm{H}$ and $\mathrm{O}$ requires a complicated chemical technique. This method of calculating energy-value is little used in biology. Pure substances are seldom used as food material, except in certain kinds of experiments.

\section{B. Measurement of E.V. of foods by calorimetric combustion.}

The principle underlying this method is the combustion of a known amount of the material in an apparatus so devised that

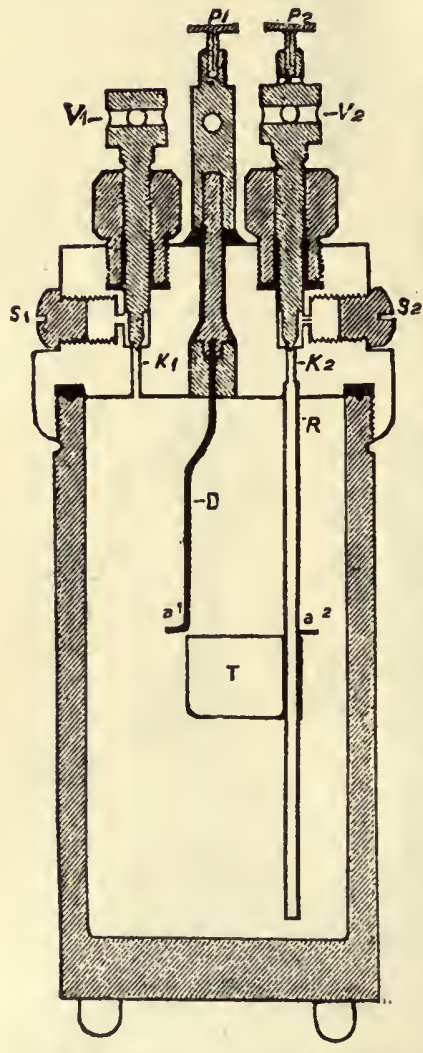

Fia. 3.-Section throngh a Kroeker bomb (see text). practically all the heat evolved is absorbed by a known amount of water and by the apparatus it.self (which is of known heat capacity). Some form of bomb calorimeter is now universally employed for this purpose. The instrument (Fig. 2) consists of three main parts.

1. The bomb itself is constructed.of steel, nickel-plated, with a cover to be screwed on firmly against a lead washer. Its capacity is about 300 c.cs. Through the cover the entrance and exit gas channels pass; $K \boldsymbol{2}$ with its continuation platinum tube, $R$, is for the introduction of oxygen, and $K 1$ for the withdrawal of the gaseous products of combustion. Both channels are closed by means of the screw spindles $V 1$ and $V 2$, running in stuffing boxes. $S 1$ and $S 2$ are screws to stop the lateral communication with $K 1$ and $K 2$. Into these may be screwed nickel-plated tubes. Through the centre of the cover passes a strong platinum wire, $D$, and this, as well as $R$, is fitted with short pegs, $a^{1}, a^{2}$, on which hangs the crucible

T. A short collar, just above these pegs, is for the attachment of the ignition wire. $P 1$ and $P 2$ are two small screw-clamps for attaching to the electric wires for ignition (Fig. 3).

2. The insulating chamber is a double-walled copper vessel of about 11 litres capacity, and the space between the walls is to be filled with water at room temperature. It is lined with 
white enamel, and contains within it, but insulated from it by a thin ebonite stand, 3 . the bright nickel-plated water holder.

Besides this it is necessary to have a stirring device, a thermometer to read to $1 / 100^{\circ} \mathrm{C}$., and a means whercby oxygen at 15-20 atmospheres pressure can be put into the bomb.

\section{Calibration.}

Certain values have got to be determined before the apparatus can be employed.

\section{Calorie Value of Match.}

In order to convert energy from the potential to the free state, we have already seen that some free energy must be addedthe material must be ignited. Various forms of match are employed. Some workers prefer to suspend a dried cotton thread of known weight from a platinum wire connecting $D$ and $R$. The thread dips into the crucible $T$, and touches or is embedded in the material to be burned. On completion of an electric circuit through $P 1$ and $P 2$ the platinum wire glows and sets off the cellulose match, which in turn causes the foodstuff to ignite. Others prefer to weigh out a piece of iron wire, 5-6 cms. long and $0.1 \mathrm{~mm}$. thick, and put it in place of both the platinum wire and the cotton thread. In any case, the amount of heat evolved in the ignition process has to be determined carefully, and deducted from the heat evolved, in a complete estimation or in the determination of the water equivalent.

\section{Water Equivalent.}

The apparatus itself-vessels, thermometer, stirrer-is heated along with the water it contains. Its water equivalent, i.e. the quantity of water which has the same heat capacity as the apparatus, must be determined and added to the quantity of water actually employed in the experiment. Several methods exist for this determination. The most exact, and at the same time the most convenient, is to burn in the calorimeter a weighed quantity of a substance whose calorie value is known with absolute certainty, and ascertain the resultant change in the temperature of the water. The water cquivalent is:
$\left(\frac{\text { Total heat generated (calculated) }}{\text { Observed increase in temperature of calorimeter water }}\right)-\left(\begin{array}{c}\text { Quantity of water in } \\ \text { apparatus (in gins )) }\end{array}\right.$

\section{Calibration of Thermometer.}

The thermometer has to be calibrated, and a correction applied for this. 


\section{Cooling Constant.}

Another correction to be made in the final calculation is that of the cooling constant of the apparatus. The chief source of error in calorimetric experiments lies in heat exchange with extcrnal objects by conduction and radiation. To reduce this error to a minimum (a) the chemical action must go on 'as fast as possible, hence the use of oxygen under pressure; $(b)$ the temperature of the calorimeter water is kept as nearly as possible at the same value as the temperature of the room. We have already stated how the grosser errors of conduction and radiation are avoided by the structure of the insulating chamber. In spite of this there is a certain loss, which is measured as part of the regular routine of an experiment and is allowed for.

In order to calculate the energy of any material one must know what the end-products of the combustion are. We have seen that $\mathrm{C}$ and $\mathrm{H}$ are always under these circumstances completely oxidised to $\mathrm{CO}_{2}$ and $\mathrm{H}_{2} \mathrm{O}$, which undergo little or no further energy changes. $\mathbf{S}$ and $\mathbf{N}$, on the other hand, are converted into sulphuric and nitric oxides, which in turn dissolve in and combine with water forming $\mathrm{H}_{2} \mathrm{SO}_{4}$ and $\mathrm{HNO}_{3}$. A correction has to be applied for their heats of solution and combination. For very fine work, corrections may be applied for the latent heat of evaporation of water and for the heat of solution of $\mathrm{CO}_{2}$.

Determinations of the energy-value of the proximate principles of food have shown that only minute differences exist between the various members of any class. For example, one gram of each of the following carbohydrates has the accompanying value in calories :

\section{TABLE II.}

$\begin{array}{llll}\text { Starch } & =4 \cdot 191 & \text { large calories. } \\ \text { Cane Sugar } & =3.955 \quad, & , \\ \text { Maltose } & =3.94 \quad, & , \\ \text { Milk Sugar (Lactose) } & =3.95 \quad, & , \\ \text { Glucose } & =3.74 \quad, & , \\ \text { Fruit Sugar (Fructose) } & =3.75 & , & ,\end{array}$

Average values have therefore bcen adopted and accepted as standard. E.g.

Carbohydrate -

Fat -

Protein
- $4 \cdot 1$ Calories.

- $9 \cdot 3 \quad$,

- $5 \cdot 3 \quad$, 
Of course, the discerning student will understand that, except in rare and restricted feeding experiments which have a special end in view, pure carbohydrate, fat and protein are not exhibited. Determinations are made of the energy-value of actual foods. This gives opportunity for the display of some ingenuity on the part of the investigator, since some of the commoner articles of diet do not readily lend themselves to combustion and are not easily dried. Nevertheless, extended experiments are being conducted by physiologists, in which, as part of the routine, the total energy-value of the daily diet is determined.

The energy-value of the diet does not represent the energy used by the organism.

(a) Some energy-carrying substances cannot be digested, and therefore are excreted unchanged in chemical composition and energy content, e.g. cellulose.

(b) Other constituents of the diet may undergo some chemical alteration, but may be excreted not fully deprived of their energy.

(i) Proteins are not completely oxidised in the body. Their end-products are urea and allied substances.

Because of the difference in the end-products there is a physiological calorie value for proteins different from their purely physical value. Rubner determined this physiological value by deducting from the absolute value, the heat value of nitrogenous end-products in faeces and urine with their heats of solution. $\mathrm{He}$ arrived at the figure 4.015 . The accepted average value is $4 \cdot 1$ calories per gram of protein.

(ii) Certain substances are excreted in combination with protein disintegration products, e.g. hippuric acid.

(c) Certain substances or their disintegration products seem to be necessary constituents of faeces, e.g. fats (see Chap. XXVII.).

The energy-value of all excreta must therefore be deducted from the energy intake before an energy balance can be struck.

\section{Measurement of the E.V. of foods by animal calorimetry (a) direct, (b) indirect.}

It is obvious as a direct deduction from the first law of energetics that if this law holds in living as well as in non-living matterenergy transformations, the same amount of energy should be evolved from the utilisation of food inside as well as outside the body, provided always that the physical state and chemical end-products are the same in each case. If an animal could be put inside a calorimeter and given a definite amount of food, 
the heat evolved should, providing our hypothesis is true, be exactly the same as would be evolved in direct food calorimetry. Each gram of carbohydrate should produce $4 \cdot 1$ cals., and so on. This can be put to the test in either of two ways. The first is known as direct (animal) calorimetry, and consists in accurately measuring the heat evolved by the animal under investigation. The second or indirect method is based on a knowledge of the amount of heat evolved per litre of the respiratory gases and per gram of urinary nitrogen.

(a) The direct method was first employed by Crawford (1779). His calorimeter, in principle, consisted of a double-walled box with a known amount of water between the walls. The animal was placed in the inner box for a definite time and the increase in temperature of the water noted at the end of the experiment. The method is, of course, primitive, and the veriest tyro in physics could suggest quite a host of sources of error, but on this crude instrument are based those finer implements of research which, in the hands of Benedict and his colleagues, have contributed so much to the knowledge of nutrition. Crawford found that for every $100 \mathrm{ozs}$. of oxygen used during the combustion of carbon in his calorimeter, the temperature of the water was raised $1.93^{\circ} \mathrm{F}$. A live guinea pig consuming the same amount of oxygen produced an increase of $1.73^{\circ} \mathrm{F}$. This seemed sufficient evidence for him to conclude that, in each case, the heat produced was due to the conversion of pure air into fixed, or, as we should now say, to the combination of $\mathrm{C}$ and $\mathrm{O}_{2}$.

A year later, Lavoisier and Laplace published the result of experiments which confirmed Crawford's results, and made firm the principle of indirect calorimetry. They detcrmined the amount of ice melted by the combustion of a weighed amount of carbon (a candle) and the volume of the $\mathrm{CO}_{2}$ evolved. A similar experiment was then tried with a guinea pig. They found that for equal volumes of $\mathrm{CO}_{2}$ formed, the candle yielded $25 \cdot 4$ cals. as against the guinea pig's 31:8. The experiment is bristling with errors, many of which the authors realised. For instance, the respiratory and calorimetric determinations were not, as by Crawford, made simultaneously, and obviously thermal conditions were not the same. As we shall see later, cold raises the $\mathrm{CO}_{2}$ output. If allowance is made for this and for other minor errors, the figures for candle and animal come close enough to justify the conclusion that the processes are similar, and that the source of heat in both is the combination of $\mathrm{C}$ and $\mathrm{O}_{2}$. 
The various sources of error due to faulty technique have been gradually eliminated, and the resultant calorimeters that bear the names of Atwater, Rosa, and Benedict and that of Williams produce results that are sufficient to convince even the most sceptical of honest observers that the oxidation of assimilated foodstuffs in the living body produces the same evolution of energy as they would if burned in the bomb calorimeter, provided the end-products are identical.

The direct method is not of such general use as the indirect. Study of the papers from the Carnegie Institute of Washington or of those from Cornell University makes clear the complexity of the machine and the intricacy of its manipulation. The cost, except for the smallest Williams' boxes, is prohibitive. The apparatus can be much simplified if the direct estimation of the energy-changes is omitted and the observer confines himself to measuring the respiratory gases and the urinary output.

(b) Indirect. As we have seen, the basis of this method also was laid by Crawford. It depends upon the following established facts :

(I) The quantity of energy liberated depends on the chemical composition of the food used.

(II) The quantity of oxygen absorbed depends also on the chemical composition of the food used ; therefore,

(III) There must be some relation between the energy evolved and the quantity of oxygen absorbed.

(IV) The three proximate principles of food differ markedly in chemical composition. (a) Proteins contain nitrogen, which is eliminated almost entirely in the urine. (b) Carbohydrates and fats differ widely in their proportion of $\mathbf{O}$ to $\mathbf{C}$.

(V) If a determination were made of the amount of heat and the amount of $\mathrm{C}$ and $\mathrm{O}_{2}$ which corresponds to each gram of urinary nitrogen, one could, from the nitrogen excreted, calculate the heat liberated from the protein of the diet. ( 1 gram of urinary nitrogen $=\mathbf{2 6 . 5 1}$ cals.) Having deducted the protein $\mathrm{O}_{2}$ from the total $\mathrm{O}_{2}$ absorbed and the protein $\mathrm{CO}_{2}$ from the total $\mathrm{CO}_{2}$ eliminated, one arrives at the figures corresponding to the non-protein $\mathrm{O}_{2}$ and $\mathrm{CO}_{2}$ respectively.

(VI) Now, as we have said, carbohydrates differ from fats in their respective contents of $\mathrm{C}$ and $\mathrm{O}_{2}$. Carbohydrates have the general formula $x\left(\mathrm{CH}_{2} \mathrm{O}\right)$, while fats contain less $\mathrm{O}_{2}$ compared with their content of oxidisable matter, e.g. $x\left(\mathrm{C}_{9} \mathrm{H}_{12} \mathrm{O}\right)$. Therefore, when carbohydrates alone are used, the ratio of the volume 
of $\mathrm{CO}_{2}$ eliminated to the volume of $\mathrm{O}$ absorbed will be 1 , as may be deduced from the equation :

$$
\begin{aligned}
\mathrm{C}\left(\mathrm{H}_{2} \mathrm{O}\right)+\mathrm{O}_{2} & =\mathrm{CO}_{2}+\mathrm{H}_{2} \mathrm{O} \\
1 \mathrm{vol} & =1 \mathrm{vol}
\end{aligned} \quad \mathrm{R} . \mathrm{Q}=\frac{\mathrm{Vol} \mathrm{CO}_{2}}{\mathrm{Vol} \mathrm{O}_{2}}=\frac{1}{1}=1 .
$$

Fats are compounds of the trihydric alcohol, glycerol, with organic acids of the aliphatic (fatty) homologous scries. The simplest fatty acid is formic, H.COOH. The higher acids are built up by successive additions of $\mathrm{CH}_{2}$.

TABLE III.

Saturated Series. $\mathrm{C}_{n} \mathrm{H}_{2 n} \mathrm{O}_{2}$.

E.g.

$\mathrm{H} \cdot \mathrm{COOH}$-formic acid $\mathrm{CH}_{2} \cdot \mathrm{HCOOH}-$ acetic acid

$\mathrm{CH}_{2} \mathrm{O}_{2}$

\begin{tabular}{cc}
$\mathrm{CH}_{2} \cdot \mathrm{HCOOH}$-acetic acid & $\mathrm{C}_{2} \mathrm{H}_{4} \mathrm{O}_{2}$ \\
$\mathrm{CH}_{2} \cdot \mathrm{CH}_{2} \cdot \mathrm{HCOOH}$-propionic acid & $\mathrm{C}_{3} \mathrm{H}_{6} \mathrm{O}_{2}$ \\
$\mathrm{CH}_{2} \cdot \mathrm{CH}_{2} \cdot \mathrm{CH}_{2} \cdot \mathrm{HCOOH}$-butyric acid & $\mathrm{C}_{4} \mathrm{H}_{8} \mathrm{O}_{2}$ \\
\hline &
\end{tabular}

$\left(\mathrm{CH}_{2}\right)_{15} \cdot \mathrm{HCOOH}-$ palmitic acid $\mathrm{C}_{16} \mathrm{H}_{32} \mathrm{O}_{2}$

$\left(\mathrm{CH}_{2}\right)_{16} \cdot \mathrm{HCOOH}$-margaric acid $\mathrm{C}_{17} \mathrm{H}_{34} \mathrm{O}_{2}$

$\left(\mathrm{CH}_{2}\right)_{17} \cdot \mathrm{HCOOH}$-stearic acid $\quad \mathrm{C}_{18} \mathrm{H}_{36} \mathrm{O}_{2}$

$$
\begin{aligned}
& \text { Unsaturated Series. } \mathrm{C}_{n} \mathrm{H}_{2 n-2} \mathrm{O}_{2} \\
& \text { oleic acid }
\end{aligned}
$$

A glance at this list will make it clear that the amount of oxygen does not increase although the $\mathrm{C}$ and $\mathrm{H}$ are increased. This paucity of oxygen content is more marked in the fats than in the fatty acids.

Palmitic Acid

Glycerol

Palmitin

$$
\begin{aligned}
& \mathrm { C } _ { 1 5 } \mathrm { H } _ { 3 1 } \mathrm { CO } \longdiv { \mathrm { OH } } \mathrm { H } \mathrm { O } \\
& \mathrm{C}_{15} \mathrm{H}_{31} \mathrm{COOH} \quad \mathrm{H} O-\mathrm{C}_{3} \mathrm{H}_{5}=\mathrm{C}_{51} \mathrm{H}_{98} \mathrm{O}_{6}+3 \mathrm{H}_{2} \mathrm{O} \\
& \mathrm{C}_{15} \mathrm{H}_{31} \mathrm{CO} \mathrm{OH} \quad \mathrm{H} \mathrm{O}^{-} \\
& \mathrm{C}_{51} \mathrm{H}_{98} \mathrm{O}_{6}+145 \mathrm{O}=51 \mathrm{CO}_{2}+49 \mathrm{H}_{2} \mathrm{O} \text {. } \\
& \text { Now ratio }=\frac{\mathrm{Vol} \mathrm{CO}_{2}}{\mathrm{Vol} \mathrm{O}_{2}}=\frac{51}{72 \cdot 5}=0 \cdot 70 \text {. }
\end{aligned}
$$

That is, ratio for carbohydrates is 1 .

$$
\text { " "fats } \quad, 0.7 \text { (circa) }
$$

(Zuntz gives 0.707 as an average figure for fats.)

(VII) Values for a non-protein ratio lying between $0 \cdot 7$ and 1 denote the utilisation by the body of a mixture of fats and carbo- 
hydrates; the closer the ratio comes to unity the more carbohydrates are being oxidised, and vice versâ.

(VIII) Now, knowing the proportion of carbohydrate and fat in the diet, one may calculate the amount of energy set free from the two following figures :

(a) If carbohydrate alone is used each litre of $\mathrm{O}_{2}=5 \cdot 047$ cals.

(b) If fat , , , , , , , $\quad=4 \cdot 686$ cals.

Intermediate values may be obtained by interpolation. The results obtained by indirect calorimetry are within 2 per cent. of results from the respiration calorimeter.

In a series of twenty-two different experiments with a dog, Murlin and Lusk obtained the following results :

Indirect calorimetry - $\quad-\quad-2244$ cals.

Direct,$\quad$ - $\quad-2230$,

Difference - - - - 14,

Percentage - - - - 0.6 , 


\section{CHAPTER IV}

\section{LIBERATION OF ENERGY}

\section{(2) THE ANIMAL AS MACHINE}

"The living and the dead, things animate and inanimate, we dwcllers in this world, and this world wherein we dwell, are bound alike by physical and mathematical law."

THOMPSON.

WE have just seen that:

(1) Some of the radiant energy of the sun is stored by plant agency, and is ingested by the animal as food; and (2) the sum total of the energy taken in by the organism in this way can be accounted for. There is neither gain nor loss of energy in the living animal : the physical law of conservation of energy holds good.

We must consider the physics underlying the liberation of this energy. Does it follow any of the methods well known to us? Can we compare the foodstuffs to fuel and the body to a heat engine? In other words, what intermediate stage, if any, does the potential energy of, say, starch, reach before becoming apparent as animal energy? The physiological text-books are so full of references to combustion, fuel value, burning of foodstuffs, that it is natural for the student to look upon the life processes as somewhat similar to those of a steam engine. In spite of this it can be definitely said that the animal body bears little resemblance to any form of heat engine. The intermediate stage between potential and free energy is not the wasteful one of heat. In order that heat may be converted into work there must be a certain allowance for "spillage." There must also be a certain gradient of potential. In other words, unless there is a certain minimum difference in temperature between the source of heat and the sink (or heat condenser), the machine will not work. (Principle of Carnot.) In 1824 Carnot determined, theoretically, the percentage of heat that any heat engine could convert into work. A theoretically perfect engine, working 
between the absolute temperatures $T_{1}$ and $T_{2}$, takes up $Q$ cals. from a heat reservoir at the temperature $T_{1}$ and transforms the part $W$ into work, then

$$
W=Q \frac{T_{1}-T_{2}}{T_{1}} \text { (Carnot's Equation). }
$$

Evidently the fraction $\frac{T_{1}-T_{2}}{T_{1}}$ is that part of the $Q$ units of heat which represents the amount of energy made available for work. That is, even under unattainably perfect conditions no more heat than $\frac{T_{1}-T_{2}}{T_{1}}$ of the amount given can be converted into work. This equation gives the efficiency of the heat engine.

The most efficient steam engine yet constructed-a Nordbeg air compressor of 1000 h.p.-converts 25 per cent. of the heat energy it receives into work. Most steam engines are only 8 to 10 per cent. efficient, i.e. only 8 tons out of every 100 tons of perfect fucl burned have their energy converted into work.

\section{TABLE IV.}

Comparative Thermal Efficiencies.

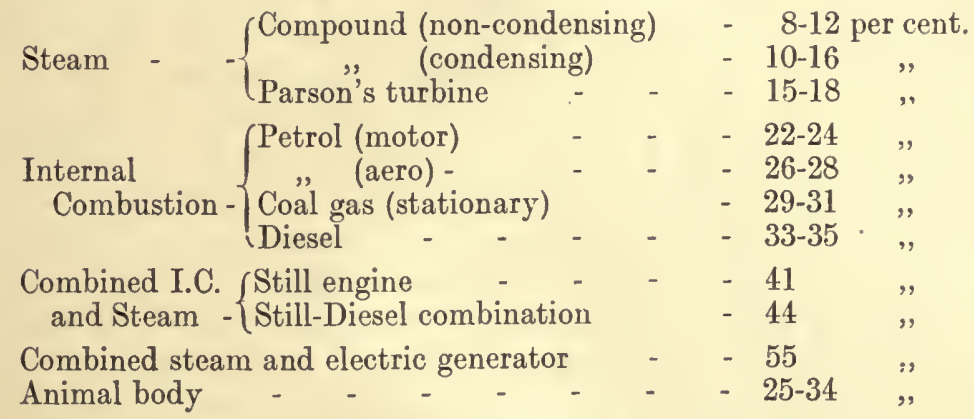

If one were to consider the animal as a heat engine, then it must operate between two temperatures. One of these temperatures we know, viz. body temperature, which is $38^{\circ} \mathrm{C}$. or $273+38=311^{\circ}$ absolute. This is the condenser or "sink" temperature. The other temperature, that of combustion, must be higher. How much higher may be calculated from the equation above.

or transposing

$$
\text { Efficiency }=\frac{T_{1}-T_{2}}{T_{1}}=E,
$$

$$
T_{1}=T_{2} / I-E .
$$

B. B. 
Suppose we take a low figure for animal efficiency, say 20 per cent. Then, substituting, we find that

$$
T_{1}=\frac{311}{1-0 \cdot 2}=\frac{311}{0 \cdot 8}=389^{\circ} \text { absolute or } 116^{\circ} \mathrm{C} \text {. }
$$

That is to say, in order to have an efficiency of 20 per cent. with a condenser temperature of $38^{\circ}$, the temperature of the heat source would need to be $116^{\circ} \mathrm{C}$. Experience teaches that the production of any such temperature in any tissue would cause death. Lethal temperature is somewhere about $47^{\circ} \mathrm{C}$. However the animal may transform bound energy into free, it does not do so by conversion to heat as one of the stages.

It is not definitely known how the living organism is able to make use of the chemical energy of the foodstuffs. Analogy with familiar non-living machines breaks down here. An electric battery is able to transform chemical energy into kinetic energy without the middleman heat, the go-between in this case being certain unknown but ordered atomic movements. Observation shows clearly that muscle at least is not similar to an elcctric motor. Similarly, one can dispose of all other forms of energytransformation used in machines to get work from bound energy.

To attempt to gain an insight into the workings of the living organism one must go back to elementary principles, and study the machine itself. The history of the foodstuffs after ingestion must be followed, and any changes they undergo must be noted. The processes of digestion, absorption and assimilation will be noted later. Meanwhile, we want to know what, in general, happens to all foods used as sources of energy. Have they, in the main, a common history? Of one point at least we may be sure, and that has been dealt with at some length in the preceding chapter, namely, that liberation of energy in the animal and oxidation are invariably concomitants. Thus the amount of oxidation may be taken as a measure of the energy transformation.

Again, it has been definitely proved that all energy changes and all vital oxidations take place in the living cell. Physiological chemists, while unable to arrive at a definite conclusion as to the composition of the cell, are at one with the histologists in stating that the cell material is of the nature of a solution. Cell protoplasm consists of over 75 per cent. of water acting as the solvent for certain crystalloids and as the dispersion medium for various colloids. The cell comes into intimate contact with other cells, and all cell contents are not of the same chemical composition 
nor in the same physical state. There will, therefore, arise differences in surface tension and may be differences in osmotic pressure. It will, therefore, be profitable for us to examine the energetics of simple solutions; then of colloid complexes; and finally to apply any relevant knowledge so gained to ascertained facts regarding cell behaviour.

We must not forget that our aim in this digression (to solutiondynamics) is to elucidate the processes by which the potential energy of foods is rendered kinetic. 


\section{CHAPTER V}

\section{LIBERATION OF ENERGY}

\section{(3) ENERGY OF SUBSTANCE IN SOLUTION}

"The problem of achicving perpetual motion contrary to the second law" (of thermodynamies) " is that of bringing order and direction once more into the chaotic rush of the molecules, to marshal and drill the mob so that once more they can act together to produce a common effect." SoDDY.

\section{Osmotic Pressure.}

The first process that affects food is that of digestion. Digestion is merely the breaking down of the material supplied so that it can pass through the absorbing medium in solution. It follows (from this statement and from the physical state of the living cell) that all energy manifested by an animal comes from substances in solution. No material is of any use for energy purposes unless it is soluble, and until it is rendered soluble it cannot be absorbed and utilised.

That is, the availablc energy of a cell may be divided into :

(1) The potential energy inherent in the various substances that compose it.

(2) The kinetic energy these substances have because they are in solution.

These two statements together imply that the mere solution of a substance may so alter the state of that substance that energy is set free. (Cf. heat evolved on diluting concentrated $\mathrm{H}_{2} \mathrm{SO}_{4}$.) Further, it may be inferred from this that the physical conditions which determine the charactèr and behaviour of living cells depend on the composition of the latter and on their environment.

Far-reaching dicta such as these cannot be accepted without question. First of all, has the solution of a substance any effect on its energy content? Does sugar, for instance, lose some of its energy-content when dissolved in tea? Does the bound 
energy so liberated appear as kinetic energy without the intermediation of heat, electricity, etc.?

When a solid goes into solution it at once loses the properties characteristic of the solid state. Its particles become mobile, and all the properties dependent on regular molecular arrangement disappear. Thus the solid may be optically active or doubly refracting, and the solution quite void of these properties.

The passage of the substance into solution bears some resemblance to its passage into the liquid state. A doubly-refracting crystal almost invariably loses its double refraction when it melts ; and most substances which are optically active in the solid state are inactive when fused.

The substance might conceivably have passed into the gaseous state. Physical chemists are agreed that this is the most probable course. They find that for dilute solutions, at any rate, the simple gas laws hold good.

In order to explain and correlate these gas laws and the phenomena of solution, evaporation, 'etc., the Kinetic Theory of the structure of matter has been formulated. The views that have been held regarding the constitution of solutions have been very varied, and since Thermodynamics is too general in its method of treatment to yield a complete answer to the problem, hypotheses, guided and tested by experiment, are accepted. The following theory was first propounded by van't Hoff in 1885, and it has been improved by later physicists. It allows the Second Law of Energetics to be applied with conspicuous ease and clearness to the theoretical investigation of the quantitative relations between the properties of solutions. Matter is regarded as an aggregation of particles (molecules), each of which is perfectly elastic and structurally independent. Between them there exist spaces.

Two opposite forces are at work on molecules.

(1) A Cohesive Force. Newton's Law states that every portion of matter attracts every other portion of matter. The stress between them depends on the mass of the particles and the distance between them. Stress $=\frac{m_{1} \times m_{2}}{d^{2}}$ where $m_{1}$ and $m_{2}$ are the masses of the particles and $d$ the distance between them.

(2) A Repellent Force (Real Kinetic Energy $=\frac{1}{2} m v^{2}$ ). Every molecule is free to vibrate in a straight line within the limits of the intermolecular spaces. In a solid these spaces are small, 
and therefore the attractive forces are predominant. If a greater kinetic energy be given to the molecules by means of heat, for instance, their path will be increased at a rate corresponding to the coefficient of expansion. At a point, the repellent force will exactly balance the attractive force, that is, $\frac{1}{d^{2}}=\frac{v^{2}}{2}$. The substance then assumes the liquid state, gravity alone determining the arrangement of the molecules.

If the temperature of the liquid be raised, some of the molecules will have sufficient vclocity to burst through the surface layer and become free gas molecules. If these gas molecules move away unhindered, other molecules from the liquid will take their place, and the liquid will evaporate. If, however, the liquid is kept in a closed space, the gas molecules which leave its surface will be able to proceed no farther than the walls of this space, and rebounding from these must eventually return in the direction of the liquid. Some will strike the surface of the liquid and will be retained by it. But the molecules still continue as before to leave the surface of the liquid, so that, at one and the same time, there are molecules cntering and leaving the liquid. When the pressure of the molecules leaving the surface of the liquid balances the gaseous pressure above it, a stationary state will be reached, i.e. the same number of molecules will be freed from the liquid as are being absorbed by it. That pressure is the Vapour Pressure of the substance. (Cf. tension of gas in solution.)

In addition to the Kinetic Theory of gases, one must assume the statement generally known as the Hypothesis of Avogadro: "Equal volumes of different gases, at the same temperature and pressure, contain the same number of molecules." 'This proposition has been adopted as a working hypothesis, and as such has stood the test of time. It is, in fact, a necessary supplement to the Atomic 'Theory.

The laws governing the physical behaviour of gases are simple statements correlating pressure, volume and temperature.

(1) Boyle's Law. The volume of a given mass of gas varies inversely as the pressure on it, if the temperature of the gas remains constant.

$$
V \backsim \frac{1}{P}
$$

(2) Charles' or Gay Lussac's Lare. The volume of a given mass 
of any gas varies directly as the absolute temperature if the pressure remains constant.

$$
V_{T}=V_{0}(1+\alpha T) .
$$

(3) The pressure of a given mass of any gas varies directly as the absolute temperature, provided the volume of the gas remains constant.

$$
P_{T}=P_{0}(1+\alpha T) .
$$

Any one of these laws may be deduced from the other two. The whole may be summed up in the formula

$$
P V=R T,
$$

where $R$ is a constant varying only with the unit of energy used.

\section{TABLE V.}

UNIT OF ENERGY.

Gram-Centimetre -

Joule (Volt-Coulomb)

Volt-Faraday -

Litre-atmosphere -

Gram-calorie
VALUE OF $R$.

- 84,760 .

- $8 \cdot 315$.

- $0.8613 \times 10^{4}$.

- 0.08207 .

- $\mathbf{1} \cdot 985$.

The thermal equation with the gram calorie as unit is the one most often employed in Biophysics, and is generally taken as 2. That is, the gas equation assumes the approximate form

$$
P V=2 T \text {. }
$$

What is the pressure of a gas? The gas only manifests its kinetic energy by alteration in its pressure or its volume. As has already been stated, the molecules of a gas are free to move in a straight line till they collide with another molecule or with the walls of the containing vessel. The particle will then rebound in its line of approach with a velocity equal to its orginal velocity, but, of course, with the opposite sign.

The pressure of a gas is due to the bombardment of the walls of the containing vessels by the molecules.

For unit volume, $\frac{2}{3}$ of the total kinetic energy of the gas is responsible for the pressure of that gas. Another conclusion that may be drawn from the kinetic theory of gases is that the velocity of a gaseous particle is inversely proportional to its mass. 
This brings us to the study of gaseous diffusion. Before entering on this subject it is necessary to keep in mind Dalton's Law of Partial Pressures, which may be stated as follows : In a mixturc of gases each gas exerts the same pressure as it would exert if it were alone present in the volume occupied by the mixturc. The pressure of each gas is called its partial pressure. In other words, if several gases are brought together, each of them will be distributed through the whole space as if the other gases were entirely absent.

Gaseous diffusion takes place, and as a result there ensues a perfectly uniform mixture of the gases no matter what thcir

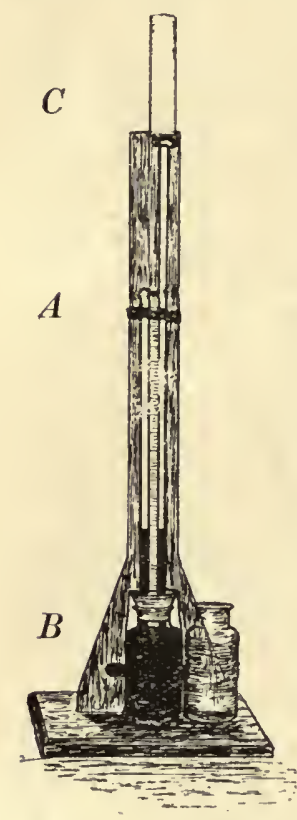

Frg. 4.- Simple diffusio. meter. original proportions were, and irrespective of the masses of their respective molecules. This diffusion takes place independent of gravity. A heavy gas will diffuse upwards into a lighter one.

Now, suppose we separate the two gases, $A$ and $B$, by a thin porous septum such as a plug of plaster of Paris. It was observed by Graham that the pressure of the gases did not remain the same on both sides of the membrane. The pressure was greatest on the side of the heavier gas. The molecules of lighter gas $B$ would bombard the septum far oftener than those of the heavier gas $A$, and therefore there would be a greater chance of some of them hitting the pores and getting through and so raising the pressure in $A$.

That this is so may be very easily demonstrated by a simple piece of apparatus (Fig. 4). $C$ is an unglazed earthenware cell such as is usually employed to hold the zinc rod in a Leclanché battery. Into its mouth is fixed a rubber stopper carrying a glass tube, the lower end of which passes just through one of the holes in a similar rubber stopper of the bottle $B$. The glass tube $A$ passes right through the other hole of this stopper and goes to the foot of $B$. $B$ is filled with coloured water. Both stoppers must be thoroughly air-tight. If now a wide-mouthed bottle containing coal gas is inverted so as to enclose $C$, the coloured fluid will rise in $A$ showing increase in pressure in $C$. If the gas used were heavier than air, negative diffusion would take place, 
and pressure in $A$ would fall. This demonstrates the conversion of unordered molecular motion into ordercd hydraulic motion capable of doing work.

The relative velocities of diffusion of any two gases even through a thin porous septum are inversely proportional to the square roots of their densities.

This does not hold if the septum is not very thin, for then the velocity is decreased by the impact of the molecules on the inside surface of the pores.

Graham further found that it was possible to procure semipermeable membrancs - that is, a membrane which would allow free passage to one gas but not to another. What will happen in such a case? Suppose $B$ can pass freely through the septum while $A$ cannot. Both gases are at 1 atmos. pressure. Then $B$ will diffuse through the membrane, and fill up the next space as if $A$ were not there, i.e. there will finally be $\frac{1}{2}$ atmos. of $B$ on both sides. The total pressure on $A$ will be $1 \frac{1}{2}$ atmos. The excess of pressure is due to the gas $A$, which cannot pass through the septum. So that by taking the difference of pressure on the two sides of a semi-permeable membrane, we obtain the partial pressure of the gas to which the membrane is impermeable. (See Respiration, Chap. XXIII.)

An attempt may now be made to apply these laws (which are only absolutely true for perfect gases) to solutions-in the first instance to simple solutions only.

$$
P V=R T=2 / 3\left(\frac{1}{2} n m v^{2}\right) .
$$

All these symbols seem applicable to a substance in solution except $\boldsymbol{P}$. What is the pressure of a solute? This may be determined in a way similar to the determination of gascous pressure. If an osmometer be fitted up (Part II. p. 398) with a solution of sugar inside and watcr outside, in a short time the fluid inside will increase in volume and will rise in the osmometer tube developing a hydrostatic pressure. To what is this pressure due? Obviously water (and pressure) will be transferred from a point where its pressure is high to a point where its pressure is low. In some way or other the presence of sugar (or other solute) has lowered the pressure of the water. Can this be explained by reference to the kinetic energy ? Reasoning backwards, it may be argued that the sugar acts as a drag upon the water molecules-that is, the bombardment of the membrane becomes unbalanced. The pure solvent is able to cxert a greater 
pressure than the solution. When, then, will the pressure inside become equal to the pressure outside - that is, when will the hydrostatic pressure developed become great enough to balance the reduction of pressure to the solute? Experiment has shown that the maximal rise of hydrostatic pressure is reached when its value is equal to the difference in vapour pressures between the solvent and the solution. Vapour pressure, as we have seen, depends on the kinetic energy of the molecules in a liquid. Experiment has further shown that for simple dilute solutions the magnitude of the osmotic pressure depends on the molecular weight of the substance dissolved, the amount of substance in the solute per unit volume and on the temperature of the solution. That is, osmotic pressure is controlled by just those factors which control gaseous pressure. Suppose the gram-molecular weight of the (undissociated) substance to be taken as $m$ grams, dissolved in $V$ litres of water, at the absolute temperature $T$. The concentration, i.e. the number of mols. $(n)$ per litre would be $\frac{n}{V}$.

Now, we may consider that dilute solutions obey the gas laws, and therefore

$$
P V=R T \text { or } P=\frac{R T}{V} .
$$

We have seen that $\frac{2}{3}$ of the kinetic energy of a gas is manifested as gaseous pressure, and so we may state that

$$
P=\frac{2}{3} \frac{\frac{1}{2} n m v^{2}}{V} \text {. }
$$

That is, osmotic pressure is equivalent to $\frac{2}{3}$ of the total kinetic energy of the particles in solution. Put in another way, it might be stated that in a simple solution the osmotic pressure of a substance would be numerically equal to the gaseous pressure which the substance would exert were it a gas occupying the same volume as the solution.

Now we have seen that the variables connected with gaseous pressure are $T$ and $V$. As, according to Avogadro's hypothesis, equal volumes of gases under equal $T$ and $P$ eontain the same number of molecules, we may state that, if $T$ is kept constant, $P$ varies as the number of molecules. De Vries (1884) found that one gram-molecule of sugar dissolved in water to make up a litre, has at $0^{\circ} \mathrm{C}$. an osmotic pressure of $22 \cdot 4$ atmos. (Practically all gases at $0^{\circ} \mathrm{C}$. and $760 \mathrm{~mm}$. pressure have a gram 
molecular volume of $\mathbf{2 2 . 4}$ litres, or conversely at $0^{\circ} \mathrm{C}$. it would require a pressure of $\mathbf{2 2 . 4}$ atmos, to reduce a gram molecular volume to one litre.) De Vries, Pfeffer, and others have shown that this is true not only for sugar, but for all simple (undissociated) solutions. Van't Hoff (1887) pointed out that the osmotic pressure of simple solutions is the same quantitatively as gas pressure. We have already pointed out that vapour pressure is a function of molecular activity, and may be taken as an index of the kinetic energy of the liquid. The kinetic energy again varies with the temperature of the liquid system. It follows that vapour pressure varies directly with temperature. We have seen that the putting of a substance into solution lowers the vapour pressure of the solvent and, therefore, lowers its heat content. This can be deduced from the second law of energetics. From what has been said regarding the lowering of vapour pressure, which always occurs when one substance is dissolved in another, it may be inferred that the boiling point of a liquid is always raised when a substance is dissolved in it. (These only apply to instances where the V.P. of the solute is negligible.) A very volatile substance, ether, for instance, would raise the V.P. and lower the B.P.

Correlated with these two sequelae of solution is the lowering of the freezing point. (Part II.)

The magnitudes of the osmotic pressure, lowering of the vapour pressure and freezing point, and raising of the boiling point depend in general on $\frac{n}{V}$, the number of particles in solution per unit volume. Because these magnitudes are all interrelated and are interdependent they have been named the colligative properties of a solution. They are definite physical quantities quite independent of semi-permeable membranes, etc. The membranes make osmotic pressure apparent.

Osmotic pressure is of considerable magnitude. We have seen that a gram-molecular solution has an osmotic pressure of $\mathbf{2 2} \cdot 4$ atmos., i.e. $330 \mathrm{lbs}$. per sq. inch. The ordinary dilute laboratory reagents develop a pressure of about 50 atmos. In a plant, root pressure has been estimated at about 60 feet of water.

If, however, one were to tabulate the osmotic pressure of gram-molecular solutions of all substances, one would find that solutions eould be divided into three great classes according to pressure. 
1. O.P. Approximately

$22 \cdot 4$ atmos.

2. O.P. Decidedly greater than $22 \cdot 4$,

3. O.P. , less, ,22.4,

The first class have been termed simple (undissociated) solutions. According to the kinetic theory the second and third classes have a larger or smaller number of particles in solution than theory warrants.

Class 2. Where have the extra particles come from? Has the molecule divided? If one compares the osmotic pressure of cane sugar and sodium chloride in gram-molecular solution, one finds them (roughly) as $1: 2$. How can this be explained ? In 1887 Arhennius propounded his dissociation theory, which has since been proved, amplified and universally accepted. According to this theory, some of the molecules of certain salts when dissolved in water split up or dissociate into their constituent ions. An ion is an atom or a sub-molecular group charged with electricity and attached to certain water molecules.

For example,

$$
\begin{aligned}
\mathrm{NaCl}(\text { solid })+\mathrm{aq} & =\text { cat-ion +an-ion } \\
& =\mathrm{Na}+\mathrm{Cl} \\
& =\left(\mathrm{Na}\left(\mathrm{H}_{2} \mathrm{O}\right) x\right)+\left(\mathrm{Cl}\left(\mathrm{H}_{2} \mathrm{O}\right) y\right) .
\end{aligned}
$$

It is the presence of these ions which gives a solution the power of conducting electricity, and so any substance which dissociates, i.e. becomes ionised on going into solution, is said to be an electrolyte.

All salts may therefore be classed as

Electrolytes, Class 2.

Non-Electrolytes, Class 1 and Class 3.

It is worthy of note that electrical conductivity is not a property either of the solvent or of the solute, but of the solution.

Pure distilled water is a non-electrolyte.

Pure dry hydrochloric acid is a non-electrolyte.

But an aqueous solution of hydrochloric acid is a very good electrolyte. All electrolytes are not dissociated to the same extent. A salt of cither a strong acid or a strong base requires the addition. of comparatively little water completely to convert all its molecules into ions. On the other hand, a weak acid or base is difficult to dissociate.

If the gram-molecular weight of an electrolyte be dissolved in a litre of water a certain fraction of the molecules will split into ions. This fraction is the degree of ionisation of the clectrolytc 
at this concentration. The degree of ionisation may be determined by estimating the amount of resistance of the solution to a small electric current (conductivity method), or it may be approximately calculated from the lowering of the freezing point. (For univalent strong electrolytes at concentrations not excceding $\mathbf{0} \cdot \mathbf{1}$ molar, Noyes and Falk consider that the percentage error is in most cascs between 1 and 4.)

One may note in passing that the ions of many electrolytes possess the property of uniting with other ions, or even with non-electrolytes in solution, to form complex ions. For example, ions cannot normally remain free in aqueous solution, but become hydrated. A hydrated ion is sometimes termed an ionic micelle.

In solutions of the third class, the O.P. and other colligative properties point to a reduction in the number of particles in solution. A clubbing of molecules has taken place. Because the substances that compose this group have a somewhat gluey consistency, Graham called them colloids (Gr. ко́ $\lambda \lambda \eta=$ glue). The physics of colloidal complexes will be dealt with in a separate chapter. Here we merely wish to draw attention to their low osmotic pressure. Colloid substances may be converted into noncolloid or crystalloid derivatives, and so liberate energy, e.g. starch, a colloid having practically no O.P. may be readily hydrolysed to maltose, which is a crystalloid-non-electrolyte, having a molal O.P. Glucose, which has a molal O.P., may be stored in the liver as glycogen-a colloid, which again readily undergoes hydrolysis to glucose. (Sce Chap. VIII., Colloids.) 


\section{CHAPTER VI}

\section{THE LIBERATION OF ENERGY}

\section{(4) SURFACE ENERGY}

"This Phaenomenon proceeds from a propriety which belongs to all kinds of fluid Bodies more or less, and is caused by the Incongruity of the Ambient and included Fluid, which so acts and modulates each other, that they acquire, as neer as is possible, a spherical or globular form."

НоОке, 1665.

(See also Chap. XIII. Muscular Contraction; XIV. and XV. Secretion and Excretion; XVI. Nerve Conduction; XXVI. Respiration.)

\section{A. Pure Liquids.}

Two forces act on molecules :

(a) A repellent force-kinetic, revealed in osmotic pressure, vapour tension; etc.

(b) A cohesion or attractive force-Newton's "Gravity."

"Every particle attracts every other particle with a force inversely proportional to the square of the distance between them." This gives rise within the liquid to intrinsic pressure, whose magnitude we have no direct means of measuring, and whose energy we cannot utilise. Why? Because the various tractative forces acting on each and every molecule within the liquid neutralise one another. The attractions, except on the surface layer, are uniform and cancel out. Consider a single internal molecule. The tractative forces acting on it may be resolved into four components acting cyclically at right angles to one another. It is obvious that these forces are paired. That at twelve o'clock is equal to and opposite to that at six, and therefore ineffective. Similarly, the eastwards pull at three o'clock is neutralised by the westwards pull at nine. In the surface layer, matters are different. One component, that is the force pulling downward at 6 o'clock, has no opposing force at 12 to stabilise the molecule. There is, therefore, a state of strain 
in the surface area. This state of strain is called the surface tension of the fluid, and by release of this strain work may be done. That there is apparently an elastic skin over fluids at their junction with air is casily demonstrated. (Physicists call the junction of a fluid with any other substance an interface. They write of fluid-air, fluid-gas, fluid-fluid interfaces.) At a water-air interface substances heavier than water can be supported. A clean needle floats on water. Water-beetles, etc., move freely on the surface. Resistance to deformation is greater on the surfacethan in the body of the liquid (cf. Searle's torsion balance).

How can this energy be utilised? How can S.T. be either raised or lowered? Whatever alters intrinsic pressure will, of course, alter surface tension. The magnitude of the intrinsic pressure depends inversely on the kinetic energy of the molecules. The less the kinetic energy the less the mean frec path of the molecules, and the less the distance between the molecules. Intrinsic pressure varies as $\frac{1}{d^{2}}$. This variation of S.T. with K.E. does not concern the biologist, as alterations in K.E. imply alterations of temperature, and we have seen that only slight alterations in temperature are compatible with life.

It is possible to alter surface tension without altering intrinsic pressure by altering the electric charge on the surface layer. According to the Helmholtz-Lippmann theory, at any surface there are two electrical layers equal in amount but opposite in sign:

1. On the surface molecules of the fluid.

2. On the immediate external layer of the surrounding medium -air, glass, etc.

Therefore, any alteration in the amount of the charge on the liquid layer will produce an alteration in the surface tension. If the charge on the surface is increased, the K.E. of the molecules (i.e. repulsion of like signs) will be increased, " $d$ " will be increased and S.T. will be diminished. Conversely, an increase in S.T. is brought about by decreasing the electrical charge. The S.T. cannot, of course, be increased beyond that which the superficial layer would have in the absence of any charge or double layer. This alteration may be brought about dircetly or indirectly:

I. Directly. Lippmann's capillary electrometer. If a capillary tube be taken and a drop of mercury placed in it, the mercury will run down and some will gather as a drop at the tip. If now the tip of the capillary be immersed in dilute $\mathrm{H}_{2} \mathrm{SO}_{4}$, the $\mathrm{Hg}$ 
will become + and the $\mathrm{H}_{2} \mathrm{SO}_{4}$ surface layer - . The S.T. decreases and some $\mathrm{Hg}$ will drop out. Alteration in this charge by connecting the $\mathrm{Hg}$ to a negative electrode will produce an increase of S.T. and an upward movement of the mercury. The amount of movement depends on the difference of potential existing between the $\mathrm{Hg}$ and the $\mathrm{H}_{2} \mathrm{SO}_{4}$, and may be used as a means of measuring small differences of potential (see Fig. 5).

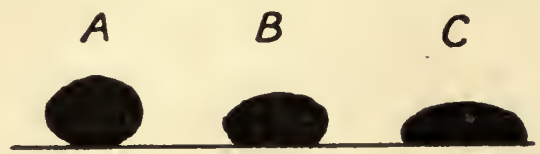

Fig. 5. - Form assumed by mercury globules under different electrical states. $B$ is a mercury globule immersed in dilute $\mathrm{H}_{2} \mathrm{SO}_{4}$. It assumes a more spherical form $\boldsymbol{A}$ when connected with the negative pole of a battery, while connection to the positive pole reduces surface tension as shown at $\boldsymbol{C}$.

II. Indirectly. Effect of solutes. Substances which when fluid have a lower surface tension than water, lower surface tension when dissolved in water, and vice versâ. Why this happens is not known. A plausible explanation is that of ionisation; but if ionisation is the cause, why should weak organic acidsonly slightly dissociated-have great lowering power, while strongly dissociated inorganic salts have very little effect? Very few substances raise S.T., and that only to a very slight extent. Most organic substances lower S.T. markedly, e.g. addition of butyric acid to water to make a 1 per cent. solution lowers S.T. from 75 to 35 dynes.

A solid-liquid interface has always a lower S.T. than either a liquid-liquid or a liquid-air interface. That is why water rises in a capillary tube.

It is obvious, therefore, that means exist for readily lowering S.T. and so setting free energy.

\section{B. Solutions.}

The addition of a solute makes some alteration in the intrinsic pressure of a fluid and necessitates a redistribution of energy. Solutes are not universally dispersed throughout a solution. "The concentration throughout a fluid tends to be so adjusted as to reduce the energy at every point in it to a minimum" (GibbsThomson Principle). Solutes that lower surface tension are more concentrated at the surface, while those raising the surface tension are found in smallest amounts at the surface. This may be deduced from the second Law of Energetics. (See Part II. for demonstration of S.T. and for methods of estimation : adsorption will be treated in Chap. VIII., Colloids.) 


\title{
SECTION II.: CELLULAR MECHANICS
}

\section{CHAPTER VII}

\section{IONISATION}

\author{
IONS-THE 'WORKMEN' OF THE CELL
}

"Many things move me to suspect that everything [natural as well as mechanical] depends upon certain forces, in virtue of Which the particles of bodies, through forces not yet understood, are either impelled together...., or are repelled and recede from onc another."

Newton.

Trrss. subject has been alluded to in connection with abnormal osmotic pressures (Chap. V. p. 44), where it was pointed out that clectrolytes, on going into solution, were more or less dissociated into their constituent ions. The extent to which an electrolyte is thus dissociated determines whether it is a strong or a weak electrolyte. Inorganic acids and bases and their salts are almost completely dissociated in solution, the dissociation increasing with dilution until, of course, complete dissociation is reached. Organic acids and bases, as a rule, are dissociated with difficulty, complete dissociation being reached only at great dilutions. There are exceptions, some organic bases are just as well ionised as the strongest inorganic bases. Guanidin salts, for instance, have dissociation values lying between sodium and barium salts. Salts formed of a weakly dissociated acid and a strongly dissociated base or of a weak base and a strong acid have dissociation values intermediate to those of their constituents.

There are two outstanding points of interest about ions.

1. Ions are always electrically charged. The "metal". ion having a positive and the "acid" ion a negative charge. (The former, in Faraday's terminology, is called a cation and the latter an anion.)

2. Ions are never free, but arc always hydrated.

B.B. 
1. Electrical Charge. It is obvious that if two electrodes from a source of supply be dipped into a solution containing ions, that in virtue of their charge the anions (negative ions) will be attracted towards the anode (positive electrode) and the cations (positive ions) will be drawn towards the cathode (negative electrode). Such a solution will therefore conduct electricity, and further, its efficiency as a conductor will depend on the number of ions present, i.e. on the dissociation of the solute.

This provides the basis on which the method for estimating the concentration of ions has been devised. In doing this the electrical resistance, in ohms, is measured. Conductivity is the reciprocal of resistance (Part II. p. 415).

Relative Speed. Another factor must be taken into account. We have seen that ions do pot all move at the same rate. The rate depends on the atomic weight of the ions, the degree of hydration and the influence of other ions. (Ions by their electric charge influence one another.) Under similar conditions, each ion moves at a constant ratc.

That the rate is slow is shown by passing an electric current through a solution containing coloured ions at one electrode and noting the time they take to reach a similar concentration at the other electrode. Kohlrausch determined the relative speed of ions at $18^{\circ} \mathrm{C}$. and for a constant potential gradient found as follows :

TABLE VI.

\begin{tabular}{|c|c|c|c|c|c|}
\hline \multicolumn{3}{|c|}{ Cations + } & \multicolumn{3}{|c|}{ Anions - } \\
\hline Ion. & Atomic Wt. & Relative Speed. & Ion. & Atomic Wt. & Relative Speed. \\
\hline $\mathrm{H}$ & 1 & 318 & $\mathrm{OH}$ & 17 & 174 \\
\hline $\mathrm{K}$ & 39 & $64 \cdot 6$ & $\frac{1}{2} \mathrm{SO}_{4}$ & 48 & 68 \\
\hline $\mathrm{NH}_{4}$ & 18 & $61 \cdot 4$ & $\mathrm{Br}$ & 80 & 67 \\
\hline$\frac{1}{2} \mathrm{Ba}$ & $68 \cdot 5$ & 55 & I & 127 & $66 \cdot 5$ \\
\hline$\frac{1}{2} \mathrm{Sr}$ & $43 \cdot 7$ & 51 & $\mathrm{Cl}$ & $35 \cdot 5$ & $65 \cdot 5$ \\
\hline$\frac{1}{2} \mathrm{Ca}$ & 20 & 51 & $\frac{1}{2} \mathrm{C}_{2} \mathrm{O}_{4}$ & 44 & 63 \\
\hline$\frac{1}{2} \mathrm{Mg}$ & 12 & 45 & $\mathrm{CH}_{3} \mathrm{COO}$ & 59 & $33 \cdot 7$ \\
\hline $\mathrm{Na}$ & 23 & $43 \cdot 5$ & & & \\
\hline $\mathrm{Li}$ & 7 & $33 \cdot 4$ & & & \\
\hline
\end{tabular}

Bredig has pointed out that with organic ions the longer the carbon chain, the less the speed. The decrease in speed is, however, comparatively slight.

2. Hydration. Consideration of the numerical values of the relative ionic rates gives a means for calculating the hydration of the various ions. It may be taken for granted that the specd 
of ions apart from hydration is proportional to their mass, e.g. potassium and chlorine have approximately similar atomic weights and similar speeds. Any variation from this proportion is usually attributed to the different hydration of the ions. It is generally conceded that, as stated above, all ions are hydrated. Therefore potassium and chlorine must be hydrated to almost the same extent. Bousfield has shown that 9 watcr molecules are attached to both ions of potassium chloride when completely dissociated. Now, as the speed of $\mathrm{K}$ to $\mathrm{Cl}$ is as $\frac{64 \cdot 6}{39}: \frac{65 \cdot 5}{35 \cdot 5}$, i.e. as $16: 19$, almost as $4: 5$, it may be considered that $K$ has 4 and $\mathrm{Cl} 5$ water molecules per ion.

In the group of alkali metals tabulated above it will be seen that the lightest metal, lithium, furnishes the most sluggish ion of the three, and, conversely, the most mobile ion is that of the heaviest metal, potassium, sodium being intermediate both in atomic weight and in speed. This is supposed to mean that lithium is more heavily hydrated than sodium, and sodium more than potassium. The number of molecules of water combined with their chlorides when completely dissociated is respectively, 21,13 and 9 . If the 5 molecules of water which form an envelope for the chlor-ion, be subtracted from the total, lithium is found to be hydrated to the extent of $\mathbf{1 6}$ and sodium to 8 molecules.

\section{Effect of Temperature.}

Increase in temperature according to the kinetic theory and laws of energy will increase the specd of ions, provided of course that dissociation is complete. Partially dissociated salts are more completely ionised by increase in temperature. For equal increment of temperature, different ions inerease in speed according to their degree of hydration. The more highly hydrated the ion, the greater is its temperature co-efficient. 'This is explicablc on the hypothesis that a rise of temperature will favour the disruption of hydrate-complexes and decrease the size of the ion, and so reduce the frietional resistance to its passage through the fluid.

When dealing with surface tension (p. 47), the Helmholtzian double layer or surface electrical charge was mentioned. This may now be attributed to the different ionic speeds. Whichever of the two ions has the greater mobility will get into the surface layer and of course will carry its charge with it. This will cause the mobilisation on the immediately opposite "side" of the surface of an equal and opposite charge. As has been said above, 
this gives rise to a difference of electrical potential, which may explain some of the anomalies of diffusion through living animal membranes.

Of course there exists an enormous electrostatic attraction between ions of opposite sign. The introduction of other electrolytes into a solution may therefore alter not only the rate of migration of the original ions but the nature of the surface charge. The addition of $\mathrm{HCl}$ to a solution of $\mathrm{KCl}$ would increase the diffusion potential that would be produced at the boundary between solutions of $\mathrm{KCl}$ at different concentrations; the more $\mathrm{HCl}$ present, the greater the diffusion potential.

This is due of course to the relatively greater speed of the hydrogen ion. The $K$ ions move at about the same speed as the $\mathrm{Cl}$ ions, while the $\mathrm{H}$ ions move about five times as fast. The boundary surface previously charged negatively with a low E.M.F. would take on a positive charge with a higher E.M.F.

It is imperative to note that unless the electrostatic force mutually exerted between anion and cation is overcome, these ions though separated will never be far apart.

In ordinary solutions the "metal" ion, no matter what its relative speed, cannot be separated from its " acid" ion by mere

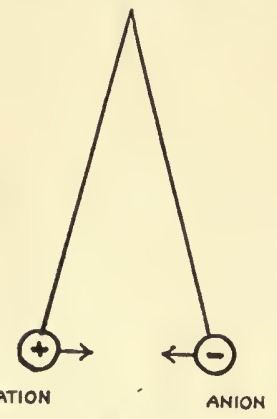

FIG. 6.-Model of anion and catlon. Two pith balls suspended by silk threads attract one another if carrying opposite charges. When the charges are of the same sign, the balls diverge, i.e. repel one annther. diffusion. The disturbance of electrical equilibrium caused by the introduction of electrodes into the solution will produce a separation of the salt into metal and acid.

Now, if there exist equal and opposite charges on an- and cat-ions, tending to draw them together, why, in the first instance, did they separate, and what keeps them apart? This brings us to the discussion of the dielectric constant. To put a name on a thing or on a process does not explain it. Neither is it sufficient to say that the dielectric constant or specific inductive capacity of any medium is a measure of the capacity of that medium to act as a dielectric (nonconducting) substance of an electric condenser. The higher the value of the constant, the greater is the value of the condenser.

If two pith balls (Fig. 6) are hung by a dry silk thread and given equal and opposite charges of electricity, they may be regarded as representing ion-hydrates. 
There is a constant relation between the charge of a body and its eleetric potential. This ratio is ealled the capaeity of the body as a conduetor, and depends on the nature of the medium separating the two charged bodies. The tendeney of two oppositely charged bodies to eome together is altered by altering the dielcetric or medium separating them. Air is taken as the standard dielectric, and all other dieleetric constants are referred to that of air as unity. From the accompanying table it will be secn that watcr has a high dielectric constant.

\section{TABLE VII.}

$$
\begin{aligned}
\text { Air } & =1 \cdot 0 \\
\mathrm{CO}_{2} & =1 \cdot 0004 \\
\mathrm{H} & =0.9997
\end{aligned}
$$

$\begin{array}{ll}\text { Water } & =81 \cdot 7 \\ \text { Alcohol } & =25 \cdot 0 \\ \text { Formaldehyde } & =84 \cdot 0 \\ \text { Acetic Acid } & =6 \cdot 46 \\ \text { HCN (liquid) } & =95 \\ \left.\begin{array}{l}\text { Vaseline } \\ \text { Turpentine } \\ \text { Benzine } \\ \text { Paraffin } \\ \text { Liquid Fat }\end{array}\right\}=2 \cdot 2 \\ \end{array}$

('The determination of the diclectric constant of different substances is of interest from its bearing on Maxwell's eleetromagnetic theory of light. The diclectric constant of a substance in the ease of light of long wave-length is the same as its refractive index squared.)

According to the electron theory, an atom is composed of electrons. Electrons are all similar, and are supposed to be not sensible matter, but the smallest possible unit of negative electricity Atoms of different substances owe their different qualities to the varying number of eleetrons they contain and to the diversity of their combination. These electrons are supposed to exercise an obstructing influence on the passage of an electrie charge due to their tendency to move in the direction opposite to the direction of the current. The larger the number of the eleetrons, therefore, the greater the obstruction and the greater the value of the dielectric constant. Water has a high dielectrie constant, and so once the molecule has beeome dissociated, the resultant ions may approach very near to one another without combining. In short, the dielectric constant is a measure of the insulating capacity of the substanee. The addition of solutes alters the value of the dieleetric eonstant of the solvent.

The atoms in a molecule are held together by very strong 
electrostatic forces. A very large amount of energy must therefore be expended in separating these atoms. Energy is also expended in removing one of the valence electrons from each cation. This energy is supplied by the energy of combination of the elcetronegative molecules of the solvent (heats of dilution and hydration) and by the heat of combination of the anions with the freed valence electrons. It is thus that Sir J. J. Thomson explains the charges of the ions. The ionising power of a solvent seems to be some function of its dielectric constant. On the other hand, the degree of ionisation of a salt seems to be due to the electronic structurc of its constituent atoms. The whole subject is bristling with difficulties and so far explanations can only. be regarded as reasoned guesses.

\section{Water.}

The solutions dealt with above have all been aqueous. Solutions in water as the solvent were early recognised as the most important. According to the old Greek philosophers water was "the beginning of all things." Thales said, "All things have their origin in water and return unto the same." 'The importance of water as a solvent was generally recognised early in the seventeenth century. Aqueous solutions are fundamental for all biological phenomena. The physical properties of water are in general extreme-their numerical cxpressions arc either extremely large or extremely small, and usually the former. Its specific heat and its dielectric constant are the highest of any of the more common liquids. Therefore, water should have a very high ionising power as a solvent.

One has been accustomed to look upon water as a simple inert substance, of the chemical formula $\mathrm{H}$. $\mathrm{OH}$ and with a molecular weight of 18. Physical chemists have proved that this conception does not account for all the properties of water. Lewis and also Langmuir, from thermodynamical principles and also from the study of the colligative properties (sec p. 43) of water, have constructed diagrams of the molecule of water. Discussion of this work is somewhat without the bounds of this book.

In recent years it has been amply demonstrated that a triatomic molecule could not possess the properties of water. For instance, it is composed of gases with extremely low freezing and boiling points. Oxygen boils at $-181^{\circ}$, while the figure for hydrogen is $-253^{\circ} \mathrm{C}$. From comparison with compounds of known composition, ice should form at $-150^{\circ}$ and the tempera- 
ture of steam should be $-100^{\circ} \mathrm{C}$. The inference from this is that the molecule of water is bigger than $\mathrm{H}_{2} \mathrm{O}$. Each simple molecule or hydrol is supposed to combine with another hydrol so as to form a dihydrol or three hydrols may polymerise to trihydrol, and so on. Water, as we know it, consists of a mixture of these various hydrols. The relative amount of each kind is determined $(a)$ by the temperature of the fluid, and $(b)$ by the substances present in solution or, in a less degree, in suspension.

(a) Temperature controls the kinetic energy of the molecules and so the size of the intra-molecular spaces. Increase of temperature, therefore, by increasing the kinetic energy will cause a disruption of polyhydrol into its simpler constituents. Decrease of temperature has the reverse effect. Theoretically, there is the gas $\mathrm{H}_{2} \mathrm{O}$ and the solid $\left(\mathrm{H}_{2} \mathrm{O}\right)_{3}$, and between these extremes the liquid $\left(a\left(\mathrm{H}_{2} \mathrm{O}\right)+b\left(\mathrm{H}_{2} \mathrm{O}\right)_{2}+c\left(\mathrm{H}_{2} \mathrm{O}\right)_{3}\right), a, b$ and $c$ being constants dependent on the temperature. At each temperature there is equilibrium between the amounts of the various hydrols. The temperature of water has thus an importance in deciding its physical and chemical properties, and therefore, in all reactions involving water, temperature should be stated.

(b) As has been pointed out above, there is a certain equilibrium composition of water at each temperature. This equilibrium is disturbed by the presence of a solute, especially if it is dissociated. Hydrol is abstracted to hydrate the ions or molecules of the solute and a rearrangement of equilibrium takes place.

\section{Ionisation Constant.}

Absolutely pure water is almost, but not quite a non-electrolyte. As absolutely pure water has not yet been prepared, this is a deduction from the behaviour of water under certain circumstances.

Water is ionised according to the equation

$$
\mathrm{H}_{2} \mathrm{O} \rightleftharpoons \mathrm{H}^{+}+\mathrm{OH}^{-} \text {: }
$$

According to Guldberg and Waage's Law of Mass Action (p. 61), the product of the concentrations of the reacting substances, $\mathrm{H}^{+}$and $\mathrm{OH}^{-}$, bears a direct relationship to the mass of the resultant substance $\mathrm{H}_{2} \mathrm{O}$.

That is

$$
\frac{\left[\mathrm{H}^{+}\right] \times[\mathrm{OH}]^{-}}{\left[\mathrm{H}_{2} \mathrm{O}\right]}=\text { constant } K_{w}
$$

where $\left[\mathrm{H}^{+}\right]=$the fraction of the total water which is dissociated into hydrogen ions. 
$\left[\mathrm{OH}^{-}\right]=$the fraction of the total water which is dissociated into hydroxyl ions

and $\left[\mathrm{H}_{2} \mathrm{O}\right]=$ the fraction of the total water which is left undissociated.

Stated in words, the product of the concentration of hydrogen ions and hydroxyl ions is always equal to a constant quantity $\boldsymbol{K}_{w}$, The value of $K_{w}$, the ionisation constant of water, depends only on the temperature.

$$
\begin{aligned}
\text { At } \quad 0^{\circ} \mathrm{C} . & K_{w} & =\frac{1}{10,000,000,000,000,000} \\
\text { At } 23^{\circ} \mathrm{C} . & K_{w} & =\frac{1}{100,000,000,000,000} \cdots \\
\text { At } 40^{\circ} \mathrm{C} . & K_{w} & =\frac{28}{100,000,000,000,000} \cdots \\
\text { At } 100^{\circ} \mathrm{C} . & K_{w} & =\frac{48}{100,000,000,000,000} \cdots
\end{aligned}
$$

To save writing those cumbrous fractions, the index notation is used. Thus fraction

$$
\begin{aligned}
& (1) \text { is }=0.01 \times 10^{-14}=C_{w} \text { at } 0^{\circ} \mathrm{C} \text {. } \\
& (2) \text { is }=1 \times 10^{-14}=C_{w} \text { at } 23^{\circ} \mathrm{C} \text {. } \\
& (3) \text { is }=28 \times 10^{-14}=C_{w} \text { at } 40^{\circ} \mathrm{C} \text {. } \\
& (4) \text { is }=48 \times 10^{-14}=C_{w} \text { at } 100^{\circ} \mathrm{C} \text {. }
\end{aligned}
$$

Now, as the quantity of water dissociated is so very small compared with the total quantity of water, it is clearly legitimate to put $\left[\mathrm{H}_{2} \mathrm{O}\right]=1$ in the mass action equation, which now becomes :

$$
\left[\mathrm{H}^{+}\right] \times\left[\mathrm{OH}^{-}\right]=K_{w} .
$$

It is obvious that $\mathrm{H}^{+}$and $\mathrm{OH}^{-}$are produced in equal amounts, and therefore

$$
\left[\mathrm{H}^{+}\right]=\left[\mathrm{OH}^{-}\right]=\sqrt{K_{w}} \text {. }
$$

Between $22^{\circ}$ and $23^{\circ} \mathrm{C}$. water has a dissociation constant with which it is convenient to work, and measurements of hydrogen ion concentrations are usually made at this temperature or referred to this temperature;

$$
\begin{aligned}
& \text { i.e. at } 23^{\circ} \mathrm{C} ., K_{w}=10^{-14} ; \\
& \therefore\left[\mathrm{H}^{+}\right] \times\left[\mathrm{OH}^{-}\right]=10^{-14} \text {. }
\end{aligned}
$$

$\left[\mathrm{H}^{+}\right]$is therefore equal to $\sqrt{10^{-14}}=10^{-7}$,

and $\quad\left[\mathrm{OH}^{-}\right] \quad, \quad, \quad, \quad \sqrt{10^{-14}}=10^{-7}$.

It is usual to write $\mathrm{H}^{*}$ for $\mathrm{H}^{+}$and $\mathrm{OH}^{\prime}$ for $\mathrm{OH}^{-}$. 
Still further to shorten the symbols, S $\phi$ rensen suggested the use of the logarithm to denote the hydrogen ion concentration. Instead of writing $10^{-7}$ one may write merely the positive index 7 , keeping the rest of the formula in mind. This is called the $p_{\mathrm{H}}$, $p$ denoting the index to the base 10 , and $H$, of course, showing that hydrogen ions are under consideration. That is, in neutral water at about $23^{\circ} \mathrm{C}$.

or

$$
\begin{aligned}
& p_{\mathrm{H}}=p_{\mathrm{OH}}=7, \\
& C_{\mathrm{H}}=C_{\mathrm{OH}}=10^{-7} .
\end{aligned}
$$

In words, neutral water has a hydrogen ion concentration of $\%$ Appended is a list of values of $\boldsymbol{P}_{\mathrm{I}_{2} \mathrm{O}}$ for various temperatures, calculated thermodynamically.

TABLE VIII.

\begin{tabular}{c|c||c|c}
\hline T. & $p_{\mathbf{H}_{2} \mathbf{O} .}$ & $\mathrm{T}$. & $p_{\mathrm{H}_{2} \mathbf{O} .}$ \\
\cline { 2 - 3 } 0 & $16 \cdot 04$ & 31 & $13 \cdot 70$ \\
18 & $14 \cdot 14$ & 32 & $13 \cdot 67$ \\
19 & $14 \cdot 11$ & 33 & $13 \cdot 64$ \\
20 & $14 \cdot 07$ & 34 & $13 \cdot 61$ \\
21 & $14 \cdot 04$ & 35 & $13 \cdot 58$ \\
22 & $14 \cdot 01$ & 36 & $13 \cdot 56$ \\
23 & $13 \cdot 96$ & 37 & $13 \cdot 53$ \\
24 & $13 \cdot 93$ & 38 & $13 \cdot 51$ \\
25 & $13 \cdot 89$ & 39 & $15 \cdot 47$ \\
26 & $13 \cdot 86$ & 40 & $13 \cdot 45$ \\
27 & $13 \cdot 83$ & 50 & $13 \cdot 34$ \\
28 & $13 \cdot 80$ & 75 & $12 \cdot 77$ \\
29 & $13 \cdot 76$ & 100 & $12 \cdot 31$ \\
30 & $13 \cdot 73$ & & \\
\hline
\end{tabular}

Some people prefer a more cumbrous but nevertheless a more comprehensible method of recording ionic concentrations. In Sørensen's method it is rather difficult to see at a glance the relative concentrations of ions at two temperatures. As the temperature decreases, dissociation increases, but the negative exponent or $p_{\dot{\mathrm{H}}_{2} \mathrm{O}}$ decreases. At $18^{\circ}$, for example, the $p_{\mathrm{H}}$ is $\mathbf{7 \cdot 3}$, and at $23^{\circ}$ it is $7 \cdot 0$. Put in this way, one does not readily grasp the fact that the $p_{\mathrm{H}}$ at $23^{\circ}$ is double the $p_{\mathrm{H}}$ at $18^{\circ}$. If, however, the negative exponent be kept a whole number and the fraction be put as a multiplier, the relation is seen at once, e.g.

$$
\begin{aligned}
& 18^{\circ} p_{\mathrm{H}}=7 \cdot 3=0.5 \times 10^{-7}=C_{\mathrm{H}}, \\
& 23^{\circ} p_{\mathrm{H}}=7 \cdot 0=1 \times 10^{-7}=C_{\mathrm{H}} .
\end{aligned}
$$


The conversion of one expression into the other is simple.

For example: To convert $p_{\mathrm{H}} 7 \cdot 6$ to other notation

$$
\begin{gathered}
p_{\mathrm{H}} 7 \cdot 6=10^{-7 \cdot 6}=10^{-7.0} \times 10^{-0.6}=0.25 \times 10^{-7}, \\
\text { antilog of }-0 \cdot 6=0 \cdot 25 .
\end{gathered}
$$

Conversely we find the short expression for

$$
\begin{aligned}
C_{\mathrm{H}} 5 \times 10^{-6} & =\log 5+\log 10^{-6} \\
& =\cdot 6990+(-6 \cdot 0000) \\
& =5 \cdot 3=P_{\mathrm{H}}, \\
5 \times 10^{-6} & =10^{\cdot 699} \times 10^{-6}=10^{-5 \cdot 3}=p_{\mathrm{H}} 5 \cdot 3 .
\end{aligned}
$$

or

(Graph for conversion from one notation to other, Part II. p. 424.)

\section{Reaction.}

It is very important to be able to ascertain with great exactness, the true acidity or alkalinity of physiological media. It is not sufficient to state that a certain fluid is acid to litmus, etc. Litmus, for one thing, is not nearly sensitive enough to indicate the minute changes in reaction which alone are of physiological value. The whole activity, of the mammal at any rate, is regulated by reaction. Alterations in acidity are the causative factor in the regulation of respiration, the activity of muscle, the excitability of nerve, and play an important part in regulating secretion and excretion. Physical and chemical means are employed to keep the healthy body within a narrow range of reaction, about the neutral point. Any marked deviation from this is pathological, and is the result of pathological (or experimental) conditions. As we shall see later, the neutrality of the organism is an equilibrium, any disturbance of which will produce change, and, moreover, any change in the organism will tend to disturb this equilibrium (Chap. XXX.).

Examination of a number of acids shows that when they dissociate in water they disturb the balance existing between the concentrations of $\mathrm{H}^{+}$and $\mathrm{OH}^{-}$ions.

For example :

$$
\begin{array}{ll}
\mathrm{HCl} & =\mathrm{H}^{+}+\mathrm{Cl}^{-} \\
\mathrm{HNO}_{3} & =\mathrm{H}^{+}+\mathrm{NO}_{3}^{-} \\
\mathrm{H}_{2} \mathrm{SO}_{4} & =\mathrm{H}^{+}+\mathrm{HSO}_{4}^{-} \\
\mathrm{CH}_{3} \mathrm{COOH} & =\mathrm{H}^{+}+\mathrm{CH}_{3} \mathrm{COO}^{-}
\end{array}
$$


In each case the acid produces $\mathbf{H}^{+}$ions. Now, as $[\mathrm{H}] \times[\mathrm{OH}]$ is a constant, the result of this increase of $\mathbf{H}^{+}$ions must cause a decrease in the concentrations of $\mathrm{OH}^{-}$ions.

In the same way, examination of the behaviour of alkalies shows also a disturbance of the ratio of $\left[\mathrm{H}^{+}\right]$to $\left[\mathrm{OH}^{-}\right]$.

For example :

$$
\begin{aligned}
& \mathrm{NaOH}=\mathrm{Na}^{+}+\mathrm{OH}^{-} \\
& \mathrm{NH}_{3} \mathrm{OH}=\mathrm{NH}_{3}{ }^{+}+\mathrm{OH}^{-} .
\end{aligned}
$$

The concentration of $\mathrm{OH}^{-}$ions is increased.

In water the concentrations of $\mathrm{H}$ and $\mathrm{OH}$ are equal. These facts lead to the following definitions :

(a) Any substance which when dissolved in water yields $\mathbf{H}^{+}$ as one of the direct products of its ionisation is an acid.

(b) Any substance which when dissolved in water yields $\mathbf{O H}^{-}$ as one of the direct products of its ionisation is a base.

(c) Any substance which on ionisation yields at least one positive ion other than $\mathrm{H}^{+}$and at least one negative ion other than $\mathrm{OH}^{-}$is a salt.

(d) If, in addition to the positive and negative ions mentioned in $(c)$, the salt yields an $\mathrm{H}^{+}$ion it is called an acid salt.

E.g.

$$
\begin{aligned}
& \mathrm{KHSO}_{4}=\mathrm{K}^{+} \quad+\mathrm{SO}_{4}^{--}+\mathrm{H}^{+} \\
& \mathrm{NaHPO}_{4}=2 \mathrm{Na}^{+}+\mathrm{PO}_{4}^{--}+\mathrm{H}^{+} \\
& \mathrm{COOH} \\
& \mathrm{COONH}_{4}=\mathrm{NH}_{4}^{+}+(\mathrm{COO})_{2}+\mathrm{H}^{+}
\end{aligned}
$$

(e) If, in addition to the positive and negative ions mentioned in $(c)$, the salt yields an $\mathbf{O H}$-ion, it is called a basic salt.

E.g.

$$
\mathrm{Fe}(\mathrm{OH})_{2} \mathrm{Cl}=\mathrm{Fe}^{+++}+\mathrm{Cl}^{-}+\mathbf{2 0 H}-\text {, }
$$

$\mathrm{CH}_{2} \cdot \mathrm{NH} \cdot \mathrm{OH} \cdot \mathrm{COOK}=\mathrm{K}^{+}+\mathrm{CH}_{2} \mathrm{NH}_{3} \mathrm{COO}^{-}+\mathrm{OH}^{-}$.

(f) Substances which produce both $\mathrm{H}^{\cdot}$ and $\mathrm{OH}^{\prime}$ ions on dissociation are called amphoteric electrolytes or ampholytes. They must evidently have two ionisation constants, $K_{\mathrm{H}}$ and $K_{\mathrm{OH}}$. It is obvious that acidity depends on the preponderance of hydrogen ions over hydroxyl ions, and conversely, alkalinity is due to the presence of hydroxyl ions in excess of hydrogen ions. Neutrality is an equilibrium between $\mathrm{H}^{\circ}$ and $\mathrm{OH}^{\prime}$.

This neutral point occurs in water at $23^{\circ} \mathrm{C}$. when the concentration of hydrogen ions is $1 \times 10^{-7}$, i.e. $p_{\mathrm{H}}=7$. If the concentration is greater than this, e.g. $1 \times 10^{-5}$, or $p_{\mathrm{H}}=5$, then the 
concentration of $\mathrm{OH}^{\prime}$ must be correspondingly decreased according to the equation,

or

$$
\begin{aligned}
& {\left[\mathrm{H}^{+}\right]\left[\mathrm{OH}^{-}\right]=10^{-14}} \\
& {\left[\mathrm{OH}^{-}\right]=\frac{10^{-14}}{\left(\mathrm{H}^{+}\right)}=10^{-14(-5)}=10^{-9} .}
\end{aligned}
$$

A $p_{\mathrm{H}}$ of 5 will be accompanied by a $p_{\mathrm{OH}}$ of 9 . This will be an acid solution.

Conversely, if the concentration of hydroxyl ions is increased there is a corresponding decrease in hydrogen ions. $\boldsymbol{E} . g$.

$$
\text { if } p_{\mathrm{OH}}=3 \text {, then }\left(\mathrm{H}^{+}\right)=\frac{10^{-14}}{10^{-3}}=10^{-11}=p_{\mathrm{H}} \text { of } 11 \text {, }
$$

an alkaline solution.

Reaction may, therefore, be expressed in terms of $p_{\mathrm{H}}$ or of $p_{\mathrm{OH}}$. Generally the former is used, and alkalinity is expressed as decrease of acidity. The quality as well as the nature of the reaction is expressed by the $p_{\mathrm{H}}$. The greater the concentration of hydrogen ions, the greater is the degree of acidity and the smaller the degree of alkalinity.

It is rather confusing for the beginner, but he must note:

(1) that as acidity increases, the exponent or $p$ figure decreases ;

(2) that as the figures are logarithms, multiplication is done by addition and division by subtraction;

(3) that this does not give a measure of the amount of acid present, but of its strength. The $p_{\mathrm{H}}$ is not an index of quantity but of intensity. It gives the number of $\mathrm{H}$ ions per litre, but of course says nothing of how many litres or c.c. of acid are present.

The strength of an acid (or alkali) may be expressed as normal or as a fraction of normal. A normal solution contains in one litre, the gram-equivalent weight of the substance. A normal solution of acid, for instance, has in each litre one gram of hydrogen capable of forming hydrogen ions. If the acid is completely dissociated, i.e. if it is a "strong" acid, it will contain one gram of hydrogen as $\mathrm{H}^{+}$. The strength of acid commonly used for laboratory purposes is $1 / 10$ of normal $=\frac{N}{10}$. The hydrogen ion concentration of such a solution would be 1/10 gram per litre $=\left(\mathrm{H}^{+}\right)$of $1 \times 10^{-1}$ or $p_{\mathrm{H}}$ of 1 and $p_{\mathrm{OH}}$ of 13 .

Water of $p_{\mathrm{H}}=p_{\mathrm{OH}}=7$ is thus, at $23^{\circ} \mathrm{C}$., $\mathrm{N} / \mathbf{1 0}, 000,000$ acid and $\mathrm{N} / \mathbf{1 0 , 0 0 0 , 0 0 0}$ alkaline. If the acid added to water is not completely dissociated (i.e. a weak acid), then, of course, the degree of dissociation must be taken into account. A decinormal solution of 
acetic acid, for instance, at $23^{\circ}$ is dissociated 1.36 per cent. Therefore its $\left(\mathrm{H}^{+}\right)$would be equal to $\frac{1 \cdot 36}{100} \times 10^{-1}=1 \cdot 36 \times 10^{-3}$ or $p_{\mathrm{H}}$ of
$2 \cdot 86$.

Normal solutions of acid are all equal as regards the amount of alkali they can neutralise. 1 c.c. of any $\mathbf{N} / \mathbf{1 0}$ acid is exactly neutralised by 1 c.c. of any N/10 alkali. That is, they have the same titratable acidity. They differ in their concentration of hydrogen ions.

As we have seen

$$
\begin{aligned}
& \frac{\mathrm{N}}{10} \mathrm{HCl} \text { in water at } 23^{\circ}=p_{\mathrm{H}} 1 \text { or } C_{\mathrm{H}}=1 \times 10^{-1}, \\
& \frac{\mathrm{N}}{10} \mathrm{CH}_{3} \mathrm{COOH} \quad, \quad=p_{\mathrm{H}} 2 \cdot 86 \text { or } C_{\mathrm{H}}=1 \cdot 36 \times 10^{-3} .
\end{aligned}
$$

'That is, hydrochloric acid, under the above conditions, has

$$
10^{-1} \div 10^{-2.86}=73 \cdot 5
$$

times the amount of hydrogen ions per litre that acetic acid has. $\mathrm{N} / 10$ Hydrochloric acid at $23^{\circ} \mathrm{C}$. is therefore $\mathbf{7 3 . 5}$ times as strong as $\mathrm{N} / 10$ acetic acid.

\section{Salts.}

It is very seldom that acids, weak or strong, occur alone or diluted with water in physiological fluids. Salts are always present. In $(d)$ and $(e)$ are mentioned two classes of salts which alter the $[\mathrm{H}]$ of water when dissolved in it. They do so directly in virtue of their possession of an additional $\mathbf{H}^{*}$ or $\mathrm{OH}^{\prime}$ ion.

Other salts cause alterations in acidity by upsetting the balance between $\mathrm{H}^{*}$ and $\mathrm{OH}^{\prime}$ in water. Their action is indirect.

(1) The salt of a strong acid and a strong base, e.g. NaCl, causes little or no change in [H].

(2) If one of the constituents of a salt be weak, changes occur.

(a) If the salt $\mathrm{BA}$ of the strong base $\mathrm{B} \cdot \mathrm{OH}$ and the weak acid $\mathrm{HA}^{-}$be dissolved in water it forms $\mathrm{BA}=\mathrm{B}^{+} \mathrm{A}-$. But owing to the ionisation of the solvent there are present $\mathrm{H}^{+}$and $\mathrm{OH}^{-}$ions and a second change takes place, $\mathrm{H}^{+}$and $\mathbf{A}^{-}$ions are present. According to the law of mass action

$$
\frac{\left[\mathrm{H}^{*}\right] \times\left[\mathrm{A}^{\prime}\right]}{[\mathrm{HA}]}=K_{\mathrm{HA}} \text { or } \mathrm{H}^{*}+\mathrm{A}^{\prime} \leftrightharpoons \mathrm{HA} \text {. }
$$

As no $\mathrm{HA}$ is present to balance the reaction, $\mathrm{H}^{*}$ will combine with $\mathbf{A}^{\prime}$ to form $\mathbf{H A}^{\prime}$ until the point of equilibrium for that dilution has been reached. The removal of hydrogen ions from the 
solution by this reaction, however, disturbs the equilibrium between $\mathrm{H}^{\circ}$ and $\mathrm{OH}^{\prime}$ and some more water must ionise to maintain the product $[\mathrm{H}] \times[\mathrm{OH}]$ constant.

Summarising these reactions as follows :

$$
\mathrm{A}^{\prime}+\mathrm{H}_{2} \mathrm{O}=\mathrm{HA}+\mathrm{OH}^{\prime} \text {, }
$$

the net result is the liberation of $\mathrm{OH}$ ions. The addition of a salt of a strong base and a weak acid is to make the solution alkaline, i.e. to reduce the hydrogen ion concentration. This is a fact of great physiological importance, as most of the salts of the body are composed of organic acids combined with the strong bases sodium and potassium.

KCN, a powerful poison, dissociates as follows :

$$
\left.\begin{array}{l}
\mathrm{KCN}=\mathrm{K}^{+}+\mathrm{CN}^{-} \\
\mathrm{H}_{2} \mathrm{O}=\mathrm{H}^{+}+\mathrm{OH}^{-}
\end{array}\right\}=\mathrm{HCN}^{+} \mathrm{K}^{+}+\mathrm{OH}^{-} .
$$

This causes an alkalinity equal to that of potassium hydrate. The alkalinity of solutions of sodium carbonate is due to the reactions,

$$
\begin{array}{ll}
\mathrm{Na}_{2} \mathrm{CO}_{3} & =2 \mathrm{Na}^{+}+\mathrm{CO}_{3}^{-} \\
\mathrm{H}_{2} \mathrm{O} & =\mathrm{H}^{+}+\mathrm{OH}^{-} \\
\mathrm{CO}_{3}^{-}+\mathrm{H}_{2} \mathrm{O} & =\mathrm{HCO}_{3}^{-}+\mathrm{OH}^{-} \\
\mathrm{HCO}_{3}^{-}+\mathrm{H}_{2} \mathrm{O} & =\mathrm{H}_{2} \mathrm{CO}_{3}+\mathrm{OH}^{-} \\
\mathrm{H}_{2} \mathrm{CO}_{3} & \leftrightharpoons \mathrm{H}_{2} \mathrm{O}+\mathrm{CO}_{2}
\end{array}
$$

If the $\mathrm{CO}_{2}$ is allowed to escape, the last reaction will only ceasc when all the $\mathrm{H}_{2} \mathrm{CO}_{3}$ has been decomposed. The total result is an increase in $[\mathrm{OH}]$ and, therefore, of alkalinity.

(b) In the case of a weak base combined with a strong acid, the solutions become acid, as the following equations denote.

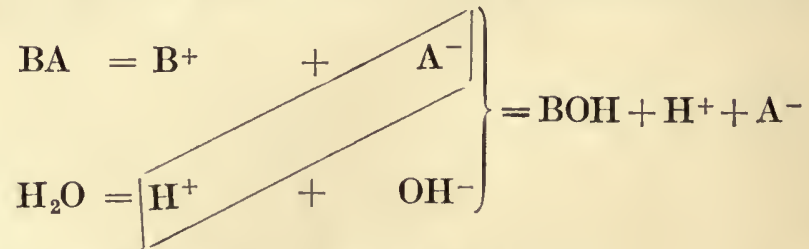

and $\mathrm{HA}$ is a strong acid and $\mathrm{BOH}$ a weak base.

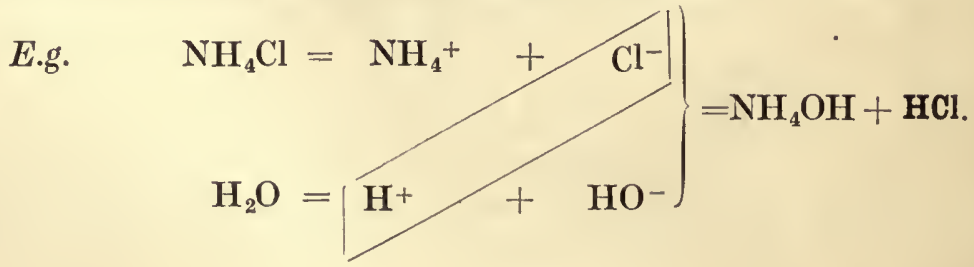


(3) When both the constituents are weak the solution will remain neutral, if acid and base are of equal strength, if the aeid be the stronger, the solution will be acid, and conversely an alkaline solution will be produeed if the base be stronger than the acid. E.g.

$$
\mathrm{CH}_{3} \mathrm{COONH}_{4}+\mathrm{H}_{2} \mathrm{O}=: \mathrm{NH}_{4} \mathrm{OH}+\mathrm{CH}_{3} \mathrm{COOH} \text {. }
$$

This solution will be almost neutral, beeause the degrees of ionisation of ammonium hydrate and acetic acid are almost identical.

\section{Effect of Temperature.}

The effect of temperature on the dissociation of water has been dealt with above (p. 56 and Table VIII.). Increase in temperature causes a very large increase in the amount of water ionised. An increase in temperature of $1^{\circ} \mathrm{C}$, say from $38^{\circ}$ to $39^{\circ}$, causes the $[\mathrm{H}] \times[\mathrm{OH}]$ to rise from $10^{-13.5}$ to $10^{-13.47}$, an increase of about 20 per cent. Strong electrolytes have a low temperature coefficient of dissociation. It is, therefore, obvious that increase of temperature will affect salts according to the dissociation constant of the acids and bases composing them.

(a) Both strong, temperature of little effect.

(b) Weak aeid +strong base. Inerease of temperature causes the degree of dissociation of acid to increase. Acid ions combine with hydrogen ions from $\mathrm{H}_{2} \mathrm{O}$ and liberate $\mathbf{O H}^{-}$.

(c) Strong acid and weak base. Increase of temperature causes the degree of dissociation of base to increase. Base ions combine with hydroxyl ions from the $\mathrm{H}_{2} \mathrm{O}$ and liberate $\mathbf{H}^{+}$.

(d) Both weak. The result of any inerease in temperature is to increase the dissociation of the weaker at a greater rate than the stronger with correspondingly slight changes in $[\mathrm{H}]$ and $[\mathrm{OH}]$.

It will be seen that apart from the action of temperature on the dissociation of water itself, in $(b)$ increased alkalinity and in (c) increased acidity result from increase in temperature. This action is slight, however, compared to the action of temperature on the weakest salt known, water.

The effect of alterations of temperature on a salt solution where one of the constituents of the salt is weak is the combined effect of

I. the alteration in $\mathrm{K}_{\mathrm{H}_{2} \mathrm{O}}$;

II. the alteration in $\mathbf{K}_{\text {Salt }}$.

In brief, the increased acidity or alkalinity produced by increase of temperature is greater (theoretically) than could have been 
produced from increased disscciation of the salt. The signifieance of this will be seen later.

At present the point under consideration is the mechanism for converting the potential energy of the food-stuffs into the kinetic energy exhibited by protoplasm. Enough has been said to indicate

(1) That slight alterations in hydrogen ion concentration may produce large alterations in surface tension (Chap. VI.).

(2) That slight alterations in hydrogen ion concentration may produce large alterations in the degrec of dissociation of salts.

(3) That the degree of dissociation of salts, acids and bases governs the value of surface tension and osmotic pressure. The next chapter deals with the inactivation of these factors. 


\section{CHAPTER VIII}

\section{DISPERSE SYSTEMS}

\section{COLLOIDS-THE RESERVOIRS OF ENERGY}

"The properties of colloidal solutions ean be most ellieiently inquired into by application, as far as possible, of the same views and methods as those generally applied to true solutions."

S.pRENSEN.

IN Chapter V. colloids were mentioned as a series of substanees which when dissolved in water have a lower osmotic pressure than would be expeeted from their moleeular weight. The reason for this, deduced from the eolligative properties of their solutions, is that in water they form aggregates or colloidal particles of extramolecular size.

The effect of this is enormously to increase the effective surface of the solvent. Therefore the phenomena of surface tension and surface adsorption will be marked.

'The appended table makes elear the enormity of the inerease in effeetive surface that takes place when a sphere is divided into a large number of small shot and these are, in turn, divided into particles of colloidal size.

\section{TABLE IX.}

Increase in Surface of a, Sphere when its Radius is Decimally Divided.

\begin{tabular}{|c|c|c|}
\hline Length of Radius. & $\begin{array}{l}\text { Number of } \\
\text { Spheres. }\end{array}$ & Total Surfaee. \\
\hline $\begin{array}{l}1 \mathrm{~cm} . \\
1 \mathrm{~mm} . \\
0.1 \mathrm{~mm} . \quad \text { Small Shot } \\
0.01 \mathrm{~mm} . \text { Coarse } \\
1 \mu \\
0 \cdot 1 \mu \quad \text { Suspensions } \\
0 \cdot 01 \mu \quad \text { Typical } \\
1 \mu \mu \quad \text { Colloids } \\
0 \cdot 1 \mu \mu \text { True Solution }\end{array}$ & $\begin{array}{c}1 \\
10^{3} \\
10^{6} \\
10^{9} \\
10^{12} \\
10^{15} \\
10^{18} \\
10^{21} \\
10^{24}\end{array}$ & $\begin{array}{cc}12 \cdot 6 \mathrm{sq} . & \mathrm{cm} . \\
126 & \text { ", } \\
1260 & \text { ", } \\
1 \cdot 26 \mathrm{sq} & \text { metres } \\
12 \cdot 6 & \text { ", } \\
126 & \text { ", } \\
1260 & \text { ", } \\
12,600 & \text { ", } \\
126,000 & \end{array}$ \\
\hline
\end{tabular}


This table shows how a molecular solution of particles of $0 \cdot 1 \mu \mu$ radius which has no effective surface acquires an effective surface of 12,600 square metres when the particles are increased in size sufficiently to give them an effective surface, i.e. to bring them into the colloidal realm. These figures demonstrate the cxtraordinary adsorbing surface of a small amount of matter highly dispersed. In connection with the theory of surface tension Wo. Ostwald has introduced the term specific surface to denote the ratio of surface to volume or $S / V$. In a sphere $S=4 \pi r^{2}$ and $V=\frac{4}{3} r^{3}$ : therefore $\frac{S}{V}=\frac{3}{r}$. It has been found in physical chemistry that adsorption to a surface becomes an important factor when the specific surface reaches a value of about 10,000. It has also been noticed that when the specific surface becomes greatcr than $6 \times 10^{7}$ or thereby, i.e. when the material is so finely subdivided that it is in molecular solution, adsorption phenomena cannot be detected.

Further, it has been demonstrated that colloids, as a rule, carry a definite charge, some positive some negative. The sign of the charge depends both on the nature of the colloid and on the nature of the medium in which it is.

(1) As colloids have extremely low osmotic pressures they are a suitable medium for the storage of potential energy. Carbohydrates may be stored as starch or glycogen, both colloids, and changed readily into maltose or glucose, which are crystalloids.

(2) The salts adsorbed by a colloid are so rendered osmotically inactive, but may be set free again by alteration of the colloidal electric charge.

(3) Some colloids imbibe water and compress it. A hydrated gel (jelly) has therefore a store of hydraulic pressure within it. Gels may thus be regarded as the great reservoirs of energy in the body (Part II.).

A great deal has bcen done to elueidate the nature of colloids. A full diseussion of that work is out of place here, but a brief account of the results may be acceptable.

Protoplasm maybe considered as a watery solution of crystalloids and colloids. The division is due to Graham, the pioneer in colloidal research. As the result of a large series of investigations on the rates of diffusion of various substances in water, he was led to divide all substanees into two classes, e.g. Crystalloids, which have a high rate of diffusion and which crystallise from 
saturated solutions, and Colloids, which diffuse very slowly and in general have a gluey consistency. "They appear," he writes, "like different worlds of matter, and give occasion to a corresponding division of chemical science." He noticed that erystalloids passed through animal membranes while colloids did not.

That is, if a mixture of colloids and crystalloids were put into a simple dialysing drum (such as described in Part II. p. 406), immersed in running water, after a time most of the crystalloidal material would have been dialysed out of the mixture, while the colloidal matter would still remain in the drum. The dialyser furnishes a method for the separation of crystalloids.

It has now been proved that matter may exist either in a crystalloidal or in a colloidal state, and that by suitable means a colloid may be erystallised and so pass through a membrane previously impermeable to it. The converse process may also take place.

The solvent is sometimes the factor on which depends the state of the solute. The alkali salts of the higher fatty acidsstearic, palmitic, oleic-form a true molecular solution in alcohol, but with water they act as colloids. On the other hand, sodium chloride, a typical water-soluble erystalloid, assumes the colloidal state in benzol.

Von Weimarn and others have prepared colloidal solutions of over two hundred substances usually considered as crystalloids. By proper manipulation, almost any solid can be dispersed through a liquid either as a crystalloid or as a colloid. Consequently, one now speaks of the colloidal state rather than of certain substances as being colloids.

The differenee between a crystalloidal and a colloidal solution depends, in the main, on the size of the particle in the fluid.

There is some diffieulty in expressing the relationship between the eolloid and the fluid in which it is. It is not in true solution, but is suspended and dispersed throughout the medium. The colloid may, therefore, be called the dispersed substance or dispersate and the fluid the dispersing medium or dispersant.

The application of the " Phase Rule" (of W. Gibbs) has helped to clear up several difficulties in physiological physies, and some writers have adopted terminology suitable for use when this rule is discussed. It is sufficient here to say that the dispersed phase is the substance which is suspended or distributed throughout the continuous phase. In nearly every ease the former is the colloid and the latter the fluid. 
As an illustration, attention may be drawn to a disperse system having two phases and only one component, e.g. A fine mist of liquid water suspended in water vapour.

The dispersed, internal or non-continuous phase is composed of the droplets of water; the continuous or external phase, or dispersion medium, is the water vapour. The stability of this dispersion depends on two factors, $(a)$ the temperature of and (b) the diameter of the droplets, (Such a system is called divariant.) The smaller the droplets, the greater is the ratio of surfaee to mass and the higher is the vapour pressure. All the droplets will not be of the same size, and therefore the larger droplets will tend to become larger still.at the expense of the smaller ones. The system is, on this account, said to be metastable.

Disperse systems may be classified according to the nature of the contact surfaee between the phases. Taking the three states of matter, solid, liquid and gaseous, five different kinds of contact surface can be produced, as is indicated in the following table, in which are also given examples of the various disperse systems.

TABLE X.

\begin{tabular}{|c|c|c|c|c|}
\hline Class. & Contact Surface. & $\begin{array}{l}\text { Dispersed } \\
\text { Phase. }\end{array}$ & $\begin{array}{c}\text { Continuous } \\
\text { Phase. }\end{array}$ & Examples. \\
\hline I. & Gas-Liquid & $\begin{array}{l}\text { Gas } \\
\text { Liquid }\end{array}$ & $\begin{array}{l}\text { Liquid } \\
\text { Gas }\end{array}$ & $\begin{array}{l}\text { Foam, Suds, Lather. } \\
\text { Mist, Spray. }\end{array}$ \\
\hline II. & Gas-Solid & $\begin{array}{l}\text { Gas } \\
\text { Solid }\end{array}$ & $\begin{array}{l}\text { Solid } \\
\text { Gas }\end{array}$ & $\begin{array}{l}\text { Hydrogen in platinum, lava, } \\
\text { meringues. } \\
\text { Smoke, dust and some fumes. }\end{array}$ \\
\hline III. & $\begin{array}{l}\text { Liquid-Liquid } \\
\text { (Emulsoids) }\end{array}$ & Liquid & Iiquid & $\begin{array}{l}\text { Milk (fat in water), } \\
\text { Lymph, egg white (raw). }\end{array}$ \\
\hline IV. & $\begin{array}{l}\text { Liquid-Solid } \\
\text { Suspensoids }\end{array}$ & $\begin{array}{l}\text { Liquid } \\
\text { Solid }\end{array}$ & $\begin{array}{l}\text { Solid } \\
\text { Liquid }\end{array}$ & $\begin{array}{l}\text { Rock inclusions. } \\
\text { Colloidal metals, etc. }\end{array}$ \\
\hline V. & Solid-Solid & Solid & Solid & Ruby Glass (Gold in Glass). \\
\hline
\end{tabular}

Class III. (Emulsoid) is of the most importance in biology, but Class IV. (Suspensoid) has been most studied and is of considerable industrial value. Colloids met with in nature are all dispersed in water, having salts in solution. They might therefore be classified aecording to their degree of dispersion. The degree of dispersion of a phase is the ratio of total surface to volume, or 
the surfaee exposed to each c.c. of the dispersed phasc. There would be a continuous series of systems ranging from a nondispersed two-phase system on the one hand to a homogeneous mixture of an ionised salt in water, i.e. a true solution. Colloids may thus be regarded as intermediate in this series, e.g. Gold coin in water, gold dust suspended in water, very fine gold dust suspended in water, range of colloidal gold in water ((Zsigmondy), solution of gold salt (undissociated) and, finally, completely dissociated gold salt in aqueous solution.

Physiological colloids differ from this metallic series in one respect at least. They dissolve in water and they also imbibe water. A solution of albumin, for instance, cannot be regarded as a solid dispersed throughout a liquid, but is a strong solution of albumin dispersed throughout a weaker solution.

This state is not peculiar to natural organic colloids, but, as has been amply demonstrated by Von Weimarn, can be obtained from such materials as $\mathrm{NaCl}, \mathrm{Al}(\mathrm{OH})_{3}$ and silver salts. $\mathrm{Hc}$ has enunciated a postulate called the law of corresponding states, which is as follows: "The degree of dispersion and the general physical appearance of precipitates are always the same irrespective of the chemical nature of the precipitates provided that the precipitation takes place under corresponding conditions." Working with substances as widely apart in their chemical nature as the various salts of aluminium, barium, silver, sodium and many others, Von Weimarn has prepared precipitates with almost any desired degree of dispersion ranging in each instance, all the way from coarse and obviously crystalline precipitates, to gelatinous precipitates and thick transparent jellies.

Colloidal matter may be further divided into two groups. White of egg is an emulsoid colloid. In its ordinary state, as obtained from the egg, it can be dissolved in water to form a clear solution. Boiling the solution causes coagulation of the egg white. It comes out of solution in the form of a white solid, insoluble in water. Those colloids which form solutions like egg white are called sols. According to the medium in which they were dispersed they were termed by Graham, hydrosols, alcosols, glycerosols, etc. These colloids which assume a semi-solid form like coagulated cgg white are called gels. In a gel the more liquid phase is dispersed through the less liquid phase.

An examination of the optical properties of thesc various disperse systems makes it clear that there is a regular gradation in the size of the particles dispersed, which passes from the easily visible 
suspension to the invisible solute. If the size of a particle is decreased below $200 \mu \mu$, it cannot be seen even by the most powerful microseope made, or that could ever be made. The particle is ultra-microscopic because its diameter is less than half the wave-length of light. But, just as a beam of sunlight renders visible innumerable specks of dust floating in the air, so light may be diffracted by ultra-microscopic particles above a certain diameter.

\section{Faraday-Tyndall Phenomenon.}

When a strong beam of light is sent through a rectangular cell containing pure water, the beam may be rendered visible before and after its passage through the water, but no cone of light is seen in the water itself when viewed at right angles to the direction of the light and against a dark background. If now a colloid be dispersed through the water, light will be diffracted from the particles in the water and the beam will appear in the solution as a diffuse cone of light. This diffracted light is plane polarised (p. 102), and is always produced when light passes through any medium containing particles whose diameter is small in comparison with the wave-length of light.

White light is composed of waves of different lengths varying from $760 \mu \mu$ to $450 \mu \mu$. When white light is scattered from a surface instead of being reflected as in a mirror, it gives rise to the sensation of white. Ice, in mass, docs not appear white because light is not scattered from its surface. If the ice is powdered, light is scattered from the powdered surfaces and the whole appears white. Crystallised copper sulphate appears blue, but the light scattered from the surfaces, of the finely powdered crystals is white. The white colour of the lily or of white hair is not due to the presence of a white pigment, but to the scattering of light from the surfaces of innumerable minute air bubbles embedded in the tissue. From this it follows that particles of different sizes will seatter light of different wave-lengths. In short, the colour of the seattered light may serve as an indication of the size of the particle, provided the difference in the index of diffraction between the dispersoid and the dispersant be kept constant.

The blue colour of the sky is explained by considering that the fine particles of dust, globules of water, etc., suspended in the atmosphere cause lateral diffusion of light of short wave-length giving a blue colour, while the red rays are transmitted direct, 
producing the gorgeous sunset colours (see Spectroseope, Chap. II.). In one of Tyndall's experimental verifications of this theory he passed light through a tube containing a mixture of gases (butyl nitrate in air and hydrochlorie acid in air), which gradually combined to form a dust-like suspended precipitate. At first the particles were exeeedingly small and the colour seen from the side of the tube was a delieate tint of blue. As the particles increased in size the blue became more intense, "until at length a whitish tinge mingled with the pure azure, announeing that the partieles were now no longer of that infinitesimal size which scatters only the shortest waves."

The colour of some samples of stained glass is eaused not by an even distribution of the pigment or stain throughout the glass, but by the dispersion of fine metallie partieles. Water of suffieient depth appears blue due to the presenee of tiny suspended partieles. If larger partieles are present, some light of longer wave-length, e.g. yellow, is diffracted and the colour becomes green. The water of the Rhone as it leaves Lake Geneva is intensely blue, while the Rhine at Strassburg is green. The Rhine eontains about 70 per eent. more caleium carbonate in suspension than the Rhone.

Tyndall observed that the blue of the eye has a similar origin to the blue of the sky, the sea, and the Rhone, viz. seattering of light from small suspended partieles. The uvea, the dark pigmented layer at the back of the iris, prevents the refleetion of light and prevents the colour of the blood in the vessels behind it from beeoming apparent. In an albino this pigment is absent and the eye appears pink. The colour of blue eyes is due to finely suspended unpigmented colloid particles in the iris. The various colour stages between the blue and the grey eye arise from differences in the mean size of the dispersoid partieles - the finer the particles, the more intense the blue. Except with people who have very black eyes, the pigment on the posterior surface of the iris does not develop at birth. That is, most babies are born with deep blue eyes. As they become older the colloidal particles become larger and the blue beeomes less intense. Further, the uveal pigment may develop and the colour change from blue to hazel, brown or black. The reverse change never takes place (Baneroft).

Colour may be due, as we saw in Chapter II., to the reflection of non-absorbed light. Complete absorption of light gives rise to the sensation of black. A perfect reflecting surface would be, of course, invisible. If follows that particles of different sizes 
will "select" light of certain wave-length for absorption, and, as a consequence, colour may result from "selective" absorption, reflection or diffraction.

In the following table, from Ostwald, is given the relationship between size of particle and colour $(a)$ from light absorbed, and (b) from light transmitted.

\section{TABLE XI.}

Corresponding Absorbed and Subjective Colours.

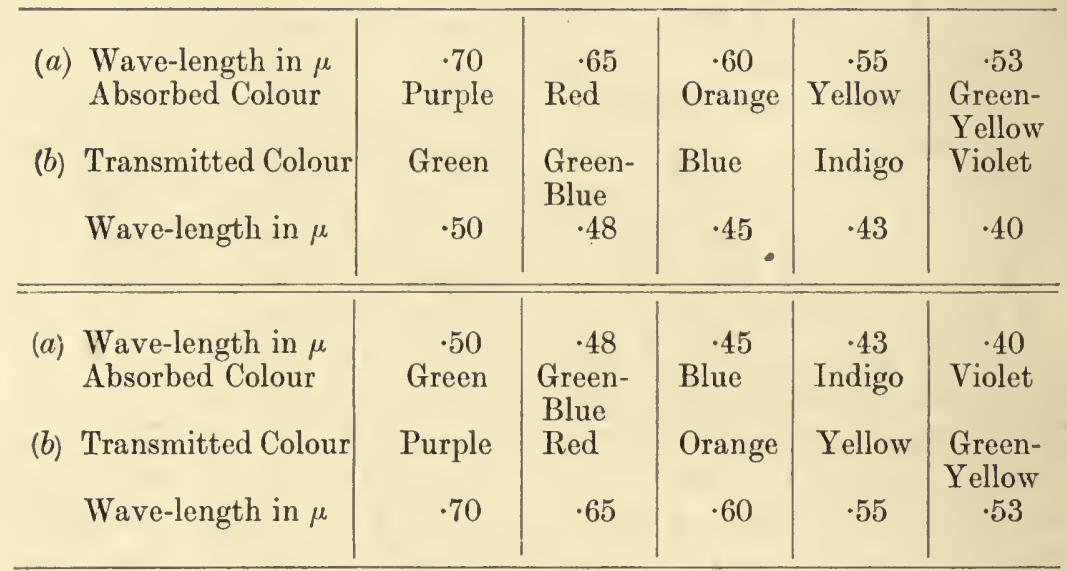

One must, however, take into account the other optical components, e.g. refraetive index of medium. The absorbed colour given above does not necessarily indicate the colour of light seattered by the particles.

As the particle beeomes smaller, the colour alters to light of longer wave-length, e.g. from blue or green, through various shades of yellow and orange to red. If the suspended particles are very fine, blue light is, as we have noted above, scattered laterally, while red light is transmitted. Such a system will appear red by transmitted light and blue by reflected light (e.g. skim-milk, tobacco smoke and colloidal gold). A very interesting series of coloured plates to illustrate this will be found at the end of Zsigmondy's monograph. It has also been shown that, as the particles decrease in size, the absorption bands in the spectrum of the solution shift towards the ultraviolct (Ostwald).

The amplitude of vibration of a particle is a function of its mass, temperature being kept eonstant. As the mass alters so will the period of vibration. According to Wood, metallie particles, if highly dispersed, owe their colour not to ordinary 
reflection, diffraction, interference, ete., but to optical resonance. Resonanec is the production of vibrations in a body by the periodic application of a stimulus which has the same period as the natural period of the body. The vibrations of a tuning fork may be transmitted through the air and cause to vibrate another tuning fork of the same pitch. Sinee the resonator owcs the encrgy necessary to set it into vibration to the stimulating body it follows that the stimulating body must lose energy to the resonator. The partieles in colloidal solution are supposed to be vibrating with the same frequency as light of a certain wave-length. Consequently, they will reeeive energy from the light which will tend to increase their amplitude of vibration. The kinetie energy of the solution will tend to increase, but any increase in kinetic energy would mean increase in temperature and a slight alteration in frequeney. This opens up the possibility of considerable energy ehanges in comparatively short times.

What effect will be produced when the rates of vibration are nearly but not quite the same? If two pendulum-controlled clocks which are keeping nearly the same time when on separate stands are placed on the same stand they will keep time exactly. Both pendulums transmit vibrations to the stand, and so to one another. The faster pendulum exerts a periodic force on the slower pendulum and is itself slowed by the loss of energy. In the same way the slower pendulum tends to cause forced vibrations in the stand and so influence the faster pendulum. Finally the two pendulums (and stand) vibrate at periods exactly the same. Is it possible that light may cause forced vibrations of colloidal particles?

Certain investigators have elaimed that the Brownian movement may attain an increased velocity because of incident light. Exner found that exposure to light of a suitable wave-length had a positive accelerating effect. Compared with the movement as a wholc the alteration brought about by incident light is negligible.

One effect of optical resonanee is the production of surface eolours. When light of a certain wave-length is strongly absorbed by particles, they may also reflect that light "seleetively." For instance, magenta crystals (aniline colour) transmit red but reflect green. If the partiele is made small enough it will scatter the light that it previously transmitted, and will transmit, of eourse, the light that is not scattered. This is readily earricd out with indigo. In mass, this colloidal dye absorbs red and transmits blue. It reflects red. If a fine suspension is made it scatters bluc, i.e. appears blue when observed laterally to the plane of incidence of light. By transmitted light it is red, i.e. appears red when looked at against the light. 
The ultra-microscope is, in principle, just a means of vicwing the Tyndall cone through a microscope. A powerful beam of light is thrown horizontally through a small body of fluid placed under a microscope set vertically. The only light entering the

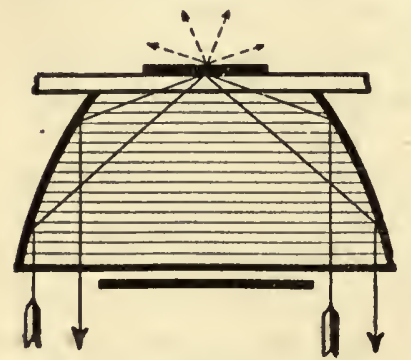

FIG. 7. - Diagrammatic section through a paraboioid condenser to show the direction taken by the rays of light. (Hatschek.)

objective is that diffracted from the partieles present in and optically different from the fluid (Fig. 7). The apparent image bears no relation to the actual size of the particle, but depends on the intensity of the light, and on the indices of refraction of the particle and the dispersant. Nevertheless, by making certain assumptions, the size of the particles may be calculated.

Particles visible under the ordinary microscope are called microns. Smaller particles are termed sub-microns, if they are rendered apparent by the ultramicroscope; if not, they are amicrons. The smallest particle of gold observed by Zsigmondy, using bright sunlight illumination, was $1 \cdot 0 \mu \mu$ in diameter. Bearing in mind the large difference in index of refraction between gold and water, this may be considered as the smallest particle ever observed. The following table (from Z/sigmondy) shows the limits of size of the various classes of particles :

\section{TABLE XII.}

LOWER LIMITS OF DIAMETERS OF SMALL PARTICLES.

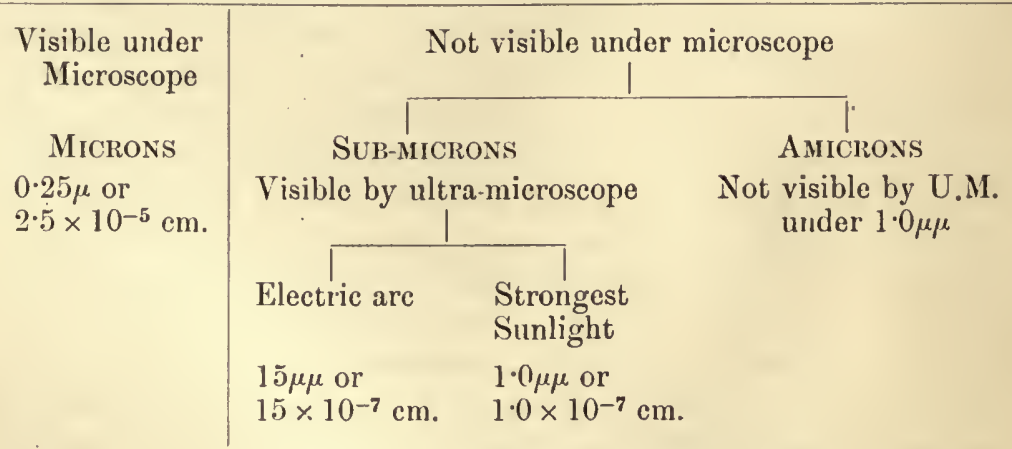

$\mu$ equals $10^{-3} \mathrm{~mm} .=10^{-4} \mathrm{~cm} ., \mu \mu=10^{-7} \mathrm{~cm}$. 
Evidence tending in the same direction and towards the same limits of size is afforded by experiments initiated by the classical series of ultrafiltrations of Bechhold. Membranes of known permeability are prepared, i.e. the diameter of the pores is known, and the colloidal solution is filtered through these by pressurc. A series of filters is tried till one is obtained which has the smallest pores which will allow the colloid to pass through. Obviously the particles must be smaller than the pores, and probably, though not necessarily, they are larger than the next filter in the series. The sizes of particles obtained in this way are in reasonable agreement with the values obtained from ultramicroscopic calculations.

The little dots of light seen under the ultramicroscope are not at rest. They dart about hither and thither in a seemingly inexplicable way. According to the kinetic theory of matter, a fluid was assumed to be made up of molecules in a state of very rapid motion and having a mean free path intermediate between that of a solid and that of a gas. The colloidal particles in the liquid are hustled into motion by continuous collision with the rapidly moving molecules of the liquid. If the particles have a natural period of vibration which is a multiple of that of the water molecules their amplitude of vibration will be increased (e.g. by suitably timing blows on a pendulum its excursion can be increased to a considerable extent. Each blow need be very slight).

This motion of the particles, while a very striking feature in the field of vision of the ultramicroscope, is not characteristic of colloidal solutions. Particles sufficiently small to be influenced by the high velocity bombardment of the molecules or ions of the solvent may still be well within the limits of visibility under an ordinary microscope. This movement owes its name to its discoverer Brown, a botanist, who described the peculiar oscillation of pollen grains suspended in water in 1827. This Brownian movement may be seen by means of an ordinary microscope in a solution of the water-colour gamboge especially when the diaphragm of the microscope is almost closed. The rate of movement is independent of the chemical nature of the particles, but depends on three factors, viz. (a) the size of the particle, $(b)$ the temperature, and $(c)$ the viscosity of the dispersion medium. The rate is increased by decrease in the mass of the partiele, by increase in temperature or by decrease in the viscosity of the medium. The movement persists, never changing, once equilibrium has set in, for all time. It has been observed in granite and in other 
rocks in small pockets of liquid, which they must have occluded for millions of years. But equilibrium must first be reached.

Direct observation of the absolute motion of the particles is very difficult, although differences in motion are easily perceptible. This difficulty has been overcome by the applieation of the cinematograph to the microscope. A glanee at Fig. 8, obtained in this way, shows that a particle oseillates apparently in a haphazard fashion about a certain mean position during a short interval of time. Any alteration in the kinetic energy of the dispersing medium, of course, produces alterations in the mean velocity of the particles-e.g. increase of temperature increases

A.

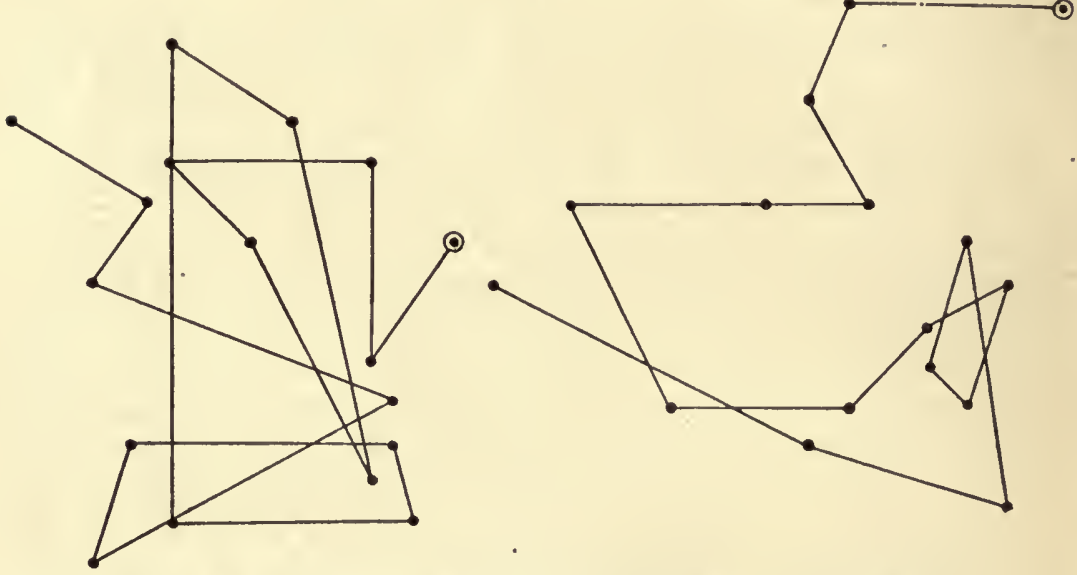

FIG. 8.-Movements of two particles of india-rubber latex in colloidal solution, recorded by cinematograph and ultra-microscope. (Henri.)

velocity. The velocity may also be modified by alterations in the hydration of the particles. Ramsay considers that the particles in pure water do not touch one another at any time, each particle being surrounded by a liquid layer. This layer is destroyed by the addition of salts, which thus cause negative aeceleration.

To use a somewhat homely illustration, the colloidal particle may be likened to a morsel of bait dropped into the water of a river estuary. The moment that it reaches the water it is pushed to and fro by a multitude of hungry small fish. 'The velocity and amplitude of the oseillatory movements of the bait depend principally on the size of the bait and on the energy with which it is attacked. 
If a colloidal solution or a fine suspension of gamboge or mastic be kept undisturbed at eonstant temperature for some time, Perrin found that there was a distribution of the colloidal partieles under the influence of gravity. At the bottom of the container will be found a denser distribution than at the higher levels. This is exactly similar to the deerease in the density of the atmosphere with height above sea level, and Einstein argued that the

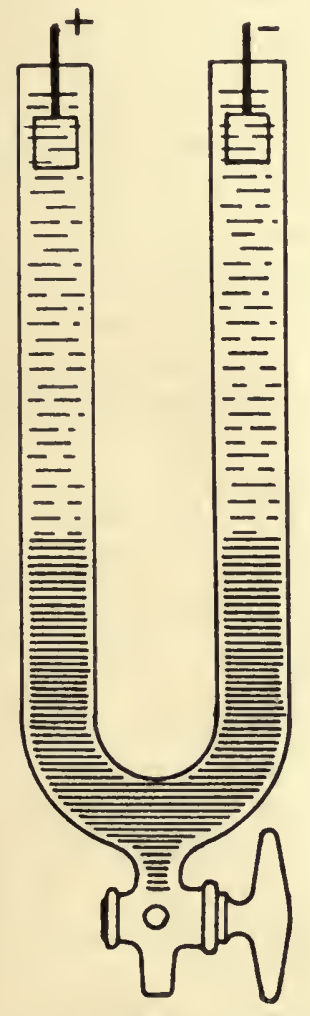

Fig, 9.-Apparatus for demonstrating cata. phoresis. The deeply shadcd lower portion of the U-tube is filled with a colloidal sol, the upper part with ordinary distilled water. On the passage of an electric current the collold rises towards the electrode of opposite sign to the sol. (Hatschek.)

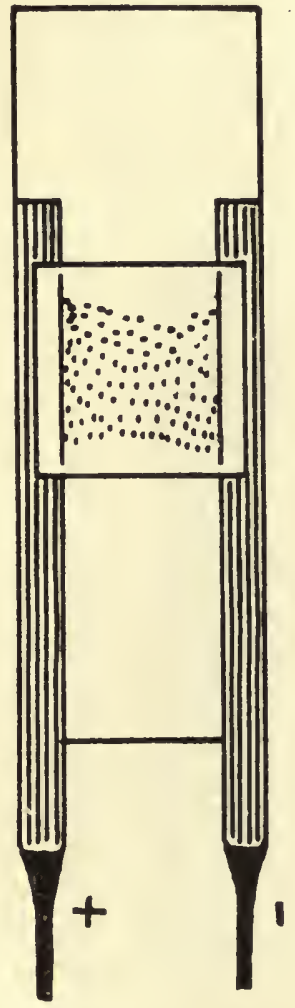

FiG. 10.--Apparatus for ultramicroseoric obscrvation of the movements of colloids in an clectric fleld (see Part II.). (Hatschek.)

distribution of suspended particles with height should follow the law which governs the density of the atmosphere with height. Perrin proved by experiment that this was true. In one experiment with mastic at four different levels $12 \mu$ apart he found 116 , 146, 170 and 200 particles per unit. For the same levels the follow- 
ing values were calculated: 119, 142, 169, 201. This and numerous other experiments confirm quantitatively the theory that the Brownian movement is the result of molecular impacts. After this adjustment of concentration to level has becn reached, no other change seems to take place. To this cause may be attributed a share at least of the responsibility for the stability of colloidal solutions.

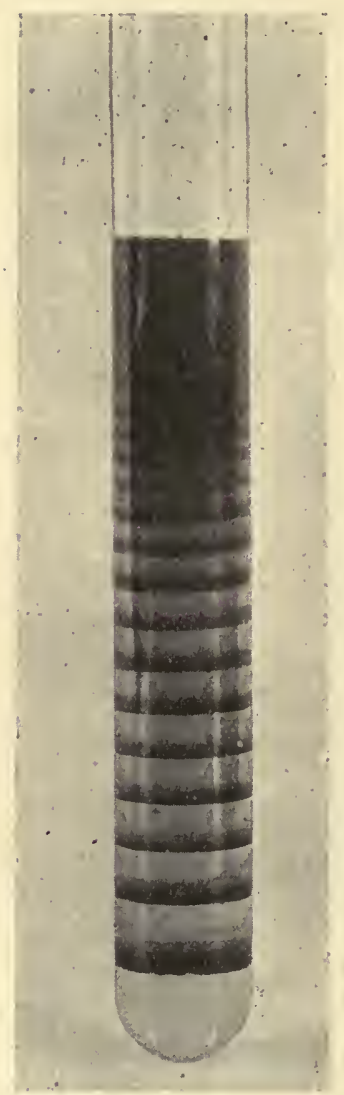

FIG. 11.-Adsorptive stratifcation of silver bichromate in an agar gel. (Bradford, Biochemical Journal.)

The electrical properties of a colloidal dispersion may have much to do with the permanence of the suspension. Each colloidal particle carries a definite charge scemingly dependent on the hydrogen ion concentration of the dispersing medium. The colloid generally has a greater conductance than the intermicellar liquid itself. This is due to the uncqual adsorption of ions of electrolytes present in the dispersion medium and in some instances by ionisation of the colloid itself. By virtuc of this charge the particles of the disperse phase will act like ions and will migrate through the solution to any point of opposite charge. This electrical migration is called cataphoresis (Figs. 9 and 10).

\section{Diffusion of Electrolytes.}

Cataphoresis should not be confused with the electrical diffusion of elcctrolytes into gels. That dissolved substances diffuse into or out of gcls was a fact familiar to Graham. The rate of diffusion may be altered by the addition of certain substances to the gel. A gel, after treatment with sodium sulphate, glucose, alcohol, glycerol, etc. (dehydrating agents), offers considerable resistance to the diffusion of electrolytes. Urea, iodides, and chlorides, on the other hand, cause acceleration of the rate of diffusion. These added substances cause alteration in the relative amounts of water held by dispersoid and dispersant and so produce alterations in the more liquid phase. The degree of continuity of liquidity is a causative factor in the velocity of diffusion. 


\section{Liesegang Phenomenon.}

If a gel contains a substance in solution and a second substance capable of reacting with the first is allowed to diffuse into the gel, the product of the reaction is deposited in strata separated by clear intervals (Part II.). In Fig. 11 is illustrated a test tube filled with 1 per cent. agar gel containing potassium bichromate. On top of this was placed a solution of silver nitrate. It is obvious that the silver bichromate formed is deposited in strata separated by clear agar. No satisfactory explanation of this phenomenon has been offered (Part II. p. 413).

\section{Electrical Diffusion.}

The rate at which electrolytes diffuse into gels may be increascd by the passage of an electric current. This method is sometimes employed in the administration of drugs, - so called ionic medication. "Metal "-ions (cations) are carried into the tissues from the positive electrode of any current-supply device, while " acid"-ions (anions) are driven in from the negative electrode (sce Chap. X. and Part II. p. 413).

\section{Coagulation of Gels and Precipitation of Sols.}

If a colloid has a positive charge when in a liquid of high $\mathrm{H}^{+}$ concentration and has a negative charge when the $\mathbf{H}^{+}$is low, an intermediate point (isoelectric point) can be reached when the colloidal particles has either no charge or, which comes to the same thing, half of them with + and the rest - . In such a case the colloid would lose its electrical stability. Positive and negative particles would coalesce to form aggregates too large to exhibit Brownian movement and the colloid would separate into discrete phases.

This coagulation may be brought about by adding $(a)$ acids or alkalies, $(b)$ suitable electrolytes or $(c)$ colloids of opposite sign. The coagulation of suspensoids (Class IV. colloids) by the above means is easily carried out and is a reversible process. On washing out the adsorbed precipitant the dispersoid is re-established. Emulsoids (Class III.), on the other hand, are more stable than suspensoids. They usually need the addition of a large quantity of the coagulating substance and the resulting coagulum is frequently irreversible. This may be due to alteration in the continuous phase. We have seen that an emulsoid is a diphasic system where the continuous phase is more or less a continuation of the disperse phase. If a substance $A$ is dispersed in water to 
form an emulsoid what really results is a dispersion of a solution of water in $A$, throughout a solution of $A$ in water. 'The stability of such a system will depend in great measure on the viseosity of the intermicellar liquid. The viseosity depends on the concentration of the more viseous $A$ in the less viscous water. The range of viseosity making for stability will be bounded on the one hand by a certain minimum and on the other hand by a certain maximum concentration of water in the continuous phase.

\section{Protective action of Emulsoids.}

Many emulsoids when added in comparatively minute quantities to suspensoids prevent the coagulation of the suspensoids by electrolytes. As a matter of fact, each emulsoid which exhibits this property has a characteristic protective power which may be used as a definite factor for the identification of the colloid. The suspensoid generally used in the test is colloidal gold. Zsigmondy, who devised the method, defines the "gold number" as the number of milligrams of an emulsoid which are just sufficient to prevent 10 c.e. of a bright red gold sol (prepared under certain speeified conditions) from changing into violet or shades of violet after the addition of 1 c.e. of 10 per ecnt. sodium chloride solution (Part II.).

He divides colloids into four classes according to their "gold number," viz. :

TABLE XIII.

\begin{tabular}{|c|c|c|}
\hline Class. & Gold Numbcr: & Examples. \\
\hline $\begin{array}{l}\text { I. } \\
\text { II. } \\
\text { III. } \\
\text { IV. }\end{array}$ & $\begin{array}{l}0 \cdot 005-0.1 \mathrm{mg} \\
0 \cdot 1 \quad-10 \mathrm{mg} \\
10 \quad-500 \mathrm{mg} \\
\text { Inactive }\end{array}$ & $\begin{array}{l}\text { Gelatin, caseinogen, animal glue. } \\
\text { Crystalline egg albumin, gum acacia. } \\
\text { Dextrin, starch. } \\
\text { Mucin, silicic acid. }\end{array}$ \\
\hline
\end{tabular}

The general opinion seems to be that the emulsoid forms a pellicle round each suspensoid particle and prevents coagulation, either (1) beeause, as we have seen, emulsoids are less sensitive to the preeipitating action of clectrolytes and the compound particle is endowed with an emulsoid coat; (2) because the electrolyte does not eome in eontact with the suspensoid particle and does not neutralise its electric charge, or (3) merely by offering a material obstacle to the coaleseenee of the particles.

The fluids of the body eontain two colloidal substanees of peculiar interest. Albumin and globulin are both emulsoids, 
but they differ physically in at least three respects summarised below.

TABLE XIV,

\begin{tabular}{|c|c|}
\hline Albumin. & Globulin. \\
\hline $\begin{array}{l}\text { Sol in water. } \\
\quad \text { (Sol in } 5 \text { per cent. } \mathrm{NaCl}^{\text {) }} \\
\text { Not ppt. by } \frac{1}{2} \text { sat. }\left(\mathrm{NH}_{4}\right)_{2} \mathrm{SO}_{4} \text {. } \\
\text { Protects suspensoids. }\end{array}$ & $\begin{array}{l}\text { Insol in water. } \\
\quad(\mathrm{Sol} \text { in } 5 \text { per cent. } \mathrm{NaCl} \text {.) } \\
\text { Ppt. by } \frac{1}{2} \text { sat. }\left(\mathrm{NH}_{4}\right)_{2} \mathrm{SO}_{4} \text {. } \\
\text { Ppts. suspensoids. }\end{array}$ \\
\hline
\end{tabular}

Albumin has a protective action on gold sol while globulin acts almost as if it were a suspensoid. The proportions of albumin and globulin in the various body fluids is practically invariable in health, but during the course of various diseases the balance is upset. If the globulin content is increased relatively to the albumin, then the body fluid will lose a portion of its protective power. In some cases the globulin is not incrcased, but carries an increased positive electric charge. This increases its precipitating action. (Method given in Part II.)

Evaporation or dehydration, if it reduces the water content below the minimum, will cause coagulation. Conversely, dilution causes a disperse system to break up.

Heating and Cooling, which alter viscosity directly and also indirectly by altering the amount of water distributed between the two phases, also cause coagulation. Heating certain sols changes them into the more rigid gels. Various native proteins, for instance those of egg white, serum, muscle, coagulate to a gel on heating to a temperature specific for each protein. This process is irreversible and takes place in the presence of clectrolytes. On the other hand, gelatin forms a sol on heating and a gel on cooling-a reversible reaction which is profoundly modified by the presence of electrolytes.

\section{Action of Radium. (See also Chap. XI.)}

The intimate connection between coagulation and the charge carried by the particles is shown by the action of the $\beta$ rays of radium. As these rays are negative charges of electricity, they should stabilise negative colloids by increasing their charge, and precipitate positive colloids by neutralising their charge. Hardy found that positively charged acid-globulin was reduced to a state of jelly in three minutes, while the particles of negatively charged alkaline-globulin were rendered more mobile by exposure to $\beta$ radiation. 
The behaviour of most organic gels is complicated not only by the presence of electrolytes, and by the fact that the content of the intermicellar fluid in electrolytes may be rapidly altered, but also by the fact that the dispersed substance is a mixture of closely related substances. Thus agar-agar, a carbohydrate superficially similar to the protein-hydrate gelatin, consists of at least two substances $\alpha$ and $\beta$ agar-agar which are mutually convertible under certain conditions. Purified, $\alpha$ agar-agar is practically insoluble in water. The $\beta$ form is very soluble in water. On warming some of the former with water it gradually passes into the soluble form and thus goes into solution. Insoluble $\alpha$ particles may be dispersed in larger particles of $\beta+$ water. They in turn form a true sol with water. Alteration of physical or chemical conditions will therefore alter the relative concentration of $\alpha$ and $\beta$. The $\beta$ colloid protects its $\alpha$ relative from coagulation by thus forming a pellicle round it. Starch-a pseudo-colloid-is a mixture of several carbohydrates of high molecular weight, each of which is capable of taking up a different quantity of water. (See under Emulsions.)

Of great physiological interest are soaps, the alkali salts of the fatty acids. These soaps are found in the body wherever fats are found-in bile, blood, faeces, ear wax, sebum, etc., as well as in some pathological fatty secretions. The soaps furnish a series in which the molecular weight regularly increases. Step by step with this increase in molecular weight there is a regular gradation of the properties of the dispersoid from the true solution of the soaps of the lower fatty acids to the colloidal gels of the higher homologues. Still more important physiologically is the effect of altering the anion. Sodium, potassium, ammonium, calcium and magnesium soaps are found in physiological analyses and these differ from one another, especially in their power to hold water. Ammonium and potassium soaps are so hydrophilic that they do not solidify but form jellies (soft soap). Sodium soaps also hold a considerable amount of water, but only about $\frac{2}{5}$ of that held by "soft" soaps. So little water is held by the soaps of calcium and magnesium that they do not form a sol to any appreciable extent. The addition of alkali to a sodium soap greatly increases its hydrophilic properties. Soap solutions may be broken up in various ways.

(a) The addition of an acid stronger than the fatty acid frees the fatty acids, e.g. $\mathrm{H}_{2} \mathrm{SO}_{4}+2 \mathrm{Na} \overline{\mathrm{A}}=\mathrm{Na}_{2} \mathrm{SO}_{4}+2 \mathrm{H} \overline{\mathrm{A}}$.

(b) On adding a powdered neutral salt to a soap solution the 
soap is "salted out" as a eurdy mass. The salt reduees the hydrophilic powers of the soap and so reduces the stability of the dispersoid. This is a different phenomenon from the preeipitation of a eolloid by electrolytes.

(c) On adding a soluble salt of ealeium or magnesium to a soap of ammonium, sodium or potassium a curdy precipitate is produced. This curd is a calcium or magnesium soap, which, as we have seen, has little or no affinity for water.

(d) Solvents of soaps added to a water-soap dispersoid lead to a partition of the soap between solvent and dispersion medium. The effect of the anaesthetics on soap sols is interesting. Alcohol brings about a rapid separation of soap and water, practically all the soap dissolving in the alcohol. Chloroform has much the same effect, but the partition is not so complete. To get anything like a complete extraction large amounts of chloroform must be used. Ether has hardly any effect.

Soaps have a powerful effect in lowering surface tension, which effect is greatly increased by the addition of small quantities of alkali (Shorter and Ellingworth). A stalagmometer reading of oil dropping into water was 65 drops. When 1 per eent. soap was added to the water the drops increased to 260 (Hatsehek).

\section{Emulsions.}

Although, as far as is at present known, emulsions do not take a direct part in the energy exchanges of the body, and should therefore not be treated in this seetion; yet as they are so closely allied to the colloids, and are really never found unless mixed with colloidal or semi-colloidal matter, it is eonvenient to deal with them now.

An cmulsion may be regarded as an emulsoid with somewhat larger dispersed particles (microns). The term, as usually employed, has, however, a narrower connotation, the disperse phase being considered as a fat or fat-like substance distributed throughout water in such a way as to remain stable for an indefinite period. Oil and water are two immiscible liquids and no amount of mechanical mixing will induec them to form a permanent emulsion. It is true that after a prolonged beating of the two together a maximum of 2 per eent. of the oil may be taken up by the water, forming a stable dispersoid. Measurement of the particles, however, demonstrates that they are of the order of sub-microns, and thus a true colloidal system has becn formed. An example of this is the condensed water of steam engines, which contains lubricating oil in suspension. 
Analyses of natural and artifieial emulsions, like milk, bile, rubber, eod-liver-oil emulsion, etc., demonstrate the presenee of more than merely oil and water. A eolloid or semi-eolloid must be present.

TABLE XV.

\begin{tabular}{|c|c|c|c|c|}
\hline Emulsion. & Disperse Phase. & Continuous Pliase. & Colloids. & Crystalloids. \\
\hline Milk & $\begin{array}{l}\text { Oil } \\
3 \cdot 8 \text { per cent. }\end{array}$ & $\begin{array}{l}\text { Water } \\
87 \text { per cent. }\end{array}$ & $\begin{array}{l}\text { Caseinogen } \\
\text { Albumin } \\
\text { Globulin } \\
3 \cdot 2 \text { per cent. }\end{array}$ & $\begin{array}{l}\text { Lactose and } \\
\text { Salts } \\
\mathrm{Na}_{2} \mathrm{CO}_{3} \text {, etc. }\end{array}$ \\
\hline Bile & $\begin{array}{l}\text { Fats and } \\
\text { Lipoids } \\
5 \cdot 9\end{array}$ & $\begin{array}{l}\text { Water } \\
77 \cdot 5\end{array}$ & $\begin{array}{l}\text { Soap } 3 \cdot 2 \\
\text { Mucin } 0 \cdot 45\end{array}$ & \\
\hline Egg yolk & $\begin{array}{l}\text { Fat } \\
35 \cdot 3\end{array}$ & $\begin{array}{l}\text { Water } \\
47 \cdot 2\end{array}$ & $\begin{array}{l}\text { Protein } \\
15 \cdot 6\end{array}$ & \\
\hline Ear-wax & $\begin{array}{l}\text { Fat } \\
26\end{array}$ & $\begin{array}{l}\text { Water } \\
10\end{array}$ & $\begin{array}{l}\text { Potas. Soap } \\
52\end{array}$ & $\begin{array}{c}\text { Mostly organic, } \\
\text { little ash. }\end{array}$ \\
\hline Butternut & $\begin{array}{l}\text { Water } \\
4 \cdot 4\end{array}$ & $\begin{array}{l}\text { Fat } \\
55 \cdot 1\end{array}$ & $\begin{array}{l}\text { Protein } \\
23 \cdot 7\end{array}$ & \\
\hline $\begin{array}{l}\text { Human fatty } \\
\text { tissue. }\end{array}$ & $\begin{array}{l}\text { Water } \\
15\end{array}$ & $\begin{array}{l}\text { Fat } \\
82 \cdot 5\end{array}$ & $\begin{array}{l}\text { Protein } \\
2 \cdot 5\end{array}$ & \\
\hline Rubber latex & $\begin{array}{l}\text { Rubber } 20 \\
\text { and } \\
\text { Resin } 2\end{array}$ & $\begin{array}{l}\text { Water } \\
76 \cdot 2\end{array}$ & $\begin{array}{l}\text { Protein } \\
2 \cdot 8\end{array}$ & $\begin{array}{l}\text { Sugars, } \\
\mathrm{K} \text { and } \mathrm{Ca} \text {, etc. }\end{array}$ \\
\hline $\begin{array}{l}\text { Pharmaceu- } \\
\text { tical } \\
\text { Emulsions }\end{array}$ & $\begin{array}{l}\text { Oil } \\
50\end{array}$ & $\begin{array}{l}\text { Water } \\
50\end{array}$ & $\begin{array}{l}\text { Egg white } \\
\text { Gum arabic } \\
\text { Saponin }\end{array}$ & $\begin{array}{l}\text { Sugar } \\
\text { Phosphates } \\
\text { Carbonates }\end{array}$ \\
\hline $\begin{array}{r}\text { Lubricating } \\
\text { Emulsion }\end{array}$ & $\begin{array}{l}\text { Water } \\
1\end{array}$ & $\begin{array}{l}\text { Oil } \\
99\end{array}$ & $\begin{array}{l}\text { Soap } \\
1\end{array}$ & \\
\hline
\end{tabular}

If the generie term oil is used to denote any liquid that is not miseible with water, we may note that there are two entirely different types of emulsions, the one being drops of oil suspended in water and the other being drops of water suspended in oil (ef. emulsoid sol and gel). For example, milk belongs to the former and butter to the latter elass. It is important to know 
under what conditions each of these types is formed. One might at first imagine that the governing factor would be the relative amounts of oil in water, much water and little oil producing the oil-in-water type and excess of oil over watcr producing the water-in-oil emulsion. This is not so. The nature of the emulsoidcolloid determines the type of the emulsion absolutely. The relative amounts of oil and water have nothing to do with it. To understand the significance of this, one must examine the function of the colloid.

Some means must be adopted once the oil has been dispersed to $(a)$ decrease the interfacial tension between the droplets and the dispersion medium so that the dispersed particles will not coalesce, $(b)$ confer on the droplets an electrical charge so as to cause mutual repulsion, and $(c)$ mechanically keep the droplets separate. The presence of an emulsoid seems to confer stability on an oil-water emulsion. 'Two theories to account for this are of suffieient importance to warrant attention.

1. Most physical chemists prefer the theory which postulates a third phase, namely, a thin layer of eolloid or semi-eolloid separating the disperse from the continuous phase. This interfaeial film reduces the surface tension on the film-water interface, confers a charge on the droplets by adsorption, and, by having the remainder of the eolloid as an outer phase, provides a medium sufficiently viscous to keep the droplets in suspension.

2. Recently Fischer and Hooker have promulgated their theory of the action of the protective eolloid. They consider that an emulsion may be triphasic but need not necessarily be so. Their idea is that a diphasic system is all that is required for stability, e.g. oil and an emulsoid in water.

The nature of the emulsoid determines the type of emulsion produced. If the eolloid is one which is "wetted" by water (hydrosol or hydrogel), and is adsorbed by oil, it (or its solution) will form a film round the oil droplets and give an emulsion of oil in water. On the other hand, if the colloid is dispersed through oil and is adsorbed by water it will emulsify water in oil. Most emulsions are of the first type, oil-in-water.

The oil cannot be dispersed throughout a hydrated colloid until a certain lower limit of water content has been exceeded, nor can it be divided permanently into a hydrated colloid after an upper limit has been passed.

Emulsions are broken through the institution of conditions that are the reverse of those that make for their stabilisation. 
In other words, a colloid is a suitable emulsifying agent only when it holds a eertain amount of water. That amount may vary between an upper and a lower limit. If at any time the water in the system oversteps either of the limits the emulsion will lose its stability and will separate out. The emulsions hardest to break are those where the emulsifying agent is a earbohydrate like gum acacia, starch or dextrin. They hold their water of hydration with avidity. Salts, acids, or alkalies in moderate eoneentrations, alcohol, ehloroform and ether have very little action on them. Milk, an oil in protein emulsion, is very difficult to break. Dilution has little effect and fat solvents do not readily extract the fat. This is probably due to an adsorption effect in which the earbohydrate plays a part as yet unknown. The colloidal material comes to be eoneentrated on the surface between the oil and the aqueous phase. These protecting films drawn over the oil globules keep them from eoaleseing even when brought elose together and also form a membrane impermeable to fat solvents.

At this point the two theories seem to be on common ground. Neither of them can, however, give a satisfactory explanation of the stabilising effect of the presence of a small quantity of carbohydrate on oil-protein or oil-soap emulsion. 'The earbohydrate need not be a hydrophilie eolloid itself. Cane sugar is an exeellent stabiliser. Why are tissues less easily poisoned by anaestheties and other poisons when glyeogen is in the cells?

Similarly the colloid in a water-in-oil emulsion must be hydrated. Using soap as his stabiliser, Pickering emulsified 99 per cent. oil by volume in one volume of water. The resulting emulsion was a stiff jelly which eould be eut with a knife and the eube so prepared would stand alone. These solid eubes when left standing in dry air seem to liquefy. The reason for this is that the soap film loses moisture by evaporation, eracks, and sets free the oil. The mass does not beeome liquid because of the adsorption of water but heeause of the loss of water. Several of the heavy lubricating oils contain a considerable quantity of ealeium soap. Now, ealeium soaps are very insoluble in water but form colloidal solutions in oil, therefore, in these lubricants the water is emulsified into the oil and a thick grease is formed. Rosin acts similarly to ealcium soap and is used in the preparation of cheap brands of ready-made paints as an instrument for the emulsification of water in the linseed oil. As much as 80 per eent. water may be absorbed in this way. 
The hydrophilic properties of sodium and ealeium soaps have already been mentioned. Their behaviour in emulsion-making throws light on some peculiar problems in physiology. Loeb and his co-workers found that certain marine organisms died when put into fresh water. This will not appear surprising to the student who remembers the phenomena of endosmosis, e.g. plasmolysis, haemolysis, ete. That this explanation is not correct is shown by putting the organisms into solutions of sodium chloride or of calcium chloride having the same osmotic pressure as sea water. If, however, the organisms which would have been killed by immersion in these isotonic solutions were plaeed in a solution having a definite ratio between the amount of sodium and calcium present, life was maintained quite normally. All protoplasm may be considered as an emulsion of lipoid material in a colloidal-crystalloidal complex. The presence of the sodium soap formed by interaction with the lipoids causes the formation of a lipoid-in-water emulsion while the calcium soaps emulsify water-in-lipoid. The two types of emulsion thus formed are in equilibrium with an environment containing a definite $\mathrm{Na} / \mathrm{Ca}$ ratio, that of sea water. Alteration in this ratio upsets the balance between the two types of emulsion and eauses the cessation of growth and subsequently of life (see Nerve, Chap. XVII.).

The rigidity of tissue is to a large extent due to their emulsion character. We have up till now considered protoplasm as a liquid, arguing that it is so because it shows the phenomena of surface tension, because it allows the ready diffusion of erystalloids into and through it, and because it reaets chemieally as a liquid. On the other hand, tissues, as we handle them, are more or less rigid, having elastieity and definiteness of form. Do Piekering's solid emulsions and the $\mathrm{Na} / \mathrm{Ca}$ ratio not suggest a fairly plausible explanation of this double nature of protoplasm ? The "softening" of tissues observed in various pathological states may be due to the breaking of the protoplasm-emulsion from any cause (Part II.).

Our food materials as well as our tissues are colloidal complexes. They are derived in part from the animal, in part from the vegetable kingdoms.

A. Animal foods may be classified as :

(1) Milk and its products-cream, butter, and cheese.

(2) Flesh.

(3) Eggs.

(1) Milk is a fine emulsion of fat in a protein-colloidal solution. 
(a) The fat globules each secm to be enveloped by a covering of adsorbed protein.

(b) The chief protein in milk is caseinogen, a phospho-protein which exists in milk as a soluble calcium compound. This compound is broken by the action of acid, and protein separates as a curd.

(c) The carbohydrate of milk, lactose, is split by various microorganisms, forming lactic acid, thus souring the milk and causing curdling.

Butter is simply the fat of the milk more or less completely separated from the other constituents and forming a water-in-oil emulsion. Whole, unchanged milk shows no tendency to form butter. To form butter the fat particles are concentrated at the surface by centrifugal action (or merely by allowing the cream to rise), and then by causing the cream to sour, the fat is freed from its emulsion with the colloidal matter. Since the hydrated colloids tend to collect in the surface layer between the fat globules and the dispersant aqueous phase of the cream, churning is performed to break these layers and hasten the coalescence of the fat. "The combined efforts therefore bring about a progressive increase in the concentration of the oil with a decrease in the concentration of the hydrated colloid until the instability of the oil in hydrated eolloid beeomes so great as to 'break' and yield the hydrated colloid-in-fat emulsion which we call butter" (Fischer and Hooker). That milk and cream are oil-in-water emulsions can be proved microscopically. They wet paper and are not greasy to the touch. Butter is a water-in-oil emulsion, fecls greasy, oils paper, and microscopically appears as a finely divided aqueous colloid phase in a continuous oil phase.

(2) Flesh. Under this head is included, not only the muscles of various animals, but such cellular organs as the liver, kidneys, thymus, etc. The colloidal nature of such tissues has already been dealt with (see effect of cooking, below).

(3) Eggs. The white of eggs is practically an albumin hydrosol containing some crystalloids, while the yolk is an emulsion of lipins (lecithin, etc.), in a hydrosol of protein (ordinary proteins, and vitellin, a phospho-protein).

\section{B. Vegetable Foods.}

In the food of man, vegetable foods play as important a part as animal products. Generally, their make up is that of a mixed hydrogel of protein, higher carbohydrates (and in the case of 
oatmeal, maize, nuts, ccrtain legumes and vegetables), a fair proportion of fat. This gel is enclosed in a capsulc of cellulosea higher carbohydrate which is very resistant to the action of the human digestive juices. The capsule must be destroyed by previous treatment, e.g. milling, cooking, chewing, etc., before the contents can be utilised. Far and away the most important of our foodstuffs are derived from cereals. From 30 to 50 per cent. of the energy of an ordinary diet comes from them. They are generally used as flour, baked into bread, or as meal made into porridge. Wheat flour is a complex gel powder consisting of about 10 per cent. protein, about 75 per cent. carbohydrate (starch and cellulose), and about 2 per cent. fat in the colloidal state. The individual particles contain molecularly dispersed salts, sugar, water, and adsorbed gases such as air and carbondioxide. Of the 10 per cent. of protein, gliadin forms about 4 per cent. and glutelin about 4 per cent. There is less than 1 per cent. of globulin $(0 \cdot 6$ per cent.) and albumin $(0 \cdot 3)$ present. The mixture of glutelin and gliadin is known as gluten. Gluten is insoluble in water or in dilute salt solutions, and therefore readily forms a disperse system with water called dough. Dough is a polydispersoid composed of the glutelin (and other proteins) carbohydrates and crystalloids mentioned above bound together by colloidal gliadin. It is a viscous semi-liquid mass which, however, may be cut like a solid, and when torn exhibits a fibrous surface. The elastic properties of dough depend upon the proportion of electrolytes present, especially on the phosphates. When it is dried it changes into a gel and later becomes brittle like glue. There is doubtless a close connection between the viscosity of flour-water mixtures, and the stickiness, rising property, power of absorbing $\mathrm{CO}_{2}$ of the dough, hydration of the starch and the porosity and volume of the resultant loaf.

The viscosity is found to increase with the concentration of the flour and also to become greater for some time after mixing. This is doubtless due to the slow swelling of the starch and albumin. If concentrated solutions are suddenly diluted the viscosity is too great at first, but gradually approaches a normal value. This is probably caused by a slow increase in the dispersion, because when the larger particles are removed by means of filter paper normal results are obtained.

Cooking. While many reactions occur in cooking, the changes that are of paramount importance are of a colloidal nature. Dough, for instance, undergoes a marked alteration in its physical 
characters during the baking process. The proteins are coagulated (gel formation) and the degree of dispersion of the starch is increased. Adsorbed gases are set free and the bread "rises." Further alterations take place in the loaf after it is removed from the oven.

The physical nature of flesh is profoundly altered by subjection to cooking. In roasting, grilling, boiling, or frying, the meat is exposed directly to heat. The proteins in the outer layers are immediately coagulated, thus forming a more or less impermeable covering which prevents the escape of the meat juices, leaving the centre portion of the flesh only slightly altered chemically, but with all sols converted into hydrogels. On the other hand, if the meat is immersed in cold water and boiled much of the protein-sol and practically all the salts and extractives are dissolved out and form soup. In this soup the protein-sol is coagulated as the temperature rises, and on cooling it is adsorbed to the surface and often is removed with the fats as a scum. The remaining meat undergoes coagulation, but is flavourless. Stewing is a modification of boiling, but the extractives, salts and soluble protcins, are served as gravy. 


\title{
CHAPTER IX
}

\author{
ENZYMES
}

\section{THE TOOLS OF THE CELL}

"Instances of Magic; .... By which I mean those wherein the material or efficient cause is scanty and small as compared with the work or effect produced; so that even when they are common, they scem like miracles, some at first sight, others even after attentive.consideration." BAcoN.

THE living eell is a factory where, without any great display of energy, work is earried on whieh, outside the body, eould only be done by the use of strenuous proeesses. In the cell are prepared seeretions which aet on insoluble raw material, rendering it soluble and so fit for transit to the eell and passage into it. Within the eell, these prepared materials undergo further ehange; some are used as sources of energy; from others, the cell builds up eomplex tissue; others again are altered somewhat and stored for future use. The cell manufactures from the material supplied, various substanees such as are required, it may be by distant cells which are so oceupied by some speeial process that they are unable to perform the particular synthesis. The by-produets of manufacture are rendered harmless by proeesses possible, as yet, only in the eell. Some eells, as indieated above, have a speeialised funetion. To a certain extent, all the cells of a multicellular organism are speeialised. They are divided into eommunities, each engaged on some speeial work and requiring speeial raw material. Some of these eommunities, however, engage to a eertain extent in general manufaeture. They are almost, though not quite, self-supporting. The white eells of blood, for instanee, are really unicellular organisms. Other communities are almost entirely dependent on imports for their sustenance. Nerve cells, for example, form the means for intereommunication between cell-communities. Their general metabolism is peculiar.

Contrast the quiet, economical, and neat living-faetories with the places where things are made outside the body. Our manu- 
facturing cities are not spotless nor are our processes there economical. Smoke, sound, and slag-heaps are universal accompaniments of a manufacturing community. Most of the processes carried on in the cell have not been reproduced in the laboratory. Fischer, the finest physiological chemist of this or any century, has failed to synthesise the simplest protein. Fat and carbohydrates are interconvertible in vivo but not in vitro. True, steps have been taken towards the building up of a protein. Polypeptides-compounds containing eighteen amino acidshave been the crown of Fischer's efforts, but at what a cost of material, time, and energy. It has been well said that laboratory processes are just a roundabout way to the sink.

How does nature accomplish her work? What tools does she use ? How does she harness her power?

Nature employs catalytic methods. A catalyst is defined as a substance which, while not entering into the final product of the reaction, alters its rate and in some cases alters the point of equilibrium. A model may make this clearer. A sheet of glass may be inclined at such an angle that a body placed at its upper end just slips slowly to the foot. The momentum of the sliding body may be insufficient to carry it to the foot of the glass plate, and motion may thus stop midway down the plane. If a small quantity of oil be placed either on the glass or on the bottom of the weight, it will slide rapidly to the foot of the plane. The oil remains unchanged. No energy has passed from the oil to the weight, and yet the rate of falling and the point of equilibrium have been altered. The lubricant may be taken as representing a catalyst. Some one has said that a catalyst, like a tip to a waiter, accelerates a reaction that otherwise would proceed with infinite slowness. It takes no part in the main reaction, is adsorbed to the reacting body, and may be recovered intact at the end of the reaction by destruction of the substrate.

Catalysts are of very many kinds, and the mechanism of their action is so varied and so little understood that few, if any, general principles can be enunciated. They may be classified according to the means they adopt to influence a reaction.

1. Contact agents. Many reactions seem to be accelerated by the adsorption of the reacting substance on the surface of the catalyst, e.g. effect of colloidal catalysts.

Colloids, as we have seen, are characterised by the development of surface. If we take a sphere of metal which just fits into a cubical box, and divide that sphere into smaller spheres of uniform 
size, the same mass of metal may be packed into the box regardless of the size of the spheres, provided they are uniform in size. Mass and total effective volume are not altered, but surface is increased. The surface of a sphere is $4 \pi r^{2}$. If the original sphere be divided into 100 small shot, then the new surface would be $100 \times 4 \pi r_{1}{ }^{2}$ where $r_{1}=$ radius of small shot. Now $r_{1}=\sqrt{\frac{3}{100}}=4 \cdot 64$, i.e. the surface would be increased over four and a half times. If the subdivision were carried still further till there were $10^{30}$ small shot, then the total adsorbing surface would be increased $10,000,000,000$ times. The intensity of adsorption is chiefly dependent on the area of adsorbing surface (cf. Table, p. IX.). In other words, contact catalysis is indicated where the specific surface of the eatalyst comes within the colloidal range. Charcoal is used as an adsorbent in the clarification of sugar. A cubic metre of charcoal consisting of particles $1 \mathrm{~mm}$. in diameter has a surface of about $600 \mathrm{sq}$. metres. If the particles are reduced to colloidal dimensions, say to $0 \cdot 1 \mu$ diameter, then the adsorbing surface becomes $60,000,000$ square metres.

2. Carriers. In some cases the catalytic agent combines chemically with one of the reacting substances to form an unstable intermediate compound. This, in turn, breaks up, regenerates the catalyst, and liberates the reagent in the active atomic state-so called nascent. Many oxidations and reductions are brought about in this way.

3. Ionic Catalysts. Hydrogen and hydroxyl ions act as catalysts for many reactions which occur in aqueous solution. The velocity of such a reaction in dilute solution is proportional to the concentration of the ions in question, provided the thermodynamic environment remains constant. The ion probably acts as a carrier, forming an unstable perhydrate as intermediate product.

The great majority of vital catalytic reactions have, as catalyst, an enzyme. Enzymes themselves cannot be detected or estimated. Their presence is made apparent by their action. By estimating the amount of the products of enzyme activity an idea of the rate of reaction may be gained. Many attempts have been made to isolate and purify certain enzymes and, though complete success has not been granted to any investigator, much has been learned of their nature and of the conditions necessary for enzyme action.

(a) Enzymes are colloidal. They can readily be separated from erystalloids by dialysis or ultrafiltration. Chemically, they resemble their substrate or are so closely associated with their 
substrate that existence apart is impossible. It may be that the colloidal character of enzymes is the secret of their action. At any rate an artificial oxidising enzyme has been prepared by mixing a suspensoid - finely divided manganese, with an cmulsoid -gum acacia. The adsorption complex so formed, if suitable crystalloids were present, reacted as an artificial "laccase."

(b) Enzymes retain their activity only over a very well-defined range of temperature. It is common knowledge that physiological processes takc place most readily at body temperature. Every biological laboratory is equipped with devices for keeping incubators at a constant temperature-say, $37^{\circ}-40^{\circ} \mathrm{C}$. Before these appliances had been perfected, investigators in this realm had to keep their experimental material on their person. The Abbé Spallanzani (1729-1799), in his classical work on digestion, carried his digest-tubes in small pockets in his armpits for several days. During the Great War, when scientific work had to be carried out in all sorts of places, at lcast one physiologist, bereft of gas regulators, had to resort to this simple but efficient method of maintaining a fairly uniform temperature. In this way, reactions in which they play a part differ from those usually styled chemical. The rate of most chemical processes is doubled or trebled when the temperature is raised $10^{\circ} \mathrm{C}$. The enzymes follow this rule only from $0^{\circ} \mathrm{C}$. to a temperature called their optimum temperature, above which the rate decreases rapidly. The optimum temperature of most enzymes lies between $30^{\circ}$ and $40^{\circ} \mathrm{C}$. The decrease in rate of reaction when the temperature is allowed to go over $40^{\circ} \mathrm{C}$. is probably due to coagulation of the enzyme. Increase in temperature causes alterations in the physical state of colloidal matter. These alterations, in viscosity, in colour, and in conductivity, all indicate an increase in the size of the colloidal particles, and consequently a decrease in their specific surface. The effective adsorbing surface is diminished. At the optimum tempcrature the increased chemical action due to tempcrature more than balances the decreased adsorbing surface. Beyond this temperature, the loss of surface becomes relatively important. If the temperature is raised till the specific surface is reduced, by coagulation, to a value bclow 10,000 , adsorbing power is totally lost, chemical action is stopped, and the enzyme is said to be dead.

In the appended figure (Fig. 12) curve 1 (dotted line) shows how, as the temperature increases, a pure chemical action is accelerated. Curve 2 (dash line) represcnts the rate at which the 
effective surface is decreased by rising temperature. The process, it will be noticed, is not an instantaneous one, but proceeds with a definite velocity which increases very markedly somewhere about $30^{\circ} \mathrm{C}$. Curve 3 (firm line) is the graph of the rate of the same chemical reaction as shown in (1), but carried out by cnzyme action. This curve may be drawn by plotting the differences of the ordinates of (1) and (2) on the same scale of temperatures.

(c) The hydrogen ion concentration of the medium in which the enzyme acts has much to do with its activity. Each enzyme is active only when the bathing fluid has a $p_{\mathrm{H}}$ of a certain range with an optimum $p_{\text {н }}$ at which the action proceeds at its best.

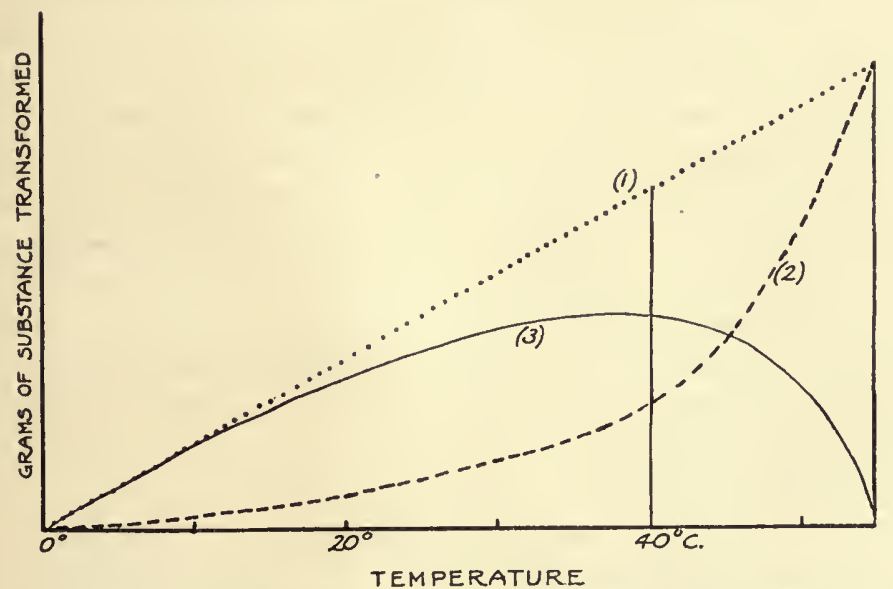

FIG. 12.-Graph to show how the effect of increase of temperature on the rate of enzyme action is the result of the interaction of two factors, (1) increased chemical action and (2) increased destruction of enzyme.

The extraordinary sensitiveness of colloids to the $p_{11}$ has been mentioned.

(d) The crystalloid content of the substrate solution is peculiar for each enzyme. Certain salts are, of course, destructive. All salts which break up colloidal complexes, inhibit or destroy enzyme action. Enzymes are "salted out" by the neutral salts that precipitate colloids and may thus be separated.

(e) Anaesthetics have no effect on enzyme action.

Chloroform, thymol, etc., may therefore be used to keep experimental enzyme solutions free from bacteria.

To sum up,-the ranges of temperature, $p_{\mathrm{H}}$, salt content, etc., all point to the colloidal nature of enzymes.

The material on which an enzyme acts is called its substrate, and cach enzyme acts on a specific substrate and on no other. In 
many cases the name applied to the enzyme is derived from that of its substrate by altering the terminal syllable to-ase. Thus maltase acts on maltose.

$\begin{array}{ll}\text { Lactase acts on lactose } \\ \text { protease }, & \text { protein } \\ \text { aldehydase }, & \text { aldehyde } \\ \text { lipase }, & \text { lipin } \\ \text { peroxidase ," } & \text { peroxide. }\end{array}$

Sometimes the function of the enzyme may be indicated by its name, viz. :
oxidase
oxidises (=peroxide +peroxidase)
catalase breaks down peroxides
invertase inverts cane sugar.

The majority of enzymes of physiological importance, however, have no accepted systematic name. They are the ones first known and they were named to suit the fancy of their discoverer. Ptyalin (Gr. Pteuin-to spit) acts on starch and should be called salivary amylase. Several others are in a similar position, e.g. Pepsin (Gr. Pepsis-digestion) =acid or gastric protease. Trypsin (Gr. Tribein-to rub-prepared by rubbing pancreas with sand and glycerol) $=$ alkaline or pancreatic protease.

Some writers prefer to use names which point to the splitting power of the enzymes, e.g.

proteolytic or proteoclastic enzymes act on proteins amylolytic or amyloclastic , , , starches lipolytic or lipoelastic

$$
, \quad, \quad \text { fats. }
$$

On the other hand, hydrolytic enzymes produce their effect by adding or subtracting water.

Some enzymes act in the cells while others are secreted by the cells and aet on a substrate outside the cell. The former, endoenzymes, have been little studied. An active suspension of them may be prepared by grinding up tissue with sand and extracting with watery glycerol. It is probable that all musele cells contain enzymes which act on protein-disintegration products, either rebuilding proteins from amino acids or breaking down these amino aeids. Similarly; the regeneration and the disintegration of carbohydrates and fats have been attributed to endo-enzymes. There are also special enzymes to carry out oxidations and reductions in the cell. The various stages in the production of uric acid from nucleoprotein have been studied exhaustively, and each stage has been shown to have its enzyme or series of enzymes. 
The ecto-enzymes are secreted in the various digestive juices and act on their substrates in some portion of the alimentary eanal. They really act outside the body and have one function only-to break down the food into a state in which it ean pass through the gut wall into the body.

Zymase Secretion. Some of these enzymes seem to be secreted ready for action. They themselves are in the active state, and the juice of which they form a part contains the neeessary salts and has a suitable $P_{\mathrm{H}^{\circ}}$. The moment that the juice comes in contact with the substrate, digestion begins.

\section{Zymogen Secretion.}

Pseudo-activation. Others, however, enter the alimentary canal in an inaetive state. Their inactivity is not due to the laek of a suitable medium, but to the form in whieh the enzyme appears, i.e. as a pro-enzyme or precursor of the enzyme. An activator is required. For example, the active prineiple of gastric juice is secreted as pepsinogen which becomes aetive pepsin on coming into contact with a fluid of a eertain $P_{\mathrm{H}}$. This is not a true aetivation. Acid does not so much aetivate pepsinogen as form a necessary concomitant for pepsin. That this is so may be demonstrated by neutralisation of the acid, with consequent loss of activity in the enzyme. On reacidifying digestive activity restarts. Acid and pepsin have been termed co-enzymes-a misleading term. True activation is irreversible. Once an enzyme has been rendered aetive its aetivity eannot be withdrawn or restored at will. As an example of true activation, the panereatie enzyme trypsin may be taken. Panereatie juice drawn from the duet eontains trypsinogen. This preeursor gives birth to aetive trypsin on eoming into contact with enterokinase of the succus enterieus. The meehanism of the ehange is unknown. Enterokinase is an enzyme whose sole funetion is to aet on the zymogen form of trypsin. No other protease ean be substituted. The rate of activation is peeuliar and suggests autoeatalysisi.e. it starts slowly at first and the rate rapidly increases with time. Vernon suggests that a third enzyme, deuterase, acts as a middleman.

A simpler explanation might be found in the adjustment of equilibrium between two hydrophilic colloids with different crystalloid eontents.

In order to explain the immunity from digestion of the living cells, anti-enzymes have been postulated. The stomach wall, for 
instance, contains protein which is not digested by gastric protease as long as the blood supply is intact. Occlusion of the blood supply to any part leads to the formation of a gastric ulcer. Parasitic worms live in contact with enzymes that would eause rapid digestion in the event of their death. Neither Cohnheim nor Bayliss is inclined to accept the anti-enzyme idea as correct. (1) The latter has shown that the phenomenon can be explained without any such hypothesis-e.g. by the adsorption of the enzyme by another colloid. Agitation of a suspension of trypsin with charcoal results in a loss of digestive activity due to the adsorption of the enzyme by the chareoal. The chareoal here acts as an anti-enzyme. (2) Enzymes as colloids are sensitive to any alteration in their environment. A slight alteration in salt content, colloid or water concentration, or $\boldsymbol{P}_{\mathrm{n}}$ leads to alteration in their power of adsorbing or being adsorbed by their substrate.

\section{Specificity.}

Each enzyme acts on a specific substrate, and if the substratc is a mixture of optical isomers, one of these (and always the same one) will be selected for preferential treatment. Examples may make this clearer. If maltase be added under suitable conditions to the following disaccharides it will be found to act on one only -maltose.

TABLE XVI.

\begin{tabular}{ll|ll|l}
\hline \multicolumn{1}{c|}{ Sugar. } & \multicolumn{1}{|c|}{ Components. } & \multicolumn{1}{|c}{ Split by. } \\
\hline Maltose & - & Glucose $\alpha$ glucoside & - & Maltase. \\
\hline Isomaltose & - & Glucose $\beta$ glucoside & - & Emulsin. \\
\hline Centiobiose & - & Glucose $\beta$ glucoside & - & Emulsin. \\
\hline Cellobiose & - & Glucose $\beta$ glucoside & - & Emulsin. \\
\hline Lactose - & - & Glucose $\beta$ galactoside & - & Iactase (crude emulsin). \\
\hline Isolactose - & - & Glucose galactoside & - & ? \\
\hline Melibiose - & - & Glucose galactoside & - & Melibiase (crude emulsin). \\
\hline Trehalose & - & Glucose + glucose & - & Trehalase. \\
\hline Cane Sugar & - & Glucose + fructose - & - & Invertase. \\
\hline Turanose - & - & Glucose + fructose - & ? (not invertase). \\
\hline
\end{tabular}


Sirnilarly, lactose and melibiose are both glucose galactosides differing only in the hydroxyl of the glucose molecule united to the galactoside. As galactosides, both are slowly hydrolysed by crude emulsin (known to be a mixture of at least three enzymes). Laetase is, however, without aetion on melibiose, and melibiase does not split milk sugar. Till further experimental work has been done attempted explanation of these facts is mere guesswork. Fischer has suggested that the enzyme is to its substrate as a key is to its own particular lock. The evidence at present available does not altogether lend itself to this explanation. It looks as if a careful study of the alterations brought about in the configuration of colloids by slight modifications of the surrounding conditions might lead towards an acceptable explanation of specificity. (Sce also Optical Activity, p. 101.)

Weight is given to this suggestion by examination of the synthesising power of enzymes. Since enzymes accelerate reactions that would take place without them and all reactions are theoretically reversible, the synthesis of complex bodies from their constituents might be expected by the aid of the same enzyme as brought about the splitting of the eomplex to simple. That is, a lipase should not only split a fat into fatty acid + glycerol, but should regenerate fat from fatty acid + glycerol.

A reversible or balanced reaction is one in which, under definite conditions, there is a certain equilibrium point at which the amount of material being broken down is exactly balanced by the amount being built up. For example, take a stoppered bottle half full of water. Two processes are going on simultaneously. (a) Liquid water is undergoing vaporisation and the gaseous hydrol is passing into the air, (b) Gaseous water particles are passing from the air into the water to form, say, dihydrol. When the air is saturated with humidity for that particular temperature, exactly the same number of water molecules will leave the water as enter it. Now alter the conditions, (1) open the bottle to a dry atmosphere, i.e. to unlimited air containing infinitely little moisture. The reaction will proceed entirely in one directionevaporation. (2) If the bottle be opened to an air supersaturated with moisture, the reverse process, condensation, will predominate.

The effect of the removal of the maltose in increasing the speed of digestion of starch is shown very clearly in the following experiment by Lea, in which the course of the digestion of the stareh was followed by the iodine reaetion. In one case, the 
digestion was carried on in a bcaker, and in the other in a dialysing tube immersed in running water so that the maltose dialysed out.

TABLE XVII.

\begin{tabular}{c|l|l}
\hline Time (in mins.). & Dialysed Starch Solution. & \multicolumn{1}{c}{ Not Dialysed. } \\
\hline 0 & Pure blue & Pure blue \\
20 & Trace of violet & Violet " \\
20 & Red with violet tinge & Red with violet \\
20 & Colourless & Very faint red \\
15 &, & Colourless \\
60 &, & \\
\hline
\end{tabular}

Ecto-enzymes generally have a catalytic function. The byproducts of their activity are removed as rapidly as they are formed. Many endo-enzymes have for the most part an anabolic activity. They are brought into contact with simple compounds and proceed to build them into more complex substances. All enzymes have both breaking-down and building-up functions. The conditions under which they work determine their function.

A pcculiar phenomenon has been noted in this connection, namely, that the substance built up by an enzyme may not be quite the same as the complex substance originally broken down by it. Maltase, for example, splits maltose into molecules of glucose, but the substance formed by the action of maltase on glucose is not maltose but its $\beta$ form, isomaltose. On the other hand, isomaltose is split by emulsin into glucose, while emulsin causes two glucose molccules to unite to form maltose. This is explained by supposing that the nature of the enzyme-substrate eomplex influences the rate of the reaction. If $\mathrm{HCl}$ is used as catalyst, the equilibrium point is reached with glucose, maltose, and isomaltose present in the same proportions, irrespective of the original proportions present in the substrate. The point of equilibrium is changed by the enzyme. If maltase is used, the proportion of maltose is diminished, but if emulsin is the enzyme employed the point of equilibrium is shifted towards isomaltose. The whole subject requires re-examination from the point of view of colloid chemistry, especially with regard to the influence of $\boldsymbol{P}_{\mathrm{H}}$ on activity. The following table gives the optimum $\boldsymbol{P}_{\mathrm{H}}$ for certain enzymes: 
TABLE XVIII.

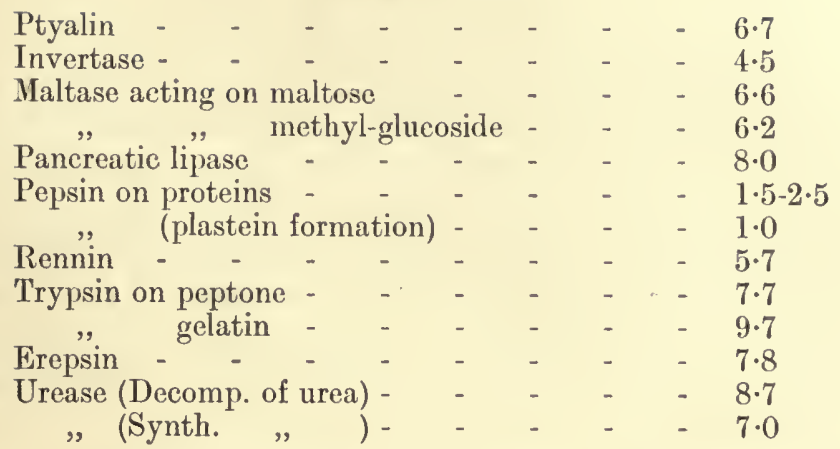

Much has been made of the fact that enzymes scem to be rather finical as to what compounds they will attack. Two compounds may exist side by side similar except in one respect. They may differ in strueture as the right hand differs from the left. That is, the one compound is strueturally a mirror image of the other. The enzyme selects one for attention and hardly looks at the other. If the enzyme is engaged in synthesis, it invariably builds right-handed sugars and left-handed leueine (an amino acid). If engaged on demolition the enzyme will hydrolyse all or nearly all of the right-handed sugar before touching its mirror image, and similarly with leucine. How ean this be explained?

\section{Optical Activity.}

It is obvious that a paper-cutter or strip of metal ean pass through a book only in the plane of the pages, and may pass through a second book when both books are similarly placed or when one has been placed upside down, i.e. rotated on its central axis $A C$ by $180^{\circ}$. If, after passing through book one, the strip of metal is given a twist, then book two will have to be turned through a corresponding angle before the metal will slip through its pages. The rotation of book two may be taken as an index of the twisting of the plane of the metal strip. Various factors may modify this twisting :

(a) The nature of the metal. The same twisting foree would produce very different results in, say, copper and steel.

(b) The length of the strip exposed to the twisting foree. The longer the strip between $B 1$ and $B 2$ the greater will be the twisting, other conditions being equal. 
(c) Temperature. Increase in temperature will increase the twisting.

(d) Obviously the nature and strength of the distorting force will modify the angle of rotation of the strip.

A polarimeter is a device in which these basal facts are applied to light. If a beam of light (at $A$ ) is made to take the place of the metal strip and for the books we substitute some optical arrangement which will allow light vibrating in one plane only to pass, then the eye (at $C$ ) would see a lighted field when $B 1$ and $B 2$ were in the same plane and only then. As we shall see presently, the plane in which polarised light vibrates may be twisted by the action of various crystals and of several substances

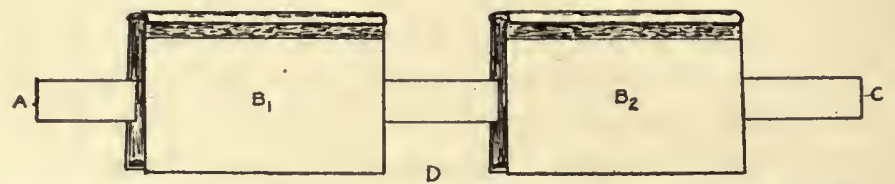

FIG. 13.-Model of polarimeter. $A=$ source of light, $B_{1}=$ polariser, $D=$ point at which twisting force is applied, $B_{2}$ analyser, the amount of twisting at $D$ can be estimated from the angle through which $B_{2}$ has to be rotated to allow of the passage of the metal strip $A C, C=$ eyepiece.

in solution and when fused. The amount of the rotation depends on the factors enumerated above, viz. :

(a) The nature of the light. The angle of rotation depends on the wave length of the light; the shorter the wave length the greater the rotation.

(b) The length of beam exposed to the optically active material.

(c) Temperature as above.

(d) I. Nature of the optically active material : each such has a specific rotatory power.

II. Strength of solution; double the concentration produces double the rotation.

The modification of a prism for producing light vibrating in one plane was devised by Nicol and so bears his name. He made usc of a property of Iceland spar (calcium carbonate), namely, its double refraction. Iceland spar crystallises in many forms, but they are all split most readily along certain planes which are all inclined to each other at fixed angles, and by cleavage the crystals can always be reduced to the rhombohedral form. If such a crystal of Iceland spar be placed on a piece of paper in the centre of which a black dot has been made, on looking down through the crystal, two black dots will be seen. If now the crystal be rotated without lifting it from the paper, one dark spot will remain station- 
ary while the other will rotate round it as a centre. This phenomenon of double refraction may be demonstrated in another way. If a strong beam of light be allowed to fall on one of the faces of a crystal of Ieeland spar and the transmitted light be received on a sereen, two spots of light will be seen, and if the erystal be rotated as before one spot will circle round the other. That is, the beam of light has been split into two rays of equal intensity. One ray, the stationary one, has travelled through the erystal just as it would pass through glass-obeying the ordinary laws of

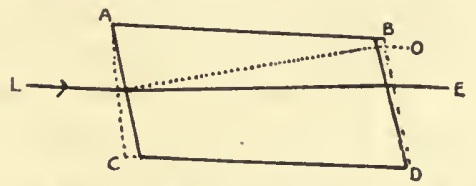

FiG. 14.-Diagram of the paths of the ordinary and extraordinary rays of light through a rhombohedron of Iceland spar. The light, falling on the face $A C$ divides into two rays, both of whlch are polarised. The extraordinary ray $(E)$ is the lesser refracted ray : the ordinary ray $(O)$ is the more refracted ray.

refraction (Snell's Law). It is ealled the ordinary ray. The other ray is ealled the extraordinary ray, and it does not obey the ordinary law of refraction. It is this ray which gives the movable image when the erystal is rotated. (Snell's Law states that the ratio of the sine of the angle of ineidence to the sine of the angle of refraction is constant, $\frac{\sin \alpha}{\sin \beta}=\mu$.

Both rays are plane polarised, but in planes at right angles to one another. Nicol's problem was to get rid of one of these rays

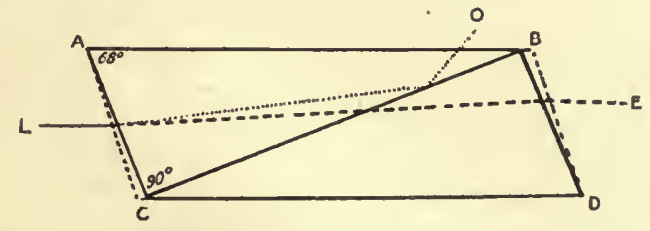

FIG. 15.-Diagram of refraction in a Nicol's prism.

so as to get light vibrating in one plane. The method he adopted is very ingenious. The angular separation between the ordinary and extraordinary rays is not very great, so that it is not possible to sereen off one of the rays unless a very thick erystal be employed.

$\mathrm{A}$ rhomb of Ieeland spar was cut in two by a plane $B C$ (Fig. 15) perpendicular to the principal plane for the faee $A B$. The cut surfaces were carefully polished and then cemented in their original position by a thin film of Canada balsam. The index of refraction of balsam $(\mathbf{1} \cdot \mathbf{5 5})$ is intermediate between the minimum 
values for the ordinary ray $(\mathbf{1} \cdot \mathbf{6 6})$ and the extraordinary ray (1.48). Therefore the ordinary ray falling on the surface $A C$ at an angle greater than the critical angle will be totally reflected, while the extraordinary ray will pass through the prism. This ray, as we have stated above, is plane polarised. To the unaided eye it differs in no way from ordinary light, but, when viewed through a second Nicol's prism, its condition is recognised by the fact that on rotating the prism the beam of light from the first prism alters in colour, passing through the various colours of the spectrum and returning again to white when the rotation has been carried through $180^{\circ}$. If monochromatic light has been used the field will be illuminated when the principal planes of the two prisms are parallel. On rotating the second prism through an angle of $90^{\circ}$ the ray is extinguished and

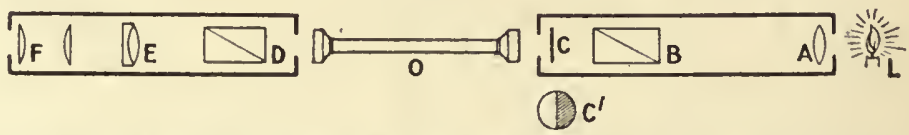

FIG. 16.-Diagram of Laurent Polarimeter. Monoehromatic light from the source $L$ passes through the lens $A$ wlieh renders the rays of light parallel, and then through the polariser $B . \quad O$ is the observation tube containing the fluid under examination, while $D$ is the analysing Nicol prism. The field of vlew is observed through the telescope $\boldsymbol{E F}$. At $\boldsymbol{C}$, the eirenlar opening of the tube carrying the polarising prism is half covered by a thin quartz plate (shown at $C^{\prime}$ ), the thickness of whleh is sueh that the light in passing tlirough the plate is altered in phase by half a wave-length.

the prisms are said to be crossed. If the rotation be carried on to $180^{\circ}$ the planes are again parallel and again the field is bright, and so on. In two positions the planes are parallel and in two at right angles. 'The first prism is called the polariser, the second, by which alone we can recognise the polarisation of the light from 1 , is called the analyser (Fig. 16). If now a plate of quartz cut with the faces perpendicular to the optic axis be placed between crossed Nicols, it will be found that some light passes through the analyser. That is, the quartz has rotated the plane of the light polarised by the first prism. By rotating the analyser a position can be found when all light is stopped. 'The amount of rotation of the analysing Nicol is a measure of the rotation of the plane of polarised light by quartz. A body which has this property of rotating the plane of polarised light is said to be optically active.

Some samples of quartz rotate the plane of polarisation in a clockwise or right-handed (or t) direction, other samples have a reverse (or - ) direction of rotation. (The direction is taken as from the direction in which the light is travelling, not from the analysing eye.) A dextrorotatory piece of quartz superimposed 
on a similar lacvorotatory picce would be optically inactive. Physical examination of quartz crystals shows that $d$-crystals differ from $l$-crystals in one respect only, viz. : the position of their secondary facets. The ordinary form of a quartz crystal is a six-sided prism topped by a six-sided pyramid. The alternate solid angles where two prism faces meet two pyramid faces is gencrally levelled off to form a small secondary face or facet. When the erystal is viewed with the pyramid upmost and these facets slope to the right, the spccimen will rotate the plane of polarisation to the right, and vice versa whon the facets incline to the left. The one crystal is a mirror image of the other, and is called its optical isomer.

If the crystal is symmetrical with no secondary facets then optical activity is impossible. Any perfect cube is an exact

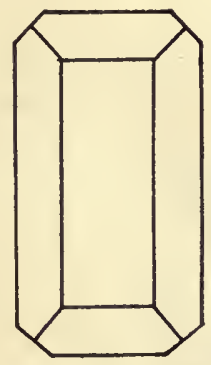

A

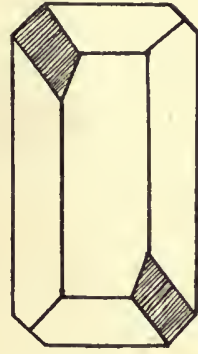

B

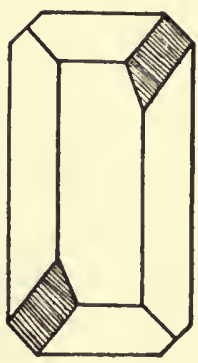

C

Fig. 17.- Crystals of Ammonium Hydrogen Malate. (a) Symmetrical crystal, optically inactlve; (b) Asymmetrical crystal, dextrorotatory; (c) Asymmetrical crystal, laevorotatory. (After van 't Hoff.)

duplicate of any other perfect cube. Such holohedral crystals can be prepared. In Fig. 17, $A$ represents a holohedral erystal of inactive ammonium hydrogen malate ; $B$ represents a dextrorotatory crystal, while $C$ represents its mirror image, a laevorotatory crystal of this salt.

Of amorphous bodics which are optically active, with the exception of one or two little known compounds of nitrogen, all are compounds of carbon in which one or more of the carbon atoms has its valencies satisfied by four different atoms or radicles. Such a carbon atom is termed asymmetric (Fig. 18).

Compounds containing asymmetric carbon atoms are a geometrical necessity and exist in proteins, carbohydrates and fats. Each member of a pair of optical isomers is identically equal in every respect but one. As stated at the beginning of this section, enzymes prefcrentially act on one isomer. For example, those 
sugars which are dextrorotatory are more readily hydrolysed than their laevorotatory isomers. The mould penicillium glaucum destroys $l$-leueine and $d$-glutamic aeid without having any extensive action on $d$-leucine or $l$-glutamic acid.

Fischer showed that the proteoclastic enzyme, trypsin, aeted asymmetrically on synthetic polypeptides, e.g. inactive d.l.alanyl-leucine was digested in such a way that only the eompound of $d$-alanine and $l$-leueine was hydrolysed, whereas the compound of $d$-alanine and $d$-leucine was undigested. That is, the natural

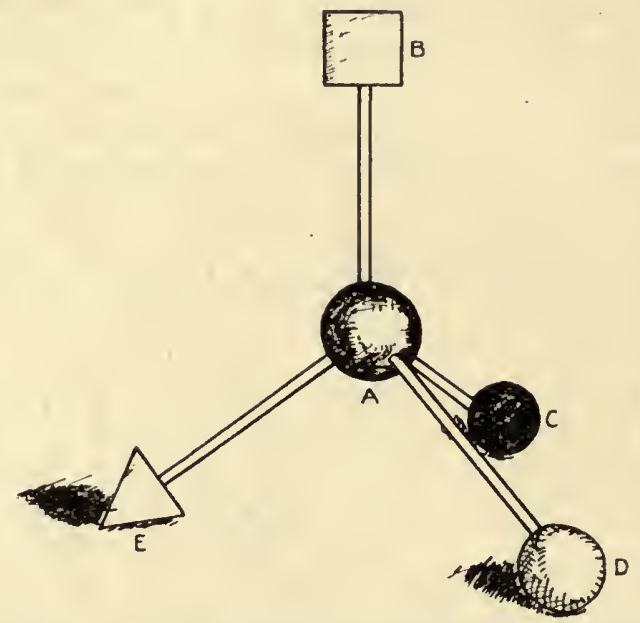

FIG. 18.-Diagram of a carbon atom $(A)$ having its valencies-supplied with four different atoms $B, C, D, E$. The mirror image of this structure would be its optical isomer.

isomers were destroyed by the enzyme before the isomers not oceurring in nature were manifestly attacked.

Mueh researeh has been done to elueidate the reason for this preferential treatment, and some faneiful explanations have been put forward. The problem is a difficult one and the bias of the enzyme at present inexplicable. One fact, however, may be of importanee for future development, viz. : if inactive reagents are used to destroy or produce eompounds having an asymmetric $C$ atom, then both isomers will be produeed or destroyed equally ; if, on the other hand, optically active agents are employed, one isomer has preferential treatment. 


\title{
CHAPTER X
}

\section{MEMBRANES (PLASMAHAUT)}

\author{
THE HOUSE OF THE CELL.
}

" The retention of an individuality by the cell must be determined by chemical and physical differences between this layer and the surrounding fluid."

Starling.

THE unit of life is the cell. It follows that all changes that affect life take place in the cell. The metabolism of a complex organism is the sum of the changes of the cells that compose it. It is therefore logical to study unicellular animals with a view to the application of the knowledge so gained to the elucidation of the more intricate problems of multicellular organisms.

We have seen that the cell consists of protoplasm, which may be regarded as a watery solution, containing all three classes of solutes (i.e. colloids, dissociated and non-dissociated crystalloids) and also substances in suspension. Now it is clear, that as amoeba, for instance, lives in water, some skin or pellicle is necessary to prevent the protoplasm from suffering infinite dilution. Further, if osmotic pressure is to be converted into hydraulic pressure, a membrane is necessary, as we have seen. In plants, growth is, in part, due to osmotic energy, and therefore plant cells must be bounded by a cell wall which will allow the passage of water, but not of, say, sugars. Nägeli, Pfeffer, De Vries and others have demonstrated the existence of such a cell wall. If plant cells are immersed in a hypertonic salt solution, i.e. in a salt solution having a greater osmotic pressure than the osmotic pressure of the cell contents, then exosmosis will take place. Water will pass from the ccll, causing the cell substance to shrink. But the cell wall does not shrink and a space is left between the contents and the container, so rendering the latter apparent. This process is termed plasmolysis.

The cell wall differs considerably from the cell contents in chemical composition as well as in physical state. It is a secretion 
or exeretion from the eell. In plants, it generally consists of cellulose. Certain animals develop an exoskeleton of the exereted salt of lime, of silica or of chitin. These excreted membranes should not be confounded with the true cell membrane or plasmahaut, which term connotes the layer of cell protoplasm which, in animal and plant cells alike, lies between eell and environment. Only through this layer or membrane ean the cell be influeneed by ehanges in the surrounding medium.

The presence of a eovering for animal eells eannot be proved in quite the same way. Animal cell membranes are more elastic than those of plants. Mieroseopic examination shows generally a difference in refractive index (page 103) round the border of cells. Free cells like red blood corpuscles may be submitted to experiments similar to the plasmolytic one detailed above. If eorpuscles are put into a solution of lower osmotic pressure (hypotonic solution) than their contents, they will swell up because of the passage inwards of water, i.e. endosmosis, and will probably burst. This is called haemolysis, and may be brought about in other ways, which are, however, all obviously methods for destroying a membrane (page 243). Artificial membranes may be made which act in a similar way to animal cell coverings. These experiments, together with the fact that it is quite impossible to conceive of energy changes taking place in naked protoplasm, are sufficient evidence of the need for cell membranes.

Much research and much speeulation has been published on the rature of these membranes. What conditions have they to fulfil ? At least four qualities are essential :

(1) The membrane must prevent the outward passage of eell substance while allowing water to pass freely in and out.

(2) The membrane must permit of the intake of nutrient material and of the output of undigested and nonutilised material.

(3) The waste produets of metabolism, gaseous and liquid, must find a way out, while oxygen must find a way in.

(4) Finally, the membrane must be of such a nature as to allow of expansion. Mere elasticity will not answer this end. The membrane must be eapable of almost instantaneous growth.

The animal cell membrane must not be considered as a box or eontainer in which the cell protoplasm has been placed. It is not something apart from the cell like an eggshell. It is not even 
something made by the cell and deposited outside like the crustacean shell. It is just as much part of the cell as the protoplasm itself. Unless this point is understood, difficulties will be found in the study of alterations in permeability. The animal cell membranc must be considered as a part of the cell, having a similar metabolism to the interior of the cell and dying when the rest of the cell dies.

The exact chemical composition of animal cell membranes is not known, but modern research tends to show that it is similar to that of the cell as a whole. We are meantime more concerned with their formation and structure. The fourth essential quality of a cell membrane mentioned above gives a clue as to the mode of its origin.

\section{Formation.}

The only membrane that could answer to this test, i.e. as capable of instantaneous formation and expansion, is one formed by a Gibbs-'Thomson deposition of solutes on the surfaces (see p. 48). 'That such a membrane can be formed is readily demonstrable.

1. Brailsford Robertson's artificial amoeba (Part II. p. 403) shows mobility and keeps intact for some time.

2. Egg albumin solution forms a pellicle or coat of great toughness, cf. meringues.

3. Traube's membranes, especially in the hands of Leduc (Part II. p. 399), yield life-like growths.

Strictly speaking, a substance which is adsorbed under certain circumstances will be set free when the circumstances are reversed. Many substances, however, undergo alteration in physical statc on adsorption. For example, in the formation of meringues, the egg white becomes coagulated and so becomes incapable of reentering the liquid state. Such an irreversible reaction is termed pseudo-adsorption.

Adsorption (including pseudo-adsorption) is, as we have seen in the last chapter, dependent on the ability of the adsorbed substance to lower surface tension. Now, from its very nature, surface tension has a negative temperature coefficient. Increase of temperature lowers surface tension. It follows that incrcase of temperature will diminish the amount of material adsorbed, and, conversely, a decrease in temperature will increase the adsorbability of substances in solution. Can we associate with this fact the varying thickness of membranes according to their degrec of exposure to cold ? 


\section{Structure.}

In spite of many attempts to overthrow it, the most satisfactory explanation of the structure of a cell membrane is the pore theory. The question as to whether the pores are like those of a sponge or like those of a honeycomb is not of importance, for the membrane is of extreme thinness. It has been proved that the rate of passage of a fluid through an artificial membrane is the same as the rate of flow through eapillary tubes. For our purpose, then, we may consider that cell membranes are composed of some of the cell material concentrated at the surface and admitting water, etc., through the spaces between the molecules or other complexes which compose this layer.

\section{Permeability.}

Artificial membranes may be prepared of any desired permeability (Part II. p. 405). A membranc which allows water to pass through and no solute is said to be semipermeable. A perfect semipermeable membrane has never been prepared, though Traube's copper ferrocyanide membranes are very nearly so.

If an animal membrane, such as a pig's bladder, be stretched across the end of a cylindrical tube so as to form a drum-head, one has a simple dialysing membrane such as was employed by Graham in his classical researches. When this membranecovered end is immersed in water, the liquid cannot rush into the dialysing vessel all at once, but slowly oozes through. A solution of sodium chloride passes in almost as rapidly as water alone. Sugar passes through the membrane slowly, while a starch solution fails to penetrate at all.

A list of hydrated ions could be drawn up in the order of their magnitude or, which comes to the same thing, in the order of their speed of migration. With certain apparent exceptions, which will be mentioned immediately, the ability to pass through a membrane is a function of the size (or speed) of a particle in solution. By a careful selection of membranes a mixed solution may be separated into its constituent solutes. In general, a membrane acts like a filter-paper made infinitely fine-so that ultramicroscopic particles may be retained on the filter. Indeed, the process of separating substances in solution from one another has been termed "ultra-filtration."

A living membrane, however, alters in its permeability. It may at one time allow a solute to pass through and at another prevent its passage: or at times allow a comparatively large particle to 
pass through while retaining smaller particles. It may also appear to "select" certain constituents of the surrounding fluid to pass in, seemingly quite irrespective of their size compared with their fellows. Again, the process of negative osmosis may take place through an animal membrane. That is, water may pass from the morc concentrated side to the more dilute side. This flow of water takes place against osmotic pressure. Of course a cell is in close juxtaposition to several other cells, and therefore the composition, structure, and permeability of any one cell membrane may vary from place to place according to the nature of the interface. One interface may ke such as to allow free passage of solutes to which other interfaces may be scmipermeable.

Alterations in permeability may be due to (1) alterations in the membrane or (2) alterations in the material presented to it.

(1) The membrane itself may undergo ehange in composition and permeability as the cell contents or the environment change in $(a)$ composition, or in $(b)$ physical state. The composition of the surface layer depends on the substances present in solution in the interior and on the nature of the interface. Any altcration in the chemieal state of either of these phases will produce such an alteration at the surface as will alter permeability. The electrical double layer on the surface plays a considerable part in deeiding the composition of the membrane. If a solute of opposite electrical sign to the membrane come within the electrical sphere of attraction it will be adsorbed and will either thicken the membrane or may occlude, wholly or partially, some of the interstices. In any case, adsorption will alter the permeability of the adsorbing surface. It may have a further effect. The adsorbed material may entcr into combination, chemical or physical, with the membrane, producing a second alteration in permeability. It may even cause a third alteration, by ultimately passing through the membrane and going into solution on the other side.

If the adsorbed material be an amphoteric eolloid, then the electrical charge on the membrane may be modified and so produce apparently abnormal osmosis. Collodion membranes, for instance, are practically indifferent as regards electrical charge. Water passes through these membranes into solutions of nonclcctrolytes and of electrolytes more concentratcd than $\frac{M}{8}$ at a rate in accordance with the van t'Hoff theory of osmotic pressure, i.e. a linear function of the concentration of the particles (colloidal 
aggregates, moleeules or hydrated ions) in solution. 'Treatment of the membrane with an amphoteric eolloid like gelatine or haemoglobin causes an anomalous osmotic pressure. These colloids, as we have seen, form salts with either acids or bases. One may prepare, for instance, gelatine hydrochloride or sodium gelatinate. In the first instance, cationic gelatine has a + charge, while in the second case it acts as an anion and so has a - charge. The result of this is that when the membrane has a positive charge it will attract water as if the water had a negative charge, and vice versa. That is, the rate at which water will pass through the membrane will depend on the intensity of the charge in the membrane, not on the sign of the charge.

(2) The material presented to the membrane may undergo changes :

(i) Its particles may be increased in size,

(a) by adsorption of other material,

(b) by combining with similar particles,

(c) by hydration.

An increase in size, if sufficiently great, will prevent passage where previously passage was free.

(ii) The converse may take place, i.e. the particles may be dissociated and so be able to pass through interstices previously too narrow for them.

(iii) The electrical state of the material on either side of this membrane may undergo alterations. This is a general statement in which is included the effect of hydrogen ion concentration on permeability. The diffusion of water through an indifferent membrane depends on two forces, $(a)$ pure osmosis, $(b)$ electrical osmosis caused by the presence of electrolytes. The intensity of the electrical forces depends on the nature of the electrolytes. Neutral salts of mono- or di-valent cations influence the rate of diffusion as if they conferred a positive charge upon the water molecules. In other words, the molccules of the pure solvent are attracted by the charge on the anions and repelled by the charge on the cations of the electrolyte, the attraetive and repulsive forces obviously increasing with the valency of the ion and diminishing inversely with the radius of the ion. Alkalies act in the same way. If, howevcr, one considers neutral and acid salts of tri- or tetra-valent cations then one finds the reverse to be the case. The water molecules aet as if they were negatively charged and so are attracted by the cations and repelled by the anions of the electrolyte. Acids act in this way and have a high electro- 
statie effeet on aeeount of the small ionie radius of the hydrogen ion. It is important to note that eertain salts of biological interest have a marked electrostatic value-very dilute solutions of oxalates, phosphates, and eitrates and of the tetra-valent ion $\mathrm{Fe}(\mathrm{CN})_{2}$ attraet water violently. On the other hand, the effect of the anion may be masked by the opposite eleetrostatic effeet of the eation. As the valeney of the cation inereases, the attractive foree of the anion decreases. Calcium ehloride, for instanee, has little more action than distilled water, because the ealeium almost neutralises two positive charges on the two anionie charges (ef. Hydrophilie property of Ca, Chap. VIII.).

The value of this eleetrieal foree has been determined by Loeb in a very neat manner. Inside a collodion bag he placed an $\boldsymbol{M} / \mathbf{1 2 8}$ solution of $\mathrm{KCl}$ and outside the bag an $M / 64$ solution of sugar. These solutions are approximately isotonie, i.e. movement of water through the membrane by osmotie forees is thus eliminated. He found that water did diffuse from the sugar solution to the $\mathrm{KCl}$ solution. This transport of water must be due to the electrical pull of the $\mathrm{KCl}$. He then raised the eoneentration of the sugar outside the bag till its osmotie pressure just balaneed the attractive forees of the $\mathrm{KCl}$. The sugar solution was now $M / 8$. Therefore the electrical forees which are at work eorrespond to an osmotie pressure which is the differenee between the osmotie

pressures of an $M / 8$ and an $M / 64$ solution of sugar $=\frac{7 M}{64}=\frac{7 \times 22 \cdot 4}{64}$ $=2 \cdot 4$ atmos. (approx.).

These electrieal forees also account for negative osmosis-the passage of water from a more to a less coneentrated solution. As far back as 1835, Dutroehet observed that water diffused out of a pig's bladder filled with a dilute solution of oxalie aeid, into pure water. Early investigators tried to explain this on the assumption that there was a greater imbibition of water on the acid side of the membrane and a lesser on the side in eontaet with the pure water. In 1914 negative osmosis was observed taking place through a poreelain filter and, therefore, the imbibition theory beeomes untenable. Loeb has shown that negative osmosis oecurs when neutral salts as well as aeids and alkalies in eertain well-defined coneentrations are separated from water by a membrane capable of taking up either a positive or a negative eharge. At these eoneentrations the repelling action of the ion with the same sign of charge as that of water beeomes greater than the attractive action of the ion with the opposite charge. 
The appended curve (from Loeb) shows the effect of concentration on the attractive force of $\mathrm{Na}_{2} \mathrm{HPO}_{4}$ on water. Various concentrations of this salt from $M / 8192$ to $M / 8$ were put into collodion bags fitted with a manometer. The ordinates are the values for the rise in the level of the solution in the glass tube (after the first twenty minutes) which occurred when the collodion bags filled with different concentrations of disodium phosphate were dipped

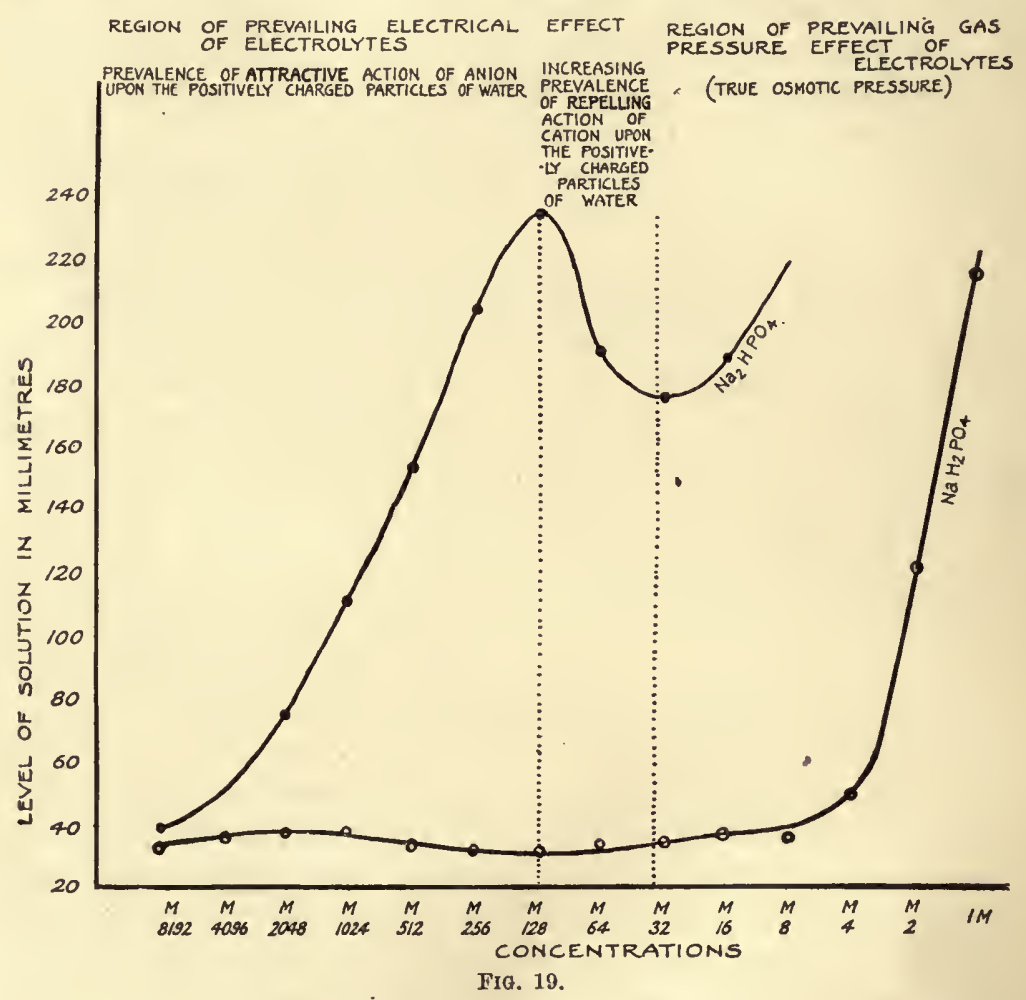

into beakers of distilled water. The abscissae are the logarithms of the concentrations of the phosphate solutions. This curve shows clearly that at a very low concentration of the salt the rate of diffusion of water from pure solvent into the solution through the collodion membrane increases rapidly with increasing concentration, and that it reaches a maximum at a comparatively low concentration of the salt, viz. : $M / 128$. This increase in rate has been shown to be due to the predominance of the attractive action of the anion upon the positively charged hydrols. With an increase in concentration beyond $M / 128$ the rate of diffusion 
falls abruptly to reach a minimum at a concentration of $M / 16$. This fall is caused by the increasing prevalence of the repelling action of the cation on the positively charged particles of water. Further increase in conccntration causes an increase of rate of diffusion. This final passage of water into the solution is due to true osmotic pressure. At the concentrations where the rate of diffusion is decreased, i.e. where the curve falls $(M / 256-M / 16$ in the case of $\mathrm{Na}_{2} \mathrm{HPO}_{4}$ ) water passes from the solution through the collodion membrane to the pure solvent. That is, negative osmosis takes place.

Negative osmosis is a particular instance of electrical osmosis.

In Part II. p. 399 will be found ANODE details of an experiment which shows that water can be drawn through certain colloidal membranes by direct electrical means. If the $p H$ of the water is greater than 7 (i.e. acidulated water) the attraction is towards the anode, but if the $p H$ is less than 7 , the water rises in the tube containing the cathode. To obtain this result, the membrane used must be of material capable of combining either with anions or with cations - e.g. proteins. Collodion does not form such compounds and so cannot form a membrane suitable for experiments on electrical osmosis until it has adsorbed an amphoteric colloid. In Fig. 20 is represented a gelatine-collodion membrane in acidulated water-i.e. in water with a slight excess of hydrogen ions. The membrane adsorbs some of these excess ions, interacts chemically with them to form gelatine hydrochloride and so acquires a positive electrical charge. The passage of a current through the membrane and water depends on the carriage of the charge by ions-in this case $\mathrm{H}^{+}$and $\mathrm{OH}^{-}$. The negative ions are attracted to the positively charged membrane till the charge on it is equalised. The positive ions attracted by the negative potential pressure at the cathode, pass through the membrane, and raise the hydrostatic pressure on the cathodal side. It is 
obvious that the hydrogen ion concentration must increasc at the cathode and decrease at the anode. (Pole finding paper is blotting paper soaked in phenolphthalein-an indicator which while colourless in neutral solutions becomes red in distinctly alkaline solutions).

Water passes through the membrane in the reverse way when the solution on both sides of the membrane is alkaline. A dilute acid solution separated from a dilute alkaline solution of the same relative strength by an amphoteric membrane will produce a passage of water from the anodal to the cathodal side due to the greater speed of the positive ion.

Polarisation. When a current is passed between two electrodes immersed in an aqueous solution, the potential difference between the electrodes tends to decrease and will in time fall off altogether on account of the deposition of ions of the opposite sign on the surface of the electrode. This polarisation of the electrode may be prevented by physical or chemical means (cf. various types of concentration cells). A similar ionic layer forms on membranes when a current is passed through them for some time (see also Chap. XII., Polarisation Current).

Selective permeability of mombranes has often been noticed in electrical transference experiments. The classical experiments of Hittorff are now known to be, in some cases, vitiated by his use of ox-gut membranes to prevent connection currents. For instance, such membranes are much more permeable to $\mathrm{SO}_{4}$ ions than to $\mathrm{Cu}$ ions. A large error is thus introduced into electrical diffusion expcriments with $\mathrm{CuSO}_{4}$ due to the adsorption of the copper ions on the substance of the membrane.

Till more is known of the physical state of the cell and its environment, definite statements cannot be made concerning the causes of alterations in pcrmeability of membranes. Phrases like "selective" adsorption should meanwhile be avoided, as they postulate intelligence in the cell to "select." Although the unknown must be explained in terms of the known, the day is surcly past when it is necessary to assume a Maxwellian "demon" or a cellular intelligence. It is certainly not unscientific to admit the possibility that the unknown is similar to the known or may be explained by analogy to known physical processes. 


\section{CHAP'TER XI}

\section{RADIO-AC'TIVITY}

\section{THE ATOM IN DISSOLUTION}

"From harmony, from heavenly harmony This universal frame began;

When nature undêrneath $\mathrm{a}$ heap

Of jarring atoms lay." Dryoen.

Tre various manifestations of energy already dealt with have all bcen associated with matter in the form of small aggregates (colloids), atoms, or ions (charged hydrated atoms). Chemists once defined the atom as the smallest non-divisible portion of matter. Néedless to say, many scientists were content to be decrycd as old fashioned and refused to accept this opinion of the atom. My old teacher, Prof. John Ferguson, would allow no one to refer to atoms. He preferred the moire cumbrous but exact term "Combining Proportions." Modern work has confirmed these opinions of the atom. Physicists are now interested in the structure of the atom. No longer is it considered as nondivisible. No longer does it remain as fundamental. Of what then does the atom consist? Many and varied are the presentday theories of its structure, but in general most schemes arc similar. It is supposed to consist of a number of smaller units, negative electrons, all moving rapidly and irregularly round a central positive charge. A negative electron is nothing more than a unit charge of electricity. The number of clectrons in each ring is definite and may undergo alteration in definitc quanta only.

(1) Not more than a certain number of electrons can continue in stable motion in one ring. If more are added the system breaks up into two or more rings.

(2) If the orbital velocity of the rings exceeds or falls bclow a certain critical value, the electrons are rearranged to ensure stability for that speed. 
A model may make this clearer. The outer particles may be represented by a number of exactly similar sewing-needles, magnetised simultaneously in a solenoid. They are floated vertically in a small trough (Fig. 21), by having, say, their $N$ poles inserted each to the same depth in exactly similarly pieces of cork. The place of the positive core is taken by a bar magnet set vertically, $N$ pole upwards, below the trough. It will be noticed that the needles arrange themselves in two rings. If ten

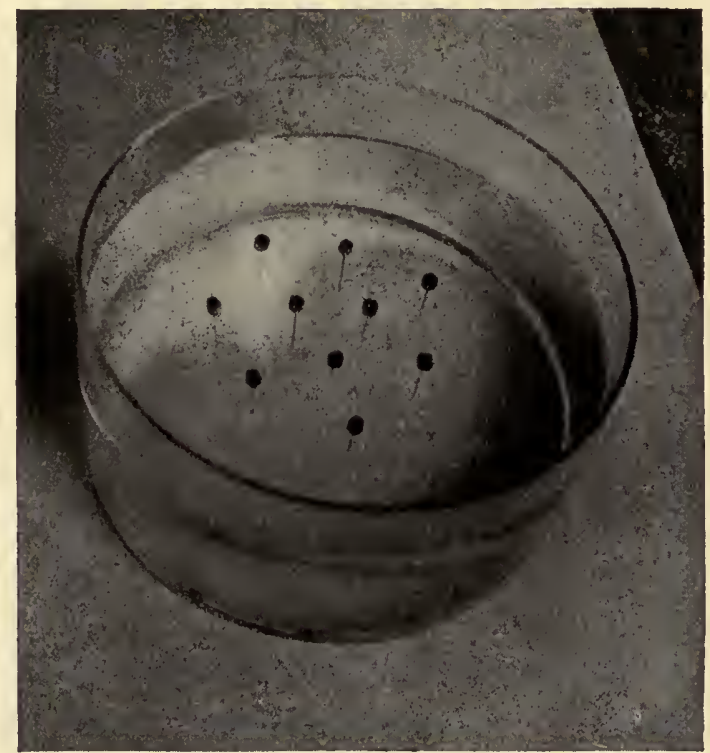

FIG. 21.-A "Model" Atom. (From Crowther's Molecular Physics.)

needles are floated, seven will be in the outer ring and threc in the inner.

It has been found that the greatest number of magnets which we can have in an empty ring is five. If a sixth is added, two rings are formed with five needles on the outside and one in the middle. The number which must be placed in the middle rapidly increases with the number in the outer ring. The removal of one needle from the outer ring may cause a complete rearrangement of the needles, i.e. a new series of concentric circles may be formed differing from the first series in the number of the component needles in each ring.

As we have mentioned, the electrons forming an atom are supposed to be in constant rapid and irregular motion. If for 
some reason the motion of an electron becomes centrifugal, then, if sufficient speed be developed, it will tend to fly off. The atom will be ruptured and a new atom will be formed.

TABLE XIX.

\begin{tabular}{c|r|r|r|r|r}
\hline \multirow{2}{*}{$\begin{array}{c}\text { Total number } \\
\text { of needles. }\end{array}$} & \multicolumn{5}{|c}{ Number in each ring. } \\
\cline { 2 - 6 } & Outer. & \multicolumn{4}{|c}{ Concentric inner rings. } \\
\cline { 2 - 5 } & & $(1)$ & $(2)$ & $(3)$ & $(4)$ \\
\hline 5 & 5 & - & - & - & - \\
6 & 5 & 1 & - & - & - \\
10 & 7 & 3 & - & - & - \\
15 & 10 & 5 & - & - & - \\
30 & 15 & 10 & 5 & - & - \\
45 & 17 & 14 & 10 & 4 & - \\
\hline 51 & 18 & 15 & 11 & 6 & 1 \\
\hline
\end{tabular}

In 1878, Crookes found that the passage of an intermittent high-tension current of electricity through a tube from which air had been so thoroughly withdrawn that only about $10^{-7}$ of atmospheric pressure was present, produced the so-called Kathode Rays. Thesc rays originate at the kathode at right angles to its surface and proceed in straight lines like light independent of the position of the anode. Whatever comes in the path of the rays is caused to fluoresce, e.g. the walls of the tube. They heat the object struck. By using a concave kathode, they may be focussed on a piece of platinum which soon becomes red hot, and may even be fused. Mechanical pressure is exerted by the rays. If directed on to light vanes attached to an axle they may be made to turn little mills, or in the "railway tube" they drive a wheel along glass rails. The stream of rays is deflected by a magnet as if it were a stream of negatively charged particles. In 1893, Lenard, following up Hertz's discovery that metal was transparent to the kathode rays, made a small window of aluminium foil in the end of the vacuum tube and so brought the kathode rays through the foil into the open air.

In 1895, Roentgen, repeating Lenard's work, accidentally discovered the X-rays. He had covered the vacuum tube with a black paper case to shield the eyes from the kathode fluorescence, so that the effect of the rays outside the tube might be more easily observed. He thus noticed that a barium-platinocyanide screen which happened to be near became fluorescent whenever the tube was working though no visible rays could reach it. On placing 
his hand between the sereen and the tube, he saw, for the first time, the now familiar sciagraph of the bones of the hand. The $\mathrm{X}$ - or Roentgen rays originate from the place where a kathode ray strikes, from the walls of the tube, in the first instance, or in a focus tube from the piece of platinum (anti-kathode) upon which the kathode rays are focussed. They issue equally in all direetions and travel in straight lines. For any tube, the power of penetration of the $\mathrm{X}$-rays is inversely proportional to the density of the substance penetrated. The higher the degree of exhaustion of the tube the greater the penetrating power of the rays produced. In a " hard " tube the vacuum is so good that a very great difference in potential between the electrodes is necessary to force the diseharge through. The kathode rays therefore attain a high velocity and the $\mathrm{X}$-rays they produce on impact with the antikathode have a high penetrating power. On the other hand, if the tube is not well "exhausted," the X-rays evolved are easily absorbed. Such a tube is termed "soft." Unlike the kathode rays they are not affected by the most powerful magnetic field. Like the kathode rays they excite fluoreseence, act on sensitised photographic plates and ionise gases, i.e. they make air, or other gas through which they pass and which under ordinary circumstances are practically insulators, capable of conducting limited quantities of either positive or negative electricity.

Poincaré suggested that the production of $\mathrm{X}$-rays might be an effect common to all fluoreseence. In 1896, Becquerel, acting on this idea, examined some fluorescent salts of uranium. He found that the double sulphate of uranium and potassium exposed to sunlight eould affeet a sensitised plate even when the plate was protected by a layer of copper or aluminium foil. This metallic layer excluded the possibility of action by ultra-violet light or by chemical vapours emitted by the salt. Further inyestigation showed that the phenomenon was exhibited by uranous salts which are not fluorescent as well as by the fluorescing uranic salts. Both arc active in proportion to the amount of uranium they contain. That is, the continuous emission of these rays is a specific property of uranium now generally termed Radioactivity.

The characteristies of the radiation from uranium are very similar to those of the X-rays. They are found to consist of three very distinet types of rays, differentiated in the first instance by their power of penetrating matter. They have been termed by Rutherford $\alpha, \beta$ and $\gamma$ rays. The $\alpha$ rays are particles of the gas 
helium expelled radially from the uranium with the eolossal speed of 20,000 miles a second. They have so fecble a penetrating power that they are completely stopped by a single sheet of notepaper or by a few centimetres of air. The $\alpha$ rays carry a positive eharge, but are only slightly deviable by an intense magnetic field. The $\beta$ rays resemble the $\mathbf{X}$-rays in penetrating power, and pass with ease through thin metal, glass, etc., but are nearly all stopped by a single coin. Becquerel proved that the $\beta$ rays are identical with the kathode rays, i.e. negative charges of electrieity. Their superior penetrating power is due to their enormously greater velocity. The $\gamma$ rays are not deflected by magnetic fields. They resemble in all respects the X-rays, but are far more penetrating than rays even from the hardest vacuum tube. They will readily pass through a pile of twelve coins. Their nature is probably the same as that of X-rays, i.e. thin pulses in the ether.

The power of ionising a gas which is a common characteristic of the radiations from radio-active matter is used as a means for measuring the intensity of radiation.' The simplest apparatus for this purpose is a gold-leaf eleetroscope. Fig. 22 represents the type of electroscope used by Soddy. It eonsists of a tin can with a movable bottom $E$ for the insertion of the substance to be tested. A paraffined rubber cork $I I$, is pierced in the centre by the metal wire $G$ which carries at its end a rod of fused quartz, $A$.

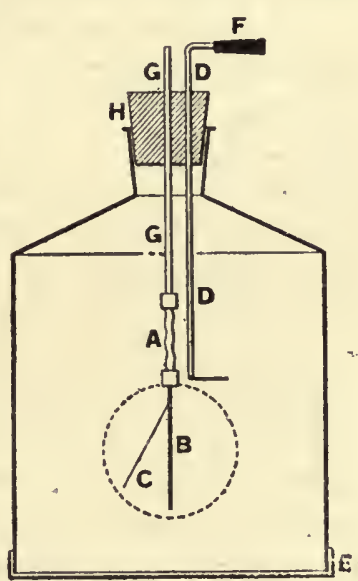

Fig. 22.--Seetion through iroldleaf electroscope as used to determine the ionising power of radioastive matter. See text. (From Soddy's Radioactivity. Electrieian Press.)

A thin brass strip, $B$, to which a single gold leaf, $C$, is attached is fastened to the lower end of the quartz rod. $F$ is a vuleanite handle by means of which the charging $\operatorname{rod} D$ can be brought into contact with $B$. The rate of collapse of the gold leaf may be observed by means of a reading microseope through a window in the can (dotted line).

In 1903, the Curies, who were examining the minerals containing uranium, discovered a new element, radium, in pitchblende. This very radio-active material was obtained pure in 1911. From a ton of pitchblende may be extracted about 200 mgrms. of radium chloride, which was responsible for over 80 per cent. of the radio-activity of the raw material. 
Subsequent investigations by the above workers, and principally by Rutherford, Soddy, and their collaborators, have shown that there are three series of radio-active elements. The appended chart from Soddy shows the relationship between the members of the series and between two of the series themselves. This chart demonstrates to us the remarkable fact that the atom of the heavy elcments at the head of each series are continuously and regularly undergoing disintegration. Matter and energy are being lost at a rate which, so far, cannot be modified in any way.

Lately Campbell and Wood have discovered that certain of the elements of low atomic weight are also radio-active. One of these, potassium, is found universally and in abundant quantities in animal and vegetable cells. Potassium is a necessary permanent constituent of every living cell. Of the 12-15 elements essential to life, it is the only one possessing distinct if minute radio-activity. The activity of potassium may readily be demonstrated by means of the gold-leaf electroscope. It is shown that $\beta$ rays are emitted. Potassium is $\mathbf{1 0 0 0}$ times weaker than uranium and 1,000,000,000 times weaker than radium in the emission of $\beta$ rays.

As is well known, potassium is an absolutely necessary constituent of the fluid used for the perfusion of an organ. If a potassium-free Ringer's fluid is passed through a frog's heart, the heart will come to a standstill in about half an hour. The frog's peripheral vessels may be perfused with Ringer's fluid for hours without any sign of oedema. As soon as a potassium-free fluid is used, marked oedema begins, causing the frog to swell and increase in weight. Further, the frog's kidneys when perfused with Tyrodé's fluid or similar fluid containing glucose allows no glucose to pass out into the urine. If the potassium is omitted in making up the fluid, glucose at oncc escapes into the urine. Ringer demonstrated, long before its radio-active nature was discovered, that rubidium may be substituted for potassium in equimolecular amounts. He explained this by its similar chemical nature. Similarly, caesium, another of the lighter radio-active elements, may take the place of potassium in the perfusion fluid. No non-radio-active element has been found which is capable of acting as a substitute for potassium. Further, Zwaardemaker was able to perform normal perfusions provided a substance emitting $\beta$ rays was within effective distance of the frog.

The last named worker and his collaborators then set out to determine the amounts of the heavy radio-active elements necessary 
TABLE XX.

TABLE OF RADIO-ACTIVE DISINTEGRATION.*

I. MAIN SERIES.

A. Uranium, Radium and Aftinium Series.

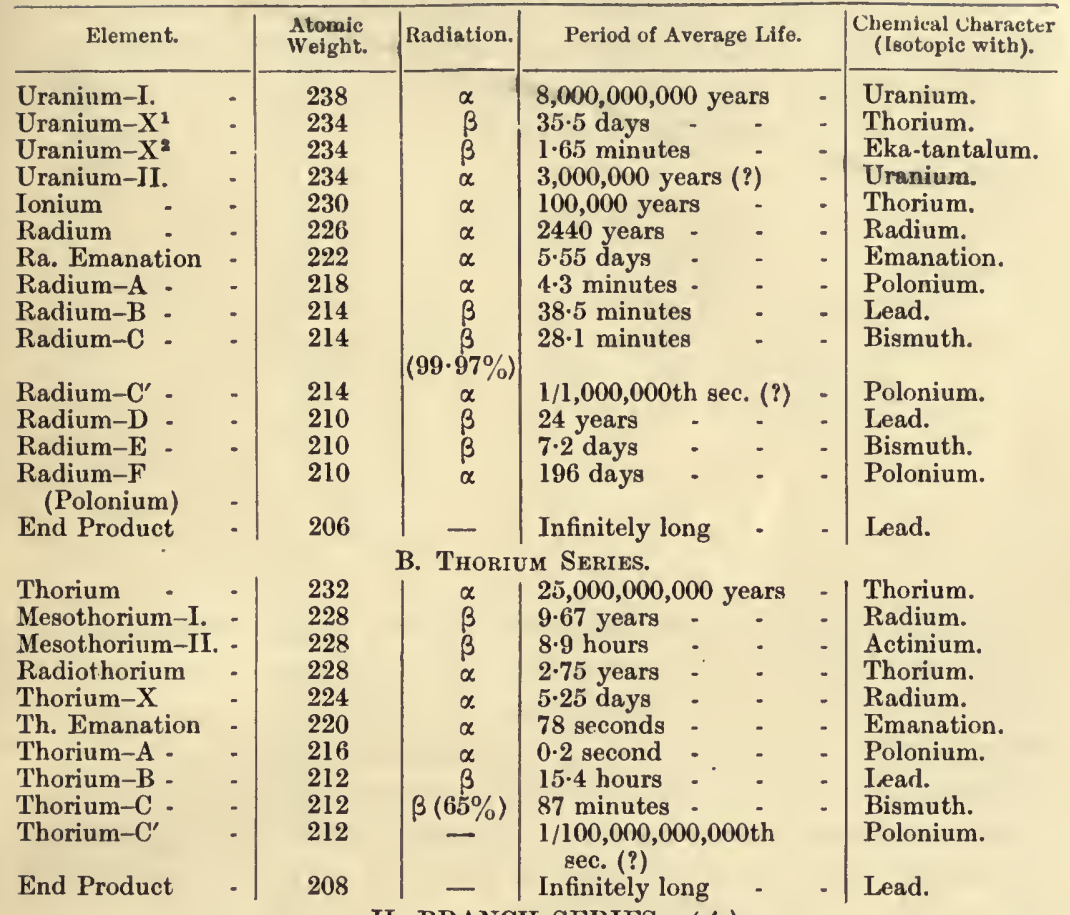

II. BRANCH SERIES. (A.)

(At either Uranium-I. or Uranium-II. the series branches, and 8 per cent. of the total number of atoms disintegrating, follow the branch Actinium Series.)

Uranium-Y

Eka-tantalum

Actinium -

Actinium-X.

Ac. Emanation

Actinium-A

Actinium-B

Actinium-C

Actinium-D

End Product

\begin{tabular}{c}
$\beta$ \\
$\alpha$ \\
$\beta(?)$ \\
$\alpha$ \\
$\alpha$ \\
$\alpha$ \\
$\alpha$ \\
$\beta$ \\
$\alpha$ \\
$\beta$ \\
\hline
\end{tabular}

2.2 days. -
1000 to 10,000 years (?)
(?) -
28.1 days -
16.4 days -
5.6 seconds -
0.003 second
52.1 minutes
3.1 minutes -
6.83 minutes
Infinitely long

Thorium.

Eka-tantalum.

Actinium.

Thorium.

Radium.

Emanation.

Polonium.

Lead.

Bismuth.

Thalium.

Lead.

(At Radium-C, 0.03 per cent. of the atoms follow the branch series.)

Radium-C - $\quad 214$

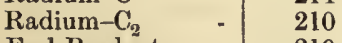

End Product - 210
(B.)
(At Thorium-C/35 per cent. of the atoms follow the branch series.)

Thorium-C - - 212

Thorium-D - : 208

\begin{tabular}{ll|l} 
End Product & - $\quad 208$
\end{tabular}

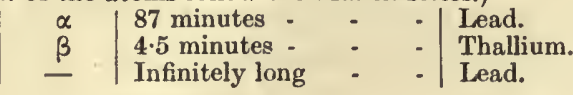

* (From Soddy.) 
to replace potassium. These radio-elements; as we have seen, emit $\alpha$ rays in marked excess of the $\beta$ rays necessary for physiological purposes. They found that, as was to be expected, the $\alpha$ radiation eompletely masked the $\beta$ radiation. If means were taken to exclude the $\beta$ rays these $\alpha+\beta$ radiating salts acted as excellent substitutes for potassium. Radio-active substanees may thus be elassified for biological purposes into two groups.

\section{TABLE XXI.}

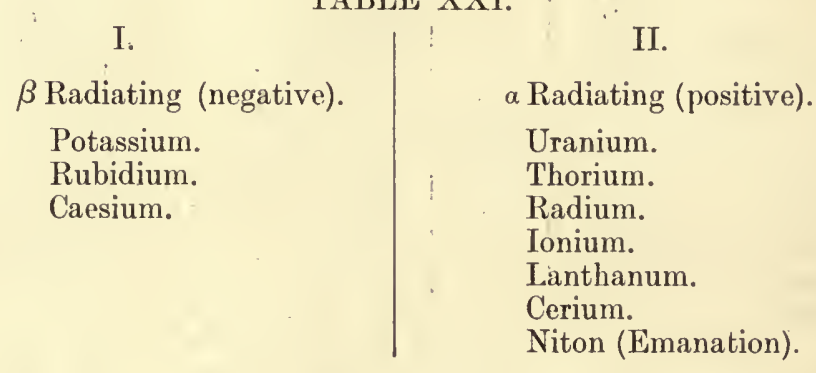

A heart beating with a fluid containing the appropriate quantity of any of Group I. may be switched on to any other group I. element in aequi-radio-active amounts. Similarly, the group II. elements are interchangeable. But direct transference from a I. fluid to a II.; or vice versa at once produces complete stoppage. The two groups are antagonistic. If, however, the heart is washed completely free from one group with radio-active-free fluid it may without harm be perfused with a fluid containing one of the elements of the antagonistic group.

Fluorescein and eosin adsorb the $\alpha$ and $\beta$ rays unequally. If one of these dyes be added to the perfusion fluid the amount of radio-active material present may be reduced appreciably and still produce normal aetion. In summer, smaller quantities of radioactive salts are needed than in winter. This is related to the lowered ealcium content in the frog's blood in winter.

To summarise, potassium is a necessary constituent of all living matter because of its property of emitting negative electrons ( $\beta$ rays). It may be replaced by other radio-active substances in aequi-radio-active proportions provided these substances are not otherwise toxic. How potassium acts in the living cell can as yet be only a matter of surmise. Presumably the freed electron passing with great velocity through erowds of ions, molecules and colloidal aggregates will have some effect on them. It is known to have at least two effects : 
(1) Because of its velocity, the $\beta$ ray accelerates the rate of migration of gaseous ions in a similar way to ultra-violet light of extremely short wave-length (below 2000 Ångström units), i.e. the ionised gas becomes an electrical eonductor.

(2) On account of its unit negative charge, it has a disturbing effect on all systems in electrical equilibrium through which it passes.

Rutherford has recently shown that $\alpha$ particles (positively charged atoms of helium, atomic weight $=4$ ) may cause trivalent nitrogen (14) to disintegrate with the formation of monovalent hydrogen (1). He considers that the hydrogen ion is nothing more or less than a unit positive charge. Other atoms are spheres, composed as we have seen of a positive core (probably an atom of hydrogen) surrounded by negative electrons. The negative electric charge is evenly distributed over the surface.

The modern tendency is thus to postulate the sameness of all elementary matter. What we have been accustomed to look upon as elements may merely be stages in the disintegration of more complex substances into their positive and negative units. When the disintegration takes place explosively and continuously the substance is considered as radioactive.

In the preceding portion of this chapter, ultra-violet rays, kathode rays, $\mathbf{X}$-rays and the $\alpha, \beta$, and $\gamma$ rays of radioactive matter have been mentioned as types of radiation. These various radiations differ from one another in their effects on living matter in degree rather than in kind. In general, the lower the velocity of the ray, the greater its physiological action, provided always that its velocity is sufficiently great to produce any physiological effect. (A high velocity bullet cuts a clean hole in a piece of glass, while a spent bullet shatters the glass). 'The effect seems to depend more on the velocity of the ray than on its nature, e.g. $\alpha$ rays are material while the others are not, yet similar actions may be produced under proper conditions (Zwaardemaker's expts., l.c.). (A soft candle may be fired through a wooden target, eutting a hole just as if it were a hard-nosed bullet). The physiological effect of any ray is proportional to its power to ionise air. $\beta$ rays have 60 times the ionising power of $\gamma$ rays, and experiment has shown that $\gamma$ rays require to operate for 60 mins. on living matter to have the same effect as one minute's exposure to $\beta$ rays. That is, by varying the length of exposure, similar results may be obtained from radiations having different ionising powers. If rays are classed according to their power to ionise 
air, then those having the greatest ionising effect will have a toxic rather than a beneficial effect on living organisms, while, conversely, the weaker rays will promote the function of the organism. The power of ionisation being equal, then generally a long exposure produces toxic effects and a brief exposure beneficial.

This latter effect has induced experimentalists to study the effect of radium on plant growth. They have found that up to a certain optimum point the rays of radium act as a positive stimulus. In early stages, root growth is stimulated, from which there is, as result, an increased growth of shoot. Inflorescence is generally fuller and is better coloured. Ultra-violet rays acting for a brief period on sugar cane not only produce growth but produce an increase in the percentage of sugar. If, however, this optimum amount of radiation be overstepped, that is, if the plant is submitted to a longer exposure or to a greater concentration of rays, depression, culminating in complete arrest of physiological function, is produced. Further exposure to the rays causes death of tissue. The beneficial effects of short exposures are not considered sufficiently great to justify the employment of radio-active matter in horticulture or agriculture.

Similar results have been obtained by those who studied the effect of radiation on eggs and cells. For example, exposure of the fertilised eggs of arbacia to rays of radium, if short, causes stimulation of the cell function. If the radium is applied during the approach of the germ nuclei, then cell division is accelerated. If the exposure is long, cell division is retarded. The effect of radium is more marked during the metaphase than during either the prophase or the telophase. Eggs are not so easily influenced by radium emanations after the dividing stage is passed. In order to produce any effect on the rate of growth of ascaris eggs about ten times the intensity of radium has to be applied as was effective during the dividing stage, or the length of exposure has to be increased tenfold. The $\beta$ and $\gamma$ rays seem to act on different parts of the egg. The nucleus, especially if it is undergoing mitosis, is influenced by the $\gamma$ rays, while the $\beta$ radiation has most effect on cytoplasm. The fertilisation membrane of nereis is thickened as a result of exposure to radium. The length of exposure being, in this case at least, more efficacious than the intensity.

The physician is interested in radiant energy of this type because of its lethal influence on pathological growths and on bacteria. Ultra-violet rays, or lights like the Simpson Light, which emit a 
large proportion of ultra-violet rays, have been employed as germicides in surface wounds. The penetrating power of these rays is slight, and, therefore, they can have little effect on deeplying structures. Nevertheless their action on certain bacilli have been somewhat extensively studied. Typhoid bacilli are killed by exposure to rays of wavc-length $2100-2800$ Angström units. Bacilli vary in vulnerability, e.g. on exposure to light from a Cooper-Hewit (mercury vapour) lamp placed $12 \mathrm{~cm}$. above them, $b$ mucosus capsulatus was killed in 20 secs., staphylococcus aureus in 90 secs., while 150 secs. elapsed before the death of $b$ subtilis. Lupus (tubercular ulceration), carcinoma and other morbid growths are occasionally treated with ultra-violet light. It is worth while noting that normal cells equally may suffer through exposure to rays over $2800 \AA$ A. Digestive enzymes are killed. Protection may be provided by passing the light through 1 per cent. solutions of gelatine-peptone, amino-benzoic acid, cystine, tyrosine and leucine. Tyrosine has especially good detoxifying action in alkaline solution. These solutions absorb rays of wavelength $2480-2710 \AA$. and so reduce the toxicity and bactericidal action of ultra-violet light.

Similarly, X-rays have a strong lethal action. Pioneers in radiography suffered from this action. There is no doubt as to the power of the $\mathbf{X}$-rays to kill $b$-typhosus suspended in water, or to inhibit the growth of tumours. But care has to be exercised in their application. For instance, a number of mice were artificially immunised against a transplantable carcinoma. Half of them were then exposed to the $\mathrm{X}$-rays. It was found that the mice so exposed had lost their immunity and had been rendered susceptible to carcinoma while the controls were still immune. Animals which have been $\mathrm{X}$-rayed repeatedly are generally more susceptible to certain diseases than unexposed animals, e.g. monkeys more readily develop poliomyelitis after being exposed to the X-rays.

The rays emitted by radio-active elements, especially radium, have been employed more extensively in the treatment of morbid cell growths than either ultra-violet light or X-rays. The cells are not killed outright but division of the nuclei is inhibited, eventually leading to death of the cell. The successful treatment of cancer patients by radium is well known. The rays of radium are capable of causing definite regressive changes in deep seated tumours such as mediastinal lympho-sarcoma, carcinoma of the lungs, and abdominal metastases of carcinoma of the testis. 
Several investigators have reported results to show that the growth-promoting substance in yeast may be partially inactivated by exposure to radium emanation. It is probable that the therapeutic effect of radium treatment may be due to this destruction of the growth-promoting substance. It has been known for long that radium rays have a destructive effect on colloidal solutions, due probably to a disturbanee of their electrical state. Globulin and vitellin are coagulated and lecithin suspensions are decomposed on exposure to the emanation from radium. That the action is electrieal is borne out by the antagonism betwecn $\alpha$ radiation and $\beta$ radiation. Either of them prevent bacterial growth in agar cultures, but the simultaneous application of both kinds of rays is ineflective (cf. antagonism of colloids, etc., p. 81). Of course, normal as well as pathological tissue may be damaged by exposure to radium. Especially sensitive are the sexual cells. Spermatozoids of sea urchins are enfeebled and killed, as are also the gametes of the grasshopper by exposure to radium sufficiently weak to have no action on other cellular units of the testicles. The action is similar to exposure to cold. Radium causes an immediate decrease in the total number of white cells in the blood (Chap. XV.). This result is probably due to inhibition of the formation of the leucocytes rather than to the destruetion of already formed cells. The greatest deerease occurs from $\frac{1}{2}$ to 6 hours after application of the radium. Within $\mathbf{2 4}$ hours a normal concentration of white cells may be obsérved.

By the operation of Le Chatelier's principle (p. 9), matter exposed to radio-active elements should develop some protective mechanism against the action of the rays. Becquerel noticed that $\beta$ rays changed yellow phosphorus into its red form, which is not aeted on by the rays. We have already mentioned that the fertilisation membrane of nereis is thickened where exposed to radium. Some observers find that the presence of chlorophyll is protective. Others deny this. 


\section{CHAP'TER XII}

\section{THE CELL}

"Citizens of the state which the entire multicellular organism seems to be."

WE have seen that foodstuffs are broken down into units sufficiently small to pass through the intestinal wall. Logically, we ought next to study the system by which these absorbed substances are conveyed to the cell. It is important to realise that until they are inside the cell they are useless. All energy changes take place in the living cell. It will, however, be convenient first to examine a cell, note its imports and exports and study the various activities by virtue of which it is said to be alive.

In 1893, Schwann put forward the theory that animal tissues were an aggregation of large numbers of cells. Later work has justified this assumption. It is now generally held by biologists (1) that the earliest form of living matter was undifferentiated protoplasm, and that from this simple form of life there has been evolved, first the unicellular and.then the polycellular organism; and (2) that each individual life follows this evolutionary course, originating as a single cell and gradually gaining in complexity with age. In view of these two beliefs, the evolutionary hypothesis (phylogeny) and the developmental history (ontogeny), it is logical to subject a unicellular organism to close examination in order that the various manifestations of life may be, at least, catalogucd.

Amoeba is a unicellular animalcule which may be found in the stagnant water of almost any ditch. It is made of material differing so slightly from the medium in which it lives that it can only be seen under the microscope after patient search. When seen it is found to be non-homogeneous. Apparently it consists of a greyish mass in which there are oceasional granular aggregates, spaces containing water, spaces containing extraneous matter and a darker more compact mass, the nucleus. If the amoeba were 
cut in two the part which did not contain the nucleus would only live for a short time, while the other part would functionate normally. The nucleus is, therefore, necessary for life. Ultramicroscopic examination shows that the grey mass is a colloidal (emulsoid) solution in watcr. Chemical analysis of dead amoeba confirms the ultramicroscopic examination. Water to the extent of about 75 per cent. acts as dispersion medium for a colloidal complex and as a solvent for certain crystalloids. The colloid is an aggregate containing protein, fat and carbohydrate. The crystalloids are to some extent adsorbed on the surfaces of the colloidal mass and to some extent are in free solution. The elementary chemical composition conveys little information as to the properties of the complex. To say that protoplasm contains a certain percentage of carbon, hydrogen, oxygen, nitrogen, sulphur and phosphorus in a colloidal state, and potassium, calcium, sodium, chlorine and phosphorus in solution is not of much use as a contribution to the study of life. It is just as preposterous to appraise the value of great pictures in terms of the chemical composition of the paints and pigments employed as to attach any great significance to the chemical elements of a dead cell. What is of great importance is the physical state of the matter, just as the value of a painting lies in the physical juxtaposition of pigments, an artistic blending of colour, light and shade, whereby the eye is pleased, so the life of a cell depends on the size, consistency, etc., of the colloid-crystalloid complex forming its protoplasm. "When," says Schäfer, "the chemist succeeds in building up this complex it will, without doubt, be found to exhibit the phenomena which we are in the habit of associating with the term "life'." What are the phenomena commonly associated with the term "life," especially as manifested by a unicellular animal ?

(a) Movement is the commonest phenomenon indicative of life. Amoeba moves. It extrudes footlikc processes, pseudopodia (Gr. pseudio, false (=similar to), podes, foot), at one part and retracts them at another and so moves along. Similar amoeboid movements are characteristic of the white cells or leucocytes (Gr. leukos, white) of the blood. Recently, Goodrich has carefully studied these movements of the leucocytes. He produces camera lucida drawings to show that the pseudopodia usually take up the form of expanded motile membranous folds when the living leucocytes are examined suspended freely in the normal fluid which is their habitat. One of his drawings is reproduced in 
Fig. 23. Movements of a precisely similar character may be produced in substances which are certainly not alive, such as Brailsford Robertson's model amoeba made of camphor, benzene and water (Pt. II.). These purely physico-chemical reactions are produced by alterations of the surface tension of the fluids under observation. Macallum has shown (pp. 140 and 151), that alterations in surface tension oceur in living tissue during motion. Movement can, therefore, not be considered as a specifically vital phenomenon. Certain parts of the cell, e.g. the vaeuoles, show a rhythm in their movements. In polycellular organisms, certain organs, $e$.g. the heart, pulsate. It is comparatively easy to produce rhythmical movement in material which is not living. A globule

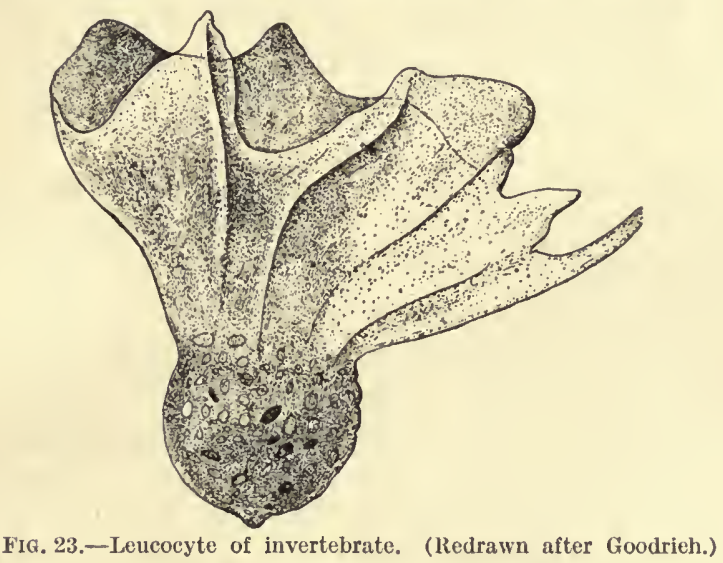

of mercury more than an inch in diameter may be made to pulsate with perfeet regularity for hours. (See Ostwald's "Physical Heart," Pt. II.).

(b) Irritability is a general property of living matter. When amocba is touched, it withdraws its pseudopodia (barotaxis). It moves towards and over suitable food and moves away from quinine or from a hypertonic solution of crystalloids (negative ehemiotaxis). Hydrogen ions if not too concentrated exert positive chemiotaxis, whilc hydroxyl ions have a repellent effect. This may explain galvanotaxis. Strong light repels while a moderate illumination attracts many lower organisms. Further, the more refrangible rays of light exert a negative phototaxis, while the less refrangible rays are positively attraetive. If the swarm spores of certain algae are placed in a tank with a cover, half of which is blue glass and half is red, and exposed to light, they will stream away from the blue and towards the red end of the 
box. Ultra-violet rays have a marked effect on living organisms. They kill, e.g. the tubercle bacillus is killed by ultra-violet light and lupus is cured by projection of the Finsen are on the growth. Change of temperature may exert either a positive or a negative effect, the animalcule avoiding the abnormal. That is, too high or too low a temperature exerts negative thermotaxis. Nonliving matter shows irritability. Wc have seen how sensitive colloids are to slight alterations in their environment. They exhibit chemiotaxis and galvanotaxis very markedly. Even inorganic matter may respond to stimulation. Lillie has demonstrated this in the case of iron. A piano wire which has been dipped in concentrated nitric acid and then suspended in dilute nitric acid will show changes if "stimulated" mechanically, chemically, or electrically. The irritability of living matter is, according to Verworn, of a specific type and is thus indicative of life.

(c) Ingestion and excretion arc phenomena cxhibited by all living cells. Nutrient material is taken from the environment, prepared, uscd, and the non-utilisable rest is forced out. Amoeba engulfs food and forms a vacuole in which will be found food and water. Into this vacuole are secreted digestive enzymes which reduce the ingested material if possible from the colloidal to the crystalloidal state. It then passes into the protoplasm and the undigested residue is forcibly excreted by contraction of the vacuole. These proccsses all have their physico-chemical counterparts. A drop of chloroform will reject a piece of capillary glass tubing forced into it. If the glass be coated with shellac it will be drawn into the chloroform, the shcllac dissolved from it and then the clean glass is cxpelled from the interior of the chloroform to the surface.

(d) Growth is not a property characteristic of living mattcr. Leduc has taught us that by osmosis life-like forms may be produced which grow.

(e) Electric Phenomena. The electrical power generated by living matter has always been a subject of interest and of amazcment. Quite apart from such animals as possess electrical organs, e.g. the elcctric eel which can generate an E.M.F. of several hundred volts, every living animal, in fact every living cell, produces electromotive forces. The ordinary potential differcnces observed in living matter may seldom reach $0 \cdot 1$ volt, but everyone knows that if $n$ small units are connected in series, the resultant voltage is $n$ times the voltage of the single unit. Dissection of an 
electric organ shows that it is built up serially of large numbers of units. The cause of the potential differences in cells must be sought for in the "selective" permeability of the cell membranes, or in alterations of the content of the protoplasm in electrolytes.

(i) Differential permeability. Bayliss separated a concentrated from a dilute solution of the sodium salt, congo red, by a membrane of parchment paper which is permeable to the sodium ion but not to the anion. He found that the dilute side became elcetro-positive on account of the preponderance of cations on that side.

(ii) Differential permeability does not afford a sufficient explanation for all bioelectric phenonena. Even when the membrane is freely permeable to both ions of the salt and when the anion is the faster of the two, the dilute side of the parchment becomes electropositive. This brings us again to the charge on the membrane. Parchment has a negative charge in water, and in dilute solutions of neutral salts-so has baked clay, wood, bone, charcoal, natural gelatine, etc., and all these cause a positive charge to develop on the dilute side. That is, the generation of a potential difference is just the reverse of electrical endosmose (Chap. X.). This may be confirmed by altering the charge on the membrane. Gelatinc may be induced to take up a positive charge. Mines found that when a dilute solution $\left(\frac{\mathrm{N}}{80}\right)$ was separated by a gelatine membrane from a more concentrated $\left(\frac{N}{8}\right)$ solution of sodium chloride, the dilute solution became electropositive. Gelatine is made positive by trcatment with the ions of polyvalent metals. When an electropositive gelatine membrane was used, the dilute solution became negative.

(iii) A slight alteration in hydrogen ion concentration occurring on one side of a membrane will cause the development of E.M.F. If two solutions, one of $p H 7$ and the other of $p H 8$ are separated by a membrane more permeable to $H^{+}$ions, an E.M.F. of about 30 millivolts may be obtained. The living cell has a $p H$ of about $7 \cdot 4$ and its E.M.F. is not usually greater than 30 millivolts.

\section{Polarisation current.}

In all chemical processes, alterations in potential difference take place. The living complex, known as a cell, is a system in which chemical transformations proceed continually and, therefore, electromotive force is being generated continuously. These currents may be demonstrated if special arrangements are made 
to prevent polarisation of the eleetrodes (Part II.). 'The electrodes which are used to lead the current from the eell (or group of eells) to the galvanometer are subjeet to polarisation as explained in Chap. X. The produets of electrolytic decomposition of the eell substance are transported to the eleetrodes and aecumulated there. The deposition of these products at the two poles, in eourse of time, alters the nature of the electrodes. The eathode, for instanee, because of the aceumulation of positive ions on it, beeomes more and more anodal. This produces an electric tension that eauses a eurrent, the so-ealled polarisation-current, to flow in the opposite direction to the original one. As this eurrent grows in strength it reduees the value of the tissue-eurrent and after a short time completely obliterates it. (See also Musele, Chap. XIII., and Nerve, Chap. XVII.)

(f) Electrical effects are produced in living cells by suitable stimulation. If a eell is injured the injured part becomes electropositive to the rest. This phenomenon, apart from any other conditions, would be quite suffieient to justify the postulation of a cell membrane. Consider the eell as a mass of protoplasm in an envelope of matter which is permeable to the negative ion but not to the positive ion of a dissoeiated electrolyte. This will eause a differenee of potential on the two sides of the membrane. Inside will be a preponderance of negative ions while outside will be an equal preponderance of positive ions. Current of Injury.-If now we could eonneet the inside of the membrane with the outside, there would be a flow of current till the difference of potential had been equalised. Current would flow to the piereed, injured (or inside) part from the outside. That is, the injured part would be similar to the zine pole of a zine-copper galvanic eouple. There the flow of eurrent is from the zine to the eopper inside the battery. The zine is therefore said to be electropositive. The eurrent, however, flows from the eopper to the zine, outside the battery. The zine is, therefore, said to form the negative pole. Current of action.-When alterations of tension or stress take place in a cell they are aceompanied by alterations in eleetrie potential. 'The part under stress beeomes as if injured, i.e. electropositive or zincy to the normal or unstressed part. This may be due to an inerease in the permeability of the membrane at the stressed part, so that the positive ion gains aecess to the eell. The seat of stress does not, however, remain at its point of origin but passes as a wave of inereased stress over the whole cell, followed immediately by an electropositive wave. 


\section{SECTION III: CELL COMMUNITIES}

\section{CHAPTER XIII}

\section{THE ARMY WHEREWITH THE BODY WAGES WAR WITH NATURE-THE MUSCLE CELLS \\ " Tho' born to fight, \\ Yet, mix'd and soften'd, in his work unite ;" \\ Pope.}

Is the animal body there are various kinds of cell communities. There seems to be no doubt that originally each cell was selfsupporting, and a small cell-community, like a small village in a remote corner of civilisation, was able to perform all necessary activities without the help of other communities. In a big complex concern like the mammalian body, however, each cell community has specialised in some form of activity, and it has therefore to depend on other communities for certain necessities. No such cell is absolutely self-supporting. For the same reason we cannot validly consider any cell as typical of all others. Each has its own particular duty to perform and is adapted to perform that particular duty most economically. It could, if circumstances compelling it arose, do other things usually left to other cells, but would perform these unaccustomed duties clumsily and uneconomically.

The dominant cell communities in the somatic body are those forming the muscles. Their activity, to a great extent, regulates all other changes taking place in the body. They demand for their use the lion's share of the energy intake of the body. The bulk of the repair material in the food is earmarked for their use. They keep a firm hand on the transport system and soon cause a "speeding up" if supplies fall short of their needs, or if the byeproducts of their activity are not removed with sufficient rapidity. The system of inter-communication between cell-communities 
(the nervous system) exists in large measure to suit the muscles. In short, the muscles are the master-tissues of the soma. They are not a manufacturing community but are power users. In another sense the muscles are the servants of the body. By means of them the body fights a war not-merely of defence but of aggression against its environment. As civilisation has advanced, man has found it convenient by means of tools and machines to add to his muscle power. In this way, he has bcen able to harness and utilise power from sources that could not have been tapped without the use of these machines. Tools and machines are thus as it were extended and detachable limbs.

Muscle is a transformer of potential energy into kinetic energy, and of course into heat. The source of the energy is, as we have seen, the foodstuffs as broken down by enzymes, i.e. glucose, fat and deaminised amino acids. There seems to be no doubt as to the means by which the energy is ultimately liberated from these food units. In Chapter III. we saw that the intake of oxygen and the output of carbon dioxide was so intimately connected with the process of energy liberation that we could calculate the amount of energy set free in an organ by measuring these gases. That is, the basis of muscular activity is oxidation, just as the basis of the activity of a steam engine is the oxidation of coal. In Chapter IV. there was a discussion of this, and evidence was produced proving that in all other details the oxidative process in muscle differs from that of coal. What then happens in muscle? There secms to be three stages in the translation of potential energy of food into muscular work.

(1) Contraction. The muscle shortens and thickens. During this phase oxygen is not necessary. An excised frog muscle in nitrogen will give a maximal contraction once every five minutes for over two hours before showing signs of fatigue. The output of carbon dioxide is not increased over the amount evolved during rest. The heat evolved is negligible if the muscle is allowed to shorten under certain conditions. If it is made to contract isometrically i.e. against a spring that does not permit of its shortening, the energy developed, that would in ordinary course produce contraction, appears as heat. This heat is directly proportional to the length of the muscle fibres. Further, increase of temperature causes a decrease in the tension developed on stimulation, i.e. contraction has a negative temperature coefficient. A muscle at $0^{\circ} \mathrm{C}$. in an experiment of Bernstein's developed a tension of $\mathbf{3 7 5}$ grams. On raising the temperature 
to $18^{\circ} \mathrm{C}$. the maximal tension was found to be $205 \mathrm{~g}$. Surface energy is the only possible form of energy that could be associated with muscular contraction which has a negative temperature coefficient.

In dealing with surface tension (Chap. VI.) it was pointed out that most physical and chemical actions are accelerated by increase of temperature, while surface energy is diminished as temperature rises.

A glance at Fig. 24 may make it clear how surface energy may be made to do work.

A wire frame is made, to one side of which is attached a silk thread. Over the whole area is a film of soap. The thread $M$

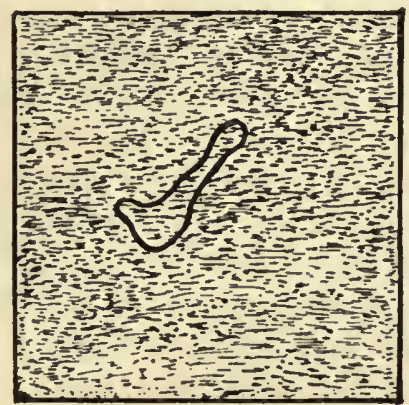

A

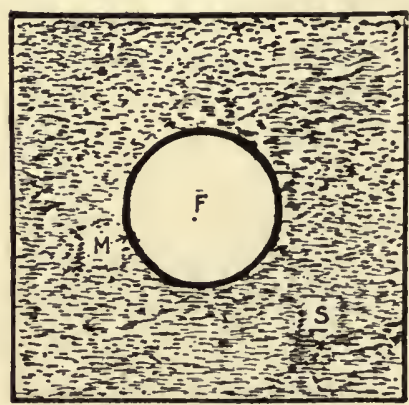

B

Fra. 24.-Frame of wire enclosing a Soap Film.

In $A$ there is a loop of fine silk floating in the fllm.

In $\boldsymbol{B}$, the film enclosed by the loop has been broken. (After Van der Mensbrugghe.)

takes up an indifferent position as shown in $(A)$ as the surface tension at the interface between $F$ and $S$ is exactly balanced by the internal energy of $F=$ internal energy of $S$. If now the film is broken inside $\boldsymbol{F}$, say by pricking with a needle, $\boldsymbol{M}$ tends to become a circle. That is, the internal energy of $S$ is increased relatively to that of $F$. However it is brought about, the result is an increase in the surface tension at the interface $F-S$, i.e. the thread. It is of value to note that it is not necessary for the film to be broken. Theoretically, all that is necessary is a difference in internal energies on the two effective sides of the thread, the lower internal energy being inside the loop. Further, no matter how slight the difference on the two sides of the thread the movement would be maximal.

Muscle consists of a number of long fibrillae immersed in sarcoplasm. The membranes of the fibrillae may be represented by the thread mentioned above, the protoplasm of fibril and sarcoplasm as the soap film. Anything which causes a difference 
of surface tension at the interface between fibril and sarcoplasm will cause the fibril to contract to its fullest extent. Of course the student will understand that the subject bristles with difficulties, and the above explanation can only be taken as a very crude and incomplete basis for further elaboration.

The only metabolite of muscular contraction that stands on a very firm experimental foundation is lactic acid. In the absence of oxygen muscle becomes acid. If contraction takes place in the presence of oxygen, lactic acid does not appear. Lactic acid formation in muscle has been a veritable red herring drawn across the track. The problem looks so simple with lactic acid as an intermediate step in the oxidation of carbohydrates. The careful investigations of Prof. A. V. Hill of Manchester have made it clear that no such simple process is possible. First, the lactic acid is not a step in the oxidation of carbohydrates, and secondly it is not oxidised itself to $\mathrm{CO}_{2}$ and $\mathrm{H}_{2} \mathrm{O}$ as was thought. It is not part of the fuel but is a necessary part of the machine, moving to and fro like the piston of a gas engine. The arrival of the stimulus (frec kinetic energy) is the trigger setting free lactic acid from some physico-chemical combination and so causing an increase in $\mathrm{H}$ ion concentration and consequently an increase in tension at the surface of the fibril and sarcoplasm. If this tension is not allowed to cause contraction, the energy of tension can be converted, as we have seen, into heat. The amount of heat so obtained has been shown by Hill to be quantitatively equal to the amount of work derivable from the tension. That is, the efficiency of contraction is 100 per cent.

$$
\text { (Mean maximum value }=91 \text { per cent.) }
$$

(2) Restitution. This extraordinarily efficient first stage of muscular activity where stored energy is converted into work

\section{TABLE XXII.}

Gaseous Exchange in $M$. Levator Labii Superioris of the Hürée pep. gram of muscle per minute (Chauveau and KaufmanN).

\begin{tabular}{|c|c|c|c|c|}
\hline & \multicolumn{2}{|c|}{ REST. } & \multicolumn{2}{|c|}{ ACtivitY. } \\
\hline & Oxygen absorbed. & $\mathrm{CO}_{2}$ given out. & Oxygen absorbed. & $\mathrm{CO}_{2}$ given out. \\
\hline $\begin{array}{l}1 \\
2 \\
3\end{array}$ & $\begin{array}{l}0.0032 \text { c.c. } \\
0.0079 \\
0.0028\end{array}$ & $\begin{array}{l}0.0019 \text { c.c. } \\
0.0058 \\
0.0026\end{array}$ & $\begin{array}{l}0.054 \text { c.c. } \\
0.014 \\
0.010\end{array}$ & $\begin{array}{l}0.063 \text { c.c. } \\
0.018 \\
0.013\end{array}$ \\
\hline
\end{tabular}


must be followed by a stage in which energy is again stored for work. During this phase four things are evident, viz. :

I. Oxygen is necessary.

II. Carbon-dioxide is evolved.

III. Lactic acid disappears.

IV. Heat is evolved.

Examination of table XXII. given above will make it clear to the student that I. and II. are different parts of the same reaction. Oxygen is used to oxidise some carbon compound which is excreted as $\mathrm{CO}_{2}\left(+\mathrm{H}_{2} \mathrm{O}\right)$. If oxygen is not present we learn from the work of Fletcher and Hopkins that the lactic acid set free during the contraction phase is not removed. The amount of heat evolved has been very carefully estimated by Hill and others. They find that it is almost exactly equivalent to the tension developed in contraction. If the tension be estimated in heat units and found to be $5 \times 10^{-6}$ cals. per gram-weight of tension per centimetre of muscle length, the heat evolved during the restitution phase would also be $5 \times 10^{-6}$ cals. per gram-weight. 'The work done in putting the muscle back into its precontraction state is equal to the tension developed during contraction.

'Two views are held regarding the mechanism of restitution. The commoner idea is that lactic acid is in muscle as elsewhere an intermediate compound in the oxidation of glucose. Glucose, we know, is stored in muscle and this store is decreased during contraction. The amount of heat liberated from glucose in the formation of lactic acid is very small, while the amount liberated when lactic acid is itself oxidised to $\mathrm{CO}_{2}+\mathrm{H}_{2} \mathrm{O}$ is considerable. 1 gram of lactic acid in oxidation sets free 3700 cals. These facts seem to fit in well to the following scheme. During contraction lactic acid is formed from glucose. For this, very little oxygen is required and very little $\mathrm{CO}_{2}$ is evolved. Practically no heat appears. During restitution the lactic acid is removed by oxidation and heat is evolved.

Neat though this theory is, it has been rendered untenable by the brilliant researches of A. V. Hill and V. Weizsacker with their ingenious myothermic apparatus, and by Fletcher and Hopkins who devised a delicate means of estimating lactic acid. When 1 gram of lactic acid disappears from muscle, only 450 cals. instead of 3700 are produced. Obviously, only a small fraction of the lactic acid is oxidised if any. Fletcher and Hopkins could not detect any oxidation of lactic acid. 
The lactic acid set free in the contraction phase is, in the restitution phase, once more built up into the physico-chemical compound of which it was a part before the arrival of the stimulus provoked a contraction. As A. V. Hill has said, "The lactic acid is part of the machine and not part of the fuel." During contraction it is set free, during restitution it is built up again. To provide energy to build the lactic acid into its old place, i.e. to restore equivalence of internal energies between sarcoplasm and fibril, glucose has to be oxidised to $\mathrm{CO}_{2}$ and $\mathrm{H}_{2} \mathrm{O}$.

There seems to be little doubt about the experimental evidence regarding the utilisation of glucose during restitution. The glucose stored in the muscle furnishes the main reservoir of energy on which the muscles draw for carrying out this work. There is some evidence, not very clear it is true, suggesting that stored fat may also be called on to supply energy for muscle restitution. Either because carbohydrate is more readily mobilised or because it requires a lower tension of oxygen for disintegrative oxidation than fat or for both reasons, muscle utilises carbohydrate in preference to fat.

The liberation of lactic acid in the first phase of muscular movement produces not only contraction but a whole series of physico-chemical changes which have got to be reversed during restitution. I. As a dissociable acid (Chap. VII.) it will produce an increase in $\mathrm{H}$ ions. II. This increase in $p H$ reacts on the colloids in suspension in the muscle, causing them to alter in electrical charge (Chap. VIII.). III. This in turn sets free salts adsorbed to the colloidal surfaces and so produces an increase in osmotic pressure. IV. Further, the membranes will become polarised. V. From III. and IV. will result endosmosis and the water content of muscle will increase.

Roaf has shown that there are definite alterations in $\mathrm{H}$ ion concentration associated with different stages of muscle contraction. Macallum proved that activity caused an alteration in the concentration of salts in muscle, and Fletcher has demonstrated the increase in water content after exercise.

What is the effect of temperature on the restitution phase? We have seen that the contraction phase has a negative tempcrature coefficient. Theoretically, each of the five sequelae to the liberation of lactic acid as mentioned in the preceding paragraph has a positive temperature coefficient. The building up of lactic acid into a complex would be accelerated by tempcrature just like any other chemical reaction. 
That is

(I.) The dissociation of lactic acid, the setting free of $\mathbf{H}$ ions, is increased in rate and extent by increase in temperature (Chap. VII.).

(II.) No change known.

(III.) Temperature increase causes increase of salt de-adsorption.

(IV.) No change known.

(V.) Because of the increased dissociation of salts by the increase in temperature and because of the increased kinetic energy of water seeking admission the rate of endosmosis will increase with increase in temperaturc.

These have all to be restored to precontraction state, and therefore do not materially contribute to this part of the discussion. But the temperature coefficient of contraction is negative, therefore all these reactions must fall within the phase of restitution. Experimentally it has been found that this phase increases in rate with temperature. (The other effects of temperature on muscular contraction will be dealt with later. Just now we are concerned with isolated muscle.) A moderate increase of temperature thus increases the removal of lactic acid and the restoration of potential energy to the muscles, while not appreciably lessening their power to transform potential into kinetic energy, i.e. to contract. Further, it has been shown by Lagrange that an increase in temperature increases the efficiency of muscle. Lately, workers have ascribed this increased efficiency to the more rapid removal of lactic acid.

Now we have seen that :

(a) The restitution phase is accompanied by an increase in the temperature of muscle.

(b) The rate and efficiency of contraction is reduced by increase in temperature, and

(c) The rate and efficiency of restitution is increased by increase in temperature.

It therefore follows that there will be a temperature at which muscle work (contraction and restitution) will be performed most efficiently. Further therc will be an optimum speed at which work will be carried out. This speed will be regulated

(1) By the natural rhythm of contraction of the muscledepending on the length of the contractile body (Fig. 25).

(2) By the optimum temperature, and

(3) By the amount of resistance that has to be overcome in shortening. (See also Chap. XXVIII.) 
The efficiency of this second phase of muscle work is less than that of the contraction phase, which we saw was 91 per cent.

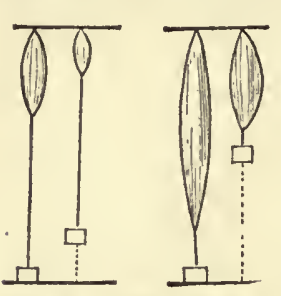

FIG. 25.-Influence of the length of a muscle upon the work done. A muscle one inch long (left-hand figure) in contracting to half its length lifts a weight to half an inch. A muscle of two inches, on the other hand, is capable of lifting the weight to one inch.

(Noël Paton's Essentials of Human Physiology.)

Taken together they give a gross efficiency for a complete muscle twitch as 50 per cent. But to this one might apply a correction to take into account the energy expended during muscle rest.

(3) Rest. During complcte inactivity, energy is used for maintaining the muscle in a state of preparedness for action, just as a nation has to spend money maintaining an army in peace time, so the musele cell must always be ready for action. This is the third phase of muscular life-erroneously termed rest. As we shall see in the sequel, this phase is anything but restful. Again, just as in peace time, the coordinating and integrating machine of empire, the Cabinet, keeps our standing army in a high state of efficiency, so the nervous system constantly sends impulses to the muscles, keeping them ready for instant action. This state of resting readiness may be called the tone of muscle, and is, as indicated above, regulated in part by the nervous system (q.v.). During rest, energy is expended which if subtracted from the total energy expended during restitution would raise the efficiency of that phase by about four per cent.

\section{TABLE XXIII.}

OXYgen used By CAt's Gastrocnemius M. (Verzìr, 1912).

\begin{tabular}{|c|c|c|c|}
\hline & & \multicolumn{2}{|c|}{ c.c. Oxygen used by muscle. } \\
\hline & - & per minute. & $\begin{array}{c}\text { per gram } \\
\text { per minute. }\end{array}$ \\
\hline Rest (Normal) & $\cdot$ & $0 \cdot 050$ & $0 \cdot 003$ \\
\hline Contraction & & $0 \cdot 178$ & $0 \cdot 010$ \\
\hline Restitution & $\begin{array}{l}15 \text { secs. later } \\
11 ", \quad, \\
11 ", \quad,\end{array}$ & $\begin{array}{l}0 \cdot 336 \\
0 \cdot 208 \\
0 \cdot 154\end{array}$ & $\begin{array}{l}0 \cdot 020 \\
0 \cdot 012 \\
0 \cdot 009\end{array}$ \\
\hline Rest (Normal) & $146, \quad$, & 0.059 & $0 \cdot 0035$ \\
\hline
\end{tabular}


The efficiency of muscular contraction is found from the formula

$$
E_{g}=\frac{a}{b} \times 100,
$$

where $\quad a=$ actual work done (in cals.) per unit of time.

$b=$ total energy used (in cals.) , , , ,

This gives the gross efficiency. The net efficiency is obtained by correcting for the energy expended during complete inactivity during a similar unit of time.

Net efficiency

$$
E_{n}=\frac{a}{b-c} \times 100,
$$

where $c=$ energy expended during inactivity (in cals.) per unit of time.

As no external work is done during inactivity it is difficult to assess the value of the efficiency of this phase.

The temperature co-efficient for a complete muscle cycle is 1.8 , which means that the rate of the physico-chemical reactions involved is almost doubled by an increase of $10^{\circ} \mathrm{C}$. As we have scen this rate is a compromise between the decrease in the rate of the physical reactions of the contraction phases and the increases in the physical and chemical reactions of the restitution phase.

\section{Character of the Electrical Variations in Muscle.}

The existence of electrical currents in tissues did not find direct proof until the year 1824, when Nobili devised the galvanometer and showed that "natural currents" occur in the frog. Other investigators examined this current of rest and found that in a muscle removed from the body the current in the muscle passed from the ends to the middle and in the external (galvanometer) circuit from the middle to the ends. It has been conclusively proved that these "natural " currents are not natural at all but are an indication of injury to the muscle. Slight injury is unavoidable in the process of removing the muscle from the body - the less the preparation is injured the smaller is the current obtained from it. In other words, normal resting muscle is isoelectric and therefore currentless.

\section{Current of Injury or Demarcation Current.}

The injured part of a muscle is like the injured part of any cell (p. 134), "zincative" or electropositive to the uninjured part. That is, if non-polarisable electrodes are led off from injured and non-injured parts to a current-detecting device, it will indicate 
a passage of current from the uninjured to the injured parts of the preparation through the galvanometer. Within the tissue, of course, the circuit will be completed by the passage of the current from injured to uninjured. This difference of electromotive force may be demonstrated without a galvanometer. If the nerve from an uninjured muscle be laid over an injured muscle in such a way that at one point it touches a cut portion, then, the undamaged muscle will contract every time the circuit is completed by laying a second point of the nerve on an uninjured portion of the injured muscle.

This difference in E.M.F. persists as long as the injury. In a degenerating muscle its degenerating portion is electropositive, galvanometrically negative or "zincative" to its normal portion. Naturally, the difference ceases when degeneration is complete. The whole mass is then isoelectric. The current is due, as has previously been explained (p. 133), to physico-chemical differences at the junction of living and dying tissue. Dead tissue gives no current.

\section{Current of Action.}

Similar physico-chemical changes are answerable for the wave of "negativity" which precedes the mechanical change in a contracting muscle. The part which is just about to contract is clectropositive, or "zincative," to the rest. Consider for a moment a muscle, say $5 \mathrm{~cm}$. long. The preparation is supposed to be perfect and, therefore, there will be no demarcation current. If such a muscle be stimulated by a single induction shock at one end and two points $\mathbf{A} 3 \mathrm{~cm}$. and B $5 \mathrm{~cm}$. from the point of stimulation be led to an electrometer, then each stimulus will cause a wave of contraction to pass along the muscle, preceded by a wave of "negativity." "That is, A will become "zincative" to the rest of the muscle-so that current would pass through a galvanometer from $\mathbf{B}$ to $\mathbf{A}$. A fraction of a second later, the disturbance will have passed on to B which will now be "zincative" to the rest, causing a current to pass through the galvanometer from $\mathbf{A}$ to $\mathbf{B}$. That is, $\mathbf{A}$ has first been electropositive and then electronegative to $\mathbf{B}$. Such a current is termed diphasic and is an indication of a propagated change.

A muscle nerve preparation may be used to demonstrate the presence of the current of action. If the sciatic nerve of a frog's gastrocnemius be placed on another gastrocnemius, the former muscle may be made to contract by stimulating the nerve of 
the latter. The essential point about this preparation which is called the rheoscopic frog is that it actually proves the occurrence of a diphasic current in muscle in consequence of its activity. If the free nerve is stimulated by a tetanising current both muscles go into tetanus. This secondary tetanus demonstrates that although the stimuli are being applied so rapidly that the contractions of the "battery" muscle are fused, the diphasic nature of the excitatory process is still quite distinct and is indicated by the contraction of the "galvanometer" muscle.

The current of action may be considered as inclusive of the current of injury. Injury is stimulation. Therefore, the current produced by an injury confined to a small area should be weaker than that obtained by the excitation of the whole muscle. The E.M.F. of the current of action of a sartorius is about 0.085 volts, while the demarcation current may be about 0.053 volts.

An important piece of research work by A. V. Hill and W. Hartree has just been published. They devised instruments and methods enabling them to record photographically, not only the mechanical response of a muscle to a stimulus, but the heat produced at each phase of the mechanical response. Their apparatus was sensitive to $0.000001^{\circ} \mathrm{C}$. One may summarise their main findings as follows :

(1) "The time relations of the heat production in the first few seconds after excitation are independent of the presence of oxygen." It has been stated above that the magnitude of the heat production was independent of the presence of oxygen. One may therefore consider that the energy required for the initial chemical changes caused by excitation does not arise from oxidation.

(2) A complete muscle twitch may be resolved into four phases.

Heat Production.

(a) Contraction - - - Initial rapid production diminishing gradually in rate as the stimulus proceeds.

(b) Maintenance of Con- Small constant value ending shortly traction after stimulus ceases.

(c) Relaxation

Relatively large evolution of heat; occurring rather suddenly during the later stages of relaxation.

(d) Recovery

B. B. 
(3) "The absolute amount of heat liberated in relaxation increases as the duration of the stimulus increases, up to a certain limit, after which it remains more or less constant."

(4) The heat developed during relaxation is derived from the mechanical potential energy liberated on excitation.

A close analogy is drawn by these workers, between the energy changes of muscle and of an accumulator.

(a) The energy of an accumulator-stored electrical energy-is liberated by the application of a "trigger," i.e. by completing the circuit between positive and negative poles. In the same way, the potential energy of muscle is liberated by the application of a stimulus. The chemical changes that accompany the evolution of energy from an accumulator do not involve oxidations-just as the initial processes of contraction in muscle do not.

(b) The amount of energy used in making electrical contact, e.g. depressing key, is very small and bears no relation to the amount of energy so liberated from the accumulator, as is the amount of energy required to stimulate a muscle fibre.

(c) If a suitable machine is in circuit, the energy set free from the accumulator will manifest itself as "work" ; if not, it will be converted into heat.

(d) The moment the key is pressed the current starts in the electrical machine-say an electric motor. It passes round the coils of the armatures, and their soft iron cores develop attractive powers. The current, however, does not immediately rise to its full value owing to the self induction of the coils, nor do the soft iron cores become magnetised instantaneously under the influence of the magnetic field of the coil. Hence, the attraction exerted by the fixed poles on the armatures increases gradually up to a certain limit and then remains constant. These phenomena are similar to the development of mechanical response in a muscle.

(e) As long as the circulation is complete and the accumulator inexhausted, the motor will rotate. Roughly speaking, the mechanical response and the length of stimulation are synchronous.

$(f)$ If the current is left on too long, the accumulator becomes polarised, the current falls off and the magnetic field consequently decreases. After a period of rest, the electromotive force of the storage element rises to its full value and the magnetic field is restored. This may be compared to muscular fatigue.

$(g)$ On breaking the electrical circuit the magnetic field of the armature diminishes rapidly, though not instantaneously, to zero, and the motor slows down and stops. This process is analogous to relaxation.

(h) The current passing through the coils of the armatures and transforming them into magnets, endows them with (magnetic) potential energy which, as we have just seen, is, after a brief latent period converted into the kinetic energy of rotation. If the load on the motor is so great that revolution is prevented, then although tension is developed, no work is done. In the same way, muscle develops elastic potential energy on excitation which may result in the performance of external mechanical work if the muscle be allowed to shorten, but in an isometric contraction, shortening is prevented and no "work" is done. "The work actually performed depends in both cases on the conditions of loading."

(i) Heat production.

(i) Developmental. The electrical energy sent through the armature 
coils is converted partly into magnetic potential energy and partly into heat energy (Joule's heat) which is dissipated. The magnetic potential energy is converted partly into the kinetic form (rotation) and is partly dissipated as heat. The proportion of the incident energy which manifests itself as "free" and as "bound" depends on the length of time during which the current passes. A short excitation leads to the development of power in preference to heat while the reverse is the result of a prolonged excitation. Similarly, with muscle - a single twitch develops very little initial heat while an increasing fraction of the potential energy appears as heat as the mechanical response is prolonged.

(ii) Maintenance. In order to maintain a constant magnetic field a constant current has to be maintained in the coils of the armatures. The coils heat up. This is analogous to a tetanic contraction.

(iii) Relaxation. The induced currents, set up in the coils and in the neighbouring conductors by breaking the circuit, are converted into heat, i.e. the evolution of heat continues until the whole of the magnetic energy of the field has been dissipated as heat. Similarly in the muscle when the stimulus ends, the heat production does not stop at once; it continues until all the elastic potential energy of the muscle has disappeared.

(iv) Recovery. None of the above processes require the immediate presence of oxygen. In order to restore the electrical system to its former level, i.e. to recharge the accumulator, some mechanism has to be employed to convert kinetic into electrical energy. The normal process implies oxidation - an engine is started, oxygen and fuel are consumed, a dynamo is driven and current produced. Similarly oxygen is necessary during the recovery phase of muscular contraction.

(v) Rest. Accumulators "run down" when not in use, and liberate a certain small amount of heat. To keep them in condition they must have periodical additions to their material and energy contents. This recharging involves heat production and oxidation. In the same way, muscle at rest (in the absence of oxygen) liberates heat (and lactic acid). In the presence of oxygen this liberation is made good by oxidation. That is, muscle normally is prevented from " running down" by " continuous recharging " with, of course, a steady evolution of heat.

The foregoing notes are taken materially and almost verbally from an article by Prof. A. V. Hill and W. Hartree in the Journal of Physiology, Vol. LIV., p. 84. The student will, of course, bear in mind that no theory of muscular contraction is implied. A physical phenomenon which bears a very close resemblance to certain phases of the mechanical response of muscle to stimulation is given as suggestive of a type of mechanism. But, as has been said, "Resemblance is no proof-analogies can never replace analysis." 


\section{CHAPTER XIV}

\section{MANUFACTURING CELLS}

\section{"For know, whatever was created needs \\ To be sustained and fed ; of elements}

The grosser feeds the purer."

Milton.

IN the preceding chapter attention has been drawn to the muscles as cell communities which consume power but do not produce commodities for the use of the body as a whole. Other cell groups, the glands, may be regarded as the industrial communities manufacturing goods for use elsewhere. Others again are mere handlers of goods. These latter, the organs of absorption or excretion (negative absorption), do not as a rule alter the chemical state of the material, raw or manufactured, that thcy handle. They accept delivery, repack in suitable containers it may be, and forward for transport.

The glands may be divided for convenience into two classes. First, those which by means of a duct, opening outside the body, secrete manufactured material. The glands of the alimentary tract and the skin glands (sweat and milk) belong to this class. The other class prepares material which itself is used by the body cells. They secrete into the blood stream. The former may be termed organs of external secretion, the latter organs of internal secretion, ductless glands or endocrine organs.

- As far as is known the principle underlying the activities of all:glands is the same. Each manufactures some material which is stored up, and when wanted this material is washed out by a stream of water. That is, they all consist of a workshop and a dispatch department. These two functions are seemingly under different control and have to be studied separately.

The work done by a gland may be divided into three phasesjust as we saw that muscle work could be so treated-viz. : (a) Activity,'(b) Restitution, (c) Rest or Maintenance. 
(a) Activity. The outsider may gauge the activity of a factory by studying its output, and so, much may be learned of a gland by noting how much it secretes and when. Some glands secrete continuously, others in spurts. With the former should be placed the endocrine organs, with the latter the digestive glands. Of course those which maintain a steady output may, under stress, greatly accelerate their rate of secretion, and of the latter class the salivary glands at least maintain normally a level of secretion which under a suitable stimulus is enormously increased.

There seems no doubt but that the industrial cell-group consists of four different parts or activities. (I.) The factory itself where the secretion is prepared. (II.) The store room where it is packed and kept in bulk. (III.) The dispatch department where it is first packed small and ready for delivery and then (IV.) is sent out. Now when we speak of the activity of a gland we refer exclusively to this. last function, viz., active secretion. What then regulates the rate of secretion? Just those factors come into play which operate in our industrial world.

1. Stock on hand and rate of output from workshop.

2. Efficiency of the dispatchers.

3. Demand for goods.

Normally, the store of goods on hand and the rate of manufacture do not materially influence the output. Of course, if the operatives are poorly nourished or badly supplied with raw material, then output will fall. Similarly, insufficiently fed or overworked dispatchers will perform their duties half-heartedly and output will be decreased, but as a rule this factor does not come into play.

The decisive element controlling rate of output is the demand for goods. The store of goods is drawn upon and the factory speeds up to replenish the store. If the stored material is sent out more rapidly than it can be replaced, then overtimc has to be worked in the factory, and if persisted in, industrial fatigue is caused and total cessation of work is the final result.

These various conditions may be studied conveniently by studying the intake of oxygen or output of $\mathrm{CO}_{2}$. In some instances the intake of potential energy may be measured. From these it is found, as in muscle, that a very small proportion of the total $\mathrm{O}_{2}$ intake goes to the dispatch department. That is, the actual setting free of the secretion does not require much energy (cf. muscle contraction). 
(b) Restitution. Just as in muscular, so in glandular activity the great proportion of the oxygen used is associated with the phase of restitution. Energy is required for the building up of material to replace that lost during secretion.

(c) Then, as in muscle, the gland requires a certain amount of energy for domestic use. To keep its parts in repair and to prescrve its identity, it requires a maintenance allowance. The following figure from Barcroft will help the student to realise the energy expended during these three phases in the activity of the salivary gland in the cat.

From the figure it will be seen that the maximal rate of secretion occurs sometime before the maximal consumption of oxygen, and

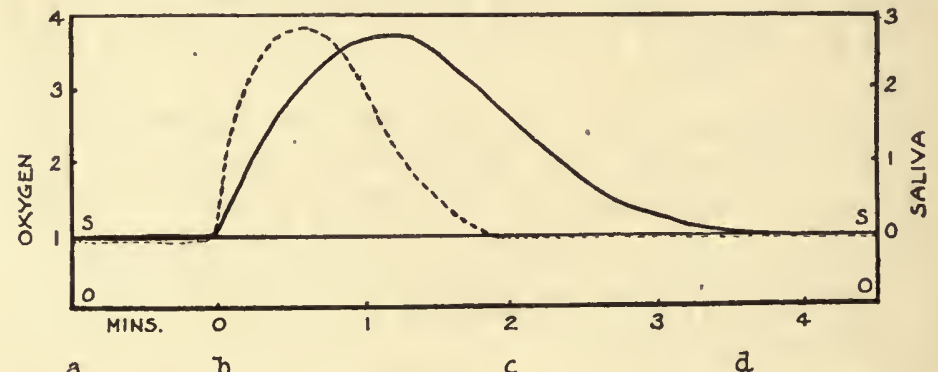

FIG. 26.-Oxygen used by the salivary gland during rest, activity and restitution. From $a$ to $b$, the gland was not secreting, but was using a fairly constant amount of oxygen. From $b$ to $c$, the gland was active-secreting saliva at the rate denoted by the dotted line. From $c$ to $d$, the gland was being restored to its pre-secretory state. $o-o=0 x y g e n$ base line. The area, ooss, represents the basal or resting metabolism of the gland. Dark continuous line = oxygen consumption. $8-s=$ base line for saliva. Dotted line =saliva formed in c.e. per minute. (After Barcroft.)

that the increased consumption of oxygen lasts for some time after the saliva has ceased to flow. Barcroft and his colleagues found that the length of this period of increased oxygen consumption depended upon the previous degree of activity of the gland as well as on its functional capacity. In other words, if a previous inroad upon the store of material had not been made up, the factory cells would have to work at high pressure to kecp pacc with the demand. Work at high pressure is not economical. Each gram of secreted material is formed at an increased cost in oxygen and energy.

The energy required for secretion comes from the oxidation of glucose. (Again compare with muscle.) For the dispatch of the material, little extra oxygen and little extra glucose is required. Asher and Karalov found that the restitution phase required the most energy. That is, the glucose content of the blood was markedly diminished in the post-secretory period. The amount 
of glucose used runs, as one would expect, parallel to the oxygen consumption.

The mechanism of secretion has been provocative of much controversy. A regular pitched battlc results when vitalists, neovitalists and mechanists discuss the problem. What are the facts?

1. Microscopical examination of the gland shows that during inactivity the lumen (storehouse) becomes filled with granules and the gland increases in volume. When the gland is excited to secretion, these granules disappear with the secreted fluid and the gland decreases in volume.

2. Water passes from the blood into the gland and out with the secretion.

There seems to be no difficulty in giving a plausible explanation of the second of these phenomena. The postulation of a semipermeable membrane is sufficient. The first fact presents difficulties.

(a) The osmotic pressure of the secretion is often greater than the osmotic pressure of the blood.

(b) The pressure in the duct against which the saliva may be secreted was found by Ludwig, in 1851, to be greater than that of the artery supplying the gland. Hill and Flack recently estimated this difference in pressure. They found that the pressure of secretion was as high as $240 \mathrm{~mm}$. $\mathbf{H g}$. and the arterial pressure $130 \mathrm{~mm}$.

3. Macallum demonstrated alterations in surface tension during secretory activity.

As mentioned in Chap. VI. this worker made use of the GibbsThompson distribution of salts to determine the relative values of surface tension in cells which had been killed and fixed almost instantaneously. He found, in the pancreas for instance, that during rest there was an unequal distribution of potassium. but when the gland was stimulated to activity potassium salts were found equally distributed throughout it.

Theoretically, in an active gland thcre must be at least three different values for surface tension, viz. :

(1) Cell-lymph interface, i.e. on the outer face through which raw material and power enter.

(2) Cell-cell interface where the cell wall is in contact with some of the other cells of the gland.

(3) Cell-lumen interfacc through which the secretion and the leaching out water pass. 
Now during activity he found that there was the densest condensation of potassium at (3), the cell-lumen interface, less potassium was found at the cell-cell interface and least at (1), the cell-lymph interface. According to the Gibbs-Thompson principle these results may be taken as an indication.

(a) That during rest there is no marked difference of surface tension at the gland interfaces, and

(b) That during activity a high tension develops at the surface between cell and lymph, a low tension between cell and lumen and that the cell-ccll interface has a value intermediate.

4. It is well known that during glandular activity there is an increase in the rate at which blood enters the gland. In other words raw material and power are taken into the factory at an increased rate. The view was at one time held that the secretion was due to this increased flow of blood. Barcroft's experiments have shown that this cannot be true, because

(a) The increase in the blood flow through the organ is initiated after the secretion begins and is continued for some time after secretion has ceased; and

(b) Vaso-dilatation may take place without secretion.

The increase in blood flow or vasodilatation is a consequence of secretion and not the secretion a result of the vasodilatation. The actively secreting gland, as it were, sends out a call for oxygen, for power and for material. This call is in part met by this increase in the transport service (see Chap. XXIV.).

5. Alterations take place in electrical potential of one part of the gland to another. These have been studied principally by Bayliss and Bradford on the salivary gland and by Orbelli on the skin glands of the frog. The results vary somewhat with the means of investigation, but may be taken as indicating two things.

(a) The secretion of water, i.e. dispatch of secretion, is a different function of the gland or a function of a different mechanism in the gland from the elaboration of the true secretory material. That is, we have to consider two phenomena, the preparation of material and its flooding out of the cell by water. The former is accompanied by

(b) A large difference of potential between the cell-lymph interface and the cell-lumen interface, the latter by a small potential difference of the opposite sign from the former.

The cause of the former difference may be sought in the increased permeability (lowered surface tension) of the cell-lumen 
interface; allowing free passage to cat-ion and an-ion. That is, at this surface the electrical potential recorded will be that of the interior of the cell (cf. muscle-current of injury).

An explanation of the current which flows during the elaboration of secretion is more difficult. There seems no doubt that just before being carried out through the duct, the granules undergo some change. The large colloidal particles either break down into smaller particles or go into solution. Either of these actions is accompanied by the setting free of adsorbed salts and alterations in the electrical charge.

6. These two processes, water secretion and the elaboration of the organic secretory material, seem to be controlled by different sets of nerves. Secretory nerves when stimulated cause the gland to be flooded with water, while "trophic" nerve fibres have to do with the elaboration of the granular material of the secretion. (Heidenhain, 1868, and Babkin, 1913.) Both sets of fibres may go to the gland in the same nerve. It is interesting to note that acid and other irritants excite secretory fibres only, while normal excitants stimulate both secretory and trophic fibres.

Can we from these facts construct a picture of the mechanism of secretion?

(1) The formation of granules in the cell may be similar to the formation of starch in the plant. Substances are thus put out of action. The colloidal granules not only have a low osmotic pressure but they adsorb crystalloids and so prevent endosmosis.

(2) On stimulation, these granules are broken down into smaller particles and water rushes in. It may be that stimulation of the gland follows the same course as in muscle and produces acid. This acid would interfere $(a)$ with the colloids present, especially with their power to hold water (imbibition) and salts (adsorption) and so bring about alterations in their size, electrical charge and the osmotic pressure of their dispersion medium. (b) Acid has a direct action on the electrical charge of any solution and, therefore, acts on its surface tension, lowering it. The only surface where this can take place is between the cell and the lumen. The alkaline reserve of the blood is sufficient to keep the cell-lymph interface normal ; or rather supernormal, while the cell-interfaces obviously need not be considered.

(For a neat model of Mucoid secretion due to M. Fischer, see Part II. p. 415.)

In short, the arrival of the appropriate stimulus causes the 
cell to draw on its store of material, alter the packing of the material and launch it into the duct on a current of water. The stimulus may be nervous or it may be a hormone (chemical messenger) formed in another organ and transported to the gland by the blood.

Of the mechanism of these glands which secrete directly into the blood stream little is known. Seemingly the secretion is extruded from the cell and washed away by the blood itself. Their oxygen consumption has never been measured nor yet their utilisation of glucose.

Bayliss and Hill have shown that the salivary gland does not become heated during activity. From this we may deduce that all the additional energy set free during the course of activity is used in doing work (in elaborating the secretion and in setting it free, ctc.), and in maintaining to some extent the normal temperature of the body (cf. Muscle). Thus leaving alone the latter sink of energy we may consider a gland as $\mathbf{1 0 0}$ per cent. efficient and calculate the work done from the oxygen intake or carbon dioxide output or from the diminution of sugar in the blood passing through it.

A considerable amount of work has been done in connection with the electrical changes which take place when a gland secretes. Bayliss and Bradford found that two kinds of changes occurred in the salivary gland. That associated with the secretion of water produced changes in the opposite direction from that associated with the output of the colloidal matter. The causes of this phenomenon are not yet certain but two "pointers" may be indicated. (1) The work of Loeb and his colleagues has shown how the presence of colloidal matter may alter the sign of electrification of water (p. 111). (2) In accordance with the accepted theory of secretion, the onset of true secretion leads to an increase in the permeability of the cell membrane at one end. It is obvious that, at the more permeable end, we are in electrical contact with the interior of the cell and so obtain the potential difference of the Helmholtz double layer between permeable and impermeable parts of the surface. During a mere secretion of water permeability is not supposed to undergo alteration. 


\section{CHAPTER XV}

\section{THE ARMY FOR HOME DEFENCE}

"Whatever uncertainty and variety may appear in the world, we remark, nevertheless, a certain secret coneatenation and regular order at all times carried on by Providence, which causes everything to proceed in its eourse, and to follow the law of its destiny."

La Rochefoucauld.

There are certain cells and certain cell-communities whose function it is to guard the organism from the invasion of its cells by noxious substances and by predatory parasites.

1. Cells. The leucocytes or white cells of the blood are amoeboid in character and act as scavengers and dust cart combined. They absorb, kill and digest micro-organisms which have invaded the organism. They also ingest and digest effete tissues, such as the tail of the tadpole when the frog stage is reached. This is termed phagocytosis. Certain drugs, e.g. iodoform, are supposed to increase the amoeboid movements of leucocytes and so increase their phagocytic power. This takes for granted that the bacteria, ctc., are enclosed by the pseudopodial processes of the leucocyte. In the blood vessels it is very rare for leucocytes to be seen with extruded processes. They are found as spherical cells, and Ledingham has shown that when a leucocyte collides with a bacterium, ingestion, death, and digestion of the bacterium follows as a matter of course. They act just as we saw that amoeba acted, and phagocytosis is just the same as any amoeboid organism feeding. There seems no doubt but that they are subject to chemiotaxis like other amoebae-chemical lowering of surface tension applied unilaterally. Exposure to an electric field causes the leucocytes to move towards the cathode. Ccrtain substances, so called opsonins, cause leucocytes to take up bacilli more readily. This is due, as Ledingham has pointed out, to the agglutination of the bacteria so that more are ingested at each encounter. The clumping of the bacteria by an opsonin follows the law of colloidal adsorption. It was once thought that the 
opsonin either stimulated the leucocyte or sensitised the bacterium, making it more chemio-attractive to the destroyer (Fig. 23).

2. The kidneys are the great eliminating organs of the body. Each of them is built up of a number of long unbranched tubes closed at one end and, at the other, opening, along with several other similar tubules, into a common collecting tubule. This in turn opens into the pelvis of the kidney. The production of urine goes on in these unbranched tubules, the collecting tubule serving apparently only as a conduit to the pelvis. The closed end of each tubule is invaginated within itself to form a Bowman's capsule, where its epithclium lies in close contact with the capillary tuft of blood vesscls - the whole end-structure being called a Malpighian corpuscle (sce over, Fig. 28).

The kidney does not manufacture any of the constituents of its secretion except hippuric açid, but mcrely eliminates unchanged certain of the bodies brought to it by the blood.

It is not a mere filter, as the concentration of the constitucrits of the urine are vastly different from the concentrations of the same substances in the blood. There seems to be a threshold value for each and every substance in the blood which when exceeded is at once reduced to its normal value by the elimination of the excess by the kidney. It keeps the salt content of the blood steady; therefore, abnormal constituents will be eliminated in thcir entirety. Not only is there an alteration in the relative concentration of the various substances eliminated, but there is in general a concentration of solutes. This concentration of solutes necessitates the expenditure of energy.

The total energy used may be estimated, as in other glands, by the consumption of oxygen. When the kidney is at rest, that is, when little or no urine is being formed, very little oxygen is consumed. During activity the amount of oxygen used increases greatly. The following table taken from Bareroft and Brodie shows this :

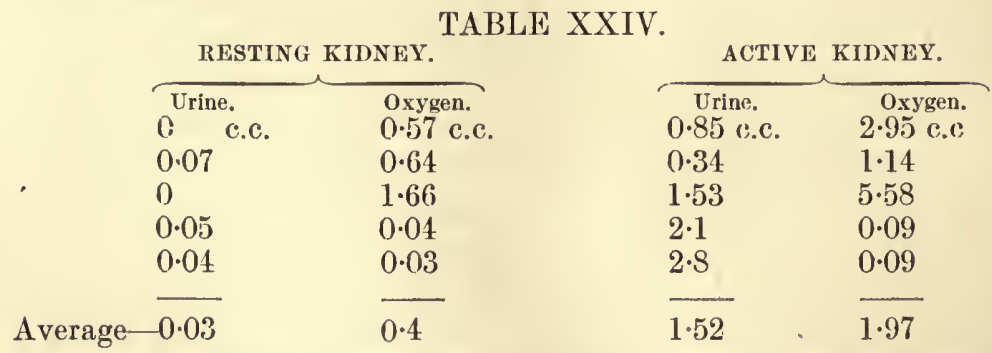

Work per minute $=320$ gram centimetres $=1650$ gram centimetres. 
During rest, the bulk of the oxygen consumed goes to the maintenance of the kidncy cells. On the average, the kidney cells use about 0.04 c.c. of oxygen per gram per minute and sccrete about 0.003 c.c. of urine. During a period of increased activity, the oxygen absorbed may rise to 0.28 c.c. per gram of kidney per minute. Each c.c. of normal urine costs about 1.05 c.c. of oxygen over and above what is required for cellular use.

The $\mathrm{CO}_{2}$ output varies very much even during rest and does not always increase in proportion to the oxygen absorbed. It may be that this metabolite is excreted by some other channel than the blood stream.

Attempts have been made to correlate the total energy exchange in the kidney with the work done, calculated from the alteration in the osmotic concentration in the various urinary constituents. The minimum work done in the formation of a litre of urine may be calculated from the Hill-Donnan formula.

$$
\text { Work }=\mathrm{R} \cdot \mathrm{T} \cdot\left[\Sigma\left(C_{u} \log _{e} \frac{C_{u}}{C_{b}}\right)+\Sigma C_{b}-\Sigma C_{u}\right]
$$

where $\quad R=$ the gas constant, $T=$ absolute tempcraturc,

$C_{b}=$ concentration in the blood of any constituent $a, b, c$, etc.

and $\quad C_{u}=$ its concentration in the urine.

This, of course, would only give the minimum work of the kidney, even if we knew the concentration and degree of dissociation of each and every urinary constituent. It may be advisable to call the student's attention to the fact that the energy used in effecting any change is independent of the means by which that change is effected. The work done, calculated from the HillDonnan formula, is simply the minimum necessary to cause the neccssary change in the molecular concentration. It is independent of any process and commits one to no theory (see Chap. III.). Attention to this point will prevent many a ludicrous mistake.

Rhorer has calculated the work done by the kidney in concentrating urea and sodium chloride, and from his figures Cushny considers that as the concentration of urea causes the consumption of about 0.7 cals., and similarly about 0.05 cals. are used in concentrating sodium chloride (per litre of urine), it would not be an overestimate to state that the production of a litre of urine entails the expenditure of at least 1.2 cals. This value, however, is but a fraction of the chemical energy used as determined by the oxygen consumption. We have seen above that for each volume 
of - urine secreted, the kidney consumes about an equal volume of oxygen. Assuming that the oxygen all goes to the oxidation of glucose, then each cubic centimetre of oxygen will cause the liberation of 0.05 cals. of energy from 0.015 grams of glucose. That is, the intake of energy for the output of about a litre of urine will be about 50 cals. There is thus a discrepancy between the total energy absorbed and the apparent work done. Meltzer and others account for this on the principle of the "factor of safety."

Macallum dissents from this explanation. He adduces evidence of a permanent low surface tension on the lumen-cell interface and ascribes the cxcess of energy used to the continuous maintenance of this surface energy gradient. On the other hand the difficulties to be overcome in measuring the fall in oxygen potential in the blood passing through the renal vessels are very great, and it may be that although the results are relatively accurate their absolute values may be somewhat high. Barcroft and Brodie estimate that about $\frac{1}{10}$ of the total oxygen intake goes to the kidney.

These workers have attempted, by means of estimations of the oxygen intake of the renal cells, to tell when the kidney acts as a passive filter and when the renal cells take an active part in secretion. During filtration, they say, no osmotic work is done, and therefore no energy is required and no oxygen used. Actual renal activity will entail expenditure of energy and consumption of oxygen.

A solution made up so that in composition it approximated to blood minus the colloids was injected into a blood vessel of a cat. Immediately there was an increase in the amount of urine secreted but no increase in the amount of oxygen consumed-proof positive of the non-participation of the renal cells. Now let us see what has happened. The introduction of the saline fluid causes :

(1) A temporary increase in the volume of blood corresponding to the amount of the fluid injected.

(2) An increase in general blood pressure and therefore an increased pressure in the renal arteriolcs.

(3) An increase in the rate of the blood flow through the kidney vessels.

(4) A decrease in the concentration of the corpuscles of the blood. This results in a decreased oxygen earrying power and a decreased viscosity.

(5) A dilution of the colloids of the blood. 
The saline diuresis may have been caused by all or any of these concomitants. They may be climinated one by one.

(1, 2, and 3) Increased blood volume, pressure and flow may be considered together. Increase in pressure, etc., produced mechanically without altering the concentration of corpuscles or of colloids, certainly does produce an increased flow of urine, the constituents of which have a concentration approximating to that produced after injection of Ringer's solution. Barcroft and Straube overcame this difficulty very ingeniously.

They previously removed a quantity of blood equal in volume to the Ringer they were about to inject, thus keeping the blood volume, etc., normal. The diuresis was produced as before, entailing no extra oxygen consumption.

(4) The addition of blood corpuscles to make up the deficient concentration made no appreciable difference in the flow of urine.

(5) Knowlton introduced a colloid, gum acacia or gelatine into the perfusion fluid so that the colloidal osmotic pressure of the injected fluid was equal to that of the blood (25-30 mm. of $\mathrm{Hg}$.). This prevented the onset of marked diuresis, gelatine being more efficient in this respect than gum acacia. 'Two causes may be ascribed to the lower efficiency of gum: $(a)$ its lower osmotic pressure (5 per cent. gum has an osmotic pressure of about $12 \mathrm{~mm}$. compared with 5 per cent. gelatine whose O.P. is $23 \mathrm{~mm}$. of $\mathbf{H g}$. Bayliss recommends a 7 per cent. solution). (b) Gelatine has a certain water holding power which is altered by treatment with salts (see Imbibition, Chap. VIII.).

The conclusion that one would draw from this series of experiments is that the passage of fluid and salts through the kidney by filtration is controlled by the concentration of colloids in the blood plasma.

Let us consider now a case where oxygen is consumed and, presumably, work done. Sodium sulphate is a diuretic. It is less diffusible than sodium chloride. A collodion membrane can be prepared which will allow the chloride and not the sulphate to pass through. Yet in the kidney the very reverse seems to take place. Sodium chloride acts very much like Ringer's solution, and though after a large injection of $\mathrm{NaCl}$ the chloride content of the urine rises, it does not materially alter the concentration of the other solutes. On the other hand, the injection of $\mathrm{Na}_{2} \mathrm{SO}_{4}$ is followed by the secretion of a urine almost entirely a water solution of the sulphate. Cushny has shown that, after the 
injection of a mixture of equal amounts of chloride and sulphate of sodium, more sulphate than chloride is excreted, and while the chloride elimination falls to normal in about an hour, at the end of three hours the sulphate content of the urine is above the normal. These results point to the sulphate as having a direct action on the renal cells. It is known to be a cell irritant. The question now is, does the kidney use up more oxygen during a sulphate diuresis than during a Ringer diuresis? Fig. 27, from Barcroft and Straube, shows that the oxygen used increases as the amount of urine increases. Therefore, one may say that the sulphate diuresis entails energy expenditure.

The various factors dealt with above as concomitants of saline diuresis may now be dealt with.

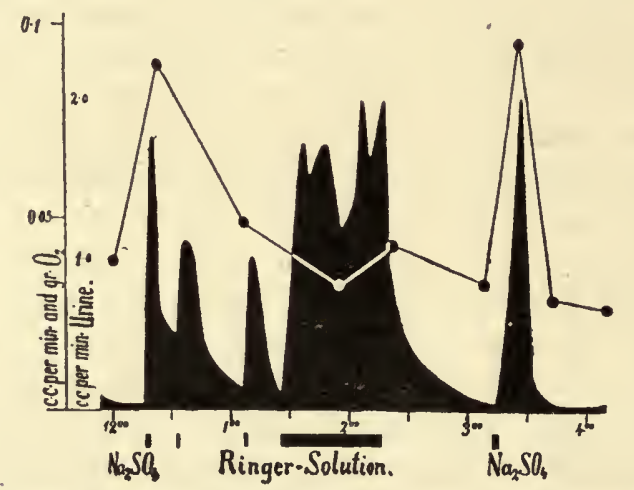

FIG. 27.-To show the relationship between the production of urine and the consumption of oxygen by the kidney under the influence of Ringer-Solution and of Sodium Sulphate. The black area indicates the amount of urine secreted, the thin line the consumption of oxygen. (Barcroft.)

1, 2, and 3. Increase in flow of blood, etc., do not play a part. Bainbridge and Evans showed that in a perfused living kidney, sulphate diuresis may occur without any increase in volume. Gottlieb and Magnus are inclined to think from a study of kidney volume that circulatory conditions are less favourable for sulphates than for chlorides.

4. The corpuscular concentration of the blood has as little effect under sulphate as under chloride injection.

5. The introduction of a colloid after a sulphate made little difference in the flow of urine, while it diminished it markedly after a chloride injection (Knowlton).

In short, filtration plays but a small part here. No doubt sulphates have a certain salt action but this is masked by their strong secretory effect. 
Next, one wants to consider what cells the sulphate stimulates. Cushny caused one kidney to secrete against a pressure of $30 \mathrm{~mm}$. Hg., leaving the other kidney free. During the height of a $\mathrm{NaCl}+\mathrm{Na}_{2} \mathrm{SO}_{4}$ diuresis he found that for equal weights of urine the obstructed kidney produced a fluid containing less chloride and more sulphate than the kidney with unobstructed ureter. The result of one experiment is appended.
(a) Unobstructed side -
Urine Gms.
C1. Gms.
$\mathrm{SO}_{4} \mathrm{Gms}$.
(b) Obstructed side
24
$0 \cdot 081$
$0 \cdot 108$
$0 \cdot 014$
$0 \cdot 067$

He supposed that the filtrate from Bowman's capsule must be of identical composition in both kidneys, as both had the same blood supply. Therefore, some change must have taken place during the passage along the tubules. In one case (obstruction) the fluid remained in contact with the lining cells for a prolonged period, while on the other side free passage was allowed. Either sulphate must have been added to the fluid during its stay in the tubule or chloride and water absorbed. The two main modern theories of renal action differ on this point. The experiment is quoted at this stage to demonstrate that it is probable that sulphate stimulates the cells lining the tubule, and that their activity entails the consumption of oxygen and the expenditure of energy.

It is very difficult to get reliable experimental results from the kidney. Its nature, blood supply and position do not lend themselves to surgieal interference, and the student ought to be keenly critical of results which are produced under uncontrolled abnormal conditions. Some facts, however, are obtainable and may be detailed here shortly.

1. Function. No one doubts that the kidney as a cell-community has specialised in excretion. Every cell in the body has the power of eliminating waste products. Most of these substances find their way into the blood and those that are non-volatile are voided by the kidney cells.

\section{Structure.}

The functioning parts̀ seem to be structurally, two, $(a)$ the capsules, and $(b)$ the tubules. Each capsule is lined by flattened pavement cells supported by a delieate basement membrane. The tubules are formed of columnar cells containing rows of granules running radially towards the lumen and becoming finer as they reach the striated border of the cell-lumen interface. 
3. Blood Supply. The artery supplying the kidney breaks up in the cortex into a large number of capillaries, each of which forms a nodule or glomerulus invaginated in Bowman's capsule. The capillaries again coalesce to form the efferent vessel, and this again breaks into a number of capillaries entwining round the tubules. After this the blood leaves the kidney by way of the renal vein. That is, the blood is first supplied to the glomeruli and then to the tubules.

4. Blood Pressure and Secretion. If the blood pressure is lowered to between 40 and $30 \mathrm{~mm}$. Hg. secretion stops. Starling

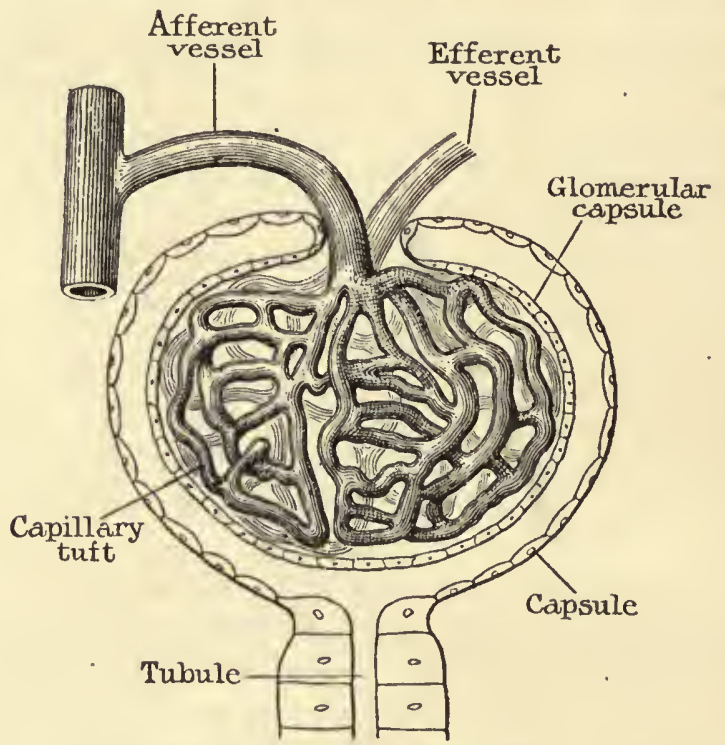

Fig. 28.--Diagram of Malpighian corpuscle. (From Cushny's Secretion of Urine.)

measured the osmotic pressure of plasma and found it to be about $30 \mathrm{~mm}$. Hg. It is generally inferred from this that unless the blood pressure be greater than the osmotic pressure of the plasma colloids no secretion will take place. Starling confirmed this by obstructing the ureter so that the Hydrostatic pressure therein was equal to $92 \mathrm{~mm}$. Hg. when secretion stopped. The blood pressure was 133. That gives a filtration pressure of 133 minus the osmotic pull back of the colloids (30), i.e. 103, approximately equal to the pressure in the ureter.

It is only fair to point out that, though modern theorists are at one regarding the forced filtration of colloid free blood through the capsule by means of glomerular pressure, i.e. heart work, 
arguments against the supposition may be found. For instance, the thin layer of epithelial cells is not strengthened in any way to stand a large filtration pressure. Again it is doubtful whether any such pressure exists in the glomeruli. Measurements are given of general arterial pressure, say in the carotid artery. The capillary pressure may be under ${ }_{5}^{1}$ th of this.

Simple diffusion through a membrane impermeable to colloids will answer as well. Increase in blood flow instead of pressure regulates the amount of dialysate. Furthermore, it is generally stated that capsular fluid has the same composition as blood, less the colloids. No direct evidence of this has been produced. Theoretically, it is not probable. Colloids have not only the power of holding salts by adsorption, but globulin especially holds water and sodium chloride in solution. This was proved by Milroy and Donegan, who showed that even when 250 c.c. of water per hour passed the outside of the collodion membrane, a solution of globulin (containing 0.15 per cent. nitrogen) in 0.15 per cent. sodium chloride, lost practically no salt in six hours. Any salt over the amount mentioned rapidly passes through the membrane.

5. The bone of contention between the two modern schools is the function of the tubule. One group holds that the tubular epithelium absorbs water and threshold salts (i.e. salts of use to the organism) from the fluid passing down the lumen. The other group holds that salts are excreted into the lumen by its lining epithelium. Much of the evidence produced is of equal value to both sets of thinkers. Macallum's work, already mentioned, showing that a constant low surface tension was maintained at the cell-lumen interface rather weights the scales in favour of the second view. There is also no doubt that experiments where dyes, etc., are injected show that matter does pass, under these conditions, from tubular capillary through the tubular cells to the lumen of the convoluted tubule. On the other hand, there is nothing to hinder the reverse process from taking place if need arises. Consider the cell as middleman between blood and secretion. Any abnormality in the blood would produce an alteration in the cell, which, if it could, would pass on the change to the secretion. Let us take a concrete example. Say there is a deficit in $\mathrm{NaCl}$ in the tubular capillary. As a result, because the cell $\mathrm{NaCl}$-tension must be equal to the blood NaCl-tension, salt will pass from the cell to the blood. Similarly, if the dialysate or filtrate in the lumen has any $\mathrm{NaCl}$ at all, some of it will pass 
into the cell to make up the defieit. The experiments of Milroy and Donnegan, already referred to, contain a series demonstrating the passing of $\mathrm{NaCl}$ from a watery solution to one containing a globulin.

Cushny's obstrueted ureter experiment referred to above may be interpreted in this light. Assuming, as he does, that the fluids coming from both capsules are identical in both kidneys, then on the obstrueted side there is a fluid in prolonged contact with the tubular epithelium, while on the other this fluid passes away more or less rapidly. Take for granted, for the sake of a standard, that the freely passed urine remains unaltered, that is, it is equal to the glomerular filtrate on the obstructed side-e.g. $24 \mathrm{gms}$. water, $0.08 \mathrm{gms}$. $\mathrm{NaCl}$ and $0.11 \mathrm{gms}$. $\mathrm{Na}_{2} \mathrm{SO}_{4}$. Sodium chloride is more diffusible than sulphate and readily penetrates cells, therefore the positive tension of $\mathrm{NaCl}$ in the tubule will cause some $\mathrm{NaCl}$ and water to enter the lining cells and so into the blood stream. The sulphate, not being so diffusible, will not so enter the cell. Thus the result would be a concentration of the urine with a decrease in ehloride, i.e. with sulphate steady; chloride would drop to a quarter $=0.02$ and water to a half $=12$ gms. But no great energy need be expended here, only sufficient to evaporate urine to half its bulk. The water and salt so seereted into the blood stream would cause a further diuresis and so on. On the other hypothesis, viz. that the sulphate is to a great extent seereted by the tubule epithelium into the lumen, this difficulty does not to the same extent arise.

In short, two factors may come into play in the secretion of urine, $(a)$ the adjustment of the eell to alterations in its environment, and $(b)$ a meehanical dialysis of water and crystalloids in solution through the capsule under suffieient pressure to wash the actively seereted material through the collecting tubule and on towards the pelvis of the kidney.

\section{Other Glands of Elimination.}

Of the physics of the other detoxifying glands, little or nothing is known. The largest of these is the liver, but beyond the isolation of enzymes, the physico-chemical mechanism has not been to any great extent investigated.

The spleen is the burying-place of dead erythrocytes. It is a modified lymph gland where the blood comes into intimate contact with the splcen cells or "pulp." In strueture it is a spongework of fibrous tissue, in a capsule of the same material 
containing muscle fibres. These fibres contraet and relax continuously, causing the whole organ to beat, like the heart, only much more slowly. The spleen contracts slowly about once a minute.

The intestine. Much waste matter is excreted by the large intestine and here the physico-chemical mechanism is more clearly indicated (sce Chap. XXVII.).

Skin glands-sweat excretion will be considered under regulation of temperature (Chap. XXXI.), and elimination by the lungs under Transport (Chap. XXIII.). 


\title{
CHAP'TER XVI
}

\section{THE CIVIL ENGINEERS OF THE BODY}

\section{CONNECTIVE TISSUE CELLS}

\begin{abstract}
"Which doth neatly declare how nature Geometrizeth and obscrveth order in all things."

Sir Tiromas Browne.
\end{abstract}

WE have just seen how increase in the size of an organism necessitates increase in its complexity. Groups of simple naked cells held together only by a pellicle resulting from surface adsorption, would at the best form unwieldy organisms which would easily be distorted beyond their elastic limit and so destroyed. Some means of binding the component cells together to form a body sufficiently rigid to withstand shock and yet possessing sufficient mobility to seek its prey and avoid its enemies, is a logical outcome of growth in size and in complexity. "Moreover, if the animal is to have an effieient museular system under complete control and able to be employed under all environmental conditions, some absolutely rigid systems of portable levers and fulcrums must be presupposed.

The Vegetative Tissues are those which support, bind together and mechanieally protect the other tissues of the body. They may be divided into two groups - the epithclial tissues which protect surfaces, and the connective tissues which bind together and support the various organs of the body.

\section{Epithelium.}

The shape of the cells forming a protective layer or series of protective layers depends entirely on the resultant of the forecs acting on them. We may take it for granted that here as well as with the single cell the agency of surface energy is obviously of first importance.

The theory underlying the phenomena associated with the manifestations of surface energy depends on the principle of Le Chatelier. Surface tension is proportional to the area of the surface of contact. It is also proportional 
to a coefficient which is specific for each pair of substances provided temperature is kept constant. It may be profoundly modified by the slightest alteration in one or more of the physical or chemical conditions of one or both of the phases forming the contact surface.

The form of a cell depends in great part on the magnitude of the surfacc forces brought to bear on it. If it is surrounded by exactly similar cells then it will tend to assume a more or less spherical form. This is exactly what one finds in the centre of a mass of soap bubbles or in the middle layers of stratified squamous epithelium. The cells are not absolutely spherical in shape, not only because the cells in mass are not absolutely similar but because the cells have to fit the space. No vacant spaces occur. Now, according to the principle of Le Chatelier, the surface energy will manifest itself by tending to reduce the area of contact. Mathematical proof has been given that the least possible area of contact surface is attained when the partition walls meet together in groups of three, at equal angles, i.e. at angles of $120^{\circ}$.

The outer and inner laycrs differ markedly in shape from one another and from the middle layers. The outer layer is exposed to air (skin) or to the free external fluids of the body (mouth and gullet) on the one side, but is in contact. with cells on all other sides. In addition, the outer surface is liable to undergo chemical changes - oxidations, etc., and physical changes-adsorption, etc. These again affect tension. The result is that the outer layers are flattened and scale-like.

The inmost layer of cells is in contact on one side with the structure on which the epithelium is laid and from which it takes its origin and its nourishment. These younger cells are more or less elongated in shape. Their form is governed by certain forces in addition to those acting on the more central cells. (a) It is obvious that the surface tension will be different at that surface where the cell is in contact with a cell differing from itself in structure and condition. These cells are in contact on either side with similar cells, but above, they press against fully grown spherical cells, while below they form interfaces with the structure on which they lie and from which they derive their nourishment. (b) These decper cells are in process of division, and, therefore, one must take into account the pressures of segmentation and of growth (cf. Plant Cells). (c) The outmost layer, away from the nourishing fluids of the body, undergo keratinisation and resist the outwards push of young cells which are thus put under stress. These various factors modify the shape of the deeper layers. 


\section{Connective Tissues.}

To appreciate the significance of the structure of the vegetative tissues, due attention must be directed to their function. These tissues are cell communities with an important but little studied industry. They are the civil engineers of the body. The structures they build are designed to stand stress and strain. Before critically examining their handiwork let us study some elementary engincering problems, so that we may the better understand the phenomena of cell structures.

All the tissues of the body are more or less elastic. This property includes $(a)$ change of form under the action of some force and $(b)$ the return of the body to its original form when the deforming force ceases to act.

The elasticity of connective tissues plays an important part in the body. (1) It is a permanent resistance to permanent distorting forces such as muscular tension and gravity. The elasticity of the intervertebral dises, and of the ligamenta subflava, assists in maintaining the erect posture of the body. (2) The form of tissues is preserved against distortion by temporary forces (Buffer action) and by intermittent forces. The elasticity of the costal cartilages and of the ribs restores the chest wall to its original position when the inspiratory muscles relax. (3) Intermittent movement is transformed into a continuous movement by transmission through an elastic medium (see circulation). (4) Elasticity economises muscular work by coming into play in the intervals between successive shocks (Marey).

The amount of elasticity is determined by ascertaining the force necessary to change the form of the object to which the force is applied, and the perfection of the elastic action, by the quickness and accuracy with which the object returns to its former condition on release from the mechanical force. Thus, when a strong force is required to produce deformation of a body, that body is said to be highly elastic. On the other hand feeble elasticity is overcome by the application of a feeble force.

The force which is applied to a body is termed by engineers the strain. The resistance to strain by a body necessitates the postulation of a stress within the body. Hooke (1660) statcd that stress was directly proportional to strain. As a formula this is known as Young's Modulus,

$$
\frac{\text { stress }}{\text { strain }}=Y(\text { constant })=\frac{\text { load on specimen } \div \text { area of cross-section }}{\text { alteration in length } \div \text { original length }} .
$$


Let $P$ be the pull, $a$ the eross-sectional area, $l$ the length of the fibre, and $e$ the elongation produced; then :

$$
\frac{\text { stress }}{\text { strain }}=Y=\frac{P / a}{e / l}=\frac{P l}{e a} \quad \text { or } \quad e=\frac{P l}{Y a} \text {. }
$$

Wertheim gives the moduli of the following substanees in grams weight per sq. $\mathrm{cm}$.

TABLE XXV.

$\begin{array}{lllllllr}\text { Bone - } & - & - & - & - & - & - & 2304.1 \times 10^{6} \\ \text { Tendon } & - & - & - & - & - & - & 163.41 \times 10^{6} \\ \text { Nerve } & - & - & - & - & - & 18.89 \times 10^{6} \\ \text { Muscle (resting) } & - & - & - & - & - & 0.95 \times 10^{6} \\ \text { Vein - - } & - & - & - & - & - & 0.87 \times 10^{6} \\ \text { Artery - } & - & - & - & - & - & - & 0.052 \times 10^{6}\end{array}$

The above values are given in order of increasing "perfection" and decreasing "strength" of elasticity. The figure last given, that of arterial walls, may be taken as substantially that of elastic fibrous tissue.

Now strains may be applied in two ways. They may press or they may pull. A pressing or erushing foree is called a thrust and a pulling or tearing foree is ealled a stretch.

The stress set up in the tissues is a function of the colloidal matter which we have seen gives rigidity to the tissues. Water and aqueous solutions of crystalloids are practically ineompressible, i.e. their volume elasticity is negligible. It is obvious that they cannot have any elastieity of shape. The dispersion of less than a gram of gelatine in a hundred eubie centimetres of water endows the solution with rigidity.

The emulsoid gel has elasticity of shape, i.e. it returns to its original shape after the applieation of a strain by thrusting, stretehing or bending provided it has not been strained beyond the elastie limit.

A moment's thought will convince one that a quite different structure is required to meet strains of the stretehing and of the thrusting varieties. (a) The material used in the building of struts to withstand thrust must have a high erushing limit, while that going to form ties requires high resistance to tearing. In the following table drawn up by Sir Donald MacAlister, are given the approximate values of the erushing and tearing limits of some building materials. 


\section{TABLE XXVI.}

\section{AVERAGE STRENGTH OF MATERIALS}

(in kgs. per sq. mm.).

\begin{tabular}{lrrrrr} 
Material. & & & \multicolumn{2}{c}{ Crushing Strength. } & Tensile Strength. \\
Steel - & - & - & - & 145 & 100 \\
Wrought Iron & - & - & - & 20 & 40 \\
Cast Iron - - & - & - & 72 & 12 \\
Wood (fibrous tissue) & - & - & 2 & 4 \\
Bone - - - & - & - & $12-16$ & $9-12$
\end{tabular}

A glance at this table is sufficient to show that a material which may make a very good strut may make a very poor tie, e.g. cast iron. A further factor has to be taken into account, viz. elasticity. In the following table, borrowed from "Growth and Form" by Prof. D'Arcy 'Thompson, are given the loads which various fibres and various wires were found capable sustaining just at their elastic limit.

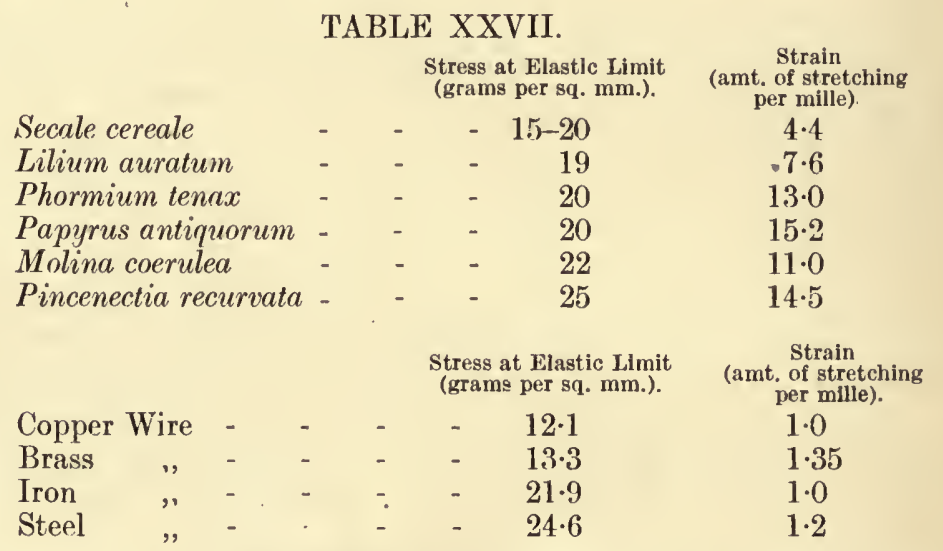

Comparison of these figures with those of the previous table will demonstrate the suitability of fibrous tissue to withstand a stretching strain and yet retain a very high degree of elasticity.

The engineer plans his structures to give the maximum strength with the minimum weight. Nature is equally economical. Examination of the girders holding a roof will show that they are of two shapes. Those running from wall to wall having a crosssection like the capital letter "I." This girder is a tie and has to withstand a stretching force. How has the engineer arrived at this form? Figure 29 represents a beam of square section. When such a beam is loaded midway between its supports it is slightly bent to give a concave upper surface. The upper 
surface is compressed while the lower is stretched. Therefore midway between the upper and lower surface lies a neutral zone or line of no stress and in its neighbourhood the material needs to have little strength. The girder maker ean therefore quite safely cut away the centre of his beam, leaving only the upper and the lower surfaees, and of course some connection between them which may be almost as thin as he likes without destroying
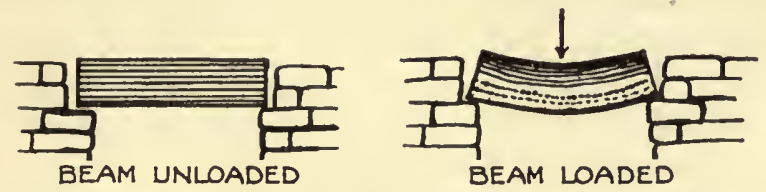

FIG. 29. -To show lines of compression (dark) and lines of tension (dotted) in a loaded rectangular beam. The clcar space between the strut-lines and the tie lines indicates the neutral zone.

the strength. In other words, if the engineer can map out the lines of stress or directions of compression and tension in the loaded strueture, all the manufacturer has to do is to see that these lines lie in his material; all the rest may be cut away.

By means of the truss (Fig. 30) the simple girder beeomes a tie between two struts. The horizontal member of the truss undergoes tension only, while the sloping beams are compressed.

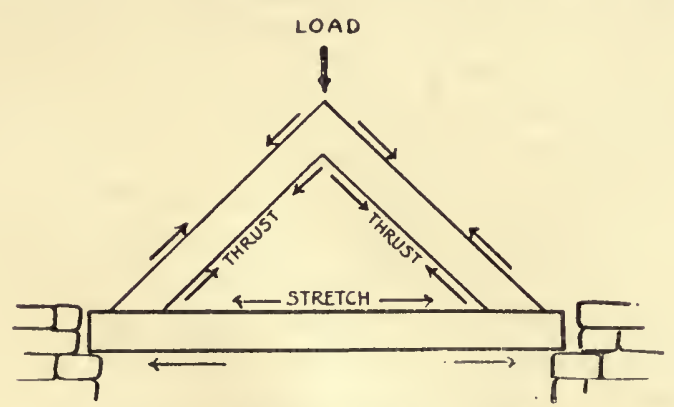

FiG. 30.-A simple triangular roof truss.

Such a structure permits of the use of two kinds of materialmatter with a high tensile strength for the tie and matter able to bear up under compression for the struts.

The two prineipal connective tissues are fibrous tissue and eartilage and their modifications. Fibrous tissue is the main binding medium of the body. It is derived from the mesoblast of the embryo. The cells of the mesoblast, which arc typical spherical bodies lying close together, are gradually pushed apart by a clear transparent jelly-like exudant from the cells. They 
retain connection with one another by elongated processes giving the whole tissue the appearance of an attenuated sponge filled with a gel. The cells apparently secrete a colloid in a nonhydrated form which then swells up to form a gel by the imbibition of water. A model of this process may be made by adding water to a mixture of gum and oil (Part II.).

As development advances the cells of this mucoid tissue become longer and more spindle shaped (fibroblasts). The fibres are of two classes, differing from one another in chemical constitution as well as in physical properties.

(a) The white fibres are delicate transparent non-elastic fibres arranged in bundles which do not branch.

(b) The yellow fibres are highly refractile elastic fibres which branch and anastomose with one another. (Feebly but perfectly elastic.)

The difference in their physical properties may be explained by their different chemical constitution. The former are composed mainly of a non-elastic protein collagen which readily takes up water to form gelatine. The latter have in place of collagen another sclero-protein elastin. Though difference in chemical constitution may explain difference in physical properties, it does not make any clearer how such a difference is brought about. If elastic and non-elastic fibres existed side by side in definite proportions one could easily mimic the formation by the separation of two colloids from a colloidal matrix. But there is no such definite proportion. Some tissues, e.g. tendons, are almost entirely composed of white fibres, while elastic fibres predominate in ligaments. In short, white fibrous tissue is found where binding power alone is required, and where elasticity as well as strength is desirable, there one finds elastic fibrous tissue. The function of the tissue governs its form.

Just exactly how function governs form, one cannot at present say. There is no doubt that external physical forces do affect chemical actions and internal physical properties. Material under strain acts quite differently from the same matter unacted on by any force. An almost non-elastic block of rubber may be endowed with considerable extensibility by being worked with. The optical properties of glass can be altered by submitting it to pressure. The electrical conductivity of selenium depends on the amount of light falling on it. When more is known of the laws governing matter in the colloidal state, then one may be able to give a clear answer to this problem. 
In certain situations peculiar modifications of fibrous tissue are found :

(1) Endothelium consists of flattened cells forming a membrane. It differs from pavement epithelium by having the formed material (colloidal exudate) between and not in the cells. Such endothelial layers line all the serous cavities of the body and the lymphatics, blood vessels and heart. A structure similar to endothelium may be produced when an aqueous solution of, say, fatty acid is added to a mixture of hydrated colloids of high concentration. Under such circumstances the pressure of separation deforms the originally spherical globules to form a beaded flattened honeycomb.

(2) Fat cells. The experiments upon emulsoids detailed in Chapter VIII. throw light upon the appearance of fat in the cells. There is scarcely a tissue or fluid in the body that does not contain fat in amounts in excess of the quantities that can be dispersed in colloid-free water. Finely divided fat in cell protoplasm is comparable to an emulsion. It depends for its permanence on the same factors as maintain fat in a finely divided form in an aqueous dispersant, i.e. mainly on the presence, in the tissues, of hydrophilic colloids. While the fat in the cells is not ordinarily visible or even demonstrable by microchemieal methods, when an exeessive amount of fat is present it may be seen in the network of areolar fibrous tissue, especially round the smaller blood vessels. Little droplets of oil at first appear and these become larger, run together and coalesce, forming a single large globule, distending the cell and pushing to the sides the protoplasm as a sort of capsule. Reference to the chapter on emulsions will show that when the fat in an oil-in-colloid emulsion is increased beyond a certain amount, the nature of the emulsion is changed to colloid-in-oil. This latter emulsion differs from the former not only in the visibility of the fat, but in this respect that the fat may be stained (black) by osmic acid or (orange) by sudan III.

In starvation the fat gradually disappears from the cell leaving the hydrated colloid, which also in time disappears and the cell resumes its shape.

Apart from acting as a storehouse of energy, fatty tissue has important mechanical functions. As we shall see later the layer of subcutaneous fat serves as an extra garment protecting the wearer from the too rapid loss of heat (Chap. XXXI.). Then too, fatty fibrous tissue has a considerable amount of resilience, acting as a buffer protecting organs from external violence. 
(3) Pigment cells. Fibrous tissue cells (and other cells) in certain parts of the body (e.g. eye) may contain a pigmentmelanin. How this pigment is formed and what exactly are its functions remain matters of conjecture. Chemieally, melanin is closely related with the melanoidins-dark pigments resulting from digestion of proteins with hot mineral aeids. They serve (a) as light filters-preventing the passage of light through the pigment cell. That is, the pigment absorbs energy. These pigmented areas are nearly always found in plaees cxposed to light, and one may suppose that the ineidence of strong light on fibrous tissue may cause the formation of melanin from the eell protein. Inorganic examples of the formation of light-absorbing chemieal compounds by the absorption of light will oceur to the student (ef. Silver Salts). (b) Their function is not only to protect the underlying tissue from the harmful action of radiant energy, but in many cases the pigment cells act as a transmitting station-receiving the light stimulus and transmitting it to the effectors. This dermatoptic function has been studied and described by R. Dubois. Light falling on the pigment cells of the epithelium of the siphon of Pholas, a molluse, causes a reflex retraetion of the siphon. Observation under the microseope has shown that the pigment cells in the skin of the frog contract when light falls on them. The pigments of the eye and their aetion in transmitting light stimuli will be dealt with in another chapter.

Two modifications of fibrous tissue warrant separate treatment, i.e. cartilage and bone. In lower animals and during the foetal life of higher animals (as well as in certain situations in adult life) rigidity is given to the body by cartilage. The function of eartilage cells will be dealt with later under bone and lubrieation. Hcre it is sufficient to note that the peculiarity of this tissue is the secretion of a homogeneous translucent gel which is tough and elastic. This chondro-mucoid material is a mixture of at least three colloids : ordinary protein, collagen and chondroitin. On decomposition this latter substance yields substances of a carbohydrate nature, glucosamine and glyeuronic acid (cf. emulsions).

(4) The great supporting tissue of the body is calcified fibrous tissue or bone.

(i) Development. Bone is formed by a deposition of calcium salts in white fibrous tissue. Some bones which are more or less flat, e.g. vault of the skull and the seapula, are formed directly in fibrous tissue. This is the so-called intra-membranous 
bone formation. The long bones are preformed in cartilage into which processes of fibrous tissue find their way and they in turn undergo calcification. All bone is developed from fibrous tissue. The cartilage merely plays the part of scaffolding and is all replaced by fibrous tissue before ossification takes place.

TABLE XXVIII.

Relative Strength of the Long Bones.

(MAN AGED 31.)

\begin{tabular}{|c|c|c|c|c|c|c|c|c|}
\hline \multirow{2}{*}{ Bone } & \multicolumn{2}{|c|}{$\begin{array}{l}\text { Crushing Strength } \\
\text { (in kg. per sq. mm.) }\end{array}$} & \multicolumn{2}{|c|}{$\begin{array}{l}\text { Bending } \\
\text { Strength } \\
\text { (in kg.) }\end{array}$} & \multicolumn{2}{|c|}{$\begin{array}{l}\text { Shearing } \\
\text { Strength }\end{array}$} & \multirow{2}{*}{ Place of Rupture } & \multirow{2}{*}{$\begin{array}{l}\text { Torsion* } \\
\text { (in kg.) }\end{array}$} \\
\hline & $\begin{array}{l}\text { lst appear- } \\
\text { ance of } \\
\text { breakdown }\end{array}$ & $\begin{array}{l}\text { Complete } \\
\text { erushing }\end{array}$ & Max. & Min. & Max. & Min. & & \\
\hline Humerus & $8 \cdot 5$ & - & 300 & 120 & 505 & 250 & At ends & 40 \\
\hline Radius & $5 \cdot 3$ & - & 140 & 55 & 334 & 105 & In middle & 12 \\
\hline Ulna & $5 \cdot 5$ & - & 140 & 70 & 235 & 90 & Anywhere & 8 \\
\hline Femur & 13 & 29 & 475 & 230 & 810 & 400 & At the neck & 89 \\
\hline Tibia & $6 \cdot 0$ & 42 & 500 & 135 & 1060 & 450 & $\begin{array}{l}\text { At the lower } \\
\text { end }\end{array}$ & 48 \\
\hline Fibula & 3 & 一 & 55 & 21 & 61 & 20 & In the middle & 6 \\
\hline
\end{tabular}

* Torsion applied to the extremity of the bone with a leverage of $16 \mathrm{~cm}$. produeed a spiral fraeture with the forees given above. (Amar.)

Practically nothing is known of the physical chemistry of bone formation. Microscopic investigation suggests to our mind a process similar to the formation of a honeycomb. The cells of fibrous tissue detailed to build bone, i.e. osteoblasts, secrete material containing a fair proportion of the phosphate and carbonate of calcium. It is known that the presence of a small quantity of a colloidal complex alters the solubility of inorganic matter. For example, calcium phosphate is more soluble in an albuminous hydrogel than in water. This effect is even more marked with calcium carbonate. If we presume the presence of the salts of lime in the fibrous tissue cells, then, by the principle of Willard Gibbs, they will be found in greatest concentration where the surface tension is lowest, that is at the cell borders. Another factor may be brought into play, viz., alterations in the colloidal matrix. Albumin is broken down in the body to proteoses and peptones. Now, experiment has shown that calcium salts dispersed in an albuminous hydrogel are thrown out of solution when proteoses and peptones appear in the gel. Further, calcium phosphate is much more insoluble in proteose-peptone solution than the carbonate, which is only slightly affected by the 
change. It is significant that bone ash contains about 84 per cent. of the former and only $7 \cdot 6$ per cent. of the latter salt.

One cannot say why cells in certain situations should have this property of ossification. How far stresses and strains affect the process is unknown. This we do know, however, that the internal structure of the bones undergoes alterations to suit alterations in the application of external forces.

(ii) Internal structure. In the earlier part of this chapter mention was made of lines of stress, and it was there stated that as long as sufficient strong material was present to include the course of these lines it was an obvious economy to cut away as much as possible of the matter in which there were no stress lines. If these lines lie wholly in the structural material, then the danger of rupture under shearing stress is eliminated. A shearing stress is a force which tends to cause one part of a structure to slide over another part. For example, a pile of coins compressed by a force acting at right angles to the face of the coins effectively resists the compression. If, however, the force were to act obliquely to the face of the topmost coin, it would immediately cause the pile to slip asunder. In other words, a shearing stress is ineffective along the lines of maximum compression. The same ean be demonstrated for lines of maximum tension. For all other lines, shearing stress has a definite value which is obviously at maximum at $45^{\circ}$, i.e. half way between the lines of tension and compression. Prof. Culmann, an engineer from Zurich, happened to see some drawings by Prof. H. Meyer of the cancellous tissue of the femur and at once noticed how the trabeculae of the bone coineided with the lines of stress. He gave his class of engineering students an outline of the femur and told them where the stresses fell. He asked them to draw the internal structure which would be necessary to meet these stresses. Fig. 31 shows the result. Alongside this figure is given a diagram of the Fairbairn craneone of the best weight-lifting mechanisms known. The similarity between the natural and the artificial structures is obvious. It will be noticed that the lines of the trabeculae of the femur run in two systems of curves. One system runs along the outer convex side of the shaft, curves downwards as it opens out with concavities downwards. The other system starts from the inner side of the shaft and rises spreading outwards with the concavities upwards. 'These systems correspond to the two kinds of lines of stress present, e.g. tension and eompression. The convex or outer side has to resist tension, while the inner convex side, 
ovcrhung by the loaded head, is the compression member. The head of the femur is a little more complicated than Fairbairn's crane, in that the load is applied on two points, i.e. on the head of the bone and on the great trochanter. This entails a division in the distribution of the stress lines corresponding to the incidence of the loads. In the compact tissue of the shaft the tension and compression lines run parallel. The lines of stress are closest together at the point of greatest strain, i.e. in midshaft. This place has to be thickened to prevent the bone from snapping (a walking stick pressed vertically against the floor breaks half-
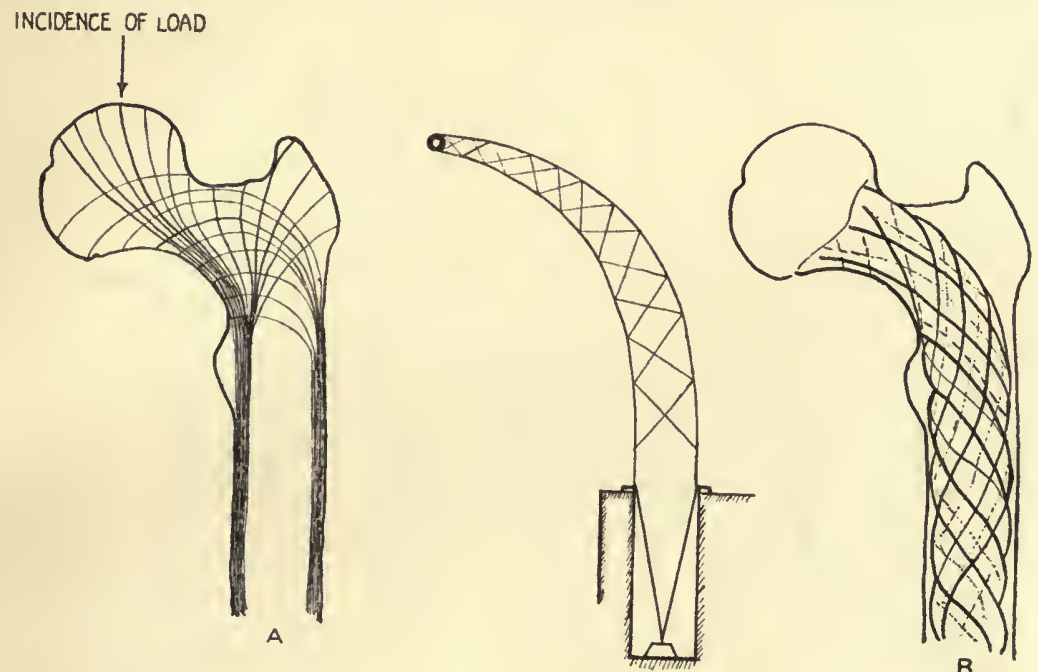

B

FIG. 31.-To show the stress lines in the head of the Femur, $A$, in section, and $B$, on the surface. The central diagram gives an idea of the location of the lines of stress in the head of a crane. (After Culmann, Meyer and Dixon.)

way up). The central portion of the shaft has to bear no strain, and therefore is hollow. It may be considered as a large mesh between the tension and compression lines. In the cancellous tissue the tension lines cross the compression lines at right angles.

The same phenomenon may be seen in any bone which undergoes tension and compression. It is very noticeable in the human foot, especially in the heel bone (calcaneus). It is roughly triangular, having three bearing surfaces. The upper surface is compressed by the weight of the body applied from the ankle bone. Therefore, compression lines start from it and run downwards. The lower surface rests on the ground, i.e. has to bear an upward 
thrust, and so compression lines run upwards from this surface to meet the compression lines from the upper surface. The third or anterior surface is in contact with the bones of the arch of the foot and transmits the ankle pressure forwards to them. This gives rise to a second system of compression lines running obliquely forwards. These two systems correspond to the two beams in Fig. 30. Now the application of a load at the apex would cause the beams to diverge at their lower ends if they were not tied together by the girder. So tension lines must exist to prevent the fracture of the bone between the two systems of compression lines. These tension lines will be scen in Fig. 32

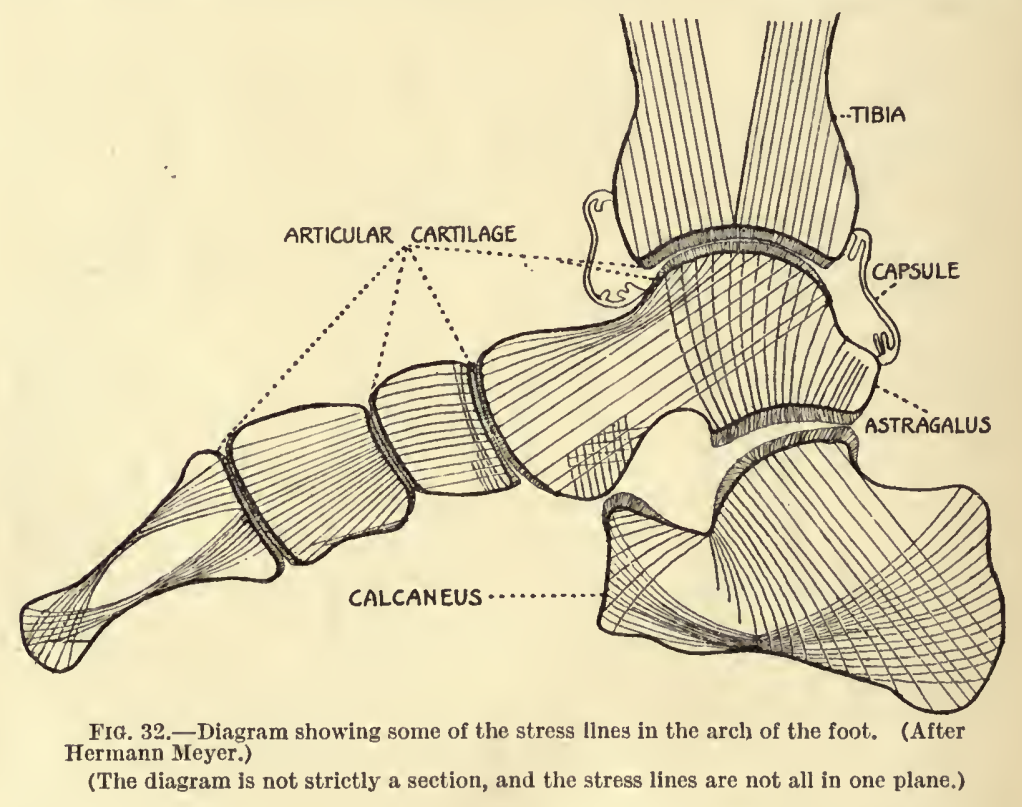

forming curves with their eoncavities upwards and orthogonal to the eompression lines. It will be noticed that these ties are closer together at the arch of the bone between the two struts, i.e. at the point where fracture is most likely to take place. Just above this point no stress lines can be seen, i.e. there is a neutral region. Examination of the bone makes clear the fact that in this neutral zone trabeculae are almost entirely absent. Where there are no stress lines it would be a waste of material to build struts or ties. As Sir Donald MacAlister puts it, "any mass of bone put there would not 'row its weight,' and it has been 'turned out'." 
This internal structure is altered to meet alterations in the incidence of stress. For example, during the first twenty years of life when the body is growing and the bone lengthening, constant alterations in internal and external structure have to be made. The unnecessary parts are decalcified and the fibrous tissue undergoes alteration. During this process some of the fibrous tissue cells become enlarged and multinucleated. Histologists call these cclls osteoclasts. The remaining fibrous cells afterwards become bone marrow. An adjustment to meet altered conditions may be seen when a bone is broken and allowed to set badly, so that its parts lie somewhat out of their former positions. Tension and compression lines do not now coincide with the trabecular structure. It has been shown by Wolff and others that in a few weeks, not only has an alteration taken place at the seat of fracture but the entire trabecular system, right to the ends of the bone, has undergone remodelling to suit the new incidence of forces. More recent work on bone grafting has amply demonstrated the astonishing rapidity with which reconstruction of the trabecular meshwork takes place. One must remember that in spite of its rigidity, bone is plastic. Physical chemists have proved that when an inorganic constituent separates as a definite phase from a colloidal matrix, the new phase is at first liquid. We may, therefore, infer that the new trabeculac are more or less liquid when formed. The action of force upon them will tend to set them along the lines of that force, e.g. straws set along the direction of the wind. They are practically "carded" into position. There they are in equilibrium and will tend to "solidify" in that position.

(5) Lubrication. Certain cartilage cells have a peculiar function, that of acting as a lubricant between rubbing surfaces. One of the most worrying problems of the engineer is to prevent " heating" up " of moving surfaces. This he attempts to do by interposing a fine uniform film of oil between surfaces where friction is apt to take place. The particles of the oil film act as microscopic ball bearings over which the moving surfaces slide with the minimum of friction. The motor cyclist knows how essential it is to have the right amount of the right grade of oil in the right place. In spite of all precautions however, "seizing" does take place. The film of oil is rubbed away just at the point where it is most required. Only one machine has, as yet, been designed which has a perfect lubricating system, and that is the animal body. In the body there are many rubbing surfaces. At joints, bone works against 
bone: tendons run like Bowden wires in sheaths, and yet the healthy animal body moves noiselessly and without " heating up " or "seizing" at any speed.

(a) Joints. There are, counting great and small, 230 joints in the human body varying in degrees of magnitude and importance. The ends of the two opposed bones in a joint are coated with a thin layer of cartilage. This cartilage, in the adult, is what is left of the scaffolding of bone. As we have seen, it is clastie and acts as a resilient buffer. The surface is always covered, in health, with a film of synovial fluid.

This synovia is kept in place by being enclosed with the joint in a flaccid membrane or joint capsule (Fig. 32). The synovial fluid results from the destruetion of the cartilage cells on the rubbing surface of the joint. In this way the supply of lubricant is absolutely automatic. The more the joint surfaees move on each other, the greater is the destruction of the cartilage cells and the more plentiful is the supply of synovia.

Two other points require our attention, (i) How is the supply of synovia kept up and (ii) what happens to the waste fluid. (i) The cartilage is constantly, like epithelium, growing. The young cells take their origin in the layer next to the bone and push their way up towards the outer surface of the articular cartilagc. Every cell destroyed to form synovia has its place taken by a cell. from the layer below and so on. Growth and destruetion exaetly balance one another. (ii) The waste synovia is drained into the blood stream through certain warty structures which project into the crevices of the joints.

In chronic rheumatism the cartilage cells fail to form synovia. The articular eartilages become dry and leathery and the joints may be heard creaking as they move. The underlying bone, stimulated by the unaccustomed friction, thickens and throws out gnarled processes. The supply of lubricant has failed, and until someone diseovers just how cartilage can be converted into synovia and what controls the process nothing can be done to prevent "seizing" of the joints.

(b) Tendon sheaths. Muscles are attached to bone by sinews or tendons and these cordy structures work in sheaths. The inner surface of the protecting sheath as well as the outer surface of the tendon is endowed with a lubricating substance similar to that of the joints.

There is one outstanding point of interest about the lubrication system of the body and that is its nourishment. As far as is 
known all other cell communities draw the material they require for maintenance and growth from the blood stream. As we shall see in the sequel the red blood corpuscle performs the duty of oxygen carrier. No red corpuscles enter articular cartilage-the gristle in joints is pearly white. One can only suppose that the plasma which reaches the cells from the rich vascular network on the surface of the underlying bone, carries dissolved in it sufficient oxygen to meet the needs of these lubricant-formers, as it carries sufficient protein, carbohydratc, etc., for their use.

The formation of cartilage and of synovia and of the relation of these two substances to bone and to fibrous tissue is a rieh field for investigation. Certain colloidal phenomena will occur to the student as suggestive of an explanation, but absolutely no definite physico-chemical facts can be brought forward as acceptable evidence. 


\title{
CHAPTER XVII
}

\section{THE INTELLIGENCE SERVICE}

\begin{abstract}
NERVE CELLS
"The messengers that preserved a communication between the soul and the outward members."

Berkeley.
\end{abstract}

IT is obvious that in an organised conglomeration of cell bodies like the animal body some means of rapid communication must exist between one organ and another. Without it, rapid coordinated movement by the body as a whole would be impossible. This work is accomplished by the nervous system. 'Two entirely different systems of rapid communication exist in the body. One runs to and from the body wall and has to do with the relation of the body to its environment. It belongs to the army of defence and defiance. The other system of rapid communication conveys messages to and from the industrial communities.

Embryologically, communication between an inland cell and the outer world is effected, in the first instance, by an ingrowth of the external epithelial covering. That is, messages are passed on to the inmost cell by a file of cells, detailed for this scrvice. These cells are, to begin with, all structurally and functionally alike (neuroblasts). Later, some few of them send out long processes towards the surface and towards the organ. Thesc processes end in branching twig-like structures called dendrites (Gr., a tree), through which they seem to be able to pass on stimuli to one another. The name synapse (Gr., a junction), is given to the juxtaposition of the dendrites from the processes of two nerve cells. The cell with its processes is called a neuron. (See Fig. 33.)

The second system of nerves, that of the viscera, is formed of neuroblasts which have migrated towards the organ from the neural canal. They all pass through at least one ganglion or a plexus which acts like a local headquarters or exchange. 
Some nerves have a sheath or coat composed of unsaturated fatty acids and lecithin (and allied lipoids). The function of this medullary sheath has not been diseovered. It is formed from separate cells, but it must retain some connection with the nerve cell, as it dies and disintegrates when dissociated from it.

1. Structure. The neuron, like any other cell, is a colloidal fluid mass. This may be demonstrated by examination of the living nerve by means of the ultra-microseope, when particles in Brownian movement will readily be seen. Some of these partieles, at times, clump together to form local large aggregates which again dissociate. Further, Carlson has shown that nerves may be stretehed without altering their efficiency, judged by rate of conduction of an impulse. Macallum states that alterations in surface tension can be detected especially in the growing nerve. It has been urged by Gothlin that, as a nerve is doubly refracting to a slight extent just like musele it must have a similar composition. These facts all go to prove that nerve is of a liquid nature.

2. Its function is to conduet. One cannot lay too much stress on the fact that it does not conduet an impulse originating outside, as a telephone wire conducts current from a battery. The battery is an integral part of the neuron.

3. The nature of the stimulus seems immaterial. Mechanical, electrical or chemical stimuli all cause the nerve to propagate the same kind of impulse. Furthermore, the excitatory result of the propagated impulse depends not on the nature of the "trigger" stimulus but on the nature of the effector meehanism to which the nerve goes. That is, stimulation of the sciatic nerve by electrical, mechanical, thermal or chemical means always causes contraction of the gastroenemius musele; stimulation of the vagus nerve by any means always slows the heart, stimulation of the chorda tympani causes the salivary glands to seerete, no matter how the stimulation is effeeted. Müller's law of the speeific energies of the senses states that, by whatever manner a sensory nerve is stimulated, the resulting sensation is always that produced by this nerve when stimulated by its specifie "trigger." That is, the receptor organ of a sensation-carrying nerve controls the sensation received. 'To be concrete, stimulation of a taste nerve (chorda tympani), by pinching, sudden heating or cooling, electrieal shock or chemical reagents, produces the sensation of taste and nothing else. Similarly, stimulation of the eye nerves by any means makes one see light. Keith Lucas 
states that there is no evidence to show that the nerve impulse is in any way modified by the nature of the stimulation. Each nerve has however a rhythm of its own-an optimal rate of stimulation known as Waller's " characteristic," which is similar to the natural rate of incidence of energy.

No difficulty should be experienced in grasping this idea, especially if an electrical model be kept in mind.

Consider an electrical circuit such as shown in Fig. 33B. C is a galvanic cell or electrical unit where chemical energy is converted into electrical energy. $\boldsymbol{F}_{1}$ and $\boldsymbol{F}_{2}$ are wires connecting $\boldsymbol{C}$ to $\boldsymbol{M}$, an electric machine, and a key closes the circuit. (a) It does not matter how the key is closed, the current passing along $\boldsymbol{F}$ will be the same, and $(b)$ the manifestation of the current will depend

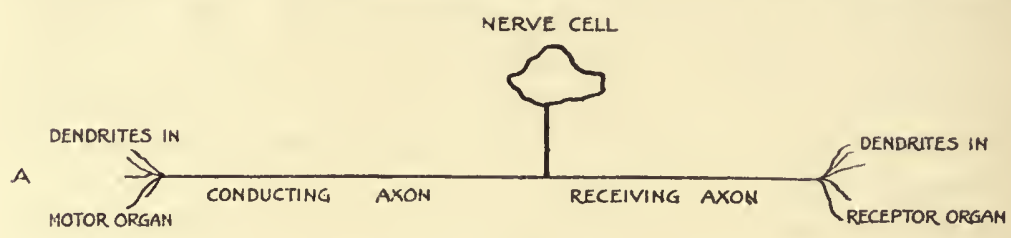

B

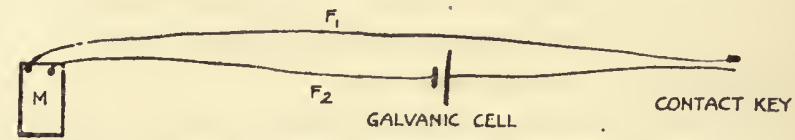

FIG. 33.-A. Diagram of a unit of the nervous system compared with $\mathbf{B}$.

B. Electrical Model to illustrate Müller's Law and the "All or Nothing" hypothesis as explained in the text.

on the nature of $\boldsymbol{M}$. If $\boldsymbol{M}$ is a telephone receiver, the closing of the key will cause a sound to be heard, if $\boldsymbol{M}$ is an incandescent globe, light will be seen, if $M$ is a motor, motion will result, and so on. The electrical energy of $C$ can thus be converted into any form of energy by an appropriate $\boldsymbol{M}$. Further, the magnitude of the force applied to the key makes no difference to the magnitude of the resulting manifestation at $\boldsymbol{M}$. That depends on the energy set free by the cell and on the resistance of the circuit.

Of course the receptor must be modified to suit different kinds of stimuli. A telegraph key or a bell push is a convenient kind of mechanism for closing a circuit mechanically, but it would not answer for electrical, thermal, sound or light vibrations. Special means for closing the circuit have to be devised to suit different kinds of stimuli. For example, sound waves may be caused to close an electrical circuit by microphone, e.g. telephone transmitter. 
The neuron may be likened to this eleetrieal model (Fig. 33A). $C$ is then the nerve cell, $F$ the process or nerve fibre, the key the reeeptor meehanism and $M$ the effeetor mechanism. A seeond eireuit of the nature of a telephone relay could be added to the first, $S$ bcing an electro-magnet which eloses the second eircuit when the key of the first is depressed (Fig. 34).

$S$ may be termed the synapse joining an effector and receptor neuron. The student will notice that there is no material continuity betwcen the two neurons and that no energy passes from one to the other.

4. "All or nothing." It is obvious in the eleetrieal model that eonnection is either made or not made. The energy available

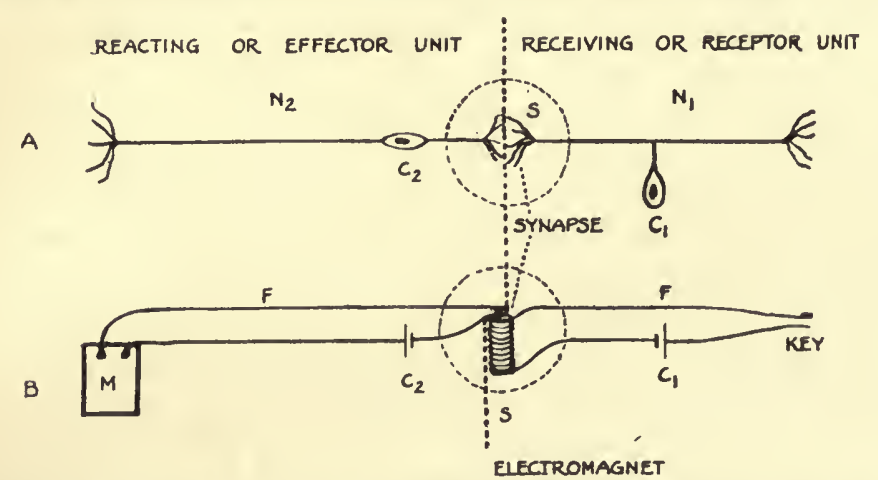

FIG. 34,-A. Diagram showing a receiving $\left(N_{1}\right)$ and a reacting Neuron $\left(N_{\sharp}\right)$, each with dendrites at its extremities, and their connection to one another through a Synapsis (S).

B. Flectrleal Model to illustrate the funetional continulty of two neurons. See text.

from $C_{1}$ is a fixed quantity independent of the energy used to close the eireuit, and similarly the energy in the system of whieh $C_{2}$ is the cell is independent of the energy used in the electromagnet $S$.

It is true also for the nervous system that the maximum motor effect is produced, if any effect is produced at all. It is a ease of " all or nothing." Nerves are, however, made up of several more or less parallel neurons, and some of these may be stimulated and some may not. As each nerve fibre activates one musele fibre and as each musele fibre responds to the activation by a maximal contraction, the result is that the extent of contraction depends on the number of musele fibres which shorten and which, in turn, depends on the number of nerve fibres implieated.

5. Temperature coefficient of the nervous impulse. When a length of nerve is cooled its power to eonduet an impulse is 
decreased; that is, nerve-conduction has a positive temperature coefficient. It was pointed out by Van't Hoff that the velocity of chemical reactions is increased twofold or more for each ten degrees in temperature, i.e. the temperature coefficient for chemical reactions is greater than 2 . On the other hand, the temperature coefficient for physical processes is less than 2 . The temperature coefficient (i.e. ratio of velocity of propagation of nervous impulse at $(T+10)^{\circ}$ to its rate at $\left.T^{\circ}=\frac{v \text { at } T+10^{\circ}}{v \text { at } T^{\circ}}\right)$ has been estimated by Lucas as approximately 1.8. This value has been proved to be right by later workers. Therefore, physical factors are involved in the propagation of a nervous impulse. This does not exclude chemical reactions but tends to show that the process is not purely chemical.

6. Decrement of the nervous impulse. If a length of nerve is cooled, not only does the velocity of the propagation of the impulse suffer diminution but there seems to be a diminution in the intensity of the impulse as well. If the degree of cold is sufficient, or if the length cooled is extensive, the impulse may be stopped entirely. If, however, any of the impulse is propagated through the cooled region into a normal piece of nerve it seems to recover its full intensity and velocity. Lucas compares this phenomenon to the transmission of fire along a fuse of gunpowder. If a section of the fuse is slightly damp, the rate of burning as well as the heat evolved will be decreased but will recover as soon as combustion starts on a dry section. Narcotisation of a nerve by ether, alcohol, cocaine or other drug has a similar effect to cooling.

7. Refractory period. The passage of a nervous impulse produces some change in the physico-chemical state of the nerve, so that it is followed by a state during which its function is depressed. A certain time must elapse between each nervous impulse. This spare time is called the refractory period, during which a stimulus will not receive normal treatment. The length of the period varies inversely as the temperature. The refractory period may be divided into three stages: (a) The absolutely refractory period when no strength of stimulus is effective. (b) During the relative refractory period the nerve is recovering and will respond to stimulus stronger than usual. (c) The supernormal stage follows during which subnormal stimuli are cffective. Two factors at least come into play to cause the refractory period, viz. alterations in excitability and alterations 
in conductivity. These two factors go hand-in-hand, i.e. the nerve is non-irritable and offers a resistance to the passage of the impulse sufficient to swamp it during the absolute refractory period; during the relative refractory period the nerve steadily recovers its irritability and its conducting power; while the last period is one of supernormal irritability and conduetivity.

8. Summation. If a second stimulus be applied to the nerve during the third refraetory period, it will give rise to an impulse which will meet with less resistance in its passage along the nerve. Now, if the first impulse be subminimal, i.e. insufficient to cause a manifestation of energy in the motor mechanism which the nerve supplies, then the second impulse if it be propagated along a nerve during the supernormal period may cause the motor endorgan to act. Such a phenomenon is called summation.

9. Fatigue. Nerve fibres can apparently act as conductors of the nervous impulses for very long periods without showing any signs of fatigue. It is generally said that nerves cannot be fatigued. While this is true of the conducting power of the fibre it is not applicable to the neuron as a whole. (1) The nerve cell loses something in the process. Granules which are apparent while the cell is at rest diminish slowly during activity. Then (2) changes take place at the synapses, the junction between neuron and neuron, and also at the "end plate" or junction between nerve fibre and organ. These potential junctions lose their power to cause the impulse of one neuron to act as stimulus to the next neuron or to the end organ. They become fatigued.

10. Metabolism. This leads one to infer that the energy exchanges during the conduction of impulses are small. The amount of oxygen used is negligible and it is doubtful whether a measurable amount of $\mathrm{CO}_{2}$ is produced. There is no doubt of the need for oxygen for the metabolic changes of the nerve cell, but the extra amount necessitated by the passage of a nervous impulse has not been estimated. It must be very small indeed. Ingenious methods have been devised by Waller and by Tashiro for the measurement of the $\mathrm{CO}_{2}$ evolved during activity, but so many uncontrolled sources of error enter into the experiment that many physiologists hesitate to accept their figures as representing the actual amount of oxidation undergone. One must bear in mind that an increased output of $\mathrm{CO}_{2}$ does not necessarily mean a simultaneous absorption of oxygen or a corresponding liberation of energy. The $\mathrm{CO}_{2}$ may be due to liberation of $\mathrm{CO}_{2}$ from solution in the surrounding tissue by the heat of the stimulus 
or from carbonates from the action of acids set frec electrolytically by cither the impulse or the stimulus.

Hill has found that when a nerve is placed in a carefully shielded thermopile, the registering galvanometer shows unaccountable fluctuations corresponding to temperature changes of the order of $7 \times 10^{-6}$ of a degree $C$. The passage of some 600 impulses docs not produce any larger variation. Therefore, the amount of heat produced must be less than this figure.

11. Electrical changes during conduction. Just as in muscle, so in nerve, an electrical wave accompanies the nervous impulse. The part excited becomes electro-negative to the rest (see Muscle, p. 143), and this negative wave passes along the nerve in the direction of and at the same ratc as the nervous impulse. It is followed by an electro-positive wave of greater potential. The combined electrical changes are thus said to be diphasic. The electrical wave complex must not be confused with the nervous impulse. In other words the nervous impulse is not electrical in nature but produces localised differences of potential in nerve as it passes. The rate of conduction of an electrical impulse along frog's nerve is about 300 metres per second, while the nervous impulse travels at about 30 metres per second.

12. Electrical changes during stimulation. This wave of negativity is the current of action (or of injury) of the nerve. It may be made manifest as indicated in Fig. 35, by rapidly

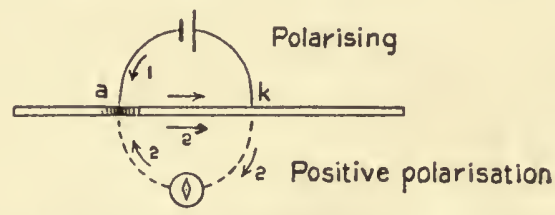

Fio, 35.-Diagram to show direction of the positive polarisation current, due to a break excitation at the anode.

connecting anodal and cathodal parts of a nerve through a galvanometer. If a stimulating current is passed through a section of a nerve so that $a$ is the positive electrode and $k$ is the negative electrode, then on breaking the circuit and connecting $a$ and $k$ through a galvanometer (circuit 2), it will be obvious that a current flows momentarily along the nerve from $a$ to $k$, i.e. in the same direction as the previous stimulating current. This is sometimes termed a positive polarisation current.

Under certain conditions it is possible to observe an electrical change in the opposite direction after cessation of the stimulus 
(Fig. 36). Nerve consists of a conducting core of electrolytes and eolloids surrounded by a sheath enelosing electrolytes and colloids. The passage of a constant current through this mass gives rise to certain physico-chemical changes in core and in

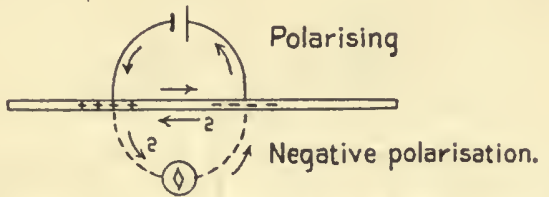

FIG 36.-Diagram to show direction of the negative polarisation current.

sheath. These electrolytic and polarisation changes set up a current which tends to restore equilibrium (back E.M.F.). This is negative polarisation.

The changes that take place may be studied conveniently by means of a model (Fig. 37). A platinum wire, forming a con-

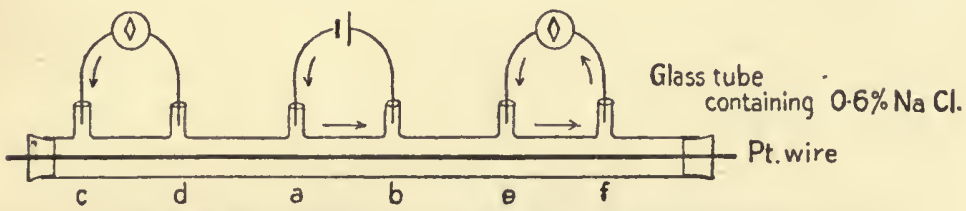

FIG. 37.-Apparatus for imitating the polarisation phenomena in medullated nerve.

ducting core, runs inside a glass tube filled with cotton wool soaked in $0 \cdot 6$ per cent. sodium chloride solution.

The points $a$ and $b$ are connected to a battery and the extrapolar points $c$ and $d, e$ and $f$ are led off to galvanometers. On the passage of a current from $a$ to $b$ it is found that an extra-polar

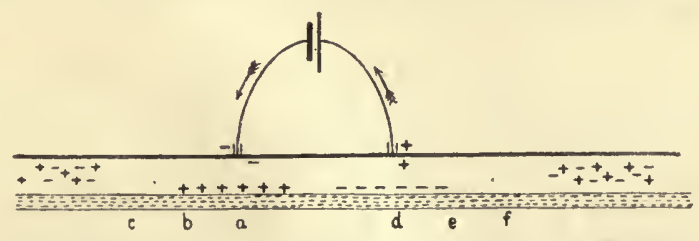

Fig. 38.-Diagram to show polarisation at the surface between conducting core and electroiyte sheath.

current is flowing from $c$ to $d$ and from $e$ to $f$ (cf. Fig. 40). The cause of these extra-polar or, as Du Bois-Reymond called them, electrotonic currents, is to be.sought in the movements of the dissociated salts in the sheath. Opposite the anode (Fig. 38), the positive ions are concentrated on the surface of the core. This causes opposition to the passage of the primary current and 
also sets up currents in the electrolytic fluid (Fig. 39) from $a$ to $b$, $b$ to $c$, ete. These eurrents are indicated by the galvanometers.

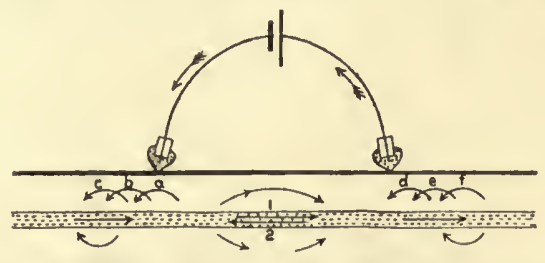

FIG. 39.-Diagram to Ishow polarisation currents in a medullated nerve or in a polarisation model.

Emphasis must be plaeed on the faet that these electrotonie eurrents are absolutely distinct from the nerve impulse as well as from the wave of negativity or current of action and the eurrent of injury. (a) The former have a much greater velocity than the nerve impulse, as indieated by the wave of negativity

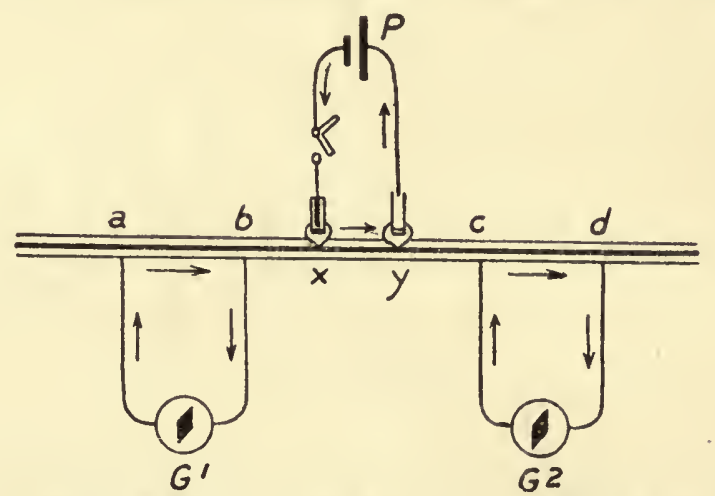

FrG. 40.-Diagram showing electrotonic eurrents. $P$, polarising circuit; $G^{1}, G^{2}$, galvanometers.

(see 11 above). ( $\beta$ ) Their E.M.F. may attain a value twenty-five times that of the eurrent of injury. $(\gamma)$ The direetion in which eleetrotonie currents flow depends entirely on the direction in whieh the primary eurrent is flowing, reversion of the latter leading to reversion of the former. Action and injury eurrents always maintain a flow in the nerve from a stimulated or injured part to a resting or uninjured portion of the nerve. 


\title{
CHAPTER XVIII
}

\section{OU'TPOSTS OF THE INTELLIGENCE SERVICE}

\author{
(a) GENERAL AND INTRA-COMMUNAL RECEPTORS
}

"By mine eye, I do not know that I see, or by mine ear that I hear, but by my common sense who judgeth of sound and colours."

Burton.

The Cabinet which controls a nation has to set up machinery to provide itself with two different kinds of intelligence. First it needs to know how its orders are being earried out by the civilian population as well as by the military. The internal or interoceptive intelligence staff is distributed among the factory workers, along lines of transport and in the various effective units of the army. Their duty is to report on the conditions in their sector. Before a shortage of raw material has become so marked as to cause an outery from, or mayhap, a strike of some part of the population, the outposts of the intelligence staff should have their report " on the wires." Very little is known of how this work is carried out. It is mere guesswork to say that slight alterations in the physico-chemical condition of the material surrounding a nerve-ending is sufficient to cause stimulation of the nerve. The other intelligence staff operates on matters outside the organism. They are exteroceptors.

Sherrington divides interoceptors into two groups:

1. General, which have to do with sensations of hunger or thirst, nausea, respiratory and circulatory sensations, sexual sensations, visceral pain, etc.

2. Special consists of end organs for taste and smell. These are distinctly chemical in their actions and are the chief exteroceptors in many animals (see later).

To these fall to be added a group with a double function :

3. The somatic proprioceptors, which are situated in the muscles, tendons and joints, and are concerned with the production of the muscle sense. To this group also belong the organs which have to do with the sensations of equilibrium. Not only have 
the proprioceptors to report on work done but it is obvious that they have to form some opinion of the relation of the organ to its environment. They thus have a function closely allied to that of the true exteroceptors which are stimulated under ordinary conditions by forces outside the organism.

It is a good thing to bring in the aid of comparative physiology when about to study a fresh group of organs. One may then see how various modifications arise and how the simple undifferentiated cell becomes specialised and fitted to act as a receptor for one particular form of external energy. Time and space do not permit such a digression here, but the student would do well before reading further to revise his knowledge of the comparative zoology of the sense organs.

The sense organs or receptors may be considered as points of least resistance, gateways through which the manifestations of external forces may reach the internal structures. They are much more than that. 'They are specialised outposts of an intelligence service which pick up minute alterations in the energycomplex of the environment, make a rapid but incomplete analysis of these changes, and send in a report to departmental headquarters for complete analysis and transmission to headquarters.

Only by specialisation can efficiency be obtained. The organism is subject to stimulation from various forms of energy which may be classified into vibratory and chemical.

\section{A. Vibratory Energy.}

1. Mechanical impacts received by the tactile corpuscles of the skin. They may be perceived as separate stimuli even when they arrive as rapidly as $\mathbf{1 5 5 2}$ per second.

2. Slow vibrations especially in air are received by the ear. The human ear may be stimulated by vibrations ranging from 16 to 40,000 per second. Practice may extend this range.

3. Rapid vibrations in ether.

(a) Radiant heat. Vibrations with a frequency of between 3 billions and 400 billions per second stimulate the temperature receptors of the skin.

(b) Light. The retina is capable of receiving as light, ether waves, the frequency of which varies between about 400 billions and 800 billions per second.

\section{B. Chemical Energy.}

The various chemical stimuli to which the organ is exposed, have receptors in the skin, giving rise to sensations of pain or 
discomfort, and in the special end organs to those of taste and smell.

The function of the receptors is to receive that form of energy for which they are fitted and to transform that energy into nervous cnergy. We have previously shown that any one form of energy can be transformed into any other form. It has been found convenient, for instance, to calculate all forms of energy manifestations found in the body in heat units - calories. Nervous energy may be electrical energy. It can readily be demonstrated that any form of energy can be converted into the electrical form.

As receptors for these various manifestations of energy we have the so-called five senses. That is, five different means are employed for the purpose of orientation, viz. touch, hearing, sight, smell and taste. These senses come into contact with the external forces through the skin, ear, eye, nose and tongue. But some of these are composite end-organs. The skin, for instance, includes not only touch corpuscles but the end-organs for pain and temperature. The ear not only analyses sounds but contains organs for the static and dynamic senses. In all there are over twenty different kinds of receptors and sense-organs in the body.

Specific irritability. In the preceding chapter we have alluded to Müller's law of specific irritability, and an electrical model was discussed as illustrative of this idea. A very little consideration suffices to show $(\alpha)$ that the same physical stimulus applicd to various receptors will give rise to absolutely different sensations and $(\beta)$ that different physical stimuli applied to the same end-organ, if they arouse any response at all, give rise to the specific sensation of that organ or to pain.

Stimulus and Sensation. Each receptor has a certain functional incrtia and will not respond to stimulation until the energy of the stimulus has reached a minimal value which is specific for cach receptor and for each form of stimulus. This threshold value is lowest, as has been said above, for the form of stimulation specific for that organ. Once this value is gained, the resulting sensation bears a definitc relationship to the incident stimulus until an upper limiting value has been reached, after which increase of stimulation is of no avail. In fact, fatigue rapidly sets in, and the resulting sensation is sub-maximal (Fig. 41).

Touch is the sense by which mechanical force is appreciated Mere contact is gentle pressure, a greater amount of applied force causes a feeling of resistance referred to the skin, a still greatcr 
amount evokes a response from receptors in the muscle, while pain results from great pressure. The total number of tactile corpuscles (excluding those on the head) has bcen estimatcd as 500,000 . These are not evenly distributed over the skin but are more numerous and more sensitive on certain of the more mobile parts of the body, e.g. tongue and fingcrs. The degree of sensitiveness of the skin may be determined by some form of aesthesiometcr

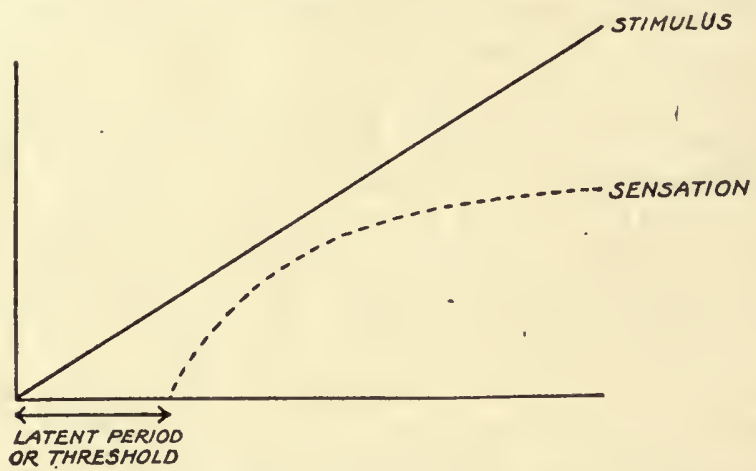

FIG. 41.-Diagram to show relationship between stimulus and sensation.

(say a pair of compasses) by means of which one may measure the smallest distance at which impress of the two points may be perceived as two distinct sensations. The following table gives the activity of the discriminating sense for different parts of the skin :

\section{TABLE XXIX.}

Tip of the tongue - $\quad$ - $\quad$ - $\quad$ - $\quad$ - $1 \cdot 1$

Third phalanx of finger, volar surface - $\quad-\quad-2-2 \cdot 3$

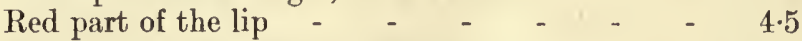

Second phalanx of finger, volar surface $\quad$ - $\quad 4-4.5$

First phalanx of finger, volar surface - $\quad$ - $\quad 5-5 \cdot 5$

Third phalanx of finger, dorsal surface - - $\quad$ - 6.8

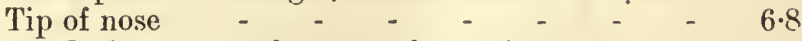

Head of metacarpal bone, volar surface - $\quad$ - 5-6.8

Ball of thumb - $\quad$ - $\quad$ - $\quad$ - $\quad$ - $\quad$ - $\quad$ - $6-5 \cdot 7$

Ball of little finger - $\quad$ - $\quad$ - $\quad$ - $\quad$ - $\quad$ - $5 \cdot 5-6$

Centre of palm - $\quad$ - $\quad$ - $\quad$ - $\quad$ - 8-9

Dorsum and side of tongue ; white of lips ; metacarpal part of the thumb $\quad-\quad-\quad-\quad-9$

Third phalanx of the great toe, plantar surface - $11 \cdot 3$

Second phalanx of the fingers, dorsal surface - $11 \cdot 3$

Back - - $\quad$ - $\quad$ - $\quad$ - $\quad$ - $\quad$ - $\quad$ - $11 \cdot 3$

Eyelid - $\quad$ - $\quad$ - $\quad$ - $\quad$ - $\quad$ - $\quad$ - 11.3

Centre of hard palate - $\quad$ - $\quad$ - $\quad$ - $\quad$ - $\quad$ - 13.5 
Lower third of the forearm, volar surface Millimetres.

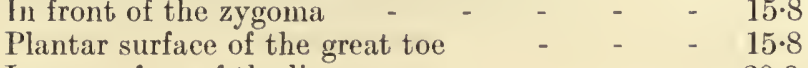

Inner surface of the lip - $\quad$ - $\quad$ - $\quad$ - $20 \cdot 3$

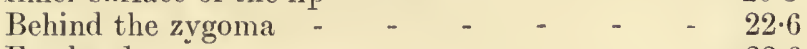

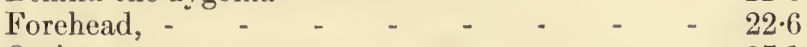

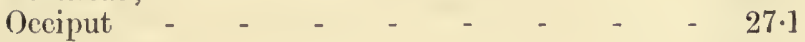

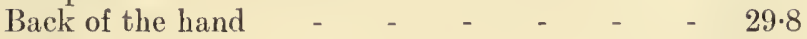

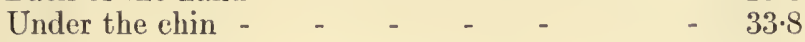

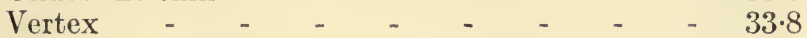

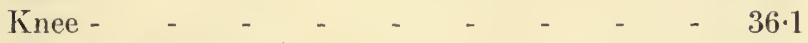

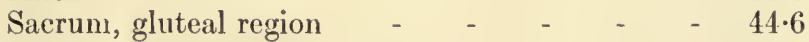

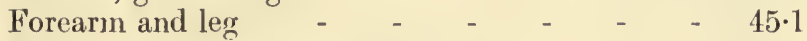

Neck - - - - - - $\quad$ - $\quad$ - $\quad$ - $54 \cdot 1$

Back of the fifth dorsal vertebra; lower dorsal and lumbar region - $\quad$ - $\quad$ - $\quad$ - $\quad$ - $54 \cdot 1$

Upper arm ; thigh ; centre of back - - $\quad$ - 67.7

Middle of the neek - $\quad$ - $\quad$ - $\quad$ - $\quad$ - 67.7

The intensity of the contact sensation is increased in a mechanieal way by the presenee of hairs, because they act as levers on the tactile corpuscles. The whiskers of the cat render the touch points of the jaw very sensitive in this way, being able to detect even sliglit air currents.

Absolute sensitiveness as indicated by a sense of pressure is generally determined by finding a minimum pressure necessary to evoke a minimal sensation. Below is given the weight in grams which could just be detected when placed on various parts of the skin. The values given are normal values ('Iable XXX.). Practice may increase the diseriminating point. Every one knows how a blind man "sees" with his fingers.

\section{TABLE XXX.}

\begin{tabular}{|c|c|c|c|c|c|c|c|}
\hline Tongue and nose & - & - & - & - & - & - & 2 \\
\hline Lips - - - & - & - & - & - & - & . & 2 \\
\hline Finger-tip and forehe & $\mathrm{ad}$ & - & - & - & - & - & 3 \\
\hline Back of the finger & - & - & - & - & - & - & 5 \\
\hline Palm of the hand, ar & in a & tl & & - & - & - & 7 \\
\hline Forearm - - & - & - & - & - & - & - & 8 \\
\hline Rack of the hand & - & - & - & . & - & - & 12 \\
\hline Back of the leg and s & hot & & - & - & - & - & 16 \\
\hline Abdomen - - & - & - & - & - & - & - & 26 \\
\hline Sole of the feet & - & - & - & - & - & - & 28 \\
\hline Back of the forearm & - & - & - & - & - & - & 33 \\
\hline Gluteal region - & - & - & - & - & - & - & 48 \\
\hline
\end{tabular}

In a similar way one could map out the hot and cold spots and the pain spots in the skin. They vary in distribution but not in 
the same order as the pressure spots. For example, the minimum perceptible difference of temperature in degrees centigrade is given in the sueeeeding list for various regions :

\section{TABLE XXXI.}

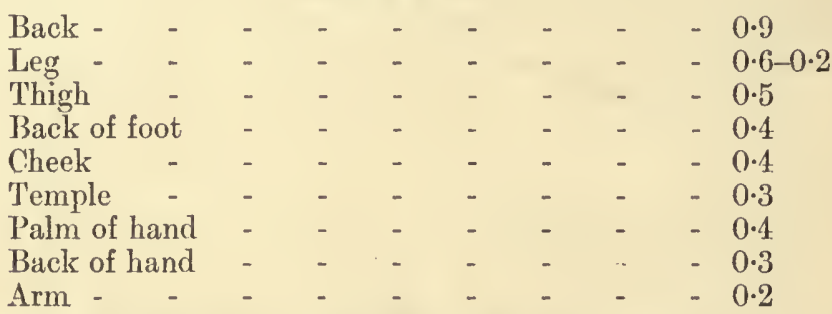

Taste and smell are the chemical senses (partly ehemieal and partly physical) and are closely allied to touch. To stimulatc the end organs of chemical sense, the substance must be in a fine state of division and capable of going into solution in the fluid on the superficies of the sense organ. In spite of much research, little more can be added to this brief statement. Of the two senses, taste is the more limited as well as the less useful. Four kinds of taste may be discriminated, viz. sweet, salt, acid and bitter. Flavours are odours and really give rise to an olfactory sensation. Smell is the ancestral chemical sense and may be classed, especially in the lower animals, as a distanee receptor. In civilised man, this sense, unless rendered acute by training, is merely vestigial.

The areas of nasal mueosa associated with this perceptive mechanism, are small reetangular strips in the upper part of eaeh nasal eavity, just above the superior turbinate bone. In ordinary respiration, air does not pass directly over the olfaetory mucous membrane, but some air diffuses backways through the posterior nares (Fig. 42). This is important for the preservation of the sense. The receptor neurons have retained their primitive condition of cell body in the epithelium itself (Parker). They are rapidly fatigued and readily destroyed. Now, by their situation in a backwater they do not eome directly into contact with high concentrations of odoriferous substanees and, furthermore, air attains body temperature and moisture and is freed from suspended particles (dust, baeteria, etc.) before reaching the sensory surfaee. The physical details of the mechanism for the perception of smell, that is, for the conversion of chemical into nervous energy, have not yet been brought to light. The sense is extraordinarily delicate. Mereaptan, in as low a concentration as 0.0000000004 
gram per litre of air, can be detected. Training renders the sense more acute. The working chemist relies on his sense of smell to a great extent to help him in the identification of compounds. The tea blender and the wine expert can detect very slight differences in "flavour."

It is worth while noticing that receptors all depend for stimulation on the existence of an alteration in external energy. This

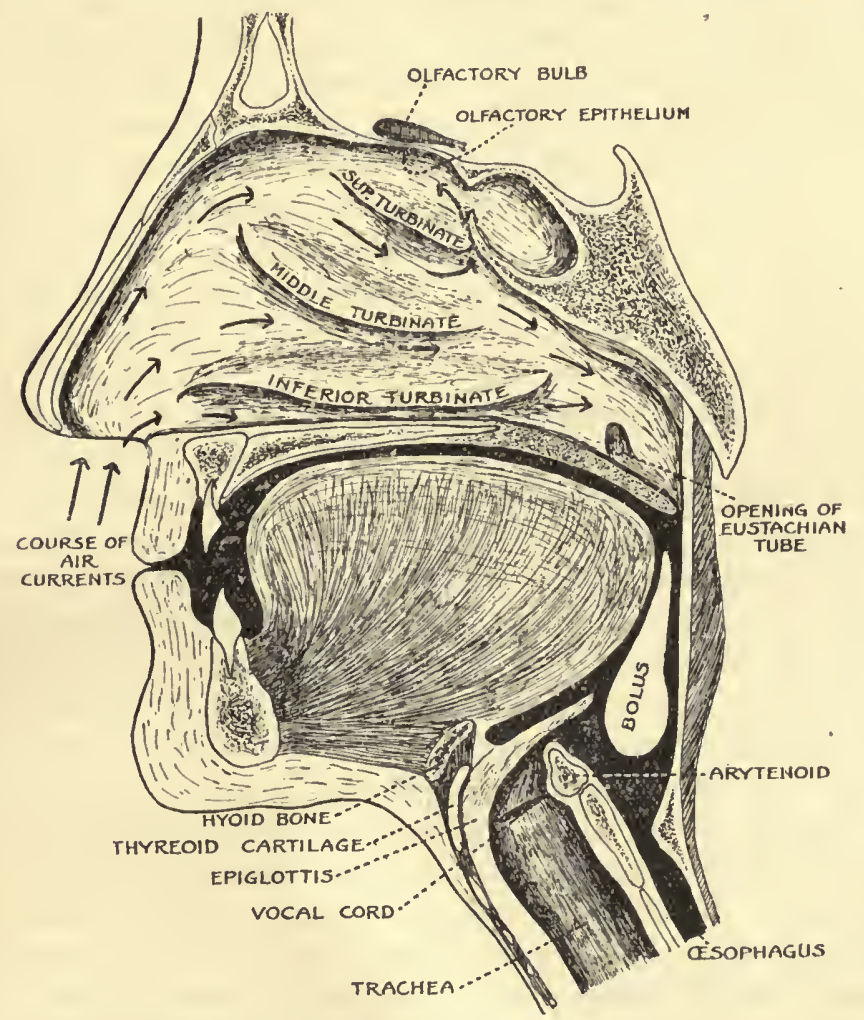

FiG. 42.-Antero-posterior section throngh nasal fossae, month and neck. The arrows show the direetion of the air currents during inspiration.

is specially marked in the case of this ancestral chemical sense. Our accustomed environment presents no stimulus. Air has no smell and water no taste. The introduction of a trace of foreign body alters the energy content of the environment and stimulation follows. It is a common experience to find that people do not experience sensations that have, for the time being, become permanent in their environment. A room may be stuffy to an incomer but quite comfortable to the tenants. 'The physiological 
chcmist works in an atmosphere which causes his visitor to choke and splutter, but the introduction of a new odour, say ammonia, is at onec perceived and produces instant action.

Hunger is a sensation which must be regarded as primitive and basal. It is not our business to analyse the feelings of hunger, but to consider the mechanism by which the lack of nourishment is signalled to consciousness. The evolution of knowledge of this sensation is largely due to Prof. Cannon, whose book on the subject should be read by every student. There can be no doubt that the fceling of hunger is closcly allied to pain.

"The sensation of hunger is difficult to describe, but almost cveryonc from childhood has felt that dull ache or gnawing referred to the lower mid-chest region or epigastrium, which takes imperious control of human actions. As Stcrnberg has pointed out, hunger mày be suffieiently insistent to force the taking of food which is so distasteful that it not only fails to rouse appetite but may even produce nausea. The hungry being gulps his food with a rush. The pleasures of appetite are not for him-he wants quantity rather than quality, and he wants it at once.

Hunger may be described as having a central core and certain more or less variable accessorics. The peculiar dull ache of hungriness referred to the epigastrium is usually the organism's first strong demand for food; and when the initial order is not obcyed, the sensation is likely to grow into a highly uncomfortable pain or gnawing, less definitely localised as it becomes more intensc. This may be regarded as the essential feature of hunger. Besides the dull ache, however, lassitude and drowsiness may appear, or faintness, or violent headache, or irritability and restlessness such that continuous effort in ordinary affairs becomes inercasingly difficult. That these states differ much with individuals-headache in one and faintness in another, for, example-indicates that they do not indicate the central fact of hunger, but are more or less inconstant accompaniments. The ' feeling of emptiness,' which has been mentioned as an important elcment of the experience, is an inference rather than a distinet datum of consciousness and can likewisc be eliminated from further consideration. The dull pressing sensation is left, therefore, as the eonstant characteristic, the central fact to be examined in detail" (Cannon).

Cannon and his colleagues have definitely proved that the sensation of hunger is caused by strong contractions of parts of the alimentary eanal. As we shall see latcr when dealing with 
transport (Chap. XXVII.), there arc certain definite movements of the alimentary canal designated as peristaltic associated with the forward transference of the contents of the canal. In the absence of any content other than gaseous, the cavities of the stomach, lower oesophagus and upper intestinal region, at least, are almost obliterated. This wave of contraction precedes the sensation of hunger and may be regarded as the cause of it. Carlson and his students, who were fortunate in having a subject with a permanent gastric fistula, have confirmed Cannon's work and carried it further. They have shown that the local contraction is a sign of a general state. According to Carlson and Luckhardt the blood of a fasting animal, if injected into the vein of a normal animal, is capable of producing in the latter, contraction of the gastric muscles, an effect which does not occur when the blood of a well-fed animal is injected.

The significance of this phenomenon is plain. In Cannon's words :

"The very condition which causes hunger and leads to the taking of food is the condition, when the swallowed food stretches the shortened muscles, for immediate starting of gastric peristalsis. In this connection, the observations of Haudek and Stigler are probably significant. They found that the stomach discharges its contents more rapidly if food is eaten in hunger than if not so eaten. Hunger, in other words, is normally the signal that the stomach is contracted for action ; the unpleasantness of hunger leads to eating, eating starts gastric digestion and abolishes the sensation. Meanwhile the pancreatic and intestinal juices as well as bile have been prepared in the duodenum to receive the oncoming chyme. The periodic activity of the alimentary canal in fasting, therefore, is not solely the source of hunger pangs, but is at the same time an exhibition in the digestive organs of readiness for prompt attack on the food swallowed by the hungry animal." 


\title{
CHAPTER XIX
}

\section{OUTPOSTS OF THE INTELLIGENCE SERVICE}

\author{
(b) DISTANCE RECEPTOR FOR SOUND
}

THE EAR

\begin{abstract}
"A elue to the structure of a machine lies in the discovery of the purpose for which it was designed and the manner in which its various parts are co-ordinated to seeure that end. That is eminently true of the ear." KErTir.
\end{abstract}

THE ear is a modified touch receptor. In the lower invertebrates it consists of hair-like appendages, either on the frce surface or in a depression, more or less protected. In the higher vertebrates it is a much more complicated structure. The human ear may be considered as composed of three structural elements, viz.:

External ear-collector and conductor of sound to the middle car. Middle ear-converter of air vibrations to a to-and-fro move. ment of a piston-like lever and the accentuation of these movements.

Part of internal ear-transformer of mechanical pressure, via hydraulic pressure, into nervous energy.

1. External ear. The structure of this presents no outstanding points of physical interest. It consists of the pinna and the external acoustic meatus at the end of which is the membrana tympani or eardrum (Fig. 43).

(a) The pinna is a flattened horn presenting irregularities of surface. If these undulations are filled in with wax or if the pinna is awanting, the quality of sounds is altered and difficulty in localising sound is increased. This may be due to a differential reflection of tones by the pinna, e.g. it may reflect a fundamental tone more strongly than the partial or vice-versa.

(b) The external acoustic meatus is a curved tube about 21-26 $\mathrm{mm}$. long. Its function is two-fold. (i) On account of its shape, secretion, and hairs (at orifice) it protects the delicate tympanic membrane from draughts and dust, and from the incursion of 
inseets. This is its main function. (ii) The sound waves are conducted by reflection from the walls without loss of intensity, and directed almost perpendieularly on to the drum whieh lies at an angle of $150^{\circ}$ to the axis of the canal.

2. Middle ear. The mechanism found in the middle ear converts vibrations in air into vibrations in fluid by means of membranes and a series of levers. It consists of an air-filled cavity hollowed out of the petrous part of the temporal bone. It is separated from the external ear by the tympanic membrane, and

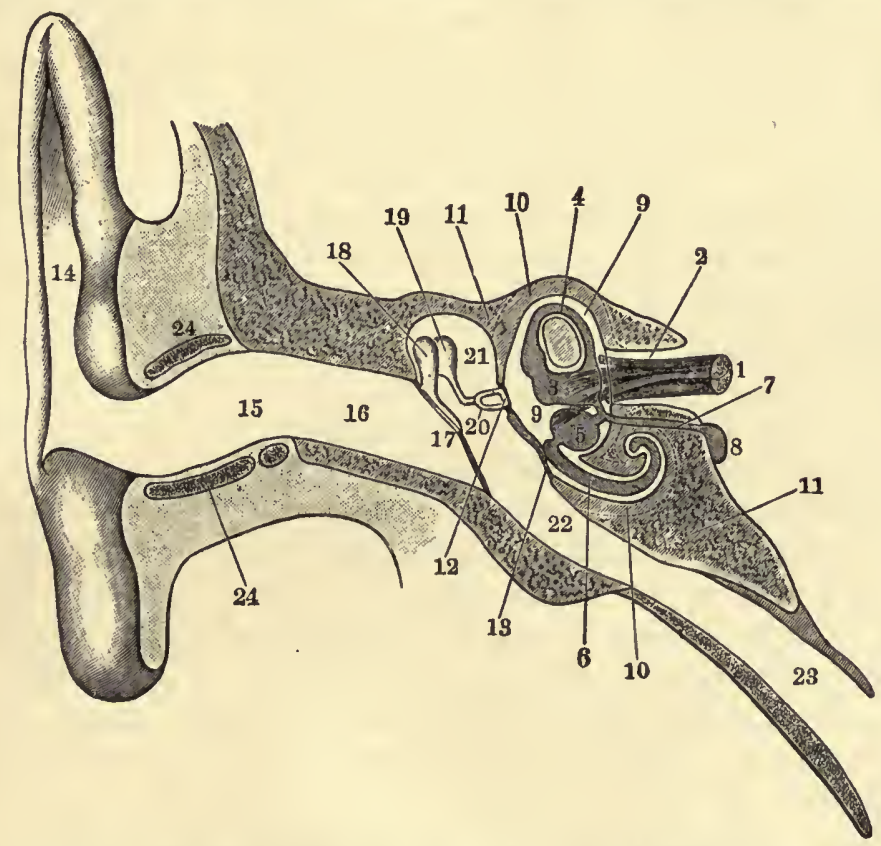

FIG. 43.-Diagrammatic view of auditory organ. (After Schafer.)

1, Aconstic nerve; 2 internal acoustic meatus; 6 , canalis media of cochlea: 9 , vestibule contalning lympl ; 12 , stapes ; 13, fenestra cochleae (rotunda); 19 , incus; 18, malleus; 17, meinbrana tympani ; 16, external aconstic meatus ; 14 , auricle or pinna; 23, Eustachian or auditory tubc.

from the internal ear by the membrane closing the round window and by a disc of bone- the foot of the stapes, which along with the membranous collar surrounding this bone makes a fluid-tight packing or gland filling the fenestra ovalis, the oval opening into the internal ear. Between the drum and the stapes lie two bony levers-the malleus and the incus.

(a) Membrana tympani. This structure is fixed in a frame of bone which is almost cireular (vertical diameter $10 \mathrm{~mm}$. ; horizontal diameter $8.5 \mathrm{~mm}$.). Although it is not more than $\mathbf{0 . 1} \mathrm{mm}$. 
thick, it is constructed of three layers. On the outer surface there is a layer of epithclium protecting the membrane proper which is of fibrous tissuc and is covered on the inner side by a layer of mucous membrane. The fibres of the fibrous layer are arranged partly circularly and partly radially-the circular fibres being most marked near the rim. To the inner surface is attached the handle of the malleus, the first of the chain of three auditory ossicles. This attachment to the malleus, which is pulled inwards by the tensor tympani muscle, gives the tympanic membrane the form of an eccentric funnel opening outwards. The membrane is highly elastic and responds very readily to very slight variations in the pressure of the air waves cntering the external ear. The peculiar form of the membrane contributes to its value as a sound transmitter. In the first place, it acts synkinetically, i.e. moves passively with the vibrations of the sound-waves. It begins and ends its vibrations synchronously with the impact of the sound vibrations. There is no latent period, no waiting for a summation of impulses before it can get into its swing, having no swing to get into. It does not continue to vibrate after the sound vibrations have ceased. It is dead-beat. Further, it does not vibrate sympathetically to any special overtone present in a compound tone reaching the ear. This is brought about by (i) the damping effect of attachment to the ossicles and (ii) by the dragging inwards at the point of attachment (umbilicus). On this account the fibres vary in tension as well as in length, so endowing each bit of the membrane with a different period of vibration resulting, in toto, in an aperiodic membrane. It is obvious that such a property is valuable in rendering hearing distinct. In the second place the arched sides of the membrane act as a lever of the 1st class.

"As the outward curvature of the radial fibres is slight, each fibre may be regarded as the long arm of a lever, while the handle of the hammer is the short arm. This mechanism secures that a slight pressure of the air corresponding to a sound wave, exerts a considerable force upon the malleus. To aid in understanding the mechanism, it will be easier to consider, first, the effect of pressure upon a single radial fibre. The fibre may be regarded as inextensible and slightly curved outwards; hence variations in pressure on the convexity of the curve will cause the degrce of curvature to change, while the length of the are will remain the same.

In other words, the radius of the arc and the chord of the arc will change, while the length of the arc remains constant. But 
the length of the are may be regarded as the length of a radial fibre; henee

$$
l=2 r \sin ^{-1}\left(\frac{\lambda}{2 r}\right)
$$

where $l=$ length of fibre, $r$ radius of the eirele of eurvature, and $\lambda$ ehord of the are $l$, beeause $\frac{\lambda}{2 r}$ is the sine of half the angle at the eentre belonging to the arc $l$. This equation may also be written

$$
\lambda=2 r \sin \left(\frac{l}{2 r}\right) \text {. }
$$

Now, if we subtract the (each side) from $l$, we have

$$
l-\lambda=2 r\left\{\frac{l}{2 r}-\sin \left(\frac{l}{2 r}\right)\right\},
$$

which gives the difference between the ehord of the are and the eurve. But as the eurve is very slight, $r$ is large in eomparison with $l$ and the divisions become rapidly very small as the sine in the formula is developed by the involution of its are. Henee

$$
\sin \frac{l}{2 r}=\frac{l}{2 r}-\frac{1}{6}\left(\frac{l}{2 r}\right)^{3}
$$

and from this the preceding equation becomes

$$
l-\lambda=\frac{1}{24} \frac{l^{3}}{r^{2}}
$$

Again, let $s$ be the distance of the eentre of the are from the eentre of the ehord. Then the degree of eurvature is found by the equation

$$
\frac{r-s}{r}=\cos \frac{l}{2 r}
$$

so that

$$
\begin{aligned}
s & =r-r \cos \frac{l}{2 r} \\
& =r\left(1-\cos \frac{l}{2 r}\right) .
\end{aligned}
$$

Sinee $\quad \cos \frac{l}{2 r}=1-\frac{1}{2}\left(\frac{l}{2 r}\right)^{2}$ approx.,

we have

$$
s=r\left[1-\left\{1-\frac{1}{2}\left(\frac{l}{2 r}\right)^{2}\right\}\right],
$$

that is

$$
s=\frac{1}{8} \frac{l^{2}}{r} .
$$


Now, eliminate $r$ from equations (1) and (2), and we obtain

$$
l-\lambda=\frac{8}{3} \frac{s^{2}}{l} \text {. }
$$

This equation gives the amount of shortening of the chord which occurs when the eurve of the are is increased; that is to say, it gives the extent to which the two ends of the fibre are drawn together. Now, if $s$, the displacement of the middle of the fibre, be very small in comparison with $l$, then $l-\lambda$ obviously becomes very small in comparison with $s$. Conversely, the very small increase in the magnitude of $l-\lambda$ must cause a relatively great increase of $s$; that is to say, it must cause a relatively great displacement of the centre of the fibre.

Again, if $t=$ the tension of the fibre, $p=$ the pressure on each unit of its length, and $r=$ the radius of curvature, then

$$
t=p r
$$

and the forces which act upon both ends of the fibre must be equal to the pressure which acts upon the diameter of the semieircle through a width equal to that of the fibre (Helmholtz). Therefore

$$
2 t=2 p r .
$$

Hence the greater the radius of curvature, the greater will be the alterations in tension of the fibre caused by alterations in the pressure of the air. Further, as the radial fibres are those which are attached to the malleus, it is evident that the variations in the tension of the fibres cause movements of the bones when sound-waves strike the drum-head. Thus a very small change of pressure in the air causes a considerable change in the tension of the fibres; and further, in aceordance with the laws regulating the action of the lever, as the force which fibres exert upon the handle of the malleus increases, amplitude of movement of that bone diminishes. In this way, the special form of the drum-head secures a maximum of efficiency for tones of the feeblest intensity" (M'Kendriek).

Briefly, energy applicd to the mombrane is passed on to the handle of the malleus' diminished in amplitude but with increased intensity.

(b) Ossicles. The three bones of the middle ear,- the malleus, the incus and the stapes, - stretch across the tympanic cavity forming an articulated chain of levers, so that cvery normal movement of the tympanic membrane is transmitted by the stapes to 
the fluid of the internal ear. The Malleus, or hammer, is about 18-19 $\mathrm{mm}$. long, and has an average weight of $23 \mathrm{mgms}$. It consists of a thickened rounded head and a long handle-the manubrium, which is attached to the tympanic membrane, the tip of the handle reaching the umbilicus. Near the insertion of the head and handle rises a bony proeess-the processus gracilis or processus Folianus, which projects forward and is continued by a ligament, the anterior ligament by means of which the hammer is anehored to the wall of the tympanum. There is also a shorter protuberance, the processus brevis, which presses against the edge of the upper surface of the drum. Three other ligaments are attached to the malleus, the external ligament, binding it to the

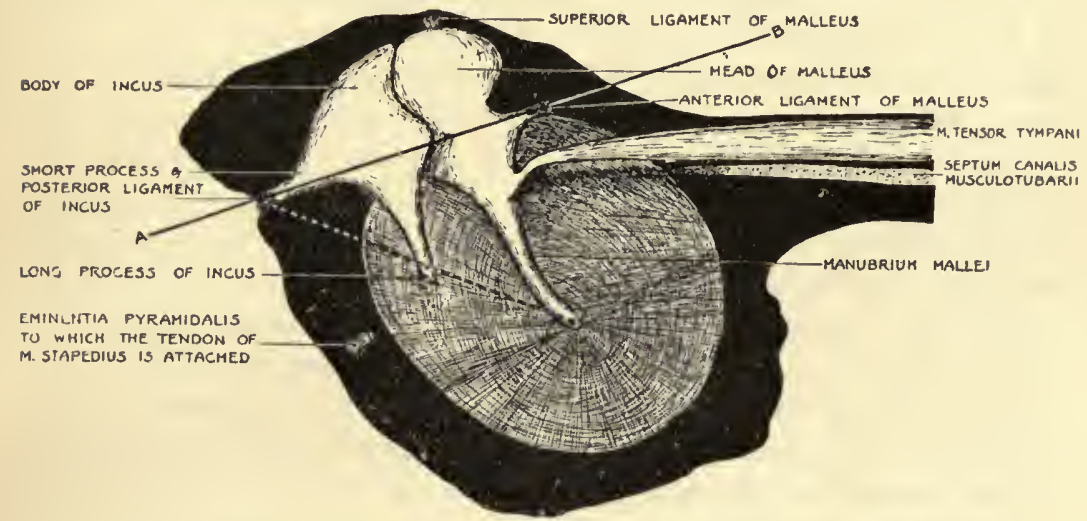

FiG. 44.-Dlagram of the left Membrana Tympani and Chain of Tympanic Ossicles scen from the medial aspect:

The line $A-B$ is the axis of rotation of the malleus and incus. The dotted line represents the line of leverage applied from the handle of the malleus to the posterior ligament of the incus. The stapes lies almost at right angles to the plane of the paper.

external face of the tympanic cavity, the superior or suspensory ligament, attaching the top of the head to the roof of the cavity, and the posterior ligament. These ligaments prevent the malleus from rotating in any other axis than a horizontal one whose line passes through the head of the malleus and the anterior ligament (Fig. 44). The posterior surface of the head of the hammer fits into the saddle-like hollow in the anterior surface of the body of the anvil-bone or incus. This is a larger bone than the malleus, weighing on the average $\mathbf{2 5} \mathrm{mgms}$. The body of the incus is drawn out on its posterior side to a proeess-the short process, which is attaehed by a ligament to the posterior wall of the tympanic cavity, forming one end of the malleo-ineal axis mentioned above. Almost at right angles to the short proeess, the inferior surfaee of 
the incus tapers down to the knob-like os orbiculare, forming the long proeess.

The os orbiculare articulates with the knob on the top of the stirrup bone or stapes. This bone, a flattened stirrup areh, weighing only about $3 \mathrm{mgs}$., is set almost at right angles to the long process of the incus. Its oval footplate is attached to the margin of the fenestra ovalis by a short stiff membrane, the annular ligament.

\section{Muscles of middle ear.}

Two slender muscles are attached to the ossicles :

(i) The stapedius is inserted into the knob at the head of the stapes and is attached to the posterior wall of the tympanie cavity.

(ii) The tensor tympani arises from the inner wall of the eavity, passes outwards and upwards above the Eustachian tube, to be inserted in the upper part of the handle of the malleus.

\section{Function of the muscles.}

The tensor, on eontraction, draws the handle of the malleus inwards, and so, as its name implies, increases the tension on the tympanic membrane. This decreases the natural period of vibration of the drum, and this makes it more sensitive to high tones, and better fitted to adjust its vibrations to rapid ehanges of phase. Paralysis of this musele impairs hearing.

The stapedius prevents the footplate of the stapes from having purely a piston-like action in the fenestra ovalis. Its line of traction (Fig. 44), which is almost parallel to the long axis of the oval window, eauses the footplate to move on the posterior annular ligament as on a hinge. Contraction of this muscle thus draws the anterior end of the footplate outwards.

These two muscles are therefore antagonistic; simultaneous eontraction balances the ossicles and regulates the degree to which the perilymph of the internal ear is displaced. Further, the tension of the two museles prevents a slack engagement between the ossicles. If the bearings were not kept together with suffieient foree, slipping, knocking and loss of power would ensue. This state of equilibrium is absolutely necessary if the system of membranes and ossicles is to move in immediate response to the slightest alteration in air pressure.

Before going into the mode of action of the ear bones, a pressure equalising device eomes up for consideration. As has just been said, perfect equilibrium of vibrating parts is necessary for perfect 
transmission of energy. One can therefore realise how important it is for there to be some open communication between the tympanic cavity and the atmosphere. By means of the Eustachian tube, communication is established between the middle ear and the pharynx and through the latter with the exterior, and so both sides of the tympanic membrane are kept at atmospheric pressure. Normally, it is closed by an arch of cartilage which surrounds the lower end. The tensor palati muscle is inserted in one side of this arch, and when this muscle contraets during the act of swallowing (Chap. XXVII.), it draws down and flattens the cartilage and so opens the tube. Occlusion of the tube by mucus or by inflammation of the throat, isolates the air in the middle ear. The air is gradually absorbed by the tissues, pressure is thus reduced and the drum is sucked inwards. This increased tension in the membrane makes it less responsive to sound. Temporary deafness caused by a rapid alteration in external air pressure (e.g. rising in an aeroplane; descending in a submarine, or diving in a bell or suit, entering a caisson, etc.) is immediately relieved by movements of swallowing. The Eustachian tube is also the drainage tube to the middle ear, preventing the accumulation of mucus (Figs. 42 and 43).

\section{Mechanism of the middle ear.}

The function of the mechanism is to transform the alternate eondensations and rarefactions of air, which we call sound, into a series of hydraulic movements of the fluid in the internal ear. Direct observation has shown that the ear-bones form a chain of levers which together conduct the vibrations incident on the drum to the foot of the stapes.

A. Let us look first at the mechanism of the levers. In Fig. 44 is given a schematic sketch of the ossicles illustrating their lever action. The axis on which the malleus and incus together turn is represented by the line $A-B$ passing from the tip of the short process of the malleus to the tip of the short process of the incus. A movement inwards of the manubrium will cause the head of the malleus to swing outwards, carrying with it the upper part of the incus and so moving the long process of the incus in the same direction as the manubrium. This movement is directly transmitted to the stapes. The chain of bones, therefore, acts as a bent lever whose fulcrum is at $a, *$ the power arm being represented by the dotted line and the load arm by the line $\mathbf{i}-\mathbf{a}$. According to

* $\mathrm{a}=$ junetion of dotted line with $A-B ; \mathbf{1}=$ tip of long process of incus ; $\mathrm{p}=$ point of application of power, i.e. tip of namubrium mallei. 
Helmholtz, the distance $\mathbf{p}-\mathbf{a}$ is $9.5 \mathrm{mms}$, and $\mathbf{i}-\mathbf{a}$ is $6.3 \mathrm{~mm}$. The movement at $\mathbf{i}$ therefore will be only $\frac{2}{3}$ of the movement at $\mathbf{p}$, but will have $1 \frac{1}{2}$ times the intensity. We have now to consider the transmission of this power to the foot of the stapes. If $x-y$ represents the range of the tip of the incus, $c-d$ the distanee from $c$, the hinge (lower annular ligament) to $d$ the centre of the foot of the stapes, and $c-r$, the distanee from the tip of the incus to the lower end of the stapes, then the range of motion of the centre of the foot of the stapes will be $\frac{(x-y) \times(c-d)}{(c-r)}$ which, aceording to the seale of a drawing given by Helmholtz, would give a leverage of about $2-1$.

So that, on the whole system of bones there is a leverage of about $3-1$. This theoretical value is, however, redueed by the frietion 'of the levers and by the damping effeet of the air filling the internal ear. It has been estimated that half the foree is thus dissipated.

Three further points about the ehain of ossieles elaim our attention. Firstly, by the position of the axis, $a-b$, the mass of the heads of the hammer- and anvil-bones are above the line, while the lever arms are below the line on which the bones rotate. This keeps these two bones suspended in equilibrium. Seeondly, there are tooth-like processes on the surface of the hammer which engage with the body of the anvil, enabling each to move the other in the to-and-fro movements of the drum. In the ease of unusually sudden alterations in air-pressure, e.g. a blow on the ear, these proeesses slip over each other and prevent damage to the internal ear. Thirdly, by the way in which they are hung on opposing ligaments, and eontrolled by opposing muscles, they form a kind of balanee wheel which is very sensitive to the transmission of power in small vibrations. Its efficiency in this respeet is derived from the fact that the elastie forees balanee one another in the meehanical eentre of the system, and so practically the whole power applied to the drum is transmitted to the foot of the stapes.

B. The pressure in the internal ear is reinforeed not only by the system of lever transmission but by the relative sizes of the membranes at either end of the ehain of ossieles. The area of the tympanie membrane is about twenty times the area of the fenestra ovalis. This means that, keeping the total power constant, the power per unit area is inereased twenty times. This is augmented by the intermediate leverage (eorreeting for airdamping, frietion, ete.), which we have seen has been estimated 
as not less than $1 \frac{1}{2}-1$. This would give a total incrcase of effective pressure of at least $30-1$. (Wrightson puts the value as high as $60-1$ on the assumption that no slip occurs at the malleo-incal joint, etc.)

3. Internal ear. The internal ear is a somewhat complex cavity in the petrous part of the temporal bone. Two separate organs are housed in this eavity, viz. the labyrinth by which equilibrium is maintained, and the cochlea.

The Cochlea is a tube, $20-30 \mathrm{~mm}$. long, which takes two and a half spiral turns round a conical bone, the modiolus through the centre of which the auditory nerve passes. The eochlea is divided into three portions by means of $(a)$ a spiral lamina of bone extending from the modiolus about $\frac{2}{3}$ across the tube, and $(b)$ joined to the walls of the tube by two membranes, Reissner's and the basilar membrane. The former is a thin layer of cells and separates the vestibular duet from the intramembranous middle duct. The part below the basilar membrane is ealled the tympanic duct. The fenestra ovalis closes the vestibule-the swelling at the wide end of the scala vestibuli-while the membrane of the fenestra rotunda does similar service to the lower duct, the scala tympani. The two ducts are united at the apex of the cochlea by an irregular erescentic aperture called the helicotrema. This opening has an average area of $\mathbf{0 . 1 5} \mathrm{sq}$. mm.-markedly less than the sectional area of the terminal part of either scala. 'These sealae are filled with a fluid, perilymph, which obviously, because of the fenestra rotunda, is normally under atmospherie pressure.

Chief interest in the internal car lies in the structure of the scala media and its contents (Fig. 45). It is triangular in section, having for basc the basilar membrane which separates it from the tympanic duct; the long side is composed of Reissner's membrane, which divides it from the vestibular duct. The short side is separated from the outer wall of the osseous cochlea by a vaseular layer (stria vascularis), laid on and in a continuation of Reissner's membrane, which in turn is placed on the spiral ligament, or pad. Roughly, the cubic capacity of this duct is about a quarter of that of the scala tympani and about a third of that of the scala vestibuli. It is filled with endolymph, a fluid similar to the perilymph of the rest of the cochlea. No communication exists between the seala media and any other part of the cochlea. There is a narrow tube, the canalis reuniens, which runs from this duct to the sacculc-part of the organ for maintaining equilibrium.

The reason for the attention that has been direeted to the seala 
media is that the auditory nerve, which runs down the modiolus, enters only this scala, passing along the basilar membrane and ending in dendrites among the hair-cells of the organ of Corti. This structure is a development of the epithelium lining the tube. It is set on the basilar membrane at its junction with the limbus laminae spiralis, and consists of four essential elements. (1) Certain columnar cells with short stiff hair-like processes projecting from their free border, the hair cells, to which pass, as we

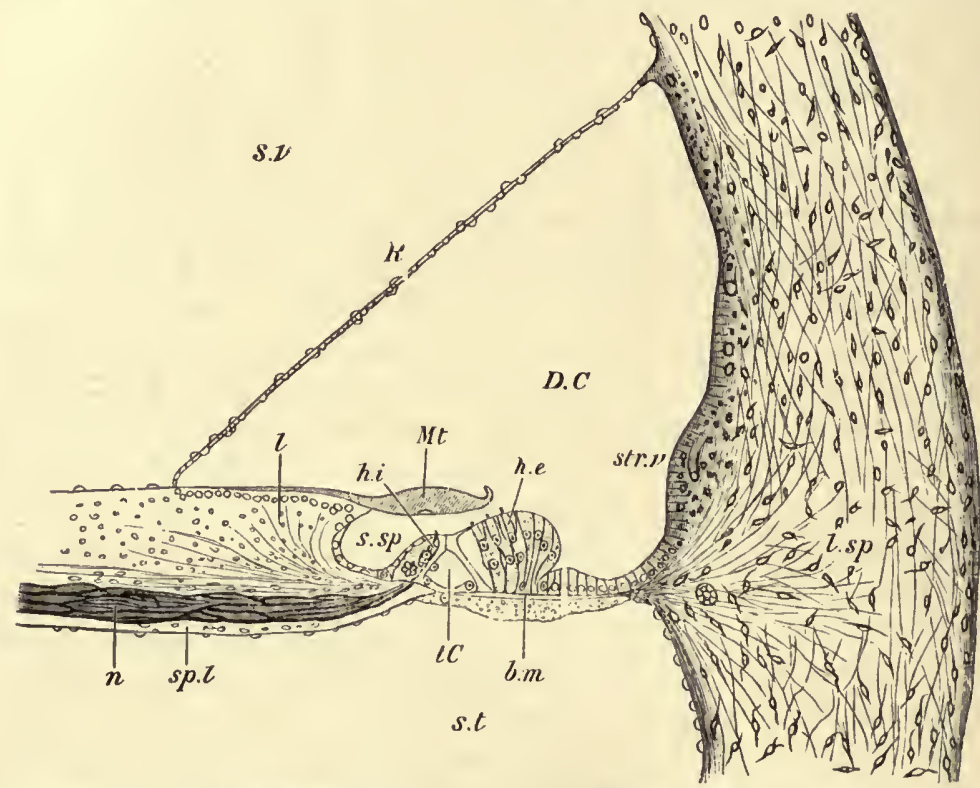

FiG. 45.-Vertical section of the first turn of the human coehlea ( $G$, Retzius).

8.v, scala vestibuli ; s.t, scala tympanl; $D . C$, scala media ; sp.l, spiral lamina ; $n$, nerve fibres; $l . s p$, spiral ligament ; str.v, stria vaseularis; m.t, membrana tectoria ; $b . m$., busilar membrane; $h . i$, and h.e, internal and external hair cells; $R$, section of Relssner's membrane ; $t . C$, tunnel of Cort ; $l$, limbus laminae spiralis.

have just said, branches of the cochlear nerve; (2) elongated strengthening cells between the hair cells, cells of Deiters, the peripheral processes of which join together to form a network through which the hair-cells project (membrana reticularis); (3) stiff short fibres set one against another in the form of an arch ; and (4) an exceedingly delicate membrane attached to the upper surface of the spiral lamina, and lying over or fixed to both the outer and the inner walls of Corti's organ.

The arch of Corti, which lies just outside the single row of inner hair cells, is composed of a row of inner " rods," shaped like ulnar bones, attached by their terminal end to the basilar membrane, and 
fitting on to the heads of the outer "rods." The latter resemble swans' heads and necks, the backs of the heads fitting into the hollows of the inner "rods."

\section{The mechanism of the internal ear.}

It is obvious that every movement of the stapes is communieated by the perilymph to the membranes of the scala media, from them to the endolymph, and so to the organ of Corti. There is also no doubt about the hair eells as being the final instruments for the transmission of the impulses to the nerve. Two main theories are held as to the mechanism of the cochlea, viz. the resonance theory and the displaeement theory.

\section{Resonance Theory.}

Helmholtz considered that the only meehanism capable of analysing compound vibrations was a system of resonators. In his own words, "Suppose we were able to connect every string of a piano with a nerve fibre in such a way that this fibre would be exeited and experienee a sensation every time the string vibrated. Then every musieal tone which impinged on the instrument would exeite in the ear, as we know to be really the case, a series of sensations corresponding to the pendular vibrations into which the original motion of the air had to be resolved. By this means, then, the existenee of each tone would be exactly so pereeived, as it is really pereeived by the ear. The sensations excited by the higher partieles under the supposed conditions, would fall to the lot of different nerve fibres, and hence be produced perfectly, separately and independently. Now, as a matter of fact, later microscopic discoveries respeeting the internal construction of the ear, lead to the hypothesis that arrangements exist in the ear similar to those which we have imagined. The end of every fibre of the auditory nerve is connected with small elastic parts which we cannot but assume to be set in sympathetic vibration of the waves of sound."

He considered that the fibres of the basilar membrane constituted this system of resonators. This membrane increases its width (about three times) as it passes from its beginning in the base of the cochlea to its termination in the apex and contains somewhere about 10,000 of these fibres within its substanee. He considers that "damping arrangements exist in the ear so as to quickly extinguish movements of the vibrators" (M'Kendriek). 
This theory reeeives eonfirmation from the following faets :

(1) Birds and other animals whose calls have a short range of pitch have short basilar membranes.

(2) Prolonged subjeetion to a definite note produces degeneration in a definite part of the membrane-e.g. in boiler makers' disease there is inability to hear high notes with degeneration of the short fibres; animals give evidenee of deafness to low notes when the long fibres of the membrane have been destroyed.

Against this theory are arrayed most psyehologists and not a few physiologists and anatomists. They find in it no adequate explanation of certain phenomena.

(1) The parrot has only half a whorl of cochlea, but is able to imitate speeeh and to whistle musical notes over a fair range, while the guinea pig, with one and a half whorls more than man, produees only squeaks and grunts.

(2) The bird has a short basilar membrane, about $\frac{1}{5}$ that of the mammal, but has numerous hair cells. These cells are set in the bird in rows of 30 or 40 , and in the mammal in rows of 4 . If equal lengths of membrane vibrate sympathetieally to the same note, then as the bird has ten times the number of hair eells stimulated as the mammal, it ought to hear the sound correspondingly louder. This does not appear to be so.

(3) It is rather diffieult to see how, even taking differences in tension into aecount, suffieient resonators could be obtained to reeeive the wide range of notes that it is known we do reeeive.

\section{Displacement Theory.}

The latest form of this theory is put forward by Sir Thomas Wrightson, an engineer. He is supported by Professor Arthur Keith, the eminent anatomist. He considers that the ear is not a physiological piano played upon by the sound waves, but a delieate spring weighing every phase of a sound wave, simple or compound, and transmitting to the brain a reeord of every fluetuation of pressure in the endolymph of the scala media. Every variation of pressure transmitted by the stapes to the perilymph is in turn transmitted to the membrane closing the fenestra rotunda. The eochlear system is a elosed one, in shape rather like a long drawn out, doubled over hour glass, with the stapes operating at one end. The only relief for the motion of displaeement is at the fenestra rotunda, at the opposite end, whose membrane moves to and fro simultaneously with the stapes. These movements are transmitted to the endolymph enclosed in the tube, the scala media, which ends blindly at the 
helicotrema. He believes that the hair eells and not the basilar membrane are the sensitive organ. They pass through the meshes of the retieulate membrane, and, according to Wrightson and Keith, have their upper ends fixed in the tectoria. The tectorial membrane, it will be remembered, is attached to the spiral lamina, as a nail grows out of the finger. Now, displacement of the fluid eauses movement of the whole reticulate membrane. This latter produees a to-and-fro movement of the base of all the hairs, and as these hairs are fixed in the teetorial membrane, they will bend. "It would only be the simple pure tones which would give to the hairlet a pure symmetrical harmonie motion, but by the displacement of liquid under pressure, every conceivable succession of bendings of the innumerable hairlets ean be obtained to convey to the auditory nerve every impulse required to produce the piteh of each resultant and eomponent tone" (Wrightson).

Thus, the eubic displacement of fluid is eonverted, by means of the areh of Corti, into a linear movement of the reticulate membrane, ete. By means of the resistance of the tectoria, the linear movement is converted into the bending of the hairlets.

Such an explanation fails to aceount for the ability of the trained musical ear to perceive as separate entities the different sounds from an orehestra reaching it simultaneously, and it does not give a very elear explanation of "tone-gaps."

To conclude in the words of Helmholtz: "On reviewing the whole arrangement there ean be no doubt that Corti's organ is an apparatus for reeeiving the vibrations of the basilar membrane and for vibrating of itself, but our present knowledge is not suffieient to determine with aceuracy the manner in which these vibrations take place."

There remains one very important matter which should be considered because of its diagnostic value to the physieian, viz. eonduction of sound waves by the bones of the head. It is eommon knowledge that sound vibrations travel more readily through a solid than through a liquid or a gaseous medium. A wateh, plaeed suffieiently far away to be inaudible, ean be heard tieking if touched by a lath held between the teeth. If something goes wrong with the mechanism of the ear, one wants in the first place to locate the fault. Is the external ear, the middle ear or the internal ear the seat of the trouble? The test is usually made by placing a vibrating body, such as a tuning fork, on one of the eranial bones. If the sound is not appreeiated, then the fault lies within the internal ear. Either the organ of Corti (or 
its nervous attachments) have broken down or the membrane of the fenestra rotunda is not normal. Provided the organ of Corti and its nervous attachments are intact and the round membrane is flaceid, sounds may be heard by bone eonduction, and ordinary hearing is not impossible. The vibrations are transmitted directly through the thick, exceedingly dense but elastie bony walls of the aural cavity, and produce a movement of the basilar membranc, ete. This can only take place if the membrane of the round window is functioning properly, or if the stapes moves normally in its oval window. If the openings were to lose their elastie windows and not move to and fro with every condensation and rarefaction, then the cochlea would be, to all intents, a sealed eavity filled with fluid. Such fluid could not oseillate; it could be alternately eompressed and released from this extra pressure, but this slight molecular movement could not stimulate the hairlets.

Further, if both the stapes and round membrane were free to move, hearing in the ease of a diseased middle ear would not be so good as when only one of the pair were free. 'This is because part of the displaeement of the cochlear fluid eaused by the vibrations of the surrounding bone is dissipated by moving the stapes outwards. People may hear fairly well after the stapes has become immovably fixed in the fenestra ovalis. In eases where the drum of the ear has been punctured, hearing may be improved by fixation of the stapes, e.g. by application of a plug of cotton wool.

When sounds are eonducted to the inner ear by means of the bones of the skull, in people with normal hearing, the intensity of the sound is markedly increased if the movement of the stapes is hindered. For example, on p. 423 of Part II. is given an experiment where a vibrating tuning-fork is placed on the region of the interparietal suture. When both ears are unobstrueted and normal, sound is heard equally by both. If the drum of one ear and appended ossieles are hindered from taking a full excursion by blocking the meatus with a finger, the sound appears most distinetly at this ear. When both ears are treated in this way, localisation is again median. A common entotic phenomenon is the audibility of the pulse in an obstrueted ear. It may be due to the transmission of the pulse-wave oscillation to the air of the middle ear-which acts as a resonator-reinforeing the vibrations and then transmitting them to the internal ear. It is more probable, however, that the beat of the carotid artery is transmitted through the parietal bone direet to the fluid of the cochlea. 


\section{CHAPTER XX}

\section{OUTPOSTS OF THE INTELLIGENCE SERVICE}

\section{(c) DISTANCE RECEPTOR FOR LIGH'T}

THE EYE

By W. F. Siranks, B.Sc., M.B., Lecturer on Experimental Physiology in the University of Glasgow.

THE following points in connection with light are recalled to the student's memory.

(1) Refraction.

When a ray of light passes from a rare to a dense medium (or vice versa) it undergocs refraction, i.e. it is bent towards

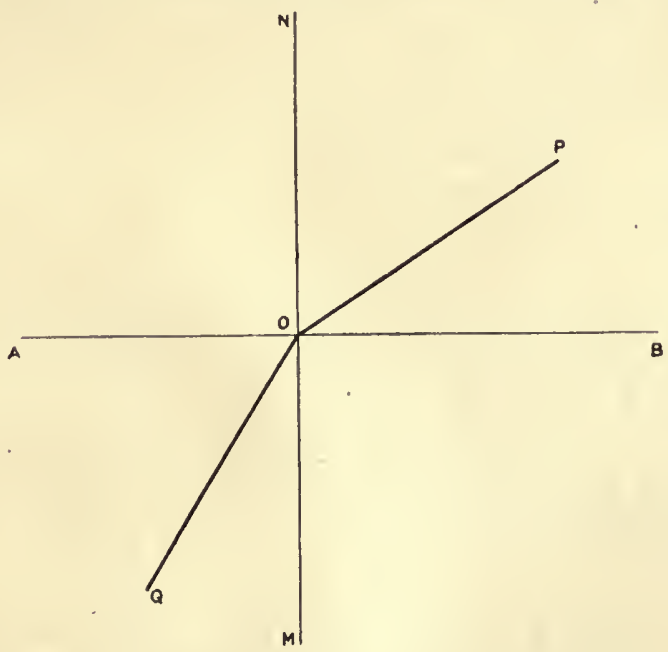

Fig. 46.-Refraction of incident ray $P O$ at interface $A B$.

(or away from) the perpendicular to the surface at the point of incidence. 'This perpendicular is called the normal. Snell's Law 
states that for any two media, the sine of the angle of ineidence bears a constant ratio to the sine of the angle of refraction.

In Fig. $46 P O$ is the ineident ray, $O Q$ the refracted ray, NOM the normal to the interface $A B$ between the media (the upper being the less dense). Then $\frac{\sin P \hat{O} N}{\sin Q \hat{O} M}=$ constant. This constant is called the refractive index, and is usually denoted by the letter $\mu$. The refractive index of air is taken as unity, and other refractive indices are expressed as numerieal values compared with it.

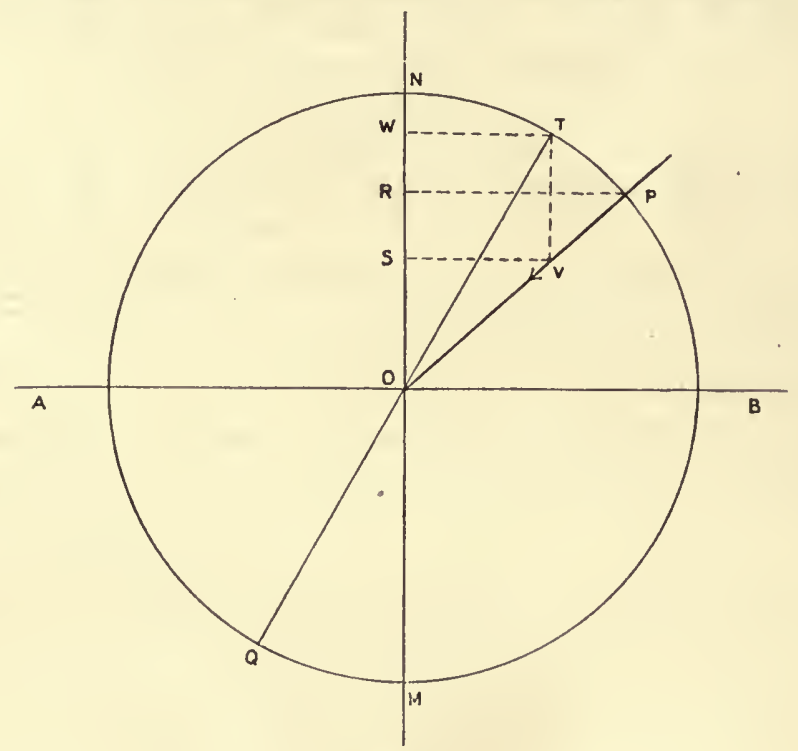

Fig. 47.

If we are given the angle of ineidence and $\mu$, we can easily find the direction of the refracted ray. Let $P O$ be the ineident ray. Measure $O V=$ unity and $O P=\mu$ (stated in the same units). With centre $O$ and radius $O P$ describe a eircle. Draw $V S, P R$ perpendicular to normal NOM. Draw $V T$ parallel to $O N$. Join $T O$ and produce it to eut eirele at $Q$. Then $O Q$ is the refraeted ray.

Proof : $\quad \operatorname{Sin} P \hat{O N}=\frac{P R}{P O}, \quad \sin \hat{T O W}($ or $Q \hat{O M})=\frac{T W}{T O}$,

that is,

$$
\frac{\operatorname{Sin} P \hat{O N}}{\operatorname{Sin} \hat{Q O M}}=\frac{P R}{P O} \cdot \frac{T O}{T W}=\frac{P R}{T W}=\frac{P R}{V S} .
$$




\section{But in the similar $\triangle \mathrm{S} P O R, V O S, \quad \frac{P R}{V S}=\frac{P O}{V O}$,} and $\frac{P O}{V O}=\mu$ by construction.

\section{$\operatorname{Sin} P \hat{O} N$}

$\therefore \overline{\operatorname{Sin} Q \hat{O O M}}=\mu$. Hence $O Q$ is the refracted ray.

If $P O$ is perpendicular to $A B, \sin P \hat{O} N=O$. Hence $\sin Q \hat{O} M=O$, i.e. the ray is unrefracted in its passage.

But, in addition to this refraction, a part of the incident light is reflected. The amount reflected varies with (i) the obliquity of incidence, (ii) the difference in refractive index.

When a source of light, e.g. a candle, is placed near a biconvex lens, we see very clearly two images produced by reflection. The first is formed by the anterior convex surface and is upright, the second is formed at the posterior surface, which is concave in respect of rays passing out of the lens into the atmosphere, and is inverted. The size of the image decreases as the convexity of the lens increases. Its brightness increases, the more obliquely the rays from the candle strike the surface and also with increase of the refractive index of the medium composing the lens.

(2) Images formed by a Convex Lens. (a) When the object is between $\infty$ and $2 f$ ( $f$ being the focal length), the image lies between $-f$ and $-2 f$, and is real, inverted and diminished.

(b) When the object is between $2 f$ and $f$, the image lies between $-2 f$ and $-\infty$, and is real, inverted and magnified.

(c) When the object is between $f$ and the optical centre of the lens, the image lies between $+\infty$ and the optical centre of the. lens, and is virtual, erect and magnified.

(3) Chromatic Aberration. When white light passes through a lens its component rays are unequally refracted, the violet being

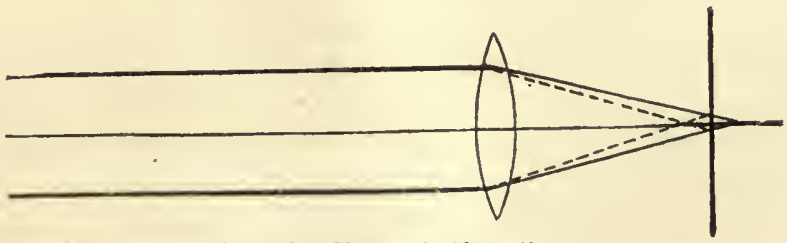

FIG. 48,-Chromatic Aberration.

brought to a focus nearer the lens than the red. If the image is received on a sereen midway between these points it will appear to be surrounded by a red and violet halo. 
(4) Spherical Aberration. Rays of light passing through the pcripheral part of a lens are refracted more than those passing through the central part. This tends to produce distortion of the image at the periphery.

We will point out the application of these facts to the cye in due course.

\section{Anatomy.}

To understand the mechanism of the eye even from the purely physical standpoint, i.e. as an optical instrument, it is necessary to have a clear conception of its? structure.

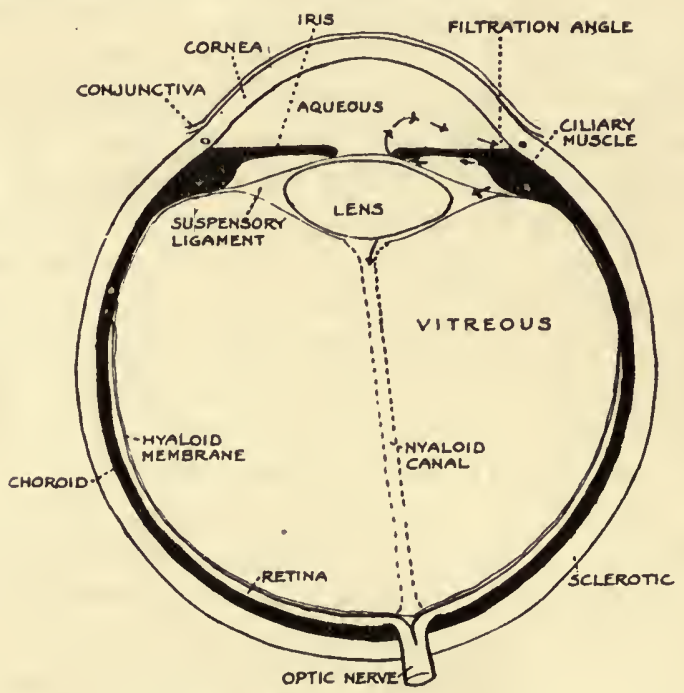

FIG. 49.-Diagrammatic section of eye.

The eyeball is a hollow sphere of dense fibrous tissue-the sclerotic. In front there is a window, the cornea, formed also of fibrous tissue, but so modified as to be transparent. Its radius of curvature is much smaller than that of the sclerotic. Inside the eyeball is a second layer, the choroid, constituting the vascular portion of the eye, and loaded with pigment. This last performs the function of the black lining of optical instruments, preventing the reflection of rays in the interior. At the corneo-sclerotic junction the choroid ceases to be in contact with the wall of the eyeball, and hangs free as a curtain-the iris. In this curtain there is a central aperture, the pupil, which in the human subject is circular. In the iris are muscular fibres, a well-marked circular set serving to diminish, and a feebly marked radial set serving 
to enlarge the pupillary opening. Thus the amount of light entering the eye ean be regulated. At the back of the eyeball, slightly internal to and just below the antero-posterior axis, the optic nerve pierecs the selerotic and choroid, and its fibres spread out on the inner surface of the latter to form the retina which extends forward almost to the ciliary body (see below). Where the antero-posterior axis meets the retina is a small yellow area, the macula lutea, in the centre of which is a depression, the fovea centralis. The macula constitutes the area of distinet vision. The retina is a sensitive screen, on which a picture of external objects is brought to a focus, and corresponds to the plate of a photographic camera. Along with the optic nerve the arteria centralis retinae enters, and its branches radiate outwards on the inner surface of the retina. Internal to the retina is a delicate layer, the hyaloid membrane, which, like the choroid, beeomes free near the corneo-sclerotic junction and splits to enclose the crystalline lens. The latter is a laminated biconvex strueture placed just behind the iris, and centred with the pupil. Between the wall of the eyeball and the lens the hyaloid membrane is considerably thickened, and forms the suspensory ligament or Zonule of Zinn. Close to the corneo-sclerotic junction the choroid is thickened and raised in radiating ridges, the ciliary processes. To these the hyaloid membrane is firmly attached, and into them are inserted fibres of the ciliary muscle. The ciliary musele arises from the corneo-sclerotic junction and its fibres are arranged in two sets-a radial passing back into the ciliary processes and a cireular. The ciliary processes, plus the ciliary musele fibres, constitute the ciliary body. The lens, with its attachments, separates the eyeball into an anterior chamber filled with clear fluid, the aqueous humour, and a posterior containing a rather more jelly-like substance, the vitreous humour. The anterior chamber is divided into two compartments by the iris, but there is free communieation between them through the pupil.

\section{Refraction in the Eye.}

Let us now consider the passage of a ray of light through the instrument we have deseribed. We must first know the indiees of refraetion of the various media. They have been determined experimentally, and may be given approximately as follows :

Cornea

Aqueous

Lens -

Vitreous
$-1 \cdot 33$

$-1 \cdot 33$

- 1.43

- 1.33 
Remembering that refraction takes place only at the plane of junction of media of different densities, we see that it will occur at (i) the anterior surface of the cornea, (ii) the anterior surface of the lens, (iii) the posterior surface of the lens. At each of these surfaces the incident ray will be bent towards the central axis, and in the normal eye the result is to bring all incident rays to a focus exactly on the retina. Thus a picture is produced.

We have seen that refraction is always accompanied by a certain amount of reflection, and this is the cause of the phenomenon known as Sanson's Images. If a candle is held at a short distance from one side of the eye, the observer can distinguish the images formed by each of the refracting surfaces. The image produced by the cornea where the change in refractive index is from 1 to 1.33 is much brighter than the images from the lens, where the change is from 1.33 to 1.43 and from 1.43 to 1.33 . In the case of the two latter also there is a certain amount of absorption of light by the media. The images from the cornea and the anterior surface of lens are upright, that from the postcrior surface of lens is inverted. The radii of curvature of the refracting surfaces are respectively, 8,10 and $6 \mathrm{~mm}$. Consequently the images differ correspondingly in size.

The combination of the three refracting surfaces constitutes the physiological lens of the eye.

\section{Accommodation.}

Every one knows that in a photographic camera it is necessary to adjust the distance between plate and lens in order to focus sharply objects at varying distances. The eye, regarded as an optical instrument, must suffer from this disadvantage, and it is a matter of daily experience with us that near and far objects cannot be seen clearly at the same time. How does the eye overcome this difficulty? The eyeball is rigid and the lens practically fixed. No change in the relative positions of the latter and the retina is possible. The adjustment, called accommodation, is brought about by changes in the lens, so that the eyeball har virtually a series of lenses of varying strength, from which it selects the one most suited to the requirements of the moment.

The lens suspended in the resting eye has not its natural shape; it is kept somewhat flattened by the tension of the capsule. If this tension can be relaxed, the lens will become more convex on account of its inherent elasticity. A mechanism for bringing this about is present. The ciliary muscle is fixed 
at the corneo-selerotic junction, when its radial fibres contract they drag the eiliary proeesses, with the adherent hyaloid membrane, forward, simultaneously the eireular fibres by their eontraction constriet the circle round which the suspensory ligament is attached. The result is to relax the ligament and lens capsule, and the elasticity of the lens eomes into play. The maximum alteration in radial eurvature, which affects the anterior surface almost exclusively, is from $10 \mathrm{~mm}$. resting to $6 \mathrm{~mm}$. fully aecom-

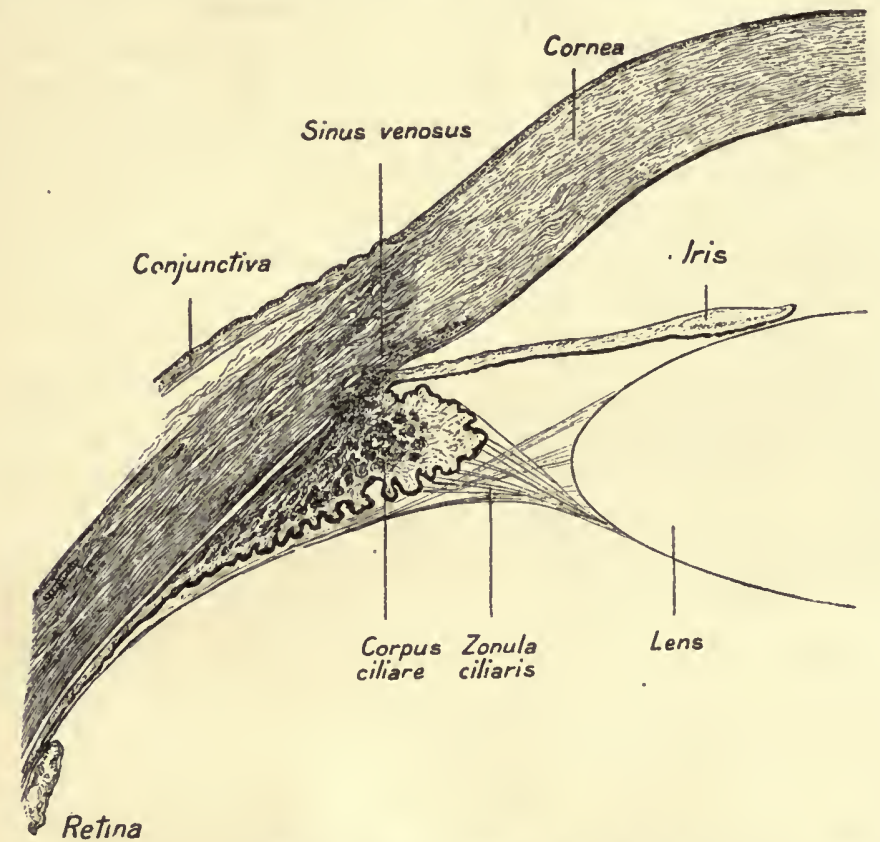

FIG. 50.-Section of anterior part of eyeball, slowing structures concerned in accommodation. (After Merkel and Kiallius.)

modated. The normal adult is thus enabled to sce objects distinetly to within 10 or $15 \mathrm{cms}$. distance. (Note. This is the theory of accommodation at present almost universally aceepted.)

\section{The Abnormal Eye.}

In the normal or emmetropic eye, parallel rays, which in practice are those coming from a distanee greater than 6 metres, are focused in the resting state. Within 6 metres accommodation begins, and it increases as the object approaches, reaching its maximum at about 10 or $15 \mathrm{cms}$. This is called the near point of vision, and the point at which aecommodation begins is called the far point. 
The eyes of a eonsiderable proportion of persons do not produee sharply focused pictures within normal limits. The defect consists most commonly in the sereen being (i) too far from the lens, or (ii) too near the lens. In the first case the picture in the resting eye falls in front of the retina. This is the condition of Myopia or short sight. Divergent rays from near objects are focussed with little or no accommodation, and images are sharply defined when objects are well within the normal near point. But parallel rays cannot be focused unless they are artificially rendered divergent before entering the eye. This is effected by the use of concave lenses. In the second case, parallel rays are focussed behind the retina in the resting eye. This is Hypermetropia or long sight. Such rays can be converged and brought to a focus by using accommodation, but the near point is reached while the object is still comparatively distant. To enable the eye to focus objects near at hand we strengthen its converging powers by interposing a convex lens.

Presbyopia is the result of a gradual diminution of the power of accommodation through loss of clasticity of the lens as age advances, the retina retaining its normal position relative to the lens.

Astigmatism is the variation of the radius of curvature of the cornea in different planes.

\section{The Dioptre.}

The measurement of the refraction of the eye is made in terms of lenses which have their focal lengths expressed in metres. A lens of 1 metre focal length is a lens of 1 dioptre, of $\cdot 5$ metre, 2 dioptres, etc. Errors of refraction are thus measured by the clinician, e.g. a hypermetropic patient who requires a lens of $\cdot 3$ metre focal length in order to render his eye emmetropic is said to have 3 dioptres of hypermetropia.

\section{Movements of the Eyeball.}

The eyeball lies at the front of the bony orbit, a cone-shaped canal with its apex directed backwards and piereed by the optic foramen. The antero-posterior or visual axis of the eye, i.e. the line passing through the centre of the cornea and the fovea makes an angle of about $20^{\circ}$ with the long axis of the orbit. The movements of the eyeball are carried out by the extrinsie muscles, which are six in number. Of these, four (called the reeti) originate in a common tendon surrounding the optic foramen, 
and pass forward to be inscrted a short distance in front of the equator of the eyeball. One is placed above (R. superior), one below ( $R$. inferior), one on the outside (R. externus) and one on the inside ( $R$. internus). The remaining two muscles are the superior and the inferior oblique. The former arises from the same tendon as the recti, and follows a course similar to but above the internal rectus. At the front of the orbit its tendon passes through a fibrous loop or pulley, and bends sharply back to be inserted in the eyeball about the equator. Its line of action makes an angle of about $60^{\circ}$ with the visual axis. The inferior oblique arises from the inner anterior part of the orbital floor, and passes outwards and backwards to its insertion rather beyond the equator. It acts on the same line as the superior oblique.

All the movements of the eyeball are rotations ruund axes passing practically through the centre of the sphere, but it can be proved experimentally that rotation never occurs round the visual axis.

The internal and external recti rotate the eye round a vertical axis, and

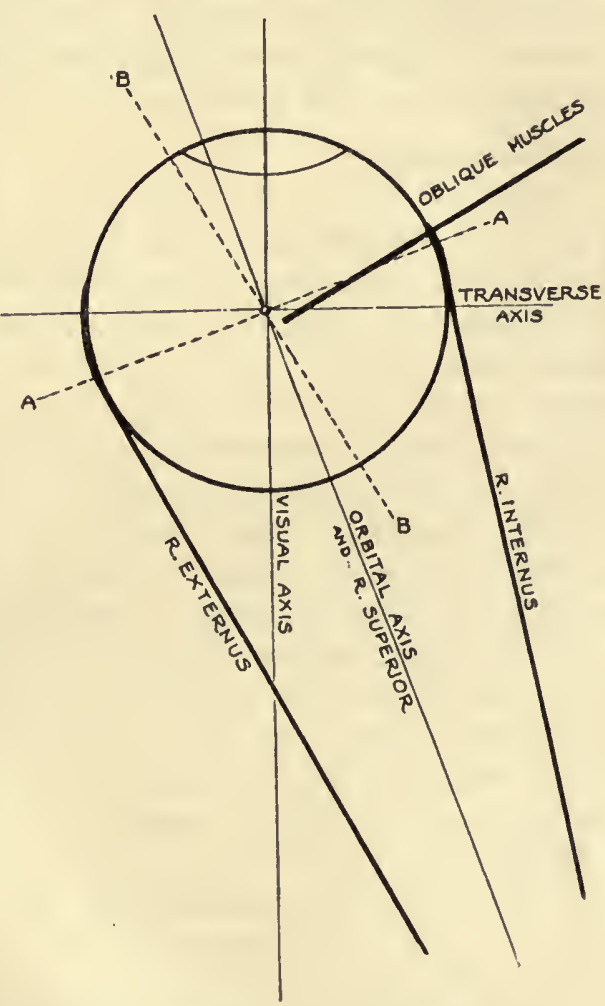

FIG. 51.-Diagram of extrinsic muscles of eye. their action is unaffected by the relative obliquity of the visual and orbital axes.

The rectus superior acts along the line of the orbital axis, and its force can be resolved into two components, the one tending to rotation round a horizontal axis at right angles to the visual axis, the other tending to rotation round the visual axis itself in a counterclockwise direction (viewed from the front). In order to overcome the latter tendency, the inferior oblique acts simultaneously. Its force can likewise be resolved, one 
component tending to rotation round the horizontal axis at right angles to the visual axis, the second component tending to rotation round the visual axis, elockwise. The two rotations round the visual axis eounteraet each other, the remaining two act as a couple, and reinforce each other. The result of the combined action is to move the cornea vertically upwards. For movement upwards and inwards, for instance, the co-operation of a third muscle, the internal rectus, is required. The rectus inferior and the obliquus superior combine in an exactly similar manner to move the eyeball downwards.

\section{Ophthalmoscopy.}

When we look at a person's eye the pupil appears perfectly black. Nothing can be seen of the interior because it is feebly illuminated compared with the outside world. If we could light up the interior it would become visible, just as we can see into a lighted room at night if the window is not covered with a blind. When we try to illuminate the interior of the eye, we find that we must always interpose our head between it and the source of light in our attempts to peer into it. This difficulty is overcome by reflecting light from a mirror provided with a small central aperture, through which the observer can look. This instrument is called an ophthalmoscope. It may be used in two ways :

A. In direct ophthalmoscopy, the mirror and the observer's eye are brought close to the observed eye, and the refracting media of the latter produce a virtual image, erect and magnificd, of the retina. The lens, etc., of the observed eye act in exactly the same way as a magnifying glass, the object being just inside the focus.

B. In indirect ophthalmoscopy the observer holds a convex lens in front of the observed eye, and places himself farther away. The interposed lens brings the rays leaving the observed eye to a focus between itself and the observer, who consequently sees an inverted image of the retina. This is real and magnified, the magnification depending on the lens used.

\section{Defects of the normal eye as an optical instrument.}

(i) The eye is not perfectly eentred, i.e. the axis of the lens does not coincide with the axis of the cornea.

(ii) The optical axis passing through the centre of the cornea and the centre of the lens docs not coincide exactly with the visual axis passing through the eentre of the cornea and the fovea centralis. 
Neither of these defects interferes appreciably with the accuracy of vision.

(iii) Slight degrees of astigmatism are almost always present.

(iv) Chromatic aberration is uncompensated optically. The retina, however, is less sensitive to the extremes of the spectrum, consequently the slight halo of red rays focussed behind and of violet focused in front produces no sensation.

(v) Spherical aberration is provided for by the iris which cuts off the peripheral rays. This is particularly noticeable in accommodation where in order to exclude the more divergent rays the pupil contracts.

\section{Binocular Vision.}

1. The Visual Field. When one eye is closed and the other fixed on a certain point the whole range of objects which can be seen without moving the eye or the head is called the visual field. The angle subtended by these objects is called the visual anglc. With both eyes open and fixed we command a greater range. (For the mapping out of the visual field and measurement of the visual angle see pages 425 and 426 .)

2. Focusing of objects within the far point. We have seen that in order to focus near objects we employ accommodation. This is always accompanied by a movement of the eyeballs, causing the visual axes to converge from their parallel resting position towards the middle line. Such a movement is necessary in order that the images in both eyes may fall on the fovea centralis (Fig. 52). If this mechanism is defcetive, strabismus or squint results. The amount of convergence varies inversely as the distance of the object. This may be proved as follows (Fig. 52) :

$$
\begin{gathered}
\operatorname{Sin} O \hat{O E P}=\frac{O P}{O E} \cdot \quad \sin O^{\prime} \hat{E} P^{\prime}=\frac{O^{\prime} P^{\prime}}{O^{\prime} E}=\frac{O P}{O^{\prime} E} . \\
\frac{\operatorname{Sin} O \hat{E} P}{\operatorname{Sin} O^{\prime} \hat{E} P^{\prime}}=\frac{O P}{O E} . \quad \frac{O^{\prime} E}{O P}=\frac{O^{\prime} E}{O E} .
\end{gathered}
$$

Since $O \hat{E} P$ and $O^{\prime} \hat{E} P^{\prime}$ are small, sin $O \hat{E P}=O \hat{E P}$ and $\sin O^{\prime} \hat{E} P^{\prime}$ $=O^{\prime} \hat{E} P^{\prime}$.

Hence

$$
\frac{O \hat{E} P}{O^{\prime} \hat{E} P^{\prime}}=\frac{O^{\prime} E}{O E}
$$

The power of convergence is rather less than that of accommodation, for we can focus an object with one eye at a slightly shorter distance than when we use both eyes. 
It is only in the emmetropic eye that convergence and accommodation correspond exactly in amount. A hypermetropic person viewing a near object may require to use, say 4 dioptres of accommodation, whereas an emmetropic person uses only 2 dioptres, but both employ the same amount of convergence. Similarly an emmetrope may focus a near object, and if concave lenses are placed in front of his eyes he can continue to see the object plainly by increasing his accommodation sufficiently to neutralise their effect. The object still remains at the same distance, i.e. the convergence does not alter. Hence we see that accommodation and convergence are to some extent independent.

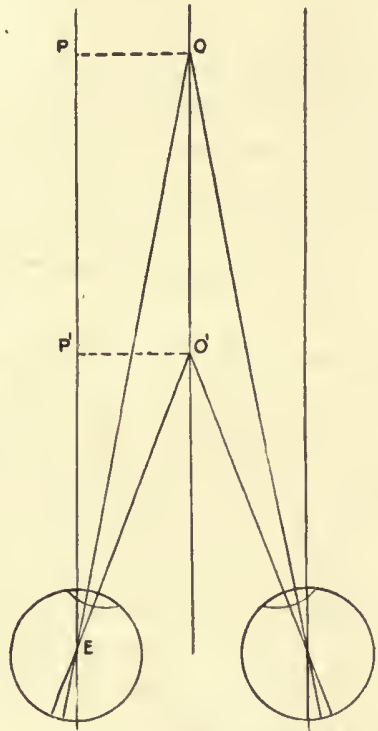

FIG. 52.-Convergence.
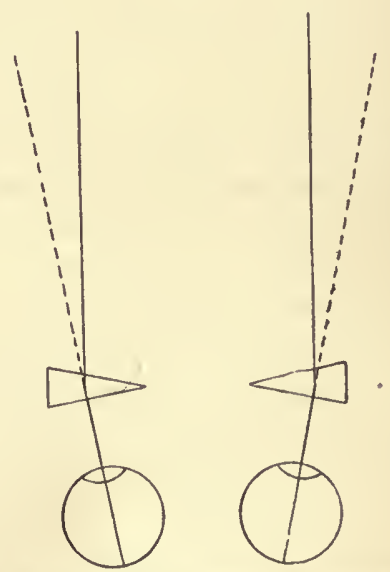

FIG. 53.-Artificlal divergence of visual axes.

3. Divergence. In normal circumstances the visual axes never diverge, for they are in parallel adjustment for objects at infinity. Divergence can however be brought about artificially. Thus if we interpose prisms to render the rays divergent we can produce a corresponding divergence of the visual axes.

4. Visual Judgments. On account of the distance between the eyes, objects are viewed from a slightly different angle by each eye. This is readily demonstrated by looking at an object first with one eye and then with the other. It is particularly well brought out by two objects almost or completely in alignment, and the phenomenon persists at long distances. Each retina thus 
receives a slightly different picture, and we are furnished with a most important means of judging solidity and distance. Objects scen with one eye only have a very flat appearance. Shadows help materially in conveying impressions of solidity, and their significance may be illustrated in the interpretation of aeroplane photographs. In such photographs taken during the War there were numerous marks which might have either a positive or a negative solidity, i.e. they might have been either projections above the ground, such as machine-gun emplacements, or depressions, such as shell holes. This could only be determined by the shadows cast, and the direction of the sun's rays was always marked on such photographs. Thus $A$ is a projection and $B$ a depression.

In judging very short distances, two eyes are an enormous advantage. Try to thread a needle with one eye closed. At rather longer distances this may be demonstrated by looking at a wall between which and the observer an object, such as the wire of an electric

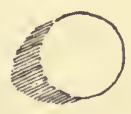

A

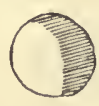

B FIa. 54.-Shadows. lamp, is suspended. Using one eye only and avoiding looking at the point of attachment to the ceiling we will judge its distance from the wall very imperfectly, but with both eyes we can make an accurate estimation.

At long distances numerous external factors come into play. Perspective, light and shade and atmospheric conditions are of importance. 'Thus "visibility" may be good or bad, and will influence our judgments. At sea, where the surface is perfectly flat and the gradations of illumination change uniformly with distance, the untrained eye commits the grossest errors. The proximity of an object of known size frequently supplies a scale against which to measure the size and consequently the distance of unknown distant objects. The faculty of judging distances is poorly developed in the average man. A trained soldier or a big game shot can make incomparably more accurate estimations of distances for rifle fire than the novice. The same thing occurs with the expert golfer for certain distances.

5. The Stereoscope: The combination of two slightly dissimilar pictures to form an apparently solid object is illustrated by the stereoscope. This instrument consists of two prisms or half lenses placed, with the thin edge inwards, about the same distance apart as the eyes. The dissimilar pictures $\boldsymbol{P}_{1}$ and $\boldsymbol{P}_{2}$ are fixed one in front of each lens, and a median screen cuts off each 
opposite picture. By means of this apparatus we obtain a single picture in the most pronounced relief, and situated apparently at $P$.

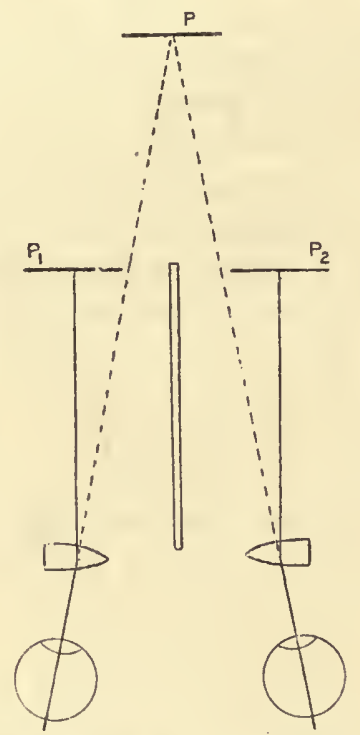

FIG. 55.-Diagram of etereoscope.

We may summarise the advantages of binocular vision as follows :

(i) The visual field is increased.

(ii) We receive impressions of solidity.

(iii) We have a most important means of judging distances

(iv) The loss of one eye does not reduce us to blindness 


\title{
SECTION IV.: TRANSPORT.
}

\section{CHAPTER XXI}

\section{THE BLOOD}

\section{INLAND TRANSPORT SERVICE}

\begin{abstract}
"If they flourish not, a kingdom may have good limmes, but will have empty veines and nourish little."

BACON.
\end{abstract}

WE have seen reason to consider the animal body as a country containing numerous towns or cell-communities, each busily engaged on its specific staple industry and connected with one another and with the seat of government by an extremely efficient means of communication - the nervous system. Such a country, on account of its complex nature, must have a system of transport. Raw materials from outside must be brought into the country and some means must exist for sorting out the imports and forwarding the suitable ones to the appropriate cell-communities, etc. It is convenient to carry still further this simile of a country.

It is obvious that some imports may arrive from overseas ready for use and have only to be handed to the distributors for transmission to the consumer. Others again have to undergo some change before they can be transported inland. That is, there are two classes of raw material arriving at the same port, viz. : gas and liquid-solid food. These are handled by different gangs of labourers. The oxygen is sent directly to the inland transport service, while the food material is sent to a series of factories where it undergoes partial manufacture and is repacked in smaller containers, before being handed to the same inland transport service as the oxygen. Just so, iron ore may be shipped to the Clyde, from which it passes through a series of factories, in which it is partially purified, smelted, etc., and then sent as pig-iron, say to Sheffield, for final treatment, before being distri- 
buted in a useful form over the country. There are, therefore, two forms of transport which we may term external and internal. As all material has finally to be carried by the inland transport service and as the amount of traffic on this system to some extent controls the rate of importation, it will be convenient to direct attention to it in the first place.

\section{Inland Transport-The Blood.}

The blood has been called the liquid tissue of the body. On two counts this is a misnomer. Firstly, it tends to detract from the liquidity of the tissues in general. Further, blood cannot rightly be considered a tissue at all. No doubt a very pretty picture could be drawn of blood and its containing membranes as a tissue, clotting, as other tissues clot, on death, but when the facts are examined they do not bear out such an idea. The evidence too, culled from comparative studies of the development of a circulatory system, is all at variance with the liquid tissue theory.

\section{Development.}

Much may be learned from a study of the evolution of any system. Material exists for such a study in Comparative Physiology.

(a) Unicellular organisms require no circulatory system. Their imports go direct to the sole factory of the place. They may be landed at any part of the coast and are at once acted on. What is suitable is accepted, the residue is rejected or left untouched. Examination of a unicellular animal leads to the conclusion that the cell contents are in a state of constant motion. Water, every now and then, is engulfed, passes more or less directly through the organism, and is excreted, carrying with it the by-products of cell activity.

(b) Some invertebrates have an open coelomic system. Their more complex structure necessitates the production of a current of fluid so that material may reach the inner cells. That is, some of the water in which the animal lives is passed by means of canals to the different parts of the body. The fluid is kept in circulation by the rhythmic contractions of whip-like processes called cilia. The ciliary waves force the water through the tubes into the lacunae of the tissues. Such a system is difficult to control. It is dependent on the nature of the bathing medium. It carries the possibility of constant changes in the salt content of the cells of the animal. Any change in the environment will be passed on 
to the coelomic fluid and at once reflected in the cell. It demands constant adaptation on the part of the organism, and thus it is not economical (cf. our system of canals).

(c) Higher invertebrates and the vertebrate amphioxus have a closed system in which the fluid passes through tubes capable of rhythmic contractions.

(d) The vertebrates have a closed vascular system with the advantages of ease of control and freedom from constant adaptation. It is the most economic system of transport known.

When the sea animals crawled on to land and became breathers of air, they included a certain proportion of the sea-water in their vessels. By the alteration in surface tension caused by the exchange of a protoplasm-water interface for a protoplasm-air interface their open coelomic system automatically closed (cf. camels' hair brush experiment, p. 403).

The vertebrate has, therefore, a fluid in its vessels having a composition similar to that of the sea from which originally it came (see salts of plasma, p. 239). Some arose from a tropical sea and therefore this included fluid was warm. Others again did not attain to this. We have, therefore, warm and cold blooded animals (Regulation of temperature, Chap. XXXI.). This is a very pretty theory. It cannot be considered as proved any more than the hypothesis of evolution, but in the same sense both fit in with certain facts.

\section{Function.}

(a) The blood-stream conveys food including oxygen to all parts of the organism.

(b) It removes the waste products of activity including carbondioxide, which would paralyse function if allowed to accumulate.

(c) The carriage of chemical substances (hormones) from the organs in which they are produced in order to influence the activity of other organs may be considered as the co-ordinative action of the circulation.

(d) The movement of blood aids in the regulation of the temperature of the body (Chap. XXXI.).

(e) It plays a very important part in the defence of the organism against parasites, etc.

( $f$ ) The preservation of the $\mathrm{H}$-ion concentration of the body is principally a function of the circulating fluid (Chap. XXX.).

(g) It maintains the water and salt content of the body at a certain level. 


\section{Composition.}

Since the function of the blood is to act as common nutritive medium to all the parts of the body, it has to convey food material from the digestive organs and oxygen from the lungs to the tissues. From these, it receives in exchange their waste products, viz., results of nitrogenous metabolism, $\mathrm{CO}_{2}$ and $\mathrm{H}_{2} \mathrm{O}$, and carries them away to the excretory organs, kidneys, lungs, skin, etc., by which they are eliminated. It is therefore evident that the composition of the blood must vary from time to time and from place to place, according to the activity and the function of the organ which it is traversing. The cells of the body are adjusted to respond to very minute changes in the composition of the blood and, therefore, changes are kept within infinitesimal limits.

The term blood or whole blood is usually applied to the fluid content of the vascular system, i.e. to the fluid plus formed elements.

\section{Fluid or Plasma.}

(a) Physical Characters.

(i) Colour, light straw.

(ii) Opacity, practically transparent.

(iii) Specific Gravity, about 1030. The specific gravity is lowered after a meal because of the dilution of the plasma by ingested water. Conversely, exercise and profuse perspiration cause a slight increase in the specific gravity on account of the loss of water (see specific gravity of blood, p. 277). Variation in activity will thereforc produce a diurnal variation-a decrease during the day and an increase during rest at night. The night worker, of course, has this reversed. It varies greatly in individuals so that a figure which is normal for one person may be pathological for another.

(iv) Viscosity. At body temperature $\left(37^{\circ} \mathrm{C}\right.$.) plasma has a viscosity about twice that of distilled water, i.e. 1·7-2.09. Salt solutions have almost the same viscosity as water. This factor is due to the emulsoid colloids present (q.v.), one of which by forming a gel under certain conditions may produce so great an increase in viscosity that the flow of plasma may be entirely stopped. The plasma is then said to clot (see fibrinogen and also viscosity of blood).

(v) Reaction. Plasma turns red litmus blue and therefore has an $\mathrm{H}$-ion concentration under $10^{-\mathbf{7}}$. It is acid to phenolphthalein and therefore has an $\mathrm{H}$-ion concentration greater than $10^{-8}$. Exact 
determinations have shown that the $p H$ of plasma is $7 \cdot 4$, i.e. just on the alkaline side of neutral. This alkalinity is due to the presence of sodium bicarbonate (see below).

(vi) Osmotic Pressure. The osmotic pressure of plasma as taken by an ordinary osmometer with a semi-permeable membrane or by the depression of the freezing point is almost the same as that exhibited by a 0.9 per cent. solution of sodium chloride. It varies with the diet and with the amount of fluid ingested. If the kidneys are not functioning properly so that the products of metabolism are not eliminated with sufficient rapidity the osmotic pressure will rise.

The student cannot guard too carefully against the errors of considering that $(a)$ the osmotic pressure of plasma is due to the presence of 0.9 per cent. $\mathrm{NaCl}$ in it and $(b)$ that the figure given even approximates to the proper value of the osmotic pressure in the blood vessels. These vessels are permeable to salts in solution, and, therefore, the true osmotic pressure of plasma must be due not to electrolytes but to colloids (see below).

(vii) Refractive Index (see p. 216). The refractive index of plasma depends primarily on the amount and nature of the proteins present. Its variations are governed by practically the same factors as are responsible for the variations in specific gravity.

(b) Components. (i) Colloids.

The major colloidal constituents of plasma are protein in chemical nature. These proteins are :
(a). Albumin
( $\beta$ ). Globulin
- $2.5 \%$ circa.
$(\gamma)$. Fibrinogen
$-3.8 \%$ - $0 \cdot 15-0 \cdot 6 \%$.

(a) Albumin, probably a mixture of three albumins. At least it is possible by careful heating to discover three separate coagulation temperatures.

$(\beta)$ Globulin is similarly a mixture of two or more globulins. Globulins are insoluble in distilled water but soluble in dilute salt solutions. They therefore require to have a certain concentration of electrolytes present if they are to remain in solution. They may be partially separated from albumin by dialysis. When the salt contents of plasma is forced below a concentration of about 0.2 per cent., the globulins are almost completely precipitated. In the blood stream they function to a great extent as regulators of the amount of $\mathrm{NaCl}$ present. It is of importance that this fact 
be thoroughly grasped. Where the amount of globulin in the blood is increased, the chloride content increases, $e$.g. in pneumonia. In patients with this infection, as well as in cases of chronic nephritis and syphilis, the total protein content of plasma is decreased and the globulin content increased both absolutely and relatively. In mild infections and in chronic septic conditions the total amount of protcin present remains normal while the amount of globulin and of chlorides shows a marked increase. $\mathrm{NaCl}$ held by globulin acts as if adsorbed, i.e. exerts no osmotic pressure. Globulin is precipitated by an increase in hydrogen ions. It is specially sensitive to $\mathrm{CO}_{2}$.

$(\gamma)$ Fibrinogen, a globulin.

The osmotic pressure in the vessels is due to proteins. They are also responsible for the viscosity of blood. The defibrination of blood lowers its viscosity to very little greater than that of water. After extensive bleeding, water pours into the vessels from the tissues through the lymph, and the specific gravity, viscosity, etc., drop. The blood ceases to be an efficient carrier. Bayliss found that the injection of a non-toxic emulsoid colloid would restore normal conditions for sufficiently long a time as would enable the cell-factories, especially the liver, to manufacture new blood proteins from the amino acids in the blood. The most efficient sol, he found, was a solution of gum arabic in Ringer's solution. The story of this discovery as told in his monograph is one of the most interesting side-lights on the medicoscientific work of the War.

\section{Clotting.}

The main use of fibrinogen lies, not in its viscosity or in its osmotic pressure, but in its property of changing from a sol into a gel. The clotting of plasma prevents the loss of blood and keeps the blood channel free from any angularities. The evolution of the knowledge of the process of clot formation has been very slow and even now the physico-chemical reactions involved are anything but well understood.

Mammalian plasma, if left standing in a tube exposed to the air, clots to a jelly in two to ten minutes. The gel has the same volume as the sol, and no heat is evolved in the process. This is a process common to most emulsoid colloids. In about half an hour the clot contracts and expresses a clear straw-yellow liquid, the serum.

i.e. Plasma $=$ Clot + Serum. 
This process whereby the fluid content of the gel is decreased is common to gels and is called syneresis.

\section{Historical.}

Observers at first thought that living tissue had a restraining influence. They noticed that in the living tissue the blood did not clot. Lister formed a living test-tube by ligature of the aorta and showed that the blood did not clot until a foreign body such as glass was introduced.

This demonstrated that clotting was not due to (1) removal from living vessels, (2) stoppage of the circulation, (3) cooling or (4) to contact with air. This latter fact has been confirmed by the observation that blood clots as readily in a vacuum as in air. Further, air embolism and caisson disease do not lead to intravascular clotting. Nor is clot formation due to cooling. As a matter of fact reduction of temperature lengthens the time taken to produce a clot and, if the plasma is cooled sufficiently, may prevent it altogether.

The classical work on blood clotting was performed by Andrew Buchanan, Professor of Physiology at Glasgow, who gave explanations of the process to the Glasgow Philosophical Society, in March, 1844, and February, 1845. Using hydrócele fluid from the tunica vaginalis of a horse he showed that it would clot if to it were added a drop or two of blood, of clot washings, of serum or of tissue juice. He compared the process to the curdling of milk by rennin and considered that the white corpuscles or leucocytes were the active agent.

In 1861, Schmidt, who had devoted some thirty years to the work, proved that :

(i) Fibrinogen, the precursor of the clot, was a globulin in the plasma.

(ii) There was a fibrin-former in plasma, in serum and in clot washings.

He also showed that this fibrin-former (now called thrombin) did not exist as such in the blood but only appeared after treatment with a fibrin-ferment or -kinase. That is, the clotting scheme as he left it appears as follows (modern names) :

$$
\begin{gathered}
\text { Fibrinogen + Thrombin }=\text { Fibrin (or Clot) } \\
\text { Pro-thrombin +" Thrombokinase." }
\end{gathered}
$$

Arthus and Pagès in 1890 showed the need of calcium in the clotting process. 
Hammersten confirmed this, and found that the calcium ions act on the pro-thrombin producing active thrombin. Later work explains the action of calcium ions here and in milk curdling as being due to the non-hydrophilic property of calcium compounds.

This still does not explain why blood does not clot in the vessels, so physiologists had to postulate the presence of some substance in the blood which would prevent the calcium ions from activating the pro-thrombin. This hypothetical substance they called antipro-thrombin. In all cells there is a large or small quantity of thrombokinase, which is the trigger setting off the whole clotting process. When a vesscl is ruptured and blood comes into contact with the tissues or into contact with disintegrating blood-cells, it takes from them thrombokinase which neutralises the inhibitory action of the anti-pro-thrombin and so allows the calcium to act. It is now known that this substance from the tissues is not a ferment or kinase. Some people, therefore, prefer to call it thromboplastin.

The scheme now stands as follows :

(2) (Clot) Fibrin (synerised gel) + Serum

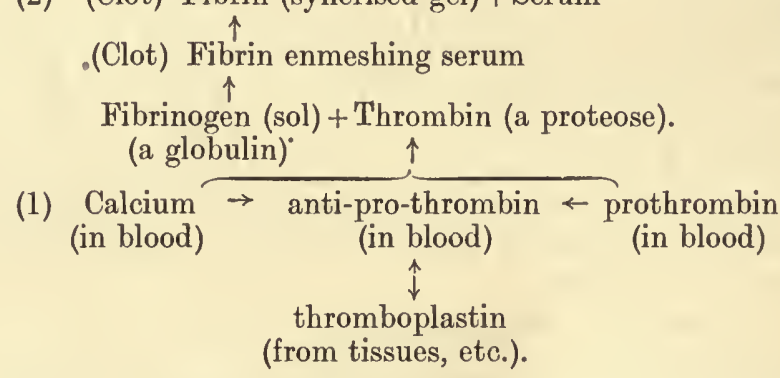

Free calcium ions are necessary for the first step, but apparently not for the second.

It has been known for long that thromboplastin is a phosphatide, a body like lecithin, containing nitrogen, phosphorus and a fatty acid. That this substance is kephalin has been proved by Howell. Pure kephalin has not been prepared in sufficient quantity to allow of complete analysis but its molecule probably consists of :

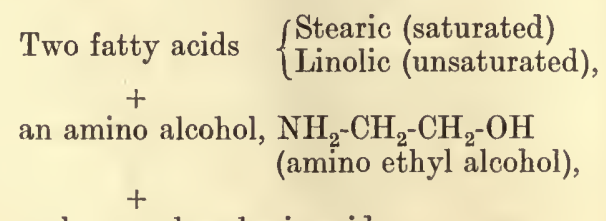

a glycero-phosphoric acid. 
It is optically active, rotating the plane of polarised light to the right.

The main point of interest for us apart from its presence in all tissues is its colloidal character. It is an extremely hydrophilic emulsoid with a strong negative charge. On exposure to air it readily absorbs oxygen (a property dependent on its unsaturated fatty acid) and undergoes partial decomposition.

The addition of calcium ions to a solution of kephalin causes it to form a calcium soap with very little water-holding power (see p. 82). Calcium seems also to combine readily with the products of decomposition mentioned above.

One must not consider for a moment that the last word on clotting has been spoken. The subject has recently been investigated from the standpoint of colloidal physics. The scheme given above does not account for the experiment of Lord Lister already quoted. Kephalin does not seem to be necessary. Freund noted that blood would not clot if it came into contact with a vaselined surface. Placed with due precautions on a nasturtium leaf, which is not wetted by water, blood does not clot. Clotting is induced by contact with a water- (i.e. plasma) wettable surface. This is normally afforded by colloidal kephalin, but may be produced artificially by the introduction of powdered glass, etc., or even by bubbling $\mathrm{CO}_{2}$ gas through the plasma.

Tait and his colleagues have shown that the precursors of thrombin are the thigmocytes of the blood. These thigmocytes or platelets are spindle-shaped cells which have a strong phagocytic action. In place of prothrombin we may write thigmocyte. Now in calcium-free plasma the thigmocytes may come in contact with a surface, but will not stick. The introduction of an ionisable calcium salt causes them to adhere to the surface, and, on account of the extreme lowering of surface tension, the covering membrane of the thigmocyte is ruptured, i.e. it undergoes cytolysis and the cytoplasm is sent into the blood stream. Thrombin comes from this cytoplasm.

To summarise : (a) Shedding of blood sets free kephalin from the cells of the blood or of the tissues, $(b)$ this forms a surface on which, in the presence of ionised calcium, the thigmocytes may spread themselves and rupture, setting free thrombin, which causes the formation of fibrin-gel from fibrinogen sol.

It is worthy of note that kephalin particles of a size just visible under an oil-immersion microscope are capable of producing intravascular clotting when injected into the blood stream, while 
powdered glass or quartz particles of apparently the same size are without effect. Coarser glass suspensions are necessary to produce the effect. Some other factor in addition to surface must come into play or kephalin particles must have a wrinkled surfacc.

Birds' blood is peculiar in that, if drawn with due care to prevent contact with the tissues it may be kept liquid for a long time. The avian thigmocytes even under normal conditions will not adhere to glass surfaces. The addition of the slightest trace of tissue extract (kephalin) causes immediate and extensive clotting.

This gel formation has been studied ultramicroscopically. The first sign of clotting is the appearance of blood platelets or thigmocytes, and from them as centres liquid crystals of fibrin crystallise out, forming a feltwork of long elastic threads.

Anti-coagulants. Certain substances by preventing the calcium from acting on the thigmocytes, i.e. on pro-thrombin, prevent clotting. One of these, called heparin by Howell, arises in the liver. Other substances are really anti-thrombins. Hirudin, a proteose prepared from the buccal glands of the medicinal leech belongs to this class and is injected in blood-pressure and similar experiments to prevent the formation of clots in the cannulae. Certain salts act on the calcium. For example, oxalates, fluorides, etc., form insoluble calcium salts, citrates form a double salt in which $\mathrm{Ca}$ is not a free ion. Differing from all the above anticoagulants which act whether injected into the blood stream or added to shed blood, are those which prevent clotting only when injected. Snake venom in amounts as small as 0.00001 gram per Kg. suffices. Commercial peptone (mixture of proteoses and peptones) injected into the circulation in the proportion of $0 \cdot 3$ gram per kg. produces a non-coagulable blood for an hour or so. This class of coagulant seems to act by stimulating the liver to manufacture heparin. Peptonisation and the injection of venom may cause some alteration in the state of the thigmocytes. This has not been investigated. Of course, plasma or blood from which the fibrinogen or fibrin has been removed will not clot.

Coagulants. Extracts of organs rich in kephalin, e.g. thymus, testes, lymph glands, produce intravascular clotting.

Similarly, certain snake venoms which contain large quantities of thrombin cause clotting of the blood in the vessels and rapid death.

\section{Components. (ii) Crystalloids.}

There is nothing more remarkable than the maintenance of a fairly constant concentration of crystalloids in plasma, under 
the most varied conditions. As we have seen, this is due in great part to the salt-and water-holding power of the colloidal constituents, especially of the globulins. Bunge, in his handbook of physiological and pathological chemistry (1889), suggested that as the notochord and branchial clefts were legacies from forebears who had lived in the sea, the high sodium ehloride content of mammalian blood might also be an heirloom from marine ancestors. No doubt the circulation fluid of marine animals with an open coelomic system is sea water. It is held by many observers, that when the ancestral form of vertebrates acquired a closed form of circulatory system, the fluid shut in was sea water. Analysis shows that while the concentrations of crystalloids in plasma and in sea water are not similar, yet there is a remarkable resemblance in the proportions of the main salts present in both.

$\begin{array}{lcccc} & \mathrm{Na} & \mathrm{K} & \mathrm{Ca} & \mathrm{Mg} \\ \text { Serum (defibrinated plasma) } & 100 & 6 \cdot 69 & 2 \cdot 58 & 0 \cdot 8 \\ \text { Ocean } & 100 & 3.66 & 3.84 & 11.99\end{array}$

TABLE XXXII.

Non-clotting Blood.

\begin{tabular}{|c|c|c|}
\hline Nature of Plasma. & Reason. & To cause Clotting. \\
\hline $\begin{array}{l}\text { Whipped } \\
\text { (Defibrinated) }\end{array}$ & $\begin{array}{l}\text { Fibrin removed as soon as } \\
\text { formed by whipping with } \\
\text { a bunch of twigs. }\end{array}$ & $\begin{array}{l}\text { Add fibrinogen to whip- } \\
\text { ped plasma (or } \\
\text { blood). }\end{array}$ \\
\hline $\begin{array}{l}\text { Salted. } \\
\frac{1}{2} \text { sat. with } \\
(\mathrm{NH})_{2} \mathrm{SO}_{4} \text {. }\end{array}$ & Fibrinogen precipitated. & $\begin{array}{l}\text { Dilute with water and } \\
\text { so reduce concentra- } \\
\text { tion of electrolytes. }\end{array}$ \\
\hline Cooled to $0^{\circ} \mathrm{C}$. & $\begin{array}{l}\text { Cooling slows the physico- } \\
\text { chemical changes which } \\
\text { are optimum at about } \\
40^{\circ} \mathrm{C} \text {. }\end{array}$ & Warm. \\
\hline $\begin{array}{l}\text { Oxalated. } \\
\text { Addition of } \\
\text { soluble oxalate. }\end{array}$ & Ppts. calcium. & $\begin{array}{l}\text { Add soluble calcium } \\
\text { salt. }\end{array}$ \\
\hline Citrated. & De-ionises Ca. & Add soluble calcium salt. \\
\hline Hirudinised. & Combines with thrombin. & Add thrombin. \\
\hline Peptonised. & $\begin{array}{l}\text { Stimulates production of } \\
\text { anti-prothrombin. }\end{array}$ & $\begin{array}{l}\text { Dilute to decrease con- } \\
\text { centration of anti-pro- } \\
\text { thrombin, or add tis- } \\
\text { sue extractorkephalin } \\
\text { or pass in } \mathrm{CO}_{2} \text { gas. }\end{array}$ \\
\hline
\end{tabular}

The similarity in proportion is not very striking because the figures given are from analysis of the ocean as it is to-day. What 
we should have is the analysis of the ocean in prevertebrate days. Not only has the concentration of the salts of the sea undergone change, but alterations have taken place in the proportion of its constituents. Sodium and magnesium have increased in concentration and are still increasing. Material lixiviated from river beds, etc., is rich in those salts.

On the other hand, potassium and calcium have decreased. The formation of soil leads to the abstraction of potassium from the river water. Water evaporated from the ocean contains potassium in not inconsiderable amounts. The rain falling in the region of Caen is responsible for an annual increment to the land of 1.23 tons of potassium per square mile. Rivers discharge more calcium into the ocean than they do of sodium, magnesium or potassium and yet the concentration of this element appears to be fairly steady. The cause for this lies in the formation of rock-beds of gypsum $\left(\mathrm{CaSO}_{4}\right)$ and limestone $\left(\mathrm{CaCO}_{3}\right)$ and in the formation of calcareous skeleta $\left(\mathrm{CaHPO}_{4}\right)$. From the study of fossil seas and of lakes surrounded by pre-Cambrian formations as well as from other geological considerations it has been decided that the ocean of Cambrian days had a ratio of salts somewhat as follows.

\begin{tabular}{|c|c|c|c|c|c|c|c|}
\hline & & & & $\mathrm{Na}$ & $\mathbf{K}$ & $\mathrm{Ca}$ & $\mathbf{M g}$ \\
\hline Present day & - & - & - & 100 & $3 \cdot 6$ & $3 \cdot 9$ & $11 \cdot 9$ \\
\hline Cambrian & - & - & - & 100 & $6 \cdot 0$ & $3 \cdot 0$ & $2 \cdot 0$ \\
\hline Serum - & - & - & - & 100 & $6 \cdot 6$ & $2 \cdot 5$ & 0.8 \\
\hline
\end{tabular}

The following table (from Macallum) shows the evolution of plasma through a series of animals.

TABLE XXXIII.

A. Marine Invertebrates.

$\begin{array}{llcccc} & & \mathrm{Na} & \mathrm{K} & \mathrm{Ca} & \mathrm{Mg} \\ \text { Ocean - } & - & 100 & 3 \cdot 61 & 3 \cdot 84 & 11.99 \\ \text { Limulus polyphemus } & - & 100 & 5 \cdot 30 & 3.83 & 11 \cdot 67 \\ \text { Aurelia flairdula - } & - & 100 & 5 \cdot 18 & 4 \cdot 13 & 11.43\end{array}$

B. Elasmobranchs, Teleosts, Mammals.

$\begin{array}{llllllll}\text { Dog-fish - } & - & - & - & 100 & 4.61 & 2 \cdot 71 & 2.46 \\ \text { Pollock - } & - & - & - & 100 & 4.33 & 3 \cdot 10 & 1.46 \\ \text { Dog - - } & - & - & - & 100 & 6 \cdot 86 & 2.52 & 0.81 \\ \text { Man - } & - & - & - & 100 & 9 \cdot 22 & 3.37 & 0.76\end{array}$

The salt content of the plasma is regulated by the kidneys. It is interesting to note that while the blood is Cambrian the tissues are decidedly pre-Cambrian in their salt content, e.g. Muscle. $\mathrm{Na}=100, \mathrm{~K}=400, \mathrm{Ca}=\mathbf{9} \cdot \mathbf{3}, \mathrm{Mg}=\mathbf{2 6} \cdot 4$. This may be in part 
accounted for by the adsorption of salts by the protoplasmic colloids. Of these salts one of the most important is sodium bicarbonate on account of its power of neutralising acid. 'This has been termed its "buffer" value-a term which, although faulty, has crept into the writings of physiologists and clinicians and seems firmly ensconced there because it is handy. As Prof. Bayliss points out, a railway buffer absorbs shock but not the engine, while $\mathrm{NaHCO}_{3}$ absorbs the acid.

The amount of $\mathrm{NaHCO}_{3}$ present in plasma has been called the alkali reserve of the body. How does it act ? The addition of acid to bicarbonate may be represented by the equation

$$
\mathrm{NaHCO}_{3}+\mathrm{HA}=\mathrm{NaA}+\mathrm{H}_{2} \mathrm{O}+\mathrm{CO}_{2} \text {. }
$$

Until nearly all the bicarbonate has been acted on by the acid, no increase in acidity can be detected. This is a mechanism of great value to the organism. Acids are constantly being produced in the tissues, especially in muscle. Unless the organism had an alkali reserve, the concentration of hydrogen ions would so increase after muscular exercise, for instance, that a serious derangement of metabolism would ensue (see Preservation of Neutrality, Chap. XXX.).

\section{Formed Elements.}

The formed clements borne by the plasma have a volume of half the plasma and weigh about the same amount.

$\begin{array}{lllcc} & & & \text { Plasma. } & \text { Corpuscles. } \\ \text { Volume } & - & - & 2 & 1 \\ \text { Weight } & - & - & 3 & 2\end{array}$

This may be determined by the haematocrite (see p. 422) or by an ingenious method due to Stewart. He made use of the fact that the presence of corpuscles reduces the electrical conductivity of plasma in proportion to their number.

They are of two kinds, viz. : the leucocytes and erythrocytes. The former have been discussed in Chaps. XII. and XV. They play a further part in stopping bleeding from a wound. As we saw (p. 237) the thigmocytes (altered leucocytes) on undergoing cytolysis set free thrombin. The blood contributes in a second way towards the arrest of haemorrhage, viz. : by the agglutination of certain cells to form a plug closing the opening. The primary event is the local adhesion of the thigmoeytes to the edge of the wound. These altered cells acquire stickiness and any other formed element coming into contact with them adheres. In this way a plug is formed. 
The erythrocytes are the carriers, submerged barges into which are packed the oxygen for the tissues and the carbon dioxide from the tissues.

Number. In health, a man has about $5,000,000$ of these corpuscles per cubic millimetre of blood.

Shape. Mammals (except Camelidae) have circular biconcave discoids. The camels have elliptical biconvex corpuscles.

Size. Human corpuscles have a fairly constant diameter of about 7 to 8 micro-millimetres.

Colour. Individual corpuscles appear pale yellow, but in bulk they appear red.

Structure. The pigment is enclosed in a fine sponge-work of lipoid nature which also forms the covering membrane of the corpuscle. This membrane is elastic, allowing the corpuscles to elongate in passing along capillary vessels.

History. Erythrocytes are born in the red bone marrow. The young corpuscle is called an erythroblast and has a nucleus. It may live and die in its place of origin. In that case the valuable constituent of the pigment, the iron, is retained by the marrow and used in the construction of other cells. Most of the cells, however, do not remain in the bone marrow. Their nuclei atrophy and the enucleated corpuscles are shot into the blood stream on their way to the liver, the crematorium of the body, where they are alleged to be destroyed after 10 to 14 days. Those which die by the way are taken out of the circulation by the spleen. Economical Nature in this way makes use of the dying erythrocyte as a beast of burden.

\section{Viscosity of whole blood.}

The presence of corpuscles prolongs the time taken by whole blood to traverse a viscosimeter as compared with plasma. The following figures show this. Serum was used instead of plasma, to prevent complications by clot formation.

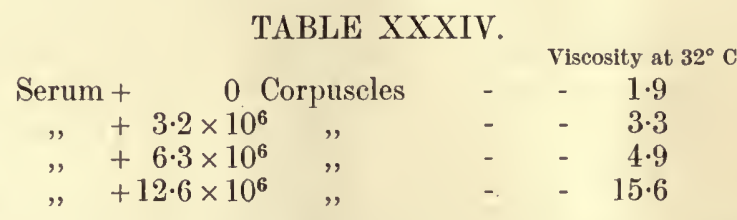

The last high value was due to the mechanical blocking of the capillary tube by the corpuscles which tend to agglutinate when so concentrated. 
The stroma (and capsule) are colloidal in character. The enmeshed fluid is also colloidal and, therefore, the corpuscle as a whole will act as a colloid. Acids increase the power of colloids to imbibe water and, therefore, one would expect that $\mathrm{CO}_{2}$ would cause an inereased imbibition of water by the corpuseles and, eonsequently, increase the viseosity of blood, due $(a)$ prineipally to the absorption of water from the plasma rendering it more viscous and $(b)$ the swelling of the corpusele itself. The experimental proof of this has not been very satisfactory, but some workers have observed increased viscosity in venous blood, especially in eases where the unsaturation of haemoglobin is low (pneumonia, gas poisoning).

Viscosimetric measurements afford a means of determining the volume of blood corpuseles. Viscosity depends principally on the total volume of corpuscles per unit volume of fluid. Having determined (i) the viscosity of whole blood $=p c$, and (ii) that of the plasma $=p$, the total eorpuseular volume $K$ may be derived from the formula

$$
\mathbf{1}-K=\frac{p}{p c}
$$

If the total number of corpuscles per unit volume be $N$, then the average volume of each will be $K / N$.

The results obtained from such an indirect method are fairly regular but eannot be considered as absolutely accurate, as viscosity does not depend, in prineiple, on either the number or the volume of corpuscles, but on the effective surface, i.e. on the area liable to friction (see relation between viscosity and bloodpressure).

The sponge-work, which is a colloidal eomplex of protein, lecithin, kephalin, cholesterol, ete., with adsorbed electrolytes, eneloses water and electrolytes in solution and the pigment haemoglobin. This pigment is an electropositive protein containing 0.399 per eent. iron. It is not in true solution in the corpuseles. The eorpusele contains 32 per eent. $\mathrm{Hb}$ in 63 per cent. water, while the solubility in water is $\mathbf{1 8}$ per eent. It may be set free by rupturing the eorpusele. This is known as haemolysis and haemolysed blood, because it is similar in colour to erimsonlae-resin (a gum extruded from tropical trees after puneture by the lac insect), is said to be laked.

Blood may be laked by various methods :

1. Mechanical, grinding eorpuseles with sand or powdered glass and taking up with salt solution. 
2. Physical, freezing and thawing, heat, condenser discharges, ete.

3. Endosmosis, dropping blood into water or into a hypo-tonic solution.

4. Exosmosis (see crenation), dropping blood into a hypertonic solution.

5. Action on Lipoid constituents of capsule.

i. Anaestheties are lipoid solvents.

ii. Bile salts and pigments affect permeability of lipoid membranes.

iii. Glucosides, e.g. saponin are adsorbed by the membrane (Willard Gibbs' Law), because they lower surface tension. They then insert themselves into the texture of the membrane and increase its permeability (see p. 111).

6. Biological Agents.

i. Toxins of certain bacteria produce haemolysis, e.g. tetanolysin of B. 'Tetani; megatheris lysin of $\mathrm{B}$. Megatherium; toxic lysins of staphylococcus and B. pyocyaneus.

ii. Cobra and rattlesnake venom cause laking both in vivo and in vitro.

iii. The serum of one animal is often haemolytic for the blood of a different species.

iv. Certain phyto-albumins, e.g. abrin, ricin, and robin produce haemolysis.

\section{Chemical Agents.}

Haemolysis may be caused by the ingestion or injection of certain drugs, e.g. chlorates, nitrites, nitrobenzene, aniline derivatives (e.g. acetanilide and phenacetin) quinine. These, generally, partially convert the haemoglobin into methaemoglobin (q.v.).

The laking of blood thus depends on altering the permeability of the stroma or capsule of the erythrocyte. Normally this membrane is impermeable to colloids and to most crystalloids. This has been determined by estimating the eleetrical conduetivity of blood before and after laking. The corpuscles hinder the passage of small electrical charges because their walls are impermeable to ions carrying the eharge. On rupturing the membranes these ions get a free passage and the conductivity of the blood increases. That this increase is not due to the liberation of haemoglobin may be shown by fixing the corpuseles with formalin which prevents the egress of the pigment but not of the salts. 
Laked blood has a lower viseosity than whole blood due to the pseudo-viscosity eaused by the eorpuscles.

\section{Haemolysis by freezing and thawing.}

It has been noticed that blood eould be repeatedly frozen and thawed as in the determination of the osmotic pressure (freezing point method) with little or no laking. If, however, the blood was suddenly cooled to below the freezing point of water, was kept at that temperature for a long time, or was rapidly thawed, pronounced haemolysis was produeed. Burton-Opitz prepared completely laked blood by eight times freezing it solid, and thawing it rapidly. The mechanism of this laking is not elearly understood. Possibly the withdrawal of water from the membranc to form ice might be adduced as sufficient reason (Guthrie). (Cf. Test for frozen meat.)

\section{Endosmotic laking.}

Normally, the corpuscle has within it a coneentration of eolloids and of crystalloids isotonie with $\mathbf{0 . 9}$ per eent. sodium chloride. A similar state prevails, as we have seen, in the plasma in which the corpusele is immersed. The corpuscular membrane is almost semipermeable. That is, water may pass through it but not certain salts in solution and not eolloids. If the concentration of salts and colloids inside and out of the membrane were not exactly balanced, water would pass from the place of low concentration to that of high eoncentration (see Osmotic pressure, Chap. V.). That means that blood dropped into water or into a solution of lower eoncentration than $0.9 \mathrm{NaCl}$ would gain water. Water would pass into the eorpuscle, eausc it to swell, and when the limit of elasticity had been passed, the corpusele would burst and scatter its contents into the fluid.

\section{Crenation.}

Loss of water by evaporation or by immersion in a solution more concentrated than $\mathbf{0 . 9}$ per cent. $\mathrm{NaCl}$ causes the corpuscles to shrink and shrivel. They then break up into fragments, duc to inequalities in the tensile strength of the corpuscle. Most peculiarly the first stage in exosmotic laking is a swelling of the corpuscle. Some change in the physieo-chemical state of the protein moicty in the envelope is indicated. It has been shown that the power of colloids to imbibe water may be altered by alterations in their crystalloid eontent. 


\section{CHAPTER XXII}

\section{RESPIRATORY FUNCTION OF THE BLOOD}

" There is no instance in whieh it can be proved that an organ increases its activity under physiologieal eonditions without also increasing its demand for oxygen."

BARCROFT.

THE erythrocyte assumes importance as the earrier of the respiratory gases, oxygen and carbon dioxide. Air has an average eomposition of about $\mathbf{7 9}$ volumes per cent. of nitrogen and 21 of oxygen. The amount of carbon dioxide present is so small ( 0.03 per cent.), that it may for the present be neglected. The partial pressure of oxygen, therefore, at normal pressure would be $\frac{21}{100} \times 760=159.6 \mathrm{~mm}$. of mercury. The partial pressure of oxygen in the lung is, on account of the carbon dioxide and aqueous vapour present, much less than this. Alveolar air contains in 100 c.c. about 5.5 vols. of $\mathrm{CO}_{2}, 13$ vols. of $\mathrm{O}_{2}$ and $79 \cdot 5$ vols. of $\mathrm{N}$. Their partial pressures will be (at normal barometric pressure)

$$
\begin{aligned}
\mathrm{O}_{2} & =\frac{13}{100} \times 760=98.8 \mathrm{~mm} . \mathrm{Hg} . \\
\mathrm{CO}_{2} & =105 \times 760=41.8 \mathrm{~mm} . \mathrm{Hg} . \\
\mathrm{N} & =7.9 .5 \times 760=604.2 \mathrm{~mm} . \mathrm{Hg} .
\end{aligned}
$$

The partial pressure of the oxygen in the lung is thus about $2 / 3$ of its partial pressure in the atmosphere. The percentage of nitrogen shows an apparent increase because the total air is decreased in the ratio $\frac{300}{350}$ by the absorption of oxygen without a corresponding production of carbon-dioxide. Then, too, the tension of aqueous vapour at body temperature is by no means negligible. It amounts to about $50 \mathrm{~mm}$. of $\mathrm{Hg}$. That is, dry air at $760 \mathrm{~mm}$. $\mathrm{Hg}$. when taken into the body has its pressure redueed to $760-50=710 \mathrm{~mm}$. $\mathrm{Hg}$. This causes the actual oxygen pressure to fall to $92 \cdot 3$, and carbon-dioxide to $39 \mathrm{~mm}$. $\mathrm{Hg}$.

The quantity of gas by weight (or by volume reduced to N.T.P.) dissolved in a liquid is proportional to its partial pressure provided chemical and physical conditions remain constant. If, for 
instance, the pressure of the gas be doubled, twice as much of it will go into solution. The appended table contains experimental verifications of this Law of Henry.

\begin{tabular}{ccc}
\multicolumn{4}{c}{ TABLE XXXV. } \\
Solubility & of $\mathrm{CO}_{2}$ IN WATER AT $15^{\circ} \mathrm{C}$. \\
P. & $\mathrm{V}$. & V./P. \\
69.8 & 0.94 & 0.0135 \\
128.9 & 1.86 & 0.0144 \\
$200 \cdot 2$ & 2.90 & 0.0145 \\
311.0 & 4.5 & 0.0145
\end{tabular}

where $\mathrm{P}=$ pressure in $\mathrm{mm}$. of $\mathrm{Hg}$. of $\mathrm{CO}_{2}$, at $15^{\circ} \mathrm{C}$.

$\mathrm{v}=$ volume of $\mathrm{CO}_{2}$ (measured at N.T.P.) absorbed by 1 c.c. of water

(The same volume of gas at constant temperature is absorbed by the fluid, no matter what the pressure is. Increase of pressure proportionally increases the weight of unit volume. Thus, if one volume of water dissolves one volume of gas weighing 1 gram at 1 atmosphere pressure, then, if the pressure be raised to two atmospheres, 1 volume of water would dissolve 1 volume of the gas weighing 2 grams, or if reduced to normal pressure, 1 volume of water would dissolve 2 volumes of the gas weighing 2 grams.)

Absorption coefficient (usually denoted by the Greek letter $\alpha$ ).

Different gases, just like different solids, vary in their solubilities. The volume of gas (at N.T.P.) which dissolves in 1 c.c. of water under a pressure of one atmosphere is termed its absorption coefficient, e.g. 1 c.c. of water will dissolve at N.T.P. 0.0489 c.c. of oxygen, 0.0239 c.c. of nitrogen, and 1.713 c.c. of carbon dioxide. The volume of gas absorbed by $\mathbf{I}$ c.c. of water under any pressure may be found by the following equation :

$$
\text { where } \begin{aligned}
L & =\alpha p, \\
& =\text { amount of gas dissolved, } \\
\alpha & =\text { absorption coefficient, } \\
p & =\text { pressure in atmospheres. }
\end{aligned}
$$

Increase of temperature causes the solubility of gases to decrease.

TABLE XXXVI.

Absorption Coefficients at Various Temperatures.

$\begin{array}{cccc}\text { Temperature. } & \text { Oxygen. } & \text { Nitrogen. } & \text { Carbon-dioxide. } \\ 0^{\circ} \mathrm{C} . & 0.0489 & 0.0239 & 1.713 \\ 10^{\circ} \mathrm{C} . & 0.0380 & 0.0196 & 1.194 \\ 20^{\circ} \mathrm{C} . & 0.0310 & 0.0164 & 0.878 \\ 30^{\circ} \mathrm{C} . & 0.0262 & 0.0138 & 0.665 \\ 40^{\circ} \mathrm{C} . & 0.0231 & 0.0118 & 0.530\end{array}$




\section{Effect of solutes.}

Plasma contains erystalloids and colloids. The erystalloids are all more or less hydrated. They combine loosely with a eertain amount of water and, therefore, reduce the effective absorption volume. Similarly, the emulsoid colloids present reduee the effective concentration of water by imbibition. They, however, are able to adsorb a quantity of gas (see p. 66).

It has been found that at the pressure of about $90 \mathrm{~mm}$. Hg., whieh we saw oxygen had in the lung, 100 c.c. of plasma will dissolve $\mathbf{0} \cdot 273$ e.e. of oxygen (measured at N.T.P.). The tension of oxygen in the tissues eannot be less than zero, and, therefore, one has as a maximum amount 0.273 e.c. of oxygen for every 100 e.c. of plasma passing through the tissue. A cat's gastroenemius muscle weighing 20 grams uses about $0 \cdot 24$ c.c. of oxygen per minute and, therefore, would need to have at least 100 e.c. of plasma passing through it per minute. A warm-blooded animal would need to have about twice as much plasma by volume as the present volume of its body. The body would be unable to eope with the wieght of its own eirculating fluid. For example, the average man weighing $66 \mathrm{~kg}$. would have to earry, in addition, at least $140 \mathrm{kgs}$. of plasma, thus inereasing his total weight to 206 kilos. As Barcroft puts it, " man would never have attained any activity which the lobster does not possess, or had he done so it would have been with a body as minute as the fly's." In the experiment quoted above the actual amount of blood passing through the eat's muscle was 4.5 e.c. per min.--just under a twentieth of the amount necessary when plasma alone was considered. This is due to the specific oxygen capacity of the haemoglobin in the blood.

The following table gives the volume (in e.e. at N.T.P.) of oxygen, nitrogen and earbon dioxide which will dissolve in 100 c.c. of fluid at $38^{\circ} \mathrm{C}$. and $760 \mathrm{~mm}$. pressure.

\section{TABLE XXXVII.}

\begin{tabular}{|c|c|c|c|c|c|}
\hline Water & - & - & $\begin{array}{c}\text { Oxygen. } \\
2 \cdot 37\end{array}$ & $\begin{array}{c}\text { Nitrogen } \\
1 \cdot 2\end{array}$ & $\begin{array}{c}\text { Carbon-dioxide } \\
5.55\end{array}$ \\
\hline Plasma & - & - & $2 \cdot 3$ & $1 \cdot 2$ & $5 \cdot 41$ \\
\hline Blood & - & - & $2 \cdot 2$ & $1 \cdot 1$ & $5 \cdot 11$ \\
\hline
\end{tabular}

In addition to the amount dissolved one has to eonsider the amount held by the haemoglobin. The table given below contains the results of a series of experiments on the blood of a horse, 
where the amount of oxygen in the blood was determined at various pressures.

TABLE XXXVIII.

\begin{tabular}{|c|c|c|c|c|}
\hline \multirow{2}{*}{$\begin{array}{l}\text { Oxygen tension } \\
\text { in inm, of } \mathrm{Hg} \text {. } \\
\text { (1) }\end{array}$} & \multicolumn{2}{|c|}{$\begin{array}{l}\text { Oxygen in c.c. (at N.T.P.) } \\
\text { per } 100 \text { c.c. of biood. }\end{array}$} & \multirow{2}{*}{$\begin{array}{c}\text { Degree of } \\
\text { Saturation } \\
\text { of Hb. \%. } \\
\text { (1) }\end{array}$} & \multirow{2}{*}{ 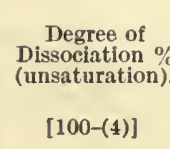 } \\
\hline & $\begin{array}{l}\text { Bound by } \\
\text { Haemogiobin. } \\
\text { (2) }\end{array}$ & $\begin{array}{l}\text { Dissolved in } \\
\text { Plasma. } \\
\text { (3) }\end{array}$ & & \\
\hline 10 & $6 \cdot 0$ & $0 \cdot 020$ & $30 \cdot 0$ & $70 \cdot 0$ \\
\hline 20 & $12 \cdot 9$ & $0 \cdot 041$ & $64 \cdot 7$ & $35 \cdot 3$ \\
\hline 30 & $16 \cdot 3$ & 0.061 & $81 \cdot 6$ & $18 \cdot 4$ \\
\hline 40 & $18 \cdot 1$ & $0 \cdot 081$. & $90 \cdot 4$ & $9 \cdot 6$ \\
\hline 50 & $19 \cdot 1$ & $0 \cdot 101$ & $95 \cdot 4$ & $4 \cdot 6$ \\
\hline 60 & $19 \cdot 5$ & $0 \cdot 121$ & $97 \cdot 6$ & $2 \cdot 4$ \\
\hline 70 & $19 \cdot 8$ & $0 \cdot 141$ & $98 \cdot 8$ & $1 \cdot 2$ \\
\hline 80 & $19 \cdot 9$ & $0 \cdot 162$ & $99 \cdot 5$ & 0.5 \\
\hline 90 & 19.95 & 0.182 & $99 \cdot 8$ & 0.2 \\
\hline 150 & 20 & $0 \cdot 303$ & 100 & $0 \cdot 0$ \\
\hline
\end{tabular}

If the tensions (1) are taken as abscissae and the degree of saturation (4) as ordinates, a curve (Fig. 56, heavy line) is obtained called the dissociation curve of blood. This curve is compound and may be resolved into its component factors :

(a) Pure Ilaemoglobin. The dissociation curve for pure haemoglobin will be found in Fig. 56, dotted line. It differs from that of whole blood in that its contour is that of a rectangular hyperbola.

(b) Solutes. The materials in solution in the blood corpuscles and in the plasma are the cause of the difference between the dissociation curve of pure haemoglobin and haemoglobin in blood. If the pure haemoglobin is dissolved in the actual salts which are present in the red blood corpuscles, the curve of the haemoglobinsalt solution will be found to lie, point for point, on that of whole blood. Examination of such curves will demonstrate the value of these salts in the unloading of oxygen from the corpuscle.

From the curves it will be seen that at the pressure of oxygen in the lung-i.e. $90 \mathrm{~mm}$. Hg.-both whole blood and pure haemoglobin solution are saturated to about the same extent with oxygen. (To say that they are 92 per cent. saturated is equivalent to saying that 92 per cent. of the haemoglobin has got its full cargo of oxygen, and 8 per cent. has no oxygen at all. This must not be considered as admitting the correctness of such a supposition. It may be that each molecule of haemoglobin has got 92 per cent. of its maximum load.) That is, the presence of solutes does not materially modify the oxygen capacity of the blood at high tensions of oxygen. In the tissues, the tension of oxygen is low, say $15 \mathrm{~mm}$. Hg. 
At this tension, whole blood can only be 15 per cent. saturated. Therefore the oxygen carried by 77 per cent. $(92-15)$ of the haemoglobin, is discharged. On the other hand, pure haemoglobin is still 65 per cent. saturated at $15 \mathrm{~mm}$. Hg. It will only be able to discharge the oxygen borne by 27 per cent. of its haemoglobin. In other words, because of the presence of solutes, whole blood is able to set free in the tissues the full amount of oxygen that could be obtained from pure haemoglobin, with, in addition, the amount that would be carried by the haemoglobin represented by the space between the heavy curve and the dotted curve in Fig. 56. That is, salts so aid in the unloading of oxygen that 50 per cent. of the haemoglobin

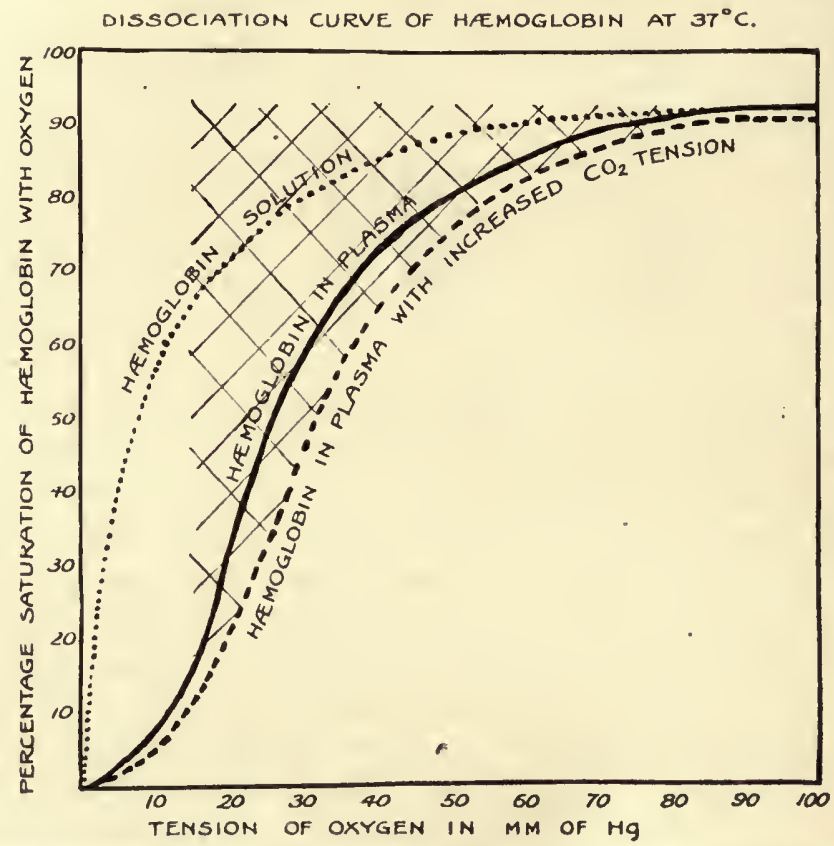

FIG. 56.-Dissociation curve representing the equilibrium between oxygen tension, oxy-haemoglobin and reduced haemoglobin :

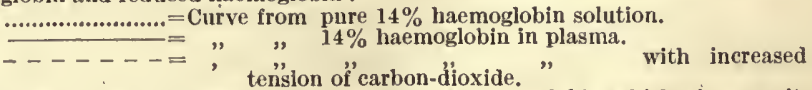

The hatched portion represents the amount of haemoglobin which gives up its oxygen when the oxygen tension is reduced from 100 to $15 \mathrm{~mm}$. $\mathrm{Hg}$.

that would otherwise have retained its oxygen, is induced to give it up to the tissues. Because of the solutes, whole blood becomes an effective carrier of oxygen, and the total volume of fluid (and mass of haemoglobin) is kept within reasonable limits.

\section{Nature of union.}

The average normal man has about 5 litres of blood, $2 \cdot 5$ litres of this is oceupied by $25 \times 10^{12}$ red corpuseles with a total surface of about 3000 sq. metres. When fully saturated with oxygen at 
atmospheric pressure (160 mm. $\mathbf{H g}$.) each litre of blood will take up 200 c.c. of oxygen. Leaving out of account the relatively small amounts of oxygen carried in solution in the plasma and adsorbed by the plasma proteins, we may calculate that each corpuscle will carry oxygen to the extent of

$$
\frac{\text { Total oxygen capacity of blood }}{\text { Total number of corpuscles }}=\frac{1000}{25 \times 10^{12}}=4 \times 10^{-11} \text { c.c. }
$$

Each cubic centimetre of oxygen will need $25 \times 10^{9}$ corpuscles to carry it.

Further, the total iron content of human blood is about $\mathbf{2 . 5}$ grams (Schmidt).

That is, each gram of iron is associated with $1000 / 2 \cdot 5=400$ c.c. of oxygen-a figure closely approximating to Barcroft's experimental finding of 401 c.c. Normal blood contains 14 grams per cent. of haemoglobin. It follows that each corpuscle carries $140 \times 5$ $\frac{140 \times 5}{25 \times 10^{12}}=28 \times 10^{-12}$ grams of haemoglobin. In other words, each cubic centimetre of oxygen postulates the presence of

$$
\frac{28 \times 25 \times 10^{9}}{10^{12}}=0.7 \text { gram. of } \mathrm{Hb} \text {. }
$$

The iron content of $\mathrm{Hb}$. must therefore be $\frac{10}{7 \times 400}=\frac{1}{280}$ gram per gram of $\mathrm{Hb}$. Putting this in molecular terms, one molecular proportion of iron ( 56 grams) enters into the composition of 15,680 grams of $\mathrm{Hb}$. The molecular weight generally given for $\mathrm{Hb}$ is 16,660 .

Evidence has been produced which shows that when haemoglobin is fully saturated with oxygen there are 401 c.c. of oxygen for every gram of iron. That is, each combining proportion of iron ( 56 grams) co-exists with two combining proportions (32 grams) of oxygen. From this, some deduce the presence of a compound $\mathrm{FeO}_{2}$ in haemoglobin. That may be. On the other hand, the idea of a chemical combination between haemoglobin and oxygen raises hosts of difficultics which would not arise on the hypothesis of adsorption of gas on a colloidal surface. However, no reliable direct experimental evidence bearing on this has come to hand. If analogics could be taken as a proof instead of analysis, the adsorption theory would hold the field undisputed. 


\section{How the tissues unload the oxygen.}

These little barges $7 \cdot 6 \mu$ in diameter squecze along the capillary vessels in the tissues. During their passage along a tube with a diameter less than their own the corpuscles naturally undergo distortion. This distortion has at least one effect on the loading and unloading of the oxygen from the corpuscles. It puts on the brake, slows down the corpuscles and gives the dock-labourers and others opportunity to carry out their work.

Another physical factor comes into play, viz.: alterations of temperature, and that has a profound effect on both the amount of gas liberated and the speed at which it is handled. The temperature in the lung where oxygen is taken on board is usually less than $37^{\circ} \mathrm{C}$. while the temperature of active tissue may be greater (see Chap. XXXI.).

Increase in temperature increases the desaturation of hacmoglobin. The amount of desaturation brought about by an increase in temperature may be calculated from the laws of van't Hoff and Arrhenius. The process of saturation and desaturation may be represented by the reaction formula

$$
\mathrm{Hb}+\mathrm{O}_{2} \rightleftharpoons \mathrm{HbO}_{2} \text {. }
$$

The velocity of this reaction depends, other things being equal, on the active masses of oxygen $-C_{0}$ and of hacmoglobin $C_{\mathrm{R}}$, i.e. $v=k\left(C_{0} \times C_{\mathrm{R}}\right)$.

Now $k_{1}$, the velocity constant of the saturation process, and $k_{2}$, the corresponding constant for desaturation, vary with the temperature. We have seen (p. 247) that $\alpha$, the absorption coefficient of oxygen in blood, varies inversely with the temperature.

$$
C_{\mathrm{H}}=C_{\mathrm{k}} \times\left(\frac{k_{1}}{k_{2}} \times \frac{\alpha}{760}\right) \times p=C_{\mathrm{R}} \cdot K \cdot p
$$

where $C_{\mathrm{\Pi}}=$ concentration of oxyhacmoglobin and $p=$ oxygen pressure.

This value, $K$, is constant for each temperature, and by the law of van't Hoff the values of $K$ for any two temperatures $T_{1}$ and $T_{2}$ are related by the equation

$$
K_{2}=K_{1} \epsilon^{\frac{-\pi}{2}} \cdot \frac{T_{2}-T_{1}}{T_{2} T_{1}}
$$

( $\epsilon=$ base of Napicrian logs, $q=$ heat evolved when 1 gram molecule of $\mathrm{Hb}$ unites with 1 gram molecule of oxygen). 
For example, let us try to determine what desaturation would arise from raising the temperature from $36^{\circ} \mathrm{C}$. to $39^{\circ} \mathrm{C}$.

Here

and

$$
\begin{aligned}
T_{1} & =273+36=309 \text { absolute } \\
T_{2} & =273+39=312 \quad, \\
q & =28,000 \text { cals., } \\
K_{39} & =K_{36} \epsilon^{\frac{-28000}{2}} \cdot \frac{3}{309 \times 312}=K_{36} \epsilon^{-0 \cdot 4356} .
\end{aligned}
$$

If $K_{36}$ be 30 per cent., then $K_{39}$ is equal to $30 \epsilon^{-0^{*} 4356}=\mathbf{1 9 \cdot 4}$, we find that haemoglobin which was 30 per cent. saturated at $36^{\circ}$ becomes only $19 \cdot 4$ per cent. saturated at $39^{\circ}$.

An increase in $3^{\circ} \mathrm{C}$. between the values of 36 and 39 causes the $\mathrm{HbO}_{2}$ to lose oxygen to the extent of about 10 per cent. of full saturation.

A physico-chemieal factor, however, is much more potent than temperature in producing desaturation. Active tissues tend to become acid. In dealing with muscle, we have seen how lactie acid is set free as the result of activity and how oxygen is required before it ean be replaced in the muscle complex. This free lactic acid performs another service. Either directly by partially diffusing into the surrounding lymph or indirectly by produeing alterations in the Helmholtz (polarising) electric charge, it causes a potential alteration in the hydrogen ion concentration of the tissue fluid. By a series of changes which we have already briefly considered, and to which we shall return, the net effect is to increase the tension of $\mathrm{CO}_{2}$ in the capillaries. The molecules of $\mathrm{CO}_{2}$ are to be the new passengers on the erythrocytes, and because of their acidity they cause an aggregation of the colloidal particles of haemoglobin and a marked desaturation. Carbon-dioxide acts as if the tension of oxygen in the tissues were reduced to $10 / 24$ ths of its real value. That is, haemoglobin parts with as much oxygen at a tissue tension of oxygen of $24 \mathrm{~mm}$. $\mathbf{H g}$. as if the tension of oxygen were only $10 \mathrm{~mm}$. For example, blood which, in the absence of $\mathrm{CO}_{2}$ would be 30 per cent. desaturated is actually desaturated to the extent of 78 per cent. by the presence of a $\mathrm{CO}_{2}$ tension of $40 \mathrm{~mm}$. Hg. The blood beeomes now a carrier of $\mathrm{CO}_{2}$ from the tissues to the lungs (Fig. 56, dash line curve).

IIandling of Oxygen. Consider an inland village supplied by a canal coming as close as possible to the community. Internal communieation is effected by waterways fed from the eanal. The by-products of manufacture (sent elsewhere for elaboration) are transported along these waterways to the canal and the same 
gangs of labourers unload the raw material from the barges and float it up to the factories.

To take a specific instance, muscle, as a result of its activity, produces carbon dioxide. This weak acid acts on the sodium hydrogen phosphate of the tissue fluid according to the following equation :

$$
\mathrm{H}_{2} \mathrm{CO}_{3}+\mathrm{Na}_{2} \mathrm{HPO}_{4} \rightleftharpoons \mathrm{NaH}_{2} \mathrm{PO}_{4}+\mathrm{NaHCO}_{3} .
$$

The sodium bicarbonate so formed finds its way into the blood stream. Now in plasma, bicarbonatc is in equilibrium with free dissolved carbon dioxide when the volume of $\mathrm{CO}_{2}$ in solution is $-1 / 20$ of the volume of $\mathrm{CO}_{2}$ combined

The result of the influx of $\mathrm{NaHCO}_{3}$ is to increase the volume of free $\mathrm{CO}_{2}$ in order to preserve the ratio $\frac{\mathrm{CO}_{2} \text { free }}{\mathrm{CO}_{2} \text { combined }}=\frac{1}{20}$. Briefly, the $\mathrm{CO}_{2}$ tension in the muscle capillaries tends to increase. As stated above, increase of $\mathrm{CO}_{2}$ tension causes increased unloading of oxygen from haemoglobin.

That is to say-increascd activity postulates increased energy usage, which renders necessary an immediately increased supply of oxygen. The amount of oxygen required is liberated by the desaturating action of $\mathrm{CO}_{2}$-the main chemical product of the activity.

The amount of oxygen in the blood does not control oxidation in the tissues, but the call for oxygen by the tissues controls the rate of unloading of oxygen.

\section{Transport of carbon dioxide.}

The principle underlying the transport of carbon dioxide is identical with that enunciated for oxygen. In the tissues, the tension of carbon dioxide is relatively high and the gas passes to the blood, is carried to the lungs and is there eliminated. Hacmoglobin, once freed from its load of oxygen, takes on a cargo of carbon dioxide. But haemoglobin is not the sole means of transport. Carbon dioxide is about twenty-five times as soluble as oxygen under similar conditions. Relatively more $\mathrm{CO}_{2}$ will, therefore, be carried in true solution in the plasma. In addition to this amount (which we have just seen is carefully regulated) a considerable quantity of the gas is adsorbed to the various colloids of the plasma. (i) Each gram of fibrinogen can carry 1/30 gram of $\mathrm{CO}_{2}$. (ii) Serum proteins may adsorb a measurable quantity of carbon dioxide-at the lowest estimate, over 5 per cent. It is 
obvious that while these factors may almost be neglected in the consideration of the transport of oxygen, they have to be reckoncd with in the case of carbon dioxide.

\section{TABLE XXXIX.}

Partition of $\mathrm{CO}_{2}$ in 100 c.c. of Defibrinated Blood (Haematocrite Value $=51$ ).

$\begin{array}{lccccc}\text { Oxygenated } & - & \mathrm{CO}_{2} \text { tension. } & \begin{array}{c}\text { Vol. of } \mathrm{CO}_{2} \\ \text { in blood. }\end{array} & \begin{array}{c}\text { Vol. of } \mathrm{CO}_{3} \\ \text { in serum. }\end{array} & \begin{array}{c}\text { Vol. of } \mathrm{CO}_{2} \\ \text { in corpuscles. }\end{array} \\ \text { Reduced - } & - & 40 & 45 \cdot 0 & 25 \cdot 9 & 19 \cdot 1 \\ & 40 & 50 \cdot 4 & 28.0 & 22.4\end{array}$

That is, in arterial (whole) blood, there is about 50 c.c. of $\mathrm{CO}_{2}$, of which amount the fibrinogen carries about 5 c.c., the serum (proteins, water and crystalloid bases) about 26 c.c. and the corpuscles about 19 c.c.

\section{TABLE XL。}

100 c.c. of Arterial Blood ( $\mathrm{CO}_{2}$ tension $40 \mathrm{~mm}$., $\mathrm{O}_{2}$ tension $100 \mathrm{~mm}$.).

Corpuscles $\quad$ in solution - - 0.85 c.c. $51 \%$ by volume $\}$ carry $\frac{2}{5}$ of total $\mathrm{CO}_{2}\left\{\begin{array}{l}\text { lind }\left(e . g . \mathrm{NaHCO}_{3}\right) 8 \cdot 45 \text { c.c. } \\ \text { boundsorbed by } \mathrm{Hb} \text {, etc. } 9 \cdot 7 \text { c.c. }\end{array}\right.$

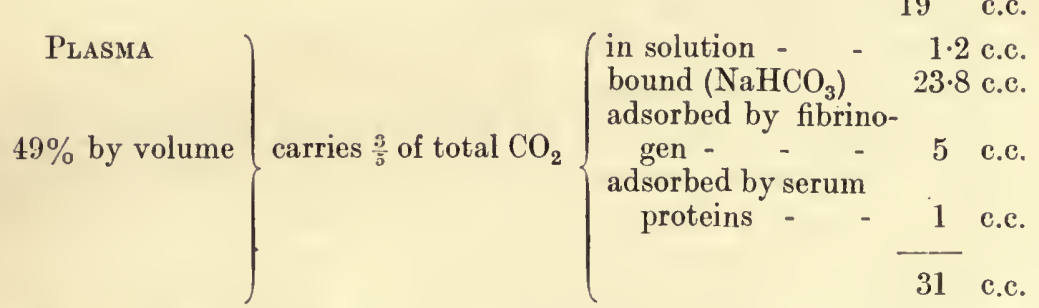

100 c.C. Of Venous Blood $\left(\mathrm{CO}_{2}\right.$ tension $=45 \mathrm{~mm}$., $\mathrm{O}_{2}$ tension $=40 \mathrm{~mm}$. $)$.

Corpuscles carry - 22 c.c. $=+3$ c.c.

Plasma carries - $\frac{34 \text { c.c. }}{56 \text { c.c }}=\frac{+3 \text { c.c. }}{+6 \text { c.c. }}$

For all practical purposes there is very little difference between the corpuscles and plasma as transporters of carbon dioxide. But, in times of stress when the $\mathrm{CO}_{2}$ tension tends to be abnormally high or when the desaturation of oxyhaemoglobin becomes abnormally great (e.g. over 40 per cent.) the corpuscles will play the major part in the transport of $\mathrm{CO}_{2}$.

Plasma must be considered as a fluid scparated from other fluids (with which it is in equilibrium) by membranes permeable to certain solutes. The whole transport system is a multi-phase fluid in equilibrium. Alterations in any phase produce regulatory 
changes in every other phase. Briefly, blood has an integrative action.

To come back to the simile of a eommunity : suppose Cottonopolis failed to funetion normally. This eould be manifested by the seareity of cotton goods in the hands of the distributors. The eause of the failure might be found by a process of elimination. In general, (1) either the supply of raw material was inadequate (bad harvest or transport strike), (2) or the supply of fuel was restrieted (coal strike), (3) or the workers were on strike, or (4) the means of distributing the finished product had broken down (transport strike). It might even happen that (5) over-production had "drugged " the market, produeing the invariable reaction on the faetory. Similar mishaps might overtake that colleetion of eell-communities called the animal organism. (1) If the various raw materials are not available even when ample fuel supplies exist, cell life beeomes narrowed and inefficient. Certain matter must be imported-it eannot be manufactured. If the raw material is imported but does not reaeh the cell, then the transport system is at fault. (2) A similar statement eould be made about the supply of energy. (3) The cell itself may be at fault-e.g. after $\mathrm{HCN}$ poisoning, in spite of adequate supplies of energy and material, metabolism is at a low ebb. (4) The transport trouble might be due to the scarcity of barges, e.g. anaemia, or to want of foree in the driving mechanism, e.g. heart failure. (5) In certain pathologieal eonditions a cell-eommunity may take the bit between its teeth and overproduee. The immediate result is to hamper its own aetivities by the presenee of the products of its activity.

To take a speeific instanee-suppose we find that an organ seems to suffer from a laek of oxygen. This may be due (i) to a searcity of oxygen in the air breathed-analysis will show that. (ii) The lung meehanism may be out of order (Chap. XXVI.). (iii) The membrane separating lung-air from blood may have lost its permeability. Comparison of the oxygen eapacity of arterial blood with its aetual oxygen content will indicate whether or not this is the fault. (iv) This will also show if the erythroeytes are taking on their full load. (v) If the blood suffers little or no desaturation on passing through the organ, then one may presume either that the haemoglobin has lost its power of unloading oxygen (methaemoglobin) or that the organ has lost the power of using oxygen. Examination of the blood pigment by means of the spectroseope may help us to choose which of these alternatives is correet. 
No matter what organ or tissue it is that fails to function normally-it must remain in dynamic equilibrium with the blood, and through the blood with every other tissue and organ in the body. Every change occurring anywhere in the body sets in motion a series of far-reaching alterations tending to restore equilibrium. It is this constant adjustment of physical and chemical forec and matter brought about mainly via the inland transport system that goes to make up the metabolism of the organism.

Other materials are carried by the plasma, viz. :

I. Substances to be used by the Tissues.

$\begin{array}{lllll}\text { Glucose - } & - & - & - & -\end{array}$ From alimentary canal and from Amino Acids - - $-\bar{A}_{\text {Accessory substances and Salts }} j^{-}$storehouses.

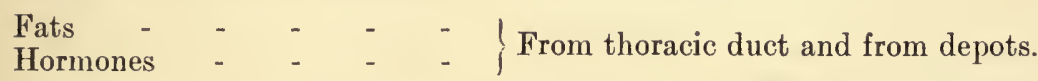

II. Substances Excreted by the Tissues.

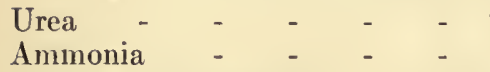

Creatin and Creatinin - $-\int$ Eliminated by the kidneys. $\left(q \cdot v_{.}\right)$. 


\title{
CHAP'TER XXIII
}

\author{
LOADING UP
} "I send it through the rivers of your blood
Even to the court, the heart, the seat o' the brain,
And through the eranks and offices of man,
The strongest nerves and small inferior veins
From me receive that natural eompetcney
Whereby they live."

SHAKESPEARE.

WE have now come to one of the most interesting parts of our study, namely the handling of the imports in their eourse between the external and the internal transport systems. As we have seen, the material brought to the body may be divided into two classes. Onc of these consists of the gas, oxygen, which comes to the port of arrival almost ready for use, and which is passed directly to the inland transport system for transmission to the various cell-communities.

The foodstuffs form the other class. They are "raw material" and have, as a rule, to undergo some process of manufacture before they can be distributed to the eonsumer. They are handled by a speeial mechanical transport service and are taken through the various factories and then handed to the inland transport.

In this chapter, we are to deal with the importation of oxygen and the mechanism by which it is received at the port, carried overland and loaded on the submersed barges on their way inland. Indissolubly associated with any system of importation is the provision of exports. Any barge travelling empty on the blood stream as on any external industrial eanal is a distinct loss to the whole community. Every ship that leaves our shores without a full cargo tells a tale of industrial inefficiency. In the body the output of carbon-dioxide and the intake of oxygen are nicely balanced. As a matter of fact, the regulation of the rate of importation by the rate of exportation is as much a law here as in the realm of Political Economy. 
A separate chapter has been devoted to the mechanism whereby the oxygen is brought from outside into the port. Briefly, by muscular movements air is drawn through filtering and warming applianees into the harbour, and after a very short interval is expclled from the harbour into the outer air.

In the average resting man, somewhat over 500 c.c. of air come into the respiratory ehambers at each ordinary quiet inspiration and somewhat less than this amount is expelled at each expiration. Onc may say, in round numbers, that the tidal air of the average adult is about 500 c.e. The tidal air at various ages and weights has been determined and is given below :

TABLE XLI.

\begin{tabular}{|c|c|c|}
\hline Age. & Weight in Kilos. & Tidal air in c.c.s \\
\hline $0-6$ months. & $3 \cdot 77$ & 48 \\
\hline $6-12$ months. & $7 \cdot 7-12$ & $85-129$ \\
$3-7$ years. & $14 \cdot 3-19$ & $124-221$ \\
8-14 years. & $22-29$ & $221-395$ \\
Adult. & $60-70$ & $440-550$ \\
\hline
\end{tabular}

If a very deep inspiration is taken, more than 500 c.c. can be sucked into the lungs. This extra quantity, which varies with the "build" and expertness of the subject but which usually is about three times the tidal volume, is called the complemental air. By a forced expiration after a normal inspiration the reserve air may be expelled from the lungs. The volume so expelled varies very much with practice. Some people can only breathe out an additional 500 to 700 c.c., while singers, physical training experts and others who practise abdomino-thoracic breathing; may register a volume of 1500 to 2500 c.c. These three quantities together give the vital capacity of an individual, i.e. the amount of air that a person can expire after a deep inspiration. It is not possible completely to empty the lungs. As we shall see later, a mechanism exists in the air vesicles which prevents their total collapse. They retain about a litre of air-the residual air.

To summarisc, taking average figures :

\begin{tabular}{|c|c|c|c|c|c|c|c|}
\hline Vital capacity & - & - & $\begin{array}{l}\text { Tidal air } \\
\text { Complement } \\
\text { Reserve air }\end{array}$ & air & - & $\begin{array}{l}- \\
-\end{array}$ & $\begin{array}{l}500 \text { c.c. } \\
1500 \text { c.c. } \\
1500 \text { c.c. }\end{array}$ \\
\hline Residual air & - & - & - & - & - & - & $\begin{array}{l}3500 \\
1000 \text { c.c. }\end{array}$ \\
\hline
\end{tabular}


This volume of 4500 e.c. ineludes not only the volume of the lungs but of the approaches to the lungs-the nasal eavity, the traehea, the bronehi and the bronehioles. These constitute the outer harbour or "dead space," which has a eapacity of about 140 c.c. That is, in ordinary quiet breathing each respiration brings about 360 c.c. of air into the inner harbours (air saes, alveolar saes, or infundibula). These funnel-like chambers to which the air passages lead are the most expansile structures in the lung, and they are largest where the expansion of the lung is greatest. All round their walls open myriads of small thin-walled air-cells or alveoli-the true wharves of the port. There and there alone takes place the interchange of exported $\mathrm{CO}_{2}$ and imported $\mathrm{O}_{2}$.

Let us look first at the area of wharfage. The interior of the air saes and their alveoli is lined by a thin transparent layer of endothelium. If the lining could be stripped from all the sacs of both lungs and inflated, it would form a spherical balloon about 17 feet in diameter. If it were spread as a continuous flat sheet it would cover a square floor of 30 feet by 30 feet. In other words, the area of wharfage is, at least, over fifty times the surface area of the body. The average diameter of an air cell is $0.2 \mathrm{~mm}$., with a volume of 0.004 cub. $\mathrm{mm}$., and an area of $0.125 \mathrm{sq} . \mathrm{mm}$. Suppose these air eells to be spherical and closely packed together, then the maximum number contained in a eubic millimetre of lung substance would be 250 cells of total surface $31 \cdot 2 \mathrm{sq} . \mathrm{mm}$. Now the average value for the total volume of lung substance is $\mathbf{1} \cdot 617$ c.c. This provides for the possible presence of 404,500,000 air cells with a surface of 50.56 square metres. Of course this is a maximum value for the number. From the volume of lung substance has to be deducted the volume of the supporting cells of the lung and of the air passages. On the other hand a minimal value is given for area, sinee no aeeount is taken of the increase of surface caused by the projection of the blood capillaries into the lumen of the alveoli. Various estimates have been made of the surface area of the alveoli ranging from that of von Husehke of 2000 sq. metres to that of Äeby given above. Hufner's value is generally taken as a mean, viz. 140 sq. metres. Of this area, about three-fourths consists of thin-walled eapillary blood vessels. That is, the effective absorptive surface is about 100 sq. metres.

Over a surface of about 100 sq. metres, interehange between alveolar air and blood is possible. Just behind this surfaceepithelium lie capillary blood vessels of such small bore that the 
red blood corpuseles are distorted in their passage through them. This naturally produces a decrease in the rate of blood flow. The rate is further decreased by the increase in the total sectional area of this capillary system which is at least seven times greater than that of the aorta (Chap. XXIV.). 'The sudden increase in the area over which the blood has to spread itself in a layer less than one corpuscle thick causes a marked decrease in the velocity of the stream. These two conditions, $(a)$ narrow bore and $(b)$ increased area of distribution, of course facilitate the processes of unloading and reloading the erythrocytes. The structure is, in principle, just the same as that of the kidney.

The next problem before us is that of the transference of carbon dioxide from the blood to the air and of the oxygen from the alveolar air to the blood. About the first process there seems to be no diffieulty. Everyone is agreed that, as the tension of carbon dioxide in the blood of the pulmonary artery just as it enters the capillary system is greater than its tension in expired air, a simple process of diffusion through a wet membrane is all that is required. The tension of $\mathrm{CO}_{2}$ in alveolar air and in the blood is 40 and $46 \mathrm{~mm}$. Hg. respectively. There is, therefore, a difference of $6 \mathrm{~mm}$. $\mathrm{Hg}$. in the $\mathrm{CO}_{2}$ pressure tending to cause a flow of $\mathrm{CO}_{2}$ from blood to air. Is this gradient of pressure sufficient to account for the 250 c.c. of gas normally expired per minute?

The passage of gas through a membrane depends $(a)$ on the nature of the membrane, $(b)$ on the strueture of the membrane, $(c)$ on the physical state of the membrane, $(d)$ on the nature of the gas, and $(e)$ on the gradient of pressure.

(a) The layer of flattened cells separating blood from alvcolar airdiffers little in chemical nature from anyother similar structure. One may note, however, its richness in lipoids. (b) It is construeted of large irregular flattened cells forming an extremely dclicate laycr as thin as the film of a soap bubble. The average thickness of this membranous layer is $0.004 \mathrm{~mm}$. (c) Not only does the protoplasm forming the membrane contain about 90 per eent. of water, but it is kept moist on both sides. (d) Carbon dioxide is very soluble in water. Water at body temperature and atmospherie pressure will absorb over half its volume of carbon dioxide. (e) Experiments by Krogh and others seem to have proved beyond question that the differences in tension existing on the two sides of the lung tissue are quite sufficient to account for the passage of the necessary volume of gas. 
It is worth while to look a little more closely at this problem. In Chap. XXII., p. 247, is given a table of absorption coeffieients of the respiratory gases. These values of $\alpha^{\circ}$ indicate the volumes of gas at N.T.P. which will dissolve in 1 c.e. of water. Later in the same chapter, figures which hardly differ from $\alpha$ were given for the solubility of these gases in plasma, ete. The velocity of diffusion depends not merely on the pressure gradient and on the absorption coefficient of the gas, but also on a factor $\mathbf{k}$-the diffusion coefficient. $\mathbf{k}$ is a constant for each gas and each temperature. The appended table (from Loewy) will amplify this.

TABLE XLII.

Diffusion Coefficients.

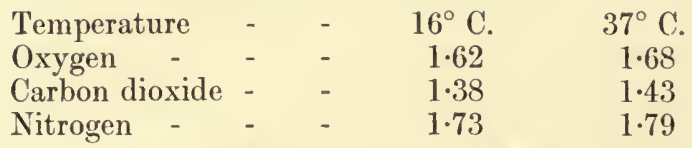

The product of $\alpha$ and $\mathbf{k}$ gives the diffusion rate in $\mathrm{cm}$. per 24 hours through a layer of water, $1 \mathrm{~cm} . \times 1 \mathrm{sq} . \mathrm{cm}$. with a pressure gradient of 1 atmos. For example, at $37^{\circ} \mathrm{C}$. carbon dioxide has a diffusion rate of $1 \cdot 43 \times 0 \cdot 57=0.815 \mathrm{~cm}$. per 24 hours.

It has been found that $\mathbf{k}$ bears a definite inverse relationship to the square root of the molecular weight of the gas. The result of multiplying the diffusion eoefficient by the square root of the molecular weight of the gas is thus a eonstant for all gases. This diffusion factor $k \sqrt{m}$ has a value, for water, of $0 \cdot 0649$.

The diffusion rate through lung substance, because of its large content of lipoids and lipins must be greater than that through water. Experiments with soap bubbles and with frogs' lungs have eonfirmed this deduction. It has also been found that the velocity of diffusion is absolutely unaltered by slight alterations in the $p \mathrm{H}$ of the lung tissue. Loewy maintains that the rate of diffusion is the same in dead and in living lung tissue. The diffusion factor through lung has been estimated as 0-139. Experiment has shown definitely that $\mathrm{CO}_{2}$ passes just as readily in either direction through the lung wall. This has been amply confirmed by Krogh, who found that the direction of diffusion depended entirely on the direetion of the gradient of pressure, and the rate of diffusion was regulated by the steepness of this gradient.

The volume of gas diffusing per minute through one sq. em. of alveolar wall may be calculated from this formula:

$$
v=\frac{\alpha\left(p_{1}-p_{2}\right) C}{760-\sqrt{m} \cdot d}
$$


Dealing with carbon dioxide we may evaluate as follows :

$\alpha$ at $37^{\circ}=0 \cdot 57$,

$p_{1}=\mathrm{CO}_{2}$ tension in the blood of the pulmonary artery $=$ about $46 \mathrm{~mm}$. $\mathrm{Hg}$,

$p_{2}=\mathrm{CO}_{2}$ tension in alveolar air $=$ about $40 \mathrm{~mm} . \mathrm{Hg}$,

$p_{1}-p_{2}=46-40=6 \mathrm{~mm}$. $\mathrm{Hg}$.

This difference of pressure, of course, only exists at the beginning of the experiment. The blood loses carbon dioxide, i.e. $p_{1}$ decreases; $\mathrm{CO}_{2}$ passes into the alveolar air, i.e. $p_{2}$ increases, and $p_{1}-p_{2}$ tends towards zero. It is, therefore, necessary to take a mean value between 6 and 0 , i.e. $3 \mathrm{~mm}$. $\mathrm{Hg}$.

$C=$ diffusion factor $=0 \cdot 139$,

$\sqrt{m}=\sqrt{44}=6 \cdot 63$,

$d=$ thickness of alveolar wall $=0.004 \mathrm{~mm}$.,

i.e. $\quad v=\frac{0.57 \times 3 \times 0.139}{760 \times 6.63 \times 0.004}$

$=0.01 \mathrm{c.cm}$. per minute.

As the effective absorptive surface of the lung is about $100 \mathrm{sq}$. metres, there can pass through it each minute

$$
100 \times 10,000 \times 0 \cdot 01=10,000 \text { c.cm. }
$$

of carbon dioxide by simple diffusion.

One may consider the problem from another aspect and determine the gradient of pressure necessary to furnish the 250 c.c. of carbon dioxide normally expired per minute. Transposing the formula one gets

$$
p_{1}-p_{2}=\frac{v \times 760-\sqrt{m} \times d}{\alpha \times c} .
$$

Evaluating this,

$$
\begin{aligned}
p_{1}-p_{2} & =\frac{250 \times 760 \times 6.63 \times 0.004}{0.57 \times 0.139 \times 100 \times 10,000} \\
& =0.063 \mathrm{~mm} . \mathrm{Hg} .
\end{aligned}
$$

That is, a difference of $\mathrm{CO}_{2}$ tension between blood and alvcolar air of only $2 \times 0.063=0.12 \mathrm{~mm}$. Hg. would be quite sufficient to eause 250 c.e. of $\mathrm{CO}_{2}$ to pass through the lung wall per minute. During work the amount of carbon dioxide eliminated by the lungs may be increased tenfold. The above figures show that there is ample wharf-space for this exportation.

The transference of oxygen from alveolar air to blood has been the cause of much controversy. Two conflicting views both backed by experimental facts are held. 
(1) The lungs may be considered as sceretory glands. Fish have a swim bladder which is, like the lungs, an outgrowth from the alimentary canal. Oxygen is secreted by it so as to equalise the specific gravitics of fish and water. The fish may sccrete oxygen against the pressure produced in the bladder by immersion to a great depth, e.g. against the pressure of hundreds of atmospheres. Against this view may be opposed the histological fact that cells composing the walls of the swim-bladder structurally do not resemble those of the lung. The former are deep granular cells typical of secretory tissue, while the latter, like the capsule of Bowman in the kidney, are thin and flat. Morcover birds, which have of all animals the most rapid and efficient respiratory exchange and so should have a lung epithelium exhibiting marked secretory qualities, have no epithelial covering at all, so that the capillaries appear to be almost completcly free and surrounded by alveolar air.

(2) Most modern workers maintain that just as $\mathrm{CO}_{2}$ diffuses outwards so does oxygen diffuse from air to blood. The wholc controversy turns on the existence of a pressure gradient for oxygen. The earlier investigators got results which indicated that the oxygen tension of the blood frequently exceeded that of the alveolar air. Later workers like Douglas and Haldane disagree with the earlier findings, and by the employment of finer technique have proved definitely that normally the tension of oxygen is always less in the blood than in the alveolar air. They still maintain, however, that under certain more or less abnormal conditions - say, acclimatisation to high altitudes-there is an active absorption and transference of oxygen to the blood on the part of the pulmonary epithelium.

A man at rest requires about 300 c.c. of oxygen per kilo of body weight per hour. The average man weighs about 66 kilos, i.e. 330 c.c. of oxygen must pass into his blood every minute. During violent exercise the necessary intake of oxygen may be as great as 3000 c.c. per minute. In order to producc this transference from air to blood a certain pressure difference is necessary.

Krogh has shown by an ingenious tonometric method, that the oxygen tension of the blood is always lower than the alveolar oxygen tension, and the difference is generally 1 to 2 - even 3 to 4 - per cent. of an atmosphere. One must now consider whether 1 per cent., i.e. $7 \cdot 6 \mathrm{~mm}$. $\mathrm{Hg}$, is a sufficient pressure gradient for respiratory purposes. 
Employing the same formula as for $\mathrm{CO}_{2}$ one finds with a differcnce of pressurc of $7 \cdot 6 \mathrm{~mm}$. $\mathrm{Hg}$ that

$$
v=\frac{0.0239 \times 3.8 \times 0.139}{760 \times 5 \cdot 66 \times 0.004}=0.0006 \mathrm{c} . \mathrm{cm} \text {. }
$$

per minute per sq. $\mathrm{cm}$. This gives a value of

$$
100 \times 10,000 \times 0 \cdot 0006=600 \mathrm{c} . \mathrm{cm} .
$$

passing through the total cffective absorptive surface of the lung. Thus we sec that the physical conditions allow for an ample supply of oxygen for ordinary purposes. As a matter of fact a difference in pressure of less than four millimetres would be quite sufficient to ensure the supply of the 330 c.c. per minute required by the average man resting but awake.

How is the rate of transference increased to meet the needs of the man doing hard muscular work who uses up 3000 c.c. of oxygen per minute? One very obvious point of difference bctween a resting and a working man lies in the volume of air passing into the lungs per unit of time. The following table shows that the ventilation of the lungs is markedly increased by the performance of work.

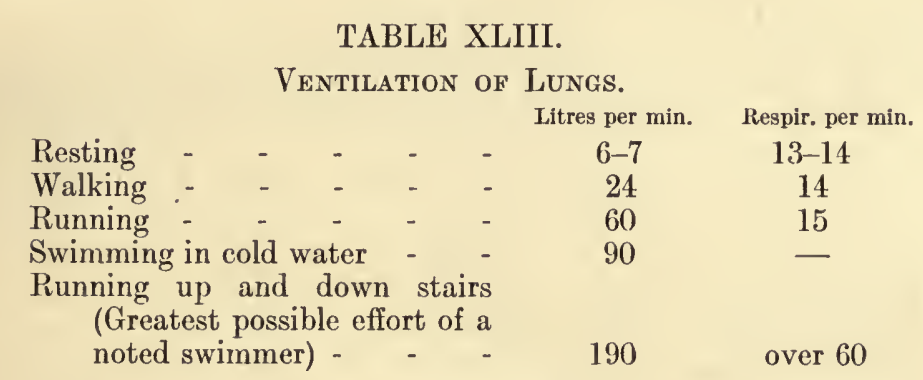

That is, by the constant addition of fresh air to the lungs the tension of oxygen in the alveoli is kept from falling. A tenfold increase in ventilation provides an ample margin for even the most strenuous work.

Those who hold to the secretory hypothesis maintain that while diffusion is capable of providing a sufficient oxygen supply for a normal existence even with hard muscular work, yet when the pressure of oxygen in the lung is brought much below normal, active secretion by the lung epithelium must be brought into play. Aviators, for instance, rise to great heights, and so come under a low barometric pressure. 
It is well known that ballooning, for instance, causes respiratory distress; so, too, does mountaineering. Mountain sickness frequently begins at altitudes of 2000 to 3000 metres, particularly if the ascent has been fairly rapid by railway. Airmen usually suffer after ascending 5000 to 6000 metres. The partial pressure of oxygen in the blood as determined by the carbon monoxide method has been found to be $35 \mathrm{~mm}$. $\mathbf{H g}$ above the oxygen pressure of alveolar air. Considerable doubt exists, however, as to the validity of this method. It depends on the careful matching of a carboxylated blood with a blood-carmine mixture, and minute quantities of blood are used.

\section{TABLE XLIV.}

Effect of Height on Barometric Pressure.

$\begin{array}{ccc}\begin{array}{c}\text { Height above sea level } \\ \text { in metres. }\end{array} & \begin{array}{c}\text { Barometer. } \\ \text { inm. Hg. }\end{array} & \begin{array}{c}\text { Per cent. of } \\ \text { atmosphere }\end{array} \\ 0 & 760 & 100 \\ 1000 & 670 & 88 \\ 2000 & 593 & 79 \\ 3000 & 524 & 69 \\ 4000 & 463 & 61 \\ 5000 & 410 & 54 \\ 6000 & 357 & 47 \\ 7000 & 320 & 42\end{array}$

TABLE XLV.

Effect of Atmospheric Pressure on Alveolar Oxygen Tension.

$\begin{array}{lcccc} & & \begin{array}{c}\text { Height above sea } \\ \text { level in metres. }\end{array} & \begin{array}{c}\mathbf{O}_{2} \text { tension of } \\ \text { air. } \mathbf{m m} \text {. Hg. }\end{array} & \begin{array}{c}\text { Alveolar } \mathrm{O}_{2} \text { tension. } \\ \mathrm{mm} . \mathbf{H g} .\end{array} \\ \text { Berlin } & - & 54 & 157 & 105 \\ \text { Brienz - } & 500 & 148 & 88 \\ \text { Brienzer Rothorn - } & 2130 & 121 & 62 \\ \text { Col d'Olen - - } & 2900 & 110 & 60 \\ \text { Monte Rosa } & - & 4560 & 89 & 61\end{array}$

One fact in the data given by those investigators is a little strange although it may have no significance. Notwithstanding that the arterial oxygen tension was always higher than that given for the alveolar air, it was never higher than that of the atmosphere at the time, although occasionally not much below it. Why should the secretory power fail just at this level and not raise the oxygen tension above that of the atmosphere? Is it possible that the blood had come into equilibrium with an oxygen tension which was not given correctly by the measurement of that of the alveolar air? Might it not also be possible that the carbon monoxide method gives different values when the 
haemoglobin content of the blood is increased, as in the case of acclimatisation to high altitudes?

\section{TABLE XLVI.}

Atmospheric Pressure and Number of Erythrocytes.

$\begin{array}{lccc} & & \begin{array}{c}\text { Height above sea } \\ \text { level ln metres. }\end{array} & \begin{array}{c}\text { Red } \\ \text { corpuseles. }\end{array} \\ \text { Christiania } & - & 0 & 4,970,000 \\ \text { Zurich - } & - & 412 & 5,752,000 \\ \text { Davos - } & - & 1560 & 6,551,000 \\ \text { Arosa - } & - & 1800 & 7,000,000 \\ \text { Cordilleras . - } & 4392 & 8,000,000\end{array}$

Hasselbalch shows that the hydrogen ion concentration is increased under those circumstances.

"This question of secretion by the lungs is instructive from the point of view of 'vitalism.' When first proposed, it was held to apply to the ordinary state of affairs; but as improvements were made in experimental methods, the absorption was shown to follow physical lines; it was then held to apply to cases of muscular exercise, and now only to acclimatisation to high altitudes. One might venture to say that the more accurate the methods of investigation the better is it found that chemical and physical'laws are capable of explaining physiological phenomena."-Bayliss, Principles of General Physiology.

Let us now consider what happens to the inland transport service when the port becomes congested with incoming traffic. Compressed air is used in all the great sub-aqueous works of to-day, in diving, in preparing foundations for bridges, in pier building, and in the construction of tunnels or shafts through water-bearing strata. It is well known that a large percentage of the men working under those conditions suffer illness and many die. In the eonstruetion of the Adour bridge 90 per cent. of the workers suffered from " compressed air" disease, and in the boring of the Hudson Tunncl 2 per cent. of the caisson workers died cach month. Compressed air sickness is characterised by its protean symptoms - loss of speech, blindness, deafness, transitory madness, vertigo, loss of consciousness, emphysema, spinal paralysis, ete. None of the symptoms, with the exception of some slight ear trouble, cver occurs while the men are under' pressurc. "Mules lived about a ycar in the Hudson tunnel and were healthy enough to kick and bite at all comers." The illness seemed to come on during or after deeompression and is now known to be due to the appearance of bubbles of nitrogen in the tissues. Boyle, in the seventeenth century, showed that bubbles of gas appeared in the humours of a viper's eye when submitted to rapid decrease of air pressure under 
an air pump. Paul Bert in a remarkable series of experiments (1870-1880) proved that these bubbles were nitrogen and that they might block up the capillaries in some part of the body and, by cutting off that part from the blood supply, produce one or other of the symptoms mentioned above.

If merely the pressure of the surrounding air is increased, why should nitrogen alone be set free on decompression? When a person is placed in compressed air, the blood passing through the lungs dissolves the same volume of the atmospheric gases as it does under normal conditions, but the weight of gas absorbed will be increased above normal in proportion to the increasc in partial pressure of each gas in the alveolar air. Now we have seen that the partial pressure of carbon dioxide in alveolar air is a constant, hence there can be no increase in the amount of carbon dioxide present in the blood during exposure to compressed air. Oxygen is carried in two ways, $(a)$ by haemoglobin, and $(b)$ in simple solution in the plasma. (a) At atmospheric pressure the haemoglobin is almost saturated with oxygen,- the little crythrocyte barges are comfortably filled. Increase of alveolar tension may produce a slightly better oxygenation of the haemoglobin, but it requires a very marked increase of pressure to make an appreciable increase in the amount of oxygen carried by this means (Fig. 56). (b) According to Dalton's Law, the amount of gas dissolved is directly proportional to its partial pressure.

At body temperature and normal pressure, arterial blood holds 3 c.c. of oxygen in solution in every litre of fluid. If the pressure is increased $x$ times, then each litre will still dissolve 3 c.c. of oxygen, but this oxygen will weigh $x$ times as much as normally. On being carried to the tissues, the blood will share its dissolved oxygen with them in proportion to its partial pressure and to its solubility in the various tissues. These tissues will use up the dissolved oxygen in preference to that carried by the corpuscles, and as the amount in solution, except after exposure to enormous pressures, is only a small percentage of the total available oxygen in the arterial blood, it will soon be used up. We again draw attention to the fact that increase in the available oxygen does not cause increase in its utilisation by the cell. A candle burns more brightly in oxygen and soon ends its light-giving career. The cell " ca's canny" - holds on the even tenor of its way, takes up the oxygen it requires for its immediate needs and keeps no store but the tiny quantity dissolved in its protoplasm.

To take a concrete example. At $38^{\circ} \mathrm{C}$. and atmospheric 
pressure 1 litre of blood contains 200 c.c. of oxygen carried by haemoglobin and only 3 c.c. in simple solution (measured at N.T.P.). Sixfold increase of pressure makes no appreciable difference to the value of the corpuseular oxygen but increases the dissolved oxygen to about 18 c.c. That is, the ratio of dissolved to "bound" oxygen is increased from about $1 / 70$ to $6 / 70$. The entire result would be that as there are about $3 \frac{1}{2}$ litres of blood in the average man the venous blood would carry not more than 20 per cent. more oxygen than normally. In other words, the desaturation of haemoglobin would take place to quite the same extent as under atmospheric pressure. This eliminates oxygen as the gas causing "compression illness" and leaves nitrogen alone to be dealt with.

Let us first consider how the nitrogen taken up by the blood from the alveolar air is distributed to the various tissues of the body. In view of what we have seen as to the ease and completeness with which the blood becomes saturated with oxygen in its passage through the pulmonary capillaries, we may take for granted that saturation with nitrogen under the same conditions is just as complete. It is also reasonable to suppose that Dalton's Law of partial pressures is just as applicable to blood exposed to compressed air as to any ordinary solution. This supposition is supported by experimental facts. When blood is exposed to compressed air it will absorb a volume of nitrogen commensurate with the absorption coefficient of this gas in blood. During its passage through the tissues it will share its load of nitrogen with them in proportion $(a)$ to the absorption coefficient of the gas in blood and tissues and $(b)$ to the partial pressure of the gas in blood and tissues. (a) With regard to the first point, the solubility of nitrogen per unit mass of tissue varies greatly. For example, fat can absorb about six times as much nitrogen gas as blood, while the earthy constituents of bone probably absorb only an infinitesimal amount. With these two tissues excepted we may consider that, as the others differ but slightly in chemical and physical constitution from plasma, they also take up approximately the same quantities of gas. (b) Normally the tissues are saturated with nitrogen at its partial pressure in the atmosphereevery gram of tissue contains approximately 0.0145 c.c. of nitrogen. If the external pressure is inereased, this volume will immediately be diminished correspondingly, and the deficit will be made good at the expense of the cireulating blood. Take for example the sudden increase in pressure to three atmospheres brought about by a rapid descent through $60 \mathrm{ft}$. of water to the 
bed of the sea. 'The volume of gas in solution in the body is at once reduced to $1 / 3$, viz.: 0.005 c.e. per gram. At the same time the blood in the lungs has its content of nitrogen redueed from its normal value of 0.87 e.e. per 100 e.e. of blood to 0.29 with almost immediate restoration to the normal figure. The litre of blood in the capillaries of the lungs would now have in solution three times the weight of nitrogen as under normal pressure. When the blood arrives at the tissues, partition of its load will take place. Each gram of tissue has a defieit of 0.01 - e.e. of nitrogen, and nitrogen will pass from blood to tissue till each gram of tissue eontains the normal value of 0.015 e.e. per gram. This value will not be reached at onee, beeause the very acquisition of nitrogen by the tissue implies the loss of nitrogen by the blood. The blood then returns to the lungs for a fresh charge, which it again shares with the tissues, and so on. Haldane ealculates that somewhere about five hours are required before the body is completely saturated with nitrogen after any change of pressure, i.e. till the partial pressure of nitrogen in the tissues eorresponds with its partial pressure in the blood and so to its partial pressure in the alveolar air.

If we consider the amounts taken up by the various tissues we may arrive at some eonclusion as to the meehanies of the processes of saturation and desaturation. 'The average working man weighs $70 \mathrm{~kg}$., of this amount 15 per eent. or $10.5 \mathrm{~kg}$. is fat or fatty material ; 5 per eent. or $3.5 \mathrm{~kg}$. represents the amount of blood; while the earthy constituents of bone (about 3 per cent.) may be neglected.

\section{TABLE XLVII.}

Distribution of Nitrogen in the Tissues of Men Weighing $70 \mathrm{Kg}$.

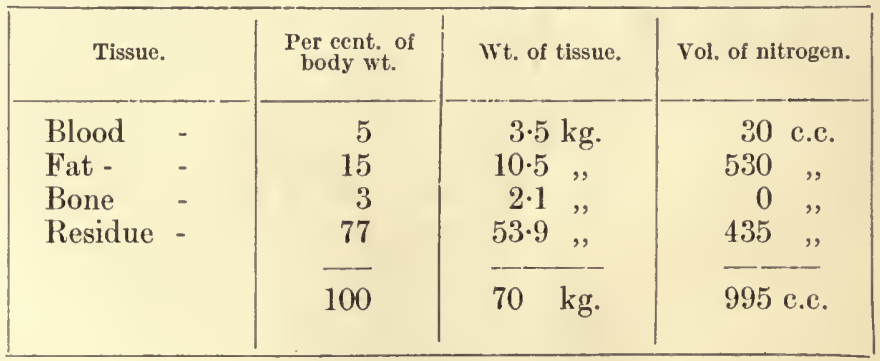

Blood, as we have seen, ean take up in simple solution about 0.87 c.e. of nitrogen for every 100 e.e. Taking the speeifie gravity of blood as 1.06 we may consider that about 30 e.e. of 
nitrogen are constantly in solution in the blood. Fat is eapable of absorbing six times as mueh nitrogen as an equal weight of blood, i.e. we may write down 500 e.e. as the volume of the gas held by the fatty matter of the body. Leaving out the earthy part of bone the remaining tissues account for about 435 e.c.

Taking round figures we see that the average man has, dissolved in his blood, about a litre of nitrogen. The weight of this litre is a function of the pressure under which it has been absorbed. Looked at from another point of view, the weight of nitrogen held in solution by the tissues is 32 times as great as that present in the blood. If, therefore, the blood is, for the purpose of this calculation, considered as spread uniformly and at a uniform rate throughout the body, the tissues would reeeive at the end of one complete eireuit of the blood after exposure to a sudden increase in air pressure, $1 / 32$ of the exeess of nitrogen corresponding to complete saturation at the new pressure. The second round of the cireulation would add $1 / 32$ of the remaining deficit in saturation, and so on. Haldane finds that it takes 23 rounds of the eireulation to half saturate the tissues at the new partial pressure of nitrogen. The progress of the saturation of the body with nitrogen may be represented by a logarithmic curve (Fig. 57). As about 3.5 litres of blood pass through the lungs every minute and as the total blood volume is also 3.5 litres, we may substitute minutes for rounds of the eirculation and state that it requires 23 minutes to render the tissues half saturated to a new pressure of nitrogen.

The process of desaturation, provided physiological conditions are kept constant, follows the same curve. If the tissues are exposed to blood earrying nitrogen in exeess of the normal amount, for sufficiently long to be in gaseous equilibrium with that bloodi.e. to be saturated-then in order to prevent the formation of bubbles, the process of desaturation would need to be carried out at the same rate as the saturation. If the desaturation rate were too rapid, then gas would be released from the tissues more rapidly than it was being passed from blood to alveolar air. This would entail a very slow and uniform rate of decompression. A diver's aseent from the sea bed might have to be spread over hours. Paul Bert, from his experiments on animals, coneluded that the decompression period should be 30 minutes for under 3 atmospheres, and 60 minutes for 3 to 4 atmospheres. This ruling of the famous French scientist has never been earried out in industrial practice, the usual period for "leaking out" being 
about 15 minutes altogether. As a result of this haste to get into "free air," constructional engineers are afraid to put their men under more than +3.5 atmospheres. Bullion has been salved from ships lying 171 feet below the surface. The divers in this case stayed below for only 20 minutes at a time and took 20 minutes to ascend. Even then some of them were stricken with paralysis. Greenwood endured compression to 7 atmospheres $(=\mathbf{2 1 0}$ feet of sea water), but took over 2 hours to decompress. These long

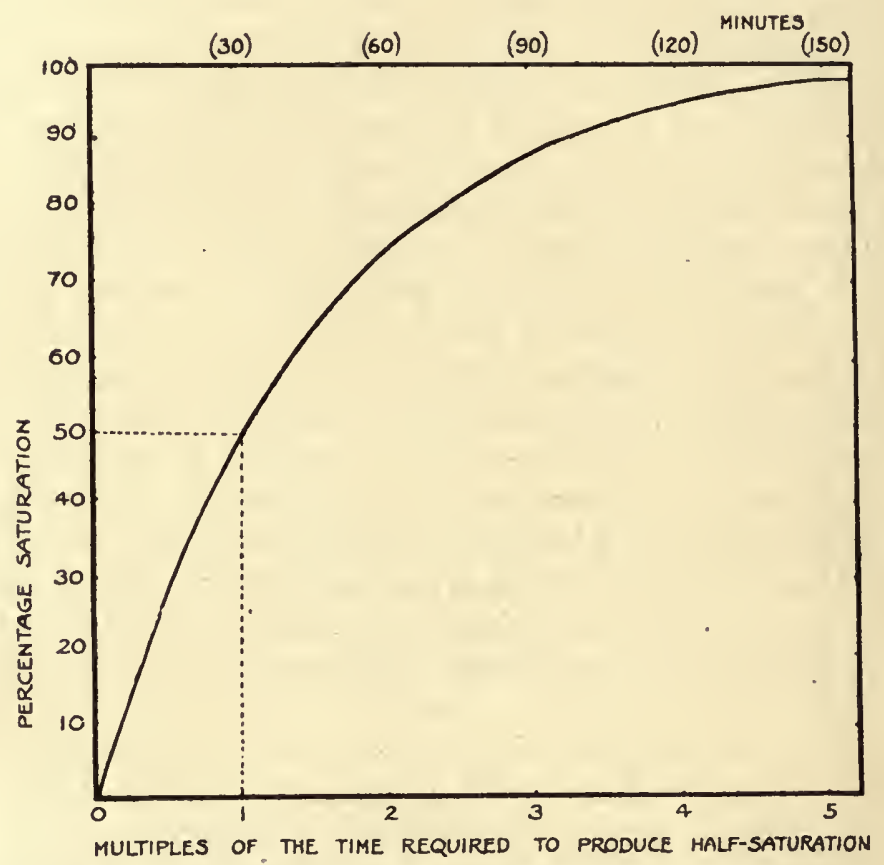

FiG. 57,-Curve showing the progress of saturation of any part of the body with nitrogen after any given sudden rise of air pressure (after Haldane).

periods of decompression which seem necessary for safety, put the men in charge in an awkward dilemma when, on account of some mishap, it is necessary to bring men at onee to the surface.

From table XLVIII. it will be seen that the diver is brought to the surface from the bottom in stages. These stages are three metres apart and the time spent at each one depends on the duration of his stay on the bottom. This method of decompression by stages depends on the empirical fact that no untoward results arise from cven a rapid decompression of one atmosphere or less. 
An atmosphere or $760 \mathrm{~mm}$. of mereury is equal to a pressure of $1 \mathrm{~kg}$. per sq. cm. or to about 3 metres of sea water. Even with this more rapid means of attaining normal pressure, the diver is limited either to a very short stay under water or to a tedious waiting at various levels.

\section{TABLE XLVHI,}

A Portion of a Diving Table used by Naval Divers.

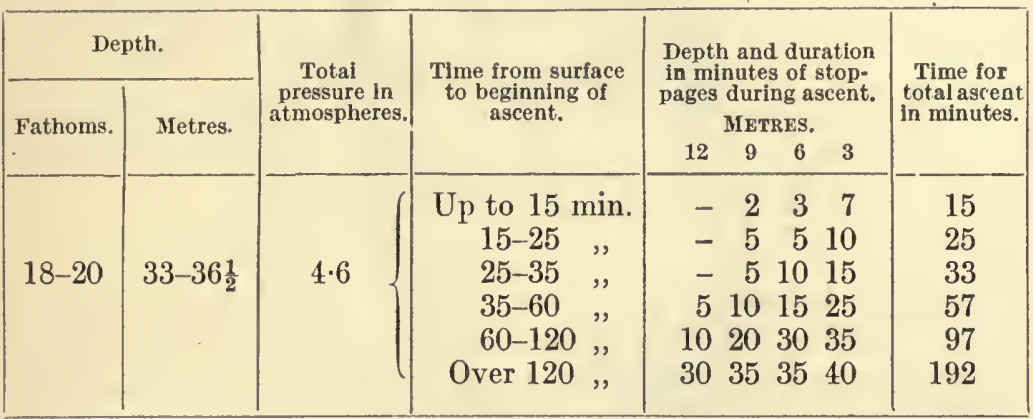

Haldane and his collaborators have very fully investigated this question. They argue that, as the volume of gas in solution is constant no matter what is the pressure, and as it has been proved to be perfectly safe to decompress rapidly from a plus pressure of one atmosphere $(\mathbf{1} \cdot \mathbf{2 5}$ atmospheres to be exact) to normal, then it must be equally safe to decompress rapidly to half pressure for any value. For example, if the total pressure were eight atmospheres, these workers advise a rapid decompression to four atmospheres, and after a pause to two atmospheres, and, after a pause, more slowly to normal pressure. The principle underlying this plan is that the discharge of nitrogen from the start of decompression is at the maximum rate consistent with safety. The rate of discharge, of course, depends on the gradient of pressurc between venous blood and alveolar air. This gradient is kept as steep as possible, and there is, therefore, a maximum elimination by the lungs. 


\section{CHAPTER XXIV}

\section{CIRCULATION}

\section{"The circling streams, once thought but pools of blood, (Whether life's fuel or the body's food) \\ From dark oblivion Harvey's name shall save."}

\section{DRYDEN.}

THe inland transport system that we have had under consideration differs materially from our canal system. Not only are the barges submersed in the plasma but the force which carries them along is the force which causes the plasma itself to move. The waterways are a series of elastic-walled tubes forming a closed circuit. In this circuit is a central pumping station, the heart which keeps the blood in motion. The accompanying figure (Fig. 58) is a diagrammatical view of a vertical-mesial section through the heart. From it we learn that the heart is not a simple structure. In the diagram four distinct cavities can be seen, viz. : right and left ventricles, left auricle and aortic space-the right auricle is not shown. The heart is really a double pump consisting of a main pump or systemic heart (left auricle and ventricle) and a subsidiary pump or pulmonary heart. In Fig. 59 is given a scheme of the circulation. By contraction of the left ventricle the blood is forced along a series of conducting tubes or arteries (Art.) which lead to every part of the body and end in the substance of the tissues in a network of innumerable hair-like canals, the capillaries ( $\mathrm{Cap})$. These capillary vessels are the wharves of the tissues. Through their walls takes place the exchange of imports and exports by which we measure the metabolism of the tissues. Consequently it is found when the capillaries join together to form the wider conducting canals, venules and veins, that the blood has lost some of its cargo of oxygen and nutrient matter, and has gained a certain amount of waste matter. This withdrawal of nutrient material is made good by the diversion of some of the blood from an arterial canal to the capillaries in the 
walls of the intestine (Al.C.). The waste matter is eliminated, as we have seen, by a capillary mechanism in the kidney. Chemical

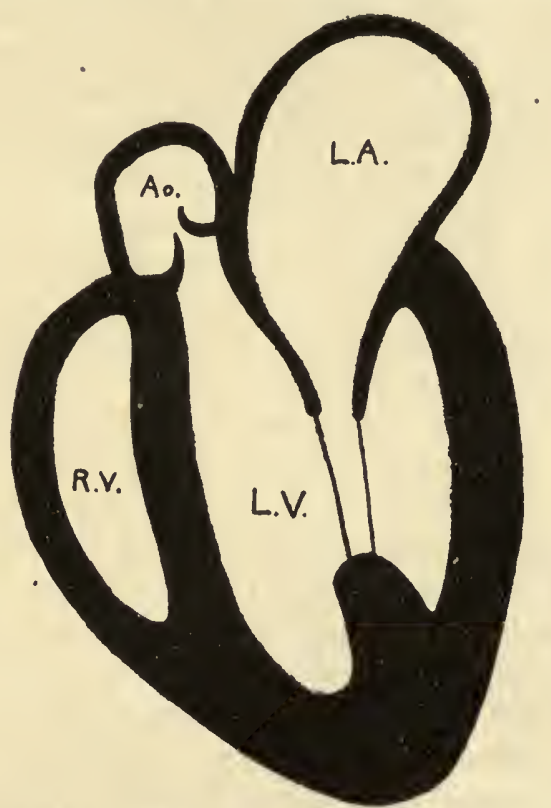

FIG. 58.-Vertical Mesial Section through Heart to show Aortic and Mitral Valves. $R$.V., right ventricle; $L . V$., left ventricle with papillary muscle; $L . A$. , left auricle with the mitral valve extending into the left ventricle: Ao., aorta with anterior cusp on top of septum.

\section{(Noël Paton's Essentials of Human Physiology.)}

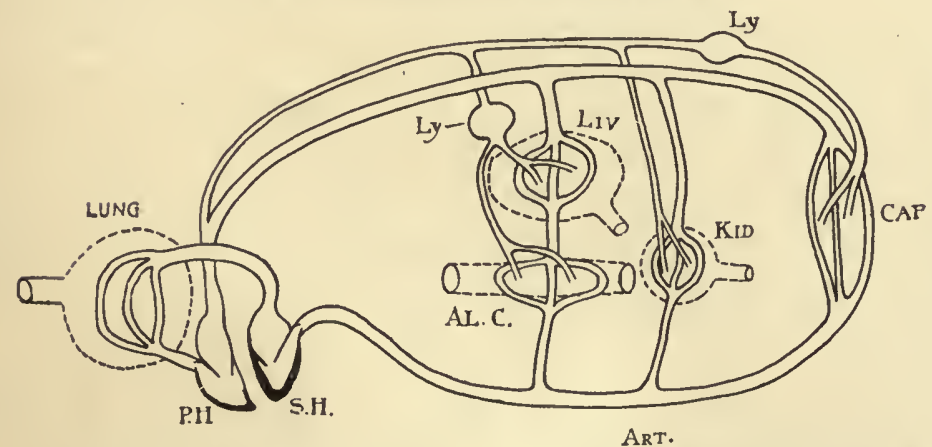

FIG. 59.- Scheme of the Clrculation. S.H., systemic heart sending blood to the capillaries in the tissues, Cap. The blood brought back by veins, and the exuded lymph by lymphatics, $L y$., passing through glands ; blood sent to the alimentary canal, Al.C., and from that to the liver, $L i v$.; blood also sent to the kidneys, Kid.; the blood before again being sent to the body is passed through the lungs by the pulmonic heart, P.H.

(Noël Paton's Essentials of Human Physiology.)

changes oeeur on the passage of the blood through the eapillaries of eertain factories, e.g. liver and spleen. The loss of oxygen is 
not made good until the blood has been carried by the veins into the right auricle, passed from this reception house into the body of the pump, the right ventricle $(P . H$.$) and forced by the action$ of this subsidiary pump into the lung capillaries. There, as we saw in the last chapter, it gets rid of the excess of carbon dioxide and makes up its deficit of oxygen. Finally the blood, with its fresh supply of nourishing substances from the alimentary canal and of oxygen from the lungs, is poured into the receiving chamber of the main pump-again to pass into the left ventricle and so to the tissues.

From the capillaries some of the constituents of the plasma are forced into the spaces between the cells as lymph. From these spaces the fluid either passes back into the capillaries or flows away in a series of lymph vessels which carry it through lymph glands $(L y$.$) from which it gains certain necessary consti-$ tuents and finally bring it back to the central pump.

This, in brief, is the circulation as we know it to-day, and this knowledge is due in great part to the labours of Harvey. Before his time little was known of how the blood was distributed in the body. Of one point the old physiologists were sure, and that was that there was no circulation of the blood, only an ebb and flow. Harvey's work is a perfect example of how scientific work should be carried out. First of all, he cleared his mind of all preconceived ideas and got down to bedrock. Then he stated his method. The method employed was that now made famous by the author of Sherlock Holmes, viz., induction, based on careful investigation. He examined the valves of the veins, and using them as sign posts, traced the course of the blood. Similarly, the valves of the heart permit a current to flow in one direction only. There never was a more complete argument than the one that Harvey pressed for the circulation of the blood. There could be no ebb and flow where all the valves were "one way." No scientific work is complete without a reference to quantities. The test of truth must rest with the balance or measuring mechanism. Harvey found that the left ventricle of a man's heart held two ozs. of blood without being distended. If only half the load were discharged at each systole and the heart beat 70 times per minute, then 700 ozs. or 44 pints of blood would be discharged into the aorta every 10 minutes. The total blood volume is under 9 pints. From this he urged the necessity of some communication between the arteries and veins. That is, after experiment, observation, analysis and argument come 
reasoned hypotheses. Four years after Harvey's death the great Italian anatomist Malpighi saw under the microscope these capillaries which the physician had seen with the eye of faith. The demonstration of the actual passage of blood from arteries to veins through capillary channels was given in 1688 by Leeuwenhoek, the illiterate janitor of the aldermen of Delft.

Dynamically considered, the blood acts in much the same way as any other equally viscous fluid driven through a series of tubes. In order to understand many of the problems which one meets in the study of physiological phenomena, it is necessary to obtain some insight into the movement of fluid under an external driving force. As Servetus says, "In order to learn how the blood" is formed it is necessary to ascertain how it moves." First of all, let us consider the flow of liquid from a reservoir through a series of tubes. In a liquid the molecular forces are in equilibrium; the kinetic forces characteristic of matter in the gaseous state are exactly balanced by the Newtonian forces predominant in solids. As Soddy would put it, the processes of pellation and tractation would not be manifest. Gravitation alone has to be reckoned with. In common parlance, liquids seek their own level and so always tend to flow to the lowest possible position. It is a wellknown fact that the speed attained by a body falling in vacuo through the distance $(\mathbf{h})$ equals $\sqrt{2 \mathrm{gh}}, \mathrm{g}$ being the acceleration produced by gravity. This formula cannot be used to estimate the velocity of fluid escaping from a reservoir. As every boy knows, when the waste water is being run out from the bottom of a wash-hand basin, the fluid tends to rotate round the orifice and to assume a conical form. This is due to the attempt of the water particles to rush the exit (so to speak). Only a limited number of them lie in the column vertically above the opening. The majority, occupying more lateral positions, tend to escape along with the minority in the queue and so exert a force applied at an angle to the line of exit. Consequently, the total energy cannot be used to produce velocity. Some of it has to be spent in overcoming the resistance at the outlet.

Still further modification of the formula is required if the orifice is fitted with an exit tube. It must be evident that the presence of this passage imposes a greater resistance to outflow and materially reduces the rate. Let us consider the effect produced on rate of flow by attaching a rigid cylindrical tube of uniform bore to the lower orifice of the reservoir. In order to simplify matters, we will place this pipe horizontally. Two causes 
tend to reduce the kinetic energy of fluid flowing through a tube, viscosity or internal friction and external friction on the walls of the tube. On account of the latter, the outermost layers of the fluid adhere to the walls of the tube and become more or less stationary. The molecules of the layers of fluid next to the outermost tend to cohere to the stationary layer on one hand and are pulled along by their cohesion to the next inner layer. As a result, their velocity is decreased. The net result is that a whole series of cylindrical layers is produced each with a different rate of flow-ranging from the almost stationary outer layer to the central axial column, which is retarded least of all and, therefore, possesses the greatest kinetic energy. In a straight tube of uniform bore, such as is under consideration, this retarding influence reduces the average rate of flow to half that of the axial stream. It is obvious, therefore, that a considerable amount of the potential energy of the liquid in the reservoir is absorbed in overcoming the peripheral resistance caused by cohesion and adhesion. Resistance to flow also depends on the area of cross-section of the tubethe wider the tube the larger the number of cylindrical layers over which the adhesive resistance spends itself and, therefore, the less the resistance met by the axial stream. A tube so narrow that only an outer layer and a central column could pass along would move with infinite slowness. Except in instances in which the conducting tube has a very large or a very small diameter, the rate of flow is proportional to the area of cross-section. Furthermore, since the resistance in a tube of uniform diameter is proportional to its length, the energy of the fluid must decrease gradually from the reservoir to the outlet of the tube. The energy of the fluid is shown by the pressure it exerts. Pressure may be measured by some form of manometer. 'It is sufficient to insert a number of vertical glass tubes, of uniform bore and open to the air, at various points of the conducting tube to see the fall of pressure with distance from the source of power. The fluid rises in these collateral tubes or piezometers to a height proportional to the pressure in the main conduit. In other words, the level of the liquid in those pressure-gauges is accurately adjusted to the peripheral resistance encountered by the liquid as it passes their points of insertion. Such a system is represented in Fig. 60 . The power furnished by the liquid, in the constant-level reservoir $(\mathbf{R})$, is the downward pressure of gravity. The pressure at various points is manifested by the height of the fluid in the branch tubes $(A) 1,2,3$, etc. If the levels of the column of 
liquid in each of these piczometers be joined by a straight line which is produced to the reservoir wall at $(\mathbf{y})$ the mass of liquid will be divided into two portions. The lower portion (r) represents the portion of the energy of the total spent in overcoming the resistance and is consequently known as resistance-pressure. Of the remainder, a certain amount (o) is spent in forcing the fluid through the orifice into the tube. The actual driving force or velocity pressure comes from the mass (v).

FALL OF PRESSURE

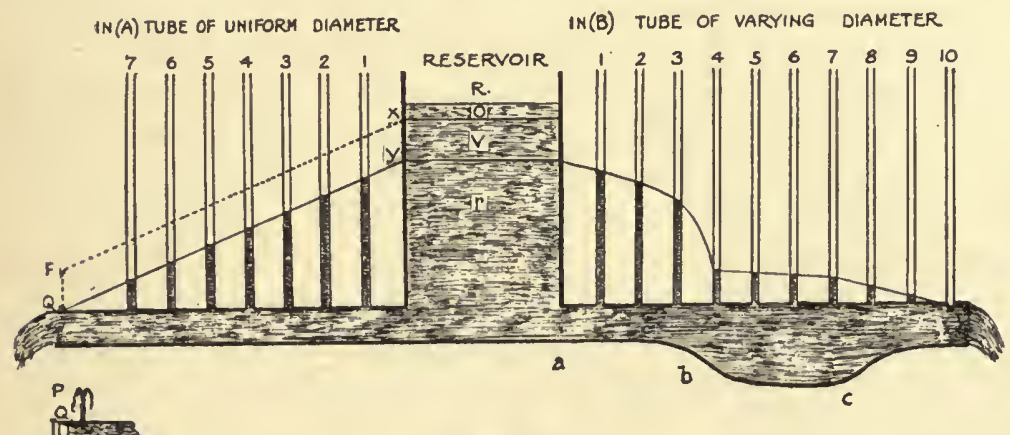

FIG. 60 .

If the main tube is not of uniform bore-suppose $(B)$ it increases in sectional area, at first gradually ( $a$ to $b$ ) and then somewhat suddenly (at b) - corresponding alterations in pressure may be seen in the manometers. Increase in width means smaller resistance, and therefore a smaller resistance-pressure is required to drive the fluid along the tube. As the total mass in the reservoir is kept constant, the amount not required in $\mathbf{r}$ goes to increase $\mathbf{v}$. There being relatively a greater head of pressure, the levels shown by the manometers will tend to decrease progressively at a slower rate than before. If, on the contrary, the bore of the tube is diminished as at c, the fall of pressure will become more rapid. Further, if at $\mathrm{b}$ a constriction is produced, resistance to flow is augmented, and therefore there is a heaping up of the fluid in the earlier tubes 1, 2 and 3, a rapid fall to tube 4, and thereafter a fall of pressure at the same rate as in the earlier part of the system. All the above is stated in terms of pressure. Putting the same matter in terms of velocity of flow, one may say that if a tube be used, the second segment of which is wider than the first and third, the speed of flow will be decreased in the central one.

In the preceding experiment, the head pressure has always been kept constant by making provision for a steady influx of 
water to the reservoir to compensate for the outflow. If, however, the head of pressure is produced by the action of a piston in a cylinder, it will not cause a continuous but an intermittent flow in the main conduit. The pressures shown in the piezometers will vary from a maximum to a minimum as the wave of pressure passes down the system after each stroke. Such conditions entail great loss of power. In order to reduce this loss to a minimum, it is necessary to replace the rigid conduit by an elastic tube. Such a tube would, of course, if rigid, permit a certain flow of fluid per unit of time per unit of pressure, say with a constant velocity of $(\mathbf{v})$. Now on the descent of the piston more water tends to be forced into the conduit than can be passed out with this velocity (v). The elastic walls distend till their elastic power exactly counterbalances the extra energy, and the fluid has an outflow velocity of ( $v)$. The influx of water having ceased, the steady pressure of the distended walls of the tube as they recoil keeps the fluid flowing at the constant velocity (v). In this way the fluid is held under a continuous pressure and, provided the pump has the proper frequency, the outflow remains practically constant. That is, the elastic tube really converts an intermittent inflow into a constant outflow, the property of elasticity preserving normal conditions of flow even during periods when the piston is not descending.

Such a system of single stroke pump and elastic regulator does not differ in essentials from the one contrived by nature to provide a perfect transport service to every unit of a complex organism like the human body. In Fig. 61 a simple force pump and its circulating system is compared with the left ventricle, aorta, etc.

The manner in which the contents are forced out from the ventricle differs in some details from that obtaining in the water pump. In the latter, a rigid piston descends within a rigid cylinder and thus obliterates the space of the main chamber and forces the water through the outflow pipe. The power necessary to drive the plunger home is derived from an engine of some sort, external to and independent of the pump itself. In the heart, the elastic muscular walls of the ventricles contract as a whole, deriving their force just as any other muscular structure docs, from the potential energy of materials brought to them by the blood and liberated in their protoplasm.

The value of the work done by a pump may be calculated approximately by the formula

$$
W=Q R+\frac{w v^{2}}{2 g}+O
$$


where $\mathbf{W}$ (gram-metres) is the work done at each stroke, $\mathbf{w}$ is the weight in grams and $\mathbf{Q}$ the quantity of fluid in c.c. expelled at each stroke; $\mathbf{R}$ is the average resistance of the circuit, $\mathbf{v}$ (metres per sec.) is the veloeity of expulsion, and $g$ is the acceleration due to gravity $=\mathbf{9 . 8}$ metres per see. per see. That is, $\mathbf{Q R}$ represents the resistance pressure ( $\mathrm{r}$ in Fig. 60) and $\frac{w v^{2}}{2 g}(\mathrm{v}$ in Fig. 60) the velocity pressure while $\mathbf{0}$ is the energy expended in overeoming the resistance to outflow at the orifice of the pump.

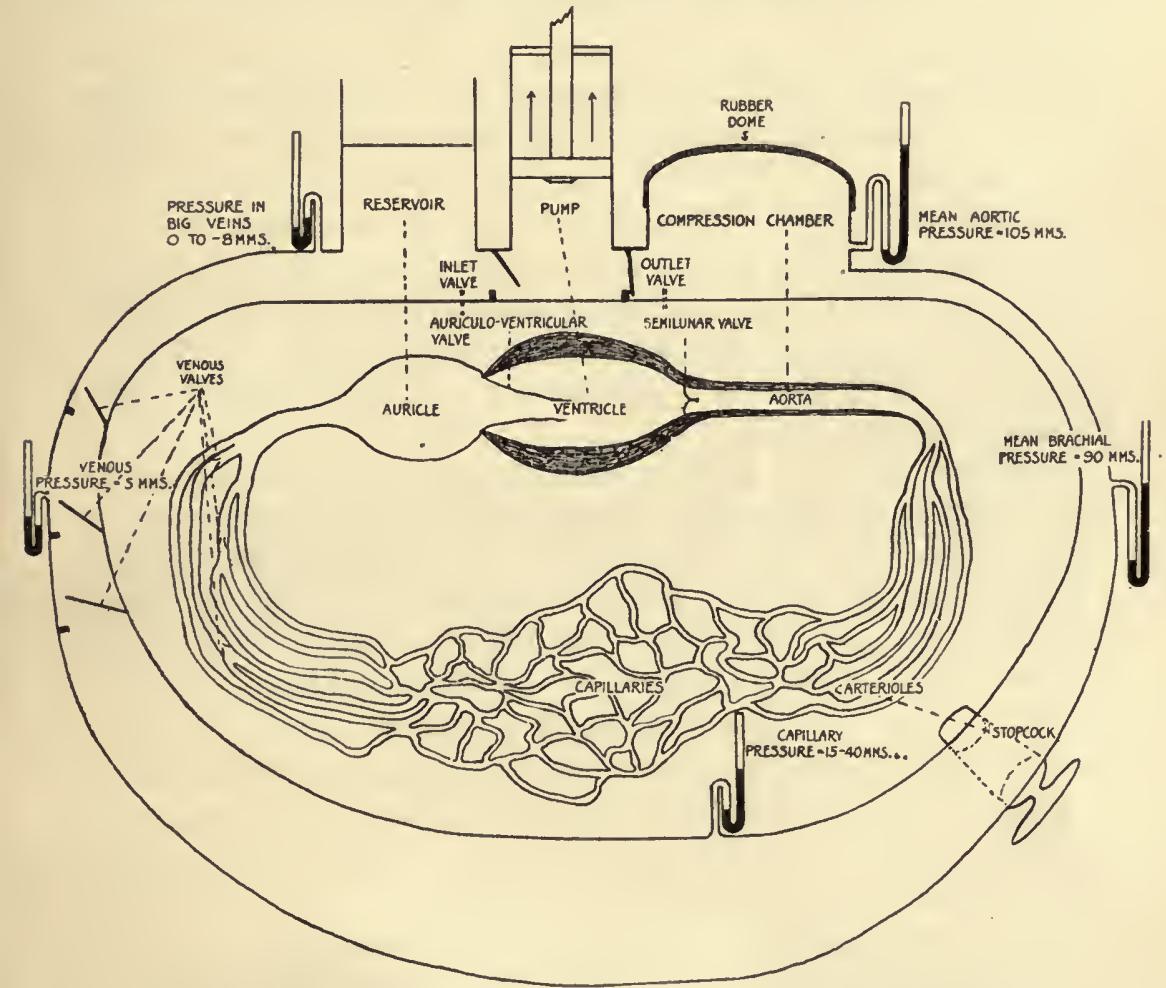

FIG. 61.-Dlagram of a simple force pump (outer circuit) to compare with diagram of circulation from left side of heart (inner circuit).

If we take average figures for the left heart as follows :

$$
Q=60 \text { e.c., }
$$

$R=100 \mathrm{~mm} . \mathrm{Hg}$ pressure in aorta

$=0.1 \times 13.6$ gram-metres (1 e.c. of $\mathrm{Hg}$ weighs

$13 \cdot 6$ grams),

the expression $Q R$ may be evaluated as

$60 \times 0 \cdot 1 \mathrm{~m} . \times 13 \cdot 6=81 \cdot 6$ gram-metres. 
That is, about 80 gram-metres of work is done in overcoming the resistance of the conducting tubes. This value is only approximate, as the work done in forcing a fluid along an elastic tube in which the pressure falls steadily, say from $150 \mathrm{~mm}$. Hg to $50 \mathrm{~mm}$. $\mathrm{Hg}$ is not strictly proportional to the average pressure, but would need to be determined by integration. The error is, however, less than 10 per cent. If the blood is cxpelled at a velocity of 0.5 metre per second, the velocity pressure will have a value

$$
\frac{w v^{2}}{2 g}=\frac{60 \times(0.5)^{2}}{2 \times 9.8}=0.7 \text { gram-metre. }
$$

This quantity is so small compared with the former that for all practical purposes the work of the heart may be taken as proportional to the output multiplied by the average arterial pressure, i.e. $W=Q . R$.

Similarly the work of the right heart may be estimated from the average pressure of the pulmonary artery $(20 \mathrm{~mm}$. $\mathbf{H g})$ as $60 \times 0.02 \times 13.6=16 \cdot 1$ say, 16 gram-metres per beat. The average heart beats seventy times per minute and, therefore, in 24 hours the work done by the heart (of a man at rest) will be about 10,000 kilogram-metres.

Muscular work, of course, augments this figure not only by increasing the volume of blood per beat and increasing the number of beats but by raising the value of the velocity factor. During a short sprint, an athlete may have a pulse rate of 180 per minute with an output of 180 c.c. at each beat and an average arterial pressure of $120 \mathrm{~mm}$. $\mathrm{Hg}$. Then for the systemic heart:

$$
Q R=180 \times 0 \cdot 12 \times 13 \cdot 6=294 \text { gram-metres, }
$$

and $Q R$ (pulmonary) $=180 \times 0.025 \times 13.6=61$ gram-metres.

If the time of outflow is considered as $3 / 8$ of each cardiac cycle, of which there are 180 per minute, then the contents of the ventricle, 180 c.c., are shot into the aorta at the rate of 1440 c.c. per second (say 1500 c.c.). If the cross-section of the root of the aorta be taken as 625 sq. mm., then the velocity of expulsion will be $\frac{1500}{625}=\mathbf{2} \cdot 48$ metres per sec. (say 2.5 metres). Therefore :

$$
\frac{w v^{2}}{2 g}=\frac{180 \times(2 \cdot 5)^{2}}{2 \times 9 \cdot 8}=57 \text { gram-metres. }
$$

The total work on both sides of the heart will be :

$$
\left.\begin{array}{c}
294+50 \\
\text { Left side }
\end{array}\right\}+\left\{\begin{array}{c}
61+57 \\
\text { Right side }
\end{array}\right\}=462 \text { gram-metres per beat }
$$

$$
=83 \cdot 2 \text { kilogram-metres per minute. }
$$


The main fault to be found with this calculation is that the various quantities required are almost impossible to obtain. For instance, the only methods by which the output of the heart in situ can be determined are indirect. Zuntz, by finding the percentage amount of oxygen which the blood gains per unit of time in passing through the lungs, and the actual amount of oxygen taken from the lungs per unit of time, calculated the amount of blood that had passed through the lungs during that period. For example, if the blood gains 5 per cent. of oxygen and the lungs part with 30 c.c. of oxygen to the blood, then, in order to have a 5 per cent. mixture, 600 c.c. of blood must have passed through the lung in unit time. Now if the heart beats 70 times per minute, and the unit of time chosen was $1 / 5$ of a minute, then the volume of the right ventricle would be

$$
5 \times 600 / 70=\text { almost } 43 \text { c.c. }
$$

Since, of course, the left and right ventricle must discharge equal amounts of blood, the output of the left ventricle is found.

Muscular work causes an increase in the output per beat. Under resting conditions, it is probable that the amount of blood entering the heart during the diastole is not sufficient to fill the ventricle up to the limits set by the fibrous inextensible bag surrounding the organ (pericardium). The first effect of the call for more oxygen set up by the muscles is to increase the output of the heart per beat. The power of the heart to thus increase its capacity is limited. By a reflex mechanism the heart rate is increased and so the output per minute is augmented. The following table shows approximately the share of the burden of increasing the output borne by increased distension of the ventricular walls and by increased pulse rate.

\section{TABLE XLIX.}

Effect of Work on Cardiac Output.

\begin{tabular}{|c|c|c|c|}
\hline $\begin{array}{l}\text { Muscular work per min. } \\
\text { in Kgms. }\end{array}$ & $\begin{array}{l}\text { Pulse rate } \\
\text { per min. }\end{array}$ & $\begin{array}{l}\text { Output per } \\
\text { beat in c.c. }\end{array}$ & $\begin{array}{l}\text { Output per } \\
\text { min. in c.c. }\end{array}$ \\
\hline At rest & 70 & 45 & 3,150 \\
\hline Moderate exercise 270 & 100 & 75 & 7,500 \\
\hline & 110 & 120 & 13,200 \\
\hline Light labour $\quad-735$ & 130 & 115 & 14,950 \\
\hline Very hard work - 1000 & 180 & 117 & 21,060 \\
\hline
\end{tabular}

It will be seen that at first the pulse rate is practically unaltered although the amount of work done has been increased from 270 to 
735 kilogram-metres while the output per beat has increased from 75 to 120 c.c. After this, the output per beat is not materially changed, if anything it tends to decrease while there is a marked increase in the pulse rate. It is interesting to note the increase in the rhythm of the heart when work has just been started, viz. from 70 to 100 . This is associated with the initial changes originated by the acts of volition and attention. The mere caution, "Are you ready?" is sufficient to cause a rise in the pulse rate due, in part, to the increase of muscular tone in the act of attention, and, in part, to psychological causes.

A fair day's muscular work may be taken at 100,000 kilogram-metres. We have seen that the work done by the heart is, at least, 10,000 kilogram-metres per day. Hence the work done by the heart is always more than $1 / 10$ of that done by the skeletal muscles.

The efficiency of the heart may be taken as the percentage amount of the energy taken in as fuel that is converted into work. Workers in this field are agreed that it is extremely probable that the sole normal source of cardiac energy is the glucose taken to the heart by the blood and in part stored as glycogen in the heart substance. This storage of glycogen renders difficult the interpretation of the results of estimations of the amount of glucose in the blood before and after passing through the coronary vessels. More accurate calculations of the energy generated during the cardiac cycle can be made from the oxygen consumption and carbon dioxide production during bodily rest and during measured work. The appended table from a paper by Evans and Matsuoka demonstrates this method for obtaining a value for the effieiency of the heart. The total output of blood from the ventricle is fairly constant-averaging about 16 litres per

TABLE L.

Efficiency of the Heart under various Conditions.

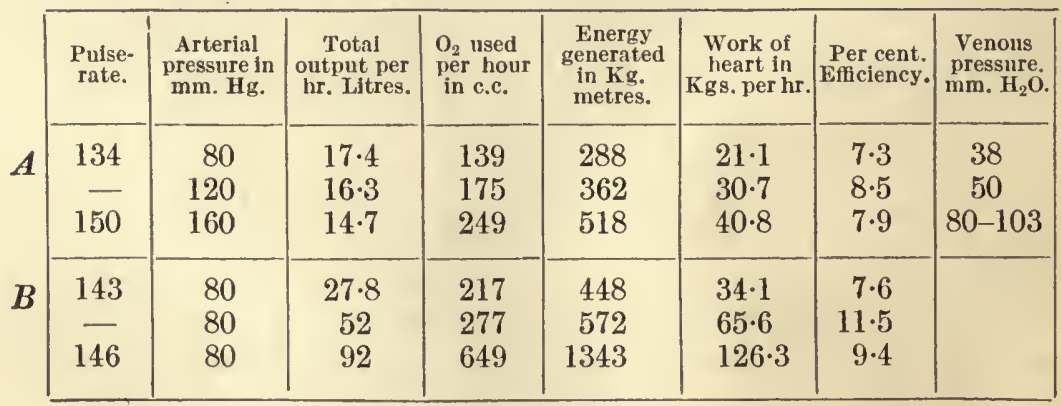


hour. The resistance to outflow was increased by steps of $40 \mathrm{~mm}$. $\mathrm{Hg}$ from 80 to $160 \mathrm{~mm}$. $\mathrm{Hg}$, corresponding to an increase in cardiac work of about 10 kilogram-metres a time.

To free the energy necessary for this increased work the heart uses up more oxygen. The amount of oxygen (in c.c.) so used multiplied by 2.07 gives, in kilogram-metres, the energy developed. It is clcar that, with a moderate increase in arterial resistance, the mechanical efficiency of the heart improves but tends to decrease when the resistance is doubled. In other words, when the arterial pressure is raised, the oxygen intake is increased, and more tension developed in the cardiac muscle. The mechanical efficiency is raised to a certain limit, beyond which it again diminishes. The venous pressure in the experiment quoted, and in most others, runs parallel with the oxygen usage. In the series of observations tabulated as $B$, the arterial pressure was kept constant at about $80 \mathrm{~mm}$. Hg, while the output per hour was increased roughly as $1: 2: 3$. This was done by varying the inflow of blood to the heart. The increase in oxygen usage is not quite proportional to the increase in work done, but is if anything, less. The efficiency values therefore tend to increase with increasing outputs up to a certain limit. Beyond this point, the amount of oxygen used increases very suddenly. In the example given, for a little less than double the output, almost two and a half times as much oxygen is required. As this involves the liberation of enough energy to lift 1343 kilograms to the height of a metre, and as only $126 \cdot 3$ kilogram-metres of work are done, the increased work is not done so economically and therefore the efficicney value falls. How can this primary increase in efficiency and subsequent decrease be explained and what factors are brought into play to settle the critical point at which maximal efficiency will be found? If output is to be increased, intake must first be increased and the ventricle must be distended to hold the extra amount of blood. That is, the muscle.fibres of the ventricular wall will be stretched. We have already mentioned, in connection with skeletal muscle, that a stretched muscle develops more tension during the isometric phase. The heart responds to increased work by such a lengthening of its fibres. If the lengthening process is carried too far, the muscle fibres per unit of area will become fewer, so that the larger the ventricular volume, the more strongly will each fibre have to contract in order to produce a given tension. At this greater length they also use up more potential energy just as skeletal muscle does. 
The maximal mechanical efficiency was obtained by moderate increase of both pressure and output and reached 26 per cent.

It has been suggested that a term Energy Index should be used to denote the total force developed by the heart per minute. If the systolic blood pressure be $120 \mathrm{~mm}$. $\mathrm{Hg}$ and the diastolic $80 \mathrm{~mm}$., then the force of each beat would be $120+80=200 \mathrm{~mm}$. Hg. This figure multiplied by the number of beats indicates the total force per minute. From an examination of about 26,500 recruits for the American army the normal index was found to be about $20,000 \mathrm{~mm}$. Hg. per minute. This Systolic-Diastolic-Rate index designates the amount of effort which the heart is putting forth. A high S.D.R. index indicates increased cardiac effort due either to inability of the heart to carry on its normal work at a normal rate or to the presence of some resistance to flow in the circulation.

For example, adrenalin causes an increased blood pressure by constricting the peripheral vessels. A man who had S.P. $=108$, D.P. $=70$, P.R. $=84$, giving an index of 19,852 , had a small injection of adrenalin. His S.D.R. index then rose to 23,520 , made up from S.P. $=140$, D.P. $=70$, P.R. $=112$.

The diagrammatic section of the heart (Fig. 58) demonstrates that the walls of the left ventricle are much thicker than those of the right. The mean of a large number of determinations furnishes the ratio of $6 \cdot 8: 1$. This may be interpreted as indicating that the left ventricle develops about seven times as much pressure as the right ventricle. Proof confirmatory of this deduction is obtained by determining the hydrostatic pressures necessary completely and symmetrically to fill these two chambers. The right ventricle is dilated by a seventh of the pressure employed in equally dilating the other ventricle.

A dog weighing 10 kilos with an average aortic pressure of $100 \mathrm{~mm} . \mathrm{Hg}$, and an output of 2,000 c.c. of .blood per minute, develops pressure in right and left ventricles of 25 and $150 \mathrm{~mm}$. $\mathrm{Hg}$ respectively - a ratio of $25: 150=1: 6$.

The pressure developed in a distended hollow elastic vessel depends on (i) the elasticity of the walls, (ii) the degree of distension and (iji) inversely, the radius of curvature of the walls. The volume output from both ventricles is the same and their radii of curvature are similar. There remains only a marked difference in elasticity. As both are formed from the same material, alteration in elasticity must be brought about by alteration in wall thickness. 
Sections of the ventricles at different points show that the ventricular walls vary in thickness at different parts. For instance in the left ventricle the apex, in the fully dilated ventricle, has, by far, the thinnest wall. As presumably the pressure in the chamber is constant over the whole wall area at any moment, some other factor must be found to account for this diminution in thickness. From the purely physical study of the shape assumed by elastic-walled cavities the conclusion has been drawn that where an elastic membrane is subjected to internal pressure, its shape will be determined by the law of distribution of radial pressure. With a given shape and size of body, equilibrium is maintained by altering the thickness (resistance to pressure) of the wall so that where curvature is least the wall is thickest and vice versa. The apex of the heart is the portion with the greatest curvature.

To take a very simple example: if an elastic band is stretched between two points on a flat surface it will exert no pressure on any part of the underlying surface. But if it is stretched over a curved surface, e.g. a cylinder, it will exercise a downward pressure depending on the radius of the cylinder. A flat surface may be considered as equivalent to a curved surface of infinite radius. As the numerical value of the radius is decreased, i.e. as the curvature is increased, the pressure exerted by the band will increase. In mathematical form $p=T / R$, i.e. Pressure per unit of surface $=$ Tension of band divided by Radius of curvature.

Where there are curvatures in two dimensions, e.g. a sphere, the two pressure effects are additive, i.e. $p=\frac{2 T}{R}$.

The ventricles are roughly egg-shaped, i.e. they have radii in two dimensions and of unequal length. The pressure will therefore be equal to the sum of these, i.e. $p=T / R+T / R_{1}$.

We have seen reason to correlate thickness with pressure.

We may therefore say that thickness of wall varies inversely with the radius of curvature. This gives the formula

$$
t\left(1 / R+1 / R_{1}\right)=C,
$$

where $t=$ thickness of the walls and $C$ a constant.

The wall of the apex of the heart has the largest mean curvature ( $R$ is least and, therefore, $t$ is least).

Similar reasoning may be applied to the consideration of the thickness of the walls of the blood vessels. The pressure $(\boldsymbol{P})$ within the vessel is balanced by (1) the elastic tension of the wall $(T)$ divided by the radius of curvature $(R)$, and (2) by the pressure 
brought to bear on the external surface of the wall by the resistance to distortion of the surrounding tissues $(p)$.

Thus

$$
T=R(P-p),
$$

or putting $t=$ thickness and $C=$ a constant, we may write

$$
t=C R(P-p) \text {. }
$$

That is, if $(P-p)$ be kept constant the thickness of the walls will vary as the radius of curvature.

\section{TABLE LI.}

Thickness of Walls and Diameter of Lumen of Arteries in mi.

\begin{tabular}{|c|l|l|l|l|l|}
\hline \multicolumn{1}{|c|}{ Artery. } & Intima. & \multicolumn{1}{|c|}{ Media. } & Adventitia. & \multicolumn{1}{|c|}{ Total. } & \multicolumn{1}{|c|}{ Lumen. } \\
\cline { 2 - 3 } & & & & \\
\hline Brachial (human) & 0.03 & 0.5 & 0.25 & 0.78 & 4.17 \\
Carotid (ox) - & 0.84 & 1.176 & 0.484 & 1.744 & 6.0 \\
, (sheep) - & 0.028 & 0.420 & 0.168 & 0.616 & 3.0 \\
Metacarpal (horse) & 0.03 & 0.513 & 0.31 & 0.853 & 2.7 \\
\hline
\end{tabular}

$$
\rightarrow
$$

(MacWilliam and Kesson.)

According to measurements made on excised vessels the carotid artery of the ox has a lumen of $6 \mathrm{~mm}$. whilc that of the sheep is $3 \mathrm{~mm}$. The maximal pressure developed in these vessels at body temperature amounted to 60 and $40 \mathrm{~mm}$. $\mathrm{Hg}$ respectively.

That is $R / R_{1}=2 / 1$ and $p / p_{1}=3 / 2$.

Now $t / t_{1}=R / R_{1}$ and as $p / p_{1}=6 / 2=3 / 1$.

The actual thickness of the carotids as measured by MacWilliam and Kesson are $\mathbf{1 . 7 4}$ and $\mathbf{0 . 6 1} \mathrm{mm}$. respectively. Of course, the main elastic resistance to distortion is met with in the muscular tunica media which in the ox is $1.12 \mathrm{~mm}$. and in the sheep 0.42 wide. Either pair of figures gives a close approximation to the ratio 3 to 1 .

The valves of the heart and veins are interesting mechanical structures. During the two years that Harvey studied at the University of Padua, Fabricius, the renowned Professor of Anatomy there, was investigating the valves of the veins. He demonstrated their presence in the veins of the arms and legs and also in the vessels at the root of the neck. These sluice-gates are very simple contrivances-just little pockets set in pairs opposite each other in the vein. 'Fabricius noted that the openings of the pockets were always directed toward the central part of the body. $\mathrm{He}$ interpreted this as indicating a mechanism to prevent the blood 
from gathering, under the influence of gravity, in the lower parts of the body. Harvey saw that this explanation did not account for the setting of the valves in the veins of the neck, and we saw how, by noting the direction in which the valves would allow fluid to pass, he discovered the circulation of the blood.

It is clear that the pockets offer practically no resistance to the passage of blood towards the heart. If, however, the pressure on the heart (or central) side of a valve becomes greater than the pressure in the preceding segment, the pockets will fill with blood, become distended and effectively prevent a back-flow. That this is so can be proved by repeating one of Harvey's experiments. He tied a ligature round the upper part of his arm and so dammed up the blood in the lower part of the arm. When he milked these swollen veins towards the hand he noticed that the blood could not pass certain points where he knew valves were placed. No valves are necessary in the arteries as there is always a positive driving pressure. The type of two of the valves of the heart is indicated in Figs. 58 and 61.

(1) The auriculo-ventricular valves are triangular sheets of fibrous tissue-tough but flexible-fixed by one side to the auriclo-ventricular ring and hanging apex downwards into the ventricular cavity. The pointed part of each flap or cusp is tied to the ventricular wall by a number of cords, chordae tendineae. The main cords are, however, not inserted directly into the ventricular wall but are attached to the finger-like papillary muscles. These muscles regulate the tension of the valve-flaps. When the ventricles contract so do the papillary muselespulling on the chordae and thus bringing the cusps closer together. The increasing pressure of the blood in the ventricle causes the flaps to bellow out and block the passage-way so that the blood cannot pass back into the auricles. The greatei the pressure developed in the ventricle, the more tightly is the valve shut. The cusps may cven bulge up into the auricles. Valves constructed on this principle are obviously fitted to occlude openings which vary in size and shape during the various phases of the eardiac cycle.

The right and left sides of the heart differ in the number of eusps in their valves and in the details of their movements. The mitral valve on the left side of the heart has onlytwo triangular flaps like a bishop's mitre, while on the other hand the passage way from right auricle to right ventricle is guarded by the three eusps of the tricuspid valve. 
During systole, the strong anterior cusp of the mitral valve does not materially shift its position. The other cusp is pulled forward against it.

On the right side, one of the cusps hangs down on the septum and is practically immovable. The other two cusps by the action of their papillary muscles are pulled over towards the septal cusp. The mass of blood pressing on the sides of the cusps completes the closing of the orifice.

When this mass of blood, under the pressure induced by the contraction of the ventricles, stretches the auriculo-ventricular valves it causes them to emit a sound which is a component of
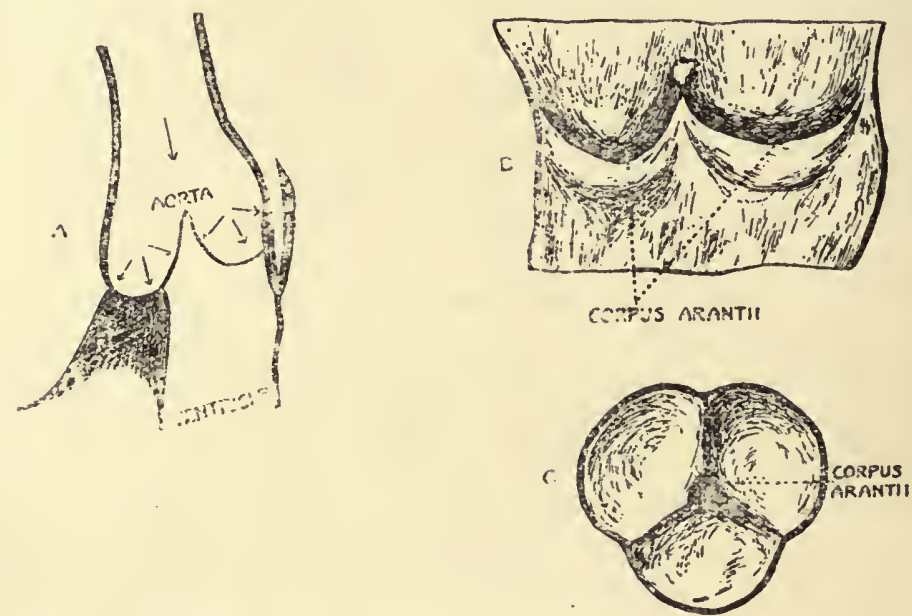

FIG. 62.- Semilunar valves, $A$, in longitudinal-mesial section. $B$, Artery laid open and exposed, and $C$, closed valves from the arterial aspect.

the first sound of the heart. The other component is the sound produced at the same time by the contraction of the ventricular walls. It is said that a trained ear can pick out the notes due to elosure of the valves from those due to stretching of the muscular walls.

(2) The valves situated at the openings of the ventricles into the arteries are similar in shape and in action to the pocket valves of the veins (Fig. 62). Each is composed of three pockets or half cups attached along their curved margins to the walls of the artery and upper part of the ventriele and with their openings set away from the ventricle.

The cusps are not placed all exactly on the same plane. One cusp lies somewhat deeper in the heart than the others. This cusp is mounted on a muscular septum which acts as a cushion, 
absorbing the shoek when the pressure falls on the valve and the other two cusps shut down on it.

The sudden stretching of these semilunar valves by the impaet of the high artcrial pressure sets the valves in vibration like the blow of a drum-stick on a drum-head. It produces a clear sharp ligh-pitched sound, the so-ealled second sound of the heart.

A third sound has been described. It has been attributed to the rebound of the semilunar valves when the ventricle relaxes and the ventricular exit again becomes patent.

When the valves are diseased eertain more or less continuous sounds or murmurs are heard. They are in the main due to either of two eauses.

(1) Stenosis. When a fluid flows along a tube of uniform bore or a tube where the bore alters gradually no vibrations are set up. On the other hand, if the cross-section is altered suddenly and appreciably, the fluid is set into vibrations. These vibrations are transmitted to the solid tube and to the material in which it is set and a sound is produced. Most people have heard the rather irritating purr emitted by the domestic water supply when there is "air in the pipe." The vibrations may not only be heard but they may be felt at the tap and seen in the water issuing. Something similar takes place when, by discase, the opening from auricle to ventriele is narrowed. During the whole period when the ventricle is filling up from its auricular reservoir, the blood flowing through the narrowed opening is set into vibrations which are transmitted through the more solid tissues to the inner earthis is the murmur of mitral or of tricuspid stenosis, according to whether the fault lies on the systemic or pulmonary side respectively. The narrowing does not need to be absolute. If the previous part is dilated, the orifice will become relatively narrower and will produce the result.

Similarly the murmur caused by stenosis of the aortic or of the pulmonary valves will be heard during the cxpulsion of blood from the ventricles.

(2) Incompetence. The failure of any of the valves to close completely, allows blood to triekle back into the empty expelling chamber. This regurgitation throws the tightly stretched cusps into vibration and produces a murmur. If this sound is heard during ventricular systole it may be ascribed to incompetence of either of the auriculo-ventricular valves-if during ventricular diastole, the aortic or pulmonary valves are at fault. 
In aortic ineompetence the sound will be best heard where the aorta comes nearest to the surface, viz. at the second right eostal cartilage; in pulmonary ineompetenee the stethoseope will be placed over the seeond left interspace just external to the margin of the sternum.

The sound of the mitral valve is heard at its best just over the apex of the heart; that of the tricuspid valve at the junetion of the fourth right eostal eartilage with the sternum.

By means of a recording microphone, a tracing may be obtained represcnting the values of these sound waves. Such a phonoeardiogram (Figs. 66 and 67), if taken simultancously with a tracing of the mechanical or electrical changes of the heart, is of great use to the physician as an indication of cardiac cfficieney.

If any of the large arteries be compressed, say by the imposition on the overlying skin of the stethoseope, murmurs will be heard. These sounds are eaused by the sudden narrowing of the lumen of the artery by the pressure of the instrument. The blood rushes through the narrowed part into the comparatively wide part of the vessel beyond the point of pressure and so sets up eddies. The vibratory movement of the fluid is transmitted to the arterial walls and passed on to the internal ear (Part II.).

Considering the circulatory mechanism as a whole one is struck by the extraordinary efficiency of this method of transport. Comparatively little energy is wasted. Fluid leaves the ventricle under a pressure of over $100 \mathrm{~mm}$. $\mathrm{Hg}$, passes through a system of large and small tubes and returns to the reservoir of the central pump with no surplus pressure. Just enough blood is provided to earry the fluid within range of the aurieular suetion and no more. It has been stated that by the rhythmic contractions (peristaltic waves) of the museular eoat of the vessels, the blood is helped along its eourse. The mechanics of peristalsis will be considered shortly (Chap. XXVII.).

One further point making for the economical working of the inland transport service, owes its enunciation to John Hunter. He wrote, "To keep up a circulation sufficient for the part and no more, Nature has varied the angle of the origin of the arteries accordingly." Suppose a point $C$ is $h$ units vertically distant from an artery $A B$, the problem is to find out the route by which the blood could be conveyed from $A$ to $C$ with the least possible loss of energy. This is not necessarily by the shortest route or by the route using the shortest piece of branch tubing. The shortest route would be $h$ units long and would arise from $A B$ at 
right angles (say at $D$ ). For the purposes of this ealeulation let us eonsider that the least loss of power oceurs when the branch originates at $X$ which is $x$ units from $D$, making an angle of $\theta$ with the main trunk. Then the distance from $X$ to $C$ would be $\sqrt{x^{2}+h^{2}}$ (hypotenuse of right-angled triangle).

Assuming that loss of pressure is due to frietion on the walls of the vessels, then it will be directly proportional to their lengths and indirectly proportional to their radii (e.g. main trunk $=\boldsymbol{R}$, braneh $=r$ ) ;

i.e. loss is proportional to $\frac{X C}{r}+\frac{A X}{R}$.

If the whole distance from $A$ to $D$ be put $=b$, then $A X=b-x$.

Substituting, we have $\frac{\sqrt{x^{2}+h^{2}}}{r}+\frac{b-x}{R}$,

multiplying by $R r$ gives us the value

$$
S=R \sqrt{x^{2}+h^{2}}+(b-x) r .
$$

Differentiating and equating to zero we obtain a value for $x$ which makes $S$ a minimum.

Thus

$$
\begin{aligned}
& \frac{d \cdot S}{d \cdot x}=\frac{2 R x}{2 \sqrt{x^{2}+h^{2}}}-r=0 ; \\
& \frac{r}{R}=\frac{x}{\sqrt{x^{2}+h^{2}}}=\frac{X D}{X C}=\cos \theta .
\end{aligned}
$$

That is, the angle of origin required is such that its cosine is numerically equal to the radius of the branch divided by the radius of the main trunk.

The size of the angle of origin is governed neither by the radius of the branch vessel nor by the radius of the main vessel but by the ratio of these two quantities. For any particular value of the ratio $r / R$, we have therefore a constant value of $\theta$; that is, all branches of equal radius will be equally inelined to the main artery.

(1) In particular, if the artery bifurcates into two equal branches, the angles of bifurcation will be equal.

(2) If $r$ is so small compared with $R$ that the amount of blood going to the branch is almost negligible, then $\cos \theta=\frac{r}{R}$ tends to be infinitely small, i.e. angle $\theta$ will be elose to $90^{\circ}$. 
(3) If $r$ differs but slightly from $R$ it is obvious that $\cos \theta$ tends towards the limiting value $=1$, i.e. $\theta$ will be very small.

While these statements are true as they stand they are not the whole truth. Other factors eome to bear on the angle of origin and produee modifieations not comprehended in Hess's Law. 


\section{CHAPTER XXV}

\section{THE ELECTROCARDIOGRAM}

"Providence ... can make a harmony

In things that are most strange to human reason."

MidDLETON.

Tire electrical changes that occur during each cardiac cycle have, of late, become rather important to the clinician, as a rapid and reliable indication of the state of the heart. Cardiac muscle, just like any other muscle, or, in fact, like any other living tissue, is the seat of electrical differences in potential. Ordinary skeletal muscle on contracting develops potential in such a way that the contracting part becomes electro-negative or zincative to the rest. This causes a current to pass through the external or galvanometric circuit to the contracting part, from the rest of the muscle. Heart muscle acts in a similar way. It has been found that the wave of contraction starts in the auricles. Therefore the auricles will become electro-negative to the rest of the heart. The auricles contract as a whole, passing on the excitation through a piece of primitive tissue (Bundle of His) to the ventricle. This will then become negative to the rest of the heart and so on.

(1) The existence of this change in the sign of the potential developed may be demonstrated, as it was in muscle, by the use of a fresh nerve-muscle preparation. The nerve is laid across the beating ventricle and produces two muscle twitches per beat.

(2) Earlier experimenters used the capillary electrometer (p. 404) as the instrument wherewith to measure the potential differences. They found (Fig. 63), on leading one electrode from the auricular sinus and one from the ventricular apex, that on the initiation of the contraction of the auricle, the mercurysean up the capillary away from the tip, indicating the presence of a negative difference of potential. This was followed immediately by a tiny positive movement constituting the second part of the auricular diphasic response. Similarly, a large upward excursion of the 
mereury followed by a smaller downward movement demonstrated a similar but greater ventrieular diphasie response. It is not neeessary to expose the heart and lay non-polarisable electrodes on it in order to see this diphasie response by the eleetrometer. The right arm may be eonsidered as eleetrieally continuous with the base and the left leg (or arm) with the apex of the heart. Connection of the arms by non-polarisable eleetrodes to the electrometer gives results similar to those obtained from animals by direet "leading."

Clinieians seem to prefer the more sensitive string galvanometer as an instrument for eleetroeardiographie work, in spite of its great expense and the diffieulty of analysing its reeords. The

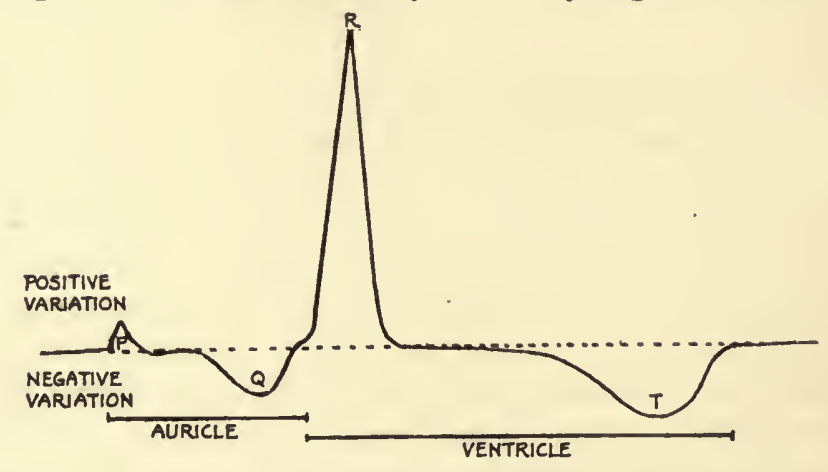

FIG. 63.- - Record of the electrical variations in the beating heart of a tortolse, taken by a capillary electrometer (after Gotch).

instrument at present generally employed is substantially that invented by Ader and modified by Einthoven. The earlier forms of string galvanometer were almost useless as a means of registering the rapid alterations in the eleetrieal state of the heart. Any recording apparatus for sueh work must be as "dead beat" as possible-moving in exaet aecordanee with the exact potential differenee developed and having no period of vibration of its own. As its name implies the moving part of the string galvanometer is a string or fibre. The string ( $C$, Fig. 64) which is an extrcmely light fibre of silvered glass, quartz, or platinum is stretched between the poles $(N, S)$ of a powerful eleetromagnet. When a current rasses along a fibre, the fibre is defleeted at right angles to the magnetie field, the amplitude of the exeursion depending on the magnitude of the potential differenee eausing the current; and the direetion of the defleetion (observer's left or right) depending on the direetion in which the eurrent is passing. . If the eurrent 
passes in the direetion of the arrow, from top to bottom of the diagram, the fibre will bend outwards, i.e. in the direction of the arrow a. Reversal of the direetion of the current of eourse eauses reversal of the movement of the fibre. The exeursions of the string ean be observed by means of the reading mieroseope $A E$, which passes through a hole in the magnet, or records may be made by plaeing an are lamp at $G$, concentrating the light on the

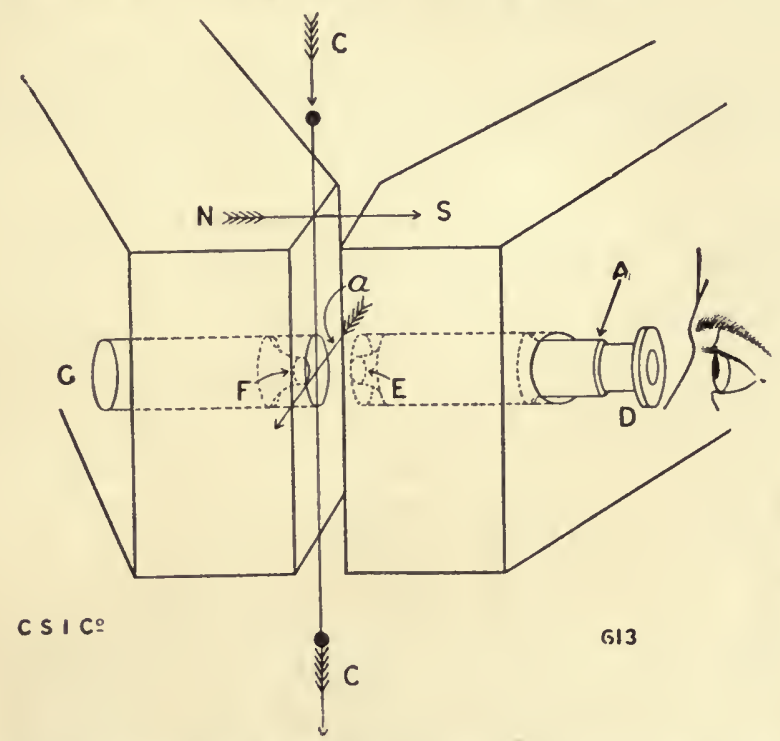

FIG. 64.-Diagram of the essential parts of the string galvanometer. $N$ and $S$ are the poles of a powerful electromagnet, between which is stretched the fibre $C$.

fibre by a lens $F$ and throwing the shadow on to a moving photosensitive surfaee. Fig. 65 shows diagrammatieally the arrangements of galvanometer and aceessories for photographing the fibre movements. The distanees are given in millimetres.

The optieal mechanism for produeing the eleetroeardiograms needs some mention. The eamera is a light-tight box fitted with a cylindrical lens and an arrangement whereby a sensitive photographie plate or film (or bromide paper) is made to travel at a uniform speed past the narrow lens. The field of the objective is projected by an eyepiece on to the lens which foeuses it as a spot of light on the part of the sensitive surfaee exposed by the slit. The shadow of the fibre appears as a dark spot in this band of light. Thus if the plate or paper be moved downwards normal to the eylindrical lens, the whole surface will be exposed to the aetion of the light exeept that portion proteeted by the shadow 
of the fibre. The movements of the fibre are, as we have seen, parallel to the plane in which the lens is set, and therefore when the fibre moves towards the reader (in the diagram) the result

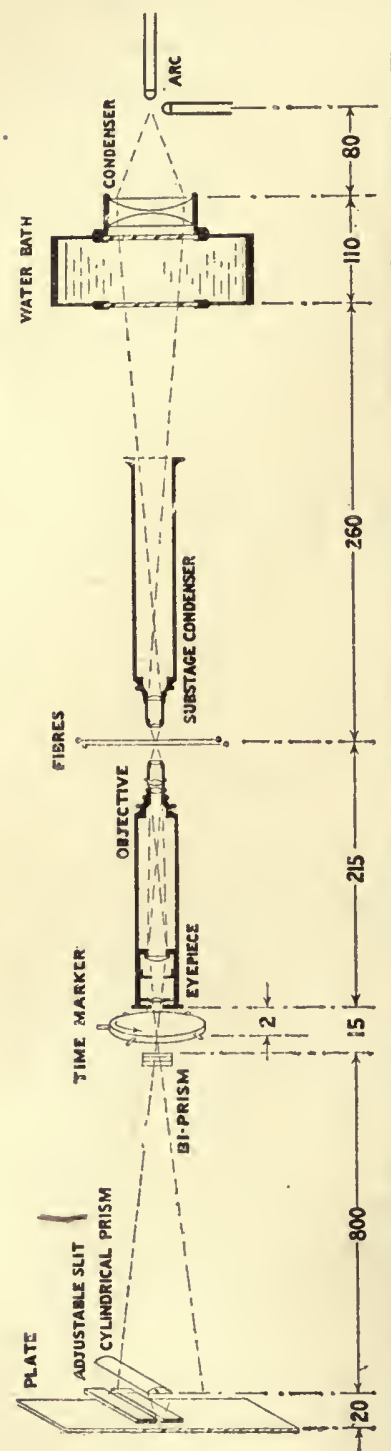
will be a corresponding alteration in 蛋 the position of the shadow spot. A continuous record of these positions is formed on the moving sensitised surface.

The records (Figs. 66 and 67) show vertical and horizontal markings as well as the electrocardiogram itself. The horizontal markings enablc one to find by inspection the potential difference generated at different phases of the cardiac cycle. The space between each line is generally $1 \mathrm{~mm} .=$ $1 / 10,000$ volt (Einthoven's standard). The lines are engraved across the width of the cylindrical lens. When illuminated they produce shadows forming lines along the length of the record. The vertical lines, shortened to ticks at the foot of the records illustrated, are a measure of timein the cases given $=\mathbf{1} / \mathbf{3 0}$ of a second.

They are produced by the interruption of the focused beam of light by a serrated wheel (Fig. 65) so that for a short interval no light falls on the whole (or on part of the sensitised surface) as it is travelling past the slit. In consequence, a sharp line falls on the record.

Before a record can be taken, it is necessary to know the resistance of the subject's body and the magnitude of the "skin-current." The latter factor is a relatively large and fairly constant potential difference caused by the glandular activities of the skin. It has to be counterbalanced by sending an equal current through the fibre in the opposite direction. The resistance of the body to the passage of 
a current is very rarely considered in routine clinical electrocardiography.

The analysis of electrocardiograms is by no means simple.

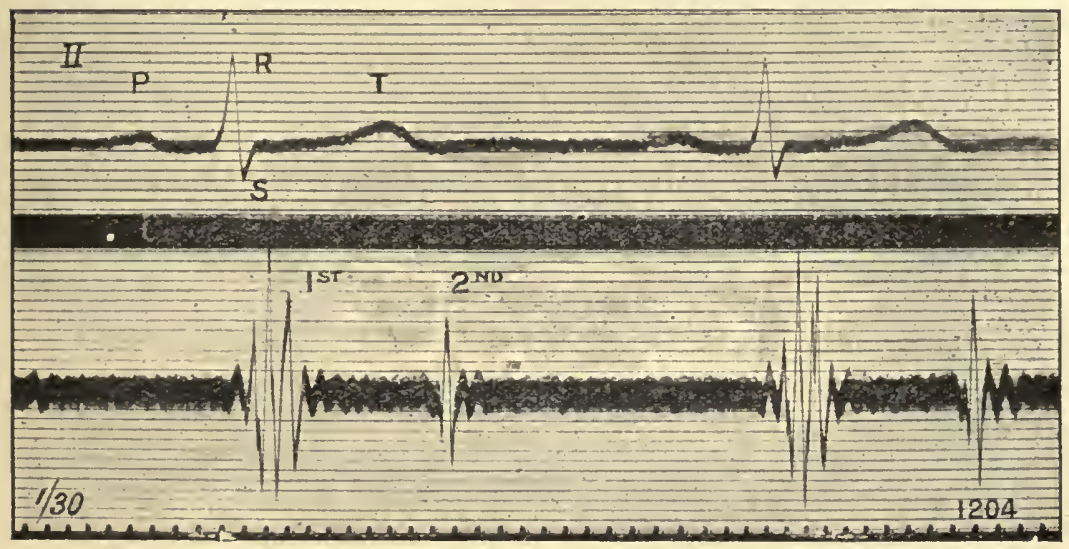

FIG. 66.-Electrocardiogram from lead II, and Pliono-cardiogram taken simultaneously from a normal subject.

Considerable uncertainty exists as to the exact interpretation of certain units in the trace. If Einthoven's symbols PQRST are

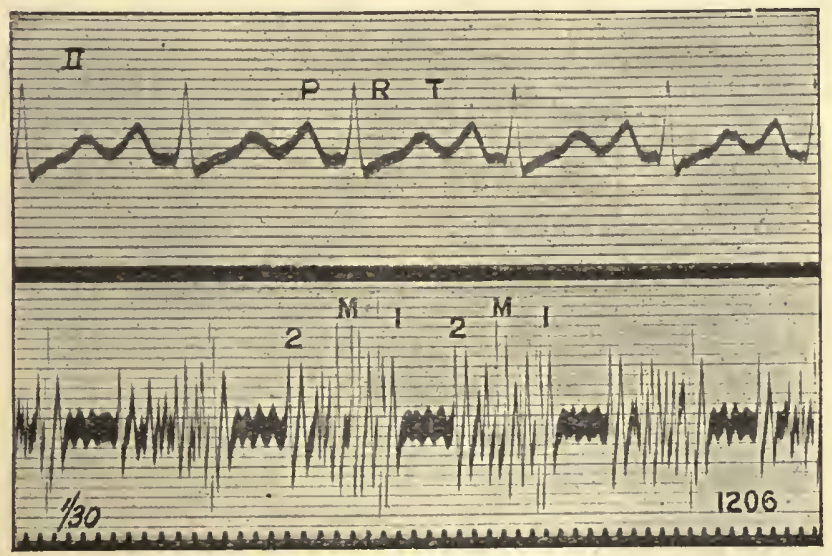

Fig. 67 - - Similar records to above, but taken from a subject suffering from mitral stenosis. The space between the first and second sound is filled by a coarse, loud, diastolic murmur $(\boldsymbol{M})$.

used it is generally agrced that $\mathbf{P}$ is pre-systolic and that $\mathbf{Q}$ (positive E.M.F.) indicates that the wave of contraction does not start at the base of the ventricle but a short distance from it. $\mathbf{R}$ is no 
doubt the wave of negativity produced by the contraction of the ventricles and $\mathbf{S}$ is the second phase or positive reaction. The space between $\mathbf{S}$ and $\mathbf{T}$ represents the time during which the whole ventricle is excited, and $\mathrm{T}$ probably indicates the arrival of the wave of negativity at the apex. Other interpretations have been given.

It has been suggested for ease in analysis, that it is advisable to compound the records from all three leads into one diagram. This so-called monocardiogram represents the algebraic sum of all the potential differences at every point of the cardiac eycle. 


\section{CHAPTER XXVI}

\section{EXTERNAL RESPIRATION}

" The body is sustained by three kinds of nutriment, food, drink, air ( $\left.\pi \nu \epsilon \epsilon^{\prime} \mu \alpha \tau \alpha\right)$, of whieh the last is by far the most important."

Hippochates.

FEw of the mechanical arrangements of the body lend themselves better to popular descriptive writing than the lungs, and fewer still have given rise to more misconception of the aetual means employed in the performance of their function. From the earliest times of which written reeords exist, one of the most important and yet most mysterious problems of physiology has been the part played by the lungs. The regular inhalation of air and its regular exhalation was recognised by all as essential to life. Prolonged stoppage of either eaused death, and death was accompanied by cessation of breathing. Hippoerates, following Hindu philosophers, maintained that "aerial nutriment" was " the chief support of animal life" (Cicero). Aristotle denied this and considered that the function of respiration was to cool the heart. The followers of Hippocrates, notieing that the arteries and veins differed in strueture, suggested that they might differ also in function. It was further observed that the arteries of a dead man were empty although the veins were full. Hence they argued that the artcrics were channels for air and not for blood (Erasistratus, circa 294 B.c.). That these philosophers had a glimmering of the truth may be adduced from Galen's writings, e.g. "The air which is drawn outwards from the rough arteries (trachea and bronchial tubes) receives its first elaboration in the flesh of the lungs but afterwards in the heart and arteries." It is our business at present to consider the first step in this sequence, viz., the passage of the respiratory gases between lungs and atmosphere.

\section{Principle of Mechanism.}

The lung mechanism may be considered as an elastic bag with one opening, the whole suspended in an air-tight box with movable 
sides. When the sides are pulled outwards the box increases in eapacity and the air is sucked into the bag to keep the pressure constant. When, however, the force which drew the sides out-

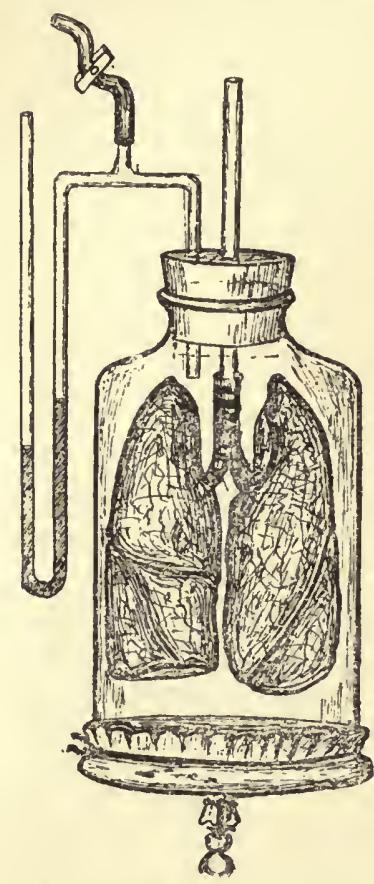

Fí. 68.-Model to demonstrate the rubber sheet downwards, alr enters the lungs and they expand. aetion of diaphragm. On pulling

wards is released, the box and bag resume their former volumes, and air is expelled. In short the lungs are a form of suction pump or bellows (Fig. 68).

\section{Structure of Mechanism.}

While the foregoing account of the principle underlying the respiratory mechanism may be taken as substantially correct, it is apt to convey a wrong impression of the details of the mechanism.

(a) The lungs are not simple elastic bags but are composed of thousands of little distensible air sacs-a spongework.

(b) These complex bags are suspended in and almost fill the thoracic cavity. Each organ is enclosed in a membranous sac-the pleura, which bends back from the bronchi and lines the entire internal surface of the chest wall. That is, the pleura consists of two layers-an outer, parietal or chest wall layer, and an inner, viseeral or lung layer. These surfaces are kept moist with lymph. It is important to note that as long as the chest rvall is kept intact the pleural cavity is only a cavity in name. The layers of the pleura are always normally in close contact with one another and with the underlying and overlying surfaces. In other words, the chest wall, the two layers of the pleura and the outer surface of the lungs move almost as onc structure. The elasticity of the lungs has been determined as about $30 \mathrm{~mm}$. $\mathrm{Hg}$. If this inwards pull of the pulmonary tissue be subtracted from the atmospheric pressure $(760 \mathrm{~mm}$.) in the lung, the resulting figure $(730 \mathrm{~mm}$.) represents the force tending to keep the lungs expanded. If, now, communication.be established between the outer air and the intra-pleural cavity, thcre will be a pressure of $760 \mathrm{~mm}$. tending to cause the lungs to collapse. As these outwards and inwards pressures (760 as against $730 \mathrm{~mm}$.) do not balance, one 
would expect to find that the lungs collapse. This is not always so. A further force comes into play. Moistening the various surfaces is the lymphatic secretion already referred to and, by the force of surface tension, the lungs are held to the chest wall, just as firmly as a boy's leather "sucker" is hold to the pavement and for the same reason.

\section{Mechanics of Respiration.}

During inspiration the capacity of the thorax is increased in all directions. That expansion occurs laterally and in an anteroposterior direction may be made manifest by measurement or by moulding strips of lead (cyrtometers) to the circumference of the chest. The movements in a vertical plane have been studied by means of the $\mathrm{X}$-rays and by percussion. If the intercostal spaces are tapped with the finger, a clear resonant note will be emitted when the percussion has been performed on a part overlying inflated lung. Otherwise a dull sound will be produced. Horizontal expansion is obtained by movements of the ribs while the vertical movements are caused by contraction of the diaphragm.

I. Structure of the diaphragm. This is a vaulted musculofibrous sheet separating the thorax from the abdomen. It consists of a central tendon like a double-arched cupola which is attached on its thoracic surface to the pericardium and marginally to the thoracic walls by muscles. These diaphragmatic muscles may be divided into two sets, (i) crural and (ii) costal. The former have their origin in the three or four lumbar vertebrae and in the arcuate ligaments and are inserted into the posterior margin of the central tendon, while the latter arise from the cartilages and lower six ribs and from the back of the ensiform process. Such a division of the muscle into crural and sterno-costal portions is supported not only (1) by their different origins, but (2) by their development from different muscular sheets in the embryo; (3) by their different blood supply-the former directly from the aorta and the latter from the intercostal and internal mammary arteries; and (4) by their different nerve supply, the crus being served by the posterior branch of the phrenic nerve and the costal by the anterior branch. Moreover, the two portions act somewhat differently, and further, people may be classed as having respiration of a crural or of a parietal type depending on whether the crural or the costal portions of the diaphragm are employed during quict breathing. The majority of individuals employ both parts of the muscle in varying degrees. 
II. Mechanics of diaphragm. The crural portion, when it contracts, acts as power to a lever of the third class. That is, the fixed point or fulerum is the point of origin of the sheet of muscle in the posterior wall of the thorax-on the vertebral column. The resistance to be overcome is mainly the pressure of the contents of the abdomen, the perieardial fixture and the point of insertion of the vena cava and other vessels. They may, on the whole, be considered as a weight applied at the central tendon. The power is thus between weight and fulcrum-giving speed at the expense of strength. The sterno-costal part of the musele connects the lower ribs with the central dome and acts as a lever of the same class as the crura. In this case, however, the fulerum is movable and is moved outwards by other museles. This results in a forward as well as a downward movement of the dome.

On the whole, the final result of the contraction of the diaphragm is similar to the descent of a piston-inereasing the eapacity of the thorax vertically. The average descent is equivalent to a drop of about half an inch all over. For ease in ealeulation, say that the distance through which the diaphragm moved in an ordinary quiet respiration were $10 \mathrm{~mm}$. and that the mean area of the piston were $250 \mathrm{sq}$. cm., then the volume of air sucked in would be 250 e.c. (complemental pleura). Now as the tidal air in quiet breathing is under 400 c.e., it will be elear that the part played by the diaphragm in ordinary respiration is of major importance.

Acting along with the diaphragm there are those museles which abduct the lower ribs, viz. : the quadratus lumborum and the deep costal muscles. These are synergic - contracting synchronously with the diaphragm, and preventing the lower ribs from being pulled inwards. In children where the musculature is poorly -developed one sometimes observes a distinct depression of the lower chest wall at every inspiration.

The antagonistic muscles together with the viseera form the resistance against which the diaphragm moves. These are the museles of the abdominal wall, viz. : external oblique, internal oblique, tranversalis and rectus abdominis on each side.

(a) External Oblique (Descendens). This is the outermost and largest of the paired abdominal muscles. It is muscular laterally and tendinous in front. Above, it is attached to the lower eight ribs by eight fleshy digitations from whieh the muscular fibres pass obliquely downwards and forwards. The musele fibres of 
the lower rib are attached dorsally to the anterior half of the crest of the ilcum. The middle and upper parts of each muscle terminate in aponeuroses which, covering the whole of the front of the abdomen, are joined together at the mid line (linea alba).

(b) Internal Oblique (Ascendens). This pair of muscles lies between the external oblique and the transversalis and is attached below to the outer half of Poupart's ligament and to the anterior two-thirds of the crest of the ileum. Dorsally it is attached to the lumbar fascia. From this origin, the fibres spread in a fanshape passing behind to the lower three ribs and in front forming an aponeurosis.

(c) Transversalis. A pair of flat muscles lying behind the other pairs. The fibres arise from the outer third of Poupart's ligament and from the anterior two-thirds of the iliac crest. They are attached behind to the lumbar fascia and above to the inner surfaces of the cartilages of the lower six ribs. The fibres run transversely and horizontally, being inserted into the aponeurosis of the linea alba.

(d) Rectus. This muscle extends along the front of the abdomen on each side of the linea alba from the sternum to the pubes.

The floating ribs (and in 40 per cent. of people, the tenth rib also) are functionally part of the abdominal wall. Their movements are controlled by the quadratus lumborum and erector spinae muscles. The twelfth rib, in addition, is anchored to the transverse processes of the first and second lumbar vertebrae by a strong ligamentous membrane, an extension of the middle layer of the lumbar fascia. In this way the upward movement of the rib especially in its spiral segment is restricted. The anterior and lateral segments have a freer movement, so permitting of a movement of the floating ribs (and the tenth) round an axis corresponding to their spinal segments. It has been noticed that during inspiration, the spaces between those ribs widen and that during expiration the reverse takes place.

Function of Abdominal Muscles. The four pairs of abdominal muscles and their fibrous attachments act antagonistically to the diaphragm. When the latter contracts the former have to yicld to accommodatc the displaced viscera. That is, during diaphragmatic breathing, inspiration is accompanied by a relaxation of the abdominal wall which will move forwards. Correspondingly, expiration will be aided by the tendency of the viscera to rcturn to their normal positions and by the return of the abdominal muscles to the position of rest.

B. в. 
This musculature has also an important part to play in the maintenance of an adequate circulation. There is no doubt that the diaphragm, with its synergic and antagonistic muscles, was evolved not in connection with respiration but with circulation. Amphibians, for instance, carry on their interchanges of air between lungs and atmosphere by the action of muscles under the jaw. Without the constant tension of the abdominal muscles applied to the abdominal viscera, the larger veins would become distended with blood. These veins are capable of holding the entire amount of blood in the body. If for any reason the muscles of the abdominal wall lose tone, considerable fall in arterial blood pressure is the result. It may even fall to zero and death cnsue. This may be determined experimentally, either by dividing the spinal cord at the level of the first dorsal vertebra, or by using an animal with poorly developed abdominal muscles such as the tame rabbit. In the first case, the influence of the bulbar centres on the part below the section is removed, and the tone of the abdominal wall is abolished. If the animal is now placed vertically erect, the abdominal veins distend under the haemostatic pressure. In them the whole of the blood collects and there is no blood to fill the heart.

III. Thoracic Respiration. The upper and lower regions of the thorax should be considered separately. The muscles and movements of the upper series of ribs are quite different from the lower series.

(a) Lower costal series (6th to 9 th or 10 th rib).

This segment moves along with the diaphragm and leads to the expansion downwards of the lower lobes of the lungs. 'The ribs are articulated to the spinal column so that during inspiration the lateral and anterior part of each moves outward more than the one above it. Two movements may be noted:

(i) The 50 to $7 \mathrm{~mm}$. of each rib next the spine to which is attached the erector spinae muscle moves forward at each respiration. The tubercle of the rib slides forward on the flat upper facet of the transverse process.

(ii) 'The non-spinal portion of a pair of ribs moves with a buckethandle action, rising and coming forward with each inspiration. At the centre of each pair is the sternum-cartilage complex which is raised and forced forwards during inspiration. The muscles concerned in this increase of the volume of the lower thorax, transversely and antero-posteriorly, are the external intercostals.

(b) Upper costal series (2nd-5th rib). 
'These ribs differ from the lower series in shape, articulation, ligamentation, musculature and, consequently, in their movements.

(i) Shape. The upper ribs have a concave upper margin and do not have such a marked twist as those in the lower costal series. The second rib as a matter of fact may be laid flat on a table.

(ii) Articulation. The spinal articulation differs from the lower series mainly in that the convex ovoid facet of the tubcrcle fits into a corresponding cavity in the transverse process instead of gliding on a flat facet. Each transverse process from above downwards is tilted a little more backwards so that the angle of articulation becomes more obliquc as one passes down the series (Fig. 69).

Further, the upper ribs not only articulate with the vertebral column by their tubercles but also the facets on the head of cach rib work against the corresponding facets on the head of the vertebra.

(iii) Ligamentation. Each of the upper series of ribs is joined directly to the sternum by a band of cartilage. The following are the lengths of these attachments in a wellbuilt man : second, $37 \mathrm{~mm}$. ; third, $50 \mathrm{~mm}$.; fourth, $62 \mathrm{~mm}$.; fifth, $75 \mathrm{~mm}$. The angle of attachment increases as the length increases, e.g. the second costal cartilage joins the sternum at right angles while the third ascends to the sternum.

(iv) Musculature. The musculature of these ribs is the intercostal interchondral.

(v) Movements. Because of the double articulation of each rib to the vertebral

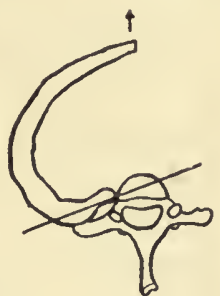
column by tubercle and head, rotation round a spino-sternal axis is limited. Very little bucket-handle action can take place. As the articulations are practically transverse, movement must occur at the manubrio-sternal articulation, i.e. chiefly forwards.

(e) The first rib provides the necessary fulcrum for the intercostal muscles. Along with the manubrium sterni, to which they are firmly bound by their broad but short costal cartilages, the first pair of ribs form the operculum or lid of the thorax. This 
lid is articulated anteriorly with the thoracic wall, at the manubriosternal joint, forming a synchondrosis. That is, the opposing surfaces of bone covered with a layer of hyaline eartilage and united by fibro-cartilage are bound together firmly by longitudinal fibres developed from the strong and thick periosteum. The cartilages of the first ribs are implanted upon the side of the manubrium forming a synehondrosis with the sterno-manubrial joint and there is no synovial cavity.

Great importance has been attached to the movements of this joint. Its amplitude varies, of course, with the type of respiration, being greatest with those who make least use of the muscles of the abdominal wall and vice versa. In other words, if the sternum moves freely then the exeursions of the sterno-manubrial joint will be small. On the other hand, in eases where the lower part of the sternum moves but little during inspiration (thoracic breathing), there will be a correspondingly large rotation of the upper end of the sternum on the end of the manubrium. Some physicians deelare that in phthisical subjeets this joint docs not move freely. Whether phthisis causes an anchylosis or whether want of free movement leading to incomplete expansion of the apices of the lungs is a factor favouring the development of the disease, is as yet an unsolved problem. On the whole the evidence tends to show that ossification of the costal cartilages in question is a consequence rather than a cause of a limited expansion of the apices of the lungs.

Posteriorly the lid is articulated to the vertebral column by a joint which is set more transversely and is wider in the extent of its attachment than any other of the costal ares.

IV. Mechanics of Thorax. The ribs are a series of bent levers.

(1) The fulcra or hinges on which the levers work have been mentioned when dealing with the ribs of the various thoracic segments.

(2) The power differs according to whether inspiration or expiration is being performed (p. 320).

(a) Inspiration.

(i) The lid or operculum is raised by the action of a flat triangular muscle (scaleni). The scalenus anticus is inserted in the upper surface of the first rib just dorsal to the cartilage and passes almost vertieally to the transverse processes of the third, fourth, fifth and sixth cervical vertebrae. The scalenus medius lies dorsally to the anticus and passes to the transverse processes of the lower six cervical vertebrae. 
(ii) The external intereostal muscles may be regarded as a triangular sheet of muscle having its origin in the dorsal part of the lid and being inserted into the upper surfaces of the ribs. It pulls upwards.

(b) Expiration.

(i) The power eausing collapse of the chest wall is mainly the elastic recoil of the lungs together with the weight and elasticity of the chest wall.

(ii) The abdominal museles, especially the external oblique, play a part in expiration in pulling down the ribs. The fixed basis from which they act is the pelvis, and they act as if attached to the lower margin of the ribs exactly opposite the external intereostals.

(3) Load. This too is different in inspiration and expiration.

(a) Inspiration.

The resistance to be overeome is :

(i) The elasticity of the lungs-a variable load, as the greater the expansion of an elastic body, the greater is the resistanec that it offers to further expansion. This factor, therefore, is numerically greater towards the end of inspiration than at the beginning.

(ii) The elasticity of the chest wall-the costal cartilages have to be twisted and the muscles overlying the chest wall have to be stretched.

(iii) The elasticity of the abdominal wall.

(iv) The elasticity of the vertebral column. During inspiration the spinal eolumn is lengthened by a stretehing of the ligaments, cartilages and articular processes.

(v) Gravity-weight of chest wall, etc.

These loads may be resolved into one applied to the upper surface of the ribs at their frontal tips. That is, we are dealing with levers of the third order where power is applied between load and fulcrum-giving speed at the expense of strength.

(b) Expiration.

The main resistance to expiration is the resistance to the outflow of air from the lungs. We have seen that the principal force causing expiration is the inspiratory load. Here then we have a lever of the second class with the load between the power and the fulcrum. During foreed expiration, when every muscle that can reduce the size of the thorax is brought into play, we have a simple bellows action. The front of the thorax acts like the movable side of a pair of bellows and is depressed towards the 
other side by the abdominal muscles. This is also a lever action of the second order.

V. Elasticity of the lungs. The work done by the respiratory musculature cannot be treated as a simple problem in hydraulics. The dynamics of the ordinary force pump cannot be applied to this question. Not only are the walls of the pump elastic and complex but (a) they are not equally extensible throughout and (b) their clastic force varies with the degrec of extension. Further, (c) the fluid enmeshed in the pulmonary capillarics has to change its position to be accommodated at evcry alteration in the cxtension of the lungs.

(a) Examination of the structure of the lungs shows that they cannot be equally extensile throughout. Anatomists divide cach lung into three zones.

(1) Root zone containing bronchus, artery, vein, lymphatic vessels, etc. This apical part contains much fibrous tissue and, thereforc, offers considerable resistance to distortion. Using physical terms one may say that its elasticity is strong but far from perfect (p. 168).

(2) Outer zone, estimated as cxtending for about $30 \mathrm{~mm}$. from the pleura containing very little fibrous tissue and made up mostly of small capillaries and pulmonary tissue. Of these the pulmonary tissue is perfectly but feebly elastic and the capillaries (empty) have a modulus of about $0.04 \times 10^{6}$-not quite so perfect as the lung substance but offering a greater resistance to distortion. Even within this zone extensibility is not uniform. The stratum lying immediately below the pleura is much more cxtensible than the inner stratum. Inflation of a lung recently removed from the body clearly demonstrates that certain parts of the surface are inflated first and that the inflation of certain parts of the subpleural stratum spreads from these points.

(3) The middle zone, lying between the apical and surface zones, is intermediatc to them in its elastic properties, containing as it does highly elastic pulmonary tissuc interspersed between the rays of the bronchial and vascular systems.

(b) That the elastic force of a material alters with the degree of distension is a physical fact that has already been considered in dealing with the force of the heart. Since the pressure of a gas acts equally in all directions, the pressure caused by any given tension of the walls of the hollow (spherical) vessel containing air will increase with the diameter of the vessel. If we consider that the diameter of each air sac is doubled during inspiration, then the 
total pressure exerted by the walls will be increased four times, i.e. distending force $=$ resistance to distension $=$ pressure of gas multiplied by area of vessel. Moreover with increasing distension, the lung substance will become more attenuated.

(c) The blood and lymph enmeshed in the pulmonary system has to adjust its position to suit every alteration in the shape of the lungs. These fluids are highly viscous and as such resist distortion roughly in proportion to their pressure and to the area of the cross-section of their vesscls. Further, the capillary vessels are so narrow that the corpuscular component of the blood viscosity becomes predominant.

(d) In addition to these factors which may be deduced from a study of lungs removed from the thorax one must take into consideration the position of the lungs in the thorax. Certain parts of the thoracic wall are stationary and the surfaces of the lungs in contact with these parts cannot directly expand.

(i) The mediastinal surface is in contact with the pericardium and with the structures of the mediastinum. (ii) The dorsal surface lies close against the vertebral column and spinal portions of the ribs. (iii) The dorsal part of the apical surface is bounded by Sibson's fascia at the root of the neck.

On the other hand the parts of the lungs in contact with (iv) the diaphragm, (v) the lower ribs (ventro-lateral aspect) and (vi) upper ribs (sternal aspect) undergo direct expansion at each inspiration.

VI. The efficiency of the lung mechanism. If figures could be obtained denoting the work done by the respiratory mechanism and its efficiency, they would be invaluable. One may arrive at an approximate value by measuring the oxygen consumed by an animal under standard conditions with normal and with increased respiration. With man, it was found that during muscular rest, 1 to 3 per cent. of the total basal oxygen intake is utilised by the respiratory mechanism. This amounts to from $0 \cdot 3$ to 0.7 c.c. of oxygen per litre of ventilation. Assuming that all the energy used is obtained from glucose, these figures indicate that from 0.0017 to 0.005 calories are expended for each litre of air breathed. This amount of energy is liberated from $0.004-0.0012$ grams of glucosc. During quiet breathing each breath (400 c.c.) costs at most 0.002 calorie obtained from just about 0.0007 of a gram of glucose and 0.28 of a cubic centimetre of oxygen. If it is assumed that the lung mechanism is at least 20 per cent. efficient, then at each quiet complete respiration, $0.00016-0.0004$ calories are eonverted into work $=1 / 3$ to $1 / 2$ kilogram-metre. 
This work is almost entirely performed by the diaphragm. The other muscles concerned, whether synergic or antagonistic, seem to play an almost passive part. This may be inferred from the fact that although they are skelctal in structure yet they undergo constant slow contraction without showing fatigue. When the respirations are forced the subsidiary musculature has to perform work and the $\mathrm{CO}_{2}$ output increases. The effort sooner or later brings on fatigue. Foreed respirations are carried out uneconomically, i.e. at a relatively higher cost per litre than ordinary quiet ventilation.

Regulation of Respiratory Rate. The activity of the respiratory centre, which lies in the medulla near the root of the vagus, is normally governed by the tension of the $\mathrm{CO}_{2}$ in the blood going to it. The rate of breathing is increased by any increase in the $\mathrm{CO}_{2}$ tension ; and, conversely, diminution of the $\mathrm{CO}_{2}$ tension leads to a decreased respiratory rhythm.

The $\mathrm{CO}_{2}$ tension of the blood and the partial pressure of the $\mathrm{CO}_{2}$ in the alveolar air are, as we have explained (Chap. XXIII.), always in dynamic equilibrium, and, therefore, any change in the one will lead to corresponding changes in the other. It has been found that an increase of 0.2 per cent. in the $\mathrm{CO}_{2}$ of the alveolar air, i.e. a rise of tension of from 40 to $41.6 \mathrm{~mm}$. $\mathrm{Hg}$, is sufficient to double the ratc of respirations. The increased ventilation leads to a "washing out" of $\mathrm{CO}_{2}$ from the blood and from the lung, thus rapidly restoring a normal condition. The power of adjustment is so extraordinarily effective that under wide variations of metabolic and atmospheric conditions, the tension of $\mathrm{CO}_{2}$ in alveolar air is maintained at an almost constant level of about $40 \mathrm{~mm}$. $\mathrm{Hg}$ (sec p. 334).

Regulation of Depth. Inpulses are eonstantly passing from the lungs, through the vagi, to the respiratory eentre and, by a reflex act, inspiration is checked when a certain tension is set up in the lung substance, i.e. the respiratory mechanism carries out the inspiratory phase of its function till this stretch-reflex inhibits it. In cases where the vagi are hyper-irritable, the stop mechanism acts too soon and breathing becomes shallow and rapid. 


\section{CHAP'TER XXVII}

\section{ALIMENTARY CANAL}

"I receive the general food at first, Which you do live upon; and fit it is, Because I am the store-house, and the shop Of the whole body:

. . . Though all at once cannot

Sce what I deliver out to each :

Yet I can make my audit up, that all

From me do back reccive the flour of all, And lcave me but the bran."

SHAKESPEARE.

As has been indicated (Chap. XXI.) the non-gaseous imports are submitted to a certain amount of manufacture before being handed over to the inland transport service for transportation to the cells of the body. For instance, proteins have to be split into their constituent amino-acids, carbohydrates are broken down into monosaceharides and fats undergo some change. In addition to these changes in molecular complexity and preceding them come, in many cases, changes of physical state. Most of our foodstuffs are solid or semi-solid and in such a state are useless to the organism. Before they ean be split into their constituent units they must be rendered soluble.

General. In brief, the function of the alimentary canal is to provide (1) a series of mills and factories where food may be comminuted and dissolved in water, (2) a series of factories for breaking down the dissolved foods into units which the organism is capable of absorbing, (3) a mechanism for absorbing these units, (4) a mechanism for eliminating the waste material, (5) a means of transport from one factory to another and (6) an adequate control over these various processes so that all may be co-ordinated.

In structure, the alimentary canal is a tube passing longitudinally through the body having anteriorly a voluntary mechanism for receiving and grinding food; intermediately, stations, not controlled by the will, for completely breaking down the food 
mass to convenient units and for absorbing the same, and posteriorly, a semi-voluntary mechanism for ejection of waste.

I. The mouth is the port of the alimentary transport system. First, by nose and eye the cargo is sighted and its nature estimated. Messages are scnt inland, factories get busy and all is ready when the ship reaches port. By means of the taste buds on the tongue, the nature of the cargo is further ascertained and appropriate secretions from the salivary glands take place. Bitter or saline substances provoke a profuse secretion of watery saliva. Flesh is met by a secretion containing a large proportion of the lubricating material-mucin. Dry mattcr causes the flow of a thinner and more watery saliva than moist matter.

(a) The functions of saliva in the mouth are purely mechanical. It acts as a lubricant: moistening the surfaces of the mouth and the passage from it : infiltering the food mass and so necessitating the expenditure of less energy in milling the food; and finally covering the outside of the bolus with mucin, thus rendering deglutition easy. Normally, saliva has no chemical action in the mouth. It contains a diastatic enzyme, ptyalin, which, however, carries out its action on polysaccharides during the earlier period of gastric digestion (q.v.).

(b) The tongue is a mobile organ lying on the floor of the mouth. It consists mainly of a mass of muscles which are paired. Some of these muscles lie wholly within the tongue (intrinsic), and for the most part, by their contraction, give rise only to alterations in shape. The extrinsic muscles have their point of attachment outside the organ, and so are capable of causing alterations in position as well as in form.

\section{Intrinsic Muscles.}

1. Superior longitudinal, pulls tip upwards and decreases length of dorsum.

2. Inferior longitudinal, pulls tip downwards and inwards, i.e. curves dorsum.

3. Vertical, working in conjunction with the transverse they produce a concave surface on the dorsum. Acting alone a convex surface is produced.

4. Transverse.

\section{Extrinsic Muscles.}

1. Genio-glossus-downwards.

2. Hyo-glossus-backwards.

3. Chondro-glossus (not always present) - backwards and downwards.

4. Stylo-glossus-backwards and towards palate.

5. Palato-glossus-side to side-continuous with intrinsic transverse. 
The tongue has a threefold duty to perform as a unit of this transport system- $(a)$ working in conjunction with the lipsphincter-orbicularis oris, and with the triangular and other muscles it acts as a suction-plunger; $(\beta)$ during deglutition it functions as a foree plunger and $(\gamma)$ it forms with the cheeks an effective hopper during the mastieation of food.

(c) The lower jaw is a horse-shoe shaped lever of the third order. The load is placed on the teeth, the fulcra are at the ends of the horse-shoe, where they artieulate with the fixed upper jaw while the power is applied at a point on either side between the teeth and the fulcrum. The jaw is pressed against the upper jaw by the action of the temporal, masseter and internal pterygoid muscles which act antagonistically to the mylo- and genio-hyoids, to the platysma and to the anterior belly of the digastric muscle. Nuts having a crushing point of about 400 kilograms may be crushed by a direct thrust of the front teeth. The molars, lying as they do nearer the fulcra and further from the applieation of the power, may exert a direct pressure of about $550 \mathrm{~kg}$. The employment of such pressures is rarely necessary on aceount of the previous treatment of the food (milling, cooking, etc.), and of the influence of saliva. Soft bread, for instanee, is merely eompressed by a pressure of $100 \mathrm{kgs}$. but, after moistening with saliva, only a twentieth of this pressure is neeessary to obtain a clean bite through.

The grinding operations of the molars (and of the incisors at times) are a compound motion made up of a side-to-side and a forwards-backwards motion. The former is produeed by the action of the external pterygoids working in conjunction with the posterior fibres of the corresponding temporal muscle. The latter movement may be aseribed to the forwards pull of the external pterygoids and the backwards pull of the posterior fibres of the temporals.

This mill-like motion tears the food with a smaller exhibition of pressure than direct crushing. Cooked meat which could be erushed by the application of from 30 to $100 \mathrm{~kg}$. pressure can be torn by a grinding movement when the pressure is only 2 to $5 \mathrm{~kg}$.

In Chap. XVI., we saw how bone was formed in aceordanee with the stresses and strains upon it. It is, therefore, interesting to note that in proportion as the food is prepared by factory milling and cooking, in proportion in fact, to the avoidance of the stimuli to growth furnished by incident stresses and strains, so the jaws of civilised men tend to beeome weak. In consequence 
faces are elongated and narrow instead of short and round like those of primitive men.

II. The act of swallowing. The food, after being chewer, is collected on the surface of the tongue by the action of the buccinator and other voluntary muscles. The tip and sides of the tongue are pressed against the hard palate and teeth. A rapid contraction of the mylo-hyoid muscles, which form a floor for the front portion of the mouth (diaphragma oris), pushes the tongue up against the hard palate. At the same time the hyoglossus pulls the tongue backwards and the bolus is shot towards the gullet. 'This closes the voluntary stage of deglutition.

Several other muscles come into play at this point. As will be seen from Fig. 42, just above the larynx is a busy crossing common to two routes. Gaseous food and gaseous excreta pass to and fro right across the track of the descending bolus. At the moment of swallowing, the nose-to-lung and lung-to-nose traffic is reflexly held up. Further, the escape of the food mass by either of these incorrect routes is prevented as follows:

(a) The naso-pharynx is closed by the action of the pharyngopalatini muscles, which form the posterior pillars of the fauces. The pharynx is thus drawn to a narrow cleft. Against this narrow opening the soft palate is pressed by the action of the levator and tensor veli palatini muscles. (b) The laryngeal aperture is kept closed by the action of the crico-arytaenoideus lateralis, arytaenoidei, and the thyreoarytaenoidei muscles, which pull the arytaenoid cartilages forwards against the back of the epiglottis. Accompanied by a quick downward motion of the tip of the epiglottis, the bolus is pushed over the back of this structure and is impelled into the gullet.

III. The stomach. By the impulse imparted to it at its entry into the gullet, aided generally by gravity and to a questionable extent by peristalsis, the bolus is forced down to the gateway to the stomach. This aperture, in common with the exit from the stomach, is guarded by a thick ring of visceral muscle. When contracted, i.e. during the normal state of tonus, these sphincters prevent the too hurried passage of material along the alimentary canal and also prevent its regurgitation. They are not controlled by the will but by local nerve centres. By its weight, the bolus usually exerts sufficient pressure to cause the opening of the cardiac sphincter and gain admission to the stomach, in which it is locked by the operation of a local automatic arrangement.

The processes of digestion or splitting of the foodstuffs by 
enzymes now commence (Chap. IX.). Polysaeeharides are broken down to maltose by ptyalin and the native proteins first eonverted to metaprotein by the action of the hydrochloric acid of the gastric juice and reduced in size and complexity to the proteose stage by the action of pepsin.

Even a casual examination of the stomach will show that it is divided into two parts, each with a distinct function. The upper or cardiae portion is a reservoir or hoppcr where the food pulp is stored for a short time without mixing. It is during its stay here that salivary digestion reaches its maximum. By the stcady pressure of the walls in the eardia, the mushy mass is fed little by little through the throat of the hopper (prepyloric sphincter) into the lower or pylorie part of the stomach. By peristaltic contractions of its walls, this pyloric seetion of the stomaeh mixes food and gastric juice most thoroughly. The acid of the juice aids peptic while inhibiting diastatic action. Cathcart showed that the prepyloric sphincter was controlled by the hydrogen ion coneentration of the duodenum and of the pylorie part of the stomach. Aeid entering the intestine undoubtedly eauses constrietion of the sphincter. While the $C_{\mathrm{H}}$ of the pylorie portion of the stomach does not seem to effect the closure of the sphincter, the above worker demonstrated that a sufficient reduetion of the $C_{\mathrm{H}}$ brought about a rapid opening of the sphineter. The introduction of an extra alkaline juice, e.g. by regurgitation from the intestine, leads to a smart flow of acid chyme into the antrum pylori.

The rate of exit from the antrum is controlled by the hydrogen ion eoncentration of the duodenum. As long as the duodenal contents are markedly aeid, the pylorie sphincter remains firmly elosed and only opens to admit more aeid chyme when its receptors are no longer stimulated by acid.

IV. The intestines have three functions to perform : $(a)$ transporting, (b) mixing and digesting, $(c)$ absorbing.

(a) Transporting. This is carried on by means of a series of peristaltic waves, i.e. a seetion of the museular wall adjacent to the anterior end of the food-mass undergoes relaxation while a corresponding posterior section contracts. This double wave of relaxation and eontraction passes along the tube and acts as a piston with a eentral orifice. In this way, the ehyme is passed along at the rate of about 1 inch a minute, and churned meanwhile.

(b) These driving peristaltie waves are not the only movements 
of the intestinal musculature. The chyme is kneaded and its surface broken by the rhythmic segmented contractions of the cireular museles of the bowel. By this means (i) the various digestive juices of the intestine are thoroughly mixed with the chyme, (ii) fresh surfaces are exposed to the absorbing surfaces of the wall and (iii) the eapillary blood-vessels of the lining membrane are compressed rhythmieally, so helping to drive the blood laden with the products of digestive aetivity on to the liver, ete.

The work of digestion, begun in the mouth and stomach, is eompleted in the intestine. Carbohydrates are redueed to single sugars and proteins are broken down to amino aeids, ete. In addition to this, the fats are attacked by lipase, which resolves them into their eomponent fatty acids and glycerol (or other alcohol). In this process, the bile salts, by lowering the surface tension at the fat-lipase interface, play an important part.

(c) Absorption seems to be a ease of passage of material through a membrane (q.v.).

V. Fæces. The materials not absorbed by the intestine are eliminated by the reetum as the fæces. One suggestive physicochemical fact about these excreta is the proportion of soap to mass in their make up. It has been found that, normally, fat forms approximately $\frac{1}{3}$ of the freal mass (dry). About 10 per eent. of this fat is in the form of soap. This may be correlated with the water-holding power of soaps and with their lubricating properties. Somewhere about 80 per eent. of their contents is water. This is somewhat remarkable, as both water, fatty aeids and soaps are readily absorbed from the gut. If one desires to reduce the water content, calcium is exhibited. As we have already seen (p. 82) ealcium soaps are hard "dry" soaps. On the other hand, the addition of easily dissociated sodium and potassium salts leads to the formation of "softer" soaps and a marked increase in the water content of the fæees. It is noteworthy that the fat content (as soap) remains constant. That unabsorbed fat is an excellent freal lubricant is an axiom in present-day prescribing when mineral oil (liquid paraffin), which cannot be absorbed, is given to produce easy defæcation.

For the final discharge of the waste alimentary contents a simple kind of "touch button" meehanism is provided. The act is initiated by a voluntary response (removal of inhibition) to the stimulus produced by the stretehing of the museular wall 
of the rectum by the freces. When the pressure of the freces in the rectum reaches a value of about $30-40 \mathrm{~mm}$. Hg, there is a call to defreate. If no response be made, the call is not repeated immediately, as the rectal walls relax and so lose their irritability to pressure. While the initiation is voluntary the act itself is purely reflex like the other movements of the intestine. The reflex contractions and relaxations are generally aided by voluntary contraction of all the museles, which will increase abdominal pressure.

From a physico-chemical standpoint practically nothing can be said of the mechanism of alimentary transport. While the movements, ete., are apparent the underlying causes are completely hidden. No help so far is given by attempting to trace the devclopment of the highly complex system of the vertebrate from the apparently simple physico-chemical response of the amoeba to contact with food. 


\section{CHAPTER XXVIII}

\section{MOVEMENTS OF THE LIMBS}

"If the mountain will not come to Mohammed, Mohammed must go to the mountain."

IN order to get food, prepare food, and preserve its life and that of its race, the higher animal makes use of a series of levers to move its body in whole or in part. These levers are generally, - but not always, made of bone, and generally but not always they work against a bony fulcrum.

In general, a lever is a rigid bar either straight or curved which is capable of a rotatory motion round a fixed point-the fulcrum. It is usual to divide levers into three classes depending on the relative positions of power, fulerum and load.

Class I. The fulcrum lies between the power and the load. In this elass of lever, if the power arm is equal to the load arm, we have a balance. The applieation of one $\mathrm{kg}$. of power will lift one $\mathrm{kg}$. of load. If the power arm is lengthened by shifting the fulerum nearer to the load, then power will be increased proportionally as speed is decreased. For example, dealing with a straight lever and putting $P=$ point of applieation of power, $F=$ fulerum and $L=$ point of applieation of load, then $P F$ represents the length of the power arm, and $L F=$ length of the load arm of the lever. If $P F=10$ times $L F$, then $1 \mathrm{~kg}$. at $P$ would balance $10 \mathrm{~kg}$. at $L$, i.e. the load of $10 \mathrm{~kg}$. would be lifted by the exertion of a little over $1 \mathrm{~kg}$. weight. This is the erowbar lever and is very little employed in the body. The most notable example of it is the forwards and downwards movement of the head when one is overtaken by uneonseiousness, e.g. s'eep. The fulerum on which the head moves is the atlas, and the weight of the prefulcral part of the head (long power-arm) outbalances the postfuleral portion (short load-arm).

Generally, speed is the desideratum. The fulcrum is placed 
near the power. The power-arm $P F$ is short and the load-arm $L F$ is long. The relative speeds of the points will be as $L F / P \cdot F$. The catapults employed by the aneients to cast stones are examples of this kind of lever. The arm is used as a lever of the first class with a short power member when a cricket ball is thrown.

Normally, the head is a lever of this order, the power being applied very close to the fulerum. The quick nod of assent is eaused by the contraction of the anterior straight muscles which are yoked elose to the fulcrum, while the slower baekward movement is due to the placing of the effeetive museles (splenii and complexi) somewhat further away from the oecipito-atlantal joint. The feature of this arrangement is stability. Another good example is when the foot is lifted off the ground and the ground pressed on by the toes on contraction of the gastrocnemius.

Class II. The fulcrum is at one end of the lever and the load lies between it and the power. That is, the power-arm is always of the same length while the load-arm may vary in length with the position of the load, e.g. nut crackers. The outstanding example of this lever in the body is the foot. On rising on the toes, the base of the metatarsals is the fulcrum, the body-weight, borne by the tibia to the ankle, is the load, while the power is applied to the os ealeis by the gastrocnemius. A foot with a long load-arm, i.e. with the load near the power, is designed for speed not power,well adapted for running. On the other hand, the further the load is from the point of application of power, in this case, the longer the heel, the smaller will be the force neeessary to lift the body. That this is so, may be inferred from a study of the development of the gastroenemius musele compared with the length of the heel bone. Europeans have short heel-bones and well-developed, bulky ealves, while Afrieans have long heels and ill-developed calf museles.

Class III. The point of applieation of the power is between fulcrum and load. This power must always be greater than the load. It is the commonest elass of lever in the body, and this is to be expeeted as its use results in the most rapid action possible. Speed is obtained, as before, by shortening the power-arm. In the arm, the brachial muscle is inserted about one centimetre beyond the fulerum (elbow) while the total length of the load-arm (forearm) is about $30 \mathrm{cms}$. The result of this arrangement is that the load (hand) moves with about 30 times the speed of the bone at the point of the applieation of the power. "Speed is gained at the expense of power." It follows that while a long- 
armed man may be able to give a quick blow he will be quite unable, unless his brachial muscles are abnormally developed, to give a heavy one.

This introduecs a point to which the author of the "Tarzan" stories paid little attention. Tarzan was able to hold his own among the tree tops. Now, man has a fore-arm eonsiderably shorter than the upper arm while the anthropoid ape has a forearm only a little short of twiee as long as its humerus. This gives it a long and quick reach. In swinging and climbing, the upper arm is the lever employed to lift the body, mainly by the contraction of the anterior brachial muscle, and the insertion of the brachial over half-way up the humerus from the elbow (fulerum) gives a power-arm with rather more power than speed. That is, a short humerus is a necessity for climbing animalsto furnish strength, just as the long forearm is necessary to give agility. To have equal climbing power, man would need to have extraordinarily bulky biceps, etc., and this would not aid him when he desired to swing and seize distant branches surely and rapidly.

So far, we have dealt with the levers of the body in a general sense, as if they were straight bars. As a matter of fact, none of the bones of the body can be considered as straight levers, and none of the museles act absolutely at right angles to the length of the bone. The lengths of the effective power and load arms may be obtained by dropping perpendiculars from the fulcrum to the lines of application of power and load. 'The ratio of these perpendiculars gives the ratio of the distribution of power and speed by the lever.

The value of the bone-musele mechanism depends on the mass of aetive museular fibres, their degree of contraction and the angle which they make with the bone to be moved. The very movement of the bone will alter the angle of pull of the muscle. For each of its positions, the lever will have a moment of rotation determined by the size of the angle made by the line of traction (axis) of the muscle and the axis of the bone. By resolving the foree of the muscle into two components, one of which acts along the axis of the bone and the other at right angles to it, one can readily perceive that the latter, the effective component, varies in value directly with the sine of the angle of pull. The ineffective or parallel component varies as the cosine of the angle of pull and represents the pressure exerted by the muscle on the fulcrum. As the moment of rotation is equal to the tension developed $(F)$, 
and the perpendicular distance $(d)$ of the axis of the muscle from the fulcrum, one may write $\boldsymbol{M}=\boldsymbol{F} d$. Then the effective component is equal to $F \sin a$ where $\alpha$ is the angle of pull, and the parallel component to $F \cos \alpha$. Hence, as the bony lever gets pulled up, the effective eomponent will become greater and the parallel eomponent will become less. In other words, the more parallel the axis of a muscle is to the axis of the bone which it is to move, the weaker will be its action-the maximum value is obtained when the line of action is at right angles to the bone.

Pulleys. By means of a single fixed pulley the direction of a force is altered, but not its magnitude. In the body, instead of reducing friction by means of a rotating pulley the tendon operates in a synovial sheath (q.v.). Good examples of the pulley may be found in the cartilaginous loop (trochlea) for the superior oblique on its way to the eyeball: and the peroneus longus looping round the outer malleolus on its passage to the inner side of the foot.

Opponents. All the muscles attached to levers in the body are set in opposing pairs or antagonistic groups. As one group contracts, the opposing group will relax to exactly the same degree. The ulna, for instance, is pulled up towards the humerus by the action of the anterior brachial and it is pulled downwards by gravity and the action of the posterior brachial muscle. Both sets of muscles act together and harmoniously, so that in any position of the ulna relative to the humerus, the opposing (muscular and gravity) forces exactly balance one another. That is, the arm may come to any position and remain there without the expenditurc of any extra energy (not taking into account gravity).

Synergists. Movement does not usually take place merely by the contraction of a muscle and the relaxation of its opponent. There are numerous other muscles brought into play, synergistswhose action, though secondary, helps the primary movements, generally by altering the pose of the body as a whole, but sometimes by immobilising the bone to which the muscle is fixed. As an example of the former, may be cited the action of the trunk muscles holding the body erect while a weight is being held above the head. The latter synergetical complex may be illustrated by the various muscles brought into action in opening a table drawer. "One hooks his fingers into the handle of the drawer and if it opens easily enough, the contraction of the flexors of the fingers is sufficient. If it works a little harder the flexors at the elbow contract to hold the bones of the forearm up so that the 
flexors of the fingers may have a firm origin. If still more force be needed the latissimus and teres major spring into action to support the humerus and rhomboid to hold the scapula. To make a strong pull one pushes against the table with the other arm and brings the extensors of the trunk into action, and finally if this does not suffice, the legs are braced and the whole body is converted by muscular action into a single solid piece in order that the flexors of the fingers may exert all their power to open the drawer." This description by Bowen shows clearly the complexity of an apparently simple action. The student will note too that as more muscles are called upon, the lever is lengthened and the position of the fulcrum altered. 


\section{CHAPTER $₫ X X I X$}

\section{THE VOICE}

"As the power of the vital soul is situated in the substance of the heart, and the power of the natural soul in the proper substance of the liver,... so also does the brain, in appropriate structures and in organs properly subserving its work, manufacture the animal spirit, which is by far the brightest and most delicate, and indeed is a quality rather than an actual thing. And while on the one hand it employs this spirit for the operations of the chief soul, on the other hand it is continually distributing it to the instruments of the senses and of movement. ..."

(1543) Vesalius quoted by Foster.

Articulate speech may be considered as the resultant of essentially two component factors, $(a)$ the production of sound, and $(b)$ the modification of the sound to produce speech.

I. The latter factor is the simpler and may be dealt with first. Spcech sound-units may be classed as vowels and consonants.

The vowels, $\mathbf{U}, \mathbf{O}, \mathbf{A}, \mathbf{E}$ and $\mathbf{I}$ are produced by the continuous issue of a blast of air through the mouth. $\mathbf{U}, \mathbf{O}$ and $\mathbf{A}$, pronounced ōō (cook), oh and ah, respectively, are simple tones. They are produced by a regular series of vibrations emitted by a single cavity formed by lips, cheeks, palate and tongue (Fig. 42).

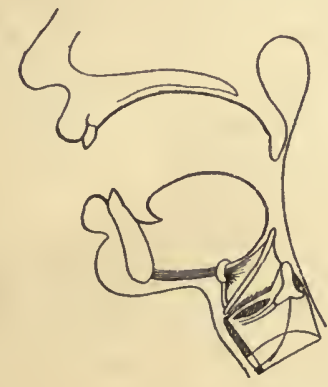

$\mathbf{A}(a h)$

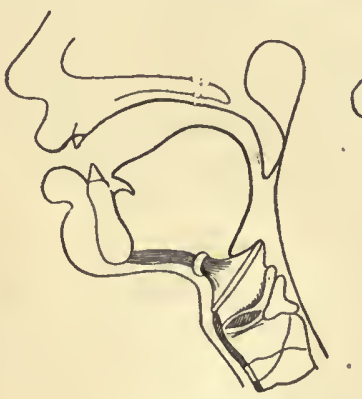

$\mathbf{U}(\hat{o} \tilde{o})$

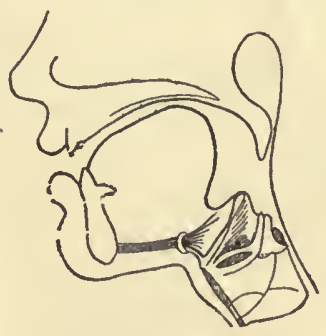

$\mathbf{I}(\bar{e} \bar{e})$

Fia. 70.- Changes in the Shape of the Mouth In Sounding the Vowels, A, U, and I. (Grützner.)

This cavity is widest and shortest with $\mathbf{A}$, longest and narrowest with $\mathbf{U}$, while $\mathbf{O}$ is intermediate. On the other hand, $\mathbf{E}$ (as in 
pet) and I (=ee) are double-toned. The back of the tongue is brought up against the front part of the soft palate so that the mouth is divided into two resonating cavities each with a characteristic note (Fig. 70).

By whispering the vowels one may readily determine the resonance-pitch characteristic of each. U has the lowest pitch, followed by $\mathbf{O}$ and $\mathbf{A}$. It is thus easier to sing $\mathbf{U}$ and $\mathbf{O}$ on low than on high notes. An attempt to go up the scale by sounding "oos" will cause a tendency to clip the full vowel and sound a short "ee." The characteristic notes of each of these vowels (by percussion, Expt. 51, p. 422) is given by Helmholtz as follows (Fig. 71) :

$$
\begin{aligned}
& \mathrm{U}=F \\
& \mathrm{O}=B^{\mathrm{I} .} \\
& \mathrm{A}=B^{\mathrm{II} .} \\
& \mathrm{E}=F^{\mathrm{I} .}, B^{\mathrm{II} .} \\
& \mathrm{I}=F, D^{\mathrm{IV} .}
\end{aligned}
$$

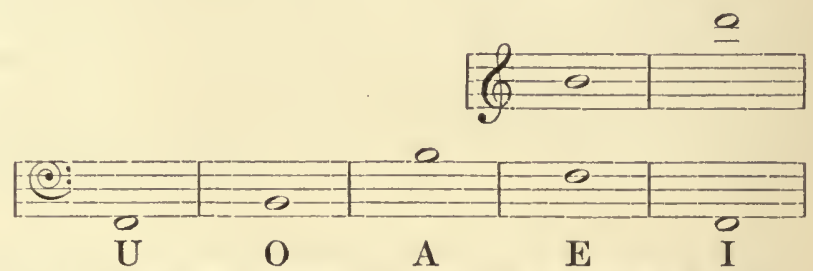

FIG. 71 (Starling).-Values obtained by percussing mouth eavity while shaped for the pronunciation of the vowels.

The English I is really a diphthong and is pronounced by rapidly uttering the component unit sounds, e.g. I (as in fight) $=\mathbf{A I} \doteq$ ah-ee.

Consonants are not continuous but are sharply interrupted sounds. The issuing air is suddenly shut off by the lips to give the labials; by the tecth to produce dentals ; by the tongue to give rise to gutturals. If the check occurs before the sound is produced, and the air is suddenly released, explosives are the result. The characteristic sounds of some consonants, e.g. M and $\mathbf{N}$ (which are mechanically the same as $\mathbf{B}$ and $\mathbf{D}$ ), are produced by keeping patent the posterior opening of the nares. In this

\begin{tabular}{|c|c|c|c|c|}
\hline Class. & . & Labial. & Dental. & Guttural. \\
\hline Explosives & - & P. B. V. & T. D. & K. G. \\
\hline Aspirates & - & F. & S. L. Th. & Ch. (Scots) \\
\hline Vibratives & - & - & 一 & R. (Scots) \\
\hline Nasals - & - & M. & $\mathrm{N}$ & $\mathrm{Ng}$ \\
\hline
\end{tabular}
way some of the air comes continuously through the resonant nasal passages.

TABLE LII.

Consonants. 
All these with the exception of the hard consonants (e.g. B and D) can be pronounced quitc well without the use of the larynx. The hard consonants are accompanied by phonation. Thus, although in pronouncing $\mathbf{D}$ there is a check at the teeth, the production of the laryngeal sound goes on.

II. Phonation, or the production of sound, is not so simple as articulation. At least two essential factors are concerned. The mechanism for producing sounds consists of a bellows or blowerthe lungs; a vibrating structure-the vocal chords; a cyclone chamber-the ventricle or space between true and false vocal cords; the wind pipe or trachea; and resonating chambersthe cavities of pharynx, mouth and nose. Musical notes can be produced without the intermediation of the vocal cords. It has been shown that the sudden expansion in bore of the windpipe at the ventricle is quite sufficient to produce a cyclonie disturbance of the air, and sound is the result. Most people are of opinion, however, that the vocal cords play the major part in sound production.

Loudness is due to amplitude of vibration and depends, in part, on the force and volume of the blast of air emitted.

In part, it depends on the size of the larynx and of the resonating chambers, and on the tension of the vocal cords. A true crescendo is obtained by relaxing the tension of the vocal cords.

Pitch, or tone-height, is a function of the rate of vibrations. This may be proved by running a gramophone record at various speeds. When running at its slowest the plate of the sound-box is receiving and transmitting vibrations at the rate of about 100 per sec., and one hears a bass voice. As the speed is increased the voice rises in pitch till it may be a distinctly light tenor with 500 vibrations per second.

The limits for the human voice are given in Table LIII.

TABLE LIII.

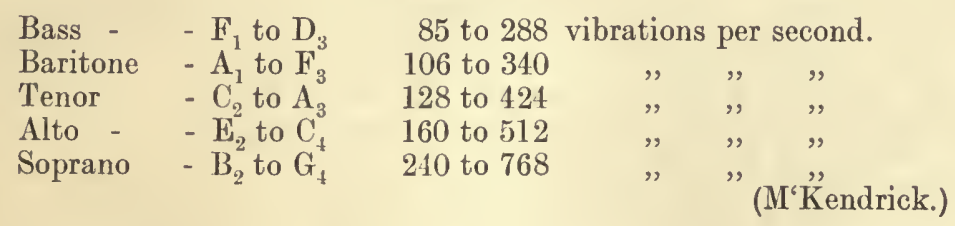

We derive the musical notion of high and low pitch from the rise and fall of the larynx in the production of sounds-an entirely subjective phenomenon. The pitch of a tone, from a physical 
point of view, is absolutely defined by its vibration number. High pitched notes have a higher rate of vibration than low pitched notes. Alterations in the pitch of a note are probably brought about in the larynx by altering the tension of the vocal cords, by the action of the crico-thyreoid muscle-the greater the tension of the vibrating membrane, the higher the pitch of the note produced. The part of the cords free to vibrate may be varied by the approximation of the arytenoid cartilages to one another. A long cord vibrates more slowly than a short one. This accounts for the high pitched voices of children.

In addition to this, it is common knowledge that when the force of the blast of air is increased, the pitch of the voice rises. There is thus a tendency to sing sharp when forcing the voice, say in a large badly built hall.

In one and the same larynx, different parts or regions of the scale are produced in different ways. Those notes of the scale which are produced by the same means are said to be produced in the same register. Thus, we produce deep notes in the chest-, or thick-register, while high notes come from the high-, head-, or small-register. The thin or middle register is used normally by tenors and when the male voice sings falsetto.

Laryngoscopical investigation has shown that, when producing notes from the chest register, the glottis forms an elongated slit and the vocal cords, stretched as tightly as possible, are vibrating as thick masses over their whole extent. In taking the lowest notes the posterior portion of the arytenoid cartilages are close together with a wide elliptical chink between the cords. As the pitch of the note rises the arytenoid cartilages are brought closer together and so shortening of the vibrating portion of the cords is produced. The thyreoid cartilage approximates to the cricoid and the vocal cords are stretched and brought close. The epiglottis rises as the pitch rises.

When the upper limit of this register has been reached the tension on the various parts is extreme and one passes with relief to the middle register-the normal mechanism in the female (and tenors) for the production of notes between $\mathbf{F}_{3}$ and $\mathbf{F}_{4}$. The thyreoid cartilage returns to its normal position, the tension on the cords is decreased and they vibrate at their thin membranous edges only. As the pitch rises the thyreoid and the cricoid cartilages are again pulled together by the action of the crico-thyreoid muscle, and this state of tension lasts in tenors, sopranos and contraltos alike from $\mathbf{F}_{3}$ to $\mathbf{C}_{4}$. Higher notes than 
this are attained by a shortening of the vocal chink. In the small or head register the notes arc produced by vibrations of only the inner margins of the cords, and the vocal chink is reduced to a small anterior aperture which becomes smaller as the pitch rises. These different mechanisms produce tones of perceptibly different quality.

Timbre or quality of the voice depends largely on the accessory resonating chambers. These cavities pick out and accentuate the overtones produced by the vibrations of the segments of the cords. Trained singers consciously or instinctively adapt the shape of the mouth so as to secure for each tone the most suitable overtones.

The work done in speaking and in singing is complex. Many muscles are brought into play and the energy expended by them varies with the rate of speech and the intensity of the sound produced. The pressure of air employed in ordinary quiet conversation amounts to between 140 and $240 \mathrm{~mm}$. of $\mathrm{H}_{2} \mathrm{O}$, while nearly $1000 \mathrm{~mm}$. are required when shouting is indulged in.

If roork (phonation only) is taken as equal to the product of the pressure and volume of air expelled, i.e. $\mathbf{W}=\mathrm{VH}$, we may make a rough assessment of the amount of work done. During ordinary conversation, a man with a tracheal cannula developed an air pressure of $100 \mathrm{~mm}$. $\left(\mathrm{H}_{2} \mathrm{O}\right)$ and expired 300 litres of air per hour i.e.

$$
V I=\frac{300 \times 100}{1000}=30 \mathrm{kgm} . \text { per hour. }
$$

Speaking in a large hall the same man expired 1440 litres of air per hour and developed a mean pressure of $150 \mathrm{~mm}$. $\left(\mathrm{H}_{2} \mathrm{O}\right)$,

$$
W=\mathbf{1 4 4 0} \times \mathbf{0} \cdot \mathbf{1 5}=\mathbf{2 1 6} \text { kilogrammetres. }
$$

One may arrive at an estimate of the work of speaking by measuring the oxygen used during rest and during speech. Delivering an oration at the rate of 150 syllables a minute caused the consumption of 28.78 litres of oxygen. Subtracting from this the amount used during a similar period of rest, viz. 16.96 litres, we find that 11.82 litres were used by the orator. In large Calories this amounts to $11.82 \times 4.9=57.9$ Cals. per $\mathrm{hr}$. In $\mathrm{kgm}$. this gives $\frac{57 \cdot 92}{4} \times 425=6154$ kilogrammetres.

The value just obtained is about 15 times as great as that of mere phonation. We must remember that the orator, and the subject of the experiment was a Frenchman too, uses many 
additional muscles in gesticulation, ete. A speceh of an hour's duration may tax his entire powers. To add to his troubles he has to make himself heard in a large hall. Table LIV. gives the relative values of the expenditure of energy in the utterance of a single perceptible note in various sizes of halls. The notes were produeed by an artifieial larynx (syren).

TABLE LIV.

\begin{tabular}{|c|c|c|c|c|c|c|c|}
\hline \multicolumn{5}{|c|}{ Nature of Hall. } & \multirow{2}{*}{$\frac{\text { Tenor. }}{1 \cdot 0}$} & \multirow{2}{*}{$\frac{\text { Baritone. }}{3}$} & \multirow{2}{*}{$\begin{array}{r}\text { Bass. } \\
7\end{array}$} \\
\hline Theatre & - & - & - & - & & & \\
\hline Church & - & - & - & - & 4 & . 6 & 42 \\
\hline Lecture room & - & - & - & - & $1 \cdot 4$ & 4 & 12 \\
\hline Dining hall ( & bad & cous & ics) & - & 4 & 6 & 66 \\
\hline
\end{tabular}

These figures, multiplied by $2 \times 10^{-5}$, give, in kgms. per sec., the minimum expenditure of energy necessary to make the sound perceptible in ten different parts of the hall.

In every ease the possessor of a bass voice has to expend more energy than the baritone or tenor. Generally speaking, the tenor has least trouble in making himself audible, but instances may occur where on account of its resonating qualities, a building may prove more suitable for a baritone than for the former. 


\section{SECTION V.: THE ANIMAL AS A WHOLE}

\section{CHAPTER XXX}

\section{THE PRESERVATION OF NEUTRALITY}

"To test a principle by its consequences is allowed by good logic and enjoined by sound reason."

JOUBERT.

Frow a physico-chemical standpoint, the animal body may be considered as a polyphase liquid, the various phases being separated from one another by a series of membranes of varying and variable permeability. From the moment of origin of the organism as an entity, that is, from the time when the conjugation of spermatozoön and ovum produced a mass of protoplasm which was not in equilibrium with its environment, the various external forees brought to bear on the organism still further accentuate this disturbance. The sum of the changes termed life may be looked on as the response of this polyphase-multimembrane-enclosed liquid to these impacts. Briefly, all changes tend to restore balance-which, when attained, is death. It is difficult to make statements on this subject without using terms implying purpose, for example we speak of water reaching its own level-cell adjusting itself to its environment, etc. To use other terminology would be cumbrous if correct.

We dealt (Chap. XVI.) with the effect produced, on the internal and external structure of bone, of altering the incidence of a load. Not only are the nearby bones altered but cven distant and apparcntly unaffected bones undergo changes. In our study of the transport system we saw how an alteration produced in one part of an organism spread throughout the whole animal.

One of the main functions of blood is to maintain constant the concentration of hydrogen ions throughout the organism. A slight potential increase in the acidity or alkalinity of the system 
acts as a trigger, setting off a series of reactions resulting, finally, in the restoration of neutrality. Acid is set free, say in muscle, and before it can be rebuilt into the muscle complex, oxidation of glucose has to take place. The introduction of this acid in a minute amount has three profound effects. Firstly, it increases the dissociation of oxyhaemoglobin (p. 253) setting free the needed quota of oxygen, secondly, by stimulating the respiratory centre (Chap. XXVI.), it speeds up the intake of oxygen, and lastly, the blood flow is increased, both locally by vasodilatation, and generally by increased cardiac action.

In the work of preserving the neutrality' of the organism, the blood is aided by the eliminating organs, - the lungs and the kidneys.

Factors tending to preserve neutrality.

I. In the plasma we have $(a)$ colloids, and $(b)$ crystalloids.

(a) The colloids of blood plasma are mainly serum albumin and serum globulin and they are amphoteric in character, i.e. they may act either as acids or as bases. Experiments carried out in the laboratory show definitely that, although the proteins of the plasma readily combine with mineral acids, they are unable to react with the weakly dissociated acids found in the body. Both albumin and globulin form hydrochlorides for instance, but protein lactates or carbonates are unknown. Apart from the amount of $\mathrm{CO}_{2}$ adsorbed by the colloidal particles, the blood colloids can play but a small part in reducing the carbonic acid, etc., produced in the organism.

(b) Of the crystalloids in solution in the plasma, sodium bicarbonate has a marked "buffer" effect. In this salt a strong base is united with a weak acid and, therefore, any acid stronger than $\mathrm{H}_{2} \mathrm{CO}_{3}$ will take the place of the $\mathrm{HCO}_{3}$ ion in its combination with $\mathrm{Na}$.

For instance,

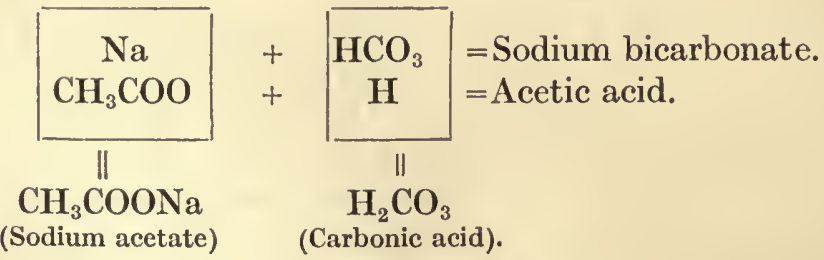

This reaction appears just to postpone matters because carbonic acid is set free and, although this acid is only slightly dissociated, yet, as an acid, it must be reckoned with. But the equation 
of the dissociation of $\mathrm{NaHCO}_{3}$ shows that it is a reversible reaction :

$$
\begin{aligned}
& \text { e.g. } \\
& \begin{aligned}
& \mathrm{NaHCO}_{3} \leftarrow \begin{array}{l}
\mathrm{Na}_{2}^{+} \\
\mathrm{OH}^{-} \mathrm{O}
\end{array}+\frac{\begin{array}{l}
\mathrm{HCO}_{3}^{-} \\
\mathrm{H}^{+}
\end{array}}{\text {Strong. }} \\
& \text { Weak. }
\end{aligned}
\end{aligned}
$$

This means that the direction of the reaction will, in the main, depend on the relative amount of $\mathrm{CO}_{2}\left(\mathrm{H}_{2} \mathrm{O}\right)$ present compared with the amount of $\mathrm{NaHCO}_{3}$. This ratio has been determined experimentally. To give the normal $p \mathbf{H}$ of $7 \cdot 4$, plasma must have 3.75 grams of $\mathrm{CO}_{2}$ bound in $\mathrm{NaHCO}_{3}$ present for every gram of uncombined $\mathrm{CO}_{2}$ : or, by volume, one volume of $\mathrm{CO}_{2}$ remains constant when associated with 20 volumes combined as carbonate. In tabular form this reads :

$$
\frac{\text { Free } \mathrm{CO}_{2}}{\text { Bound } \mathrm{CO}_{2}}=\frac{1}{3 \cdot 75} \text { by weight, } \frac{1}{20} \text { by volume. }
$$

If excess of $\mathrm{NaHCO}_{3}$ over this ratio is present, some will dissociate to balance the dissociation pressure. If too much $\mathrm{CO}_{2}$ is present it will in the first instance combine with any free base to form a bicarbonate ; if no free base offers, the excess $\mathrm{CO}_{2}$ will be eliminated by the lungs.

The bicarbonate of the plasma represents the excess of base which is left over after all the non-volatile acids have been neutralised. It is the alkali reserve of the body which can be drawn upon to neutralise any free acid stronger than $\mathrm{CO}_{2}$ which may find its way into the blood stream (Demonstration, Part II.). Not until practically all the alkali reserve has been used up, will the blood show any change in hydrogen ion concentration. Long before that point can be reached, other mechanisms will be brought into action to preserve neutrality. The bicarbonate is a nest egg of potential base which may be drawn upon when required, but the inroad must be made good at the first opportunity. It is really an emergency measure useful to tide one over the difficulties that occur suddenly and frequently. It is not a widow's cruse of oilalways magically replete. If the ratio of $\mathrm{H}_{2} \mathrm{CO}_{3}$ to $\mathrm{NaHCO}_{3}$ is kept within normal limits even though the reserve is permanently lowered, the acidosis necessitating the draft on the reserve is called compensated. If on the other hand: the amount of $\mathrm{H}_{2} \mathrm{CO}_{3}$ increases to a value greater than $\mathbf{1} / \mathbf{2 0}$ of the alkali reserve in arterial blood, the acidosis is said to be uncompensated. 
II. The lungs eliminate $\mathrm{CO}_{2}$. 'The amount eliminated per unit of time is a function of the capaeity of the lungs and the rhythm of respiration. The rate and depth of respiration are eontrolled by the amount of $\mathrm{CO}_{2}$ in the blood perfusing the respiratory centre in the medulla oblongata. Any increase in the $\mathrm{CO}_{2}$ of the blood eauses an increase in the rate of respiration. Similarly, the proeess of respiration may be slowed down, till it stops, by decreasing the amount of $\mathrm{CO}_{2}$ in the blood. It has been stated that this regulatory action of the medulla is caused not by $\mathrm{CO}_{2}$ but by the hydrogen ion concentration of the blood, i.e. any acid perfusate will quicken respiration. But, as is obvious from the context, no free acid but $\mathrm{CO}_{2}$ can occur in the blood of a living animal. Further, careful research has shown that the $p \mathbf{H}$ of blood does not alter, the regulation is so nice.

III. Excess of base, and acids in combination with bases are eliminated by the kidney. The cells of this organ have a low threshold for such salts.

IV. The red corpuseles of the blood play an ill-defined part in the preservation of neutrality. In common with other tissue elements, the erthrocytes have a phosphatebuffer system. Sodium dihydrogen phosphate, $\mathrm{NaH}_{2} \mathrm{PO}_{4}$, is an acid salt and reacts with bicarbonate, for instance, to form the basic salt $\mathrm{Na}_{2} \mathrm{HPO}_{4}$,

viz. : $\underset{\text { acid phosphate. }}{\mathrm{NaH}_{2} \mathrm{PO}_{4}}+\mathrm{Na}_{2} \mathrm{HCO}_{3} \underset{\text { basic phosphate. }}{\underset{\mathrm{Na}_{2}}{\mathrm{HPO}_{4}}+\mathrm{H}_{2} \mathrm{O}}+\mathrm{CO}_{2}$

A mixture of these two phosphates such as is found in all tissues obviously will not increase in acidity till nearly all the disodium phosphate has been converted into dihydrogen phosphate, nor will the $[\mathrm{H}] \cdot$ markedly decrease till all the dihydrogen phosphate has been eonverted into the basie salt.

In addition to this it seems as if the pigment, haemoglobin, took some part in the reaction. Some evidence has been produced which indicates that $\mathrm{Hb}$ adsorbs or combines with $\mathrm{CO}_{2}$ at high $\mathrm{CO}_{2}$ tensions and parts with it at low tensions, i.e. in the lungs. Be that as it may, the haemoglobin acts as a buffer to a degree of which the plasma proteins are incapable, and promotes the dissociation of bicarbonate during diminishing tensions of $\mathrm{CO}_{2}$. This property is due to the electrical charge of haemoglobin. In an alkaline medium, haemoglobin carries a positive charge; the more alkaline the medium, the more acidic is hacmoglobin, and conversely, when the blood is taking up $\mathrm{CO}_{2}$ from the tissues, haemoglobin is least acidic. 
V. The tissues themselves exert a neutralising effect on the blood. As mentioned above they are endowed with a phosphate buffer systcm.

To summarise :

Blood and tissue fluids normally neutral $p H=7 \cdot 4$.

Alterations caused.

1. Tending towards alkalinity-Alkaline tide after digestion.

2. Tending towards aeidity.
A. Normal.
(1) Muscular aetivity.
$\mathrm{CO}_{2}$.

Lactic acid.
(2) Protein disintegration. food $\mathrm{H}_{2} \mathrm{SO}_{4}$ musele $\int \mathrm{P}_{2} \mathrm{O}_{5}$

B. Abnormal. Mal-oxidation acidosis.

Alterations cheeked.

1. Tissue eompensation-Phosphates.

2. Alkali reserve- $\mathrm{NaHCO}_{3}$.

3. $\left\{\right.$ Respiration $\left\{\begin{array}{l}\mathrm{CO}_{2} \text { stimulates respiratory eentre. } \\ \text { Lack of free } \mathrm{CO}_{2} \text { depresses centre. }\end{array}\right.$

4. Kidney $\left\{\begin{array}{l}(a) \text { increased elimination of }<\text { alkali } \\ (b) \mathrm{NH}_{3} \text { salts. (Liver action.) }\end{array}\right\}$

An apology is necessary for the use of the word "buffer"to denote the power of phosphates and bicarbonates to maintain a steady $p \mathrm{H}$ in spite of additions of acid or alkali. Prof. Bayliss has pointed out the misleading nature of this expression and has shown how it crept into use. Nondescriptive as the word undoubtedly is, it has found a place in current physiological and physico-chemical literature, dislodgment from which will be a difficult task. 


\section{CHAP'TER XXXI}

\section{THE REGULATION OF TEMPERATURE}

"Where hot and cold, and dry and wet Strive each the other's place to get."

Prior.

ONE of the most striking phenomena in the life of man and of the hot-blooded animals generally is the remarkable constancy of the temperature maintained in spite of the variations of temperature to which they may be subjected. This is a fact which did not escape the attention of the ancients, who thought out many weird and wonderful explanations. Even well on in the nineteenth century, text-books echoed the idea of Haller (1757) that animal heat arose mainly from the friction of the blood in the vessels.

The mammal or the bird may travel from the arctic regions where the external temperature may be at $-53^{\circ} \mathrm{C}$. to the tropics at $53^{\circ} \mathrm{C}$. without much increase in body temperature. Contrast this freedom from variation with the continuously changing temperature of the cold-blooded animal as the temperature of its environment changes.

TABLE LV.

\begin{tabular}{c|c}
\hline Temp. of Water. & Temp. of Frog's Stomach. \\
\hline $2 \cdot 8^{\circ} \mathrm{C}$. & $5 \cdot 8^{\circ} \mathrm{C}$. \\
$20 \cdot 6^{\circ} \mathrm{C}$. & $20 \cdot 7^{\circ} \mathrm{C}$. \\
$41^{\circ} \mathrm{C}$. & $38^{\circ} \mathrm{C}$. \\
\hline
\end{tabular}

Within natural limits, the temperature of the cold-blooded animal is usually about $1^{\circ} \mathrm{C}$. above that of its environment. It is interesting to note that those animals which hibernate become for the time as if cold-blooded. The cvolutionists postulate that, as all animals were once marine cold-blooded organisms, the ancestors of the warm-blooded animals must have crawled out 
of a tropical sea and ever since have had to maintain this initial high temperature. The advantages that they possess by reason of their higher temperature are due $(a)$ to the well-known fact that most chemical and some physical reactions are increased in rate by heat, and $(b)$ to their freedom from constant fluctuations of temperature. Against this must be placed the fact that they have to maintain a temperature greater than their environment by about $20^{\circ} \mathrm{C}$.

Of all animals, birds have the highest temperature. For example, that of the ehicken is about $43.8^{\circ} \mathrm{C}$.: of mammals, the rabbit and the fox have a temperature as high as $40^{\circ} \mathrm{C}$., while the horse and the elephant come low on the scale with $37 \cdot 6^{\circ} \mathrm{C}$.

In health, the temperature of the human body varies so little from the normal value of $37^{\circ} \mathrm{C}$. $\left(98 \cdot 4^{\circ} \mathrm{F}\right.$.) that temperature is regularly taken as a clinical indicator and any fluctuation from the normal points to the employment of remedial measures.

Homoiothermic Animals maintain a constant temperature.

Mammals and Birds - - Birds - - about $42^{\circ} \mathrm{C}$.

Adult and not during hiber- Mammals (except man) " $39^{\circ} \mathrm{C}$. nation or activity - - Man - - _ _ " $37^{\circ} \mathrm{C}$.

Heterothermic or Poikilothermic Animals.

(a) Lethal temperature, New born Homoiothermes. about $20^{\circ} \mathrm{C}$.

(b) Hibernation starts when Hibernating animals. temperature falls to about $20^{\circ} \mathrm{C}$.

(c) Still active below $20^{\circ} \mathrm{C}$ Reptiles, Batracia, Fish, Molluscs, Insects, etc.

\section{Instruments used.}

(a) Mercury thermometer.

(b) Electrical resistance thermometers.

(c) Thermo-electric couple (Thermopile).

(a) The thermometer was probably invented by Galileo (1603), and was first used clinically by Sanctorius (1626), who reported the temperature of a fevered man.

The clinical thermometer is an adapted form of the common mercurial thermometer having, (1) a long cylindrical reservoir to admit of rapid attainment of equilibrium between body and mercury. (2) A small bulbous part just above the mercury reservoir to catch the mercury driven out of the reservoir by the expansion due to the increase in temperature to $34^{\circ} \mathrm{C}$. (3) A small bore capillary graduated from $35^{\circ} \mathrm{C}$. to $45^{\circ} \mathrm{C}$. to admit of reading to a tenth of a degree, and finally, (4) another bulbous part to catch any mercury that might be driven over by accidental heating beyond $46^{\circ} \mathrm{C}$. Usually the thermometer is made self-registering by having a small detached thread of mercury which is pushed up by the expanding fluid and remains at the highest temperature reached. 
Where a continuous record has to be made, or where great accuracy is desired, one of the electrical methods is employed.

(b) This method depends on the alteration of the electrical resistance of a platinum (or other metal) wire caused by a slight increase in its temperature. The alteration in conductivity may be measured by a Wheatstone's bridge or may be recorded photographically as in the study of the electrical changes in tissues (p. 297). This is by far the more sensitive of the two electrical methods, but great care must be exercised in its use. It has, however, some disadvantages. For example, the current flowing through the thermometer tends to heat the fine coil of wire. The heating is proportional to the square of the current, and to the resistance of the wire.

(c) The thermopile is based on the principle that, if the junction of two dissimilar metals (e.g. constantan and iron) be warmed, a difference of potential between the two will be produced. In order that small fluctuations of temperature may be measured, a second thermopile is arranged in the circuit in series with but opposed to the first. This second thermoelectric junction is kept at a certain known temperature differing but little from the temperature to be measured. By this means the bulk of the electromotive force resulting from thermopile 1 will be neutralised by the E.M.F. produced by thermopile 2, and thus the E.M.F. produced by a small change of temperature becomes a relatively large proportion of the net E.M.F. The current changes are read from a potentiometer.

\section{Location of Thermometer.}

(a) Natural Cavities.

(i) Mouth. The cavity underneath the tongue is generally chosen by the physician as suitable for the taking of temperature. The thermometer should remain at least 7 mins. in situ. If the mouth is kept open, low readings will be obtained due to the inrush of cold air and the vaporisation of moisture.

(ii) Rectum. Practically all physiologists are agreed that the most favourable position for the thermometer for the indication of the true temperature of the interior of the body is the rectum (or vagina in females). The instrument should be inserted sufficiently deeply $(7 \mathrm{~cm}$.), to make sure of the maximum temperature, and, in the case of the rectum, it should not be imbedded in faecal matter.

(b) Artificial Cavities.

(iii) Axilla. In the private practice of a physician, temperatures are generally taken from the armpit. Care has to be taken to free the skin from moisture and sweat and to close the cavity on the thermometer for a time sufficiently long to enable the surface of the skin to attain the temperature of the interior of the body.

(iv) Groin. In young children the thermometer is usually placed in the fold of the groin.

While the temperature of the body is so constant that it is taken as a elinical sign, yet it does vary regularly during the 24 hour day. From the chart (Fig. 72), it will be seen that between 3 and 4 in the morning body temperature is at its lowest 
and between 3 and 4 in the afternoon it is at its highest. This rhythm or periodicity is shown by night workers as well as by those who live a normal average life. Benedict tells of a night

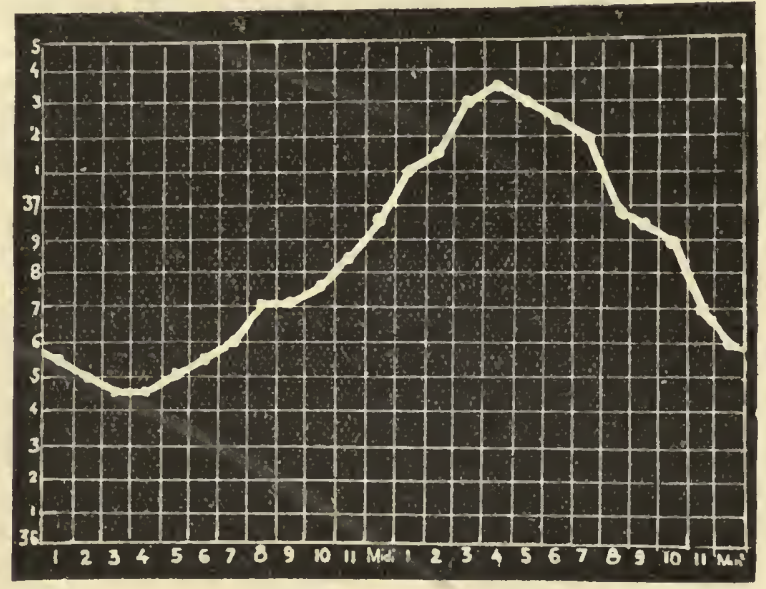

FIG. 72.-Chart of the Daily Variation of Temperature in the Normal Human Subject, in degrees Centigrade. The hours are marked from midnight. (Richet.)

watchman who for seven years had been working during the night and sleeping during the day, and had his maximum temperature about 4 o'clock in the afternoon when sound asleep and his minimum about 4 o'clock in the morning when he was awake and active.

It is common knowledge that certain means may be taken to bring about alterations in the body temperature :

1. Muscular exercise causes heat.

2. Want of muscular exercise is followed by cooling, e.g. cold has to be guarded against during sleep.

3. Heat or work causes sweating.

4. Heat produces lassitude. Compare the day's work of a man in Spain with that of a man in Scotland.

5. Still air has the same effect as that of heat on the feeling of lassitude. The production of a movement of the air removes the tired feeling.

6. A higher temperature can be endured in a Turkish than in a plunge bath. Further, a hot dry climate is comfortably endured, while air at the same temperature, but saturated with moisture, oppresses.

7. Cold air does not chill one to the same extent as water at the same temperature. Cold much more severe than is experienced in Britain may be enjoyed in the dry, Canadian climate.

For example, a temperature of $-40^{\circ}$ may be borne if the air be dry and still, while a much warmer but damp and windy atmosphere may "cut to the bone."

8. Ingestion of hot or cold food or of heat-producing food normally produces an almost negligible increase in rectal temperature. 
What we want to get at is the mechanism whereby the body temperature of the higher mammal is kept fairly constant despite variations of outside and "inside" temperature. In this respect, they obey the ordinary laws of cooling - surface phenomena. Heat may be lost by :

I. Conduction and convection.

I $a$. Ingestion and excretion. Inspiration and expiration.

II. Radiation.

III. Evaporation of moisture.

\section{Conduction.}

By conduction is meant the loss of heat from a body at a higher temperature to one at a lower temperature by passage from particle to particle, for example, the passing of heat along a poker, one end of which is in the fire. The amount of heat lost by the body in this way depends on several factors.

(i) Surface exposed. (a) The loss of heat varies directly with the area of the surface exposed. For example, the flow across two square metres is double that across one square metre. The area of surface of a child of 2 ycars weighing $10 \mathrm{~kg}$. is $5120 \mathrm{sq} . \mathrm{cm}$., and of a man of $60 \mathrm{~kg}$. is $14,079 \mathrm{sq}$. cm. That is, the area per $\mathrm{kg}$. for a child of 2 years is $512 \mathrm{sq}$. cm., and for a man is $234 \mathrm{sq}$. cm. It is obvious that weight for weight the child will lose more heat than the man.

(b) The loss of heat depends on the moistness of the surface. The thermal conductivity of all liquids except mercury is very low. Water may be boiled in the top portion of a test tube without affecting a piece of ice at the bottom.

TABLE LVI.

Thermal Conductivity.

\begin{tabular}{|c|c|c|c|c|c|c|c|c|}
\hline \multicolumn{4}{|c|}{ Substance. } & Conductivity $(c)$. & \multicolumn{3}{|l|}{ Substance. } & \multirow{2}{*}{$\frac{\text { Conductivity (c) }}{4 \times 10^{-5}}$} \\
\hline Silver . & - & - & - & $1 \cdot 52$ & Cotton flock & - & - & \\
\hline Platinum & - & - & - & $1 \cdot 14 \times 10^{-1}$ & Water at $37^{\circ}$ & C. & - & $135 \times 10^{-5}$ \\
\hline Marble. & - & - & - & $180 \times 10^{-5}$ & Sea water & - & - & $108 \times 10^{-5}$ \\
\hline Wood & - & - & - & $10 \times 10^{-5}$ & Olive oil - & - & - & $39 \times 10^{-5}$ \\
\hline Paper & - & - & - & $30 \times 10^{-5}$ & Human skin & - & - & $60 \times 10^{-5}$ \\
\hline \multicolumn{3}{|c|}{ Vulcanised rubber } & - & $8.9 \times 10^{-5}$ & Lard - & - & - & $48 \times 10^{-5}$ \\
\hline Wool & - & - & - & $5 \times 10^{-5}$ & Leather - & - & - & $42 \times 10^{-5}$ \\
\hline Compress & ed & tton & - & $3 \times 10^{-5}$ & Air (dry) & - & - & $5 \times 10^{-5}$ \\
\hline
\end{tabular}

(c) The loss of heat depends on the nature of the surface and of the subcutaneous tissue. A good layer of subcutaneous fat 
which has a low thermal conductivity will decrease the rate at which heat arrives at the surface and retard heat loss.

Every one knows that certain substances do not readily conduct heat. In the hot room of a Turkish bath, where all the objects are at the same temperature, metallic objects feel much hotter than those of wood, bone, rubber, etc. A familiar example of the retention of heat by a body surrounded by some bad conductor is found in the hay box or Norwegian cooker, which consists of a wooden box having a thick lining of felt. The partially cooked meal while still hot is placed in the box and the intervening space firmly packed with hay or paper. The felt-lined lid is closed and the meal left to cook itself. After several hours the temperature will have fallen only a few degrees. The Dewar or thermos flask depends on a vacuum as non-conductor.

Animals which have a good layer of subcutaneous fat lose heat much more slowly than lean ones.

Fat acts as a heat insulator and retards loss by conduction. On a moderately warm day, the obese person becomes uncomfortably warm. He is unable to eliminate heat with sufficient rapidity, and, as a consequence, his temperature rises, and may cause an increase in general metabolism amounting to 50 per cent. over that of a thin person. Aquatic mammals rely on their adipose tissuc to protect them from a too rapid loss of heat.

Several measurements of the temperature inside the body have been made. The natural cavities, e.g. the rectum, and vagina, are generally used, both being deep cavities into which the thermometer or thermal elements can be inserted for a considerable distance. Measurements have been made of the temperature in the inside of the stomach in patients with gastric fistulae. The tcmperature of freshly voided urine was suggested by Stephen Hales in 1731 as representing that of the interior of the body. It has been found that, whilc the temperature of the surface of the body is about $32^{\circ} \mathrm{C}$., as the depth from the surface increases, the temperature rapidly rises till the depth of about $5 \mathrm{~cm}$. is reached. It continues to rise much more slowly for the next two $\mathrm{cm}$. or so. Apparently the temperature after this is fairly uniform, i.e. $37^{\circ} \mathrm{C}$. That is, the subcutaneous tissues cause a temperature lag or thermal gradient of about $5^{\circ} \mathrm{C}$. This is due to the large proportion of water which enters into the composition of the tissues, giving the body the high specific heat of about $0 \cdot 83$. A man weighing $60 \mathrm{~kg}$. would conscquently have a water equivalent of $50.4 \mathrm{~kg}$. of water, so that a rise of $0 \cdot 1^{\circ} \mathrm{C}$. would only be registered after $5 \cdot 04$ cals. of heat had been rendered latent. 
(d) The loss of heat varies directly with the time of exposure of the surface. In actual practice, this can be determined for nonliving systems only, because, as we shall see, in the living body secondary reactions take place; alterations in the state of the surface and also of the deep-lying tissues are produced, rendering diffieult the application of this law to living beings. If the student uses his eommon sense, however, he will readily see that, if all conditions are kept constant except timc, the amount of heat lost by conduction must vary directly with the time of exposure.

(ii) Temperature gradient. Newton's law states that the amount of heat lost by a body in unit time is proportional to the difference in its temperature from that of the surrounding medium. The warm body loses heat and becomes colder, while the environment becomes warmer. This loss and gain goes on till the body and its environment are at the sanie temperature. Inspired air or cold food is warmed to body temperature at the expense of body heat. The drinking of cold water may cause a temporary reduction of rectal temperature. Conversely, hot food and drink tend to increase the temperature of the body.

The heat lost by excretion depends not so much on this factor as on the amount and nature of the excreta. Compared with the total heat lost, the amount lost by the heating of inspired air, cold ingesta, and by the excreta is trivial.

(iii) Force of wind. In still air, the loss by conduction is very slight. Air is not a very good thermal conductor. A layer of warmed air soon forms an envelope round the cooling body and prevents rapid conduction. A very slight movement of the air may produce a very appreciable effect by driving off the warm particles and bringing cool ones into contact with the body. This may arise naturally by the formation of convection currents. The heated air expands and becomes lighter and so rises and allows the colder air to flow in.

An air current may be felt when it moves at the rate of about 0.4 to 0.5 metre per second. A non-perceptible draught with a velocity of 0.2 metre per second playing on the naked arm may increase the heat loss over that experienced in still air by 19 to 75 per cent. depending on the temperature of the air. A moderate breeze at 8 metres per second (15 miles per hour) with a temperature of $20^{\circ} \mathrm{C}$. causes more rapid chilling of a naked man than exposure to still air at $2^{\circ} \mathrm{C}$. (see also p. 346).

(iv) Humidity of atmosphere. Water is a better conductor 
of heat than air. A moment's consideration of the feeling of cold before entering cold water and during the process will convince one of this. We have already mentioned the difference in the cold sensation caused by a dry cold wind compared with that produced by a wind of even a much higher temperature but laden with moisture.

\section{Radiation.}

The transmission of heat by radiation differs essentially from conduction and convection. The particles of a body have a vibratory movement depending on their kinetic energy. Increase of temperature will therefore cause increase in the velocity of these movements. In conduction some portion of another body is heated by contact with the warm body. This second body passes the heat on. There is molecular continuity. By radiation, on the othel hand, one body can affect the thermal state of another body not in contact with it without sensibly affecting that of the intervening medium. Radiation is not dependent upon the presence of air. It takes place quite readily in a vacuum. This is manifest when we consider how we derive heat from the sun whose radiant heat is transmitted through the ether at a very high velocity (about 186,000 miles per second) by means of transverse wave motion.

Radiant heat may be detected and measured by means of a suitable thermopile provided with a collecting horn or by means of Leslie's differential air thermometer. The amount of heat lost by radiation depends on :

(i) The area and colour of the surface. It has been proved experimentally as well as deduced mathematically that the emissive and absorptive powers of a body are equal. A perfectly black body absorbs all the heat energy that falls on it, and therefore, since a body cannot absorb more than is incident on it, the absorptive power of such a body is unity. The emissive power of a body is the ratio of the quantity of heat radiated per sq. $\mathrm{cm}$. of surface to the quantity radiated per $\mathrm{cm}^{2}$. of a "perfectly" black body under the same conditions. (Expt. 53, p. 424.)

TABLE LVII.

Radiating and Absorbing Powers of Bodies.

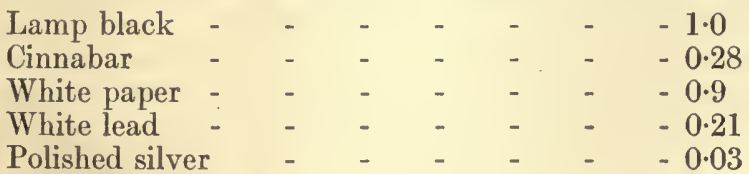


(ii) There is a connection between the amount of radiation from, and the temperature of, a body. 'The total heat-loss by radiation is proportional to the difference between the fourth powers of the absolute temperatures of the body and its environment as well as to the area and nature of the surface. If body and environment differ little in temperature, the heat lost by radiation will thus be comparatively small. For example, if the temperature of the air were $17^{\circ} \mathrm{C}$., the heat radiated from a " perfectly " black man at $37^{\circ} \mathrm{C}$. would be $(273+37)^{4}-(273+17)^{4}$ $=\mathbf{3 1} 0^{4}-\mathbf{2 9 0} 0^{4}=\mathbf{2 1 6} \times 10^{6}$ per unit surface.

Of course a perfectly black man does not exist nor yet a perfectly white man. If black skin has a radiation-coefficient of 0.98 and white skin of 0.7 , then the difference in radiating power would be expressed by $\frac{0.98}{0 \cdot 7}=\mathbf{1} \cdot 4$, a trivial advantage to black-skinned animals. This has been confirmed experimentally by Leslie, who used a differential air thermometer as a very delicate method for the detection of very small differences in temperature.

\section{Evaporation of Moisture.}

As the temperature of the air and of the body approach the same value, the heat lost by the body by radiation and conduction will be exactly balanced by the heat absorbed from the environment by the body. If the atmosphere attain a higher temperature than the body, then these means of heat elimination will become inadequate, and the body temperature should increase synchronously with that of its surroundings. . That this is normally not so is common knowledge. Many interesting instances have been known of persons submitted to high temperatures, and an examination of some of these cases may lead us to a knowledge of the

TABLE LVIII.

Time to kill Spores of Hay Bacilli at Virious

Temperatures.

\begin{tabular}{l|r}
\hline Temperature. & Time. \\
\hline $100^{\circ} \mathrm{C}$ & over 16 hours \\
$105-110^{\circ}$ & $2-4$ hours \\
$115^{\circ}$ & $30-60$ minutes \\
$125-130^{\circ}$ & $5-6$ minutes \\
$135^{\circ}$ & $1-5$ minutes \\
$140^{\circ}$ & about 1 minute \\
\hline
\end{tabular}


mechanism called into play to prevent untoward results. On one point preliminary cmphasis must be laid, viz. the times during which these extreme temperatures were endured were of very short duration. That the time factor is of immense importance may be adduced from the preceding experiment (Table LVIII.) by Christen.

In warm-blooded animals, $45^{\circ} \mathrm{C}$. is generally considered a lethal temperature, but death may occur at a lower temperature $\left(42^{\circ}\right)$, provided the time of exposure is sufficiently prolonged.

Bakers' assistants are known regularly to have entered ovens heated to over $126^{\circ} \mathrm{C}$. When the temperature approached $160^{\circ}$, they experienced extreme superficial vasodilatation. Young girl labourers are said to experience no inconvenience from a stay of 5-10 minutes in a kiln heated to about $130^{\circ} \mathrm{C}$. Chaubert, the "Fire King," is reported as having withstood a temperature of between $226^{\circ}$ and $315.5^{\circ} \mathrm{C}$. Yet immersion in a bath of water at $45^{\circ} \mathrm{C}$. is unbearable. It is a matter of common knowledge that those who habitually work in abnormally overheated places consume large quantities of fluid, and sweat profusely. The latent heat of water is the greatest of all substances known. Every gram of water which is vaporised entails the use of 536 calories. This is in accordance with the principle of energeties laid down by Le Chatelier (p. 9). In general, if any change is brought about by the incidence of energy, then alteration will take place in the substance acted on to nullify these changes, i.e. a reaction of opposite direction occurs.

Substances which expand on heating will be cooled by mechanical expansion. Water increases its volume in passing from the liquid to the gaseous state, and therefore, as the result of such an expansion, the parent fluid is cooled. The evaporation of moisture from the surface thus causes cooling of the body (see also clothes, p. 351).

The quantity of heat lost by the evaporation of moisture $(a)$ in the bronchial passages, etc., $(b)$ in the form of sensible and insensible perspiration, depends mainly. on five factors, viz. :

1. Area of moist surface exposed.

2. Colour

3. Gradient of temperature between body and environment.

4. Force of wind (partial pressure equilibrium).

5. Humidity of the air.

(1) The effective area of surface exposed to cooling depends in great measure on the state of the superficial blood vessels. Dilatation of these enormously increases the area.

(2) The effect of colour is merely a matter of the differential absorption of radiant energy producing local heating in proportion to the amount of energy absorbed and so causing a more or less rapid evaporation. The black moist muzzle of the bull-dog is much cooler than its white, comparatively dry skin. 
(3) The gradient of temperature has much to do with the amount of heat lost by evaporation. This is an indirect effect. It has been suggested that the pigmented skin of tropical races, by absorbing radiant energy and so becoming unduly warm, stimulates epidermal nerve-endings and produces vasodilatation and profuse sweating. The evaporation of this water then cools the body in a similar way to the Indian chatti or water cooler. According to G. F. Hearne, exhaustion of the sweat mechanism always preceded heat-stroke in Mesopotamia.

(4) The presence of a current of dry air removes the gaseous water from the surface, and so brings dry air in contact with the body. In other words, the partial pressure of the gaseous water in the layer next to the body is kept at a minimum. This drying effect of wind is operative irrespective of the temperature of the wind, as witness the drying of shallow pools of water and of wet clothes by cold and by warm breezes.

(5) Humidity of Air. The presence of moisture in the air affects its cooling powers in two ways. $(\alpha)$ Obviously, if the air is already saturated with moisture it is unable to absorb more, and evaporation from the body even when played upon by a draught will be at a minimum. ( $(\beta)$ On the other hand, as we have already mentioned, moist air is a much better conductor of heat than dry air, and therefore, the heat lost by conduction tends towards a maximum in a humid atmosphere. The former of these factors plays a major part when the surroundings are warm, the latter operates maximally in cold climates.

In the assessment of the conditions of the atmosphere making for ideal heat-loss, two instruments are in common use, viz., the wet and dry bulb thermometer and Hill's " Kata " thermometer (or its popular modification-the Comfimeter). The first of these instruments consists of two similar mercury thermometers fastened side by side on a stand. The reservoir of one is covered by a close fitting muslin bag which is kept moist by connection to a wick dipping in water. The water evaporates from the bulb at a rate depending principally on the degree of saturation of the atmosphere with aqueous vapour. It is obvious that, if the air is already saturated with moisture and no evaporation is taking place from the wet bulb, both thermometers will register the same temperature. On the other hand, if the difference in the temperatures recorded is great, one may consider that the air is dry.

Example. The degree of humidity of the air may be calculated from the formulae,

$$
\text { degree of humidity }=\frac{f}{m} \text { and } f=F-A L(t-\theta) \text {, }
$$


where $\quad A=$ the constant of the instrument,

$F=$ the tension corresponding to $\theta^{\circ}$, the reading on the wet bulb thermometer,

$H=$ atmospheric pressure,

$t=$ reading on dry bulb thermometer,

and $\quad m=$ maximal vapour tension at $t^{\circ} \mathrm{C}$.

If $A=0.00082, t=20^{\circ} \mathrm{C} ., \theta=16^{\circ} \mathrm{C}, H=758 \mathrm{~mm}$. $\mathrm{Hg}$.,

$F$ (from a table of vapour tensions) $=13 \cdot 63 \mathrm{~mm}$. $\mathrm{Hg}$.

Then $f=13.63-0.00082 \times 758 \times 4=11.16 \mathrm{~mm}$. Hg.

The maximal vapour tension at $20^{\circ} \mathrm{C}$. (from a table) $=17.52 \mathrm{~mm}$. $\mathrm{Hg}$.

Therefore, the degree of humidity $=\frac{f}{m}=\frac{11 \cdot 16}{17 \cdot 52}=0 \cdot 637$.

The "Kata" thermometer is a large bulbed spirit thermometer. It may be warmed to say $38^{\circ} \mathrm{C}$. The time is then taken while it cools to $35^{\circ} \mathrm{C}$. It may be surrounded by wet muslin and the experiment repeated. The dry bulb instrument gives an indication of the possibilities of heat-loss by radiation and conduction, while the wet bulb indicates, in addition, the possibility of heat-loss by evaporation of moisture.

The Comfimeter is a form of kata-thermometer designed to give an immediate indication of the cooling property of the air in rooms. It consists of a cylindrical metal box in which is inserted an electric incandescent lamp.

On the top of the box is fixed an inverted metal funnel having a long stem. An ordinary thermometer is hung from inside the upper part of this stem so that about $2 / 3$ of its length remains outside the instrument. When the lamp is lit, air enters the comfimeter by means of holes in the cylindrical box and the heated air rises and leaves by the orifice in which the thermometer is hung. The whole apparatus is cooled by radiation, convection and by conduction. When the comfimeter gives a reading of $30^{\circ} \mathrm{C}$, this indicates a cooling power of about 7 millicalories per square centimetre of effective cooling surface per second-an ideal condition. If, now, the box be screened from draughts, the comfimeter thermometer will rise to $45^{\circ}$ or maybe $50^{\circ} \mathrm{C}$. On permitting free ventilation, the instrument will again record a temperature of about $30^{\circ} \mathrm{C}$. A lower temperature than this is a sign of too rapid cooling. The designer, Prof. L. Hill, says that as long as schools, factories, etc., are kept with the comfimeter indicating somewhere about $30^{\circ} \mathrm{C}$., conditions suitable for work will be maintained.

Work of itself, as is well known, causes production of heat in the body. Some 75 per cent. of the energy generated in muscular contraction is dissipated as heat. In spite of the large quantity of heat thus liberated, the body temperature does not increase to any great extent. It may rise by about $2^{\circ} \mathrm{C}$, depending on the cooling value of the environment as well as on the severity of the work. The following figures from Pembrey (Table LIX.) illus- 
trate the influence of the rate of cooling on the body temperature after severe work :

TABLE LIX.

Soldiers on Completing a March of Seven Miles.

\begin{tabular}{c|c|c|c}
\hline \multicolumn{2}{c|}{ External Temp. } & Increase of pulse rate. & Increase of temp. \\
\hline Dry bulb. & Wet bulb. & & \\
\hline 79 & $67 \cdot 5^{\circ} \mathrm{F}$. & 62 & $1 \cdot 4^{\circ} \mathrm{F}$. \\
45 & $38^{\circ} \mathrm{F}$. & 14 & $0 \cdot 8^{\circ} \mathrm{F}$. \\
\hline
\end{tabular}

On the cold day with a percentage difference of about 15 between dry and wet bulb temperatures, i.e. under good cooling conditions, the temperature and heart rate of the soldiers showed only a slight increase, while on the hot day with almost the same humidity, the men became uncomfortably hot, and the heart rate was increased. Under these conditions work is inefficiently done.

The effect of the tempcrature and the humidity of the external air on the loss of heat from the body is very well marked in those people endowed with a good layer of adipose tissue. As has already been mentioned, this dense non-conducting material is a very effective heat insulator, thus preventing rapid heat loss. In hot weather and during exercise, fat subjects become unduly heated. If, in addition, they have poorly functioning sweat glands, then severe or prolonged work becomes impossible.

The following table gives a rough indication of the amount of heat lost per day through the various channels :

TABLE LX.

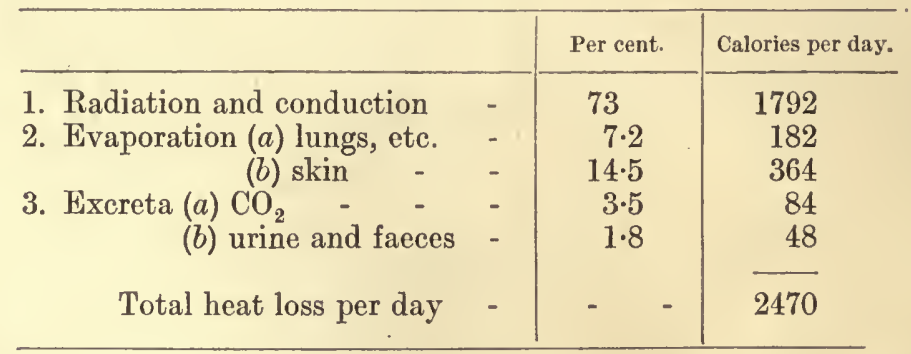

The question now under consideration is, provided some $\mathbf{2 5 0 0}$ calories of heat are lost per day, (a) how is excessive heat loss prevented and $(b)$ how is the amount lost made good? 
A. Physical Regulation-Preventative. (Usually effective between $40^{\circ}$ and $20^{\circ} \mathrm{C}$.)

This is obtained by decreasing the effective cooling surface, a result which may be produced in three ways :

1. By wearing clothes (or fur), a layer of still air is established between the body and the outer air. Heat will then be lost from the covered area by radiation only (see clothes).

2. A good layer of subcutaneous fat prevents a rapid diffusion of heat from the interior to the exterior of the body.

3. Constriction of the cutaneous blood vessels, a reflex act, results $(a)$ in a decrease in the amount of blood carried to the surface, i.e. decrease in cooling surface and $(b)$ in a decreased output from the sweat glands.

Paralysis of the vasomotor nerves leads to vasodilatation. This is given as the reason for the death of animals whose skins have been covered with a layer of impenetrable varnish. It is alleged that, at the enthronement of Pope Leo X., a boy was gilded to represent an angel. Before the ccremony was finished the boy, despite the efforts of Leonardo da Vinei and other physicians, had died. That excessive heat loss was the cause of this accident is proved by the experiments of Valentin. He showed that, under similar circumstances, the carbon-dioxide output of the subject was reduced to about $1 / 6$ of the normal, i.e. metabolism was at a low ebb. If the animal were kept normally warm, the carbon-dioxide output returned to a normal figure. On the other hand, Senator states that the human body can be covered for 8-10 days with an impenetrable layer without producing any disturbance of metabolism. He avers that, in those cases where vasodilatation occurred, some toxic substance must be absorbed from the varnish.

Alcohol produces vasodilatation-an increased cooling surface. That is, this drug, because it causes more warm blood to come to the surface, gives rise to a sensation of cutaneous warmth while at the same time materially aiding in the depletion of the body's store of heat.

B. Chemical Regulation-Curative. (Usually predominant below $20^{\circ} \mathrm{C}$.)

These mechanisms come into play to replace heat which has been lost.

(a) Voluntary or involuntary work. Wé have already seen that work causes the liberation of heat and we have discussed the reason for this. Shivering, or involuntary work is a reflex act which occurs in any person of normal muscular tone when the 
skin temperature is allowed to drop below a certain value. Anything which will prevent muscle from responding to this stimulus will do away with this curative heat production, e.g. curari, alcohol, etc. Young animals which have little muscular development are, obviously, unable to keep themselves warm by exercise and have to be carefully protected against undue heat loss.

(b) Increased muscular work ultimately leads to increased catabolism of food material and so, indirectly, to an increase in the quantity of heat liberated. Over and above this amount, however, the result of exposure to excessive cold may be combated by the ingestion of foods having a high energy value. Natives of the colder climates introduce much fatty matter into their diets.

One may just glance at a problem connected with the above. If the action of any tissue-complex, muscle, liver, etc., results in the liberation of "waste" heat, is heat then liberated during cerebral activity? At present, careful investigation has failed to show the production of heat by the brain. It is admittcdly true that the head becomes heated during prolonged mental work, but this is accounted for by the increased cranial blood supply-blood flowing away from the extremities and from the viscera to the brain.

Centre. Since the means adopted for the maintenance of an unfluctuating temperature involve the bringing into play of so many structures and of such a variety of nerves,-vasomotor, muscular, secretory and so on,-it is plain that a co-ordinating centre is a necessity. Experimental evidence leads one to the conclusion that such a centre exists in the corpus striatum. Vasoconstriction, shivering, and a rise in rectal temperature result from the stimulation of this structure with a cold object. On the other hand, the application of a warm stimulating point leads to vasodilatation, muscular relaxation, and a fall in body temperature. Such results are generally interpreted as indications of the sensitiveness of the corpus striatum to alterations of the temperature of the blood flowing through its capillary system.

Clothes. The question of the maintenance of the human body in comfort is so closely associated with the nature of clothing that a few physical facts bearing on the nature and value of artificial protective and decorative coverings are not out of place here. Liebig made clear onc aspect of the function of clothing, saying, "Our clothing is, in reference to the temperature of the body, merely an equivalent for a certain amount of food." In other words, if we were to do without the protection afforded by clothing we would have to make good the heat thus lost by eating more food. 
The protcetive value of clothing mainly depends (1) inversely on the thermal conductivity of the material, (2) on its power of absorbing water, and (3) on the arrangement of the fibres of the material in the eloth. The eonductivity of various materials is given in Tables LVI. and LXI.

TABLE LXI. (From RubNer).

\begin{tabular}{lll|l}
\hline \multicolumn{2}{c|}{ Substance. } & & Coefficient of Conductivity. \\
\hline Air - - - & - & - & $53 \times 10^{-6}$ \\
Brown human hair - & - & $76 \times 10^{-6}$ \\
Grey human hair & - & - & $74 \times 10^{-6}$ \\
Feathers (eiderdown) & - & $57 \times 10^{-6}$ \\
Horse hair - - & - & $57 \times 10^{-6}$ \\
Cotton cloth (smooth) & - & $81 \times 10^{-6}$ \\
Woollens - - - & - & $68 \times 10^{-6}$ \\
Silk - - & - & - & $68 \times 10^{-6}$ \\
Cashmere wool- & - & - & $68 \times 10^{-6}$ \\
Cambric - - & - & - & $81 \times 10^{-6}$ \\
Flannel - - & - & - & $72 \times 10^{-6}$ \\
Flannelette - & - & - & $75 \times 10^{-6}$
\end{tabular}

In order to calculate the eoefficient of protection of elothing one must know the thickness of the material. Table LXII. compiled by Rubner gives further information regarding the density of the material and of the amount of air enmeshed in the structure. This layer of imprisoned air, as we have alrcady mentioned, has a greater protective value than mere thickness of material.

TABLE LXII.

\begin{tabular}{|c|c|c|c|c|c|c|}
\hline \multirow{2}{*}{\multicolumn{2}{|c|}{ Substance. }} & & \multicolumn{2}{|c|}{ Thickness in $\mathrm{mm}$. } & \multirow{2}{*}{ Mean Density. } & \multirow{2}{*}{$\begin{array}{l}\text { Percentage } \\
\text { volume of } \\
\text { atr } \\
\text { enmeshed. }\end{array}$} \\
\hline & & & Total. & Of the Skin. & & \\
\hline Black cat fur - & - & - & $12 \cdot 6$ & $0 \cdot 6$ & $0 \cdot 0429$ & $96 \cdot 7$ \\
\hline $\begin{array}{l}\text { Black lamb's wool } \\
\text { (Astrakan) }\end{array}$ & - & - & $13 \cdot 0$ & $0 \cdot 3$ & $0 \cdot 0484$ & $96 \cdot 4$ \\
\hline Rabbit skin - & - & - & $13 \cdot 0$ & $0 \cdot 5$ & $0 \cdot 0304$ & $97 \cdot 7$ \\
\hline Musk rat skin & - & - & $14 \cdot 0$ & $0 \cdot 6$ & $0 \cdot 0576$ & $95 \cdot 6$ \\
\hline Otter skin - & - & - & $17 \cdot 0$ & $0 \cdot 9$ & $0 \cdot 0638$ & $95 \cdot 1$ \\
\hline White bear skin & - & - & $21 \cdot 5$ & 0.9 & $0 \cdot 0582$ & $95 \cdot 5$ \\
\hline Beaver skin - & - & - & $22 \cdot 0$ & $0 \cdot 8$ & $0 \cdot 0514$ & $96 \cdot 1$ \\
\hline Skunk - - & - & - & $26 \cdot 0$ & 0.5 & $0 \cdot 0410$ & $96 \cdot 8$ \\
\hline Sheepskin - & - & - & $40 \cdot 0$ & $0 \cdot 7$ & $0 \cdot 046]$ & $96 \cdot 4$ \\
\hline Cashmere wool & - & - & $0 \cdot 37$ & - & $0 \cdot 364$ & $72 \cdot 0$ \\
\hline Cambric - & - & - & 0.29 & - & $0 \cdot 179$ & $86 \cdot 7$ \\
\hline Silk - & - & - & $0 \cdot 25$ & - & $0 \cdot 329$ & $74 \cdot 7$ \\
\hline
\end{tabular}


A man entirely clothed in a garment of a total surface $(s)$ of $19 \times 10^{3}$ sq. cm., of a thickness $(t)$ of $75 \times 10^{-2} \mathrm{~cm}$. and having a difference of temperature $(d)$ on the two sides of $10^{\circ} \mathrm{C}$., loses heat $(Q)$ as shown by the following formula :

$$
Q=\frac{c \times s \times d}{t} \text { calories per minute, }
$$

where $\quad c=$ crefficient of conductivity,

i.e. $\quad Q=\frac{c \times s \times d \times 3600 \times 24}{t \times 1000}$ calories per day.

If the garment were of wool, $c=68 \times 10^{-6}$, we have

$$
=\frac{68 \times 19 \times 36 \times 24 \times 10^{-6} \times 10^{3} \times 10^{2} \times 10}{75 \times 10^{-2} \times 10^{3}}
$$

$=\mathbf{1 8 8 8} \cdot \mathbf{3}$ calories per day.

The coefficient of utility of clothing materials may be determined by covering with them a number of similar copper spheres filled with warm water and finding how long they take to cool through $10^{\circ} \mathrm{C}$. If the time taken to cool $10^{\circ} \mathrm{C}$. by an unclothed sphere with an external temperature of $12^{\circ} \mathrm{C}$. be taken as $\theta$, and the time necessary for the same sphere (clothed) to cool to the same extent be $t$, then $t / \theta=U$ (Coefficient of utility).

\begin{tabular}{|c|c|}
\hline Clothing. & Values of $U$ \\
\hline Cycling vest (tight fitting) & $1 \cdot 1$ \\
\hline Woollen shirt - - & 1.5 \\
\hline Black leather waistcoat - & $1 \cdot 6$ \\
\hline Flannel shirt - - - & 1.75 \\
\hline Rough tweed coat - & $1 \cdot 9$ \\
\hline Weatherproof cloak - & $2 \cdot 1$ \\
\hline Woollen undervest - & $2 \cdot 5$ \\
\hline Heavy greatcoat - & $4 \cdot 5$ \\
\hline
\end{tabular}

TABLE LXIII. (From Bergonié).

The efficiency of clothing depends in great measure on the arrangement of the fibres of the cloth so as to enmesh air and thus form a stationary layer between the body surfaee and the outer air. The following table (Table LXIV.) from Lefèvre gives an idea of the protective value of clothing. His subjects were placed in a rectangular box through whieh a measured amount of air was passed. The temperature of the air just before it reached the body and immediately after leaving the body was taken. If $\boldsymbol{M}$, 
the mass of air passing in $t$ mins., is heated by $\theta^{\circ}$, then the heat lost per minute $=\frac{0.237 \times \theta \times M}{t}$ calories, where 0.237 is the specific heat of air.

TABLE LXIV.

\begin{tabular}{|c|c|c|c|c|c|}
\hline \multirow{2}{*}{$\begin{array}{l}\text { Rate of } \\
\text { wind. } \\
\text { Metres per } \\
\text { sec. }\end{array}$} & \multirow{2}{*}{$\begin{array}{l}\text { Tempera- } \\
\text { ture of air } \\
\text { entering. }\end{array}$} & \multicolumn{2}{|c|}{ Loss per hour in calories } & \multicolumn{2}{|c|}{ Ratios. } \\
\hline & & Naked. & Clothed. & Fast/slow. & Naked/clothed. \\
\hline $1 \cdot 2$ & $9^{\circ} \mathrm{C}$. & 134 & 98 & $\frac{201}{134}=1 \cdot 5$ & $\frac{134}{98}=1 \cdot 36$ \\
\hline $3 \cdot 8$ & $9^{\circ} \mathrm{C}$. & 201 & 130 & $\frac{130}{98}=1 \cdot 32$ & $\frac{201}{130}=1.45$ \\
\hline $1 \cdot 5$ & $5^{\circ} \mathrm{C}$. & 185 & 143 & $\frac{277 \cdot 5}{185}=1 \cdot 5$ & $\frac{185}{148}=1 \cdot 3$ \\
\hline $3 \cdot 8$ & $5^{\circ} \mathrm{C}$. & $277 \cdot 5$ & 172 & - & $\frac{277 \cdot 5}{172}=1 \cdot 61$ \\
\hline $4 \cdot 0$ & $4^{\circ} \mathrm{C}$ & 313 & 170 & $\frac{172}{143}=1 \cdot 2$ & $\frac{313}{170}=1 \cdot 84$ \\
\hline
\end{tabular}

It will be noticed that heat production increases with the lowering of the temperature of the wind and also with increasing the speed of the wind. It is obvious that, under similar conditions, the heat lost (and the heat produced) by the clothed is less than that of the naked subject.

The colour of clothes has also something to do with their protective action. Quite apart from psychological effects, certain colours conduce to warmth and others to coolness. This is a problem that exercised the minds of those responsible for the health of white troops in tropical countries. The final result of one series of investigations was to recommend the wearing of white clothes with a black lining. The student may find it an interesting exercise to furnish a reason for this. 


\section{CHAPTER XXXII}

\section{TROPISMS--THE SLAVES OF THE LAMP}

"Behold the child, by Nature's kindly law, Pleased with a rattle, tickled with a straw :

Some livelier plaything gives his youth delight, A little louder but as empty quite ;

Scarfs, garters, gold, amuse his riper stage,

And beads and prayer-books are the toys of age, Pleas'd with this bauble still, as that before, Till tir'd he sleeps, and life's poor play is o'er."

Pope.

IT may be laid down as axiomatic that once an object has come into equilibrium with its environment, it will remain so until some change in the environment disturbs the harmony. In other words, matter has inertia-moves when it is moved, stops when it is stopped, and alters only in so far as it is altered. All inorganic substances are not in equilibrium with their environment. Radioactive minerals, as we have seen, are characterised by undergoing considerable change-seemingly independent of the nature of their surroundings. It is a moot point whether living things may be brought under this general statement. That they have inertia both in the ordinary physical sense and functionally is undoubted. Moreover, that alterations in the distribution of energy in the environment do lead to apparently corresponding alterations in the organism will be granted by most workers in this field, but all are not agreed as to how far the interpretation can be applied to animals high in the scale.

I. One of the best investigated phenomena in this line of study is that of heliotropism or phototaxis. It is well known that radiant energy is capable of influencing the rate of some chemical reactions-in proportion to the intensity of the light. This is known as the Bunsen-Roscoe Law, which may be formulated as :

$$
\text { it }=\text { constant, }
$$

where $i$ is the intensity of the light and $t$ the time of exposure. 
(1) Certain animals and free-swimming plant-organisms move towards or away from the source of light. These are said to be positively or negatively heliotropic respectively. Caterpillars of Porthesia chrysorrhoea are of the former class. They move towards the light and may starve, with abundance of food just behind them.

(2) If positively and negatively heliotropic animals are placed in a trough covered half with red and half with blue glass, those that are positively heliotropic collect at the blue end and the others at the red end of the trough. Red glass is practically opaque, as every photographer knows, to the photo-chemical rays of light. The most efficient rays for heliotropic reactions are (a) the blue between 460 and $490 \mu \mu$ and (b) the yellow-green between 520 and $530 \mu \mu$. Now, most blue glass permits not only the passage of the blue rays but of the yellow-green rays also (cf. Fig. 1).

(3) That the heliotropic animal is oriented in relation to the source of light is shown by a simple experiment due to Loeb. Direct sunlight is allowed to fall from the upper half of a window on to a table and diffused daylight from the lower half on to the same table on which is placed a test-tube in such a way that it lies at right angles to the window and is illuminated over one-half of its length (room half) by direct sunlight and over the remainder by diffused daylight. Positively heliotropic animals are introduced into the sunny end of the tube. They promptly and invariably move towards the window, i.e. out of the sunlight into the shade towards the source of light.

(4) To explain these facts (and others) Loeb has put forward an interesting theory. "Animals possess photosensitive elements on the surface of their bodies, in the eyes or occasionally also in the epithelial cells of their skin. These photosensitive elements are arranged symmetrically in the body and through nerves are connected with symmetrical groups of muscles. The light causes photochemical changes in the eyes (or photosensitive elements of the skin). The mass of photochemical reaction products" so formed " influences the central nervous system and through this the tension or energy production of the muscles. If the rate of photochemical reaction is equal in both eyes, this effect on the symmetrical muscles is equal and the muscles on both sides of the body work with equal energy; as a consequence the animal will not be deviated from the direction in which it is moving. This happens when the axis or plane of symmetry of the animal goes 
through the source of light, provided only one source of light be present. If, however, the light falls sideways on the animal the rate of photochemical reaction will be unequal in both eyes and the rate at which the symmetrical muscles on both sides of the body work will no longer be equal; as a consequence, the direction in which the animal moves will change. This change will take place in one of two ways, according as the animal is either positively or negatively heliotropic."

(5) If this is true, it follows that the animal will obey the BunsenRoscoe Law. This is rather troublesome to prove for free-moving animals. The following table shows the applicability of the law to regenerating polyps of Eudendrium. The intensity of the light was altered by varying the distance between the source of light and the polyps.

TABLE LXV.

\begin{tabular}{|c|c|c|}
\hline \multirow{2}{*}{$\begin{array}{l}\text { Distance between Polyps } \\
\text { and source of light } \\
\text { (metres). }\end{array}$} & \multicolumn{2}{|c|}{$\begin{array}{l}\text { Time in minutes required to cause } 50 \text { per eent. of Polyps to } \\
\text { bend towards the source of light. }\end{array}$} \\
\hline & Observed. & Calculated. \\
\hline 0.25 & 10 & - \\
\hline $0 \cdot 50$ & $35-40$ & 40 \\
\hline $1 \cdot 00$ & 150 & 160 \\
\hline $1 \cdot 50$ & $360-420$ & 360 \\
\hline
\end{tabular}

The calculated values' of $t$ tend to be somewhat larger than the observed results. Schwarzschild observed that when development followed exposure to light the formula should be modified to

$$
i t^{p}=\text { constant. }
$$

For silver bromide gelatine plates, the value of the exponent $p$ varies between 0.8 and 1 according to the brand of the plate.

Talbot's Law is the Bunsen-Roscoe Law modified to make it applicable to intermittent light. Intermittent light is as effective as constant light of the same intensity provided that the total duration of the intermittent light is equal to that of the constant light.

(6) What is going to be the result when the organism is subjected to two sources of light? One might predict that, if Loeb's hypothesis is correct, the organism will be oriented so that it comes to rest in a position where it is symmetrically stimulated. (a) If the two sources of light are of equal intensity and duration and 
are set at an equal distance from the organism it should be oriented with its plane of symmetry at right angles to the line joining the sources of light. (b) If the lights are of unequal intensity, the animal should move so that its photosensitive elements are in a position to absorb equal amounts of light energy. Further, the absolute intensities of light should have no effect on the deviation of the path of the organism from the perpendicular path outlined at first. The relative intensities should be the governing factor. These three predictions have been amply proved experimentally. The following results (Table LXVI.) from Patten's investigations illustrate the nature of the findings.

\section{TABLE LXVI.}

\begin{tabular}{|c|c|c|c|}
\hline \multirow{2}{*}{$\begin{array}{l}\text { No. of lamps } \\
\text { used. }\end{array}$} & \multicolumn{3}{|c|}{$\begin{array}{c}\text { Difference of intensity between the two ligits in } \\
\text { percentages. }\end{array}$} \\
\hline & 0 & 25 & 50 \\
\hline & \multicolumn{3}{|c|}{ Defleetion in degrees. } \\
\hline 1 & 0.55 & $9 \cdot 04$ & $19 \cdot 46$ \\
\hline 2 & $0 \cdot 1$ & $8 \cdot 55$ & $22 \cdot 28$ \\
\hline 3 & 0.45 & $8 \cdot 73$ & $20 \cdot 52$ \\
\hline 4 & 0.025 & $9 \cdot 66$ & $19 \cdot 88$ \\
\hline 5 & 0.225 & $8 \cdot 30$ & $19 \cdot 28$ \\
\hline
\end{tabular}

This table shows clearly that (col. 1) when the intensity of the two lights was equal, the animal varicd on the average only 0.09 degree from the perpendieular. It also demonstrates that when the one light was reduced to three-quarters (eol. 2) the intensity of the other, the angle of deviation was about $8 \cdot 86$, and that when a further reduction to a half was made, the angle of deviation was more than doubled. Finally, the figures show that the angle of deviation depends on the relative differences of light intensity and is independent of absolute intensity (provided sufficient light is present to overcome inertia (cf. stimulation, p. 193).

(7) A model with a heliotropic mechanism has been eonstructed by Hays Hammond, the inventor of the dirigible torpedo. The principle on which the maehine depends is the alteration in the electrical resistance of metallic selenium when exposed to light. The " eyes" are lenses separated from each other by a projeeting "nose" which permits the shading of one eye while the other is illuminated. The lenses are eaeh focused on separate selenium 
cells. The heliotropic machine consists of a rectangular box about $3 \mathrm{ft}$. long, $1 \frac{1}{2} \mathrm{ft}$. wide and $1 \mathrm{ft}$. high mounted on three wheels, two of which are geared to a driving motor. The third wheel, mounted at the rear-end, controls the steering. It may be turned right or left by the differential action of two solenoid electromagnets. The selenium cells are in circuit both with the driving motors and with the steering magnets. In the former case, the selenium cells control a series of very sensitive relays (cf. nervous system) in such a way that the amount of energy sent through the driving motors and hence their speed is determined by the intensity of the light falling on the lenses. The steering magnets are opposed, i.e. if both selenium cells are illuminated equally, both magnets will receive the same current and the steering wheel will lie parallel to the driving wheels. If more light falls on one selenium " retina" than on the other, the former has its power to conduct electricity increased in proportion to the relative increase in intensity; consequently the magnets controlling the position of the rear wheel are activated asymmetrically. The wheel is pulled over to make an angle with the previous line of traction of the "dog." The mechanism is so arranged that this steering movement turns the machine towards the light. It will continue to turn till both lenses are equally illuminated. As soon and as long as both " eyes" are equally illuminated in sufficient intensity, the machine moves in a straight line towards the source of the light. The apparatus is fitted with a reversing switch which will convert it from a positively to a negatively heliotropic machine.

If, say, a portable electric light be turned on in front of the machine it will immediately start to follow (or run from) the light at a speed which may attain to $100 \mathrm{yds}$. per min. On reducing the intensity of the light, the "dog" will slow down, and on switching off, it will stop. In this way, the machine follows a lantern in a dark room just like a positively heliotropic animal. By reversing the direction of the current one may make the machine negatively heliotropic.

II. Stereotropism is the term applied to the tendency of certain organisms to bring their bodies as much as possible on all sides in contact with solid bodies. "The butterfly Amphipyra, which is a fast runner, will come to rest under a glass plate when the plate is put high enough above the ground so that it touches the back of the butterfly." Man orients himself partly by appreciation of the tactile influences on the soles of the feet. When these are weakened as in locomotor ataxia, and when the orienting 
influence of the eycs is removed, the patient finds difficulty in standing and in walking (Romberg's sign).

III. Chemotropism plays an important part in the life of the lower organisms. By it, the animal is drawn towards or draws away from certain chemical substances. The organ stimulated asymmetrically is oriented so that the stimulating impacts on it are symmetrical.

IV. Orientation in space is determined mainly by three factors, light, tactile sense and gravitation. Normal equilibrium or normal geotropic oricntation is defined as that position in which the plane of symmetry of the animal passes through the centre of the earth. Any deviation from that position causes unilateral stimulation and corrective movements are instituted. The tight-rope walker perceives that his centre of gravity is tending towards unstable equilibrium and voluntary (though generally sub-consciously) corrects his balance. In the labyrinths, we have a delicate mechanism for detecting alterations in our orientation in space.

Sufficient has been said to show the nature and indicate the mechanism of those actions termed tropisms. In principle they depend on unilateral stimulation of a symmetrical animal. How far they can be accepted as explanations of all the instinctive actions of the lower organisms or of any of the actions of the higher animals remains an open and debatable question. 


\section{CHAPTER XXXIII}

\section{ADAPTATION}

"The free use of final causes to explain what seems obscure was temptingly easy .... Hence the finalist was often the man who made a liberal use of the ignava ratio, or lazy argument : when you failed to explain a thing by the ordinary process of causality, you could 'explain' it by reference to some purpose of nature or of its Creator."

Princtpal Galloway quoted by D'Arcy Thompson.

IF the environment exerts such an all-powerful effect on the organism, can the organism alter itself according to the principle of Le Chatelier so that it may live with the least possible expenditure of energy ? That is, has the animal the power of adaptation? There is no doubt whatever as to the adaptation of growing bone or growing tissue of any sort to the stresses and strains incident upon it. Various organs are known to adapt themselves to mect alterations in the conditions under which they work.

When one comes to consider the organism as a whole, the evidence for adaptation is not so conclusive. The arctic fox and the polar bear are not white because they have adapted themselves to a white background, but because their coloured relatives, not having their invisibility, have paid the penalty. It has been said that trypanosomes may be obtained which are almost unaffected by treatment with arsenic. The process for producing them is to give their host a high but non-lethal dose of arsenic, infect another host with the survivors and so on. This is clearly a case of the survival and propagation of the most resistant strains.

Animals which live in dark or semi-dark places have generally defective eyesight. Is this due to atrophy from want of use or might one not argue that the environment of the cave was the fittest for the blind or semi-blind animal ? Not only would they be at a manifest disadvantage in the struggle for existence outside, but they have a distinct advantage in the cave over any seeing animal that may stray in. 
To be brief, one must consider that, as anything but a rapid response to the distribution of forees in the environment is ineompatible with life, the animal capable of adapting itself to cireumstances will live and propagate. Man, because of his highly organised nervous and muscular systems, is able to adapt himself readily and, therefore, reigns supreme.

No case is known where acquired characters have been transmitted to offspring.

On the other hand the environment may have profound effects, not in the nature of adaptation, but on the development of the organism.

Temperature. In Chap. XXXI. the effect of alterations in temperature on physieal, chemieal and physiologieal phenomena was considered. Temperature influenees all life phenomena.

(a) Development. One of the simplest experiments of this nature is to determine the temperature coeffieient of the development of an egg. Usually the egg of the sea-urchin is chosen for this purpose. Table LXVII. (Loeb and Chamberlain) gives the time in minutes required from insemination to the first celldivision for various temperatures.

\section{TABLE LXVII.}

Effect of Increase of Temperature on Cell-division.

\begin{tabular}{ll|c|c|c|c|c}
\hline Temperature $\left({ }^{\circ} \mathrm{C}.\right)$ & - & 8 & 10 & 15 & 20 & 25 \\
\hline Time (minutes) & - & 411 & 208 & 100 & 56 & $39 \cdot 5$ \\
\hline
\end{tabular}

Inerease of temperature thus causes a more rapid development of the egg.

(b) Rate of Metabolism. Increase of temperature, within limits, as we have seen, causes an inerease in general metabolism. More oxygen is used, more carbon dioxide is excreted, etc. Organs work at a greater rate, e.g. the heart beats more rapidly. The alterations of the rate of the heart of Fundulus (embryo) keeps such regular pace with alterations in external temperature that it could form the basis for a rough thermometer as Table I.XVIII. shows. From the figures we are also justified in inferring that the influenee of temperature in this reaction is a function of this partieular temperature and does not depend on whether the organism is gaining or losing heat. 


\section{TABLE LXVIII.}

Relation between Temperature and Rate of Heart Beat in Fundulus · Embryo.

\begin{tabular}{l|c|c|c|c|c|c|c}
\hline Temperature $\left({ }^{\circ} \mathrm{C}.\right)$ & 20 & 15 & 10 & 5 & 10 & 15 & 20 \\
\hline Time for 19 beats (minutes) & $-11 \cdot 5$ & $19 \cdot 0$ & 32.5 & 61 & $33 \cdot 5$ & $18 \cdot 8$ & 12 \\
\hline
\end{tabular}

(c) The time neccssary to reach sexual maturity is decreased by increase of temperature. Stefansson reports that the Eskimo girl usually has offspring by her twelfth year. This early maturity, he states, may be attributed to the fact that the Eskimo keeps his body at a temperature as high if not higher than that of dwellers in Southern Europe. Be that as it may, other observers have noticed that growth in height and in weight is increased during periods of increased temperature, e.g. summer (see Growth). 


\section{CHAPTER XXXIV}

\section{GROWTH}

"The living organism is so constituted that each disturbing influence stimulates it to put in action a compensatory mechanism which will neutralise and render innocuous the disturbing agency."

FrédéRICQ.

GrowTH may be considered as an attempt of a system to get into equilibrium with its environment. Generally, but not invariably, increase in size is accompanied by changes in external form and in internal structure. Development is, in most cases, a necessary result of growth. This chapter will deal with increase in size quite apart from any concomitant alterations in complexity.

\section{Nature of the Phenomenon.}

At first sight it seems easy to distinguish between a mere accretion of material like crystal growth, snowball increase or accumulation of interest on capital, and organic growth. A more careful examination of the cause and resultant velocity of growth shows that in both inorganic and organic worlds similar principles are involved, and that similar factors operate towards similar ends.

A series of interesting and illuminating experiments emanating from Leduc's laboratory are suggestive. If a little seed compounded of copper sulphate and glucose be planted in a gelatine (1-5 per cent.) gel, through which a little potassium ferrocyanide has been dispersed, growth will take place. In the first place, by the interaction of copper- and ferrocyanide-ions, a membrane of copper ferrocyanide will be formed round the seed. This membrane is semi-permeable, allowing free passage of water but preventing the egress of the crystalloid ions. As a result, the seed, thus gaining water by endosmosis, will swell up and, when the elastic limit of the membrane has been reached, will burst. Immediately this happens, a new membrane will form round the copper-glucose 
solution and the proeess will be repeated. By this means remarkable life-like growths are obtained. (Details of preparation are given in Part II., p. 399.)

Botanists are agreed that osmosis plays an important part in plant growth. An experiment is given in Part II., p. 399, to illustrate the produetion of turgeseenee and eonsequent rigidity as the result of endosmosis. Plant growth is eonspieuously assoeiated with turgor, and depends in great measure on the amount of water taken up. Another and more plausible explanation may be given of the swefling of plant tissues. In Chap. VIII., p. 66 (3), we mentioned the power of colloids to imbibe and eompress water. It is extremely probable that plant turgor may be due to this imbibition, initiated by some alteration in the hydrogen ion eoneentration of the tissue.

It has been definitely proved that animal growth is aecompanied by increase in water eontent as shown in Tables LXIX. and LXX.

TABLE LXIX.

Water Content of Human Embryo. (Fehling.)

\begin{tabular}{c|c|c|c|c}
\hline Age (weeks). & Weight (grams). & Increment. & $\begin{array}{c}\text { Increment } \\
\text { per week. }\end{array}$ & Water per cent. \\
\cline { 2 - 3 } 6 & $0 \cdot 975$ & - & - & $97 \cdot 5$ \\
17 & $36 \cdot 5$ & $35 \cdot 525$ & $3 \cdot 23$ & $91 \cdot 8$ \\
22 & $100 \cdot 0$ & 63.5 & $12 \cdot 7$ & $92 \cdot 0$ \\
24 & $242 \cdot 0$ & $142 \cdot 0$ & $71 \cdot 0$ & $89 \cdot 9$ \\
26 & $569 \cdot 0$ & $327 \cdot 0$ & 163.5 & $86 \cdot 4$ \\
30 & $942 \cdot 0$ & $355 \cdot 0$ & $88 \cdot 75$ & 83.7 \\
39 & $1640 \cdot 0$ & $716 \cdot 0$ & $79 \cdot 56$ & $74 \cdot 2$ \\
\hline
\end{tabular}

TABLE LXX.

Water Content of Frog Embryo. (Davenport.)

\begin{tabular}{l|c|c|c|c|c|c|c|c}
\hline Age (weeks) - & 1 & 2 & 5 & 7 & 9 & 14 & 41 & 84 \\
\hline Water per cent. & $56 \cdot 3$ & $58 \cdot 5$ & $76 \cdot 7$ & $89 \cdot 3$ & $93 \cdot 1$ & $95 \cdot 0$ & $90 \cdot 2$ & $87 \cdot 5$ \\
\hline
\end{tabular}

In the later stages of growth and especially in the higher mammals the ratio of water to solids tends to diminish. Inhibition of growth oeeurs when means are taken to prevent the entrance of water. For example, Loeb put Tubularia and Cerianthus, which live and grow in sea-water having about 3-3.5 per eent. salts, into a more concentrated mixture. He found, when the coneentration of salts in the water was $5 \cdot 4$ per cent., that 
these organisms ceased to grow. The water-holding power of the salt solution, i.e. the exosmotic property of the artificial seawater, balanced the inwards pull of the protoplasm.

\section{Normal Rate of Growth.}

(a) Weight. Brailsford Robertson has shown that the rate of increase in weight follows a curve characteristic of autocatalytic reactions, i.e. of reactions in which one of the resultant products acts as a catalyst for the whole reaction. A simple example of a reaction of this typc may be found in the inversion of an aqueous solution of cane sugar at $100^{\circ} \mathrm{C}$. Part of the product of the reaction (glucose and fructose) appears to undergo further decomposition, giving rise to an unknown acid which accelerates the rate of inversion.

If $x$ denote the amount of invert sugar formed during hydrolysis, $x$ will also be proportional to the amount of acid produced. Now, by the ordinary compound interest law in which a function varies at a rate proportional to itself - an exponential function-we have:

$$
\frac{\delta x}{\delta f}=k x(a-x),
$$

or, on integrating,

$$
k=\frac{1}{a t} \log \frac{a x}{a-x}
$$

where $k$ is a constant.

As the result of a series of experiments on auto-inversion at $100^{\circ} \mathrm{C}$., the value of $k$ for this reaction has been put $=122 \times 10^{-6}$. With this value we can tell at any time after the inception of the reaction just how much sugar has been inverted. Further, it is obvious, that as the action proceeds, the velocity due to the concentration of the original substance gradually decreases (i.e. the ordinary mass action without the catalyst), while that due to the concentration of the newly formed substance keeps steadily increasing. Hence, there must, at a certain time, be a maximum velocity due to definite concentrations of $a$ and $x$. In an autocatalytic reaction this maximum velocity is reached when the concentration of the newly formed substance is half the concentration of the original substance, i.e. when $x=a / 2$.

Do statistical results bear out the statement that growth is an autocatalytic reaction? In the following table (LXXI.) is given for comparison, the weight of the human body at various ages, as found and as calculated from the assumption that the rate of growth is autocatalytic. 
TABLE LXXI.

\begin{tabular}{|c|c|c|c|}
\hline \multirow{2}{*}{ Age (years). } & \multicolumn{2}{|c|}{ Body weight ( $\mathrm{Kg}$.$) .$} & \multirow{2}{*}{ Number of cases. } \\
\hline & Found. & Calculated. & \\
\hline $0 \cdot 5$ & $3 \cdot 4$ & $3 \cdot 4$ & 100 \\
\hline $5 \cdot 5$ & $22 \cdot 7$ & $16 \cdot 5$ & 176 \\
\hline $6 \cdot 5$ & $24 \cdot 6$ & $20 \cdot 1$ & 327 \\
\hline $7 \cdot 5$ & $25 \cdot 9$ & $23 \cdot 4$ & 631 \\
\hline $8 \cdot 5$ & $27 \cdot 0$ & $26 \cdot 2$ & 1038 \\
\hline $9 \cdot 5$ & $28 \cdot 3$ & $28 \cdot 4$ & 1262 \\
\hline $10 \cdot 5$ & $30 \cdot 4$ & $30 \cdot 4$ & 1200 \\
\hline $11 \cdot 5$ & $32 \cdot 3$ & $32 \cdot 2$ & 1129 \\
\hline $12 \cdot 5$ & $35 \cdot 0$ & $34 \cdot 0$ & 863 \\
\hline $15 \cdot 5$ & $47 \cdot 1$ & $44 \cdot 8$ & 1451 \\
\hline $20 \cdot 5$ & $66 \cdot 1$ & $65 \cdot 4$ & 459 \\
\hline
\end{tabular}

From these results we see that the agreement between observed and calculated results is excellent in all cases where a sufficiently large number of subjects have been weighed, except at age $15 \frac{1}{2}$, where weight increases more rapidly than theory demands.

A simple but empirical formula for obtaining "expected" weight is $\frac{A}{4.75 m}$, where $A=$ conceptional age in years and $m$ is a constant for each age (see Table LXXII. for values of $m$ and for results).

(b) Length. It was at first believed that the length curve was of parabolic form of the equation $y^{2}=a(x+b)$, but later and more complete investigation has shown that this is untenable. There is for each type of body a definite relationship between length and weight, viz. : $l=\sqrt[3]{m w}$, where $l=$ length in metres, $w=$ weight in kilograms, and $m$ is a constant for each age (and each type). As $w=\frac{A}{4 \cdot 75 m}$, therefore $A=4 \cdot 75 l^{3}$ or $l=\sqrt[3]{\frac{A}{4 \cdot 75}}$. (Pfaundler.)

Pfaundler gives the following examples:

(i) A boy aged 1 year has a conceptional age $A=1.75 \mathrm{yr}$.

Hence length $=\sqrt[3]{\frac{1 \cdot 75}{4 \cdot 75}}=\sqrt{0 \cdot 36}=0.72$ metre, which compares favourably with the value given in Table LXXII.

(ii) A boy aged 8 yrs. has $A=8 \cdot 75$.

Hence length $=\sqrt[3]{\frac{8 \cdot 75}{4 \cdot 75}}=\sqrt{1 \cdot 74}=1.23$ metres.

(Average length of boy of 8 yrs. $=1.20$ metres.) 
TABLE LXXII.

\begin{tabular}{|c|c|c|c|c|c|c|c|c|}
\hline \multirow{2}{*}{\multicolumn{2}{|c|}{$\begin{array}{l}\text { Age from } \\
\text { birth. }\end{array}$}} & \multirow{2}{*}{$\begin{array}{c}\text { Concep- } \\
\text { tlonal } \\
\text { age } A \\
\text { (yrs.). }\end{array}$} & \multicolumn{2}{|c|}{ Length (motres). } & \multirow{2}{*}{$\begin{array}{c}\text { Constant } \\
m .\end{array}$} & \multicolumn{2}{|c|}{ Weight (Kg.). } & \multirow{2}{*}{$\frac{\text { Weight }}{\text { Height }} \times 100$} \\
\hline & & & Found. & Calc. & & Found. & Calc. & \\
\hline \multicolumn{2}{|c|}{3 months) } & $0 \cdot 225$ & 0.08 & - & $25 \cdot 6$ & $20 \times 10^{-3}$ & - & 0.025 \\
\hline &,$\quad$ ब & $0 \cdot 450$ & $0 \cdot 31$ & 0.45 & $46 \cdot 91$ & $635 \times 10^{-3}$ & 一 & 2 \\
\hline 8 & ", & $0 \cdot 600$ & $0 \cdot 42$ & 0.50 & $36 \cdot 1$ & $2100 \times 10^{-3}$ & - & 5 \\
\hline 10 &, 1 & 0.750 & 0.50 & 0.53 & $39 \cdot 73$ & $3300 \times 10^{-3}$ & $3975 \times 10^{-3}$ & 6 \\
\hline & month & 0.833 & $0 \cdot 54$ & 0.55 & $38 \cdot 72$ & $4 \cdot 25$ & $4 \cdot 53$ & 8 \\
\hline & months & 0.916 & 0.58 & 0.58 & $40 \cdot 24$ & $4 \cdot 95$ & $4 \cdot 79$ & $8 \cdot 5$ \\
\hline 3 & , & $1 \cdot 008$ & $0 \cdot 61$ & $0 \cdot 60$ & $41 \cdot 33$ & $5 \cdot 6$ & $5 \cdot 09$ & 9 \\
\hline 6 & , & $1 \cdot 25$ & $0 \cdot 66$ & $0 \cdot 64$ & $40 \cdot 56$ & $7 \cdot 2$ & $6 \cdot 50$ & 10 \\
\hline 9 & , & $1 \cdot 50$ & $0 \cdot 70$ & 0.69 & $40 \cdot 74$ & $8 \cdot 6$ & $7 \cdot 75$ & 12 \\
\hline & year & $1 \cdot 75$ & $0 \cdot 74$ & $0 \cdot 72$ & $42 \cdot 88$ & $9 \cdot 4$ & $8 \cdot 59$ & $12 \cdot 6$ \\
\hline & years & $2 \cdot 75$ & 0.84 & $0 \cdot 83$ & $48 \cdot 98$ & $12 \cdot 1$ & $11 \cdot 82$ & 14 \\
\hline 3 &, & $3 \cdot 75$ & 0.90 & 0.92 & $55 \cdot 06$ & $13 \cdot 2$ & $14 \cdot 34$ & $14 \cdot 6$ \\
\hline 6 & , & $6 \cdot 75$ & $1 \cdot 11$ & $1 \cdot 12$ & $68 \cdot 17$ & $18 \cdot 1$ & $17 \cdot 76$ & $16 \cdot 3$ \\
\hline 9 & , & $9 \cdot 75$ & $1 \cdot 24$ & $1 \cdot 27$ & $78 \cdot 41$ & $24 \cdot 9$ & $26 \cdot 15$ & 20 \\
\hline 12 & " & $12 \cdot 75$ & $1 \cdot 38$ & $1 \cdot 39$ & 84.94 & $30 \cdot 9$ & $31 \cdot 60$ & 22 \\
\hline
\end{tabular}

Table LXXII. is from Pfaundler's data. It gives the calculated and observed weights for each age as well as his values for $m$ and the centimetre index.

The ratio, weight in $\mathrm{Kg}$./length in $\mathrm{cm}$., is called the centimetre index. Sometimes the ratio is modified as in Levi's ratio, which is

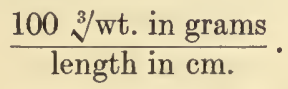

This ratio diminishes as age increases up to puberty.

Dreyer suggests that instead of the total length of the body it would be better to deal with the sitting height.

He has established the following ratios:

$$
\begin{array}{ll}
\text { Males, } & W=0.38025 \sqrt[0.319]{l} \text {; } \\
\text { Females, } & W=0.36093 \sqrt[0.313]{l} ;
\end{array}
$$

where $\quad W=$ weight of the body in grams and $\quad l=$ length of trunk in $\mathrm{cm}$.

Some organisms when their size reaches a certain limiting value tend to divide into two equal portions (Sach's Rule). Therefore, one has to deal with an increase in number quite apart from increase in individual size or weight. It has been proved by numerous experiments that the increase in the number of cells follows the compound interest law, i.e. is an autocatalytic reaction.

To summarise: When it is said that growth is an autocatalytic reaction it is inferred that (i) superimposed on the velocity of 
reaction, which may be classed as chemical and is governed by the law of mass action, (ii) there is a variation in rate due to the presence of a catalyst in one of the products of the main action. The phases of such a reaction are, at least, four :

(1) Ordinary velocity, proportional to the mass of the reacting bodies.

(2) After a short period the catalyst makes its appearance, and the total rate gradually and steadily increases.

(3) Certain limiting factors probably caused by the presence in the blood (or in the sap of plants) of endocrinetes inhibit too rapid a growth.

(4) The accumulation of the products of the reaction produces a tendency to cause a reaction in the reverse direction. 'That is, arrest of growth and even negative groreth may be produced.

Quetelet, who was the pioneer of the statistical study of growth, found that the rate of growth alters with age in a definite orderly way, and the velocity curve may be divided into fairly well-defined regions, each having a definite and characteristic slope, e.g.

(1) From conception to about 3 lunar months the velocity is low, about $2 \mathrm{~cm}$. per month.

(2) Period of rapid growth from 3-9 lunar months $=9 \mathrm{~cm}$. per month.

(3) Rate almost equal to (1), i.e. $2 \mathrm{~cm}$. per month from birth to 3 years or so.

(4) Slower but still rapid growth in early boyhood. (Marked quickening in teens (growing age).)

(5) Period of arrest-full stature has been reached.

(6) Somewhere about fifty years of age the period of negative growth sets in. That is, the curve of growth and picture of velocity follows point by point the velocity curve of a typical autocatalytic reaction.

\section{Factors modifying Growth.}

Chemical reactions may be profoundly altered by alterations in external conditions, and therefore, we may expect to find certain variations in the rate of growth which may be correlated with alterations in the conditions to which the subjects are subjected.

\section{Phase Differences.}

(a) Individual. Quetelet found that under normal conditions the variations in the rate of growth of man were just what might 
be predicted from the application of the mathematical law of probability. This law is represented by the equation

$$
y=\frac{h}{\sqrt{\pi}} \cdot \epsilon^{-h^{2} x^{2}},
$$

where $x$ and $y$ are rectangular coordinates and $h=$ parameter of the curve. Riedel tabulated the heights of nearly 4000 schoolboys of various ages, and found that the variations in height observed for each age were, for all intents and purposes, just what the mathematician predicted. Other investigators have confirmed this and have extended the scope of the equation, applying it to variations in weight, chest measurement, etc.

The index of variability, or standard deviation denoted by the letter $\sigma$, is equivalent to a determination of the point on the actual frequency curve, where it changes its curvature on either side of the mean. For example, if the curve showing the number of individuals of a certain age having a certain height, for instance, be plotted it will cut the theoretical curve at various points. $\sigma$ is a measure of this divergence.

The coefficient of variability is obtained by dividing $\sigma$ by the mean and, for convenience, multiplying by 100 ,

$$
\text { i.e. } \quad C=\frac{\sigma}{M} \times 100 \text {. }
$$

TABLE LXXIII.

Coefficient of Variability in Man at Various Ages.

\begin{tabular}{c|c|c}
\hline Age (yrs.). & Height $C$. & Weight $C$. \\
\hline 0 & $6 \cdot 5$ & $15 \cdot 66$ \\
5 & $4 \cdot 1$ & $11 \cdot 5$ \\
10 & $4 \cdot 3$ & $11 \cdot 6$ \\
15 & $5 \cdot 5$ & $15 \cdot 3$ \\
20 & $3 \cdot 6$ & $10 \cdot 8$ \\
\hline
\end{tabular}

From this, we see that the coefficient of variability tends to decrease when the rate of growth decreases and tends to increase again when rapid growth restarts in the "teens."

(b) Sex introduces a phase difference in the rate of growth. Girls run through the various phenomena of growth at a more rapid rate than boys.

(c) Difference in race, even under similar climatic conditions, has a profound effect on the final result of growth-i.e. on total stature, weight, form, etc.-but seems to have little or no effect

B. B. 
on the rate of growth. The little Jap increases in size year by year at the same rate as the tall Norwegian. The rate of growth is a specific phenomenon governed by factors deep rooted in the composition of the organism.

\section{External Factors.}

Quite apart from these more or less normal variations due mainly to hereditary influences, there are various external factors which have a modifying effect on the rate and amount of growth.

(d) Temperature. As we have seen previously, all chemical and physical reactions respond to alterations in temperature by an alteration in velocity. In the terminology of van't Hoff, it may be said that if $x$ is the temperature coefficient of a reaction, and the temperature of the reacting mass is raised $n$ degrees, the consequent alteration in velocity will be as $x^{n}$. Usually the interval taken (i.e. $n)$ is $10^{\circ} \mathrm{C}$. and $x$ is written as $Q_{10}$. For most chemical reactions $Q_{10}$ is $=2$. This may be taken to mcan that for an increase of temperature of $10^{\circ} \mathrm{C}$. the velocity of the reaction will be doubled. Van't Hoff noticed that, at low temperatures, very high temperature coefficients were obtained-in some cases $Q_{10}$ reached the value of 5 or 6 . Most physical reactions, as we have seen, differ from most chemical reactions in having a negative temperature coefficient, i.e. their rate is decreased by an increase of temperature. The various reactions which are manifested as growth are some chemical and some physical, and it is, therefore, somewhat difficult to apply the van't Hoff law to this phenomenon. Moreover, as pointed out in the earlier pages, Errera extended the principle of Le Chatelier by stating thatevery physiological process causing change, by its very action, set in being other reactions to inhibit change. It is, therefore, a difficult matter to interpret the figures obtained for the influence of temperature on the velocity of growth in animals.

Hertwig's classical work on the rate of growth of the tadpole illustrates the type of result got in this line of research. He found, for instance, that at $10^{\circ} \mathrm{C}$. the tadpole took 6.5 days to reach the same stage of development that at $20^{\circ}$ would have taken two days, i.e. the two rates are as $6 \cdot 5 / 2=3 \cdot 25$. Using the equation given above and putting $n=10$,

i.e.

Therefore and

$$
\begin{aligned}
x^{10} & =3 \cdot 25, \\
10 \log x & =\log 3 \cdot 25=0 \cdot 5119 .
\end{aligned}
$$$$
\log x=0 \cdot 05119 \text {, }
$$$$
x=1 \cdot 125 \text {. }
$$ 
The temperature coefficient for the development of the tadpole is thus $\left(Q_{10}\right)=1 \cdot 12$. That is to say, if it takes $t$ days at a certain temperature $\theta^{\circ}$ (between $10^{\circ}$ and $20^{\circ}$ ), for a certain amount of growth to take place, then it will take $t \times 1 \cdot 12^{n}$ days when the temperature has fallen to $\theta-n^{\circ} \mathrm{C}$.

(e) Climate. The various meteorological conditions-temperature, relative humidity, nature of soil, etc., which are all included under the term climate-undoubtedly exereise an influence on animal and vegetable growth. The effect of relative humidity on plant growth has been exhaustively studied and conclusions have been drawn as to the concentration of moisture at each temperature which best promotes the growth of specified plants. It is more difficult to get statistics correlating animal growth with the various climatic factors. In order to study biological problems like this experimentally, one must have the power of altering the component factors one at a time and noting the results.

$(f)$ Seasonal variation. Indubitable evidenee is available to show that the growth-rate of the lower animals is subject to seasonal alterations. There are indications that positive and negative variations occur in man in summer and winter respectively.

\section{TABLE LXXIV.}

Growth in Height of German Military Cadets in Half Yearly Periods. (Daffner.)

\begin{tabular}{c|c|c|c}
\hline & & \multicolumn{2}{|c}{ Increment in cm. } \\
\cline { 2 - 3 } Number observed. & Age. & Winter, 6 months. & Summer, 6 months. \\
\hline 12 & $11-12$ & $1 \cdot 6$ & $2 \cdot 3$ \\
80 & $12-13$ & $1 \cdot 5$ & $2 \cdot 9$ \\
146 & $13-14$ & $2 \cdot 0$ & $3 \cdot 0$ \\
162 & $14-15$ & $2 \cdot 5$ & $3 \cdot 5$ \\
162 & $15-16$ & $2 \cdot 3$ & $3 \cdot 0$ \\
150 & $16-17$ & $1 \cdot 9$ & $2 \cdot 3$ \\
82 & $17-18$ & $1 \cdot 2$ & $1 \cdot 5$ \\
22 & $18-19$ & $0 \cdot 8$ & $0 \cdot 9$ \\
6 & $19-20$ & $0 \cdot 4$ & $0 \cdot 4$ \\
\hline
\end{tabular}

Other investigations (West. Point, Sing-Sing, ete.) do not yield such a marked seasonal variation.

(g) Diurnal variations. Both weight and height vary in the course of 24 hours. The weight is lowest in the morning before 
breakfast, and is highest after supper in the evening. This may be accounted for by the faet that the weight of food eaten is greatcr than the weight of excreta. On the other hand, stature decreases during the day by from 1 to $3 \mathrm{~cm}$. This trifling shortening is attributed to compression of the intervertebral discs, curving of the spine and depression of the arch of the foot. Measurements for comparative purposes should, therefore, always be taken at the same time of the day-e.g. before breakfast.

(h) Nutrition. It is obvious that, if the animal does not get an adequate supply of the material to be built into tissuc, and of the energy necessary for these processes, the work will be done slowly and badly. In man at least, this only applies to increase in girth and weight. Growth in stature seems to bc specific and is almost independent of the quality and quantity of the food available. In the lower animals, while decrease in growth is conspicuous in underfed animals, one may also detect a clear falling off in the rate of increase of length (cf. Table LXXV.).

\section{TABLE LXXV.}

Comparative Weights and Lengths of Full Fed and UNDERFED RATS.

\begin{tabular}{c|c|c|c|c}
\hline \multirow{2}{*}{ Age (weeks). } & \multicolumn{2}{|c|}{ Length of body. } & \multicolumn{2}{c}{ Weight. } \\
\cline { 2 - 3 } & Full fed. & Underfed. & Full fed. & Underfed. \\
\cline { 2 - 4 } & $48 \mathrm{~mm}$. & 48 & $5 \cdot 4 \mathrm{gm}$. & $5 \cdot 4 \mathrm{gm}$. \\
6 & 128 & 98 & 42 & 24 \\
10 & 173 & 100 & 150 & 25 \\
\hline
\end{tabular}

The underfed rats were given food of just sufficient energy content to provide for their maintenance.

It is well known that quite apart from its energy content, food for growing animals must have certain of the amino aeids in its make up. These are the building stones or units of which the complete organism is constructed. It has been shown that if animals are deprived, say, of the amino acid lysin, their growth is inhibited. On the addition of this amino aeid to their diet, not only is growth restarted but leeway is made up and a normal growth is produced.

Certain much studied but little known accessory factors are absolutely essential constituents of the dict of the growing child. Of their ehemistry a little is known-of their physics or of the mechanism of their action, nothing positive ean be said. 
(i) Social position. The children of the well-to-do are generally markedly heavier and slightly taller than those of the working classes. Quite apart from any possible underfeeding of the latter, one must take into account the more or less sheltered life of the former and their freedom from those influences which tend to put the burdens and responsibilities of the adult on the child of the lower classes at a comparatively early age.

$(j)$ Endocrinetes. Considering the factors which influence the rate of growth, and keeping well in mind the unthinkable complexity of the polyphase solution of colloids and crystalloids composing the animal body, one can hardly be surprised that so little is known of the mechanism of growth. In some way, the various alterations in size and shape are interrelated and regulated through the blood and through the nervous system, by various secretions from endocrine organs. Growth in length is associated with the secretion of the pituitary gland. Any alteration in this gland causes alteration in the performance of other endocrine organs, e.g. the gonads and thyreoid. The growth of cartilage and bone are profoundly modified by alterations in the output of the thyreoid gland, while the gonads, and in early life, the thymus, control both growth and development, again by processes of which the mechanism, from a physico-chemical standpoint, is quite unknown.

\section{The Energy of Growth.}

It is generally believed that young animals require much food because they are growing. That this is not quite correct has been shown in Chap. XXXI., where we saw that the young animal, because of its large surface compared to its mass, lost heat most rapidly. To prove this we need only examine the metabolic balance sheet of the child. Camerer gives the following composition of a new born child (in grams) :

$\begin{array}{ccc}\text { Total weight. } & \text { Protein. } & \text { Fat. } \\ 2820 & 320 & 348\end{array}$

Now, as we have seen, in 180 days the child doubles its weight. It does not, however, do so by adding equal quantities of the material already present. In a child 180 days old, weighing 5600 grams, there are 790 grams of protein and 733 grams of fat. Thus $\mathbf{4 7 0}$ grams of protein and $\mathbf{3 8 5}$ grams of fat are added. In calories that gives $470 \times 5 \cdot 3=2491$ cals. $+385 \times 9 \cdot 3=3580 \cdot 5$ cals. = a total of 6071.5 calories for the period, or about 35 calories 
per day. A child of that agc has an intake on the average of about 500 cals. per day. That is, the energy used for growth amounts to about 7 per cent. of the total cnergy intake.

It has been calculated that each gram of infant's body substance has a value of 1.87 cals. Thus, if the child adds 20 grams a day, it "fixes" $20 \times 1 \cdot 87=37 \cdot 4$ calories per day, a result closely approximating to that just given.

Rubner has formulated the following law regarding the energy of growth.

Law of constant energy consumption. "The number of calories required to double the weight of a new born animal of all species (except man) is practically the same in spite of the enormous differences in time taken in attaining the double weight." Analysis has shown that each kilogram of body substance contains about 113 grams of protein and 120 grams of fat having an energy value of 1726 calories. Experiment has shown that in building this up the animal uses about 4800 calories. Man is an exception and requires six times the amount.

The growth quotient is the percentage of the energy intake which is "fixed" in the animal tissues. It is about $36\left(\frac{\mathbf{1 7 2 6}}{48}\right)$ for" all animals except man, who is able to "fix" only 6 per cent. of his energy intake.

The question now arises as to why growth stops. If it is an autocatalytic reaction, growth should stop when the process is balanced, i.e. when anabolism and catabolism mathematically cancel one another. According to Loeb, this happens when the organism has reached a certain size, or a certain number of cells have been formed. Rubner's second law, that of length of life, is suggestive rather of the cessation of positive growth after the cell had expended a certain amount of energy. It is certain that if growth is inhibited during a certain period, i.e. if energy which would normally have been expended on building up tissue is not used for this purpose, the whole "growing time" may be prolonged.

The healing of a wound, the regeneration of tissues and the growth of tumours, etc., bear a close resemblance to animal growth as a whole. They may be modified by the same factors, and investigation of the various processes involved has shed considerable light on the mechanics of growth.

Leo Loeb and his co-workers have made an extensive study of the healing of a skin wound. They found that if the skin is 
removed from any spot, epidermal cells from the edge of the wound creep upon the denuded spot and form a covering layera surface-tension phenomenon. The stretching of the contents of the surrounding cells so produced, causes a rapid series of cell divisions, i.e. growth under stimulation of stress takes place (Chap. XVI.). That the cause of the increased cell division is the stretching of the cells is borne out by the fact that the larger the area to be covered (within limits) the greater is the tension and the more rapid the process of forming a new skin. When the skin is formed and the internal pressure is altered from one of stretching to one of compression due to the crowding of the proliferating cells, growth slows down to normal. It is noteworthy that, before this return to a normal rate of cell division can take place, distinct pressure must be exerted by the epithelial cells on one another, i.e. excessive formation of epithelial cells occurs. Is it possible, from this and similar experiments, to consider that cell pressure is one of the limiting factors in growth?

There are, as we have seen, two main epochs of growth, each followed by a slowing down of velocity. In the first case, in early life, the slowing down is temporary, This may be correlated with (a) the fact that the increase in weight during this period is due in great part to a deposition of fat which is absorbed during the subsequent period of slower growth, and $(b)$ to the changes in glandular functions, etc., which usher in the second period of very rapid growth. This final period is followed by a complete arrest of positive growth. The increased weight is due to muscle and organ building-protein is laid on and the percentage of water decreases. No further change resulting in increased metabolic activity takes place after this. Cell pressure now developed is not relieved.

The physical chemistry of negative growth will be considered in a later chapter.

\section{Growth and Form.}

One cannot leave this subject without a brief reference to the relationship existing between growth and form. Form is determined by the specific rate of growth in various directions, i.e. as D'Arcy 'Thompson puts it, form is a function of time. If a spherical organism grew symmetrically its form would not alter, but because of its complexity, growth is not uniform in all directions. There are structural differences in protoplasm which set up unequal resistances to growth. One part may be more viscous 
than another, or may have a higher surface tension and so on. Although it has been pointed out that the presence of external resistance acts as a stimulus to growth, it has also been said that internal resistance arrests growth.

Bohn propounds the following four laws relating growth and form in plants, and they may be applied to animals with some measure of justification :

(1) Law of Vectors. A vector in distinction from a scalar phenomenon is one representable graphically by a line of known direction and definite length, i.e. a conception of a change of magnitude with time. "The principal forces of growth are directed along axes offering a geometrical disposition."

(2) Law of Depolarisation. "When growth becomes exaggerated in a certain direction, a force is developed in the living organism which tends to oppose the growth, "i.e. Errera's Rule, q.v., or the ordinary law of balanced reaction.

(3) Law of Axial Repulsions. "When secondary axes are borne on the principal axis of a plant or animal, a reciprocal repulsive force is developed between the principal axis and each secondary axis."

(4) Law of Compensation. When an axis branches in one plane there is a tendency for the re-establishment of the destroyed bilateral symmetry."

To summarise :

1. Growth is a balanced reaction having the mature organism for an end point.

2. The organism grows at a definite rate which is, at any moment, proportional to the amount of growth yet to be made.

3. The rate of growth is not uniform throughout but is specific for each epoch of life.

4. The growth in each epoch proceeds at a rate corresponding to an autocatalytic reaction.

5. Various factors which influence chemical and physicochemical reactions, influence the rate of growth.

6. If the rate of growth is arrested in any epoch, the length of time spent in that cycle is prolonged-so that the amount of growth characteristic of that epoch is accomplished.

7. Form is a function of growth. 


\section{CHAPTER XXXV}

\section{DEVELOPMEN'T}

"... I compared the cell-growth, by which Nature builds up a plant or an animal, to the glass-blower's similar mode of beginning,-always with a hollow sphere, or vesicle, whatever he is going to make."

Oliver Wendell Holmes.

OCCURRING simultaneously with increase in size, are changes in external form and internal structure-the organism develops. Mainly through the brilliant researches of J. Loeb and his school, some light has been thrown on this seemingly mysterious and apparently inexplicable process. The changes taking place are most readily perceived when the transparent eggs of the echinoderms are used as the material on which to experiment, and consequently, our ideas of the processes involved in mammalian development are largely derived from the study of processes in the lower aquatic animals which may or may not be quite analogous.

The unfertilised ovum is a moribund body which disintegrates more or less rapidly. If, bcfore disintegrative processes have become apparent, the egg undergoes fertilisation, destruction is stayed. The fertilised egg develops, grows and becomes differentiated into various structures. This process of differentiation of protoplasm is an orderly one, taking place always in the same manner and being modified always by the same conditions.

On the entry of the spermatozoön, some change in the free energy of the egg must take place. The egg is no longer static but becomes endowed with dynamic force. In order to discover the underlying physico-chemical change, Loeb attempted to induce development of unfertilised eggs by alteration of the environmental conditions. No change in a system in equilibrium can take place unless the relative amount or incidence of the free energy of the environment is first altered. The two series of 
changes-external and internal-are cause and effect. This is merely a restatement of the Law of Inertia. The entry of the spermatozoön alters the balance of free energy betwcen egg and environment. Loeb attempted to bring about the same result by altering the free energy balance between environment and egg. He found that two separate and distinct changes took place after fertilisation, viz., membrane formation and development. These involve totally different physico-chemical reactions. Membrane formation is not followed necessarily by development.

\section{Membrane Formation.}

Loeb found that all those substances or agencies which can bring about haemolysis (Chap. XXI., p. 244) also induce membrane formation. The best agent for this purpose is dilute butyric acid. Immersion of sea-urchins' eggs (unfertilised) in sea-water containing about 5 per cent. of $N / 10$ butyric acid for two to four minutes brings about typical membrane formation. 'This membrane is tough and is separated from the egg-substance by a layer of more fluid material.

Examination of the performance of the other cytolytic substances makes manifest the mechanism of the change brought about by their agency, and its similarity to that caused by butyric acid or other fatty acid. The former all lead to the abnormal production of acids in living protoplasm, and these acids produce, as a secondary effect, the physico-chemical change now under consideration. These cytolytic substances are, as we saw in Chap. VIII., just those substances which break emulsions. Egg protoplasm is an emulsion very rich in fat, and it is obvious that the breaking of such an emulsion would lead to the setting free of protein and would probably change the nature of the complex from a water-(and protein)-in-oil type to an oil-in-water(and protein) type. The protein and lipoids carried to the surface and coming in contact with sea-water would readily be adsorbed and form a membrane (Chap. X.).

Eggs undergoing artificial parthenogenesis quickly show disintegrative changes unless means are taken to confine the cytolytic effect to the surface. This is provided for in some cases (e.g. starfish and certain annelids) by the specific nature of the proteins in the cortical layer. The diffusion of the acid causes them to alter in electrical state. They imbibe water, swell up and develop normally. 


\section{Exosmosis.}

In most cases, however, unless a second alteration is made in the bathing medium, the egg will either not develop at all, or will die at some intermediate stage. It is known that after fertilisation, the electrical conductivity of the egg is increased for fifteen minutes or so. This may be interpreted as a sign of increased permeability of the membrane to surrounding salts, or it may, with equal justice, be accounted for by a withdrawal of water with a consequent increase in the concentration of electrolytes. During this period of increased electrical conductivity, the eggs readily undergo plasmolysis if placed in a solution of cane sugar. Unfertilised eggs, of course, do not show alterations at this early stage in electrical conductivity nor are they easily plasmolysed. This may be taken as a confirmation of the second hypothesis, viz., that water is removed by exosmosis and, consequently, the concentration of electrolytes in the egg is increased. Whatever be the actual physico-chemical process brought about by the entrance of the spermatozoön, the result has been imitated by simple physico-chemical means.

If, after removal from the butyric acid bath (or other cytolytic agency), the egg is placed in hypertonic sea-water for about halfan-hour and then returned to its normal environment, it will, in all likelihood, reach maturity. That is, not only does artificial membrane formation initiate the processes of development but it starts, at the same time, processes which ultimately lead to the dissolution of the organism.

These latter activities may be, for a time, suspended, by a short exposure to a hypertonic solution.

Loeb has proved that the withdrawal of water is merely the trigger setting off a series of chemical as well as physical changes. Attention has been repeatedly drawn in previous pages to the fact that while most physical processes have a low or even a negative temperature coefficient, most chemical reactions have a high $\left(Q_{10}=2\right.$ or more) temperature coefficient. This worker found that, at a temperature of $5^{\circ} \mathrm{C}$., the eggs had to remain in the hypertonic solution for at least 210 minutes. The time of exposure was decreased to 40 minutes when the temperature of the solution was raised to $15^{\circ}$. Therefore, the temperature coefficient for this process is

$$
2 \frac{10}{40}, \text { i.e. } Q_{10}=5 \text {. }
$$

Hence, superimposed on the physical process of exosmosis are secondary chemical reactions initiated by it. 
Attempts have been made to determine what part the spermatozoön plays in the process of fertilisation. Brailsford Robertson has extracted a substance oöcytin from the testicles of the seaurchin which produces membrane formation. The question then arises-"Is this substance a catalyst speeding up some slow change or does it counteract some obstacle to development ?" To the first part of the question a negative answer can be given The velocity of the process of development is not catalytic. It does not follow Schütz's law and vary in velocity with the square root of the concentration. If two spermatozoa are caused to enter an ovum, the rate of segmentation should increase by 1.4 (i.e. $\sqrt{2}$ ) times, if the process were catalytic. The rate, as a matter of fact, is unaltered by the introduction of additional spermatozoa. Therefore, the spermatozoön does not contain a catalyst for developmental processes.

Loeb is inclined to believe that the spermatozoön removes from the egg a substance or condition which inhibits or prevents the process of development.

On the other hand, it is conceivable that the entry of the spermatozoön increases the free energy of the now fertilised ovum. The potential energy of the system cannot be utilised without the employment of a small quantity of free energy. This quantity of free energy may be extraordinarily small as long as it is sufficient to start the series of reactions which once started are autocatalytic.

One result of the entrance of an effective spermatozoön into an ovum is an accelcration of the processes of oxidation, i.e. metabolism begins, and the various phases of development can be followed by the same calorimetric methods (direct and indirect) adopted in the study of the energy exchanges of the mature organism (see over, p. 386).

\section{Differentiation.}

Cell division is the most general of the specific functions of living protoplasm and it is the basis underlying the differentiation of the comparatively simple structure of the egg into a more complex organism. The division of a cell is a necessary consequence of its increase in volume. 'The metabolic activity of the cell is a function of its effective surface, i.e. its surface must be of such a size compared with its volume that an adequate supply of oxygen can reach the centre of the cell and that all the byproducts of cellular activity can be eliminated with sufficient rapidity. A freely suspended unicellular animal is spherical. 
Its surface-volume ratio is $\mathbf{3} / \mathbf{1}$. Doubling the radius increases the surface four times while incrcasing the volume eight times, i.e. $S / V=\frac{3}{2}$, i.e. the effective surface has been halved. The immediate result of decreasing the specific surface to a value below the minimal effective value is to decrease the supply of oxygen to the centre of the cell and to cause a heaping up of carbon-dioxide and other products of metabolic activity. This has, at least, two effects(a) The process of development is retarded (Law of balanced reactions), (b) The protoplasm becomes acid. The effect of acid on an alkaline gel-emulsion has already been considered and may possibly be the cause of cell division. We have, however, to inquire into the reason for the symmetrical division of the cell.

Some cells divide directly without showing mitotic figures. After a change in the distribution of free energy manifested by a division of the nucleolus into two separate nucleoli, the whole nucleus is divided equally into two daughter nuclei. This separation is followed by the formation of a cell membrane between the two nuclei dividing the entire cell into two equal and similar portions.

Usually, however, cell division is accompanied by a complex but regular series of changes in the distribution of the nuclear chromatin. These mitotic or karyokinetic changes are dependent on the bipolarity of the cell. Morphologically the polarity of a cell refers to a symmetry of visible structure about a particular axis. For instance, a line, drawn through the centres of nucleus and centrosome, symmetrically divides a typical resting cell and may be considered as its axis of polarity. This symmetry of form is an indication or expression of a symmetry of free energy.

In a bipolar cell there are two "poles" or centres of force, and the axis of symmetry must divide the field of force equally about these poles.

Typical fields of force may be plotted by scattering iron filings on a sheet of glass resting on the pole (monopolar field) or poles (bipolar field) of a magnet. The filings set them little filing becoming polarised and exerting an influence on adjacent filings. (This " carding out" under the influence of stress was dealt with in Chap. XVI.) In addition to the strength of the field and the direction of the force, the movement of particles under its influence depends on the friction of the contiguous matter and on the chemical nature of the particles themselves. Friction prevents the filings from collecting in mass round the poles while the specific inductive capacity (p. 52) or "permeability" of the particles is a measure of the influence exerted by the "force" on the particle. In the case of magnetic force, the specific inductive capacity of iron is high while that of bismuth is low. Iron filings will, therefore, be 
attracted towards the poles and will tend to lie on the lines of stress. On the other hand, bismuth filings are polarised in a sense opposite to that of the adjacent field. They are forced by the incidence of stress to move (or because of friction, to tend to move) from the stronger to the weaker parts of the field and thus take up positions as far from the poles as possible. In gencral, a body placed in a field of force will tend to move towards regions of greater or less intensity of stress according as its "permeability" to the particular form of energy in question is greater or less than that of the surrounding medium.

The introduction of an aggregate of high permeability into the field of force makes considerable changes in its configuration. Suppose a small heap of filings were placed in the magnetic field already referred to, so that it lay somewhat out of the interpolar axis but on the equatorial axis, the result would be to provide an "easier path" for the lines of force. It is obvious that, within certain limits, a longer path through a more permeable mass would be more advantageous than a shorter path through a less permeable medium, and so many of the lines of force would be "shortcircuited "through the heap of filings. If, moreover, the heap of filings were free to move, they would be drawn en masse into the field of force until a point of equilibrium was reached. This resting place would depend for its position on the relative "permeability" of the filings in heap and the filings distributed over the field.

We have dealt with a magnetic field of force because it is easy to demonstrate and may be readily modified experimentally, but our remarks are applicable to any field of force. A simple experiment, due to Leduc, shows that the lines of stress set up by diffusion may be made manifest. A layer of salt solution is spread over a flat sheet of clean smooth glass, and on top of this is placed a small drop of indian ink or blood. A drop of a hypertonic solution of common salt is placed on either side of this central drop. In a short time the pigment seems drawn out into threads ( $\mu$ iros) stretching between the centres of the two salt drops, so making a figure exactly the same as that formed by iron filings under bipolar magnetic influence.

The Bjerknes phenomenon demonstrates the applicability of this treatment to the stresses and strains set up in a fluid as the result of movement in it. Bodies synchronously. vibrating or pulsating in a liquid medium attract or repel one another according as their oscillations are identical or opposite in phase. That is, a bipolar field exists which may have, like a magnetic field, similar or dissimilar poles. In such a field of force currents are set up in the fluid (hydrodynamic lines of force) and any particles in suspension, if lighter than the fluid, act like the iron filings, if heavier like the bismuth filings above. Moreover, the lines of force set up by identically pulsating (attractive) bodies are exactly similar to those produced by similar (repulsive) magnetic poles, and vice versâ.

The first stage in the development of a cell consists in the division of the centrosome into two equal parts which draw away from one another. A field of force is set up between the two centrosomes and threads of those cell constitucnts which are more "permeable" to the form of energy existing, are carded by the incident stress into a figure closely resembling those 
mentioned above. On the "outer" side of the centrosomes can be seen starlike radiations (astral rays) recognisable as indications of incomplete lines of force which run externally to those stronger interpolar lines which eonstitute the spindle.

The nucleus is composed of material of fairly high " permeability" and, therefore, may be expected to travel towards the equatorial axis. This is found to be so. In some cases the nueleus is wholly, and in other instanees it is only partially drawn into the field between the centrosomes. Differences, too, exist in the relative development of asters and spindle which are capable of explanation by analogy to the magnetic model. If, in the experiment with iron filings, the ficld were surrounded by an iron ring, the majority of the lines of force would pass round by the ring. That is, the interpolar lines would be slight and the extra-polar rays would be heavy. Similarly, we may correlate a mitotic figure having good astral rays and a poor spindle with a marked "permeability" of the surface of the eell.

One would be entering the realms of pure hypothesis if physicochemical interpretations were attempted of the various stages of karyokinesis. The constitution of protoplasm-vaguely stated as an emulsion of various lipoids in a complex protein-water emulsoid with various crystalloids in solution or adsorbed, presents excellcnt opportunities for the theorist to draw parallels between certain manifestations of force in living things and in dead matter. The mechanisms underlying these processes are as yet unknown. The processes themselves, like all other changes in matter, are accompanied by changes in electrical potential. These changes are measurable and are not constant but fluetuate (even reversing in direction) at epochs coinciding with phases of development.

We are now in a position to consider the actual cause of eell division. To state why the cell must divide-to argue from a surface-volume ratio-is to presuppose a cell conseiousness or to postulate an external direeting force-both alternatives being without the domain of physics. The use of the final eause or the argument that division is of obvious advantage to the cell, sheds no light on the mechanism involved. Consideration must be given to the forces at work in the cell. Further, experiments such as the mueh quoted one of Brailsford Robertson, where an oil drop is divided by the imposition on it of a thread soaked in alkali, are not very illuminating. The energy of cell division is not external to the cell but depends entirely on a redistribution of forces inside the cell. 
We have seen that, as a result of the diminution of specific surface with growth, metabolic processes are retarded and acid by-products tend to accumulate. It is obvious that at the centre of the cell, i.e. at the region most distant from the surface, these changes due to maloxidation will be most marked. 'This decrease in metabolism is accentuated by the fact that the nucleus which is always in the centre of the field of energy of the cell and usually near the centre of the cell material, is the seat of the most rapid oxidation changes in the cell. It will, therefore, show the effects of the lack of oxygen at a very early stage. It follows from this, that the intrinsic energy of the fluid at the centre will either suffer an increase or a decrease. Everything points to the latter as occurring. Now, as surface tension is, as far as cell problems are concerned, a relative magnitude, we may say that the tension of the superficial layer of the cell which, on account of its proximity to the surface, remains practically normal, increases in close correspondence with the decrease of intrinsic energy of the central portion. This increase is still further accentuated by the increase in the relative " permeability" to energy of the surface of the cell, which as we have seen causes the development of radial lines of force. The high tension of the surface of the egg operating on the central region of low intrinsic energy causes the material in the centre to be dispersed into the cytoplasm of the cell. These dispersed particles first set themselves in a neutral position, i.e. on the plane of segmentation-cf. iron filings in a magnetic field of force between two similar poles. The position of the nucleus determines the first plane of segmentation, since apparently nuclear division precedes the visible division of the cytoplasm of the egg. In other words, the plane of nuclear division becomes the plane of segmentation of the whole cell. The nuclear matter as manifested by the chromosomes, gradually sets in the lines of force between the centrosomes and slowly separates into two equal portions which ultimately form the two nuclei. Hence wc have a spherical cell which is capable of division into two exactly similar portions. It is, therefore, manifest that cach potential segment, because of this similarity of structure and energy content, will repel the other half and, according to the ordinary laws of stresses and strains, will cause division in the plane of symmetry. The high tension of the cell surfaces will ensure the continuity of the surface-membrane of each of the daughter cells. These daughter cells adhere to one another but do not coalesce. From this it is inferred that the cell membrane is insoluble in the 
surrounding medium and in the cytoplasm as well. (It has been proved experimentally that hanging drops coalesce if their surface films are soluble in the drops themselves, while they separate if the film is soluble in the surrounding medium.)

After the second segmentation we have four cells each a diminutive whole egg of identical composition and each capable of developing into an embryo.

The third division brings about an unequal division of the ccll material. Three zones can be recognised in all the cells up to this stage. These three zones, viz. $(A)$ a clear cap at one pole; $(B)$ a zone with a pigmented surface; and $(C)$ a large unpigmented zone, each give rise to a definite part of the developed egg. 'Thus up to the third division every constituent of the original egg is present in the segments in the original proportions. The third division is equatorial and cleaves the cellmass unequally. Four cells are formed containing little or no $A$, and the other four cells contain only a trace of $C$. These latter form at the next division four very small cells called micromeres mostly of $A$, and four larger pigmented cells (intestinal cells). Eight large cells (ectodermal cells) are formed from material which is mostly $C$, but contains some $B$.

The ecll division proceeds and the tiny cells all gather at the surface of the egg-surface adsorption. Soon after the tenth division, when the number of cells is theoretically 1024, the processes of invagination and differentiation begin.

Organo-genesis. Various parts of the egg give rise to various organs. Always the same organ is formed from the same part. This means that the apparently homogeneous protoplasm is heterogeneous, i.e. contains colloidal matter in different parts of maybe a specific chemical nature - ccrtainly in a specific physical state. One cannot as yet say why ccrtain cells grow in certain directions or why certain organs should be evolved from certain cells and only from these cells, but certain mathematical and physical phenomena have been observed in this connection.

If one postulates, in the first instance, the presence in the egg of regions denser than others, for example, one can imagine as a result unequal growth in various parts. Unequal growth sets up strain; and strain, as we saw in Chap. XVI., influences the external form and internal structure of organs. This can be demonstrated experimentally by building an artificial blastula of little pellets of dough containing different quantities of yeast. The unequal growth of the various pellets will set up mutual 
strains and produce a considerable folding and distortion of the whole (Roux).

Both the eirculatory systems and the alimentary c: val. are evolved from tubular structures, and it is suggestive to find that certain phenomena of development are mirrored in inorgurric tubes. For instance, a thin test-tube very often cracks in a spiral way. The more homogeneous and isotropic be the glass the more ever and regular will be the spiral. That is, the crack tends to follow the shortest course on the surface of the tube between the point of origin of the crack and a point diametrically opposite-a ring formation. Generally, however, the ring winds into a helicoid form and is continued. This helicoid geodetic is shown in the coil which stiffens the tracheal tubes of an insect and is apparent in the growth of the intestine. Carey plotted the positions of the cells showing mitosis in the intestinal epithelium at various levels. He found that they formed a left-handed helix (5 per cent. right handed) having its base towards the rectum and its apex towards the ileocaecal valve. Further, the mitotic figures were few near the base and increased in number as the apex was approached. From this he inferred that growth was from below upwards and followed a helicoid path.

One must consider that a definite mechanical action is due to incidence of stress and that similar results under similar conditions are good evidence of the imposition of similar forces. The homogeneous hollow glass tube splits spirally, which can only be interpreted as the spiral path being the line of least resistance in a hollow cylinder. We can apply this with justice to the growth of intestinal epithclium.

A growth tension applied helically must lead to torsion in a structure like the intestine where there are layers of material growing at different rates, and one could present a very plausible diagram of forces to explain the twisting and looping of the gut. Similarly and inversely, dilatation, e.g. stomach formation, would produce alterations in the direction of the lines of growth leading to alteration in the arrangement, say, of the muscular fibres.

\section{Energy of Development.}

Interesting observations have been made of the amount of energy used by a developing organism. Tangl determined the energy content of fresh laid eggs and compared that amount with the energy value of the embryo and yolk found in the shell at the moment of hatching. He reported that each gram of chick 
had been formed at the eost of the energy represented by 658 small ealories.

Further, 35 per cent. (32 calories) of the total ehemical energy of the fresh egg is deposited in the tissues of the young embryo; 48 per cent. ( 44 calories) is found to a large extent in the abdomen of the ehick as a store of potential energy to be drawn upon during early life; while the balance-17 per cent. (16 calories)-has been spent in the development of the chick. That is, about one-sixth of the total energy of a hen's cgg is required for the work of elaboration of the tissues of the chick, which tissues contain onethird of the original energy of the egg. 


\section{CHAPTER XXXVI}

\section{DEATH AND DISSOLUTION}

"It is easy to show that these differences in temperature which are required to secure organic liquids from ultimate ehange depend exclusively upon the state of the liquids, their nature and above all upon the conditions which affect their neutrality whether towards acids or bases." PAsteur.

IT has been said that death is a necessary stage in the process of development. Rubner considers that death takes place naturally after the organism has utilised a certain amount of energy per kilo. His second law, that of "length of life," is as follows, "The amount of energy consumed in a kilogram of living protoplasm from maturity to death is constant for all animals (and equals 191,600 cals.), except in the case of man, who uses up four times as much." Be that as it may, and no adequate proof of its truth is offered, it does not serve as a guide to any reasonable physicochemical explanation of the process. An inorganic picce of machinery will last an indefinite time provided it is kept in repair and parts are renewed before they have become too much worn. As long as suitable energy, etc., is supplied the machine will run. The human machine, with its large repair staff always "on the spot" and with plentiful supplies of material and energy, begins to show signs of failure after 35 or 40 years of life. The curve of growth, development and efficiency each shows a maximum and then decline sets in.

Length of life is specific for each species and secms to be related to the time taken by the animal to reach scxual maturity. With that consummation, changes take place in the whole organism leading, according to Loeb following Metchnikoff, to the (unavoidable) formation in the body of some toxin or, as more modern work suggests, to the inhibition of the formation of an endocrine secretion.

Death is followed by a morc or less rapid dissolution of the body, a process whose mechanism is more easily followed. The lack 
of oxygen in the tissues leads, as we have seen, to the accumulation of acids. This, after death of the organism, occurs in every tissue, but it may also be demonstrated in cases where a particular organ or region of the body is deprived of its quota of oxygen. By the administration of certain drugs, e.g. anaesthetics, heavy metals, phosphorus, potassium cyanide, oxidation processes are inhibited and acids accumulate. The first visible change after the inhibition of oxidation-general or local-is a "softening" of the tissues concerned. If water is available the involved cells swell and become cloudy accompanied or followed by a "yellowing " and the appearance of fat globules. The cells then tend to shrink and liquefy. These changes can be mimicked by the addition of a trace of acid to an oil-in-protein emulsion. The cmulsifying colloidal proteins, under the influence of acid, develop an increased capacity for the imbibition of water. If water is available, the proteins swell and become extremely dilute and the emulsion is broken. The "graying" or cloudiness is due to the presence of colloids (globulins ?) which become less hydrated in an acid solution. The hydration of the one class of colloids and the dehydration of the other class leads to "cloudy swelling."

The breaking of the emulsion sets free the fat which is present, though normally invisible, in all cells. The tissue becomes yellow, and as the pathologists say, "fatty degeneration" has become apparent. It must be understood that the fat made manifest by this process existed previously in the cell masked by its association with proteins, etc., in the emulsion. Its appearance at this stage of dissolution is not due to the conversion of protein or any other cell-constituent into fat as the name "fatty degeneration" might suggest. Careful analysis has shown that the total amount of fat in the cell has not increased.

As an emulsion has a much higher viscosity than its constituents, one might expect that the breaking of the emulsion would lead to a decrease in viscosity or softening of the tissue concerned. Further changes take place which make this loss of rigidity more marked and cause the ultimate dissolution of the protoplasm.

Almost co-incident with the cessation of respirations, the endocnzymes begin to accelerate the processes of hydrolysis of the tissues (p. 96). Under sterile and anaerobic conditions, the tissues may be converted into an almost odourless fluid - a process termed autolysis. Proteins are broken down to their constituent amino acids and, if autolysis is carricd on sufficiently long, some of these acids may be destroyed. Instead of fat, autolysed tissue contains 
fatty acids and soaps. This self-digestion is a consequence of the lack of free oxygen in the tissues, which lack, as we have scen, causes the aceumulation of acids. It has been shown that a very slight increase in hydrogen ion concentration so alters the tissue constituents that they are readily acted on by cellular enzymes.

In Chap. IX. we mentioned the interesting fact that the enzyme which hydrolyses maltose builds up another carbohydrate, isomaltose, which it is incapable of breaking down. In general, when a synthesis is brought about by an enzyme, the product is immune from being broken down by its builder. But, by the hydrating effect of acid these synthetic products are converted into isomeric forms which can be destroyed by the enzymes which originally formed them.

In addition to autolysis, micro-organisms present in the intestinal tract or otherwise entering the body from outside, play a large part in the dissolution of the organism. Putrefaction is readily distinguished from autolysis by the odour of the products of its aetion.

Just as the matcrial composing the body returns to the earth to begin anew the cycle of life-passing from soil bacteria to plant, from plant to animal and from lower to higher animalso the energy of the constituents of the body pass into the great cistern of unavailable energy, "waste heat," from which we are unable to draw supplies, but which by raising the level of the total cosmical heat energy ever so slightly, contributes to the wellbeing of all living things by raising, in imperceptible amounts, it is true, the level of metabolism. 


\section{CHAPTER XXXVII}

\section{THE EFFICIENCY OF THE ORGANISM}

By E. P. Caticart, M.D., D.Sc., F.R.S., Gardiner Professor of Chemical Physiology, University of Glasgow.

THE consideration of the efficiency (i.e. the relation of the consumption of energy in the form of fuel to the output of energy in the form of effective work) of man in the production of external work is a question not merely of great physiological but of economic importance, as this factor plays an important rôle in the assessment of an adequate diet. Physiologically we are eoneerned with the abstract problem of the conversion of food energy into work - that is, the problem is simply the relation of the increased energy output during the actual performance of muscle work to the energy expenditure of a similar period when no work is being done. In the case of industry, armies, etc., the question is plain enough, but there are many factors both psyehic and physical which qualify the answer, in other words, the types of work, the conditions under which it is performed and the personal qualifications of the performer all play an important part in the degree of efficieney with which the work is carried out. Hence it is very essential that the "net or physiological " efficiency be differentiated from the "gross, crude, or industrial" efficiency. The "net" efficiency may be defined as the value obtained by dividing the heat equivalent of the external effective muscular work by the increase in energy output of the body developed as the result of the work done. The "gross" efficiency, on the other hand, is the value obtained as the result of dividing the heat equivalent of the external effective museular work by the total energy output of the individual during the period in which the work was done. The following table will make the point clear : 
TABLE LXXVI.

\begin{tabular}{|c|c|c|c|c|c|}
\hline \multicolumn{3}{|c|}{ Heat output per min. } & \multirow{2}{*}{$\begin{array}{c}\text { Heat equivalent of } \\
\text { external muscular } \\
\text { work per min. } \\
\text { (425 Kgm. }=1 \text { Cal.). } \\
(d) .\end{array}$} & \multicolumn{2}{|c|}{ Efficiency. } \\
\hline $\begin{array}{c}\text { Work. } \\
\text { (a). }\end{array}$ & $\begin{array}{l}\text { No Work. } \\
\text { (b). }\end{array}$ & $\begin{array}{c}\text { Increasc of } \\
\text { work over no } \\
\text { work }=a-b . \\
\text { (c). }\end{array}$ & & $\begin{array}{c}\text { Gross. } \\
\frac{d \times 100}{a}\end{array}$ & $\begin{array}{c}\begin{array}{c}\text { Net. } \\
d \times 100 \\
c\end{array} . \\
.\end{array}$ \\
\hline $\begin{array}{l}\text { Cals. } \\
9 \cdot 50 \\
5 \cdot 71\end{array}$ & $\begin{array}{l}\text { Cals. } \\
3 \cdot 09 \\
1 \cdot 14\end{array}$ & $\begin{array}{l}\text { Cals. } \\
6 \cdot 41 \\
4 \cdot 57\end{array}$ & $\begin{array}{l}\text { Cals. } \\
1 \cdot 96 \\
1 \cdot 06\end{array}$ & $\begin{array}{l}\text { Per cent. } \\
20 \cdot 6 \\
18 \cdot 6\end{array}$ & $\begin{array}{l}\text { Per cent. } \\
30 \cdot 6 \\
23 \cdot 2\end{array}$ \\
\hline
\end{tabular}

It is obvious that the two efficiencies may give very different values. The gross efficiency, which is largely influenced by the amount of work performed during the day and the amount of time which is actually expended in doing work, as a physiological measure gives little or no information regarding the capacity of the human body for work, and certainly no conception of the possibilities in the way of the efficiency of the organism as a machine. The net efficiency, which is determined by the deduction of the maintenance quota from the work quota of the energy output, does give the actual increase in cost necessitated by the performance of the external muscular work and thus permits of the determination of the actual physiological efficiency of the organism.

In view of the fact that engincers and others have found it a comparatively simple matter to detcrmine the efficiency of ordinary thermo-dynamic machines by the use of a simple formula $E=\left(T_{1}-T_{2}\right) / T_{1}$, where $T_{1}$ is the absolute temperature at the source of the heat (the steam in the boiler in the case of an engine) and $T_{2}$ the temperature at the sink (the condenser of the engine), there has been a great temptation to apply the apparently almost universal rule of the Second Law of Thermodynamics to the living organism (Chap. IV.). It is, however, obvious from a very brief consideration of the above simple thermodynamic formula that the efficiency is simply a function of the difference of potential, the higher the temperature at the source and the lower the temperature at the sink the greater is the efficiency. Now the efficiency of the living organism has experimentally been shown to be high, probably over 30 per cent., a result which would necessitate an impossible difference of potential in the tissues. It is perfectly true that this difficulty has been appreciated, but it is not solved, except on paper, by positing minute points of enormously high temperature alternating with points of low temperature at intervals of a few $\mu\left(10^{-3} \mathrm{~mm}\right.$.). The mechanism 
of muscular activity, it is true, is not yet clear, but it may be stated with a considerable degrec of certainty that, whatever the type of change which takes place, all the experimental evidenee available points to the muscle not being a heat engine. The majority of workers now look upon muscle as a chemical machine which works at a relatively constant temperature:

On the purely experimental side much work has been done on the determination of the efficiency both of isolated muscle and of the body as a whole.

If the organism be considered as a whole and its efficiency determined, it is found that, although it is high, it is never as high as the results which have been obtained experimentally with isolated musele. This result is not to be wondered at when the methods of attacking the problem are considered. In the case of the isolated muscle, its position, the amount of work to be done and the mode and time of stimulation can all be accurately controlled, conditions which are, for the most part, lacking when the whole organism has to be dealt with.

Modern work has shown very considerable agreement as regards the degree of efficiency, as is shown by the following table :

\section{TABLE LXXVII.}

Gross and Net Efficiency of the Body as a Whole.

\begin{tabular}{l|l|c|c}
\hline \multirow{2}{*}{ Authority. } & \multicolumn{2}{|c}{ Efficiency. } \\
\cline { 2 - 4 } & & Gross. & \multicolumn{1}{|c}{ Net. } \\
\hline Katzenstein (1891) - - & - & $13-19 \%$ & $25 \cdot 4 \%$ \\
Sonden and Tigerstedt (1895) & - & $17 \cdot 3$ & $27 \cdot 4$ \\
Zuntz (1909) - - - & - & - & $28 \cdot 0$ \\
Benedict and Carpenter (1909) & - & $15 \cdot 0$ & $20 \cdot 6$ \\
Amar (1910) - - - & - & - & $32 \cdot 5$ \\
Benedict and Catheart (1913) & - & - & $21-33$ \\
Lindhard (1915) - - - & - & - & $25 \cdot 0$ \\
Douglas (1920) - - - & - & - & $23-26$ \\
\hline
\end{tabular}

The outstanding difficulty in the assessment of the net efficiency is the selection of the proper base line for comparison. It is immaterial whether the work done be that of marching or mountain climbing, of turning an ergostat or a bicycle ergometer, the same difficulty crops up. As the bicycle ergometer has been most frequently used in the modern experiments it will be dealt with here.

In the determination of the mechanical efficieney with this machine no less than five base lines may be used though they are 
not all of equal value. In this type of ergometer, where the work to be done can be readily altered by increasing the resistance to be overcome, it is a comparatively simple matter to devise a wide range of experiments in which the effective muscular work can be varied. The only difficulty lies in the selection of the base line. If the work standard be taken as that of the subject sitting on the bicycle performing a definite measured amount of work, in order to find the increased cost in energy caused by the performance of this work there may be subtracted :

(1) The energy expenditure during complcte rest-the ordinary basal or standard metabolism.

(2) The energy output when the subject is sitting at rest in the saddle.

(3) The energy expended when the subject is sitting on the saddle, feet on pedals and his legs are rotated by mechanical means -internal or organic work.

(4) The energy expenditure when the subject is freewheeling, i.e. overcoming the ordinary resistance of the unloaded wheel with most or all of the concomitants of work. of this type, sitting posture, internal friction of the legs, extraneous movements associated with cycle riding, etc.

(5) The energy expenditure involved in $(a)$ the performance of light work compared with that of hard work or $(b)$ the increased cost of work done at slow and high speeds using the same load in each case.

When these various base lines are utilised experimentally it is found that there is a steady increase in the degree of efficiency. The average results are as follows :

TABLE LXXVIII.

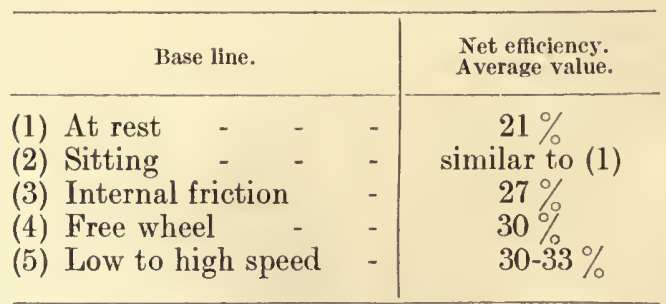

There is then a variation in the determined efficiency of approximately 10 per cent., and it is a moot question which base line should be selected. Lindhard maintains that the most reliable result is obtained when complete rest or rest in the riding position is adopted as base line, but there is much to be said in favour of 
the adoption of other base lines in which movements which play little or no part in the determination of the efficiency are eliminated. As the main object is to determine the efficiency of the body performing a definite act it has been suggested that the best result will be obtained when the various activities associated with the determination of the energy output both of the base line and of work are morc or less comparable, that is, where the extraneous muscular motions incidental to riding with weight are common to both determinations. Such a comparison is that obtained when there is a change from a moderate to a heavy load. As will be noted from the above summary of efficiencies the average efficiency under these conditions is about 30 per cent.

There is a certain amount of evidence available which would suggest that the degree of efficiency obtained varies with the groups of muscles used in performing the work. The efficiency of muscles less commonly in use than the leg muscles is somewhat lower, flexor groups may differ from extensor groups, etc. The state of training, too, probably influences, although apparently not very markedly, the degree of efficiency. And finally, some workers maintain that the efficiency may also be, to some extent, dependent on the nature of the diet. Macdonald maintains that the efficiency of muscular work is a function of body mass.

Greenwood, who has carefully analysed the data obtained by many of the workers, has come to the conclusion that although as yet no law can be formulated connecting heat production and work performance, within fairly wide ranges, simple formulae of linear regression do describe the relations subsisting between heat production, body mass and work performance, with an accuracy sufficient for such purposes as roughly computing the energetic needs of workers doing the kind of work studied.

In addition to the above-mentioned factors which influence efficiency there are certain others connected with the performance of the work itself which apparently play a determining part. These are load and speed.

Although it might be presumed that load would exercise a marked influence, such experimental work as exists tends to show that increase of load within limits does not materially influence the efficiency of the body. There is, however, a slight tendency for the work to be done more efficiently when the load is changed from a moderately heavy to a heavier one than when the change is from a light to a heavy load.

The influence of speed, that is the rate at which the work is 
done in unit time, is of much greater moment. Experimentally it has been found that the total cnergy expenditure per revolution of the pedals is constant for all speeds, but that although there is naturally an increase in the amount of the total work done, the effective muscular work per revolution deereases as the speed

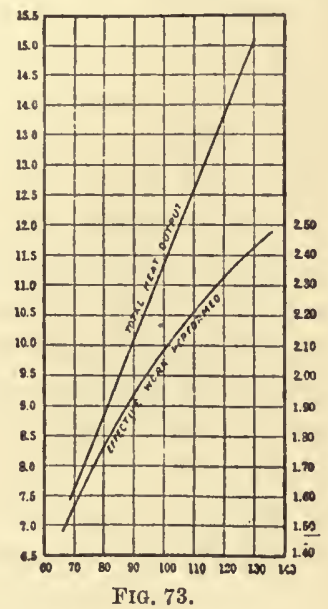

inereases, and there is therefore a steady fall in efficieney (see Fig. 73). The samc result is obtained when the speed is varied, with, however, approximately the same production of effective museular work in the two experiments, as shown in Table LXXIX. :

TABLE LXXIX.

\begin{tabular}{c|c|c}
\hline Revs. per min. & $\begin{array}{c}\text { Heat equivalent of } \\
\text { external muscular work } \\
\text { per min. in Cals. }\end{array}$ & Net efliciency:* \\
\hline 90 & 1.94 & $\begin{array}{l}22 \cdot 6 \% \\
15 \cdot 7\end{array}$ \\
\hline 124 & $1 \cdot 96$ & $22 \cdot 1$ \\
\hline 80 & $1 \cdot 77$ & $17 \cdot 7$ \\
\hline 105 & $1 \cdot 83$ & $24 \cdot 5$ \\
\hline 71 & 1.57 & $15 \cdot 6$ \\
\hline 108 & $1 \cdot 58$ & $23 \cdot 1$ \\
\hline 71 & $1 \cdot 34$ & $20 \cdot 4$ \\
105 & 1.29 & $17 \cdot 0$ \\
\hline 72 & 1.35 & $21 \cdot 5$ \\
88 & 1.20 & $19 \cdot 5$ \\
\hline
\end{tabular}

* Base line-complete rest, lying. 
As regards the work which has been carried out on isolated muscle, the results which have been obtained are of great interest, as they have led to fresh consideration of the nature of the muscular machine. A. V. Hill, in a long series of ingenious and striking experiments, using special methods of his own devising, has shown that the solution of the problem is not quite so simple as it was formerly imagined. Hill found the simple determination of the mechanical efficiency, i.e. $W / H$, the heat equivalent of the work done, divided by the energy output determined as heat, was of no real importance. The true efficiency of the muscle is the ratio between the "potential energy thrown into an active. muscle by excitation" and the "total chemical energy liberated as heat." He found further, that the heat production varied according to whether the muscle was, or was not, allowed to shorten on stimulation. If shortening were permitted the heat output might be 30 per cent. smaller than if the muscle was prevented from shortening. On examination of the potential energy developed by a stimulated muscle not allowed to shorten, it was found to be approximately $1 / 6 \mathrm{Tl}$, where $T=$ the maximum tension and $l=$ the length of the muscle. Hill maintains that the true mechanical efficiency can be determined by comparing this quantity with the heat production. This value $1 / 6 \mathrm{Tl}$ when expressed in heat units is $10^{-1 / 4 \cdot 26}$ calories. (See Table LXXX.) He found efficiencies approximating 90 per cent. in the initial phases of contraction, and if the whole process, i.e. initial and recovery phases taken together, were assessed, the efficiency, under the conditions of his experiments, was in round figures 50 per cent.

\section{TABLE LXXX.}

ExpT.-Length of muscles, $3.3 \mathrm{~cm}$.; weight of muscles, $0.135 \mathrm{gm}$.; 1 scale division of deflection $=8 \cdot 32 \times 10^{-6}$ cal. Sartorius and isometric contractions.

\begin{tabular}{|c|c|c|c|}
\hline Ouration of excitation : secs. - & 0.075 & 0.075 & 0.075 \\
\hline Initial tension : grm. wt. - & $10 \cdot 5$ & $10 \cdot 5$ & $10 \cdot 5$ \\
\hline Heat production $H$ : cal. $\times 10^{-6}$ & -574 & 740 & 757 \\
\hline Tension $T$ : grms. wt. - - & $-44 \cdot 8$ & 47 & 47 \\
\hline $\mathrm{Tl} / 6 \mathrm{H}$ & $1 \cdot 01$ & 0.82 & $0 \cdot 80$ \\
\hline
\end{tabular}

Incidentally he found that different types of muscle (e.g. semimembranosous and sartorius) definitely differed in efficiency. He also found that the maximum efficiency was only obtained under very special conditions of initial tension, strength of stimulus and the physiological state of the muscle. 


\section{PART II}

\section{ILLUSTRATIVE EXPERIMENTS}

1. Gaseous Diffusion. Experiment on page 40. Try this first with coal-gas and then with $\mathrm{CO}_{2}$. Soak the porous pot in water and com. pare the rate of diffusion inwards of carbon-dioxide with the outwards diffusion of air. What part does solubility play in diffusion through a membrane?

2. Osmotic Pressure of Crystalloids. Preparation of a Semipermeable Membrane. Take a clean porous pot such as is sold for Leclanché units. Allow it to soak for a day in distilled water. Fill it with a 0.25 per cent. solution of copper sulphate and immerse it in a 0.21 per cent. solution of potassium ferrocyanide for a day or two. Wash thoroughly in distilled water. The copper sulphate and potassium ferrocyanide meet in the porous pot and a membrane of copper ferrocyanide is there formed (see Expt. 6). The prepared pot may keep for years and be used many times.

A rubber stopper with two holes should be permanently fixed in its mouth with wax. Through one hole should be passed a long glass tube or a U-shaped glass manometer. The other hole carries a tap funnel for filling the pot. The solution to be tested should be coloured with methylene blue or other dye which is easily seen.

(1) What happens after 24 hours or so when a sugar solution is placed in the pot and the pot immersed in water?

(2) Now add sugar to the fluid outside the pot till its concentration is the same as that inside the pot and leave for the same period as before.

(3) Increase the concentration of sugar outside and note the effect on the level of fluid in the manometer.

3. Blood Corpuseles. (1) Take three test tubes and place in one about 5 c.c. of water and in another a similar amount of 0.9 per cent. sodium chloride, and in the third 2 per cent. sodium chloride. Prick the finger with a sterile needle and add the same number of drops of blood to each tube. Shake and examine the tubes $(a)$ as to opacity and $(b)$ as to depth of colour. Take a drop of the fluid from each and examine under the microscope. Measure the diameter of a number of corpuscles and average those from each tube.

(2) Add a drop of fresh blood to a drop of 0.5 per cent. sodium chloride solution on a microscope slide. Place a card on the side of the microscope stage and keeping both eyes open trace the projection of a corpuscle from time to time or measure the diameter.

(See also Haematocrite, Expt. 47.) 
4. Turgor (see Expt. 19, ii. for precautions). Take a length of sausage skin parehment. Close one end tightly round a glass stopper. Fill with treacle or a strong solution of sugar and then similarly close the other end. Suspend horizontally in water from a loop round the middle. The ends, which droop at first, giving the whole the appearance of an arch, soon begin to assume a horizontal position. In a day or so the sausage skin will be rigid and straight.

5. Chemical Gardens. (1) Place 50 c.c. of potassium ferrocyanide in a glass jar or beaker and add a small particle of ferric chloride (small pea). $\AA$ semipermeable membrance of ferric ferrocyanide (Prussian blue) is formed round the solid. Endosmosis occurs and peculiar growths may be formed.

(2) Add a drop of almost saturated potassium ferrocyanide from the end of a glass rod to a solution of copper sulphate (bench reagent). A semipermeable membrane of copper ferrocyanide is formed round the drop and endosmosis takes place. This causes an increase in the concentration of the copper sulphate immediately round the drop, and blue "rootlets" may be seen descending from the drop. These are due to the increased density of the sulphate.

(3) Leduc's Growths. A small flat-sided jar, e.g. a specimen jar, is filled with a 1-2 per cent. solution of gelatine to which is added just enough potassium ferrocyanide to give it a pale green colour. Just before the gelatine has set, a little seed made from a mixture of glucose and copper sulphate is planted on the bottom of the jar. Within an hour, growth will be visible and may proceed for several days.

See Leduc, Études de Biophysique. I. Théorie Physico-Chimique de la Vie (1910); II. La Biologie Synthétique (1912).

6. Electric Endosmose. (a) The passage of water through a membrane by electrical means may be observed in the preparation of a semipermeable copper ferrocyanide membrane when the solutions are forced into the pores of the earthenware pot by an electrical current (Expt. 2).

(b) A clean porous pot, fitted with a manometer and a non-polarisable electrode, is filled with and placed in a solution of $\mathrm{K}_{2} \mathrm{SO}_{4}(0.05$ per cent.). A current of $2-4$ volts is passed so that the electrode inside the pot is cathode. Note the rise in level of the fluid inside the pot. Note also the increase in the alkalinity of the fluid outside the pot.

(c) Make a collodion test tube to fit one limb of the U-tube (Fig. 9).

(1) Fill both limbs with dilute $\mathrm{K}_{2} \mathrm{SO}_{4}$ solution. Mark the level of the fluid in both limbs and, using non-polarisable electrodes, pass a current of 4 volts for some time through the solution. Note that water passes towards the cathode and that the cathodal fluid becomes acid.

(2) Repeat, using tartaric acid in the collodion sac and pure water outside. Test for tartaric acid.

(3) Fill the sac with gelatine sol and leave overnight. Wash out the sol and repeat the expts.

\%. Determination of the Freezing Point of Urine. Principle. The freezing point of water is depressed by the addition of salts which go into true solution. The magnitude of the depression termed $\Delta$ bears a relation to the molecular concentration of the solutes and therefore to their osmotic pressure. 
Apparatus. Beckmann's (Fig. 74). It consists of a specially devised test tube $A$ with a side neck. Through the rubber stopper, closing the main neck of this, pass a thermometer $D$ and a short glass tubular

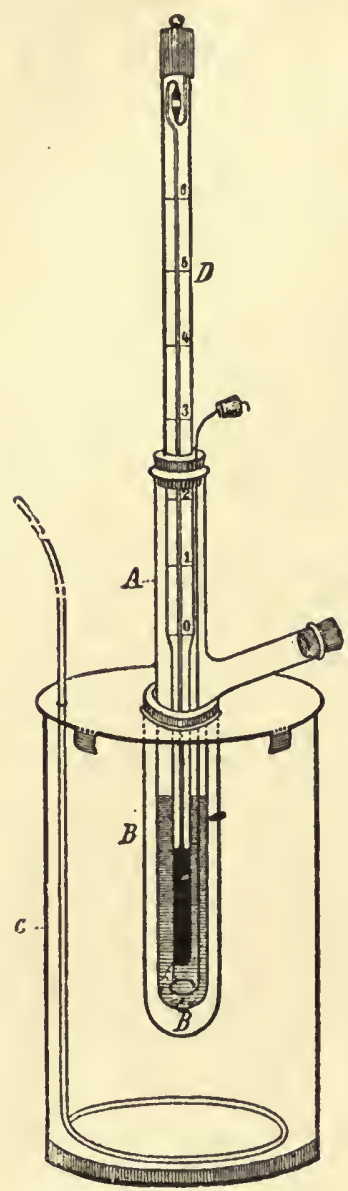

FiG. 74.--Treezing Point Apparatus. guide for a stirrer. The freezing point tube is supported in the neck of a large test tube $B$, by means of a cork or asbestos ring so that the freezing-point tube is protected from incoming heat by a mantle of still air. This ensures that the cooling of the liquid in the freezing-point tube is slow and fairly uniform. The whole apparatus is inserted through a hole. in the middle of a brass sheet, to which it is fixed by a ring of cork or of asbestos. The sheet of brass acts as a lid to a glass jar $C$ which contains powdered ice and salt- the cooling bath. Other holes in the lid permit of the passage of a stirrer, a thermometer, and a test tube containing pure water.

The Beckmann Thermometer. The thermometer in the freezing point tube must be graduated to, at least, hundredths of a degree. Such a thermometer, if made in the ordinary way, unless it were inconveniently long, would have a very short range. To obviate the necessity of having a series of thermometers for use over various ranges of temperature, Beckmann designed one which may be set to indicate temperatures over any desired range. This result is produced by a device permitting of alterations being made in the amount of mercury in the bulb. At the upper end of the thermometer there is a small reservoir into which the excess of mercury may be driven, or from which a larger supply of mercury may be obtained.

Setting the Beckmann Thermometer. Hang the thermometer in a beaker of water, the temperature of which is $2-3$ degrees higher than the highest temperature to be met with in the experiment and see whether or not the top of the mereury comes within the scale.

$A$. If there is too much mercury in the bulb and the column rises beyond the graduated part, the excess is removed by warming the mercury in the bulb till the column of mercury unites with the mercury in the reservoir. This is done, $(a)$ by placing the bulb in water just a little warmer than before. (b) When the mereury passes to the top of the capillary tube and forms a small drop there, the thermometer should be carefully inverted and tapped gently so as to cause the mercury in the reservoir to coalesee with the mercury in the top of the eapillary. $(c)$ The thermometer is returned to the upright position by a gentle steady movement and its upper end is struck a sharp tap against the palm of the hand, causing 
the excess of mereury to break off from the end of the capillary. The thermometer is again tested in the first bath.

$B$. If, on the other hand, the amount of mercury in the bulb is so small that the top of the column does not rise to the bottom of the scale, more mercury will have to be drawn from the reservoir. The procedure is similar to that outlined above, but at $(c)$ the thermometer is replaced in the first bath before breaking the mercury column. That is, the mercury in the bulb is allowed to contract and draw in more mercury from the reservoir before the connection between column and reservoir is broken by tapping.

These operations are repeated till the proper level of mercury has been attained. This is always tested by placing the thermometer in baths having temperatures equal to the highest and lowest to be encountered in the experiment, and noting that the top of the column of mercury remains on the scale.

Mcthod. (1) Set up the apparatus completely so as to ensure all parts fitting properly. See that the stirrer in the inner tube is working smoothly and does not strike against the bulb of the thermometer.

(2) Remove the thermometer and stirrer from the tube. Clean and dry the latter.

(3) Pipette in 25 c.c. of urine.

(4) Set the Beckmann thermometer so that, at $0^{\circ} \mathrm{C}$., the mereury stands not lower than the middle of the seale.

(5) Dry the thermometer and insert it along with the stirrer in the freezing-point tube, so that the bulb of the thermometer is completely immersed in the urine.

(6) Fill the outer cooling vessel with water, ice and salt. The freezing point of urine can now be determined.

(7) First make an approximate determination by placing the freezingpoint tube directly in the cooling bath so that a rapid fall of temperature occurs.

(8) As soon as the urine shows signs of freezing remove the tube from the freezing mixture, dry it quickly and place it in the air jacket in the cooling bath.

(9) Stir slowly and read the temperature when it becomes constant.

(10) Withdraw the tube and melt the ice by warming with the hand, trying to avoid raising the temperature more than $1^{\circ} \mathrm{C}$.

(11) Rapidly dry the tube and reinsert it in the air jacket and repeat the freezing process, stirring slowly all the time.

(12) When the temperature has fallen to from $0.2^{\circ}$ to $0.5^{\circ}$ below the approximate freezing point found in (9) stir more vigorously. This generally is sufficient to induce solidification to commence and the temperature will now begin to rise.

(13) If so, stir slowly and take readings of the temperature every few seconds-tapping the thermometer each time before reading. Note the highest temperature reached.

(14) Again melt and repeat the determination. At least three determinations of the freezing point should be made, the mean being taken. The deviations of the chosen readings from the mean should be less than $0.002^{\circ} \mathrm{C}$.

(15) The depression of the freezing point or, in this case, the thermometric readings may be converted into osmotic pressure in metres of water by multiplying by the factor $122 \cdot 7$.

B. B. 
Thus suppose that the $\Delta$ observed is $-2 \cdot 3^{\circ}$, the osmotic pressure of this sample of urine would be $2 \cdot 3 \times 122 \cdot 7=282 \cdot 2$ metres of water $=282 \cdot 2 / 13 \cdot 6$ $=20.7 \mathrm{~mm}$. of mercury.

Precautions. (a) The temperature of the cooling bath must not be too low. It should not exceed $3^{\circ}$ below the freezing point of the liquid.

$(B)$ Excessive supercooling should be avoided. It should not be greater than half a degree.

( $\gamma$ ) Stirring should not be too rapid-say 1 up-and-down movement per second, and it should be as uniform as possible.

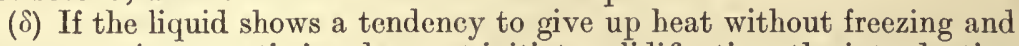
that even vigorous stirring does not initiate solidification, the introduction of a small crystal of ice through the side tube generally suffices to start solidification.

8. Osmotic Pressure by Barger's Method (Fig. 75). Trans. Chem. Soc. 85, p. 286. Prepare a number of capillary tubes by drawing out soft glass tubing of $\frac{1}{2}$ inch bore into capillaries 1-2 feet long. These should be cut into smaller pieces, having a smooth regular edge, in order that the tube may be closed tightly with the finger while it is being filled. The internal diameter of the capillaries should be between 1 and $2 \mathrm{~mm}$., preferably about $1.5 \mathrm{~mm}$.

The filling of the tubes requires a little practice. The tube is taken between the middle finger and thumb, and its upper end, which should be rounded, is closed with the index finger. The other end is then dipped below the surface of solution $A$. By lifting the index finger very slightly enough liquid is admitted into the tube to make a column of about $5 \mathrm{~mm}$. long. The finger is replaced on the end of the tube, which is then lifted from the fluid and inverted so that the open end is uppermost. It is held
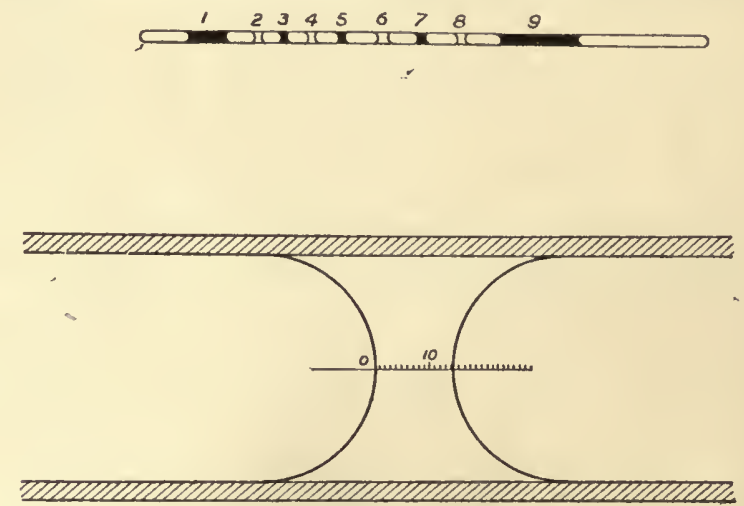

FIG. 75.- Barger's Method for determining Molecular Concentration.

Upper figure, actual size. Lower figure, as seen under the mieroscope; micrometer scale in eyepicce.

in a slanting position, and, by diminishing the pressure of the index finger on the lower end, the globule of liquid is allowed to slide down the tube, its progress being regulated by the slant of the tube. The process is repeated, using solution $B$ and so on, using solution $A$ and $B$ alternately and finishing with $A$. When all the drops are in, the collection is moved so that the last 
drop is about $1 \mathrm{em}$. from the open end of the tube and this end is sealed in a small bunsen flame. The other end of the tube may then be similarly sealed. The upper diagram, in Fig. 75, shows the appearance (actual size) of a filled and sealed tube. The dark drops are $A$. The first and last drops, 1 and 9, are large and are not taken into account. The drops are numbered in the order in which they were put into the tube, i.e. the open end of the tube is to the right of the diagram. The tubes are cemented to a microscope slide and a coverslip fixed with Canada balsam. The slide is placed in a Petri dish with enough water to cover the tubes. (Constant temperature.) Under the microscope the tubes present an appearance like that shown in Fig. 75, lower diagram. With an eyepiece micrometer, measure the drops. After an interval whose length depends on the solvent, the drops are remeasured.

In what direction, if any, does the alteration in size take place? That is, do the drops of $B$ become larger or smaller? If $B$ drops increase in size it shows that the vapour pressure of $B$ is less than that of $A$, and, consequently, the osmotic pressure of $B$ is greater than that of $A$, and vice versâ. $A=2.5$ per cent. glucose in water, $B=2.5$ per cent. $\mathrm{NaCl}$ in water. Time about 20 hours.

9. Camel-hair Brush Expts. Many illuminating experiments may be made with a small camel-hair paint pencil. Under water the hairs diverge, but when the surface tension of the water-hair surface is increased, e.g. by removing the brush from the water, the hairs form a compact pencil.

10. Boy's Leather Sucker (p. 303). To show that surface tension is the causative factor suspend a microscope slide horizontally in the receiver of an air pump. By means of a drop of water between, cause a second slide to adhere to the lower surface of the first slide in such a way that the second slide may be loaded. Load with the maximum weight and exhaust the receiver. Repeat the expt. under various conditions, e.g. trace of oil, ester, bile salts, etc.

11. Work done by altering Surface Tension. In performing the experiment mentioned in p. 137 (Fig. 24), it is necessary to have a good soap solution. It may be made as follows from pure sodium oleate and glycerol. To 500 c.c. of distilled water in a stoppered bottle of 1 litre capacity, add 200 c.c. of pure glycerol, shake and allow to stand in the dark for a week. Siphon off the clear underlying fluid and add four drops of concentrated ammonia. Keep well stoppered and away from light.

12. Experiments with Soap Bubbles. Make a film on the wide end of a conical tube (filter funnel), closing the other end with the finger. What happens when the finger is removed? Where does the film come to rest and why?

13. Camphor "Water-beetle." Prepare a rectangular piece of camphor. To one short side affix a short piece of stick and place the whole thing on the surface of water in a large dish. How do you explain the direction of the movements? Remove the stick and replace the camphor in the water.

14. Camphor-Benzene "Amoeba." (Brailsford Robertson.) The amoeba is made of a saturated solution of camphor in benzene to which a dye (e.g. carmine) has been added to make the solution easily visible when placed in water. Place a drop of the solution on the surface of clean water in a clean Petri dish. The movements may be slowed down by the addition of the faintest trace of oil. Generally the first "amoeba " disintegrates 
rapidly. Do not throw out the fluid in the dish, but add another drop of the camphor solution. What effect has inerease or decrease in temperature on the movements? What happens when a solid particle is suspended in the water near the " amoeba." ? What is the effect of putting two separate drops on the surface of the water at the same time, $(a)$ when the drops are equal in size, (b) when they are unequal in size? What is the effect of the addition of a trace of fat, obtained, for example, by touching the surface of the water with a glass rod which has been rubbed on the side of the nose?

15. Mercury "Amoeba." Place a small globule of mercury in a large Petri dish and cover it with potassium bichromate (sat. solution) to which has been added some nitrie aeid (bench reagent). How do you explain the movements?

16. Electrical Alteration of Surface Tension. Carry out the experiment detailed on p. 48. Place a small globule of mereury on an iron or enamelled plate and cover with water. Note shape of globule. Add sulphuric acid (bench reagent) drop by drop (to make about a 10 per cent. solution). What happens to the globule? Explain. Connect the plate and globule to a single cell of a battery through a commutator. First pass the current through the globule to the plate and note alterations in shape, then reverse the commutator.

1\%. Ostwald's Physical "Heart." (Verworn's Physiologisches Praktikum.) The method of carrying out this demonstration of electrical alterations in surface tension is indicated in the diagram (Fig. 76). A globule of mercury about an inch in diameter is placed in a clock glass almost filled with 10-15 per cent. sulphuric acid. Potassium bichromate

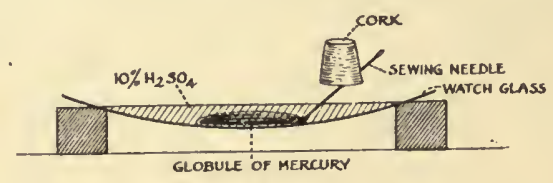

FIG. 76,-Mercury "Heart."

solution (say $N / 10$ ), is added drop by drop till the fluid becomes a light. yellow in colour. A clean sewing needle thrust through a cork is placed in a diagonal position so that the point of the needle just touches the margin of the mercury globule. At the moment of contact the globule becomes more spherical. This breaks its contact with the needle and it loses its semispherical form and so again makes contact. These rhythmic pulsations may go on for hours. When the action has stopped remove the needle and note the odour of acetylene. How do you aceount for this ? What is the reason for adding bichromate?

18. The Capillary Electrometer. This instrument for measuring differences of electric potential depends for its action upon the alteration of surface tension between mereury and sulphuric acid with alterations of the potential difference of the interface (see p. 48, and Expts. 16 and 17). For class use the simplest satisfactory form is that made by the Harvard Apparatus Co. It consists of a capillary tube containing mercury which is continuous with a reservoir in the form of a plunger pump. The position of the mercury in the capillary may be altered by adjusting the plunger by means of a miero-screw. The glass capillary dips into a small test tube containing dilute sulphuric acid and a drop of mercury to make good contact with the 
platinum wire sealed through the bottom of the tube. This platinum wire and the one coming from the mereury in the capillary are short-circuited through a spring key. The whole instrument is placed on a microscope stage set vertically.

Details. (a) Mercury. Pure dry mercury must be used. To clean mercury: shake for 10-20 minutes with a solution of mercurous nitrate acidified with nitric acid. Wash thoroughly with distilled water and dry with filter paper.

(b) Sulphuric acid. The pure (boiled) acid in six times its volume of distilled water is skaken up with a little pure mercury and is best kept, in contact with some mercury.

(c) The glass parts must be free from grease and the rubber connections from French chalk.

Filling and Setting the Electrometer. Fill the pump-reservoir with mercury, allowing free access to the capillary. Before inserting the plunger, cover the mercury surface with a film of thin oil (balance oil). The insertion of the plunger will cause mercury to be forced through the capillary. Fix the capillary in position in the test tube, which should be half full of acid. A slight turn of the plunger screw will force a little mercury into the test tube to cover the platinum contact. Adjust by means of the plunger screw till the $\mathrm{Hg}-\mathrm{H}_{2} \mathrm{SO}_{4}$ interface lies in the middle of the microscopic field. The definition of the mercury meniscus may be improved by cementing a cover glass to the test tube with Canada balsam. An eyepiece micrometer provides a scale whereby the movements of the mercury may be measured. (1) Connect the terminals by non-polarisable electrodes, one to the cut and the other to the uncut surface of a muscle. Depress the short-circuiting key and so bring the electrometer into circuit with the muscle E.M.F. Note the movement of the mercury. (2) Similarly attempt to demonstrate the diphasic electrical variation in the beating heart (frog). (3) Take off leads (salt solution) from the human heart (arms, see p. 296). (4) If the electrometer is used to find the point of balanced E.M.F. on a Wheatstone bridge (Expt. 39), it is essential to arrange that the direction of the positive current is such that the capillary mercury is the cathode, otherwise mercurous sulphate might be formed in the capillary tube on account of the passage of a rather large current. For the same reason, the short-circuiting key should only be opened for as brief periods as possible.

Fine instruments may be purchased filled, adjusted and sealed ready for use. They are of a somewhat different type, and while of value for fine measurements in the hands of a careful worker, are unsuited for class work.

The current of injury, etc., of muscle (pp. 134 and 143) is usually measured by compensation. A cell of constant known E.M.F. is put in the same circuit as the tissue giving rise to the current but sending its current in the opposite direction (Fig. 78 and Expt. 45). By moving the jockey along the slide wire $\left(R_{1}-R_{2}\right)$ till the E.M.F. from the cell exactly balances the demarcation current, i.e. till the meniscus at the mercury-acid interface becomes steady, one may determine what relationship the constant E.M.F. bears to the muscle E.M.F. Non-polarisable electrodes must be used.

19. Preparation of Membranes. I. Collodion membranes are easily made in any size or shape, and, as they are transparent, are very convenient 
for general use. They are, as ordinarily prepared, unsatisfactory for the dialysis of whole blood or of bile.

Cellulose nitrate (gun-cotton or pyroxylin) is generally sold damped with alcohol and, for very accurate work, should be dried before weighing. For the following experiments this refinement is unnecessary.

Acetic Acid Collodion. Four grams of commercial gun-cotton are placed in a wide-mouthed glass-stoppered bottle of 200 c.c. capacity; 100 c.c. glacial acetic acid are added. The mixture is shaken gently until the guncotton has dissolved, leaving no residue. The resulting sol is transparent and will keep for weeks.

Alcohol-Ether Collodion. (Bigelow and Gemberling.) 75 c.c. of ethyl ether are poured on $3 \mathrm{gms}$. of gun-cotton in a wide-mouthed stoppered bottle as above. After 10 to 15 minutes, 25 c.c. of ethyl alcohol are added and the mixture agitated until a clear solution is obtained.

Either of these collodion solutions (after standing till free from bubbles) may be used in the preparation of membranes.

(i) To cover a vessel similar to a Graham dialyser. Cleanse a piece of plate glass thoroughly and polish it. Pour sufficient collodion sol on the centre of the plate to give a large enough membrane. Avoid bubbles. By tilting the plate, spread the sol evenly over the surface of the plate and, if necessary, drain off any excess into the stock bottle, taking care to avoid any unevenness in the distribution of the collodion. The diameter of the sheet should be fully 2 inches larger than that of the dialysing glass. If an acetate sol has been used, immediately plunge the glass and adherent gel into cold water and leave it immersed for about half-an-hour to convert the acetate gel into a hydrogel. After the minimum time of immersion has elapsed, the collodion film may be readily detached from the glass, placed centrally over the rim of a dialysing cup, and fixed in place by a broad rubber band. The dialyser should now be tested for leaks by filling it with water and observing that no fluid escapes round the junction. The film must be kept moist or it will shrink and rupture.

The ether-alcohol gel is not placed in water at once like the above, but is allowed to dry in air or in alcohol vapour for a period depending on the permeability required. If a very permeable diaphragm is required, a glass trough is inverted over the film so as to prolong the period of gelation. Although the degree of drying is the crucial point of the whole process, no definite rules can be laid down. Each "make" of collodion requires treatment on its own merits and experience alone will tell when the film is ready. If the sol has been made as directed, it should be dry enough when it does not stick to the finger when touched lightly. The edges can be loosened with a spatula or paper knife and the whole film slowly lifted from the glass. When about three-fourths of the sheet has been raised vertically from the plate the rim of the dialysing cylinder is placed below it so that the edge of the rim comes in contact with the collodion surface which has been next the glass plate, i.e. with the surface which has been dried least. The edges of the membrane are carefully turned down over the sides of the cup and will adhere quite firmly. If desired, a broad rubber band may be placed round the rim to ensure tightness. Test, as above, for leaks and leave immersed in water for 10-15 minutes to allow the alcohol to be replaced by water.

(ii) To make a collodion sac. A small Erlenmeyer flask, clean and dry, 
is filled with collodion sol, care being taken to pour the fluid slowly down the side so as not to form air-bubbles. The sol is now poured back into the stock. This should be done slowly and steadily with a constant rotatory motion of the flask, leaving a thin film adherent to the glass. If this operation is carried out too quickly, the layer of collodion at the bottom of the flask will be too thin. It is convenient to allow a little collodion to overflow all round the outside of the neck of the flask to enable one to get a good grip in pulling out the film afterwards. The flask (acetate sols are at this stage submersed in water) is inverted over the mouth of a bottle containing a little alcohol (or empty, see above), and allowed to dry as before. When dry, the flask is filled with water or, better still, immersed in water and allowed to stand for at least 15 minutes. The collodion sac is loosened at the neck and earefully withdrawn. This is a slow process and must not be hurried or grave risk will be run of tearing the thin film. It is quite a good thing to remove the film in stages, letting it soak in water between times. The complete bag is usually fitted with a glass moutha piece of glass tubing of suitable size inserted in the neek and affixed thereto by broad rubber bands, or by wrapping in oiled silk, gutta-percha tissue, etc., and winding thin string over this, or by causing it to adhere with a little fresh collodion.

(iii) To make collodion test tubes. (a) Collodion tubes may be formed inside test tubes or boiling tubes in the same manner as has been described for sacs.

(b) Sometimes it is desirable to make a dialysing tube which will fit on the outside of a specified tube. A test tube of the required width is taken and a small hole blown in the end. This hole is covered with a thin film of collodion which is allowed to dry. The whole tube is then dipped in the collodion solution. The excess collodion is allowed to drip into stock, the test tube being held bottom upwards at an angle of less than $45^{\circ}$ and rotated steadily. The film is treated with water, or after drying as above, depending on the nature of the solution. After soaking in water, the test tube is filled with water and the film gently worked off like a tight glove. It is eased a little at the bottom, water meanwhile passing into the collodion tube through the hole in the test tube. Little by little a fine film of moisture will creep up between film and glass and the transparent collodion tube will slip off easily. This method yields tubes which are more uniform in thickness and permeability than the former.

(iv) Thimbles. Strong dialysing vessels may be made by impregnating Soxhlet extraction thimbles with collodion. The thimble, soaked in alcohol, is immersed in alcohol-ether collodion, withdrawn, allowed to drip and partially dried, and then the process of impregnation is repeated. It is advisable to fix a short glass tube into the mouth of the thimble before impregnation and to use a fairly thin collodion solution.

II. Parchment Paper is sold for this purpose in sheets, or made up in long tubes (sausage skins) or in thimbles. When dry the paper becomes very brittle, so that great care has to be observed in its storage to prevent creases, etc.

(i) Sheet. Select a piece of the paper free from obvious defects (pinholes, etc.) and fully two inches larger in each direction than is required. Soak in water till soft and pliable. Place it centrally over a dialysing glass as is described above for collodion sheets. The folding of the free edges 
requires some care to ensure even lying against the side of the glass. Tie with thin string. Test for leaks.

The sheet may be made into a bag as follows: "Cut a regular hexagon and soak it thoroughly in water. Then place it centrally on the bottom of an inverted beaker or jar, the diameter of which is about one-third of that of the inscribed cirele of the hexagon. Gently pinch radial folds from the circumference of the beaker to the corners of the hexagon and mould them so that the paper midway between the corners touches the wall of the beaker, and then turn the folded portions over and smooth them into cylindrical shape. The folds must not be sharp, as even wet parchment may be damaged by too drastic treatment. When the bag has been moulded as described, a string is loosely tied around it, or a fairly slack rubber band slipped over it within about 2 inches of the edge, and the bag is then drawn off the beaker. Its permanent shape is secured by threading a clean thin string through the folds, which is gently drawn tight after every completed stitch so that the circumference at the open end is roughly the same as at the bottom. The bag is suspended in a jar of suitable size by two or three strings tied at equal distances to the string which secures the circumference." (From Hatschek's Laboratory Manual, Messrs. Churchill.)

(ii) Similar care must be taken when working with parchment tubes or thimbles. The "sausage skin dialysers" are excellent for demonstration purposes, as they offer a large effective surface. They are sold flat in lengths of about a metre and are very easily damaged. They are best kept hanging from one end. Thoroughly soak and test a piece. Cut it to a convenient length and with a large cork-borer excise a circular piece from both ends about $\frac{1}{2}$ inch from the opening. Bend the tube into $U$-shape and place it in a tall cylinder. A glass rod longer than the diameter of the eylinder thrust through the holes at the ends of the dialyser acts as support. The tube may now be filled, by means of a funnel, with the fluid to be dialysed while the cylinder is filled with water at the same time and at the same rate. This is to prevent undue strain on the tube.

20. Dialysis. In using any dialyser it is advisable to look to the following points.

1. Test for leaks.

2. See that neither the preservative nor the fluid to be dialysed act on the substance of the membrane, e.g. bile pigment increases the permeability of collodion. (Bile may be dialysed through a double dialyser, i.e. a collodion tube suspended in a larger tube of the same material. Blood pigment occasionally presents the same difficulty.)

3 . If the dialysate is wanted as well as the dialysed fluid, dialysis must be carried out by changing the external fluid from time to time.

4. If it is not necessary to keep the external fluid for examination, rapid dialysis may be obtained by keeping up a continuous flow of water in the outer vessel. This is most conveniently done by placing the dialyser or a series of dialysers in a sink, the level of water in which may be adjusted by means of a wide glass tube running through the waste plug. The water supply is led to the bottom of the sink.

(1) Dialyse (a) Egg albumin + Sodium Chloride. (b) Starch + Iodine + HCl. (c) Starch + Glucose. Test dialysate for both constituents.

(2) Using a glass dialyser with a collodion membrane dialyse a mixture of either congo red, litmus or alizarin and hydrochloric acid. 
(3) Dialyse some blood serum. What is the precipitate? How do you explain this?

21. Faraday-Tyndall Phenomenon (p. 70). Arrangement of apparatus. The fluid to be examined is placed in a prismatic cell (small flat-sided specimen jar, say, $\left.5^{\prime \prime} \times 5^{\prime \prime} \times 22_{2}^{\prime \prime}\right)$. One large face of the cell is covered with a llack velvet curtain. Jight from any optical projector is passed through the cell in a plane parallel to the long side. A lens is interposed so that the focus falls about the middle of the cell forming a cone. A darkened room is essential for any but individual demonstrations.

(1) Fill the cell with water and show that the beam is hardly shown. (With conductivity water the beam is not seen.)

(2) Dust lycopodium or puff smoke into the beam outside the cell to show how small particles in air affect the visibility of the light.

(3) Add about 1 c.c. of an egg albumin solution to the water in the cell. Why is the cone bluish in tinge?

(4) Replace the solution with another containing a red gold sol. Why is the cone green?

22. Brownian Movement (p. 75 and Fig. 8). (1) Clean slides and cover glasses in hot potassium bichromate-sulphuric acid mixture, rinse in distilled water and then in two changes of alcohol. Keep till required in alcohol.

(2) When ready to examine a sol, withdraw a slide from alcohol (using forceps) and evaporate dry over a clean flame. Cocl. A large drop of sol free from air bubbles is placed on the centre of the slide. The cover glass, prepared like the slide, is gently placed on the drop. Use a good electric light, such as the Ediswan " Point o' light" tungsten arc, and focus on the central portion of the fluid. A 1 per cent. suspension of gamboge shows the Brownian movement well.

23. Gelation. $A$. Heat a small quantity of 1 per cent. solution of (1) gelatine, (2) serum, (3) dextrine. Cool. What is the result? Has reheating any effect?

$B$. Effects of Solutes on Gelation. Into four boiling tubes put the same quantity of $2 \frac{1}{2}$ per cent. gelatine. In one tube dissolve about 5-7 per cent. magnesium sulphate crystals. Potassium iodide crystals are added to the second tube, while a few drops of 40 per cent. formalin are mixed with the gelatine in the third tube. The fourth tube is left as a control. Allow all tubes to stand overnight and examine by tilting and shaking. How do you explain the varied viscosity?

Sulphates, citrates and phosphates increase the viscosity of aqueous emulsoid gels. Iodides, bromides cyanides and some chlorides similarly decrease viscosity. Alcohol, formaldehyde, etc., in small amounts increase viscosity.

24. Determination of the Relative Viscosity of a Liquid. Principle. When a liquid flows through a narrow tube the velocity of flow depends mainly $(\alpha)$ on the force producing the flow and $(\beta)$ on the resistance to flow produced by the viscosity or internal friction of the liquid. In Chap. XXIV. p. 278 we considered the shearing of the different layers of the blood stream. The liquid, we saw, could be regarded as made up of a number of concentric tubes sliding past one another. When the liquid is moving through the narrow tube there will be, under constant conditions, a constant difference in velocity between the different tubular layers. The 
force per unit area necessary to maintain this condition is proportional to the difference of velocity, $v$, of two adjacent layers, and inversely proportional to their difference apart $x$.

Briefly, Force $=\eta \times \frac{v}{x}$, where $\eta$ is the coefficient of viscosity, which is the force per unit area when $v=x$. If, now, the quantity of fluid and the pressure be kept constant and the time observed which the fluid takes to travel a certain distance, the viscosity of two liquids with densities $s^{\prime}$ and $s^{\prime \prime}$ with times of flow $t^{\prime}$ and $t^{\prime \prime}$ will be as

$$
\eta^{\prime} / \eta^{\prime \prime}=s^{\prime} t^{\prime} / s^{\prime \prime} t^{\prime \prime}
$$

Neglect of the difference of density introduces an error of less than 1 per cent. and materially simplifies the operation, i.e.

$$
\eta^{\prime} / \eta^{\prime \prime}=t^{\prime} / t^{\prime \prime}
$$

Apparatus (Denning-Watson Viscosimeter). The instrument is a modification of the Ostwald-Poiseuille viscosimeter. It consists of a U-tube with a long and a short arm (Fig. 77). The long arm $(6 \mathrm{~cm}$. in length) is blown out at its free end into a cupshaped receiver with a thin edge.

On the short arm (2 cm. in length) there is a small elliptical bulb, the capacity of which is defined by the two lines $m^{\prime}$ and $m^{\prime \prime}$.

Method of Use. The receiving cup at the end of the long arm is filled (and kept filled) with the fluid to be tested, which passes down the capillary tube. A stopwatch is started when the fluid reaches the point $m^{\prime}$ and stopped when it reaches $m^{\prime \prime}$. The time taken is compared with the time reading of water, which is recorded on the back of the tube used. Denning and Watson urge attention to the following points. (1) The tubes should be scrupulously clean and perfectly dry. (2) The viscosimeter and the fluid must be at the same fixed temperature. (3) The receiver of the instrument must be kept filled with the fluid, for pressure-height must be kept constant, i.e. compared with water. (4)

FIG. 77.-Viseosimeter (IIawksley). The movement of very viscous fluids may be initiated by slight suction applied to the short arm. (5) Clean the tubes immediately after use. They are best cleaned by a strong reagent like conc. $\mathrm{HNO}_{3}$ (depending on the fluid last measured), followed in quick succession by distilled water, alcohol and ether. Hot air is passed through the tube to dry it.

25. Imbibition. (a) A strip of thin shect rubber (dental or patching rubber) about $12^{\prime \prime} \times 11_{2}^{1 \prime}$ is cut almost its whole length into two fingers of equal width. One of the divisions is immersed in a boiling tube filled with benzol, while the other half is left hanging outside. In a few minutes the immersed division imbibes benzol and swells so that it is at least half again as long and as broad as the unimmersed division.

(b) Allow a sheet of ordinary glue to lie overnight on a moist surface so that the under portion of the glue alone is in contact with water. Note the increase in volume of the immersed portion and also the alterations in colour, opacity, elasticity, etc. 
(c) To show that imbibed fluid is held under compression. Tie a short piece of surgical laminaria tanga to the stem of a hydrometer (near the foot). Float in water and note the level. After some hours, again read the hydrometer scale. If the water imbibed is not under compression both readings should be the same.

(d) Effect of various electrolytes on imbibition. First of all, prepare a number of standardised gelatine dises as follows. Make a coneentrated solution of gelatine, adding a trace of a colloidal dye (e.g. Congo red) to render the gelatine easily visible. Pour the hot solution upon a glass plate and allow to set. With a large cork-borer (diam. 10-15 cm.), cut into discs which are dried, measured and weighed. Seven Petri dishes are required and are almost filled with the following fluids : (i) water, (ii) $\mathrm{N} / 10 \mathrm{HCl}$ or $\mathrm{H}_{2} \mathrm{SO}_{4}$, (iii) $\mathrm{N} / 10 \mathrm{NaOH}$, (iv) $\mathrm{N} / 2 \mathrm{KI}$, (v) $\mathrm{N} / 2 \mathrm{NH}_{4} \mathrm{CNS}$, (vi) $\mathrm{N} / 5 \mathrm{CaCl}_{2}$, (vii) Sat. $\mathrm{MgSO}_{4}$.

Put a few gelatine dises (not tonching one another) into each dish, immersing them quickly and completely to avoid the adherence of air bubbles. After an hour's immersion some of the discs will have visibly swelled. Leave for 24 hours and examine against a black background. Measure and weigh. Which disc has swelled most? Arrange the electrolytes in a descending order as they have favoured imbibition. This is the so-called lytropic series. Instead of gelatine, 1 per cent. agar may be used. The lytropic series will be in the same order.

(e) Effect of Acid on Imbibition. Stretch a piece of catgut vertically between a weight and a weighted frog-heart lever so that weight and catgut lie in a tall cylinder. The lever may be made to mark a smoked rotating drum. Set the drum going very slowly and almost fill the cylinder with water. Note the changes. Now add sufficient hydrochloric acid to make the whole fluid 1-2 per cent. acid and note the result.

26. Shell Formation (Rhumbler). (1) Mix a little powdered glass with chloroform and set a drop of the mixture in water. The glass particles gather rapidly round the surface of the drop.

(2) Repeat the experiment, using fine silver sand dispersed through oil and finally dropped into 70 per cent. alcohol. The movements take place more slowly and the drop requires about three hours to attain equilibrium.

27. Adsorption. (1) Adsorption of Colloids to a Surface. Into a number of flasks place a spoonful or two (2-3 gm.) of bone chareoal and pour into each, one of the following fluids. Shake vigorously and then pour into a large filter paper in a funnel.

Liquids to try : Berlin blue, congo red, acid fuchsin (2-3 mg. per 100 c.c.).

To show that lowering S.T. sets free the colloid, add methylated spirit to funnel mixture and collect filtrate.

(2) Adsorption of Colloid to Colloid. Capillary Analysis. Cut a number of strips $2 \times 15 \mathrm{~cm}$. from a good filter paper. (Do not take the slip from too near the edge of the sheet.) Hang two or three of these strips so that each one dips its edge into a narrow-necked vessel (Erlenmeyer flask) containing a fluid to be tested, taking care that the papers are immersed to the same and to a sufficient depth (about $2 \mathrm{~cm}$.), and that glass and paper do not come in contact. Filter paper becomes negatively charged in contact with water, and therefore positively charged colloids will become " fixed" electrostatically at the liquid-paper interface. while negatively charged colloids will ascend with their dispersion media. (i) Flask i. Water. 
ii. Aqueous night blue or Prussian blue. iii. Aqueous alkali blue. In 10 to 15 minutes examine the height of water and each dye on the strips.

(ii) Flask iv. Mixture of 20 c.c. 2 per cent. aqueous alizarin red and 0.5 c.c. sat. aqueous picric acid. Leave paper hanging in this mixture for 20-30 minutes. Remove and examine. Hold over strong ammonia for a moment to make alkaline (i.e. to redden the alizarin). How do you account for the extremely dark band at the junction of the stains of picric acid and picric-alizarin mixture.

(3) Adsorption of Salts to Colloids. Cut a series of dises 3-4 mm. thick from a fairly concentrated gelatine gel and place them in a Petri dish containing a 2 per cent. aqueous solution of commercial aluminium sulphate (contains iron) and leave for some days. In three days or so the gelatine becomes tinged reddish brown (ferric salts). Now test the original solution, the solution after standing with gelatine, and the gelatine itself for iron by adding a few drops of ammonium thiocyanate to each. Note the depth of colour.

28. An Acid Perfusate from an Alkaline Solution. Prepare some colloidal ferric hydrate either by dialysing 5 per cent. ferric chloride or by gradually adding 1 c.c. of 30 per cent. ferric chloride to 25 c.c. of boiling water. Put 10 to 15 c.c. of this sol into a dialysing thimble suspended in an Erlenmeyer flask, containing distilled water and some indicator (litmus or methyl red). Estimate the concentration of iron in the wash-water by abstracting, at each change of water, 10 c.c. of the fluid and adding $\mathrm{K}_{4} \mathrm{FeCy}_{6}$ solution. When the iron content becomes very small (after 48 hours) add some $\mathrm{HCl}$ to the colloid. Note the increase in the diffusibility of the Fe. How can you explain this? Why does an acid perfusate come from an electro-negative sol ?

29. Preparation of Colloidal Gold. (1) Protected Solution (Ostwald). To 100 c.c. of ordinary distilled water add a few drops of 1 per cent. neutral gold chloride. Mix and add a few drops of 0.1 per cent. tannic acid sol. Heat over a free flame till boiling, shaking it constantly. If the red colour does not appear on boiling add a little more tannic acid and a little more gold chloride alternately. Divide into two parts.

$A$. To one part, while still hot, add about an equal volume of water.

$B$. Cool the other part before diluting. $A$ is violet in colour while $B$ is cherry red. Blue gold sol. may be prepared from neutral 0.05 gold chloride. Take three portions of the gold chloride solution and add (i) 5-10 drops, (ii) 10-15 drops, and (iii) 15-20 drops respectively of a hydrazine hydrochloride solution prepared by adding a tiny crystal to about 20 c.c. of water. If (ii) does not turn blue add more hydrazine. If it is greenish, too much hydrazine has been added.

(2) Gold Sol for Colloidal Gold Test (p. 80). Heat 150 c.c. of triply distilled water (from a resistance glass still). Add 1 c.c. of 1 per cent. gold chloride solution and then 2.5 to 3 c.c. $\mathrm{N} / 5$ pure $\mathrm{K}_{2} \mathrm{CO}_{3}$. : Bring to the boil, stirring vigorously. Add gradually but not too slowly, 2-3 c.c. of 1 per cent. commercial formaline ( 1 c.c. 40 per cent. formaline in 99 c.c. of water) and remove the flame. See that the sol (which should be ruby red without any purple tinge) is neutral to alizarin red and that a 5 c.c. sample of it is completely reduced in one hour by adding 1.7 c.c. of 1 per cent. $\mathrm{NaCl}$.

(3) Determination of the $C_{12}$ of Colloidal Gold. Take a series of small test tubes of equal bore, etc., and range them in two equal rows. Into each 
tube put 1 c.c. of triply distilled water. To the first tube of one row add 1 c.c. of $\mathrm{N} / 50 \mathrm{HCl}$. Mix. Remove 1 c.c. of the mixture and add this to the second tube, and so on down the row. This will give a series of acid solutions as follows : $N / 100, N / 200$, etc. The other series of tubes is treated in exactly the same way with $\mathrm{N} / 50 \mathrm{NaOH}$. The final 1 c.c. of each series is discarded. Two drops of alizarin red and 1 c.c. of the gold sol are added to each tube and the contents mixed. The tube showing the neutral alizarin colour is picked out and its value determined. The whole gold sol is now neutralised by the addition of the exact amount of $\mathrm{NaOH}$ or $\mathrm{HCl}$ as the case may be.

30. Protective Action of Emulsoids (p. 80). Two equal portions (9 c.c.) of neutral gold sol are treated (1) with 1 c.c. of a 0.1 per cent. gelatine sol and (2) with 1 c.c. of distilled water. To both are added 1 c.c. of $\mathrm{N} / 1 \mathrm{NaCl}$ solution. Examine by pure transmitted light, i.e. by looking through the tubes at a uniformly illuminated screen of white paper.

31. Diffusion of Electrolytes and Colloids into Gels. Two-thirds fill four test tubes with 3 per cent. gelatine and allow to gel. Add 1 per cent. solution of (1) $\mathrm{CuSO}_{4}$, (2) picric acid, (3) colloidal iron, (4) Congo red, one to each tube, and put aside for some days.

32. Electrical Diffusion (p. 79). Fit up a U-tube with an electrode of platinum- or silver-foil rolled cylindrically at the top of each tube. Fill the tube two-thirds full with 3 per cent. gelatine containing a trace of citric acid, and allow to stand overnight to form a gel. Fill one limb with coloured electrolyte (e.g. $\left.\mathrm{CuSO}_{4}\right)$, the other with acidulated water. Determine roughly the rate of diffusion ( 2 hours). Then pass a current through the tube (lighting supply with a lamp in circuit) and note rate of diffusion ( 2 hours). Reverse the direction of the current for 2 hours or more and note changes. Try various electrolytes and find which are forced into the gel at the cathode and which at the anode.

33. Adsorptive Stratification. (Liesgang Phenomenon, p. 79). " 4 grams of gelatine are dispersed in 100 c.c. of water and 2 c.c. sat. potassium bichromate are added to the sol. The mixture is poured on clean glass plates to form a thin layer, about 0.45 c.c. per sq. inch of surface being allowed. The plate is supported on a horizontal surface and the sol allowed to set; 10-15 minutes will be required. A large drop of 20-30 per cent. silver nitrate is placed in the centre of the plate, preferably by allowing five successive drops of about $0 \cdot 1$ c.c. each to fall on the same spot from a small pipette.

The drop should have a clean circular outline. The plate is kept in the dark for 24-48 hours. At the end of this period any traces of the original drop may be removed with a pointed strip of filter paper, and the gel is then allowed to dry. (1) Use commercial gelatine. (2) Do not disturb the plate after adding $\mathrm{AgNO}_{3}$, till excess has been removed. (3) A trace of citric acid (5-10 drops of 5 per cent. solution to 100 c.c. of sol.) gives wider rings.

34. Electrophoresis (Fig. 10, p. 77, and letterpress, p. 78). The electrodes (Fig. 10) are two strips of platinum- or silver-foil fastened parallel to one another about $16 \mathrm{~mm}$. apart (Chatterton's compound is an excellent fixative). The slide is placed on a microscope with a paraboloid condenser (or with a small stop) and the lighting, etc., arranged to suit the particular type of condenser used. A large drop of the sol under examination is placed in 
the centre of the space between the electrodes, making contact with them and covered witl a $\frac{7}{8}$ in. glass. After 10 minutes the microscope is focussed on the central layer of liquid (particles not in contact with glass and free to move) and a current of 4-5 volts (keep amperage low) passed between the electrodes. Determine the sign of the electric charge on dialysed iron sol, gold sol, night blue, alkali blue, etc. Fit an eyepiece micrometer and with a stop-watch determine the velocity of the particles in $\mathrm{cm}$. per volt per sec.

35. Model to Illustrate some Phases of Urine Formation. (Fischer and MacLaughlin.) Prepare some cups of sodium stearate by pouring the hot stearate solution (1/10 molar) into a mould consisting of one beaker (120 e.c.) suspended within another similarly shaped (350 c.c.). A cup is supported on a filtration disc in a filter funnel whose stem enters the mouth of a graduated cylinder. Another cylinder (gas jar) or bottle inverted may be used as a constant level device. Fill the cup and the gas jar with the solution. Invert the full jar and suspend it vertically so that its mouth just dips below the surface of the fluid in the cup. From time to time measure the fluid in the lower graduated eylinder, say every hour.

Try the following solutions: (a) water (3-6 hrs.), (b) molar sodium oleate (24 hrs.), (c) NaCl 1/8 m., 1/4 m., and 1/1 m. (3-6 hrs.), (d) 1/8 m. $\mathrm{CaCl}_{2}$ (1-4 hrs.), (e) $1 / 8 \mathrm{~m} . \mathrm{NH}_{4} \mathrm{Cl}$ (7 hrs.).

Note increased flow with $(c)$ and $(d)$; initial increase and final decrease of flow with $(e)$ and total inhibition with (b). Test, in each case, the perfusion fluid, the perfusate and the cup, with phenolphthalein. How do you account for your results? Test the perfusates for fatty acids. Why does pure water dissolve out more of the acid than do the salt solutions?

36. Mimicry of Cell Structure (Herrera after Harting). A crystallising dish $18 \mathrm{~cm}$. in diameter is filled with colloidal silica. This may readily be prepared by dissolving freshly precipitated gelatinous silica in a solution of ammonia (density $26^{\circ}$ ). Silica is added till all the ammonia has been driven off and the colloid has a density of over 1.032 (i.e. 3-5 per cent. solid silica). (A solution of sodium silicate of a density of 1.020 may be used instead of colloidal silica.) At one edge of the crystallising dish place 10-20 mgrms. of recrystallised potassium bifluoride. At the diametrically opposite side of the dish place $5 \mathrm{gms}$. pure powdered anhydrous calcium chloride. Cover and keep at $20^{\circ} \mathrm{C}$. for 24 hours. Various structures which may be stained by any of the dyes used by histologists may be seen, e.g. nucleated amoebae, cells undergoing division, nuclear spiremes, granular and honeycomb structures, etc.

The figures are due to the strains produced in the silicate by the simultaneous formation of a colloid, calcium silicate and a crystalloid, calcium fluoride. Silica, coagulated by a crystalloid, gives rise to a semipermeable membrane, which, if it forms a sac round a crystalloid, may set up endosmosis. Slow amoeboid movements may be shown by some of the complexes lying near the point of insertion of the $\mathrm{CaCl}_{2}$. .Add a trace of alcohol over the $\mathrm{CaCl}_{2}$, and more rapid diffusion ensues.

3\%. Emulsions. 1. Take four test tubes and place in each 10 c.c. of olive oil. In addition add to $(a)$ a few drops of oleic acid and a drop of alcoholic $\mathrm{NaOH}$; to $(b)$ some (soft) soap solution; to $(c)$ a few drops of oleic acid and about the same quantity of conc. $\mathrm{Ca}(\mathrm{OH})_{2}$ solution and allow to stand. Which gives the best emulsions? 
2. To determine the optimum concentration of colloid for the stabilisation of an emulsion. Into each of three mortars introduce 20 c.c. of water, (a) containing 1.25 per cent. of commercial soft soap, (b) 1.875 per cent. and $(c) 2.5$ per cent. To each slowly add 120 c.c. of, say, cottonseed oil, stirring regularly but not too vigorously meanwhile. If possible, put on a mechanical shaker for $\frac{1}{2}$ hour. Pour into tall cylinders and allow to stand for some days.

3. Effect of concentration of oil on rigidity. Stir into four lots of 25 c.c. of 25 per cent. soft soap in mortars, (a) 50 c.c., (b) 100 c.c., (c) 200 c.c., (d) 400-500 c.c. of cottonseed oil. Place in shallow dishes. Note rigidity. What happens when the optinum concentration of oil has been passed.

4. Divide an emulsion of oil in water-(soap), (i.e. 120 c.c. oil in 20 c.c. 7 per cent. soft soap) into nine portions. No. (1) will serve as control. To the others add a few drops of one of the following $\mathrm{N}$ solutions, (ii) $\mathrm{HCl}$, (iii) $\mathrm{NaOH}$, (iv) $\mathrm{Ca}(\mathrm{OH})_{2}$, (v) $\mathrm{CaCl}_{2}$, (vi) $\mathrm{NaCl}$, (vii) Alcohol, (viii) $\mathrm{CHCl}_{3}$, (ix) Ether.

5. Instead of soap any hydrophilic colloid may be used, e.g. albumin, casein, acacia, dextrin, starch. The carbohydrate-stabilised emulsions are the hardest to break.

6. To 5 grams of dry casein in each of three mortars add slowly $(a) 50$ c.c. $\mathrm{N} / 20 \mathrm{NaOH},(b) 50$ c.c. water and to (c) 50 c.c. $\mathrm{N} / 20 \mathrm{HCl}$. Allow to stand overnight and then slowly stir 75 c.c. of cottonseed oil into each. Pour into clear jars and allow to stand. Why does $(b)$ separate out?

38. Model of Mucoid Secretion. (Fischer.) Grind up in a mortar a small quantity of gum acacia and one or two c.c. of cottonseed oil. Put a drop of this mixture on a microscope slide with cover glass and examine. Place a drop of water at the edge of the cover slip and note what happens when it touches the oil layer.

39. Comparison of the Electrical Conductivity of Equimolecular Solutions of Mineral and Organic Acids. Conductivity being the reciprocal of resistance, obviously can be measured by a resistance method, e.g. by the

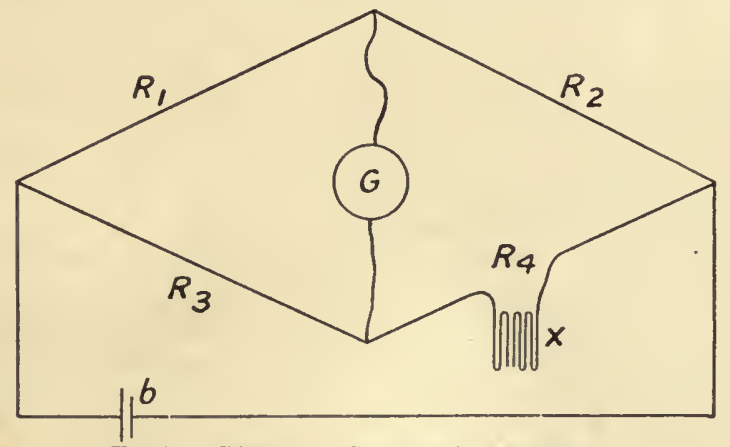

FIG. 78.-Diagram of Conductivity Apparatus.

Wheatstone bridge (Fig. 78). The current from $b$ is divided between two circuits (1) by $R_{1}$ and $R_{2}$ and (2) by $R_{3}$ and $R_{4}$ (where $R=$ resistance in ohms). The amount of current travelling by these circuits is such that the drop of potential in both is the same. If then a lead be taken from the junction between $R_{1}$ and $R_{2}$ and connection made with the $R_{3}, R_{4}$ route 
so that $R_{1} / R_{2}=R_{3} / R_{4}$, then no current will flow through the lead as shown by the indicator $(G)$, a galvanometer, lamp, telephone receiver, etc. Thus $R_{1}, R_{2}$ and $R_{3}$ being known, $R_{4}$ can be found. In practice, the lead fixed between $R_{3}$ and $R_{4}$ terminates in a jockey-piece which slides along a platinum, iridium, or nickelin wire of uniform resistance and a metre long, constituting $R_{1}, R_{2}$. The length of $R_{1}$ is read from an underlying scale when $G$ indicates that no current is passing.

Owing to polarisation occurring at the electrodes when a steady current is passed through an electrolyte, it is necessary to employ an alternating current which renders a galvanometer useless as an indicator. The alternating current is usually got from the secondary terminals of an induction coil. As an indicator, one may use a telephone receiver or a small A.C. pea lamp.

Expt. (a). Rough Demonstration. Fit up a Wheatstone bridge, using a 4 -volt accumulator with switch as $b$, and a pea lamp as $G . R_{3}$ is a resistance box and $R_{4}$ or $x$ is a simple type of conductivity cell, e.g. a beaker containing the solution to be tested with two sheet-silver electrodes. Find the point on the metre wire when the light from the lamp is at its minimum $=x$. Then conductance

$$
c=\frac{x}{R_{3}(100-x)^{2}}
$$

and the molecular conductivity is equal to $C \phi$, where $\phi$ is the volume in c.c. in which 1 mole is dissolved. Suitable solutions $=1 / 16$ molar hydrochloric, acetic, and benzoic acids; $1 / 8$ molar NaCl and glucose. (N.B.Keep the switch from $b$ open as much as possible to prevent polarisation of the electrodes of $x$.)

(b) With the same apparatus the neutral point of a titration may be determined. Place 20 c.c. of $\mathrm{N} / 50 \mathrm{NaOH}$ in the conductivity cell and arrange the resistance box $\left(R_{3}\right)$ so that the bridge reading is about $50 \mathrm{~cm}$. From a burette run in a standard $(\mathrm{N} / 50)$ solution of $\mathrm{H}_{2} \mathrm{SO}_{4}$ and mix as in titration, determining the point of balance on the wire after each addition. It will be found that the balance point will first tend towards the zero end of the scale and later will move in the reverse direction. The point at which it changes direction is the electrotitrametric neutral.

For any but very rough readings, many precautions have to be observed. These will be found in any book on practical physical chemistry. Instead of a lamp, the capillary electrometer may be used as an indicator.

40. (i) Buffer Solution. Sørensen. (a) M/15 solution of $\mathrm{KH}_{2} \mathrm{PO}_{4}$ (9.078 grams per litre). The salt should be chemically pure, and its solution should be water clear and free from even traces of chloride and sulphate.

(b) $\mathrm{M} / 15$ solution of $\mathrm{Na}_{2} \mathrm{HPO}_{4} \cdot 2 \mathrm{H}_{2} \mathrm{O}$ (11.876 grams per litre). The salt is prepared by exposing to the air the recrystallised $\mathrm{Na}_{2} \mathrm{HPO}_{4} \cdot 12 \mathrm{H}_{2} \mathrm{O}$. After two weeks' exposure on a porous plate, dissolve the salt in water and test for chloride and sulphate. 8 c.c. of $(a) \mathrm{KH}_{2} \mathrm{PO}_{4}+2$ c.c. of $(b) \mathrm{Na}_{2} \mathrm{HPO}_{4}$ $2 \mathrm{H}_{2} \mathrm{O}$ gives a solution of $p \mathrm{H} 7 \cdot 381$.

(i) To demonstrate the acid-combining power of a "buffered" solution. Take 50 c.c. of the above mixture or prepare a solution containing about 0.25 per cent. sodium bicarbonate. Place this in a tall cylinder and in another similar vessel place the same quantity of water. Add about 20 drops of neutral red (0.05 per cent. in alcohol) to each. Add N/10 NaOH 
to the water till it has approximately the same $p \mathrm{H}$ as the bicarbonate. Titrate both with $\mathrm{N} / 50 \mathrm{HCl}$ to the same end point:

(ii) To demonstrate the effect of the tension of $\mathrm{CO}_{2}$ on the $\mathrm{pH}$ of. a solution of bicarbonate. Put 5 c.c. of a $0 \cdot 25$ per cent. solution of $\mathrm{NaHCO}_{3}$ in each of three tall stoppered cylinders. To each add 2 drops of neutral red. Fill $(a)$ with air expired after a deep inspiration, $(b)$ with alveolar air (Expt. $43)$ and $(c)$ with $\mathrm{CO}_{2}$ from a generator or cylinder. Stopper and shake. Note colours. Remove the $\mathrm{CO}_{2}$ in $(c)$ by repeated changes of atmospheric air. Note that the colour goes back from crimson through the red of $(b)$ to the orange of $(a)$ or even to the yellow seen before any $\mathrm{CO}_{2}$ was added.

41. An Approximate Determination of the Alkali Reserve of Blood. (Rieger.) Principle. Erythrocytes are easily damaged by acid. This will lead to agglutination and haemolysis on the addition of acid as soon as the reserve of base has been used up.

Method. Twelve test tubes $\left(8^{\prime \prime} \times 1^{\prime \prime}\right.$ or thereabout) cleansed thoroughly and dried are set in a rack. The first or stock tube is charged with 18 c.c. of a 0.85 per cent. solution of $\mathrm{NaCl}$ (pure salt in distilled water) and 2 c.c. of whole blood (oxalated with 0.2 per cent. pure sodium oxalate). Mix thoroughly by drawing up into the pipette several times, keeping the tip of the pipette always below the surface of the liquid.

One c.c. of the diluted blood is placed in the bottom of each tube, avoiding the sides, and then, starting on the left, $\mathrm{N} / 100 \mathrm{HCl}$ is added from a graduated pipette. The first is given 0.7 c.c. acid, the next 0.75 and so on, increasing the amount by 0.05 c.c. with each tube, the last tube thus receiving 1.20 c.c. In about an hour examine the tubes. Those on the left should show no haemolysis and the corpuscles should be settled in a sharply defined clump in the centre of the foot of the tube. The tube on the right may show haemolysis and have corpuscles scattered over the bottom in an irregular manner, giving a speckled appearance. The tube with the greatest amount of acid which shows no haemolysis or scattering of corpuscles gives an indication of the alkali reserve of the blood.

For example: Normal blood-the first seven tubes (i.e. 0.7-1 c.c.) are clear, tube 8 shows scattering and slight haemolysis. Therefore $0 \cdot 1$ c.c. of blood can neutralise 1 c.c. of $\mathrm{N} / 100 \mathrm{acid}$, or 100 c.c. of blood contains base equivalent to 0.42 grams $\mathrm{NaHCO}_{3}$. This would, in Van Slyke's apparatus, give rise to 112 c.c. of " bound " $\mathrm{CO}_{2}-$ a somewhat high result (see 42 and 43), probably due to interaction of acid and protein.

42. Alkali Reserve. (C. J. Martin.) Principle. Dilution of a wellbuffered solution such as plasma does not alter its $C_{\mathrm{H}}$. If an indicator is used which has a low protein error the plasma may be titrated with acid. The titration value indicates the acid-combining power of the plasma.

Apparatus. A small wooden stand to hold three "non-sol" glass test tubes $(8 \times 0.8 \mathrm{~cm}$.) vertically in a row and close together. The central tube at its upper end runs through the rubber stopper of an inverted "non-sol" flask (100-150 c.c.).

Method. The flask is removed from the central tube and 0.5 c.c. of plasma or serum and 2 c.c. of neutral 0.9 per cent. sodium chloride added. The side tubes are almost filled with a phosphate buffer mixture of $p \mathrm{H}=7 \cdot 4$. These standard tubes are coloured by the addition of a drop of two aqueous solutions of burnt sugar and flavine $(1 / 100,000)$ till they match the fluid in the central tube. To all of the tubes are then added 2 drops of 0.05 per

B. B. 
cent. (alcoholic) neutral red. The optical effect of the turbidity of the plasma may be counteracted by placing a sheet of white tissue paper behind the tubes. The plasma mixture is titrated with $\mathrm{N} / 50 \mathrm{HCl}$ (2 c.c. burette with fine nose) till its colour matches the standards. This is done by running the plasma into the flask, adding a few drops of acid and rotating gently but steadily for 1 minute, the flask meanwhile being in communication with the air. This readily allows the thin film of plasma to give up the liberated $\mathrm{CO}_{2}$. The fluid is run back into the tube and compared with the standards. The process is repeated as often as necessary. . Rotation for at least 1 minute is necessary after each addition of acid.

Titration value for 0.5 c.c. plasma $=0.77$ c.c. $\mathrm{N} / 50 \mathrm{HCl}$, i.e. Alkali reserve of $\quad " \quad, \quad=0.77$ c.c. $\mathrm{N} / 50 \mathrm{NaHCO}_{3}$

$$
\begin{aligned}
" \quad 100 \text { c.c. " } " & =154 \mathrm{c} . \mathrm{c} . " \\
& =3.08 \mathrm{~N} " \\
& =3.08 \times 22.4 \text { c.c. } \mathrm{CO}_{2},
\end{aligned}
$$

i.e. 68.99 volumes per cent. of $\mathrm{CO}_{2}$ are bound as bicarbonate in the plasma.

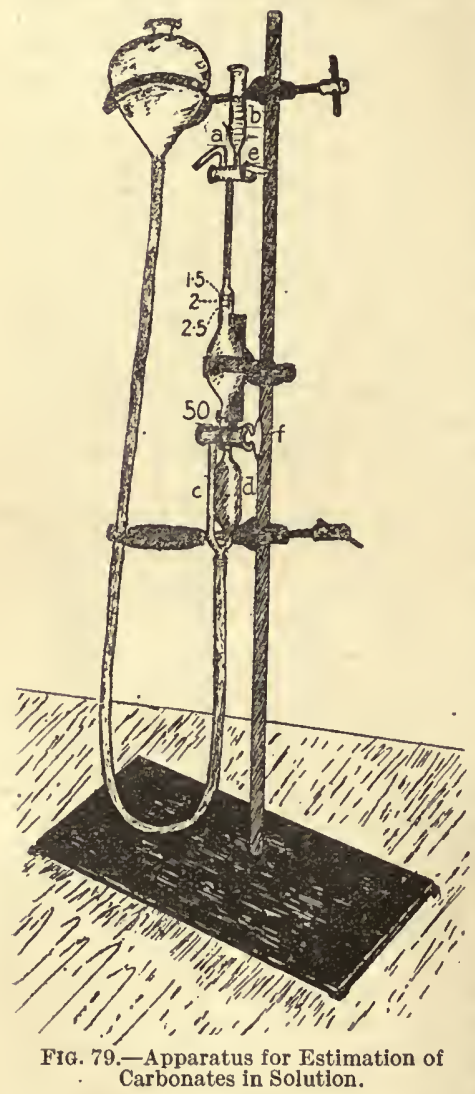

A sharper end-point is obtained by the use of phenol sulphonephthalein as indicator. In this case the standard phosphate solutions are made of $p \mathrm{H} 7 \cdot 2$ to correct the protein error.

43. Alkali Reserve by Van Slyke's Method. The Van Slyke apparatus is illustrated in Fig. 79. It consists essentially of a 50 c.c. pipette with three-way stopcocks $(e$ and $f)$ at top and bottom, and a 1 c.c. scale on the upper stem, divided into 0.02 c.c. divisions. The body of the apparatus is connected through heavy walled rubber tubing with a levelling bulb filled with mercury. The whole apparatus is supported on a stand so that, without unclamping, the pipette may be rotated round a central axis. The stopcocks are lubricated with a rubber-vaseline mixture and may be held in place by strong rubber bands.

Preliminary preparation. Open taps e and $f$ and fill the entire apparatus with mercury by raising the levelling bulb, allowing some mercury to run into $a$ and into $b$. Shut $e$, and lower the levelling bulb till the mercury falls half-way down $c$ and $d$. The bulb is then slowly raised. If the apparatus is gas-free, a sharp click will be heard when the mercury strikes the upper stopcock. If a gas cushion is present, open $e$, and force the gas out, and repeat the evacuation process, opening $f$ alternately to $c$ and $d$.

Determination. (1) Solutions required. It is convenient to have four 
dropping bottles with ground in pipettes and rubber teats containing (a) 5 per cent. $\mathrm{H}_{2} \mathrm{SO}_{4},(b) 1$ per cent. carbonate-free $\mathrm{NH}_{3}$ water, (c) caprylic alcohol and $(d)$ distilled water. The carbonate-free ammonia is prepared by adding a small amount of sat. barium hydrate solution to ordinary ammonia solution. The barium carbonate is filtered off, and the excess of barium remaining is precipitated with a little $\left(\mathrm{NH}_{4}\right)_{2} \mathrm{SO}_{4}$.

(2) Plasma. An ordinary centrifuge tube is fitted out with rubber cork and glass tubes just like a wash-bottle. The longer tube bears at its upper end a hypodermic needle. The whole apparatus-glass, tubes and needleis washed out with a saturated solution of neutral potassium oxalate. (Van Slyke and Cullen point out that it is desirable that the subject should avoid vigorous muscular exertion for at least an hour before the blood is drawn. It is also best to avoid stasis, or when stasis is unavoidable the ligature should be released as soon as the vein is entered. In this case, the first sample of blood should be neglected.) The blood should run into the tube without suction. By a gentle rotary motion, mix the blood with the finely crystallised oxalate left adhering to the walls of the vessel, and centrifuge at once. The plasma is then transferred to sampling tubes (Fig. 80),

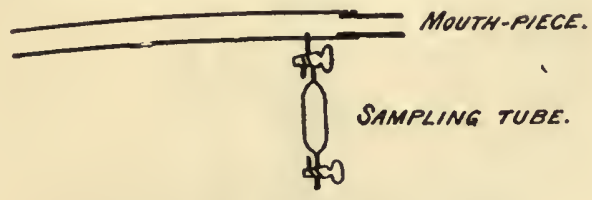

FIG. 80.-Alveolar Air Collecting Tube.

3-4 c.c. of plasma to each tube. These tubes (300 c.c.), or separating funnels of the same capacity, are filled with alveolar air (of the subject, if possible). This may be done by holding the tube horizontally, opening both taps and, without inspiring more deeply than normal, expire as quickly and as completely as possible through the tube, closing the further tap just before the expiration is finished. A bottle containing large glass beads must be interposed between mouth and funnel in order to prevent dilution of the plasma by condensation of vapour from the breath. With both taps closed, the funnel is rotated (not shaken) so that the plasma forms a thin layer over the walls, and so readily comes into equilibrium as regards $\mathrm{CO}_{2}$ tension with the alveolar air.

(3) Procedure. The apparatus is entirely filled with mercury, including the two capillaries ( $a$ and stem of $b$ ) at the top. The cup $b$ is washed with $\mathrm{CO}_{2}$-free $\mathrm{NH}_{3}$. 1 c.c. of plasma is run into the cup from an Ostwald-Folin pipette, keeping the tip of the pipette immersed in the fluid. Placing the mercury reservoir in the second ring (Fig. 79) and with cock $f$ open to $d$, open $e$ and admit the plasma to the pipette, leaving sufficient in $b$ to fill the capillary. Wash the cup twice into the pipette using about 0.5 c.c. of water each time, adding a very small quantity of caprylic acid to the second wash water. Finally run in 0.5 c.c. of 5 per cent. $\mathrm{H}_{2} \mathrm{SO}_{4}$ and seal the capillary with mercury. The fluid must come to the 2.5 c.c. mark. Wash out the cup with water and then with carbonate-free ammonia till acid-free. The mercury bulb is now taken to a position (about $80 \mathrm{~cm}$. below the second ring) so that a Torricellian vacuum is formed in the gas pipette. Allow the mercury to run down almost to (but not below) the 
50 c.c. mark. Close $f$ and replace the bulb on the upper ring. Slacken the milled head of the screw that controls the central swivel. Holding the pipette at the bulb with the right hand and gathering up the loose rubber tubing with the left, rotate the bulb through $180^{\circ}$ some 15 times. Set vertically and tighten the milled head. Lower reservoir and, with $f$ open to $d$, rapidly empty the water solution into $d$ without however allowing any of the gas to follow it. Now open $f$ to $c$ and, by raising the reservoir, fill the body of the pipette with clean mercury. Hold the reservoir in such a position that pressure inside the reservoir is atmospheric and rapidly take a reading. If thought desirable, re-extraction may be carried out.

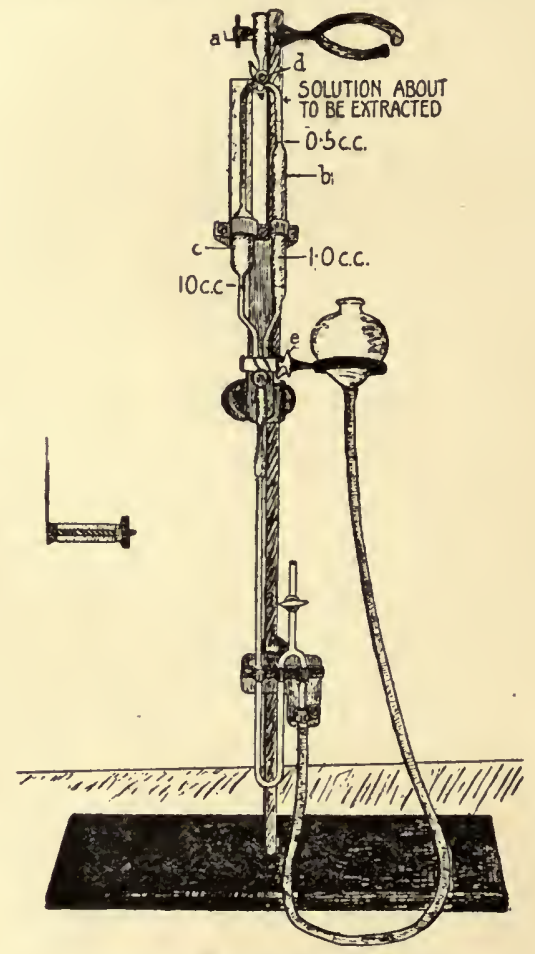

FIG. 81.-Van Slyke Micro Apparatus.

Cleaning. Lower the reservoir and run most of the mercury back through $c$. Open $f$ to $d$ and, by raising the reservoir, run the water back into the pipette. Open $e$ to $a$ and force the fluid out into a collecting jar. The apparatus is now ready for another determination.

Micro apparatus (Fig. 81). This apparatus is easier to manipulate, and as water, etc., never enters the gas pipette, it is easily kept clean. The different parts are in the same relative proportions as the corresponding parts of the larger apparatus. Each division of 0.002 c.c. on the smaller corresponds to 0.01 c.c. on the larger.

(1) It is advisable to mark the course of the canals with pencil on the butt end of the tap $d$. 
(2) No froth preventer is necessary or advisable. It merely acts on the tap lubricant.

(3) All quantities are reduced to $1 / 5$ of those given above, e.g. $0 \cdot 2$ c.c. plasma, 0.1 c.c. water, and 0.1 c.c. acid. In all, exactly 0.5 c.c. of fluid is used.

Calculation of Results.

TABLE LXXXI.

Table for Calculation of $\mathrm{CO}_{2}$-Combining Power of Plasma (from Van Slyke and Cullen).

\begin{tabular}{c|c|c}
\hline & \multicolumn{2}{|c}{$\begin{array}{c}\text { C.c. of } \mathrm{CO}_{2 \cdot} \text { Reduced to N.T.P. bound as } \\
\text { Bicarbonate by } 100 \text { c.c. of plasma. }\end{array}$} \\
\cline { 2 - 3 } & $15^{\circ} \mathrm{C}$. & $20^{\circ} \mathrm{C}$. \\
\hline 0.2 & $9 \cdot 1$ & $9 \cdot 9$ \\
0.3 & $18 \cdot 8$ & $19 \cdot 5$ \\
0.4 & $28 \cdot 4$ & $29 \cdot 0$ \\
0.5 & $38 \cdot 1$ & $38 \cdot 5$ \\
0.6 & $47 \cdot 6$ & $48 \cdot 1$ \\
0.7 & $57 \cdot 4$ & $57 \cdot 6$ \\
0.8 & $67 \cdot 1$ & $67 \cdot 2$ \\
0.9 & $76 \cdot 8$ & $76 \cdot 7$ \\
1.0 & 86.5 & $86 \cdot 2$ \\
\hline
\end{tabular}

Intermediate values may be obtained by interpolation.

$B=$ observed barometric pressure.

Normal range-adult 53-77 c.c., infants about 10 per cent. lower.

44. Alterations of the Surface Tensions of Oil-Water Interface by Alterations in Hydrogen Ion Concentration (Hartridge and Peters, Jour. Physiol. LIV., Proc. XLI.). Oil free from fatty acids or soaps is essential. Pure olive oil, castor oil, or cod-liver oil may be freed from these bodies by boiling for a number of hours with frequent changes of a considerable excess of tap water. A series of test tubes $6 \times 5 / 8^{\prime \prime}$ each receives 5-10 c.c. of the treated oil. Into each is put a capillary tube 4 " long, open at both ends. The test tube is almost filled with the fluid to be tested. Try solutions having a $p \mathrm{H}$ of $9,8,7,6$. Measure the height to which the oil rises in the capillary.

45. Principle of Measurement of H-ion Concentration by Potentiometer. The principle is much the same as that of the conductivity measurements (Fig. 78), only instead of having a single source of potential and an unknown resistance, one has known resistances and two sources of E.M.F., one of which is of unknown value.

In Fig. 78, $b$ may be taken as a cell of standard E.M.F. sending its current through the wire bridge $R_{1}-R_{2}$. If we lead into $R_{1}-R_{2}$ the wires from another battery $x$, taking care that the direction of the difference of potential is the same, e.g. both negative poles leading to $R_{1}$, as the fall of potential along $R_{1}-R_{2}$ is regular, we can readily divide the wire so that the difference of potential between the point of entrance and exit of the current from $x$ is equal and opposite to the difference of potential between the same points caused by the standard cell, i.e. the galvanometer or electrometer will 
indicate no E.P.D. The cell $x$ is of interest. It consists of two half cells or electrodes. One of these is the ordinary standard calomel electrode, i.e. an electrode of mercury covered with $\mathrm{HgCl}$ in the presence of a definite concentration of $\mathrm{KCl}$. The other half cell is a hydrogen electrode, i.e. platinum black laden with hydrogen and immersed in a solution containing H-ions. The difference of E.M.F. between electrode and solution depends on the concentration of $\mathrm{H}$-ions in the latter.

The difference of potential between the calomel and normal hydrogen electrode can be ascertained. This value is subtracted from the total E.M.F. of the cell to give a value from which the $p \mathrm{H}$ may be calculated.

46. Determination of the Relative Viscosity of Blood (see expt. 24). Blood may be taken from the lobe of the ear or from the finger. The skin is thoroughly cleansed with ether and pricked with a fine pointed lancet.

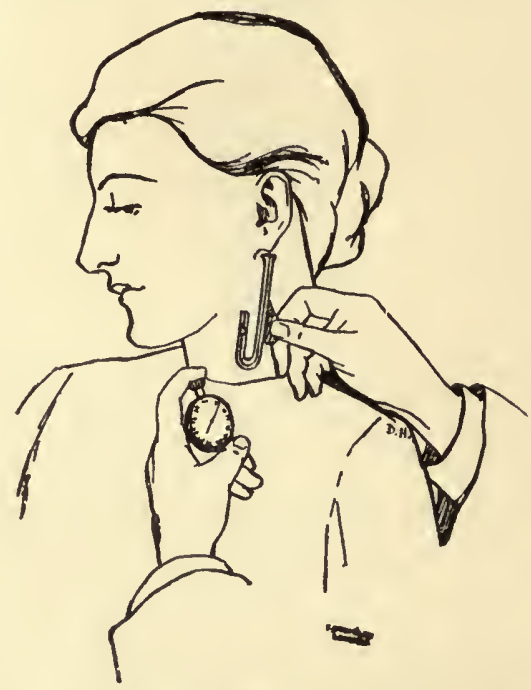

Fia. 82.-Denning-Watson Clinical Viscozimeter (Hawksley).

The viscosimeter (at body temperature) is held vertically under the bleeding spot and the receiver filled (Fig. 82). Measure as in expt. 24.

Immediately after an observation, the blood should be driven out by a blast from an inflator attached by rubber tubing to the short arm of the capillary.

It is advisable to make a blood count at the same time (p. 242).

47. Haematocrite. This apparatus consists of two similar graduated capillary tubes, which, after clipping in a holder, may be spun horizontally by a centrifuge. A small measured quantity of Müller's fluid ( $\mathrm{Na}_{2} \mathrm{SO}_{4}-1 \mathrm{gm}$.; $\mathrm{K}_{2} \mathrm{Cr}_{2} \mathrm{O}_{7}-2 \mathrm{gm}$.; distilled water, $100 \mathrm{gm}$.) is placed in a test glass. The same quantity of blood is added. Mix thoroughly with a glass rod. Fix a short length of rubber tubing furnished with a mouthpiece to each of the graduated tubes and suck up sufficient of the mixture to fill the tubes. Place them in a holder and spin for 5-7 minutes with a velocity of 8000 revs. per minute. Read off the relative length of the column of corpuscles. As the glass walls of the 
tubes are thick, it is advisable to aid the eye by looking along a glass plate held at right angles to the tube. The tubes have a bore of one square $\mathrm{mm}$. and are divided into 100 equal parts. The reading multiplied by 2 will give the volume of corpuseles in 100 parts of blood. The function of the Müller's fluid is to retard clotting and to fix the red corpuscles in their natural size.

48. Blood Pressure Model. (a) General distribution. Examine the schema (Fig. 83) of the circulation given you and identify the parts representing arteries, capillaries and veins. Disconnect the rubber ball $H$ and the two Bunsen valves $V, V$. Attach the arterial tube $A$ to the water supply and lead the tube from $G$ to the sink. Cautiously turn on the water and measure the pressure in the arteries (at $B$ ), and in the veins (at $E$ ). (It is more economical to have single vertical tubes at $B$ and $E$, the pressures read off in $\mathrm{mm}$. of water may be calculated in $\mathrm{mm}$. of mercury.)

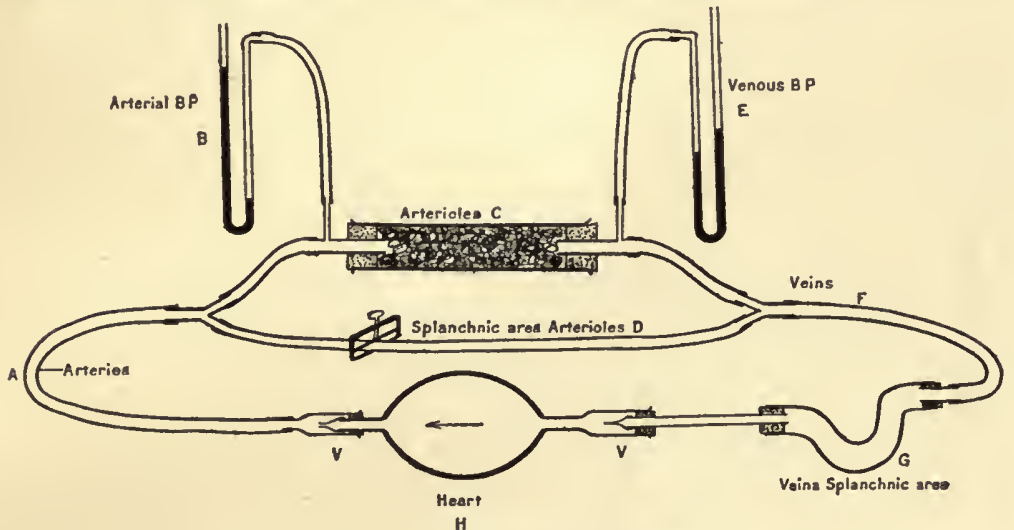

Fia. 83.-Schema of the Circulation.

Note the effect of $(a)$ varying the force of inflow by manipulation of the water tap, $(b)$ varying the resistance to flow by tightening the clip at $D$. With a steady pressure over its whole length, compress $G$ and note alteration in manometer levels.

(b) Pulse. Fill with water and replace $H$ and $V-V$ in circuit. Gently compress and relax $H$ at regular rhythmic intervals of about a second. Note the effect of this upon the arterial and venous pressures. Study the further effect of constricting $D$.

(c) Place a finger on $A$ and note the expansion with each contraction of $H$. Study the same thing on $D$ and on $F$.

49. (a) Conduction of Sound Waves by the Cranial Bones. Place a vibrating tuning fork in the region of the interparietal suture. From where does the sound apparently come? Place the tip of the finger into the auditory meatus of one ear and then block both ears. Explain.

(b) Binaural Localisation of Sound. With the eyes closed listen to the ticking of a watch through a binaural stethosoope. Pinch one of the tubes to prevent transmission of sound to one ear. Release and repeat with other tube.

50. Vowel Sounds by Percussion. Place the mouth in the position necessary for the pronunciation of the various vowels and then percuss 
over the cheek (Fig. 70). Now shift the point of percussion to a position over the pharynx just behind the angle of the jaw and percuss again. Note that the "cheek notes" rise as one passes from $\mathrm{U}-\mathbf{O}-\mathbf{A}-\mathbf{E}-\mathrm{I}$, while the "pharynx notes" rise $\mathrm{U}-\mathrm{O}-\mathrm{A}$ and fall to $\mathrm{E}$ and $\mathrm{I}$. This demonstrates the double nature of the mouth cavity in producing $\mathrm{E}$ and $\mathrm{I}$.

51. Prepare a series of bladders filled completely with $(a)$ air, $(b)$ water and $(c)$ some viscous fluid like syrup and $(d)$ lard. Percuss and palpate each.

52. Demonstration of the effect of colour on the absorption of radiant energy (L. Hill). Two similar pieces of cotton tape, one white and the other black, are suspended so that the end of each dips in a graduated cylinder filled with water. Place first in the shade and measure the amount of water evaporated from each cylinder during a period of 30 minutes. Refill with water to the same level and repeat the experiment in direct sunlight.

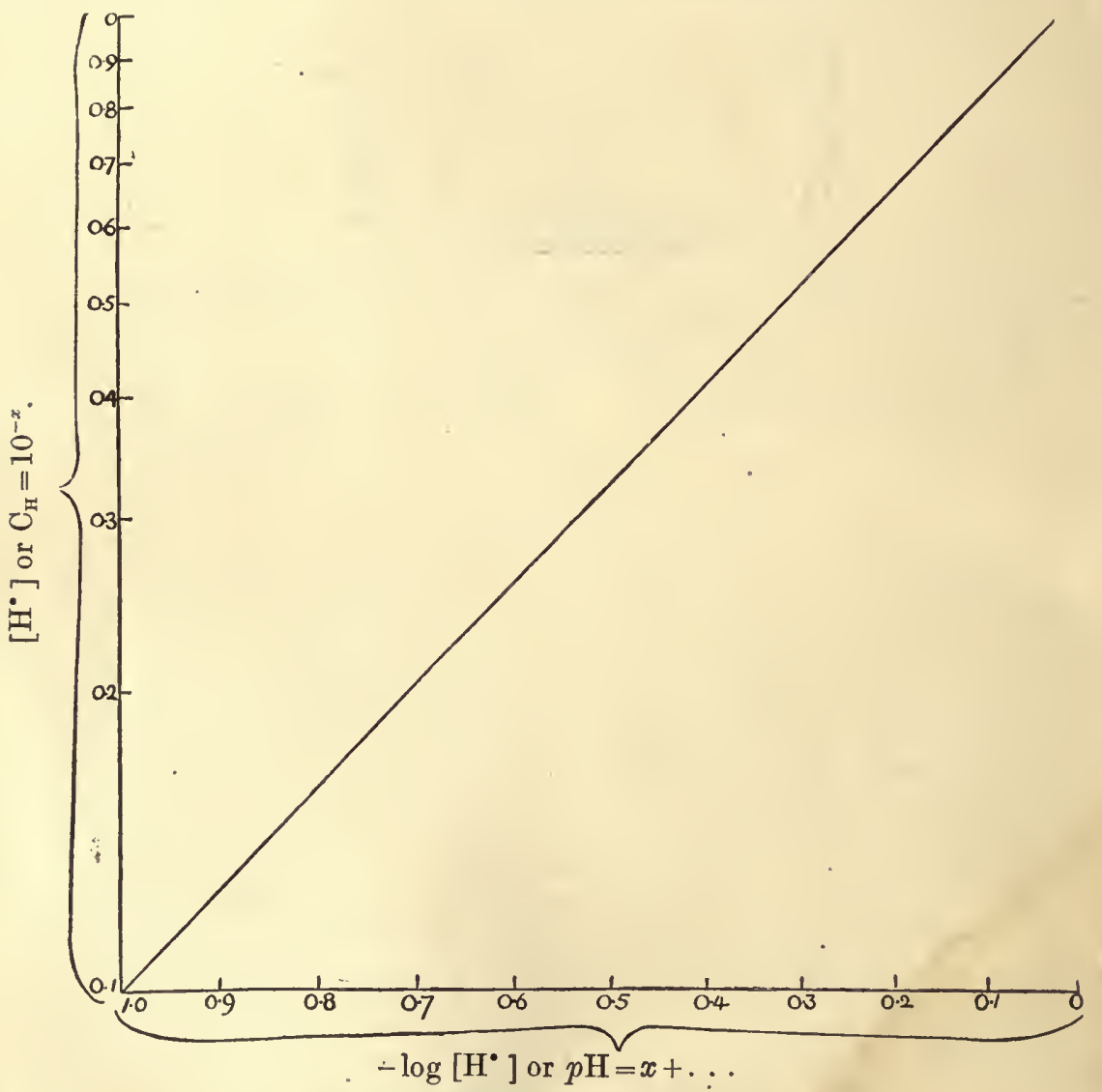

Fra. 84,-Graph for Conversion of $p \mathrm{H}$ to $\mathrm{C}_{\mathrm{H}}$.

Graphic Conversion of S $\varnothing$ rensen's $p \mathrm{H}\left(-\log \left(\mathrm{H}^{*}\right)\right)$ into Concentrations of Hydrogen Ions and the reverse (Roaf, Journ. of Physiol.). Fig. 84 is a graph 
whereby the logarithmic notation of Sørensen can be converted at sight into true concentrations. It would be advisable to redraw the figure on semi-logarithmic paper and so enable the reading to be taken to two places of decimals. For example, to convert $p \mathrm{H} 6.7$ into $\mathrm{C}_{\mathrm{H}}, p \mathrm{H}=6$ is $\mathrm{C}_{\mathrm{H}}=10^{-6} ; 0.7$ cuts the diagonal line opposite 0.2 ; therefore

$$
p \mathrm{H} \text { of } 6 \cdot 7=\mathrm{C}_{\mathrm{H}} \text { of } 0.2 \times 10^{-6} \text {. }
$$

Estimation of the Surface Area of the Body. Rubner announced that the amount of heat produced by an animal is proportional to its superficial area. This law of surface area has rendered necessary the accurate determination of the skin surface in most metabolism experiments.

Since the surface of a figure varies as the square, and that of volume as the cube of its linear dimensions, it follows that

$$
S=K \sqrt[3]{V^{2}}
$$

where $S=$ surface, $V=$ volume and $K=$ constant, or, as weight $(W)$ varies directly as volume,

$$
S=K \sqrt[3]{W^{2}}
$$

Meeh, from sixteen experiments, suggested that $K$ should be $=12.3$ for adults; and Lissauer used the value $10 \cdot 3$ for children. The average error of this calculation is about 16 per cent.

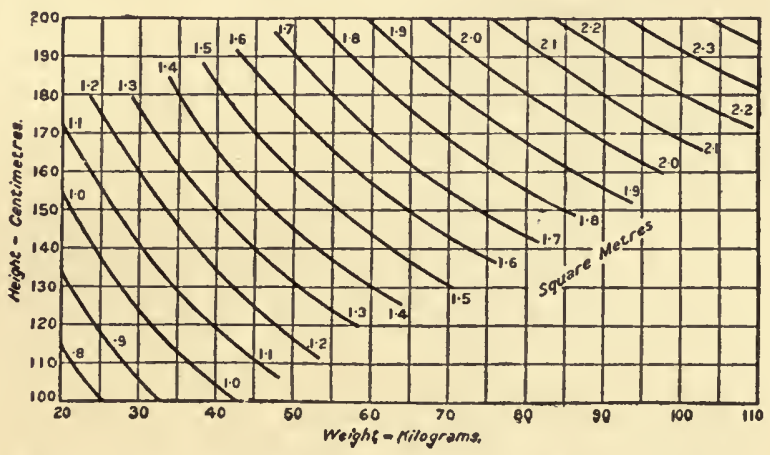

Fig. 85.-Du Bois Graphs for Estimating the Area of Body-Surface.

The brothers Du Bois covered the body-surface of their subjects with "tights" and applied melted paraffin. Paper strips were affixed to prevent change of area during the process of removing the "shell." The model of the surface, cut into pieces sufficiently small to be flat, was photographed upon squared paper of uniform thickness. The weight of each square on the paper was known. The darkened portions of the paper were carefully cut and weighed, and from this was calculated the area of body surface. The formula resulting from this work involved nineteen measurements. From this they have evolved a two-measurement formula on which the appended chart is based (Fig. 85).

The Field of Vision (see p. 225). The extent of the field of vision may be measured approximately as follows :

Describe a semi-circle on a blackboard with the free ends of the line finishing at one side. Mark the centre of the circle at the edge of the board, 
and the middle point of the circumference with an $X$. This forms a rough "Perimeter."

The subject of the experiment closes one eye and places the other at the centre of the semi-circle, directing his gaze at the middle point of the circumference. The observer slowly draws a sinall object, say a piece of chalk, along the circumference from below. The subject states when it becomes visible and the other marks this point. The process is repeated, starting from above, and the point when the object comes into view is again marked. The angle formed by joining these points to the centre of the circle subtends the vertical field of vision.

By turning the blackboard into the horizontal plane, or by using the top of a table, the horizontal field of vision may be mapped out.

Movements of the Eyeball. The movements of the eyeball may be studied by means of a ball of wool. Make some mark on it to represent the pupil, and thrust three knitting needles through the ball to represent the axes round which the eyeball rotates (Fig. 51, p. 223). The movements can then be reproduced with a fair degree of aceuracy. 


\title{
INDEX
}

\author{
(References to Part II. are in italics.)
}

Absorption coefficient of gases in liquids, 247 ; from alimentary canal, 317,318 ; of light, 15, 18, 71, 72 ; of heat, 343 , 345,424 ; of solutes by renal tubules, 163 ; spectrum of chlorophyll, 14 .

Accessory factors of diet, 372 .

Acclimatisation, 267.

Accommodation in eye, 220.

Acid, action of, on emulsions, 86, 378, 381,389 ; on fats, 421 ; on soaps, 82 ; on tissues, $381,389$.

Acid, effect of, on dissociation curve of $\mathrm{HbO}_{2}, 253$; on imbibition of water by colloids, $378,389,411$.

Acidity, numerical expression of, 57, $58,424$.

Acquired characters, transmission of, 361 .

Adaptation, 360.

Adipose tissue, 173.

Adsorbed material, state of, 66,153 .

Adsorption, 66, 98, 111, 378.

Adsorption and osmosis, 66, 153.

Adsorption by enzymes, 94, 98; cause of, 48 ; demonstrations, 411 ; effect of temperature on, 94, 109 ; of gases by colloids, 248, 332 ; of carbon dioxide by haemoglobin, 254,334 ; of oxygen by haemoglobin, 248, 251; specific surface for, 66,94 .

Adsorptive stratification (Liesgang phenomenon), 79, 413.

Agar-agar, 82.

Agglutination, 79 .

Alimentary canal, general plan of, 313 .

Alkali reserve of blood, 241, 333, 417, $418,419$.

"All or nothing," in nerve, 185.

Alveoli, 260.

Amicron, 74.

Amoeboid movement, 130, 403, 404.

Amphoteric colloids, 332; electrolytes, 59.

Anabolism, 2, 374.
Anaesthetics, action on colloids of, 83, 86 .

Analyser, 102, 104.

Angle of origin of blood ressels, 292 .

Angstrom units, 14, 127.

Anion and cation, 49, 52 .

Anode, 50.

Anti-enzyme, 97.

Anti-pro-thrombin, 236, 238.

Anti-thrombin, 236, 238.

Antrum pylori, 317.

Aortic valves, $289,290$.

Arrhenius' theory, 44.

Arteries, pressure in, 281.

Arterioles, pressure in, 281.

Artificial laccase, 94; membranes, 41, $109,398,399,405,407$; parthenogenesis, 378 .

a rays, 120.

Astral rays, 383.

Asymmetric carbon atom, 105, 106.

Antocatalysis and growth, 365 .

Autolysis, 389.

Available energy, 9 ; of cell, 36 .

Avogadro's hypothesis, 38.

Axial repulsions, law of, 376 .

Bacon, Instances of Magic (quoted), 91. Balanced chemical reactions, $99,376,381$.

Barger's vapour pressure method for determination of osmotic pressure, 402.

Barotaxis, 131.

Basilar membrane, 209.

Beckmann thermometer, 400.

Benzol, imbibition of, 410 .

Bicarbonate system, 24l, 332, 416.

Bile, function of, 318 .

Binocular vision, 225.

Bio-electric phenomena, 133.

Bjerknes' phenomenon, 382 .

Blood, alkali reserve of, $241,333,417$; coagulation of, 235; colloids of, 233, 243 ; composition, 232 ; corpuscles, 241 et seq., 398,422 ; crystalloids, 238 ; 
development of, 230 ; flow, 163, 277 ; function of, 229, 231; hydrogen ion concentration of, $232,421,424$; integrative action of, 256 ; osmotic pressure of, 157, 233, 244; plasma, q.v., 232 ; pressure, 162, 279, 423 ; viscosity of, 242,422 .

Bone, 174; adaptation of, 176, 179 ; conduction of sound by, 213, 493; development of, 174 ; internal structure of, 176 ; strength of, 175 ; stress lines in, 175 .

Bowman's capsule, 156.

Boyle's law, 38.

$\beta$ rays, 120.

Brownian movement, $73,75,409$; in neuron, 183.

"Buffers," 241, 416.

Bunsen-Roscoe, law of, 354, 356 .

Caisson disease, 267.

Calcium, action of, in coagulation of blood, 235 ; in breaking emulsions, 86 , $87,113,415$; on water-holding capacity of soap, 82, 236, 237.

Calorie, 3,21 ; value from oxygen usage, 31 ; value of diet, 26 .

Calorie, value of diet (physiological), 27.

Calorimeter, bomb, 24.

Calorimetry of animals, direct, 27 ; indirect, 29.

Cambrian period, sea water in, 240.

Capacity of a conductor, 53.

Capillary analysis, 411 .

Capillary circulation, 252, 279, 423.

Capillary electrometer, 47, 259, 404.

Carbohydrate, formation of, 15-18 ; oxidation of, $19,29,136,139,150$.

Carbon dioxide, effect of, on dissociation of $\mathrm{HbO}_{2}, 253$; cxcration of, 261 ; production of, 22,28 ; specific function of, 253 ; tension in blood and alveoli, 255 ; transport of, 254.

Carnot's principle, 32.

Cartilage, 174.

Catabolism, 2, 350.

Catalase, 96.

Catalysis, 92, 380.

Cataphoresis, 78, 413.

Cathode, 50.

Cathode rays, 119.

Cation and anion, 49.

Cell as factory, 91 .

Cell division, cause of, 375 .

Cell pressure and growth, 375 .

Centimetre index, 367 .

Charles' law, 38.

Chemical energy, receptors for, 192, 196.
Chemical gardens, 399

Chemiotaxis (Chemotropism), 131, 155, 359.

Chloroform : effect of, on dispersoids, 83, 86 ; on membranes, 244.

Chlorophyll, absorption spectrum of, 14 ; function of, 19 ; efficiency of, 18.

Chromatic aberration, 217.

Circulation of blood, general plan of, 274, 281, 423.

Coagulation of colloids, 79, 234 .

Coefficient of variability, 369 .

Co-enzyme, 97.

Cold, reaction to, 349,350 .

Collagen, 172.

Colligative properties of solutions, 43.

Collodion membranes, 405

Colloidal aggregates, dimensions of, 65 , 74.

Colloidal gold, 72, 412 .

Colloidal solutions, coagulation of, 79 , 409 ; osmotic pressure of, $66,233,234$; viscosity of, 232, 234, 409.

Colloidal state, 67 .

Colloids, elasticity of, 169 ; hydrophilic, 173.

Colour, of colloidal solutions, 71, 72 ; of iris, 71 ; of sky, 70.

Compensation, law of, 376.

Complemental air, 259.

Compound interest law, $365,367$.

Condensation in surface layer, 48, 109, 151, 189.

Conduction of nerve impulse, 185 ; of heat, 340 ; of sound, 423 .

Connective tissues, 168.

Conservation of energy, 4, 32.

Continuous phàse, 67.

Cooking, 89.

Copper ferrocyanide membranes, 41,110 , $398,399$.

Corti, organ of, 210.

Crenation, 245.

Crooke's tube, 119.

Crystalloids, 66.

Current, electrotonic, 189 ; demarcation, $134,143,145$; of action, $134,144,145$, 190 ; of injury, 134, 143, 145, 190, 405 ; polarisation, 133, 188 .

Dalton's law of partial pressures, 40 .

Dark ground illumination, 74, 409.

Dead space, 260.

Decrement in nervous impulse, 186.

Degeneration, fatty, 389 .

Degraded energy, 5,8 .

Dehydration of fertilised eggs, 379 ; of tissues, 364 . 
Demarcation current, 134, 143, 145.

Dendrites, 182, 184.

Depolarisation, law of, 376.

Dermatoptic function, 174 .

Destruction of enzyme, 94, 95 .

Dialysis, 67 ; experiments on, 408 .

Diaphragm, mechanics of, 304 ; structure of, 303 .

Diclectric constant, 52, 53.

Diffusiometer, 40,398 .

Diffusion, coefficient, 262 ; factor, 262 ; field of force of, 382 ; of colloids, 67 , 413; of electrolytes, 413 ; of gases, 40,398 ; of gases through membranes, 40,41 ; potential, 52 .

Dimension of colloidal particles, 65, 74 .

Dioptric system of eye, 222 .

Diphasic electrical response, 144, 188, 296.

Dispersant, 68.

Dispersed phase, 67.

Dispersion, degrce of, 68 .

Dispersoid, 68.

Displacement theory of hearing, 212.

Dissociation constant of water, $\mathbf{5 5}$.

Dissociation curve of oxyhaemoglobin, 249 ; effect of acid on, 253 ; effect of earbon dioxide on, 253; effect of electrolytes on, 248; effect of oxygen tension on, 249,250 ; effect of heat on, 252.

Dissociation, temperature coefficient of, 63 ; theory of solutions, 44.

Distance receptors, 191, 200, 215.

Diuresis and oxygen consumption, 160.

Diuretics, model to jmitate action of, 414.

Dynamic equilibrium, 163, 257.

Ear, 200.

Eeto-enzymes, 97.

Effective surface of blood corpuscles, 243 ; of solvents, 65 .

Efficiency, factors influencing, 395 : "gross" (physiological), 391, 393 ; "net" (industrial), 391.

Efficiency of an engine, 6, 392 ; of animal as a machine, 34 ; of heart, 284 ; of lung mechanism, 311 ; of muscle, 138 , $141,142,143,397$; of organism as a whole, 391 ; of secretory glands, 154 ; of tympanic membrane, 203.

Elasticity, 168; of tissues, 169, 310.

Elastin, 172.

Electric cliarge on colloids, 78,79 ; on ions, 50,52 ; on surfaces, 47,48 , 51.

Electric endosmose, 115, 399.
Electric phenomena of cell, 132; of muscle, 143, 405; of nerve, 188; of sccretion, 153, 154 .

Electrical conductivity, 50, 379, 415.

Electrocardiogran, 295.

Electrodes (anode and cathode), 50.

Electrolytes, 44, 49; action of, on colloids, 79 ; effect of, on dissociation of $\mathrm{HbO}_{2}, 249$.

Electromagnetic theory of light, 53 .

Electrometer, capillary, 47, 259, 404.

Electromotive force, 52.

Electron, 117.

Electron theory, 53.

Electroscope, gold leaf, 121.

Electrostatic attraction of ions, 52, 189.

Electrotonic currents, 189.

Emulsifying agents, 85 .

Emulsions, 83, 173, 414; effects of acid on, $86,378,389,415$; effects of anaesthetics on, 86 ; experiments on, 414,415 ; fatty degeneration in, 389 ; types of, 84.

Fmulsoids, 68 ; protective action of, 80 , 413.

Endocrinetes, 368, 373, 388 .

Endo-enzymes, 97, 389 .

Endosmosis, 399.

Endothelium, 173.

Endothermic reactions, 18.

Energetics of karyokinesis, 383.

Energy, absorbed by chlorophyll, 17 ; available, 9 ; available, of cell, 36 ; bound, 7; chemical receptors for, 192 ; conservation of, 4 ; consump. tion of, by glands, 150 ; by kidney, 156 ; by muscle, 143 ; by nerve, 187 ; by organism, 388 ; by respiratory musculature, 311 ; degradation of, 5,8 ; free, 3,8 ; index of heart, 286 ; kinetic, $6,7,8$; laws of, 3 ; necessary for dissociation, 54 ; of food, 26 ; of growth, 373 ; of radiation from sun, 14 ; potential, 6,8 ; vibratory, receptors for, $192,193,194,200$, 215.

Enterokinase, 97.

Entropy, 6.

Enzyme action, 92 ; effect of anaesthetics on, 95 ; effect of hydrogen ion concentration on, 95, 101; effect of solutes on, 95 ; effect of temperature on, 94 ; inhibition of, 100 ; reversal of, 99 .

Enzyme activators, 97.

Enzymes as catalysts, 93 ; chemical nature of, 93 ; physical nature of, 93 . Epithelium, 166, 375 . 
Equilibrium, 97, 99, 164, 363; is death, $2,331,377$.

Erepsin, 101.

Ergometer, 393.

Errera's rule, $370,376$.

Erythrocyte, 164, 241, 242, 267, 398.

Eustachian tube, 206, 207.

Evolution of alimentary canal, 132, 313 ; of nervous system, 131, 182; of temperature regulation, 337.

Excitation of cell, 131, 134; of muscle, 137,138 ; of nerve, 183, 192; of secretion, $149,153$.

Excretion, 132, 156, 164, 318.

Exosmosis and development, 379 .

Exothermic reactions, 19.

Exteroceptors, 191.

Eye, 215.

Faraday-Tyndall phenomenon, 70, 409.

Fat, energy value of, 22 ; function of, 173,341 ; formation of, 18 ; invisible in cells, 173,389 ; visible in cells, 173 , 389.

Fatigue, in muscle, 141, 147; (forced respirations), 312 ; in nerve cells, 187 ; in nerve fibres, 187.

Fatty degeneration, 87, 173, 389 ; rôle of acids in, 86, 389 .

Ferrocyanide membranes, 398, 399.

Fertilisation, increased permeability in, 384 ; spermatozoön and, 380.

Fibrin, 235.

Fibrinogen, 234.

Fibrons tissue, 171.

Flow through tubes, 277.

Food, changes of, in digestion, 316 ; composition of, 87 ; energy value of, 26 ; requirements for growth, 372.

Force, fields of, 381 .

Form, symmetry of, 381 .

Formaldehyde in photosynthesis, 17.

Free energy, 7, 138, 377, 380, 381 .

Freezing point, determination of, 399 ; of urine, 157.

Friction, 243, 336.

Galvanometer, string, 296.

Gas constant, $R$, value of, 39 .

Gas dispersions, 68 .

Gas laws, 38, 39.

Gas, pressure of, cause of, 39 .

Gay Lussac's law, 38.

Gel, 69 .

Gelatine, imbibition by, 411 .

Gelation, 79, 409.

Gibbs-Thomson principle, 48, 152, 175.

Glands, mode of stimulation of, 153 . $^{\circ}$
Glomerulus of kidney, 162.

Gold number, 80.

Gold, preparation of colloidal, 412 .

Graham, 40, 41, 69.

$\gamma$ rays, 120.

Growth, 132, 315, 363; and form, 375.

Guanidin salts, dissociation of, 49.

Guldeberg \& Waage, Mass action, 55, 61,368 .

Haematocrite, 241, 422.

Haemodynamics, 278, 423.

Haemoglobin, 242, 248, 334.

Haemolysis, 108, 243, 378.

Harvey's work on circulation of blood, 276.

Hearing, 211.

Heart, efficiency of, 284 ; physical (Ostwald's), 404; structure of, 275, 286 ; sounds, 290 ; thickness of walls of, 286 ; valves of, 288 ; work done by, 280 .

Heat, action of, on chemical reactions, 370 ; on efficiency, 141 ; on enulsoids, 81 ; on enzymes, 94 ; on physical phenomena, 370 .

Heat centre, 350 .

Heat, of combination, 54 ; of combustion, 22 ; of dilution, 22,54 ; of hydration, 54 ;

Heat production, $34,347,349$; in glands, 154; in muscle, 138, 145; in nerve, 188.

Helicotrema, 209.

Heliotropic machine, 357.

Heliotropism (phototaxis), 131, 354.

Helmholtz-Lippmann, double layer, 47, 51, 151, 152.

Helmholtz on ear, 211, 213.

Henry's law, 247.

Hess's law, 293.

Hibernation, temperature regulation during, 337.

Hirudin, 238.

Hoff, J. H. van't, 37, 43, 111, 186.

Hoffmeister series, see Lyotropic scries.

Homoiothermic animals, 337.

Hormonc, 231.

Hunger, sensation of, 198.

Hydration of colloids, $66,69,82$; ions, $50,110$.

Hydrogen electrode, 422.

Hydrogen ion concentration, 56 ; measurement of, 421; of blood, 232.

Hydrol, 55.

Hydrolysis, by enzymes, 96, 389.

Hydrophilic colloids, 173.

Hydrosol and hydrogel, 69. 
Hypertonic and hypotonic solutions, 107, 398.

Illumination, dark background, 74, 409.

Imbibition by colloids, $66,153,172,245$, $410,411$.

Incus, 204.

Index of variability, 369 .

Inertia, 9, 354, 357, 378.

Infundibula, 260 .

Injury, current of; 134, 143, 145, 190, 405.

Integrative action of blood, 206, 231 .

Interface, 47, 151.

Interoceptors, 191.

Intrinsic pressure, 47.

Ion, definition of, 44 .

Ionic micelle, 45.

Ionisation, 49.

Ionisation constant of water, 56 .

Ions, electrical charge of, 50 ; hydration of, $45,50,51$; relative speed of, 50 .

Iris, 218.

Iron content of haemoglobin, 251.

Irritability of matter, 131, 193, 319.

Isoelectric point, 79.

Isomeric compounds, 106, 390.

Isometric contraction, 136.

Isotomic solutions, 43, 233.

Joints, 180 ; lubrication of, 179.

Joule's heat, 147.

Karyokinesis, 381.

Kathode, see cathode.

Kephalin and blood clotting, 236, 237.

Kidney, model of, 414 ; structure of, 156 , 161.

Kinetic encrgy, $6,7,8,138$; of substances in solution, 36,46 .

Kinetic theory, 37, 75 .

Laccase, artificial, 94.

Lactic acid, of muscle, origin of, 138.

Latent heat, 341, 345.

Latent period of tympanic membrane, 202.

Law, natural, 1.

Law of Avogadro, 38; Boyle, 38 ; Bunsen and Roscoe, 354, 356 ; Charles, 38 ; Dalton, 40; Gay Lussac, 38; Guldberg and Waage, 55, 61, 368; Henry, 247 ; Hess, 293 ; Müller, 183, 184, 193; Newton (cooling), 342; (energetics), 37 ; Schütz, 380 ; Snell, 103 ; Talbot, 356 ; von Weimarn, 69.

Law of nutocatalysis, 365 ; catalysis, 380 ; cooling, 340 ; corresponding states, 69 ; least action, 9 ; length of life (Rubner), 388; mass action, 55, 61,368 ; probability, 369.

Laws of energetics, 3, 37; growth, 374, 376.

Le Chatelier, principle of, $9,128,345$, $360,370$.

Leduc's diffusion experiment, 382 ; osmotic growths, 109, 399.

Length of inuscle fibre, energy proportional to, 136, 142.

Iens of cye, 219.

Leucocytes, 130, 155, 241.

Levers, 202, 207, 308, 315, 320 .

Liesgang phenomenon, 79, 413.

Light, absorption of, by chlorophyll, 14 ; by colloids, 70, 72 .

Light, electromagnetic theory of, 53 ; energy of, 14 ; polarised, 70 ; receptors, 215,355 .

Lippmann's capillary electrometer, 47 , 404.

Load, influence of, on efficiency, 395.

Locomotion, movements of, 320 .

Lubrication of joints, 179.

Lung, mechanism of, 302 ; structure, 260 , 301.

Lungs, oxygen consumption of, 311 .

Lymph, 276.

Lyotropic series, 78, 409, 411.

IIaintenance of metabolic level, 150 .

Malignant growths and radiation, 126.

Malleus, 202, 204.

Malpighian corpuscle, 156, 162.

Mannitol, 19.

Mass action, law of, 55, 61, 368 .

Mastication, 314.

Maximum energy of solar spectrum, 14 .

Mean free path of molecules, 47.

Measurement of, alkaline reserve of blood, 117; electrical conductivity, 415; electric potential differences, 404; energy values, 22; hydrogen ion concentration, 421; lowering of vapour pressure by solutes, 402; osmotic pressure, 398, 399, 402; surface arca of tody, 425 ; viscosity, 409.

Mechanical equivalents of heat, 3, 4: heart (Ostwald), 404.

Mechanics of, bone formation, 175,331 ; locomotion, 320; mastication, 315; respiration, 303 ; speech, 325 .

Mechanism of ear, 211 ; kidney, 163.

Membrana tympani, 201.

Membrane, basilar, 209 ; Reissner's, 209. 
Membranes, adsorption, 109 ; cell, 107 , 108,378 ; for dialysis, 67,405 ; lipoid, 242,243 ; of variable permeability, 111 , 132 ; polarised, 116; selective permeability of, 116 ; semi-permeable, $41,110,398,399$.

Mercury, anioeba, 404.

Mercury heart (Ostwald's), 101.

Metabolism, definition of, 2; effect of intensity of temperature on, 337, 341, 361 ; of nerve centres, 187.

Metabolites, function of, 381 .

Micclle, ionic, 45.

Micron, 74.

Milk, 87.

Mimicry, of amoeboid movements, 131, 403,404 ; of cell structure, 414 ; of mucoid secretions, 153,415 .

Mirror images (optical activity), 101, 105, 106.

Mitosis, 381, 382.

Model of kidney, 414 ; nerve cell, to illustrate Müller's law, 184 ; polarimeter, 102 ; receiving and reacting neuron, 185.

Müller's law, 183, 184, 193.

Muscle, efficiency of, 143; electrical changes in, 143 ; energy of, a surface phenomenon, 137 ; excitatory process in, 146 ; heat production in, 145 ; oxygen consumption of, 138 ; phases of action, 136,145 .

Narcotics, action of, on nervous impulse, 186 ; on soaps, 83.

Narcotics and stability of emulsions, 86 , 389.

Negative osmosis, 113, 115.

Negative polarisation, 189 .

Nerve, carbon dioxide production in, 187.

Nerve cells, 182.

Nerve, conductivity of, 183 ; elasticity of, 169 ; electrical change in, 188 ; fatigue of, 187 ; heat production in, 188 ; mechanical stimulation of, 183.

Nervous impulse, decrement of, 186 ; nature of, 188 ; refractory period in conduction of, 186 ; temperature coefficient of, 185 .

Neuron, 182; Brownian movement in, 183.

Neutrality, definition of, 57 ; preservation of, $241,252,331$.

Newton's laws of cooling, 342 ; of thermodynamics, $37,46,49$.

Nicol's prism, 102.

Nitrogen cycle, 390.

Normal solutions, 60 .
Nucleus, 129.

Nucleus and mitosis, 381 ; and oxidative changes, 384.

Oil in water dispersions, 84,414 .

Olfactory nerve, 196.

Oöcytin, 380.

Ophthalmoscopy, 224.

Opsonins, 155.

Optical activity, 101 ; due to asymmetric forces, 105 ; factors modifying, 102 ; measurement of, 104.

Optical isomers, 105, 106 ; and enzyme action, 98, 106.

Optical resonance, 73 .

Optiunal, incidence of energy to nerve, 184 ; rate of work, 396 ; temperature for enzyme action, 94.

Organ of Corti, 210.

Organogenesis, 385.

Osmometer, preparation of, 41,398 .

Osmosis, electrical, 112, 115, 399.

Osmosis in cells, 107, 108.

Osmosis, negative, 113, 115.

Osmotic growths, 399.

Osmotic pressure, and lowering of freezing point, 43 ; and growth, 379 ; and secretion, 153 ; and turgor, 364, 393 ; and vapour pressure, 43 ; cause of, 37 ; definition of, 42 ; demonstrations of, 398 , 399; measurement of, 399, 402; of blood, 157, 398; of colloids, 45 ; of electrolytes, 44,398 ; of urine, 157 , 399.

Ossicles, auditory, 202, 204.

Ostwald, Wo., 66, 72; (physical heart), 404.

Oxidase, 96.

Oxidative removal of lactic acid, 138, 140.

Oxygen, calorie equivalent of, 31 .

Oxygen, consumption of, glands, 150 ; heart, 284 ; kidneys, 156, 160 ; lungs, 311 ; muscle, 142 ; organism, 380.

Oxygen, effects of want of, 381,389 ; solubility of, 247 ;

Oxygen tension and barometric pressure, 266.

Oxygen tension in air, 246 ; in alveoli of lung, 249 ; in arterial blood, 249 ; in tissues, 249 ; in venous blood, 249.

Oxygen transport by blood, 246.

Oxyhaemoglobin, 249.

Pacinian corpuscles, 194.

Parchment paper for dialysis, $40 \%$.

Parthenogenesis, 377 ; artificial, 378 ; stages of, 378 . 
Partial pressure of gases, 40 .

Perilymph, 209.

Peripheral resistance in vascular system, 281.

Peristalsis, 317.

Permeability as affected by calcium, 113.

Permeability, differential, 133 ; selective, 111.

Peroxidase, 96.

Phagocytes, 155.

Phases of action, of gland, 148; of muscle, 136, 145, 147.

Phases of growth, 368 .

Phosphate buffer system, 334,416 .

Photosynthesis, 15, 355 .

Phototaxis, see Heliotropism.

Physiological availability of energy, 9, 27.

Pigment, 174 ; cells stimulated by light, 174 ; of iris, colour of, 71.

Plasma, blood, eoagulation of, 234; colloids of, 233 ; composition of, 233 ; crystalloids of, $238 ; \mathrm{C}_{\mathrm{H}}$ of, 232 ; function of, 234, 241 ; osmotic pressure of, 233 ; oxygen carrying power of, 248 ; refractive index of, 233 ; specific gravity of, 232 ; viscosity of, 232.

Plasmolysis, 107.

Poikilothermic organisms, 337.

Polarimeter, $104 ;$ model to explain, 102.

Polarisation, 116; at electrodes, 116 ; currents, $133,188,189$; of membranes, 116.

Pole-finding paper, 116.

Positive polarisation current, 188.

Potassium, in Helmholtz double layer, 152; radioactivity of, 122,124 ; soaps, 82.

Potential energy, 6, 8.

Potentiometer, 421.

Preparation of artificial amoeba, 403. 404 ; chemical gardens, 399 ; colloidal solutions, 412, 413; dialysing vessels, 105,407 ; diffusiometer, 398 ; osmometcr, 398 .

Prepyloric sphincter, 317.

Preservation of neutrality, 241, 252, 331, 416.

Pressure and growth, 374, 386.

Pressure of gas, 39 .

Principle of Avogadro, 38 ; Carnot, 32 ; Gibbs, 48, 152, 175 ; least action, 9 , 11 ; Le Chatelier, 9, 128, 345, 360, 370.

Production of heat, 34, 347, 349.

Proprioceptors, 191.

Protective action of emulsoids, 80 .

Protein, energy of, 19,26 ; energy value of (physiological), 27.
Proteins as colloids, 80 ; digestion of, 317,318 ; function of, in preserving neutrality, 332 .

Protcins of blood, 233 ; function of, 239 ; osinotic pressure of, 233 ; viscosity of, 232.

Protoplasm, 2, 130 ; as an emulsion, 87, 378; Brownian movement in, 183 ; colloidal nature of, 34,130 ; liquid nature of, 34,130 ; structure of, 130 .

Proximate principles of food, 19, 26.

Pseudo-activation of enzymes, 97.

Pscudo-adsorption, 109.

Pulleys, 323.

Pulse wave, 280, 283.

Putrefaction and anaerobic action, 390.

Pyloric sphincter, 317.

Quantum of energy as stimulus, 194.

Quinine, action on haemoglobin, 244.

Radio-active phenomena, 117.

Radio-activity of potassium, 122 ; effect on heart, 124.

Radium, effect on colloids, 81 .

Rate of adsorption, demonstration on, 411.

Rate of conduction in nerve, 185.

Rate of growth, 365 .

Rate of respiration, $265,311$.

Reaction, 58.

Receptors, 191.

Refraction, 103, 215, 219.

Refractive index, 53, 103, 216.

Refractory period of nerve, 186.

Regulation of rate of growth, 375 ; respiration, 312, 334; temperature, 336.

Reissner's membranc, 209.

Reserve air, 259.

Residual air, 259.

Resonance, optical, 73 ; theory, 211.

Respiration, 258.

Respiratory centre, 312,334 ; rcaction to $\mathrm{C}_{\mathrm{H}}, 312,334$.

Respiratory quotient, 30 .

Retina, 218, 358.

Reversibility of enzyme action, 100, 390 .

Reversible reactions, 99, 376, 381 .

Rheoscopic frog, 145 .

Rhythmic movement, model producing, 404.

Rigidity of tissues, 87,389 ; experiments to demonstrate, 399,415 .

Rivers, dissolved matter and colour of, 71.

Röentgen rays, 119.

Roux's experiment on growth, 385 . 
Rubber, an emulsion, 84 ; imbibition of benzol by, 410 .

Rubner's law of constant energy consumption, 374 ; length of life, 388.

Sach's rule, 367.

Saliva, function of, 314 .

"Salting out" of colloids, 79 ; of soaps, 83.

Salts, effect on $p_{H}, 61,62$.

Saponin haemolysis, 244.

Scala media, tympani vestibuli, 209.

Scheme of circulation, 281, 423.

Schütz's law, 380.

Secretion and osmosis, 151, 153; and permeability, 154 ; by renal tubules, 163 ; electrical change in, 154; mechanism of, 151; mucoid, "153, 415 ; phases of, 148 ; source of energy for, 150 ; work done in, 154.

Secretory hypothesis of respiration, 265, 267.

Selective permeability of membranes, 116 .

Semipermeable membranes, 41 ; preparation of, 398 .

Sensation and stimulus, 194.

Sense organs, 192.

Sensitiveness, absolute, 195.

Serum, blood, 234.

Shell formation, 411 .

Simpson light, 126.

Slyke, van, alkali reserve, $241,333,418$.

Smell, sense of, 196.

Snell's law, 103.

Soap, 82 ; calcium, $82,318,415$; films, 137,403 ; in faeces, 318 ; loss of hydrophilic properties of, $82,318,415$; potassium, 82,415 ; sodium, 82,415 ; soft, 82.

Soap solution, effect of acids on, 82,415 ; effect of anaesthetics on, 83 ; preparation of, 403 .

Sodium bicarbonate and $\mathrm{CO}_{2}$ tension, 241, 332 .

Sodium bicarbonate system, $62,332,416$.

Sodium soap, 82, 415 .

Sol and gel, 69, 234.

Solutions normal, 60.

Solution tension, 163.

Soma, 135.

Sounds of the heart, $290,299$.

Source of energy, for food formation, 17 ; muscular contraction, 140 ; secretion, 150.

Specific action of enzymes, 98.

Specific inductive capacity, 52, 381 ; irritability, 193; nerve energy, 183; surface, $66,93,381,384$.
Spectrum, 14.

Speech, 325.

Spermatozoön, function of, 380 .

Sphincter muscles, 316.

Spleen, 164.

Stabilisation of colloids, 78 ; emulsions, 85.

Stapedius, 206.

Stapes, 204.

Stereoscope, 227.

Stereotropism, 358.

Stimulus for growth, 315,376 .

Stomach, 316.

Streaming of protoplasm, 131.

Stress and strain, 168, 381 ; lines of, in bone, 176.

String galvanometer, 296.

Stroma of blood corpuscles, 243.

Structure of bone, 175; cell, 129 ; ear, $200,205,209$; erythrocyte, 243 ; eye, 218 ; lung, 260.

Struts and ties, 169, 170, 171.

Submicron, 74.

Substrate, 93.

Summation of stimuli, 187.

Surface area of body and heat loss, 340 , 343.

Surface area of body and mass, 65, 381 .

Surface area of body measurcment, 425 .

Surface condensation, 151, 158, 175.

Surface energy in cell mechanics, 131 ; source of, 46 ; temperature cocfficient of, $47,109,137$.

Surface, extent of, in colloidal suspensions, 65, 237.

Surface tension, 46.48; and elcctrical charge, 47, 153; and growth, 375 ; and $\mathrm{C}_{\mathrm{H}}, 421$; effect of solutes on, 48, 237; experiments on, 403, 404; in muscle processes, 137 ; in nerve, $183 ; 1$ in urine formation, $158,163$.

Survival of fittest, 360 .

Synapse, 182, 185.

Syneresis of gels, 235 .

Synergetical muscles, 323.

Synkinetic movement, 202.

Synovial fluid, 180 ; sheath, 323.

Synthesis by enzymes, 100, 390 .

Tastc, 196.

Temperature coefficient, 47, 370; of absorption of gas by a liquid, 247 ; of development, 361,379 ; of dissociation, 51, 63 ; of growth, 370 ; of muscular contraction, 137 ; of nervous conduction, 185; of surface tension, $47,109,137$.

Temperature regulation, 336,349 . 
Tendon, 172 ; sheaths, 180 .

Tension and rate of growth, 374 .

Tension of gases, 246.

Tension, see surface tension.

Tetanus, 145.

Thermal conductivity, table of, 340 .

Thermal efficiency, 33.

Thermodynamics, laws of, 3,5 .

Thermometer, Beckmann's, 400 ; clinical, 337.

Thermopile, $145,338$.

Thigmocytes, 237, 241 .

Thorium, 123, 124.

Threshold values, 163, 193.

Thrombin, 235, 236, 237.

Thrombokinase, 235.

Thromboplastin, 236.

Thymus, 238, 373.

Thyreoid, 373.

Tidal air, 259.

Tissue, connective, 168; elasticity of, 169 ; fibrous, 171 ; strength of, 170 ; vegetative, 166 .

Tone of muscle, 142.

Tongue, 196, 314, 325 .

Touch, 193.

Touch-button mechanisms, 312, 318.

Transmission of acquired characters, 361.

Trigger action, 183.

Trigger energy, 7, 8, 138, 146.

Trophic and secretory nerves, 153.

Tropisms, 131, 354.

Trypsin, 96, 97, 101.

Turgor, 364, 399.

Tympanic membrane, 201.

Tyndall phenomenon, 70, 409.

Types of colloids, 69 ; dispersoids, 68 ; emulsions, 84.

Ultra-filtration, 75 .

Ultra-microscope, 74.

Ultra-violet light, 14, 20, 126 ; action of, on organisms, 126, 127, 132.

Uranium, 120, 121.
Urine, formation of, 162 ; work done in formation of, 157.

Valves of heart, 288 ; veins, 288.

Vapour pressure, of a liquid, 38 ; and osmotic pressure, 43 ; Barger's determination of, 402.

Variations in growth, factors causing, 368.

Vectors, law of, 376.

Vegetative tissues, 166.

Velocity of growth, 368 .

Vibratory energy, receptors for, 192, $193,194,200,215$.

Viscosity, measurement of, 409, 422 ; of blood, $242,243,422$; of emulsoids, 389 ; of plasma, 232 .

Visual judgments, 226, 227.

Vital capacity of lungs, 259.

Volition, 11.

Volume of blood, 250.

Volume of blood corpuscles, 243.

Waller's characteristic, 184 .

"Waste" heat, 6, 12, 390.

Water, chemical formula of, 54; dielectric constant of, 53 ; dissociation of, 55 ; electric conductivity of, 53 , 55 .

Water equivalent of calorimetric bomb, 25 ; of human body, 341.

Water, heat conductivity of, 340,345 .

Weimarn, von, law of, 69.

Work, done in formation of urine, 155 ; done in secretion, 150,154 ; of heart, 280 ; of lungs, 310 ; of muscle, 136 , 142 ; of phonation, 329.

X-rays, $119,120$.

Young's modulus, 168, 169.

Zymase, 97.

Zymogen, 97. 




UNIVERSITY OF CALIFORNIA

MEDICAL CENTER LIBRARY

THIS BOOK IS DUE ON THE IAST DATE STAMPED BELOW

Books not returned on time are subject to a fine of $50 \mathrm{c}$ per volume after the third day overdue, increasing to $\$ 1.00$ per volume after the sixth day. Books not in demand may be renewed if application is made before expiration of loan period. 


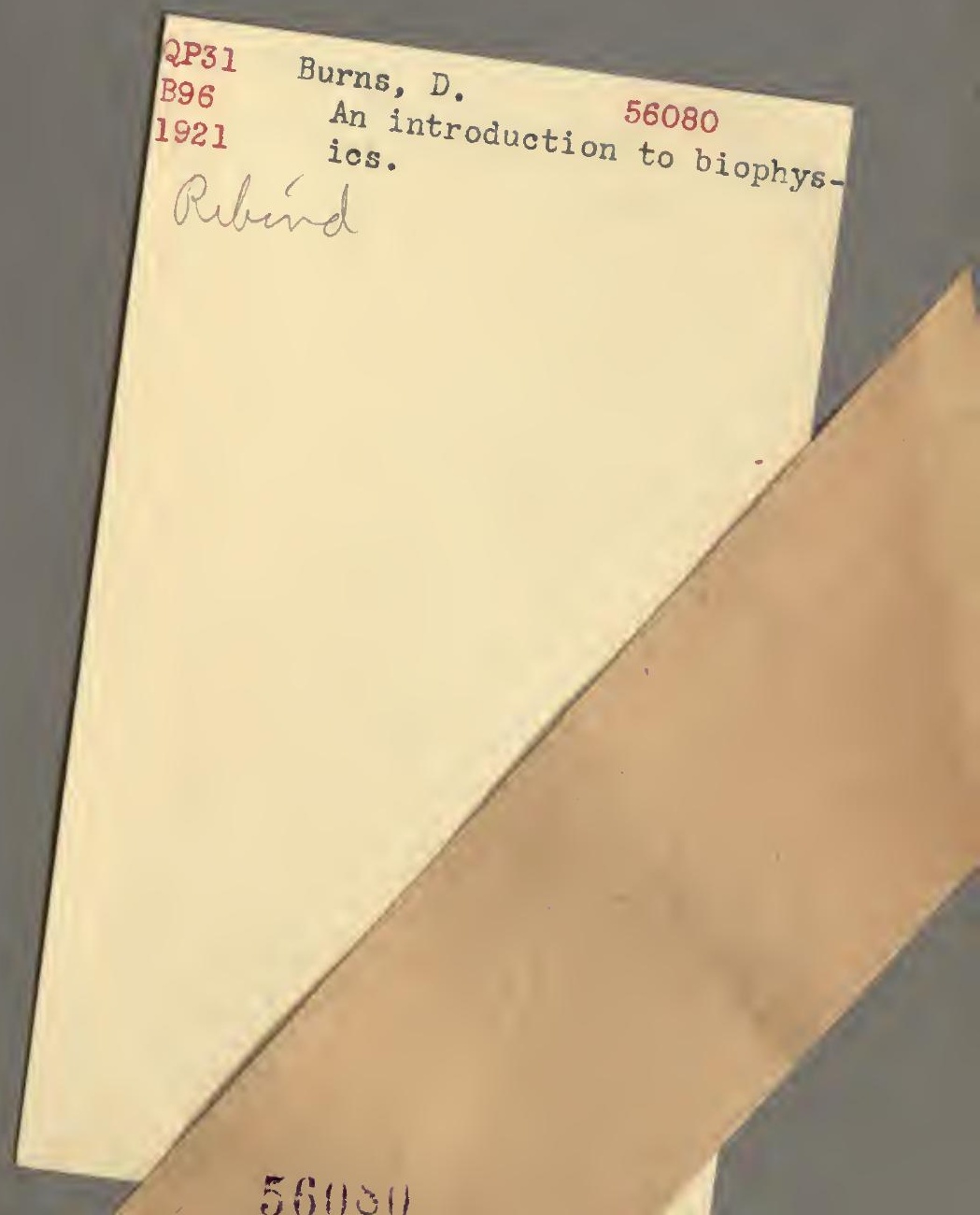


